Florida International University

FIU Digital Commons

$11-13-2019$

\title{
Isolated Single-stage Power Electronic Building Blocks Using Medium Voltage Series-stacked Wide-bandgap Switches
}

Noureldeen Mohamed Elsayad

Florida International University, nelsa007@fiu.edu

Follow this and additional works at: https://digitalcommons.fiu.edu/etd

Part of the Power and Energy Commons

\section{Recommended Citation}

Elsayad, Noureldeen Mohamed, "Isolated Single-stage Power Electronic Building Blocks Using Medium Voltage Series-stacked Wide-bandgap Switches" (2019). FIU Electronic Theses and Dissertations. 4371. https://digitalcommons.fiu.edu/etd/4371

This work is brought to you for free and open access by the University Graduate School at FIU Digital Commons. It has been accepted for inclusion in FIU Electronic Theses and Dissertations by an authorized administrator of FIU Digital Commons. For more information, please contact dcc@fiu.edu. 
FLORIDA INTERNATIONAL UNIVERSITY

Miami, Florida

ISOLATED SINGLE-STAGE POWER ELECTRONIC BUILDING BLOCKS USING MEDIUM VOLTAGE SERIES-STACKED WIDE-BANDGAP SWITCHES

A dissertation submitted in partial fulfillment of the requirements for the degree of DOCTOR OF PHILOSOPHY in ELECTRICAL AND COMPUTER ENGINEERING

by

Noureldeen Mohamed Anwar Elsayad 2019 
To: Dean John Volakis

College of Engineering and Computing

This dissertation, written by Noureldeen Mohamed Anwar Elsayad, and entitled Isolated Single-Stage Power Electronic Building Blocks using Medium Voltage Series-Stacked Wide-Bandgap Switches, having been approved in respect to style and intellectual contents, is referred to you for judgment.

We have read this dissertation and recommend that it be approved.

$\begin{array}{r}\hline \text { Ahmed Ibrahim } \\ \hline \text { Mohammed Hadi } \\ \hline \text { Sakhrat Khizroev } \\ \hline \text { Osama A. Mohammed, Major Professor }\end{array}$

Date of Defense: November 13, 2019

The dissertation of Noureldeen Mohamed Anwar Elsayad is approved.

Dean John Volakis
College of Engineering and Computing

College of Engineering and Computing

Andrés G. Gil

Vice President for Research and Economic Development and Dean of the University Graduate School

Florida International University, 2019 
C) Copyright 2019 by Noureldeen Mohamed Anwar Elsayad

All rights reserved. 


\section{DEDICATION}

For their endless support, love, and sacrifice, I dedicate this work.

To my Beloved Parents and my Sister 


\section{ACKNOWLEDGMENTS}

I would like to thank my supervisor, Professor Osama Mohammed, for supervising me in this work, and for providing me with endless research ideas and technical support. He also provided me with financial support through a research assistantship in his research group working on his research projects and for some semesters as a teaching assistant at the Electrical and Computer Engineering Department at FIU. I would also like to thank Professor Mohammed for making me a part of the Energy System Research Laboratory and for the excellent facilities made available for this project. I have gained a lot of skills and experience at ESRL with its first-class equipment needed to build and experimentally verify the results. This helped me complete my doctoral studies and enabled scholarly production resulting from this project. Also, as my doctoral research started to gain traction, Professor Mohammed provided me opportunities to grow within my professional career inside and outside the university and helped me build my own name in this field.

I would also like to thank my committee members for their support and discussions. I also acknowledge the support from the FIU graduate school for providing me with the dissertation year fellowship during my final year in the program.

Finally, thanks to all my colleagues at the Energy Systems Research Laboratory, who created a professional and collaborative environment that helped me reach my research objectives. I also like to thank the Department of Electrical and Computer Engineering Staff who have helped me tremendously throughout my years of doctoral research. 


\section{ABSTRACT OF THE DISSERTATION \\ ISOLATED SINGLE-STAGE POWER ELECTRONIC BUILDING BLOCKS USING \\ MEDIUM VOLTAGE SERIES-STACKED WIDE-BANDGAP SWITCHES}

by

Noureldeen Mohamed Anwar Elsayad

Florida International University, 2019

Miami, Florida

\section{Professor Osama A. Mohammed, Major Professor}

The demand for efficient power conversion systems that can process the energy at high power and voltage levels is increasing every day. These systems are to be used in microgrid applications. Wide-bandgap semiconductor devices (i.e. Silicon Carbide (SiC) and Gallium Nitride (GaN) devices) are very promising candidates due to their lower conduction and switching losses compared to the state-of-the-art Silicon (Si) devices. The main challenge for these devices is that their breakdown voltages are relatively lower compared to their Si counterpart. In addition, the high frequency operation of the widebandgap devices are impeded in many cases by the magnetic core losses of the magnetic coupling components (i.e. coupled inductors and/or high frequency transformers) utilized in the power converter circuit.

Six new dc-dc converter topologies are propose. The converters have reduced voltage stresses on the switches. Three of them are unidirectional step-up converters with universal input voltage which make them excellent candidates for photovoltaic and fuel cell applications. The other three converters are bidirectional dc-dc converters with wide voltage conversion ratios. These converters are very good candidates for the applications 
that require bidirectional power flow capability. In addition, the wide voltage conversion ratios of these converters can be utilized for applications such as energy storage systems with wide voltage swings. 


\section{TABLE OF CONTENTS}

CHAPTER

PAGE

Chapter 1 Introduction to Power Electronic Building Blocks................................... 1

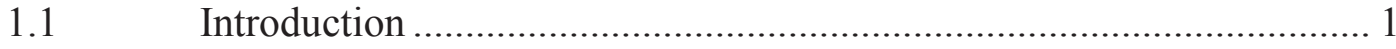

$1.2 \quad$ Overview of the Power Electronic Building Blocks ........................... 2

$1.3 \quad$ Isolated Power Electronic Building Blocks.................................... 5

1.4 Transformerless High-Order Power Electronic Building Blocks.......... 9

1.5 Series-Stacked WBG Devices for High-Voltage Applications............ 12

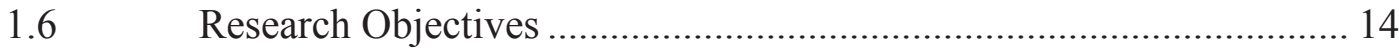

Original Contribution of This Thesis ............................................. 15

1.8 Dissertation Organization......................................................... 17

Chapter 2 Power Electronic Building Blocks for Renewable, Electric Vehicle, and Energy Storage Applications: Literature Review ........................................ 20

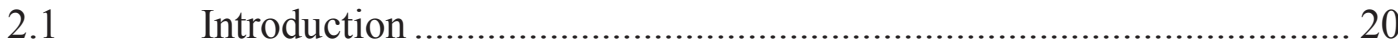

2.2 Non-Isolated Unidirectional Conventional DC-DC Structures............ 22

2.3 Non-Isolated Bidirectional DC-DC Converters ................................. 36

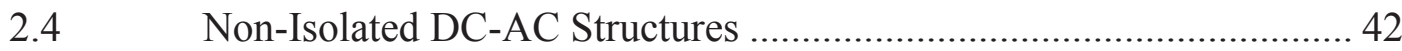

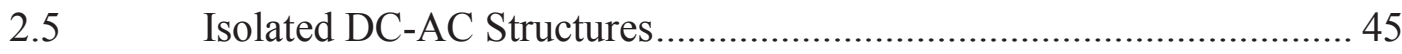

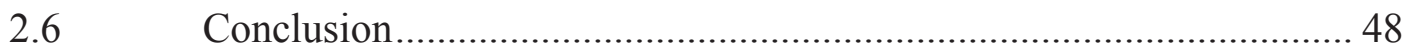

Chapter 3 Analysis and Design of a Three-Level Boost Converter with Wide Gain Range for Fuel Cell Automotive Applications .......................................... 49

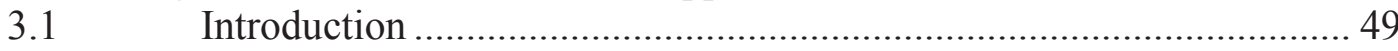

3.2 Structure and Operating Principles of the Proposed Converter .......... 49

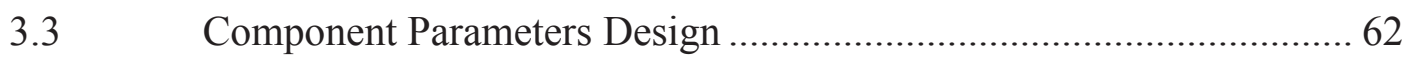

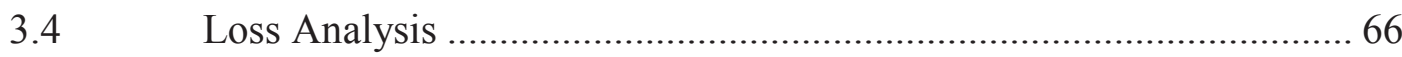

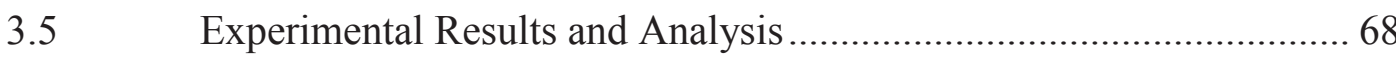

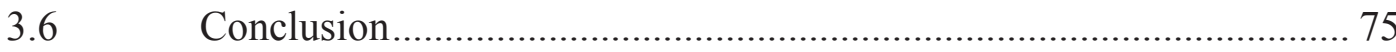

Chapter 4 A Single-Switch Transformerless DC-DC Converter with Universal Input Voltage for Fuel Cell Vehicles: Analysis and Design........................ 76

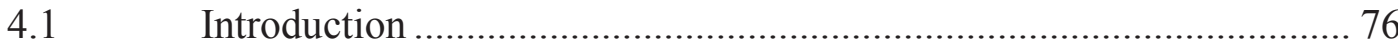

4.2 Structure and Operating Principles of the Proposed Converter ........... 76

4.3 Steady-State Analysis of the Proposed Converter.............................. 80

4.4 Comparative Study with Other Step-Up Converters .......................... 89 
4.5 Design Considerations and Components Selection............................ 96

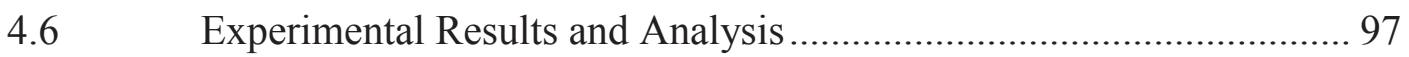

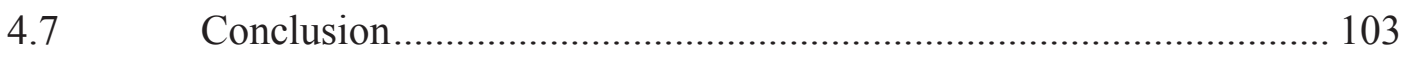

Chapter 5 A New Single-Switch Structure of a DC-DC Converter with Wide Conversion Ratio for Fuel Cell Vehicles: Analysis and Development ....... 104

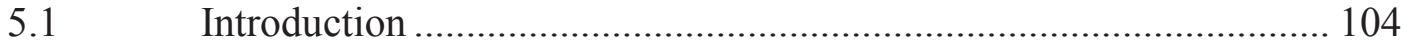

5.2 Structure and Steady-State Analysis of the Proposed Converter ....... 104

5.3 Steady-State Analysis for CCM Operation ................................... 108

$5.4 \quad$ Steady-State Analysis of DCM ................................................... 114

5.5 Comparative Study with other Step-Up Solutions ........................... 117

5.6 Design of Components ............................................................... 123

5.7 Dynamic Modeling and Voltage Loop Controller Design ................. 124

5.8 Closed-Loop Voltage Controller ................................................... 128

5.9 Experimental Results and Analysis ............................................. 129

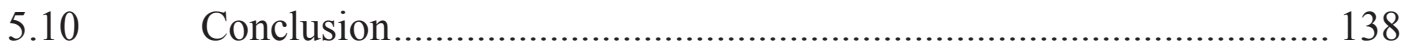

Chapter 6 A New SEPIC-Based Step-Up DC-DC Converter with Wide

Conversion Ratio for Fuel Cell Vehicles: Analysis and Design................. 139

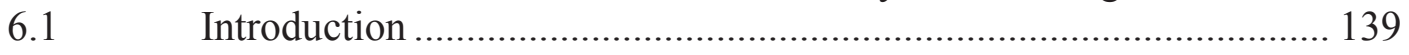

6.2 Structure and Operating Principles of the Proposed Converter ........ 139

6.3 Component Parameters Design .................................................... 150

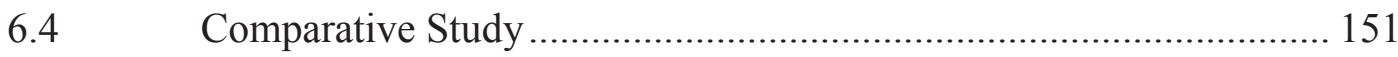

6.5 Experimental Results and Analysis ........................................... 154

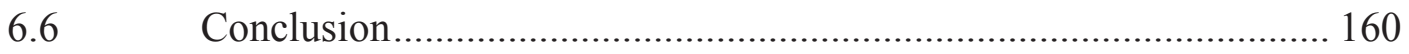

Chapter 7 Design and Implementation of a New Transformerless Bidirectional DC-DC Converter with Wide Conversion Ratios ................................... 161

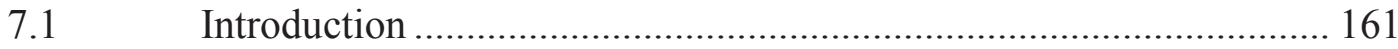

7.2 Structure and Operating Principle of the Proposed Converter ........... 161

7.3 Dynamic Modeling and Controller Design ................................... 173

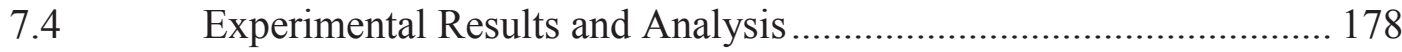

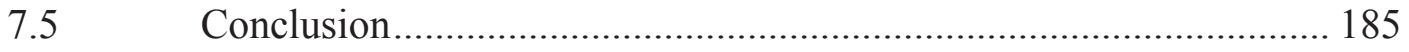

Chapter 8 Analysis and Design of A New Bidirectional DC-DC Converter with Broad Voltage Gain Range for Energy Storage Applications .................... 186

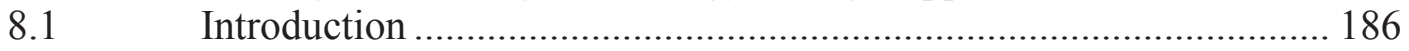

8.2 Structure and Operating Principles of the Proposed Converter ......... 187 
8.3 Components Selection and Efficiency Analysis 192

8.5 Experimental Results and Analysis 199

Chapter 9 A New Hybrid Structure of a Bidirectional DC-DC Converter with High Conversion Ratios for Electric Vehicles........................................... 206

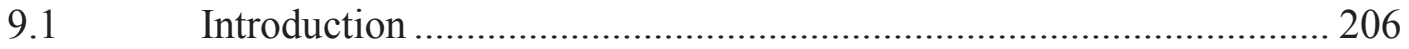

9.2 Circuit Structure and Operation .................................................. 206

9.3 Design of Components and Efficiency Analysis of the Proposed

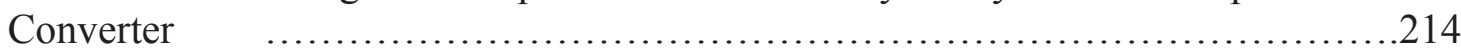

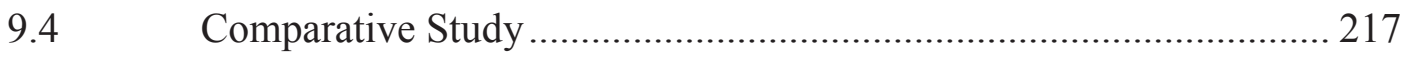

9.5 Extended Structure of the Proposed Converter ............................... 220

9.6 Experimental Results and Analysis ........................................... 226

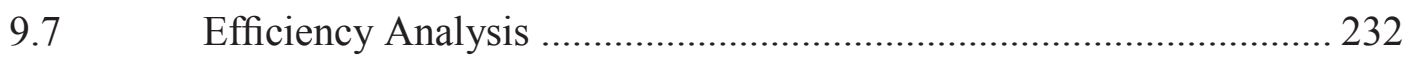

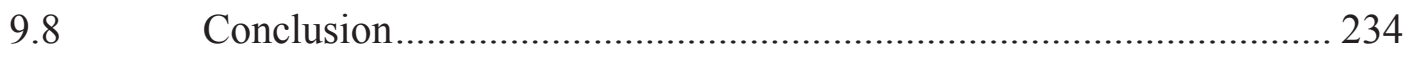

Chapter 10 Cascaded High Frequency AC-Link Systems with Reduced Switch Count for Large-Scale PV-Assisted EV Fast Charging Stations ................. 235

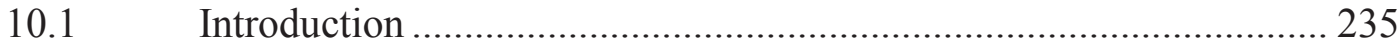

10.2 Proposed Architecture of the PV-Assisted Fast Charging Station .... 240

10.3 The Proposed Control Strategy and LVRT Capability of the System 244

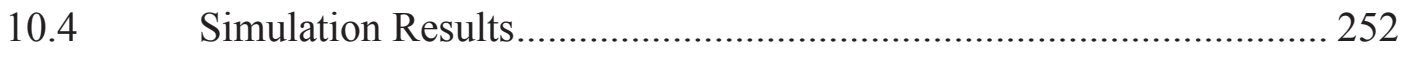

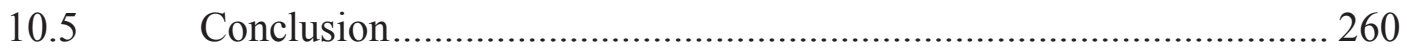

Chapter 11 An Integrated PEBB using e-GaN FETs and Nanocrystalline Inductors for Multiple DC-DC, AC-DC and DC-AC Applications .......................... 262

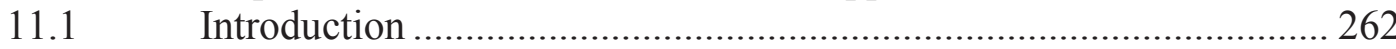

11.2 The Developed Non-Isolated eGaN FET-Based PEBB ..................... 264

11.3 Possible Topologies Using the eGaN PEBB ................................... 266

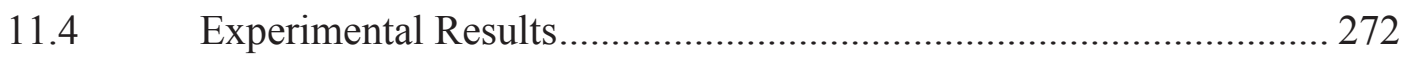

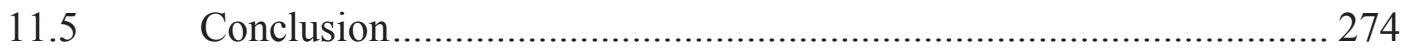

Chapter 12 Power Electronic Building Blocks Using Series-Stacked GaN eHEMT Modules

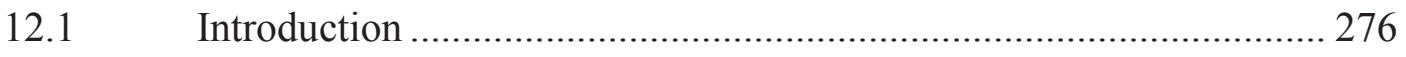

12.2 Examples of the Existing Half-Bridge PEBBs ............................... 277

12.3 The proposed PEBB Using Series-Stacked GaN HEMTs ................ 280 
12.4 The Series-Switch-Driver (SSD) 281

12.5 Possible PEBB Systems ..........................Error! Bookmark not defined.

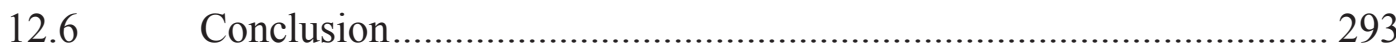

Chapter 13 Conclusions and Future Work ………………....................................... 294

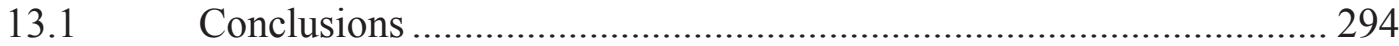

13.2 Recommendations for Future Work .................................................. 298

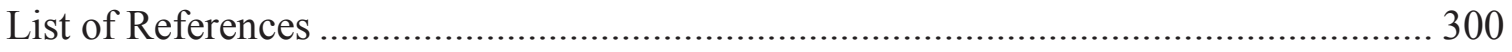

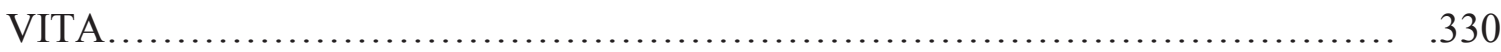




\section{LIST OF TABLES}

TABLE

PAGE

Table 3.1: Comparisons Between Proposed and Other Step-Up Solutions

Comparison.....

Table 3.2: COMPARISON BETWEEN WBG TRANSISTORS AVAILABLE IN

THE MARKET... 64

Table 3.3: MAIN EXPERIMENTAL PARAMETERS OF THE PROPOSED CONVERTER . 69

Table 4.1: SWITCHING STATES OF THE SEMICONDUCTOR DEVICES 77

Table 4.2: COMPARISON BETWEEN THE PROPOSED AND OTHER STEP-

UP DC-DC CONVERTERS. 93

Table 4.3: EXPERIMENT PARAMETERS...... 98

Table 5.1: OPERATING STATES OF THE SEMICONDUCTOR DEVICES 106

Table 5.2: COMPARISON BETWEEN THE PROPOSED AND OTHER STEPUP DC-DC CONVERTERS. 118

Table 5.3: EXPERIMENT PARAMETERS 130

Table 6.1: COMPARISON BETWEEN THE PROPOSED AND OTHER STEPUP DC-DC SOLUTIONS. 154

Table 6.2: MAIN EXPERIMENTAL PARAMETERS OF THE PROPOSED CONVERTER 155

Table 7.1: COMPARISON BETWEEN THE PROPOSED AND OTHER BBB CONVERTERS 170

Table 7.2: Experiment Parameters 179

Table 8.1: Comparison Between the Proposed and Other BDC Topologies..... 198

Table 8.2: Main Experimental Parameters of The Proposed Converter 199

Table 9.1: COMPARISON BETWEEN THE PROPOSED AND OTHER BDC SOLUTIONS.

Table 9.2: Main Experimental Parameters of The Proposed Converter 226

Table 10.1: CHF-LINK SYSTEM CELLS, THEIR FEATURES AND OPERATIONAL MODES . 
Table 10.2: THE SWITCHING MODES FOR CELL J IN PHASE A FOR THE PROPOSED HF AC-LINK CELL 2 .................................................... 247

Table 10.3: SIMULATION MODEL PARAMETERS ............................................ 253

Table 11.1: Material Properties of $\mathrm{GaN}, \mathrm{SiC}$, and $\mathrm{Si}$.................................................. 263

Table 11.2: COMPARISON BETWEEN COMMERCIAL WBG DEVICES............... 264

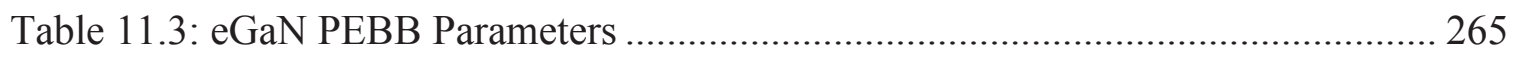

Table 11.4: Parameters For the Experimental Results ............................................ 273 


\section{LIST OF FIGURES}

FIGURE

PAGE

Figure 1.1: Possible multilevel half-bridge-based PEBBs, (a) Flying capacitor leg.

(b) Neutral point clamped leg. 3

Figure 1.2: Two level half-bridge-based PEBB, (a) Using Si/SiC MOSFETs. (b) Using $\mathrm{Si} / \mathrm{SiC}$ IGBTs. 4

Figure 1.3: NPC-based PEBB, (a) Using Si/SiC MOSFETs. (b) Using Si/SiC IGBTs. 5

Figure 1.4: FC-based PEBB, (a) Using Si/SiC MOSFETs. (b) Using Si/SiC IGBTs. ....... 5

Figure 1.5: Design example of a modular-SEPIC-based I-PEBB (a) Block diagram.

(b) Circuit diagram. (c) 3D PCB layout........................................................ 6

Figure 1.6: Possible configurations using the I-PEBB (a) IPOS. (b) ISOS. (c) Three phase differential-mode DC-AC system. (d) Consecutive stacking............... 7

Figure 1.7: A three-phase modular isolated inverter system based on the bidirectional version of the isolated Ćuk converter. 8

Figure 1.8: Generic structure of a power converter with an integrated multilevel network.

Figure 1.9: Generic structure of a power converter with an integrated high-order impedance network

Figure 1.10: Generic structure of a power converter with an integrated multilevel high-order impedance networks.

Figure 1.11: The generic equivalent circuit of a dc-dc converter including the parasitic capacitance between its grounds. 15

Figure 2.1: The typical powertrain of a fuel-cell powered electric vehicle. 20

Figure 2.2: The typical architecture of a grid-connected PV system.............................. 21

Figure 2.3: The typical architecture of a dc microgrid supported with renewable energy sources and energy storage units. 22

Figure 2.4: The typical architecture of an EV powered by energy storage units 22

Figure 2.5: The two-level unidirectional conventional dc-dc converter. 23

Figure 2.6: The three-level unidirectional conventional dc-dc converter. 24 
Figure 2.7: A unidirectional neutral-point-clamped dc-dc converter. 24

Figure 2.8: A unidirectional flying-capacitor dc-dc converter. 25

Figure 2.9: A unidirectional switched-capacitor dc-dc converter with diodecapacitor multipliers. 26

Figure 2.10: A unidirectional switched-capacitor dc-dc converter with diodecapacitor multipliers and a small resonant inductor. 27

Figure 2.11: A modular asymmetrical switched-capacitor dc-dc converter. 27

Figure 2.12: Unidirectional voltage multiplier cell dc-dc converter 1 .......................... 28

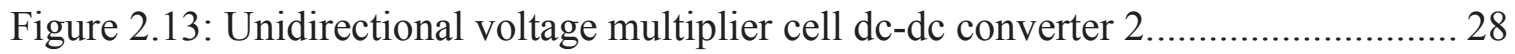

Figure 2.14: Unidirectional voltage multiplier cell dc-dc converter 3......................... 29

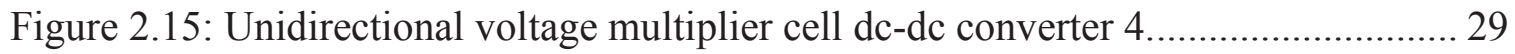

Figure 2.16: Unidirectional voltage multiplier cell dc-dc converter 5......................... 29

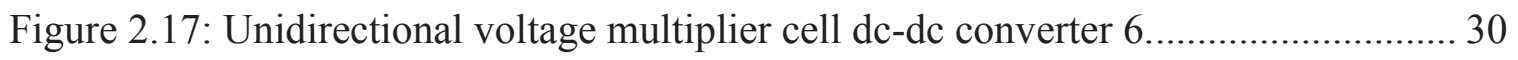

Figure 2.18: Unidirectional voltage Lift cell dc-dc converter 1 ................................... 30

Figure 2.19: Unidirectional voltage Lift cell dc-dc converter 2. ................................. 31

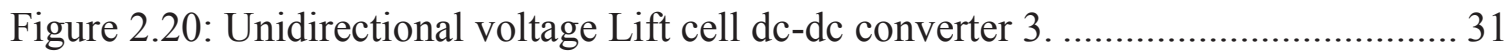

Figure 2.21: Unidirectional active-switched-inductor dc-dc converter 1 . ....................... 32

Figure 2.22: Unidirectional active-switched-inductor dc-dc converter 2 ..................... 32

Figure 2.23: Unidirectional active-switched-inductor dc-dc converter 3...................... 32

Figure 2.24: Cascaded unidirectional boost dc-dc converters. ..................................... 34

Figure 2.25: The basic unidirectional quadratic boost dc-dc converter......................... 34

Figure 2.26: Three-level unidirectional quadratic boost dc-dc converter....................... 34

Figure 2.27: A quadratic boost dc-dc converter with low capacitor voltage................... 35

Figure 2.28: Basic quadratic boost dc-dc converter 1................................................ 35

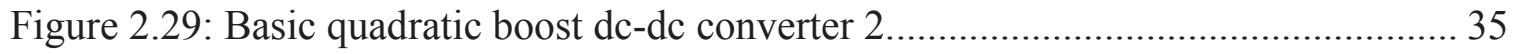

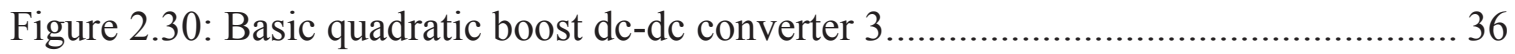


Figure 2.31: The two-level Bidirectional conventional dc-dc converter. 37

Figure 2.32: The bidirectional versions of (a) The flying capacitor converter. (b) The neutral point clamped converter. (c) The three-level converter. 38

Figure 2.33: The bidirectional versions of the switched-capacitor converters discussed in subsection 2.2.3.

Figure 2.34: The bidirectional versions of the switched-inductor converters discussed in subsection 2.2.4. 41

Figure 2.35: The bidirectional versions of the quadratic converters discussed in subsection 2.2.5.

Figure 2.36: Three-phase voltage source inverter, (a) for Buck operation only, (b) With a unidirectional boost converter. (c) With a bidirectional boost converter.

Figure 2.37: (a) Unidirectional ZSI, (b) Bidirectional ZSI, (c) Unidirectional qZSI,

(d) Bidirectional qZSI. 43

Figure 2.38: (a) Unidirectional SSI, (b) Bidirectional SSI. 44

Figure 2.39: (a) Generic DMI connection diagram, (b) Non-isolated Ćuk DMI, (c) Isolated Ćuk DMI. 45

Figure 2.40: The generic structure of an isolated dc-ac inverter. 45

Figure 2.41: The topology of the high-frequency dc-link dc-ac inverter. 47

Figure 2.42: The topology of the high-frequency dc-link dc-ac inverter. 47

Figure 3.1: The schematic of the proposed converter 50

Figure 3.2: Current flow paths when $\mathrm{D}<0.5$. (a) $\mathrm{S} 1 \mathrm{~S} 2=00$. (b) $\mathrm{S} 1 \mathrm{~S} 2=10$. (c) $\mathrm{S} 1 \mathrm{~S} 2=01$. 50

Figure 3.3: Current flow paths when $\mathrm{D}>0.5$. (a) $\mathrm{S} 1 \mathrm{~S} 2=11$. (b) $\mathrm{S} 1 \mathrm{~S} 2=10$. (c) $\mathrm{S} 1 \mathrm{~S} 2=01$. 50

Figure 3.4: Key waveforms of the proposed converter (a) $\mathrm{D}<0.5$. (b) $\mathrm{D}>0.5$. 51

Figure 3.5: Comparison between the proposed converter and other step-up converters. (a) Gain vs. duty cycle. (b) Voltage stress vs. duty cycle. 62

Figure 3.6: Experimental setup. 69

Figure 3.7: Experimental results when Vin $=200 \mathrm{~V}, \mathrm{D}=0.3, \mathrm{RL}=120 \Omega$, Pout $=$ $1.15 \mathrm{~kW}$. 72 
Figure 3.8: Experimental results when $\mathrm{Vin}=100 \mathrm{~V}, \mathrm{D}=0.7, \mathrm{RL}=120 \Omega$, Pout $=$ $1.3 \mathrm{~kW}$

Figure 3.9: Calculated loss distributions for the experiment (a) When Vin $=200 \mathrm{~V}$, $\mathrm{D}=0.3$, and $\mathrm{RL}=120 \Omega$. (b) When $\mathrm{Vin}=100 \mathrm{~V}, \mathrm{D}=0.7$, and $\mathrm{RL}=$ $120 \Omega$.

Figure 3.10: Efficiency curves of the proposed converter $(\mathrm{V}$ in $=100 \mathrm{~V}, \mathrm{RL}=120 \Omega$ )

(a) When $\mathrm{D}<0.5$. (b) When $\mathrm{D} \geq 0.5$. 74

Figure 3.11: Calculated efficiency curves in the GOA $(\mathrm{Vin}=100 \mathrm{~V}, \mathrm{RL}=120 \Omega)$........ 74

Figure 4.1: The schematic of the proposed converter. 77

Figure 4.2: Key waveforms of the proposed converter. (a) CCM operation. (b) DCM operation. 79

Figure 4.3: Equivalent circuits of the proposed converter. (a) Switching state I. (b)

Switching state II. (c) Switching state III. 80

Figure 4.4: Equivalent circuit of the proposed converter with the parasitic elements...... 84

Figure 4.5: Voltage gain curves of the proposed converter. 85

Figure 4.6: Power switch and diodes currents in DCM. 87

Figure 4.7: Boundary condition of the proposed converter. 89

Figure 4.8: Comparison of voltage gain M_CCM versus duty cycle d. (a) Between the proposed converter, conventional boost converter, converters in [179], [180], and [178]. (b) Between the proposed converter, converters in [181], [182], [33], and [110].

Figure 4.9: Normalized maximum voltage stress across the power switches in the compared converters

Figure 4.10: Normalized maximum voltage stress across the diodes in the compared converters 91

Figure 4.11: Stored energy in the inductors of the compared converters at different voltage gain values.

Figure 4.12: Stored energy in the capacitors of the compared converters at different voltage gains.

Figure 4.13: Semiconductor utilization factor of the compared converters at different voltage gain values. 92

Figure 4.14: Experimental prototype. 98 
Figure 4.15: Experimental results. (a) Current of L1, and voltage stress across Q, (b) Currents of L2 and L3, (c) Voltages across C1, C2, C3, and C4, (d) Output voltage and output current, (e) Voltage stresses across D1, D2, and D3, (f) Current stresses of Q and D1 100

Figure 4.16: (a) Inductor currents during start-up, (b) Voltages across C1, C2, and C4 during start-up, (c) Voltages across C3 and Co during stat-up. 101

Figure 4.17: Calculated power loss distributions for the experiment (Vin $=50 \mathrm{~V}$, Vo $=400 \mathrm{~V}$, and $\mathrm{R}=100 \Omega$ ).

Figure 4.18: Efficiency curves of the proposed converter $\left(\mathrm{Vo}_{\mathrm{o}}=400 \mathrm{~V}\right.$, $\mathrm{Vin}=40 \rightarrow 120 \mathrm{~V}$, output power $=800 \mathrm{~W}, 1200 \mathrm{~W}$, and $1600 \mathrm{~W})$. 102

Figure 5.1: The proposed step-up converter. 105

Figure 5.2: Current flow paths during the three operating states. (a) Operating state I. (b) Operating state II. (c) Operating state III. 106

Figure 5.3: Key waveforms of the proposed converter. (a) CCM operation. (b) DCM operation. 110

Figure 5.4: Boundary condition between DCM and CCM operations for the proposed converter.

Figure 5.5: Comparison of voltage gain $M$ versus duty cycle d. (a) Between the proposed converter, the TLB converter, converters in [184], [185], and [180]. (b) Between the proposed converter, converters in [178], [181], [186], and [183]. (c) Between the proposed converter and the converters in [187], [179], [110], and [182]....

Figure 5.6: Maximum normalized voltage stress on the power switches in the compared converters.

Figure 5.7: Maximum normalized voltage stress on the diodes in the compared converters. 121

Figure 5.8: Closed-loop PI voltage controller of the proposed converter. 128

Figure 5.9: Bode plot of the compensated transfer function of the proposed converter.

Figure 5.10: Experimental setup 130

Figure 5.11: Experimental results of case study I. 135

Figure 5.12: Breakdown of losses in Case I 135

Figure 5.13: Measured efficiency curves. 136 
Figure 5.14: Experimental results for case study II.............................................. 137

Figure 6.1: The schematic of the proposed converter.............................................. 140

Figure 6.2: Figure 6.2: Key waveforms of the proposed converter. (a) CCM operation. (b) DCM operation.

Figure 6.3: Equivalent circuits of the proposed converter (a) During State 1. (b) During State 0. 142

Figure 6.4: The proposed converter with the parasitic elements. 144

Figure 6.5: Static voltage gain curves for the ideal/non-ideal models of the proposed converter. 144

Figure 6.6: Current flow paths during the third switching state (in DCM). 149

Figure 6.7: Boundary condition between CCM and DCM operations for the proposed topology.

Figure 6.8: Voltage gain curves of the compared converters. 152

Figure 6.9: Maximum normalized voltage stress on the switches of the compared converters.

Figure 6.10: (a) Utilization factor of power switches. (b) Utilization factor of diodes. 153

Figure 6.11: Experimental prototype. 156

Figure 6.12: Experimental results 157

Figure 6.13: Distributions of the calculated power loss for the experiment 158

Figure 6.14: Measured efficiency curves of the proposed converter versus $V_{\text {in }}$ 159

Figure 6.15: Measured efficiency curves of the proposed converter versus $P_{o}$ 159

Figure 7.1: The schematic of the proposed converter. 162

Figure 7.2: Current-flow paths of the proposed converter in the A-to-B operation.

(a) State 0: G1 G2 G3 = 100. (b) State 1: G1 G2 G3 = 011 . 163

Figure 7.3: Current-flow paths of the proposed converter in the B-to-A operation.

(a) State 0: G1 G2 G3 = 100. (b) State 1: G1 G2 G3 = 011 . 164

Figure 7.4: Typical waveforms of the proposed converter. (a) A-to-B operation. (b) B-to-A operation. 166 
Figure 7.5: Other BBB converters. (a) Conventional BBB converter. (b) Converter in [192]. (c) Bidirectional version of the KY-based converter in [190]. (d) CBB-IIM. (e) CBB-CIM. (f) Bidirectional version of the quadratic converter in [191]. 168

Figure 7.6: Comparison of voltage gain between the proposed converter and other BBB converters. (a) A-to-B operation. (b) B-to-A operation. 169

Figure 7.7: Normalized voltage stress on the switches of the compared converters..... 169

Figure 7.8: Closed-loop voltage controller. (a) A-to-B operation. (b) B-to-A operation.

Figure 7.9: Bode plots of the compensated transfer functions with PI controllers. (a) A-to-B operation. (b) B-to $\neg$-A operation. 178

Figure 7.10: Experimental prototype. 179

Figure 7.11: Experimental results for case study I. 180

Figure 7.12: Figure 7.11: Experimental results for case study II. 180

Figure 7.13: Gate signals and the voltage stress across the synchronous rectification transistors. (a) Case study I. (b) Case study II

Figure 7.14: Dynamic behavior of the proposed converter due to step-change in load. (a) In A-to-B operation. (b) In B-to-A operation. 181

Figure 7.15: Calculated power loss distributions for the experiment. (a) In case study I. (b) In case study II. 183

Figure 7.16: Measured efficiency curves of the proposed converter in A-to-B and $\mathrm{B} \neg$-to-A operations $(\mathrm{VB}=400 \mathrm{~V}, \mathrm{VA}=50 \rightarrow 500 \mathrm{~V})$ 184

Figure 7.17: Bidirectional power flow transition test circuit. 185

Figure 7.18: Dynamic behavior of the proposed converter due to step-change in load. (a) In A-to-B operation. (b) In B-to-A operation. 185

Figure 8.1: The structure of the proposed step-up dc-dc converter. 187

Figure 8.2: Current flow paths for step-up mode. (a) State 1. (b) State 0...................... 188

Figure 8.3: Current flow paths for step-down mode. (a) State 1. (b) State 0................. 188

Figure 8.4: Key waveforms of the proposed converter. (a) Step-up mode. (b) Stepdown mode. 
Figure 8.5: Voltage gain of the compared converters in the step-up mode versus the duty cycle.

Figure 8.6: Voltage gain of the compared converters in the step-down mode versus the duty cycle.

Figure 8.7: Maximum normalized voltage stress on the switches of the compared converters versus the voltage gain.

Figure 8.8: Switch utilization factor for the compared converters.

Figure 8.9: Experimental prototype. 200

Figure 8.10: Experimental results of case study I. 203

Figure 8.11: Experimental results of case study II. 203

Figure 8.12: Dynamic performance under wide-range of voltage gain $(\mathrm{VH}=800 \mathrm{~V}$, $\mathrm{VL}=80 \mathrm{~V} \rightarrow 200 \mathrm{~V}$, and $\mathrm{Po}=2 \mathrm{~kW}$ ). (a) Step-up mode. (b) Step-down mode. 204

Figure 8.13: Calculated power loss distributions for the experiment. (a) In case study I. (b) In case study II. 204

Figure 8.14: Measured efficiency curves of the proposed converter $(\mathrm{VH}=800 \mathrm{~V}$, $\mathrm{VL}=80 \mathrm{~V} \rightarrow 200 \mathrm{~V}, \mathrm{Po}=1 \mathrm{~kW}$, and $2 \mathrm{~kW})$. 205

Figure 9.1: The structure of the proposed bidirectional dc-dc converter. 207

Figure 9.2: Current flow paths in step-up mode. (a) State 1. (b) State 0...................... 208

Figure 9.3: Current flow paths in step-down mode. (a) State 1. (b) State 0. 209

Figure 9.4: Important waveforms of the proposed converter. (a) Step-up mode. (b) Step-down mode.

Figure 9.5: Comparison of voltage gain between the proposed converter and other BDC solutions. (a) In step-up mode. (b) In step-down mode.

Figure 9.6: Semiconductor utilization factor for the compared BDC solutions.

Figure 9.7: The extended structure of the proposed converter with $\mathrm{n}$ switchedcapacitor cells.

Figure 9.8: Voltage gain of the proposed extended structure with different number of switched-capacitor cells. (a) In step-up mode. (b) In step-down mode. 
Figure 9.9: Semiconductor utilization factor of the proposed extended structure with different number of switched-capacitor cells.

Figure 9.10: Experimental prototype.

227

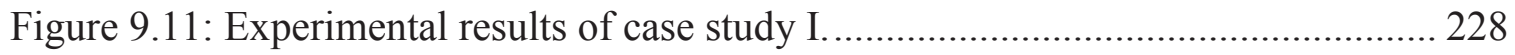

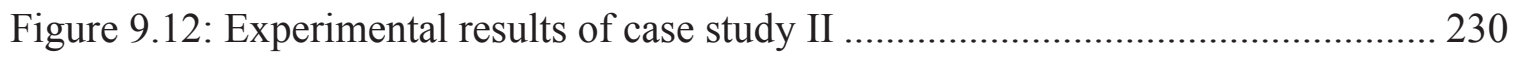

Figure 9.13: Performance of the proposed converter under wide-range of voltage gain $(\mathrm{VH}=800 \mathrm{~V}, \mathrm{VL}=80 \mathrm{~V} \rightarrow 160 \mathrm{~V}$, and $\mathrm{Po}=2 \mathrm{~kW})$. (a) Step-up mode. (b) Step-down mode.

Figure 9.14: Dynamic performance of the proposed converter under abrupt change in load. (a) Step-up mode. (b) Step-down mode. 232

Figure 9.15: Calculated power loss distributions for the experiment (a) Case study I. (b) Case study II.

Figure 9.16: Measured efficiency curves of the proposed converter in step-up and step-down modes $(\mathrm{VH}=800 \mathrm{~V}, \mathrm{Po}=1 \mathrm{~kW}, 2 \mathrm{~kW}$, and VL $=80 \mathrm{~V} \rightarrow 160 \mathrm{~V}) . .233$

Figure 10.1:Generic Block Diagram of a CHF-link System. 236

Figure 10.2: (a) The proposed PV-assisted fast charging station with the CHF aclink cell 1. (b) The proposed PV-assisted fast charging station with the CHF ac-link cell 2 .

Figure 10.3: The proposed multilevel HCC for phase a......................................... 245

Figure 10.4: The flowchart of the level selector algorithm. .................................... 245

Figure 10.5: Design example of CHF ac-link system with two cells per phase. ........... 246

Figure 10.6: Single line diagram of the proposed PV-assisted EV charging station and its control scheme in normal operation and during grid faults.

Figure 10.7: Operational modes of the proposed HF ac-link cell 2. 250

Figure 10.8: (a) Phasor diagram of the system without applying the VPCC regulator, (b) phasor diagram of the system with the VPCC regulator applied.....

Figure 10.9: Reactive current requirement during grid fault, according to the E.ON code. 252

Figure 10.10: Phase voltages of the CHF-link system with the proposed HF ac-link cell 1 with (a) 8 cells, (b) 6 cells, (c) 4 cells, and (d) 2 cells per phase...... 255 
Figure 10.11: Phase voltages of the CHF-link system with the proposed HF ac-link cell 2 with (a) 8 cells, (b) 6 cells, (c) 4 cells, and (d) 2 cells per phase...... 255

Figure 10.12: (a) THD\% for different number of cells/phase with both of the proposed cells, (b) Total number of switches of the secondary side converters with different number of cells/phase with both of the proposed cells. 255

Figure 10.13: Dynamic performance of the bidirectional power flow controller. 258

Figure 10.14: System response at two power flow levels (a) Power flow through the PCC, (b) Phase a voltage at PCC, and phase a current.............................. 258

Figure 10.15: Dynamic performance of the PCC voltage regulator. ............................ 259

Figure 10.16: Evaluation of the LVRT capability of the proposed CHF ac-link

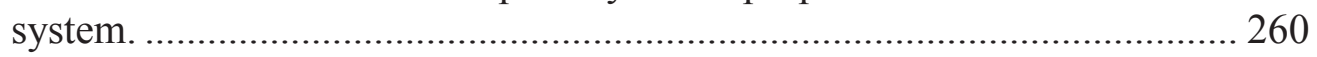

Figure 11.1: Generic structure of the lateral eGaN-FET HEMT................................. 262

Figure 11.2: eGaN FET PEBB schematic: power stage, driver, voltage regulation, filter stage and control. ........................................................................ 266

Figure 11.3: eGaN FET PEBB (a) top side, (b) bottom side. .................................... 267

Figure 11.4: Possible configurations with the eGaN PEBB. ..................................... 269

Figure 11.5: (a) Differential-mode 1-ph buck-boost inverter, (b) modulation (in case of non-inverting converters), (c) modulation (in case of inverting converters).

Figure 11.6: (a) Differential-mode 3-ph buck-boost inverter, (b) modulation (in case of non-inverting converters), (c) modulation (in case of inverting converters), (d) 3-ph line-line voltages.

Figure 11.7: (a) Differential-mode 1-ph buck-boost inverter circuit, (b) Connection diagram, (c) Experimental setup. 273

Figure 11.8: (a) Differential-mode output voltage of the inverter. (b) Output voltage of each converter. 274

Figure 12.1: Possible multilevel half-bridge-based PEBBs....................................... 277

Figure 12.2: Two level half-bridge-based PEBB................................................ 278

Figure 12.3: Two level half-bridge-based PEBB Using GaN HEMTs........................ 278

Figure 12.4: NPC-based PEBB, (a) Using Si/SiC MOSFETs. (b) Using Si/SiC IGBTs. 279 
Figure 12.5: FC-based PEBB, (a) Using Si/SiC MOSFETs. (b) Using Si/SiC

IGBTs. 279

Figure 12.6: The proposed PEBB using series-stacked GaN modules........................ 280

Figure 12.7: A GaN module of two HEMTs and the SSD. ......................................... 282

Figure 12.8: A GaN module of more than two HEMTs and the SSD......................... 283

Figure 12.9: A synchronous buck DC-DC converter (a) Connection diagram. (b)

Circuit. 285

Figure 12.10: A bidirectional inverting buck-boost DC-DC converter (a) Connection diagram. (b) Circuit. 286

Figure 12.11: A bidirectional non-inverting buck-boost DC-DC converter (a) Connection diagram. (b) Circuit. .... 287

Figure 12.12: A single-phase buck DC-AC inverter (a) Connection diagram. (b) Circuit. 288

Figure 12.13: A single-phase boost DC-AC inverter (a) Connection diagram. (b) Circuit. 289

Figure 12.14: A single-phase buck-boost DC-AC inverter (a) Connection diagram. (b) Circuit. 290

Figure 12.15: A three-phase buck DC-AC inverter (a) Connection diagram. (b) Circuit. ..... 291

Figure 12.16: A three-phase buck-boost DC-AC inverter (a) Connection diagram. (b) Circuit. 


\section{LIST OF ACRONYMS}

\begin{tabular}{|c|c|}
\hline PV & Photovoltaic \\
\hline EV & Electric Vehicle \\
\hline MV & Medium Voltage \\
\hline LV & Low Voltage \\
\hline$P C C$ & Point of Common Coupling \\
\hline LVRT & Low Voltage Ride-Through \\
\hline $\mathrm{HCC}$ & Hysteresis Current Controller \\
\hline $\mathrm{MF}$ & Medium Frequency \\
\hline $\mathrm{HF}$ & High Frequency \\
\hline $\mathrm{CHF}$ & Cascaded High Frequency \\
\hline ESS & Energy Storage System \\
\hline MPPT & Maximum Power Point Tracker \\
\hline RMS & Root Mean Square \\
\hline$n$ & Number of cells per phase \\
\hline$m$ & $\begin{array}{l}\text { Transformer turns ratio between the primary and one of } \\
\text { the secondary windings }\end{array}$ \\
\hline$C_{d c}$ & Capacitor connected to the LV dc bus of the station \\
\hline$V_{D C}$ & Voltage of the LV dc bus of the station \\
\hline$V_{P C C}$ & RMS Voltage at the $P C C$ \\
\hline$P_{P C C}$ & Active power flowing through the $P C C$. \\
\hline$Q_{P C C}$ & Reactive power flowing through the $P C C$. \\
\hline
\end{tabular}


$i_{d}^{*}, i_{q}^{*} \quad$ Reference d-q components of the 3-phase grid currents flowing through the $P C C$ under normal operation

$i_{d}, i_{q} \quad \mathrm{~d}$-q components of the 3-phase grid currents flowing through the $P C C$

$i_{d l v}^{*}, i_{q l v}^{*} \quad$ Reference d-q components of the 3-phase grid currents flowing through the $P C C$ for LVRT operation

\begin{tabular}{|c|c|}
\hline cell $_{\mathrm{ij}}$ & Cell number $j$ in phase $i$ \\
\hline$K_{i j}$ & Switching state of cell ${ }_{\mathrm{ij}}$ \\
\hline$H_{i j}$ & Desired output state of cell $\mathrm{i}_{\mathrm{ij}}$ \\
\hline$r_{i}$ & Polarity signal of phase $i$ current \\
\hline$Q$ & $\begin{array}{l}\text { Switching state of the single phase inverter connected to } \\
\text { the transformer primary winding }\end{array}$ \\
\hline$e(k)$ & Current error signal at instant $k$ \\
\hline$e(k-1)$ & Delayed current error signal at instant $k-1$ \\
\hline$i_{a}, i_{b}, i_{c}$ & 3-phase currents flowing through the $P C C$ \\
\hline Irated & Rated current of the CHF ac-link system \\
\hline$P_{E V}$ & EV chargers power demand. \\
\hline$P_{P V}$ & Generated PV power \\
\hline$K_{P 1}$ & Proportional coefficient of PI controller 1 \\
\hline$K_{I 1}$ & Integral coefficient of PI controller 1 \\
\hline$K_{P 2}$ & Proportional coefficient of PI controller 2 \\
\hline$K_{I 2}$ & Integral coefficient of PI controller 2 \\
\hline
\end{tabular}




$\begin{array}{ll}\text { GaN } & \text { Gallium Nitride } \\ \mathrm{SiC} & \text { Silicon Carbide } \\ \mathrm{Si} & \text { Silicon } \\ \text { PEBB } & \text { Power Electronic Building Block } \\ \text { SC } & \text { Switched-Capacitor } \\ \text { SL } & \text { Switched-Inductor }\end{array}$




\section{Chapter 1 Introduction to Power Electronic Building Blocks}

\subsection{Introduction}

There is a growing global interest in adopting renewable energy sources at large-scale to decrease the reliance on fossil fuels and reduce the $\mathrm{CO}_{2}$ emissions [1]-[14]. In addition, the recent developments in energy storage systems made the electrification of transportation more economically feasible [15]-[30].

Power electronic converters play a critical role in interfacing the different power sources and the loads, where they can provide the following functions:

1) Solving the voltage mismatch between the power source bus and the load bus.

2) Extract the maximum power from a power source (e.g. photovoltaic systems, wind energy turbines, fuel cells, etc.).

3) May provide galvanic isolation between the power sources and the load.

4) Control the speed and torque of electric motors.

5) In case of grid-connected power electronic systems, they can support the voltage during voltage sags and support the nominal grid frequency during contingencies, by adequately controlling the injected active and reactive power to the grid [31][45].

The concept of the Power Electronic Building Blocks (PEBBs) is based on synthesizing all the important power electronic systems from few generic power electronic structures, which are referred to as PEBBs. This approach can result in the following outcomes:

1) Reduction of the number of the spare parts of the power electronic systems onboard a ship or an aircraft. 
2) The mass production of few generic structures can dramatically reduce the total cost of the power electronic systems.

3) Reduction of the complexity of the maintenance of the power electronic systems.

The two-level synchronous buck structure (push-pull configuration) is the basic building block of all the conventional power electronic systems (i.e. buck dc-dc converter, boost dc-dc converter, buck-boost dc-dc converter, single-phase dc-ac inverter, three-phase dc-ac inverter, single-phase ac-dc active rectifier, and three-phase ac-dc active rectifier), due to its simple circuit structure, low number of active and passive components, simple controller structure, and simple gate driver circuits. In addition, it has a common ground between its input and output ports which reduces the electromagnetic interference (EMI) noise and require less periodic maintenance. Nevertheless, the voltage-conversion-ratios of this converter are low, hence, to achieve a high voltage conversion ratio, the converter needs to operate at an extreme duty cycle value where its efficiency deteriorates significantly [46].

Designing high-order power electronic converters with wide-voltage-conversion-ratios as PEBBs can be a step forward towards more efficient and compact power electronic systems. The different categories of the PEBBs and their different configurations will be briefly presented. Then, the utilization of high-voltage series-stacked wide-bandgap (WBG) devices will be discussed.

\subsection{Overview of the Power Electronic Building Blocks}

The Power Electronic Building Block (PEBB) is a generic power electronic converter circuit that can be configured in different ways to synthesize popular power electronic architectures (DC-DC, DC-AC, AC-DC, and AC-AC converters). This can reduce the number of spare parts needed onboard a ship, plane, ... etc., also the PEBB can reduce the 
manufacturing cost of the power electronic systems since the mass production of one generic power electronic architecture is more economical than producing application-specific power electronic architectures.

Many literature have discussed different possible architectures for the PEBB, however, all of them are either implemented using Silicon (Si), or Silicon Carbide (SiC) Metal Oxide Field Effect Transistors (MOSFETs) or Insulated Gate Bipolar Junction Transistors (IGBTs) [47][49], which suffer from high conduction and switching losses. In [50], a PEBB is built with Gallium Nitride (GaN) High Electron Mobility Transistors (HEMTs) to reduce the conduction and switching losses of the transistors, since the GaN HEMTs have lower on resistance (Ron) and less device total charge. The major problem with GaN HEMTs is that their break down voltage is relatively lower compared to $\mathrm{Si}$ and $\mathrm{SiC}$ MOSFETs or IGBTs, which limits the utilization of GaN HEMTs to the low voltage applications. Multilevel half-bridge configurations can enable the utilization of GaN HEMTs in high voltage applications.

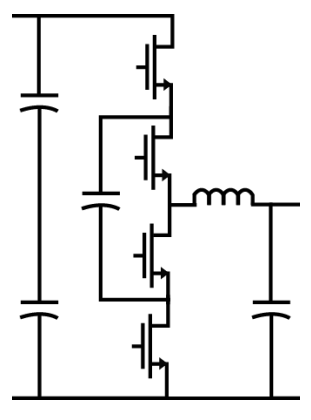

(a)

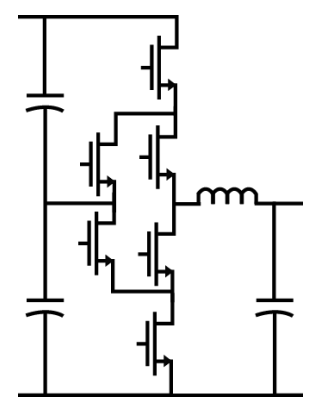

(b)

Figure 1.1: Possible multilevel half-bridge-based PEBBs, (a) Flying capacitor leg. (b) Neutral point clamped leg.

These multilevel half-bridge configurations can possibly be based on a flying capacitor (FC) leg (as shown in Figure 1.1(a)) or a neutral point clamped (NPC) leg (as shown in Figure 1.1(b)). The major problem of multilevel configurations is that they require a complex control scheme and more switches (as in the NPC) or more high voltage capacitors (as in the FC). The 
two level half-bridge-based PEBB is the most popular topology in literature and is composed of two transistors, these transistors can be either Si or SiC MOSFETs (shown in Figure 1.2(a)) or IGBTs (shown in Figure 1.2(b)). This PEBB architecture is limited by the rated voltage of the transistors and suffers from high switching and conduction losses.

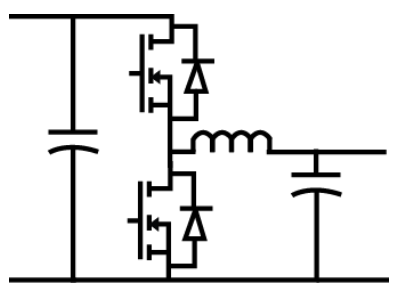

(a)
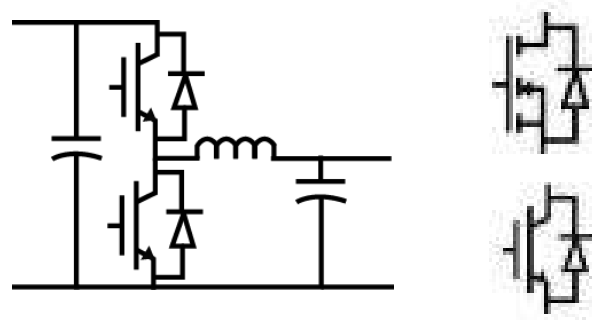

SIISTE ICAT SMntuY

Figure 1.2: Two level half-bridge-based PEBB, (a) Using Si/SiC MOSFETs. (b) Using $\mathrm{Si} / \mathrm{SiC}$ IGBTs.

As a solution to extend the operating voltage of the PEBB beyond the rated voltage of the single transistors, a multilevel neutral-point-clamped (NPC) half-bridge can be a PEBB.

The rated voltage of this $\mathrm{PEBB}=($ number of levels -1$) \mathrm{X}$ rated voltage of each transistor. In [48], and [49], a NPC half-bridge-based PEBB built with SiC MOSFETs is presented. This NPC can be built with Si/SiC MOSFETs (as shown in Figure 1.3(a)), Si/SiC IGBTs (as shown in Figure 1.3(b)), or GaN HEMTs (as shown in Figure 1.1(b)). The major disadvantages of this PEBB architecture:

- $\quad$ Requires high number of semiconductor devices.

- $\quad$ Requires a complex control scheme.

Another architecture that can be used to extend the rated voltage of the PEBB beyond the rated voltage of the single transistors is a flying-capacitor (FC) half-bridge-based PEBB, where a FC half-bridge is used as a PEBB.

The rated voltage of this $\mathrm{PEBB}=($ number of levels -1$) \mathrm{X}$ rated voltage of each transistor. 
This FC can be built with Si/SiC MOSFETs (as shown in Figure 1.4(a)), Si/SiC IGBTs (as shown in Figure 1.4(b)), or GaN HEMTs (as shown in Figure 1.1(a)). The major disadvantages of this PEBB architecture:

- $\quad$ Requires high number of capacitors, which increases the weight and size.

- $\quad$ Requires a complex control scheme.

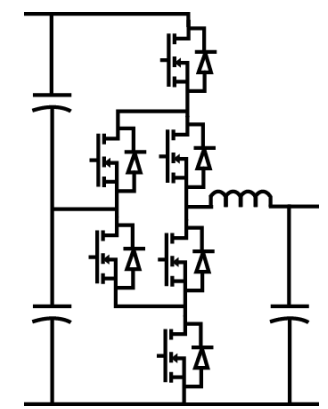

(a)

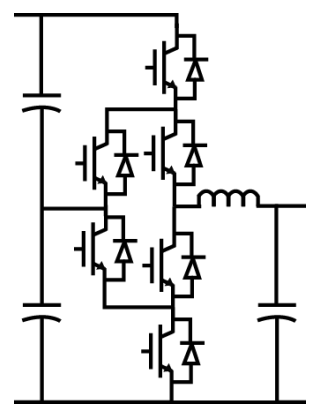

(b)

Figure 1.3: NPC-based PEBB, (a) Using Si/SiC MOSFETs. (b) Using Si/SiC IGBTs.

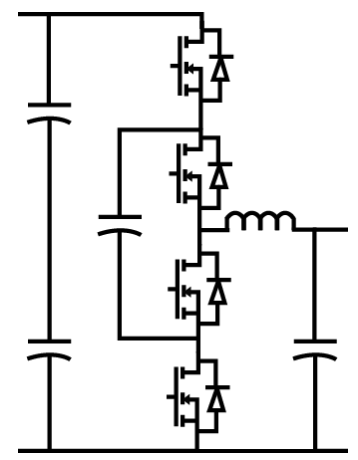

(a)

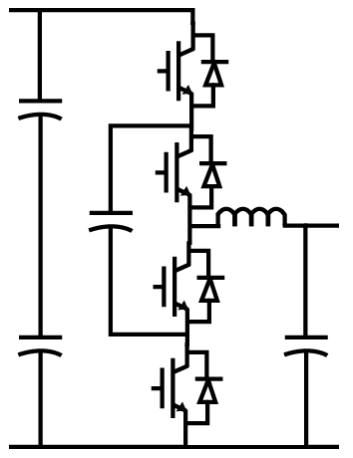

(b)

Figure 1.4: FC-based PEBB, (a) Using Si/SiC MOSFETs. (b) Using Si/SiC IGBTs.

\subsection{Isolated Power Electronic Building Blocks}

The isolated power electronic building block (I-PEBB) is basically an isolated generic power electronic structure that can be used to perform any dc-dc, dc-ac, ac-dc, or ac-ac process. This I-PEBB can be based on the bidirectional version of any dc-dc converter (e.g. 
flyback, forward, isolated SEPIC, isolated Ćuk, etc.). . A design example of an I-PEBB based on a modular bi-directional isolated SEPIC converter with an active energy buffer (AEB) is shown in Figure 1.5, where the block diagram of the I-PEBB is shown in Figure 1.5(a) and it consists of an input port (port I), output port (port II), high frequency (HF) isolation, and an AEB. The AEB can be achieved using two transistors in push-pull configuration with a small LC filter, as shown in Figure 1.5(b).

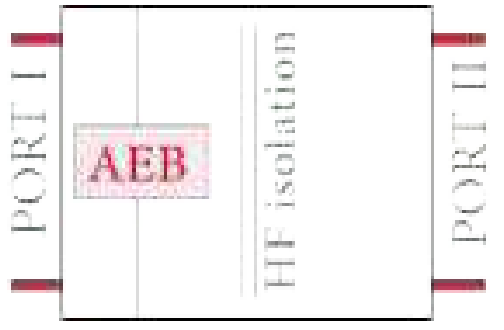

(a)

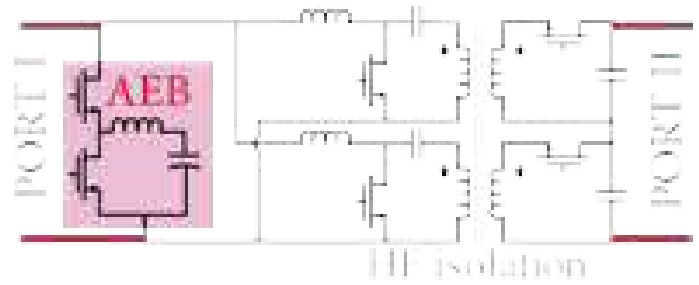

(b)

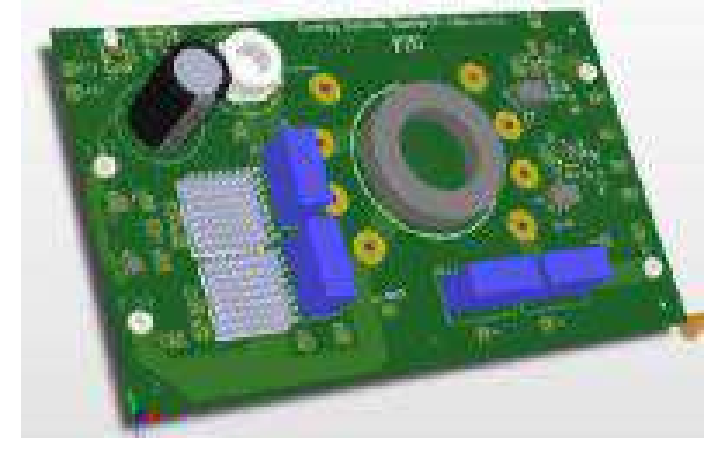

(c)

Figure 1.5: Design example of a modular-SEPIC-based I-PEBB (a) Block diagram. (b) Circuit diagram. (c) 3D PCB layout.

The AEB acts as an active power decoupling stage between two consecutive I-PEBBs. The HF magnetic isolation is integrated on the PCB of the I-PEBB, as shown in Figure 1.5(c). 


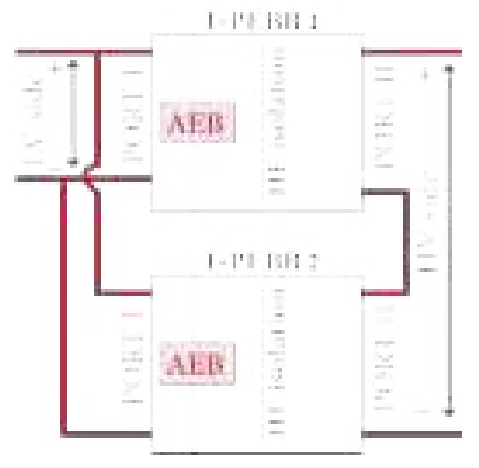

(a)

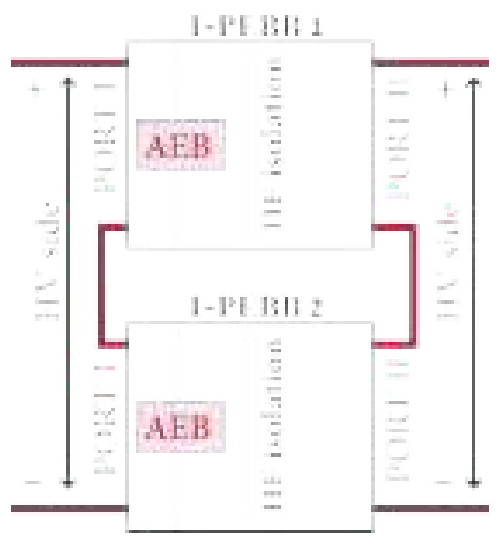

(b)

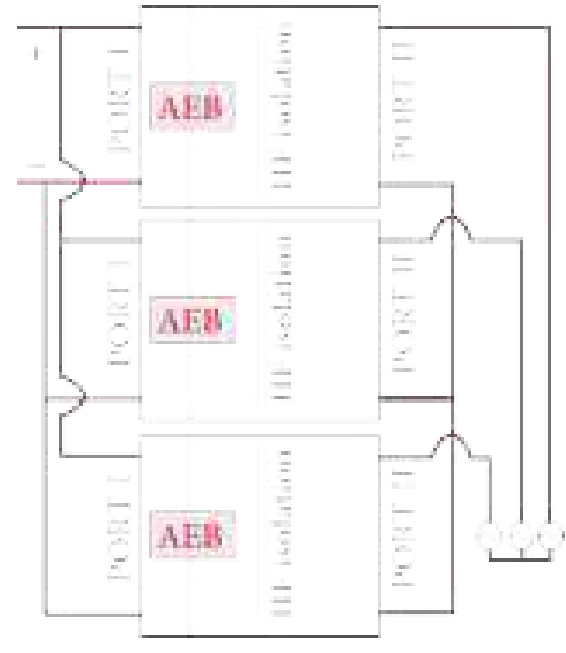

(c)

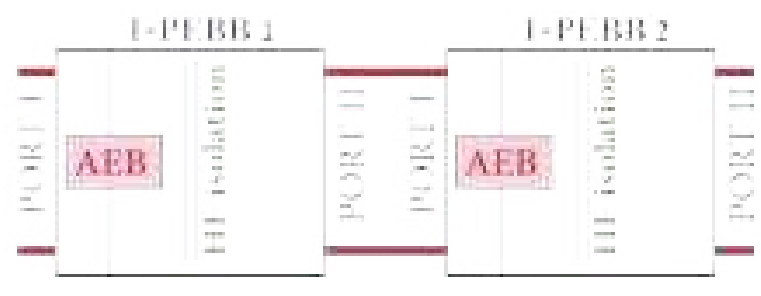

(d)

Figure 1.6: Possible configurations using the I-PEBB (a) IPOS. (b) ISOS. (c) Three phase differential-mode DC-AC system. (d) Consecutive stacking.

The I-PEBB provides galvanic isolation between the input and output ports, hence, it can be used to synthesize any power processing system based on "Input-Parallel-Output-Series" (IPOS), or "Input-Series-Output-Series" (ISOS) architectures, as shown in Fig. 1.6(a) and Fig. 1.6(b), respectively. Both ISOS and IPOS architectures can be used to synthesize power converters that can be used for medium and high voltage applications. Isolated DC/AC power processing systems can be synthesized using two I-PEBBs (for single phase) or using three IPEBBs (for three phase) systems, as shown in Fig. 1.6(c). Consecutive stacking of the IPEBBs can be used to synthesize more complex systems such as AC/AC power processing systems. 


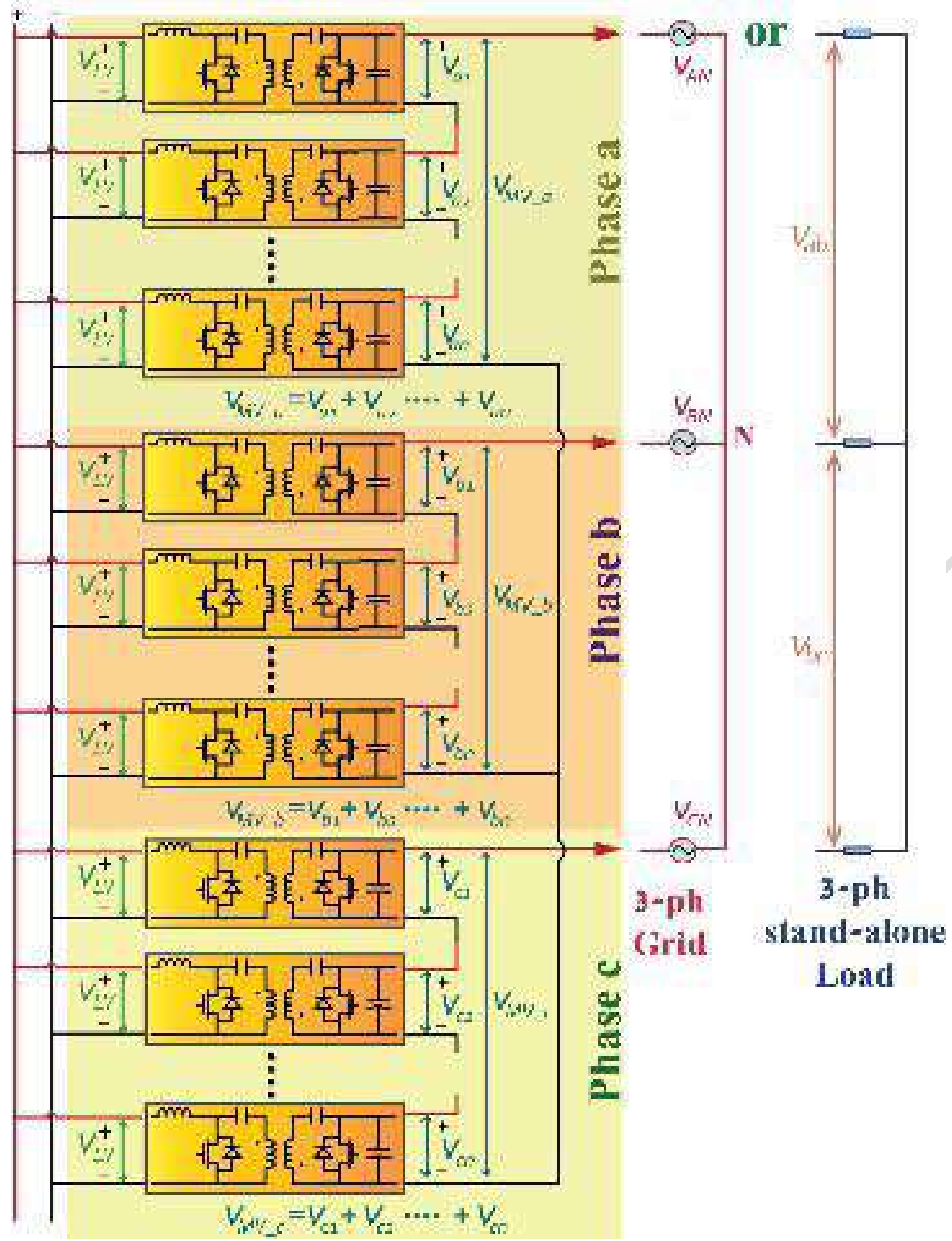

Figure 1.7: A three-phase modular isolated inverter system based on the bidirectional version of the isolated Ćuk converter.

A three-phase modular inverter based on the bidirectional Ćuk converter is shown in Figure

1.7, as each phase is composed of an IPOS system. This topology is an example of an I-PEBB based on the Ćuck converter-based I-PEBB. 


\subsection{Transformerless High-Order Power Electronic Building Blocks}

In the past decade solid-state transformers (SST) have emerged as a promising compact solution to interface low voltage sources/loads to the MVDC bus of the ship by utilizing transformers operating at high frequencies $(1 \mathrm{kHz}<$ frequency $<100 \mathrm{kHz})$.

The advent of wide-bandgap (WBG) semiconductor devices (i.e. Silicon Carbide (SiC), and Gallium Nitride (GaN) devices) which can switch efficiently at frequencies higher than $100 \mathrm{kHz}$, enables the power electronic stages to operate at these high switching frequencies.

With the advancements taking place to these WBG devices and the increasing capability to switch at much higher frequencies, the utilization of the SST with high-frequency transformers faces a big challenge. This challenge is due to the increasing core losses of these transformers which puts a limit to the reduction of the power electronic stage size and weight. Adopting multilevel switching networks have the following advantages:

1) Distribution of the voltage stress over the power transistors, which enables the utilization of transistors with low voltage rating, which leads to a more efficient power conversion process.

2) The effective frequency that is used to design the passive components (inductors, and capacitors) equals (n-1). $f_{s}$, where $n$, and $f_{s}$ are the number of levels of the switching network, and the switching frequency, respectively. This feature minimizes the needed capacitance and inductance of the converter, leading to minimization of the passive components size. For instance, if $\mathrm{f}_{\mathrm{s}}=100 \mathrm{kHz}$, and $\mathrm{n}=16$, the effective switching frequency used to design the passive components $=1.5 \mathrm{MHz}$.

The generic structure of a converter with a multilevel switching network is shown in Figure

1.8. It is composed of an array of transistors and an intermediary circuit. This intermediary 
circuit is usually a capacitor network (i.e. flying capacitor network), or a diode network (i.e. neutral point clamped network), and this intermediary network distributes the voltage stress equally across the transistors.

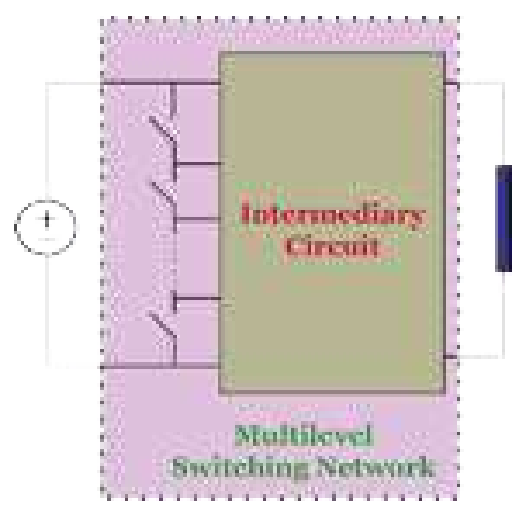

Figure 1.8: Generic structure of a power converter with an integrated multilevel network.

Adopting High-Order Impedance networks have the following advantages:

1) Enhancing the voltage gain of the power electronic stage.

2) Reducing the voltage stress on the power transistors.

The high impedance network is composed of a number of capacitors and inductors to enhance the voltage gain of the power converter and enable it to reach high values without the need for a transformer.

It is worth mentioning that, for high frequency operation $(>1 \mathrm{MHz})$, the inductors will work in continuous conduction mode (CCM) with ripple current less than 5\%, thus, the core losses of the inductors of the high impedance networks can be neglected.

A generic architecture of a converter with high-order impedance networks is shown in Figure 1.9. The impedance networks can either be before the switching network, after the switching network, or in both locations. 
The impedance network after the switching network enhances the voltage gain and reduces the voltage stress on the transistors, while the other impedance network enhances the voltage gain further.

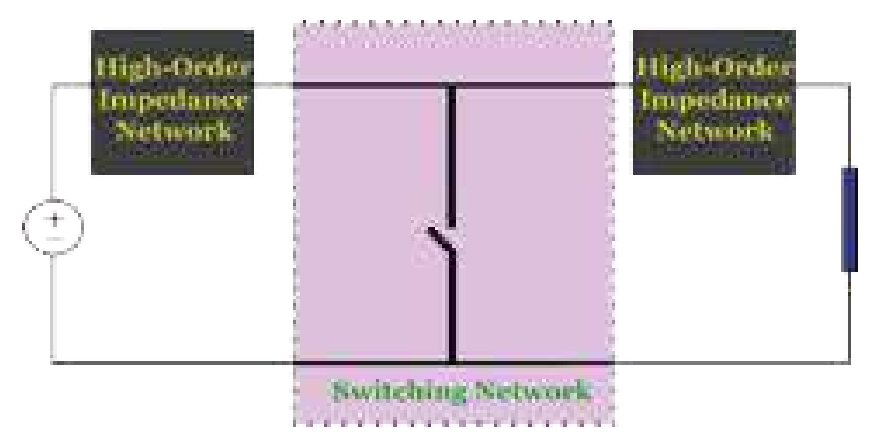

Figure 1.9: Generic structure of a power converter with an integrated high-order impedance network

Adopting High-Order Impedance and multilevel switching networks have the following advantages:

1) High voltage gain without the need for a transformer.

2) Less voltage stress on the transistors compared to conventional multilevel architecture, which makes it feasible to implement this family of converters with transistors with low voltage ratings.

(Note: Transistors with lower rated voltage have the capability to switch much faster and more efficiently compared to their counterparts with higher rated voltage).

3) The effective frequency of the proposed high-order multilevel converters can be optimized to be in the Mega-hertz range, by properly selecting the number of levels of the switching network, and optimally designing the high impedance networks.

4) Absence of core losses, because of the absence of transformers, and operating the inductors in CCM mode with low current ripples. 
A generic architecture of the proposed converters with multilevel high-order impedance networks is shown in Figure 1.10.

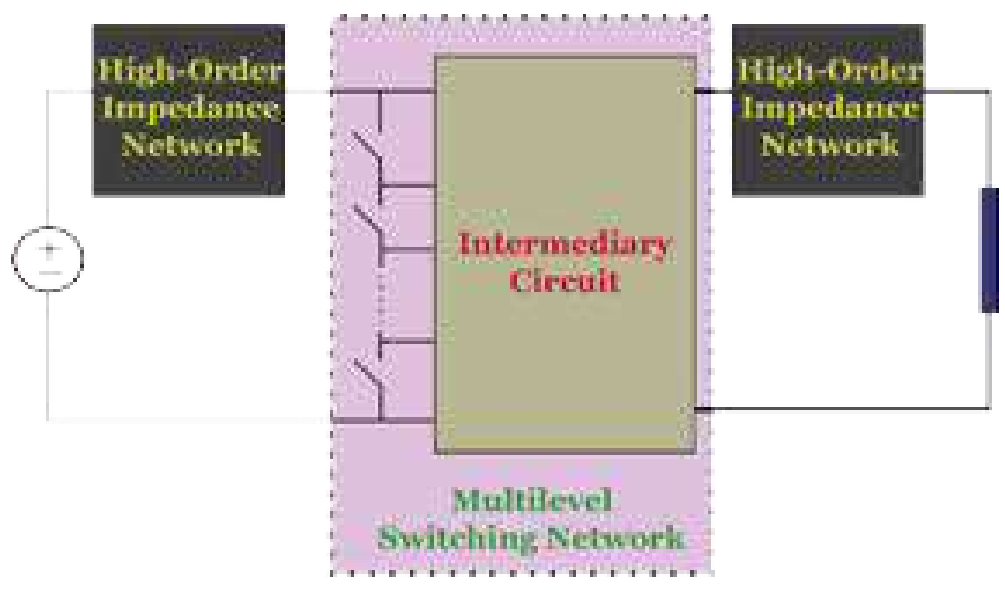

Figure 1.10: Generic structure of a power converter with an integrated multilevel high-order impedance networks.

\subsection{Series-Stacked WBG Devices for High-Voltage Applications.}

Currently the maximum breakdown voltage of available semiconductor switching devices is lower than the voltage needed for medium-voltage and high-voltage power systems. In order to increase the breakdown voltage of semiconductor switching devices, it is meaningful to use multiple of them in series connection. However, this approach is impeded by the non-ideality of the switches, leading to transit unequal voltage sharing across the series switches, which may in turn result in cascaded failure of the switches [51]. An investigation is needed when using devices in series, since both static (steady-state) and dynamic (switching transition) voltage balancing of devices are very critical and need to be satisfied.

The major concern in using semiconductor switching devices in series is identical voltage sharing between them in static and dynamic operation. When the switches are OFF (static), 
the difference between their leakage currents and also their output capacitances cause unequal blocking voltage across them. Static voltage balancing can be simply achieved by using a resistor with optimized value in parallel with each device. In switching transitions (dynamic), it is more difficult to guarantee equal voltage sharing between devices [52].

The methods for solving dynamic voltage sharing issue of series devices can be classified into loadside and gate-side techniques. The simplest technique is to use a passive snubber circuit in the loadside. In this approach, excessive power losses is introduced in the snubber resistors specifically in high-power applications [52]. To solve this problems, active gate control techniques are introduced in which a control loop is designed to control the devices voltage using an active gate control circuit. This approach requires a complex drive circuit, has low reliability and high switching loss [51], [53].

Recently, another category of techniques has been proposed that utilize simple auxiliary voltage balancing circuits in the gate-side of series connected semiconductor switching devices. These techniques that are usually referred to as quasi-active gate controllers, have less complex gate driver, lower switching losses, lower cost, and higher reliability compared to active gate control schemes [51]-[53].

So far, a lot of studies are conducted on series connection of Si switching devices and also $\mathrm{SiC}$ MOSFETs to enhance the breakdown voltage. Yet there appears to be a lack of a comprehensive study on series-connected GaN-HEMTs. As explained, GaN-HEMTs offer some superior characteristics compared to other switching devices. Increasing the breakdown voltage by connecting devices in series would make GaN-HEMTs one of the most promising candidates for high-voltage and high-frequency applications. 


\subsection{Research Objectives}

The main research objectives of this dissertation is to develop new power electronic structures that can operate efficiently under wide range of voltage conversion ratios and are suitable for high-voltage and high power applications. In addition, the developed new architectures provide high power density, high specific power, and minimal EMI filtering requirement. Accordingly, the features of the proposed new topologies can be summarized in the following points:

1) Continuous input current im order to prolong the lifetime of the power source (i.e. battery, ultra-capacitor, fuel cell, etc.) connected to the converter.

2) Wide voltage conversion ratios to be able to operate at moderate duty cycle values, hence, have an acceptable efficiency throughout the broad range of voltage gain.

3) The potential difference between the grounds of the ports of the converters should be constant in order to minimize the leakage currents, hence, reduce the required periodic maintenance.

In order to understand the effect of the potential difference between the grounds of the power converter's ports on the operation, we need to depict the converter equivalent circuit including the parasitic capacitance between the grounds, as shown in Figure 1.11:

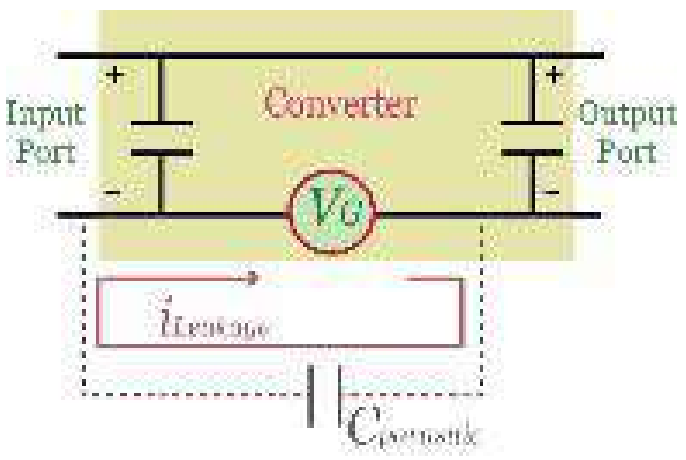


Figure 1.11: The generic equivalent circuit of a dc-dc converter including the parasitic capacitance between its grounds.

The parasitic capacitance $\left(C_{\text {parasitic }}\right)$ depicted in Fig. $\mathrm{J}$ is usually caused by the package or casing of the power converter. The potential difference between the grounds of the input and output ports is depicted by $\left(V_{G}\right)$ in Figure 1.11 . When $V_{G}$ is zero (= common ground) or a constant voltage, the leakage current $i_{\text {Leakage }}=0$. When $V_{G}$ is a high-frequency ac voltage, high leakage current will flow between the grounds through $C_{\text {parasitic }}$, as shown in Figure 1.11. Based on that, the major aspects of this dissertation are:

1) Develop new transformerless unidirectional dc-dc power converters with wide voltage gain range in order to suite fuel cell and renewable energy systems.

2) Develop new transformerless bidirectional dc-dc power converters with wide voltage gain range in order to suite electric vehicles and energy storage systems.

3) Design novel isolated high-frequency link dc-ac power converters with reduced switch count for medium-voltage supercharging stations for electric vehicles.

4) Developing high-voltage Gallium-Nitride $(\mathrm{GaN})$ switching modules using series stacking, and using these modules in developing high voltage power electronic building blocks.

\subsection{Original Contribution of This Thesis}

The main contributions of this dissertation are the following:

1) Developing a new multilevel dc-dc converter that is based on a three-level flyingcapacitor switching network and an $L C^{2} D$ network. This converter has wide voltage gain, low voltage stress on the power switches, and a common ground between the 
input and output ports. This converter is unidirectional, hence, it can be used in fuel cell and renewable energy applications.

2) Developing a new single-switch dc-dc converter with universal input voltage, high semiconductor utilization factor, and a common ground between its input and output ports. This converter integrates an $L^{2} C^{3} D^{2}$ with a boost converter to widen its gain range and reduce the voltage stress on its power switches. This converter is suitable for fuel cell and renewable energy applications.

3) Designing a novel single-switch dc-dc converter that is based on the SEPIC converter with an integrated dual-switched-capacitor network. This converter has broad voltage gain, low voltage stress on its passive and active devices, and a constant potential difference between its input and output ports. This converter is suitable for fuel cell and renewable energy applications.

4) Developing a new SEPIC based dc-dc converter that utilizes a discontinuous current quasi-Z-source network and a dual-switched-capacitor switching networks. The converter supports unidirectional power flow, thus, it suites the renewable energy and fuel cell systems.

5) Design and implementation of a new bidirectional buck-boost converter that has broad voltage gain range, as it supports the buck and boost operations in both power flow directions. This converter can be used in electric vehicles as an interface between the battery pack and the dc-link of the three-phase inverter.

6) Analysis and development of a novel bidirectional transformerless dc-dc converter with wide voltage conversion ratios, a common ground between the ports of the converter, and continuous current at the low voltage port. This converter is suitable for 
energy storage systems that have wide voltage swings in their output voltage (i.e. ultracapacitors).

7) Design and development of a new extendable bidirectional dc-dc converter with high voltage conversion ratios. This converter can directly interface the energy storage systems that have low output voltage to the load bus with voltage gain $\geq 20$, without the need to any magnetic coupling components (i.e. coupled inductor or high-frequency transformer).

8) Development of high-voltage series-stacked GaN module and utilized it in a highvoltage power electronic building block.

9) Development of two new high-frequency ac link systems with reduced switch count. These two proposed dc/ac converters provide galvanic isolation and can be used for the electric vehicle's supercharging stations that are connected to the medium-voltage ac grid.

\subsection{Dissertation Organization}

Chapter 2 gives an overview and full literature review of the non-isolated unidirectional and bidirectional dc-dc converters in literature. In addition, it gives a thorough literature review of the isolated high-frequency ac-link dc-ac converters that can be used for mediumvoltage applications.

In chapter 3, a three-level step-up converter that is based on a flying-capacitor switching network and an integrated $L C^{2} D$ network is analyzed and proposed. Its voltage gain, voltage stress on the semiconductor devices, and the current stresses on its active and passive components are derived. In the end, the experimental results are given and compared with the theoretical analysis. 
In chapter 4, a new single-switch unidirectional converter with universal input voltage is discussed for the application of electric vehicles with fuel cells. The current and voltage stresses on the power switches and diodes and analyzed. Additionally, the voltage gain of the converter and a comparative study with other step-up converters are given. The experimental verification and the conclusion are presented at the end of the chapter.

In chapter 5, a novel single-switch converter that integrates a SEPIC dc-dc converter with a dual-switched-capacitor network is discussed and analyzed. The electrical stresses on its active and passive components are mathematically derived and verified by the experimental results at the end of the chapter.

In chapter 6, a SEPIC-based dc-dc converter that utilizes a discontinuous current quasi-Zsource network and a switched-capacitor network for fuel cell vehicles is proposed and mathematically analyzed. The design of the passive and active components is given, and the electrical stresses on the power switch and diodes are discussed and experimentally verified.

In chapter 7, a new transformerless buck-boost dc-dc converter that can perform the buck and boost operations in both power flow directions is presented and analyzed. The design of the active and passive components and the electrical stresses on the power switches are given. At the end of this chapter, the experimental validation and the conclusion are presented.

In chapter 8, a novel non-isolated dc-dc bidirectional converter with wide voltage conversion ratios is presented and discussed for the application of energy storage systems. The selection of components and a comparative study with other bidirectional dc-dc converters are given, and the experimental validation is given at the end of the chapter. 
In chapter 9, a new extendable bidirectional dc-dc converter that has high voltage conversion ratios is discussed. The mathematical analyses of its voltage gain and electrical stresses on its power switches are derived and verified by the experimental results.

In chapter 10, two cascaded high-frequency-ac-link converter for super charging stations' applications are discussed and analyzed. A novel current controller is discussed and the control strategy during grid faults is presented. Simulation results from MATLAB/SIMULINK software are given at the end of the chapter to verify the theoretical analyses.

In chapter 11, A two-level power electronic building block built with GaN high electron mobility transistors (HEMTs) and a Nanocrystalline inductor is discussed. The possible dc-dc, single-phase/three-phase dc-ac topologies are presented, and the isolated gate drivers are discussed. The experimental results are given at the end of the chapter.

In chapter 12, a high-voltage series-stacked GaN HEMT module for electric vehicle applications is discussed and analyzed. The comparative study with its Silicon and Silicon Carbide counterparts are presented. The LTspice simulation results and the experimental results at the end of the chapter are used to verify the theoretical analysis.

In chapter 13, a power electronic building block with series-stacked GaN modules is discussed. The possible dc-dc, single-phase/three-phase dc-ac converter topologies are analyzed and presented. Different applications are discussed at the end of the chapter.

In chapter 14, a conclusion of this dissertation and an insight on recommended future work are given. 


\section{Chapter 2 Power Electronic Building Blocks for Renewable, Electric Vehicle, and Energy Storage Applications: Literature Review}

\subsection{Introduction}

The declining costs of sustainable energy systems and the global interest in reducing the $\mathrm{CO}_{2}$ emissions and the reliance on fossil fuels, the electrification of the means of transportation has attracted a lot of interest [54],[55]. Electric vehicles (EVs) powered with fuel cells are important players in the clean energy vehicles segment as the fuel cell is a clean source of energy with zero emissions, also it has high output current density and high efficiency [16], [17]. Nevertheless, the fuel cell has soft output characteristics where its output voltage drops noticeably as the output current increases, hence, it cannot be used to directly feed the inverter of the EV. A step-up dc-dc converter has to be used as an interface between the fuel cell and the dc-link of the inverter, as shown in Figure 2.1, where the dc-dc converter solves the mismatch between the fuel cell voltage and dc-link voltage.

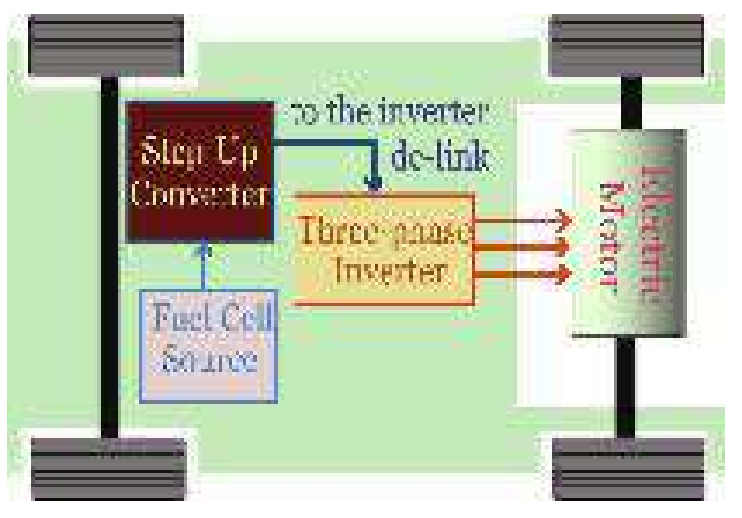

Figure 2.1: The typical powertrain of a fuel-cell powered electric vehicle.

Another approach to reduce the $\mathrm{CO}_{2}$ emissions is by increasing the integration of renewable energy systems. The output voltage of the renewable energy source changes based on the environmental conditions and the operating load point (can be varied using a MPPT). Figure 
2.2 shows a photovoltaic system connected to the grid via a dc-dc converter followed by a power inverter. A dc-dc converter with wide voltage gain range is needed to solve the mismatch in voltage levels between the renewable energy source and the dc-link bus of the inverter.

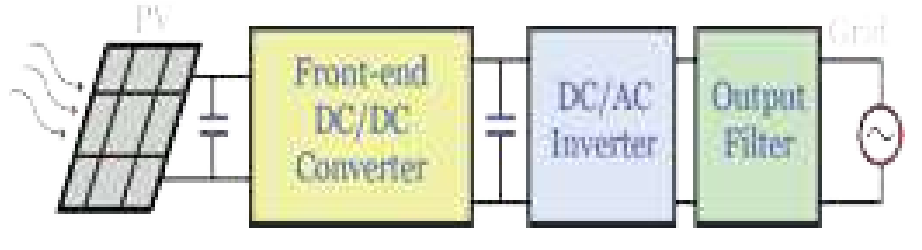

Figure 2.2: The typical architecture of a grid-connected PV system.

Due to the increasing demand of energy, and environmental concerns associated with electrical energy generation from fossil fuels, the development of microgrids integrating renewable energy sources has attracted major interest. The increasing penetration of these intermittent renewable energy systems can impose disturbances to the power grid. This requires integration of energy storage units (ESUs) to smoothen the fluctuations in power generation by maintaining the balance between renewable power generation and consumption.

The generic architecture of a dc microgrid with renewable energy generation and assisted by ESUs is shown in Figure 2.3. The renewable sources are connected to the dc bus of the microgrid via unidirectional power electronic converters, while the ESU is decoupled from the $\mathrm{dc}$ bus by a bidirectional dc-dc converter. This bidirectional dc-dc converter allows the ESU to absorb the excessive energy when the power generation exceeds the demand, and release energy when the demand exceeds generation.

Additionally, the EV powertrain is another version of microgrids, where the bidirectional dc-dc converter pushes power from the ESU to the dc-link of the three-phase inverter in the motoring mode, and absorbs power from the dc-link back to the ESU in the regenerative braking mode. 


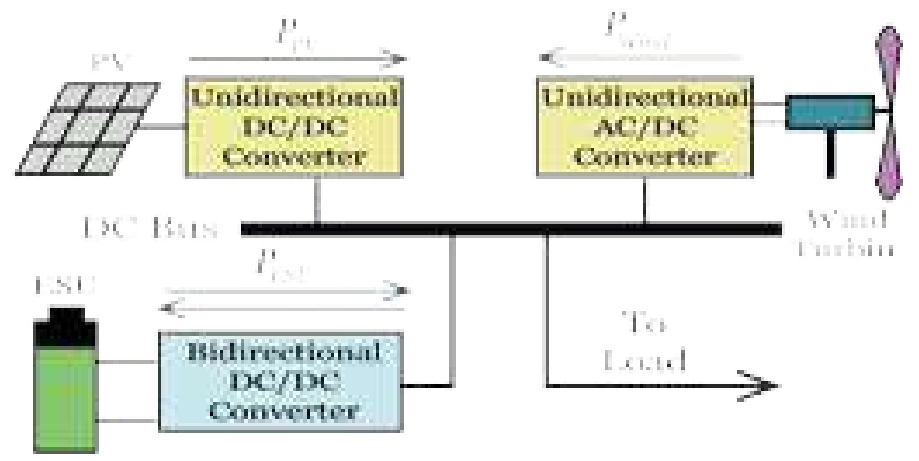

Figure 2.3: The typical architecture of a dc microgrid supported with renewable energy sources and energy storage units.

Figure 2.4 shows the typical architecture of the powertrain of an electric vehicle. The ESU is connected to the dc-link bus of the three-phase inverter via a bidirectional dc-dc converter.

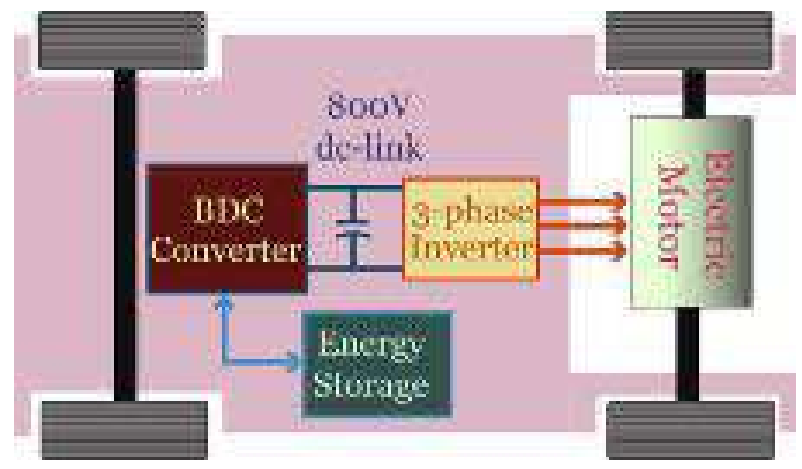

Figure 2.4: The typical architecture of an EV powered by energy storage units.

\subsection{Non-Isolated Unidirectional Conventional DC-DC Structures}

Non-isolated unidirectional dc-dc converters process the power in one power flow direction. It has many applications such as in renewable energy systems, fuel cell systems, and consumer electronics. In this subsection, we cover the two-level unidirectional conventional dc-dc converter, the multilevel unidirectional dc-dc converters, switchedcapacitor unidirectional dc-dc converters, switched inductor unidirectional dc-dc converters, and quadratic unidirectional dc-dc converters. 


\subsubsection{Two-Level Unidirectional Conventional DC-DC Converter}

The topology of this converter is shown in Figure 2.5, as it is composed of one switch, one diode, one capacitor, and one inductor. This converter is very popular for step-up due to its simple structure, having a common ground between its input and output ports, having a continuous input current, and simple gate driving. Nevertheless, this converter cannot be used for applications that require high step-up conversion ratios (> 5), due to the existence of parasitic components in its passive and active components. Additionally, at high step-up voltage gains the efficiency of this converter deteriorates noticeably due to the high voltage and current stresses on its semiconductor devices.

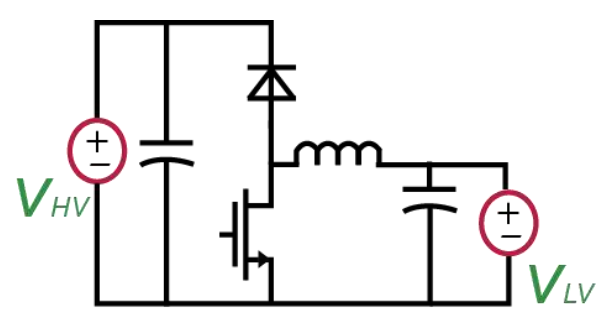

Figure 2.5: The two-level unidirectional conventional dc-dc converter.

\subsubsection{Multilevel Unidirectional DC-DC Converters}

The multilevel dc-dc converter topologies aim to reduce the voltage stresses on the semiconductor devices of the dc-dc converter, hence, power switches and diodes with lower rated voltage can be utilized which yields better efficiency compared to the two-level converter [56]-[80]. Another advantage is that the frequency of the ripple current of the input inductor increases as the number of levels increases, which results in more compact dc-dc converters with smaller and lighter power inductors.

The three-level boost (TLB) converter is one of the most commonly adopted multilevel dcdc converters due to the low number of passive and active components compared to the other multilevel dc-dc converter. Its unidirectional version is shown in Figure 2.6, as it is composed 
of two switches, two diodes, one inductor, and two capacitors. The voltage stress on its switches and diodes equal half of its output voltage. The voltage gain of this converter is similar to that of the two-level converter, which means it is not suitable for high step-up applications. Additionally, it lacks a common ground between its input and output ports which result in higher electromagnetic interference (EMI) noise and requires more filtering.

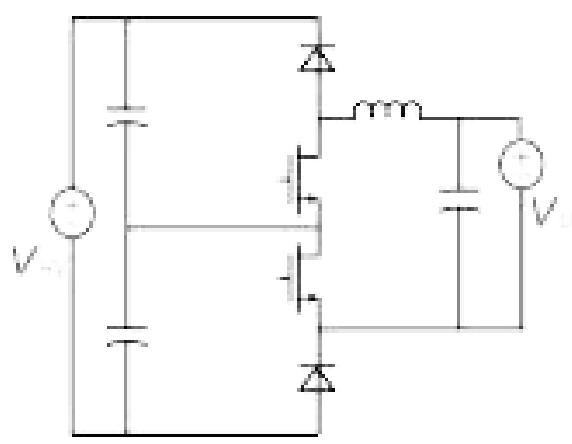

Figure 2.6: The three-level unidirectional conventional dc-dc converter.

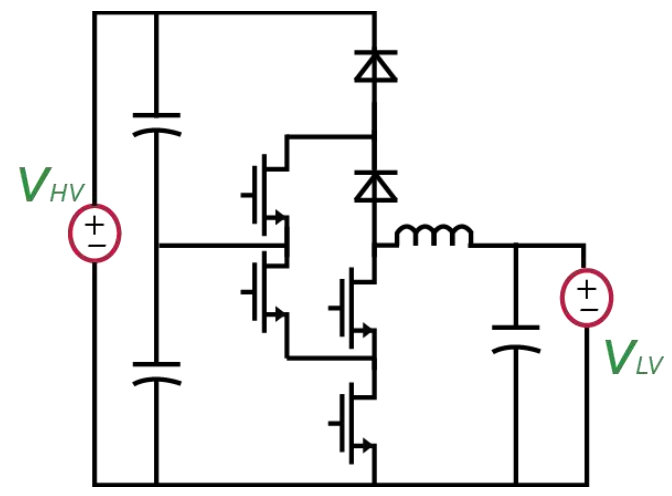

Figure 2.7: A unidirectional neutral-point-clamped dc-dc converter.

The neutral point clamped converter is another popular multilevel dc-dc converter, as it also reduces the voltage stresses on the semiconductor devices and diminishes the size of the input inductor. It has a common ground between its input and output ports and has a continuous input current. The circuit structure of this converter is given in Figure 2.7. 
The voltage gain of this converter is similar to that of the two-level converter, which means it is not suitable for high step-up applications. Additionally, it requires a higher number of power switches compared to the other multilevel dc-dc converters.

The flying-capacitor converter is another attractive step-up multilevel dc-dc converter, as it also reduces the voltage stresses on the semiconductor devices and reduces the size of the input inductor. It has a common ground between its input and output ports and has a continuous input current. The circuit structure of this converter is given in Figure 2.8.

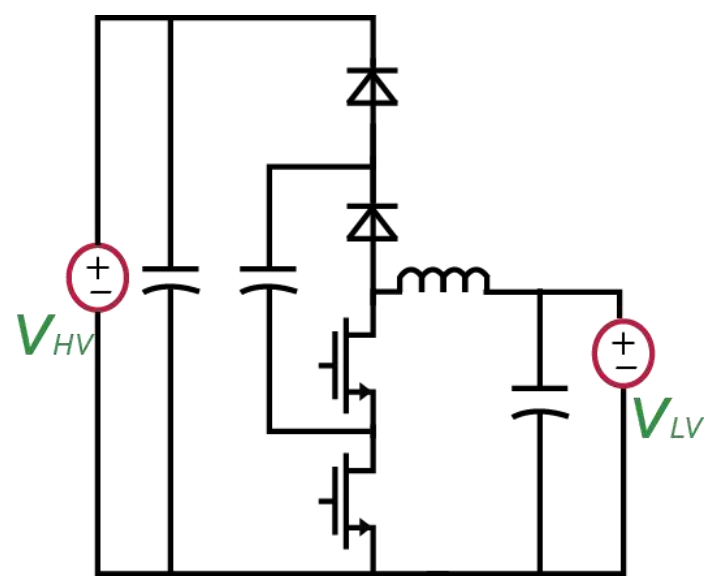

Figure 2.8: A unidirectional flying-capacitor dc-dc converter.

The voltage gain of this converter is similar to that of the two-level converter, which means it is not suitable for high step-up applications. Additionally, it requires a higher number of capacitors compared to the other multilevel dc-dc converters.

\subsubsection{Switched- Capacitor Unidirectional DC-DC Converters}

The switched-capacitor dc-dc converter is an attractive way to step-up the voltage using a charge pump circuit which is adopted in a lot of converters. The voltage level stepping-up using the charge pump circuit takes place from the transfer of capacitive energy and does not require any magnetic components. The switches capacitor converters are very popular 
topologies as they have a modular structure, thus, their voltage gain can be systematically enhanced by increasing the number of switched capacitor cells [81]-[107].

One of the major drawbacks of the switched-capacitor topologies is the high inrush current during the start instant, which may affect the efficiency, the power density, and the specific power of the dc-dc converter. One of the ways to reduce the high inrush currents in the switched-capacitor converters is by putting an inductor at the output port to construct a buck converter in the already existing power switch(es). This way provides efficient voltage regulation and reduces the inrush currents, which is known as soft charging switchedcapacitor converter.

Figure 2.9 a unidirectional switched-capacitor $\mathrm{dc}-\mathrm{dc}$ converter with the common features of the switched-capacitor converters such as compact size and low weight. This converter has a continuous input current.

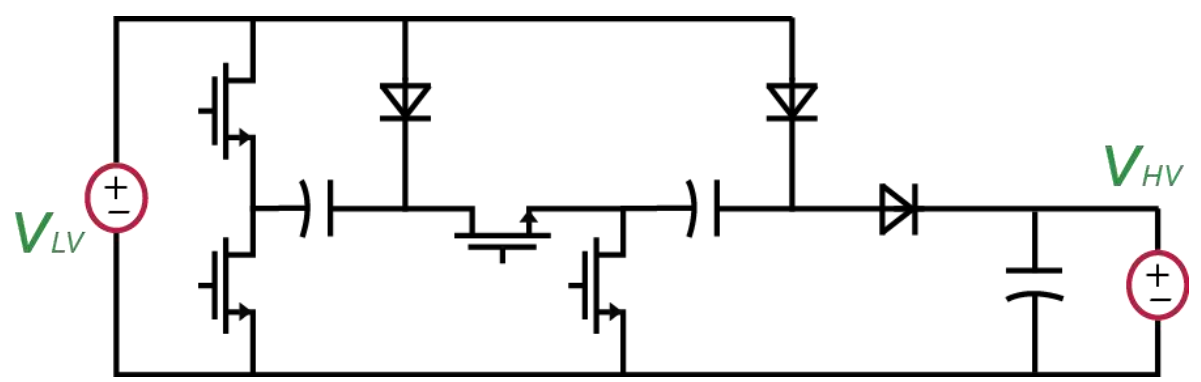

Figure 2.9: A unidirectional switched-capacitor dc-dc converter with diode-capacitor multipliers.

Another switched-capacitor dc-dc converter with a resonant operation is presented in Figure 2.10. In this converter, a resonant small inductor is utilized in the first stage to realize zero-current switching. Accordingly, the inrush that usually takes place in conventional switched-capacitor converters can be minimized. 


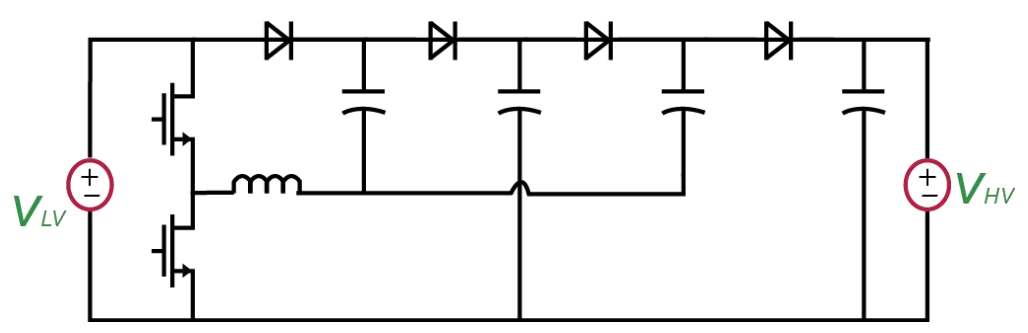

Figure 2.10: A unidirectional switched-capacitor dc-dc converter with diode-capacitor multipliers and a small resonant inductor.

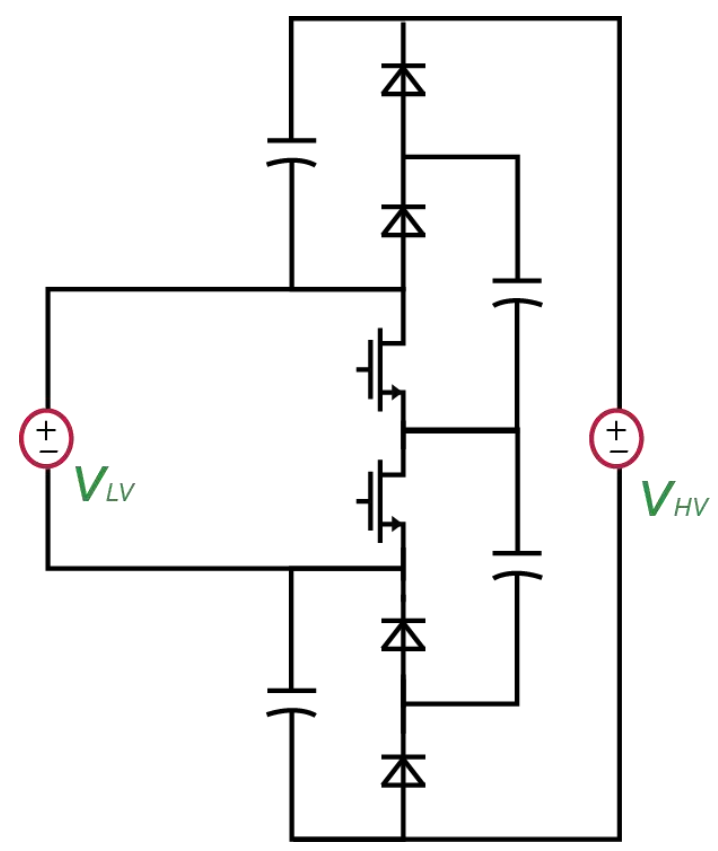

Figure 2.11: A modular asymmetrical switched-capacitor dc-dc converter.

Figure 2.11 presents a modular asymmetrical switched-capacitor dc-dc converter with a shared capacitor voltage rating. Due to the modularity feature of its circuit, this topology is capable of realizing high voltage conversion ratios and needs output capacitors with low capacitance and low voltage rating. This converter utilizes only two power switches. The voltage gain of this converter can be simply extended by increasing the number switched capacitor cells. In addition, the control of this topology is simple and voltage stress on the semiconductor devices is low. 
Voltage multiplier circuits are attracting a lot of attention in the applications that require high step-up voltage conversion ratios as they have a simple circuit structure. Figures 2-12 to 2-18 present some of the important structures known as voltage multiplier cell dc-dc converters. Some of these architectures have only diodes and capacitors (as in Figure 2-12, Figure 2-13, and Figure 2-14) and thus they are called in the literature as diode-capacitor voltage multiplier cell dc-dc converters. Other voltage multiplier cell dc-dc converters have more active components, such as an auxiliary power switch (Figure 2-15), while other voltage multiplier cell dc-dc converters utilize inductors to enhance the step-up voltage gain (Figure 2-16 and Figure 2-17). Some topologies of the voltage multiplier cell dc-dc converters with vertical structures have been introduced, as the topology shown in Figure 2-13.

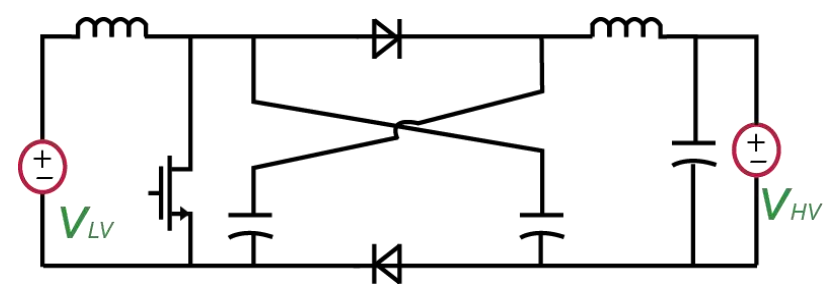

Figure 2.12: Unidirectional voltage multiplier cell dc-dc converter 1.

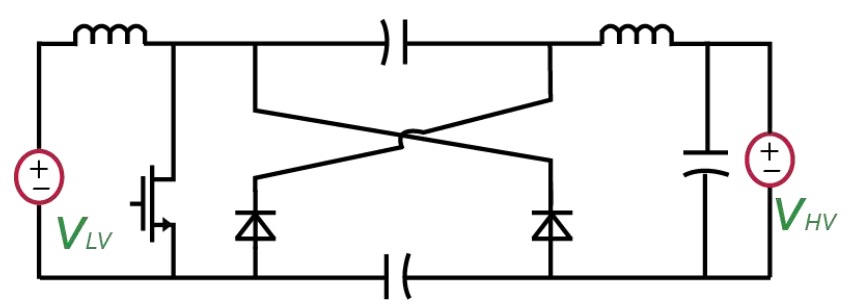

Figure 2.13: Unidirectional voltage multiplier cell dc-dc converter 2.

The operation and dynamic performance of the voltage multiplier cell converters presented in Figure 2-12, Figure 2-13, and Figure2-14 are identical and their voltage gain relationships are similar: $(1+\mathrm{D}) /(1-\mathrm{D})$, as $\mathrm{D}$ is the duty cycle of the main switch. When a small inductor (typically between 1 to $4 \mu \mathrm{H}$ ) is used in the voltage multiplier cell dc-dc converters in Figure 
2-14, a zero current switching (ZCS) transition can be be realized for the diodes and switch, which can noticeably improve the efficiency of the converter by reducing the switching losses.

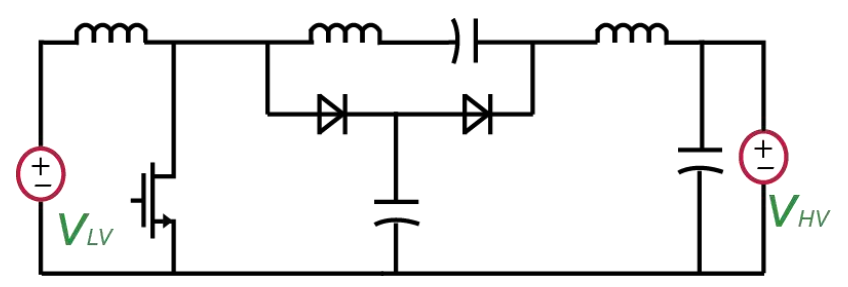

Figure 2.14: Unidirectional voltage multiplier cell dc-dc converter 3.

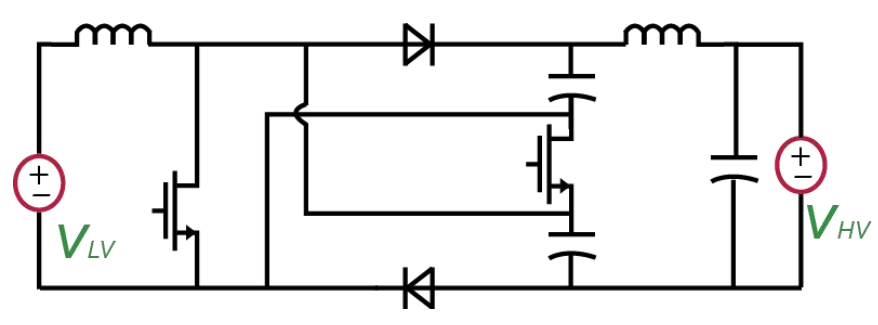

Figure 2.15: Unidirectional voltage multiplier cell dc-dc converter 4.

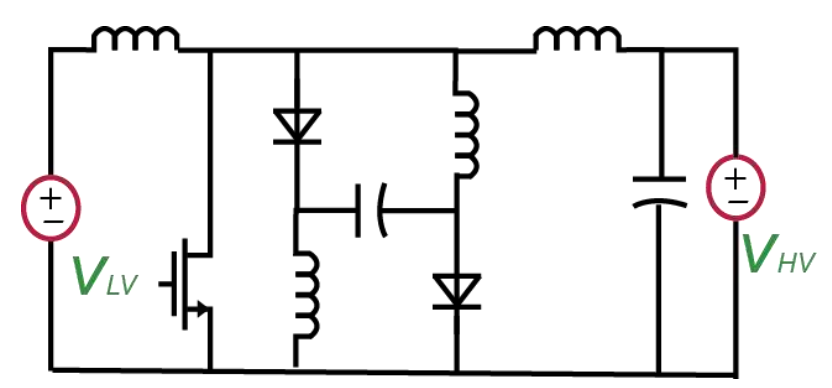

Figure 2.16: Unidirectional voltage multiplier cell dc-dc converter 5.

The voltage multiplier cell dc-dc converter in Figure 2-16 utilizes an inductor and a capacitor in order to enhance the voltage conversion ratio of the dc-dc converter. The voltage multiplier cell dc-dc converter in Figure 2-17 has the highest voltage gain compared to the other voltage multiplier cell dc-dc converters, nevertheless, the voltage stress on its switch is high.

In the voltage multiplier cell converter in Figure 2-14, a single inductor connected in first stage is capable of realizing the zero current switching on all the semiconductor devices. 


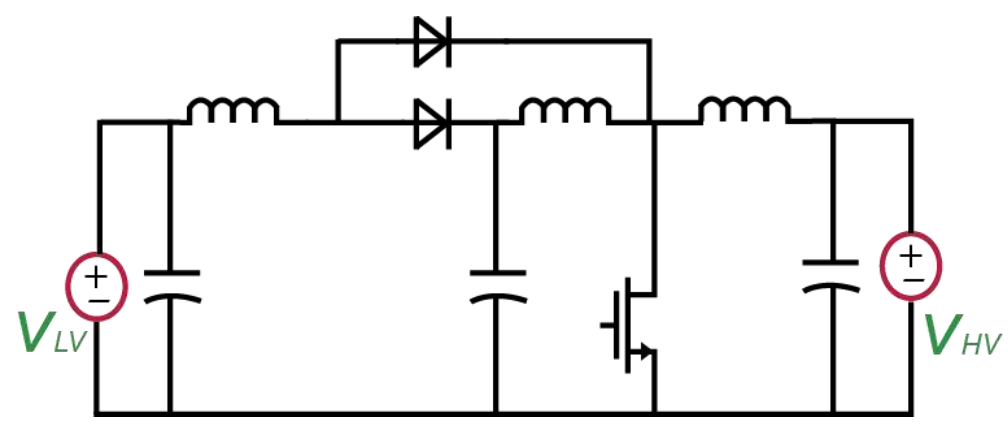

Figure 2.17: Unidirectional voltage multiplier cell dc-dc converter 6.

\subsubsection{Switched-Inductor Unidirectional DC-DC Converters}

The Voltage Lift structure is an alternative useful technique that is widely utilizes in $\mathrm{dc}-\mathrm{dc}$ converters to enhance voltage conversion ratio. This method is based on charging a capacitor to a specific voltage level (e.g., voltage of the input port) and then boosting the output voltage (stepping-up the voltage) with the level of voltage of the charged capacitor [108]-[119]. When repeating this method with the insertion of other capacitors to form a re-lift, triple-lift, and quadruple-lift topologies, the level of the output voltage can be enhanced. A lot of boost dc-dc topologies have been proposed by Luo, and the voltage lift approach has been utilized in the literature in a large number of dc-dc converters, like Ćuk, SEPIC, and Zeta topologies.

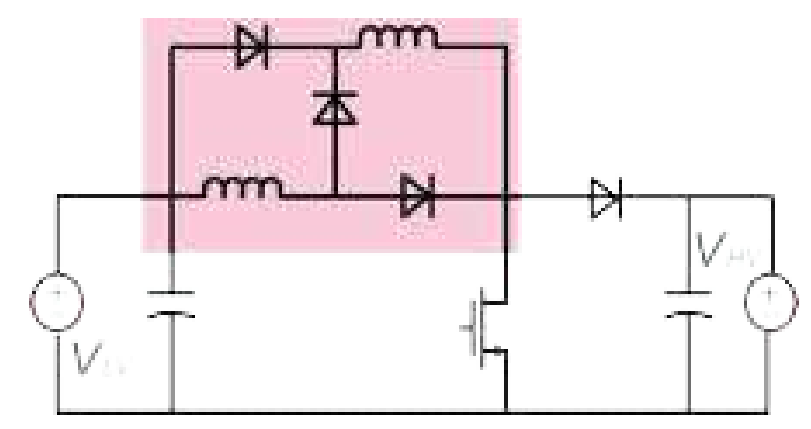

Figure 2.18: Unidirectional voltage Lift cell dc-dc converter 1. 
In order to enhance the voltage gain of the dc-dc converter, more the one lift circuits can be cascaded. Voltage Lift Switched Inductor dc-dc converters are presented in Figure 2-18, Figure 2-19, and Figure 2-20.

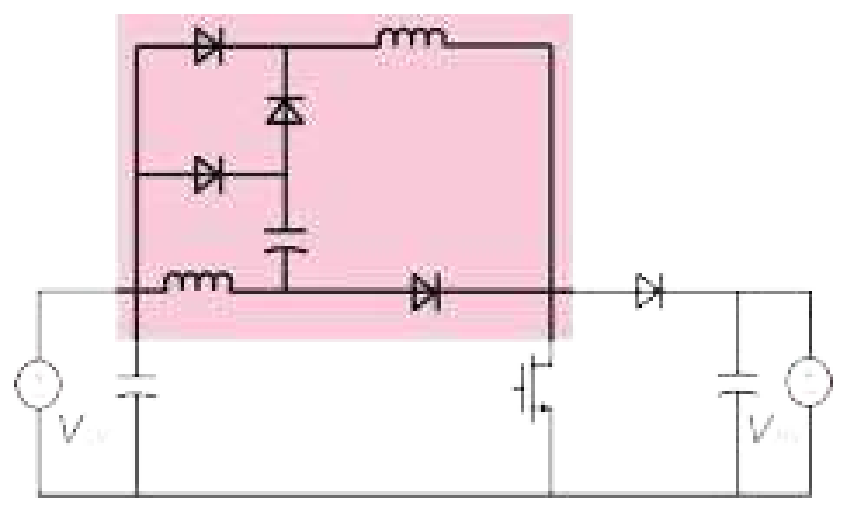

Figure 2.19: Unidirectional voltage Lift cell dc-dc converter 2.

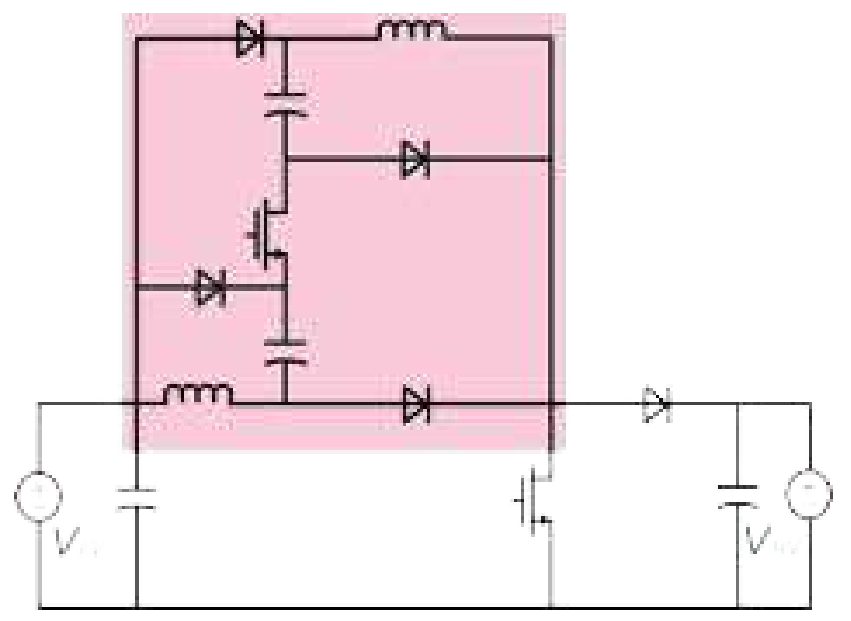

Figure 2.20: Unidirectional voltage Lift cell dc-dc converter 3.

The basic switched-inductor dc-dc converter is shown in Figure 2-18. In switched-inductor dc-dc converter, the inductors are charged in parallel and discharged in series. Where the two inductors have similar inductances and have the same conditions of operation, they can be coupled into one core in to diminish the size and reduce the weight of the dc-dc converter. 


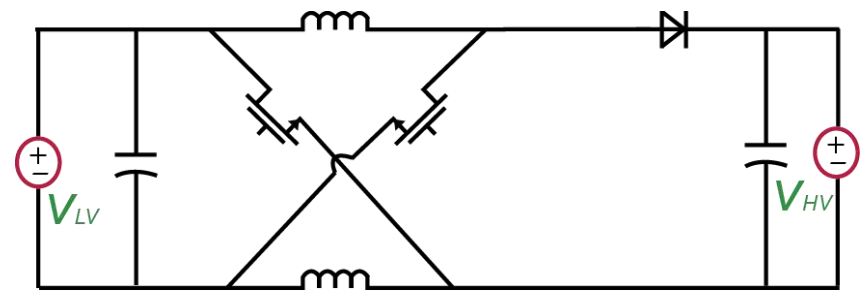

Figure 2.21: Unidirectional active-switched-inductor dc-dc converter 1.

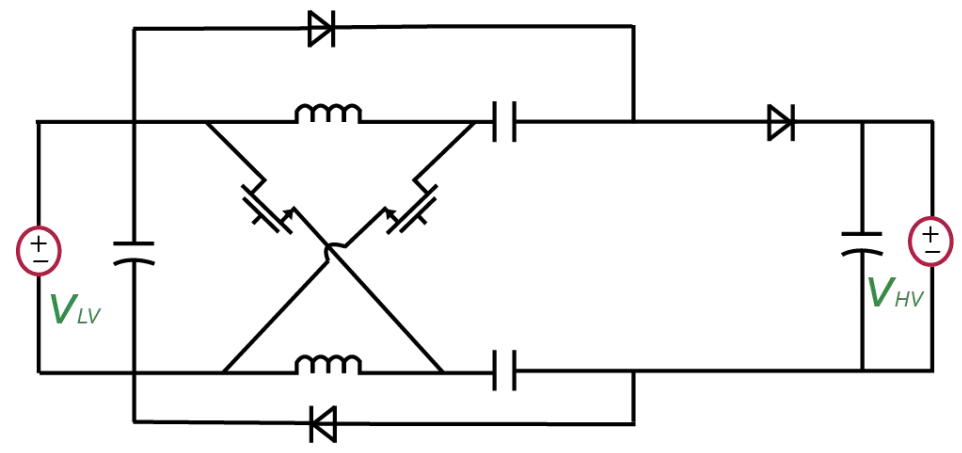

Figure 2.22: Unidirectional active-switched-inductor dc-dc converter 2.

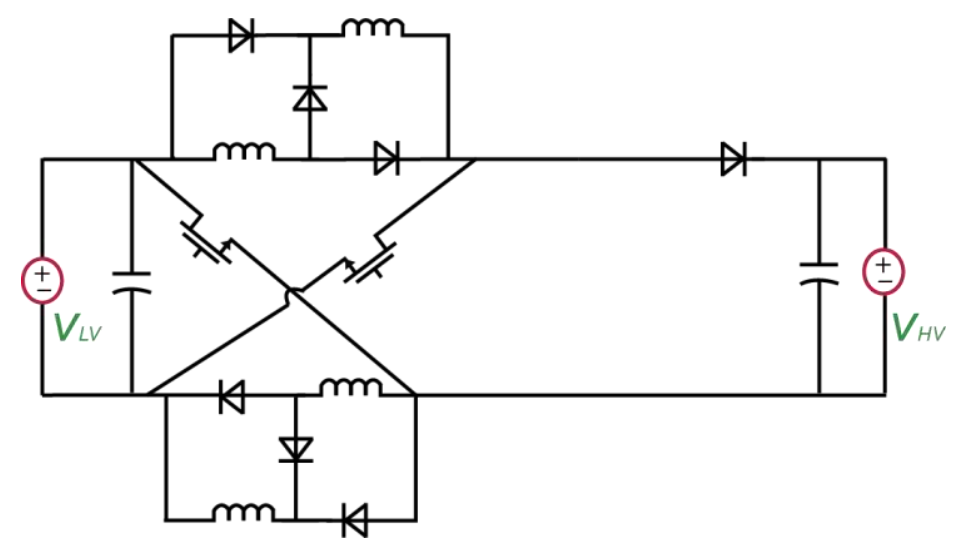

Figure 2.23: Unidirectional active-switched-inductor dc-dc converter 3.

Implementing a voltage lift structure with elementary cell in a switched-inductor dc-dc converter results in a self-lift switched-inductor dc-dc converter, as shown in Figure 2-19. When an additional diode and capacitor are added to a self-lift switched-inductor dc-dc 
converter, a double self-lift switched-inductor dc-dc converter is produced, as shown in Figure 2-20. Other high order switched-inductor dc-dc converters that can achieve high step-up gain have been discussed in literature.

As an alternative structure to that with three diodes, as in the basic voltage Lift cell dc-dc converter 1 in Figure 2-18, only two power switches are used in what so-called active switched-inductor network and there is no need for an additional power switch in the power converter circuit. A number of unidirectional active-switched-inductor dc-dc converters are shown in Figure 2-21, Figure 2-22, and Figure 2-23.

\subsubsection{Quadratic Unidirectional DC-DC Converters}

Figure 2.24 depicts a cascaded unidirectional boost converter that consists of two consecutive boost converters. The voltage stress on the first boost dc-dc converter is relatively low, thus, its operating frequency can be high which can result in high power density. Nevertheless, the second boost dc-dc converter has to operate at low frequency in order to decrease the switching losses. The quadratic converter aims to reduce the number of power switches and reduce the complexity of the converter structure and the gate driving circuits [120]-[137]. Nevertheless, one major disadvantage of the quadratic boost dc-dc converters is that the duty cycles of the two boost converters can no longer be controlled independently, unlike the cascaded boost structure in Figure 2.24. The structure of a quadratic boost dc-dc converter is presented in Figure 2.25. Figure 2.26 depicts a threelevel quadratic boost dc-dc converter that was proposed for high step-up applications. Other basic quadratic boost dc-dc converter topologies are presented in Figure 2.27 to Figure 2.30. The quadratic boost dc-dc converters have wider ranges of voltage conversion ratios than the conventional PWM boost dc-dc converter. 


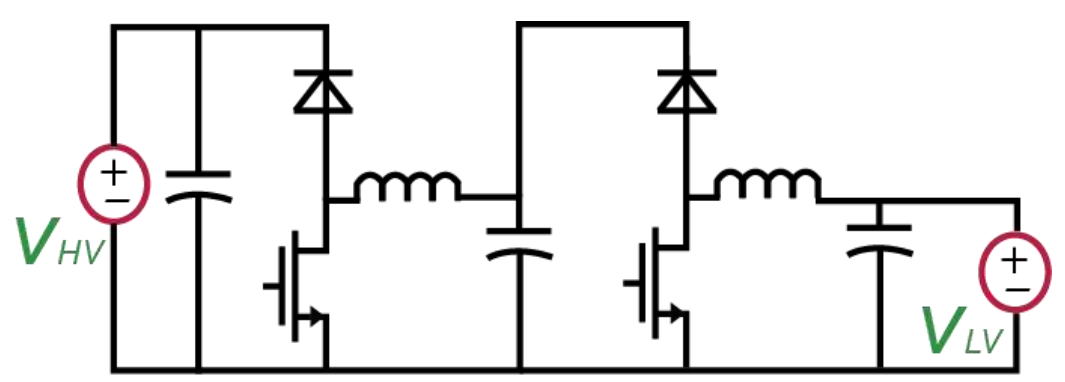

Figure 2.24: Cascaded unidirectional boost dc-dc converters.

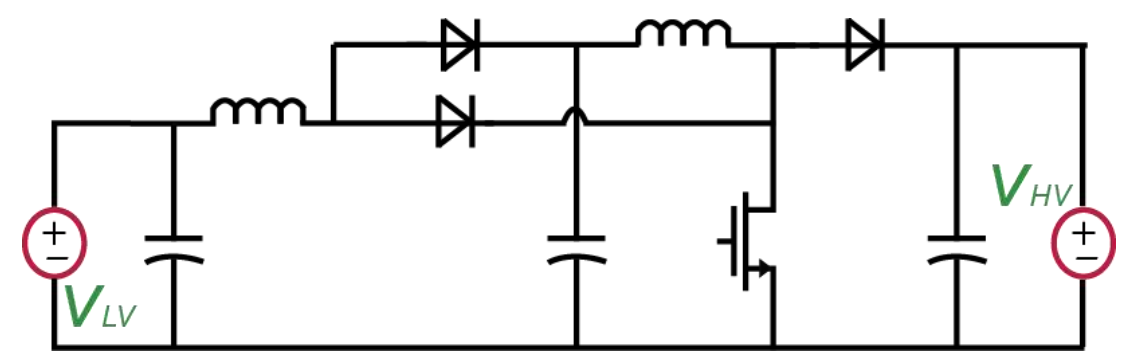

Figure 2.25: The basic unidirectional quadratic boost dc-dc converter.

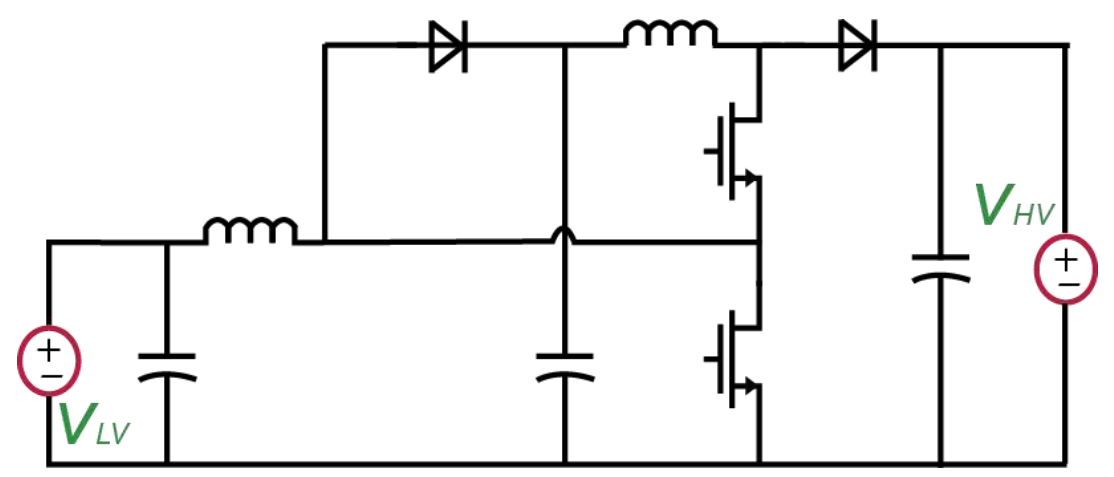

Figure 2.26: Three-level unidirectional quadratic boost dc-dc converter.

For the applications where the voltage conversion ratio is limited, the quadratic boost dcdc converters can work with narrower changes in the values of duty cycle than that in the conventional boost dc-dc converters, which results in a simple design procedure and an improved performance. 


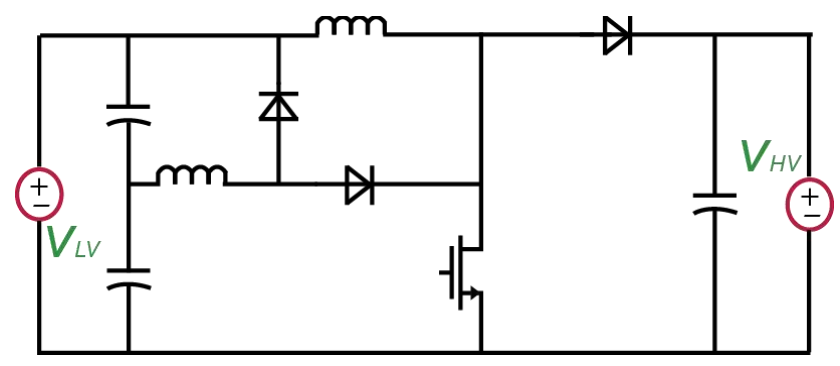

Figure 2.27: A quadratic boost dc-dc converter with low capacitor voltage.

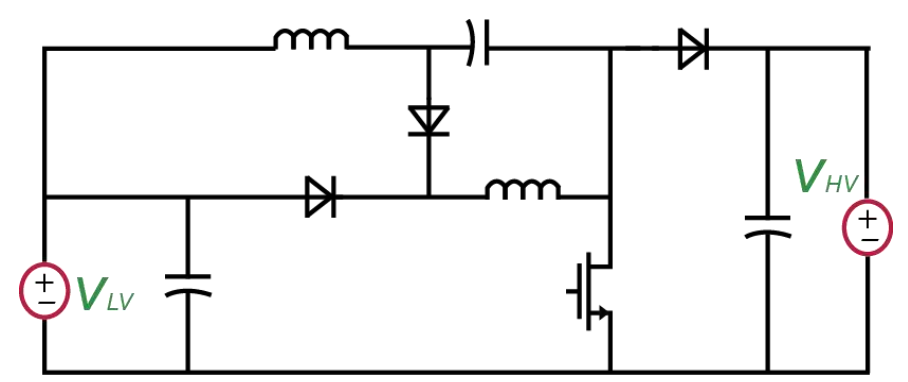

Figure 2.28: Basic quadratic boost dc-dc converter 1 .

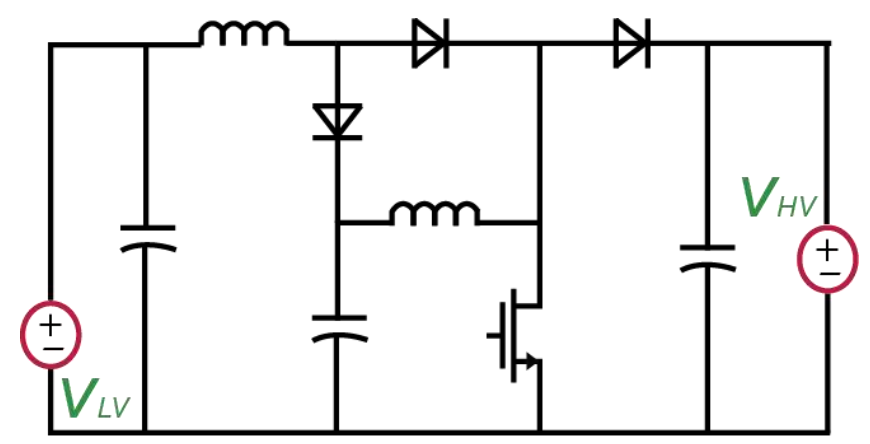

Figure 2.29: Basic quadratic boost dc-dc converter 2. 


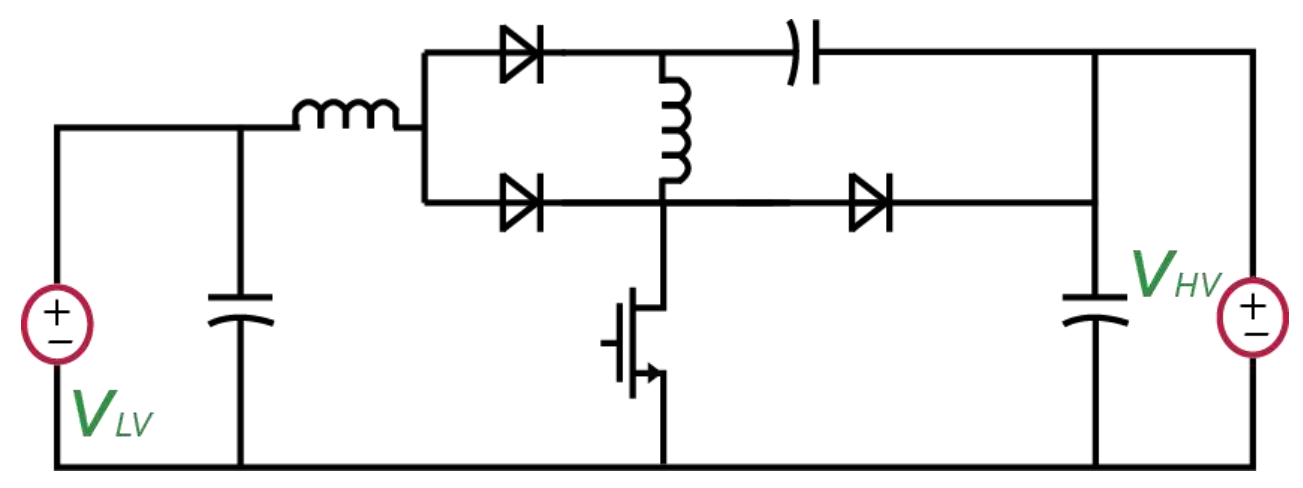

Figure 2.30: Basic quadratic boost dc-dc converter 3.

Added to that, the quadratic boost dc-dc converters have several advantages for low power applications as they avoid sophisticated magnetic designs. Figure 2.27 presents a quadratic boost dc-dc converter with low voltage stress on its capacitor. In Figure 2.28 and Figure 2.29, two topologies of quadratic boost dc-dc converters with similar components but only differ in terms of the placement of the buffer capacitor. A lot of modified versions of the quadratic boost dc-dc converter have been proposed and discussed in literature. Generally, cascaded and quadratic boost dc-dc converters, such as those in Figure 2.24 to Figure 2.30, usually have four semiconductor devices, with at least one of them is an active power switch. They usually also contain a one inductor and one capacitor for each stage of the dc-dc converter.

\subsection{Non-Isolated Bidirectional DC-DC Converters}

Non-isolated bidirectional dc-dc converters process the power in both power flow directions (from the high voltage port to the low voltage port in the step-down mode, and from the low voltage port to the high voltage port in the step-up mode). It has many applications such as in energy storage systems, battery-powered electric vehicles, and uninterruptible power supplies. In this subsection, we cover the two-level bidirectional conventional dc-dc converter, the multilevel bidirectional dc-dc converters, switched-capacitor bidirectional dc- 
dc converters, switched inductor bidirectional dc-dc converters, and quadratic bidirectional dc-dc converters.

\subsubsection{Two-Level Bidirectional Conventional DC-DC Converter}

The topology of this converter is shown in Figure 2.31, as it is composed of two switches that work in a complementary fashion, two capacitors, and one inductor. This converter is very popular for bidirectional buck/boost applications due to its simple structure, having a common ground between its input and output ports, having a continuous current at the low voltage port, and simple gate driving. Nevertheless, this converter cannot be used for applications that require high voltage conversion ratios, due to the existence of parasitic components in its passive and active components. Additionally, at high voltage conversion ratios the efficiency of this converter deteriorates noticeably due to the high voltage and current stresses on its semiconductor devices.

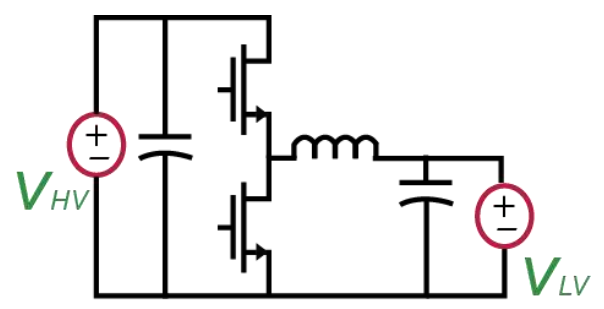

Figure 2.31: The two-level Bidirectional conventional dc-dc converter.

\subsubsection{Multilevel Bidirectional DC-DC Converters}

The multilevel bidirectional dc-dc converter topologies aim to reduce the voltage stresses on the power switches of the dc-dc converter and reduce the size of the magnetic components. The bidirectional versions of the three-level bidirectional converter, the neutral point clamped converters are shown in Figure 2.32. 


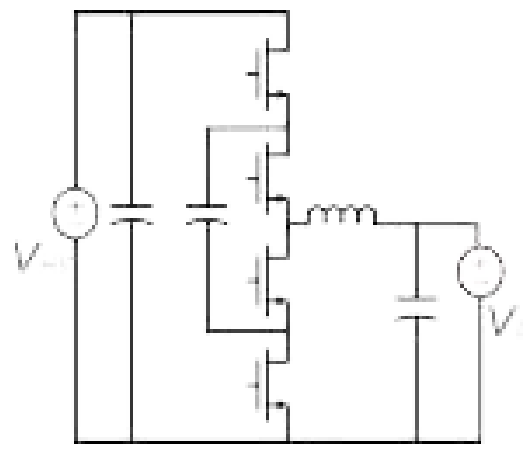

(a)

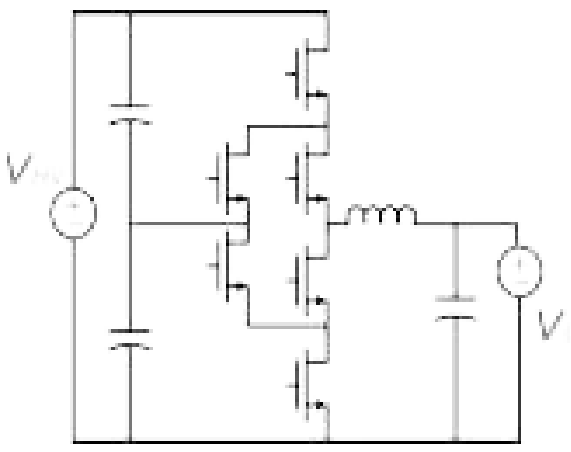

(b)

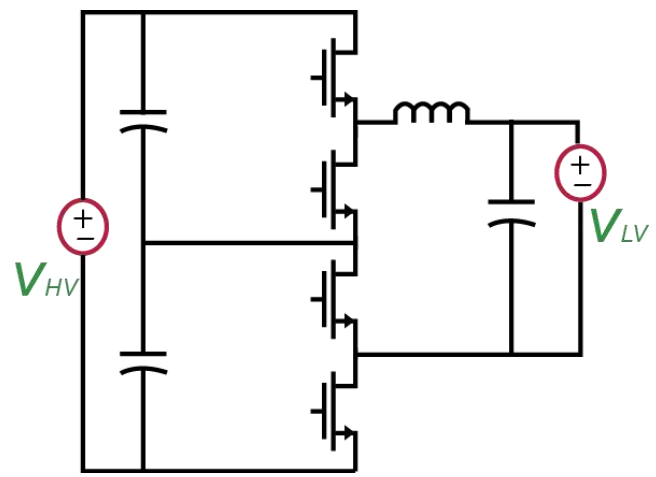

(c)

Figure 2.32: The bidirectional versions of (a) The flying capacitor converter. (b) The neutral point clamped converter. (c) The three-level converter.

\subsubsection{Switched- Capacitor Bidirectional DC-DC Converters}

The switched-capacitor bidirectional dc-dc converters have the same operational concepts as those unidirectional ones discussed in subsection 2.2.3. The bidirectional versions of these converters can be directly derived by replacing the diodes with power switches, as shown in Figure 2.33, in order to allow power flow in both directions.

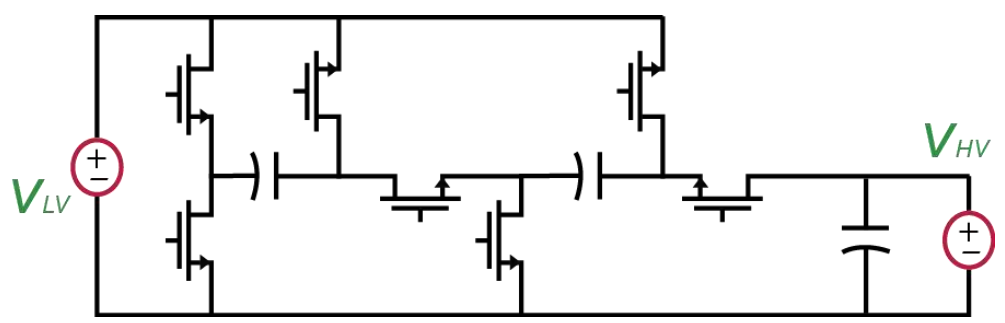

(a) 


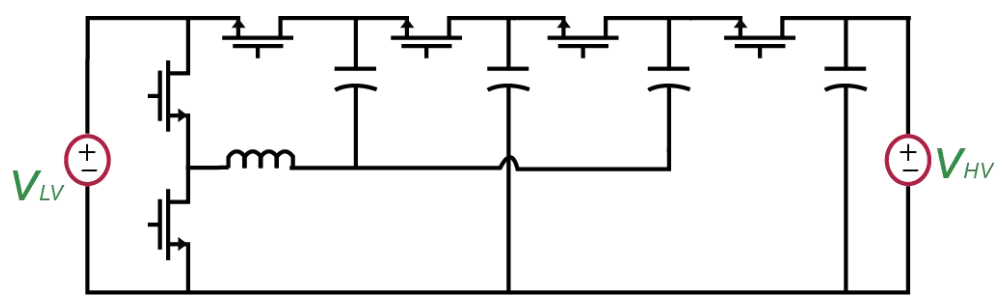

(b)
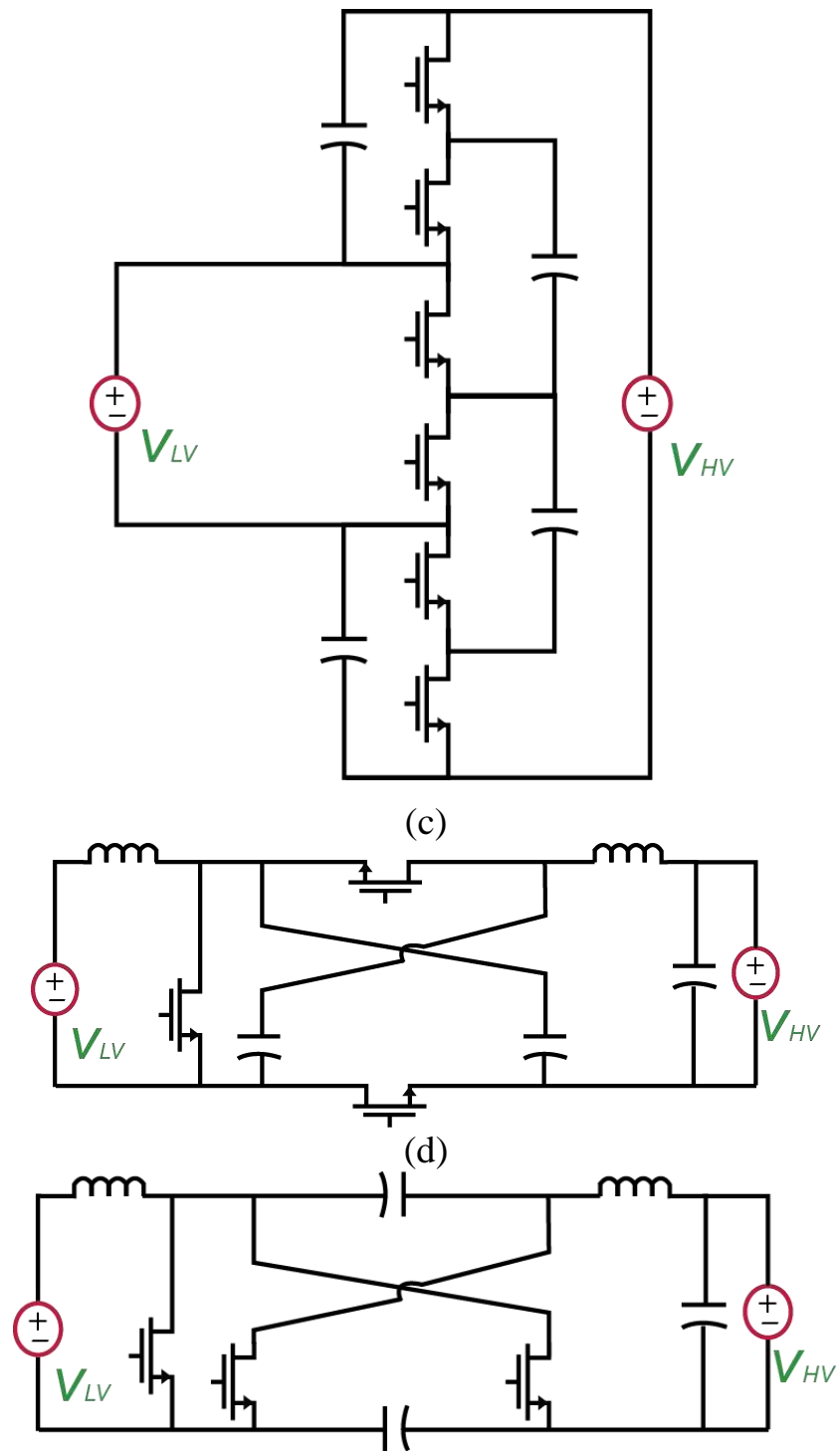

(e)

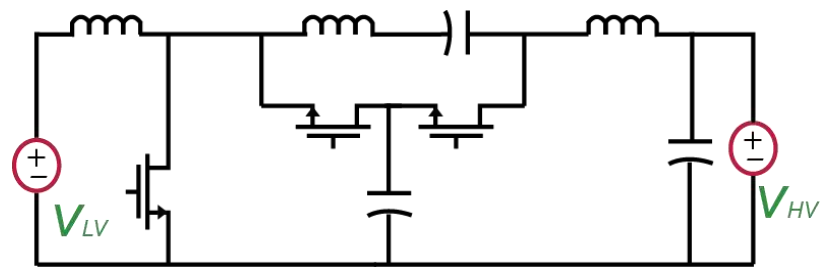




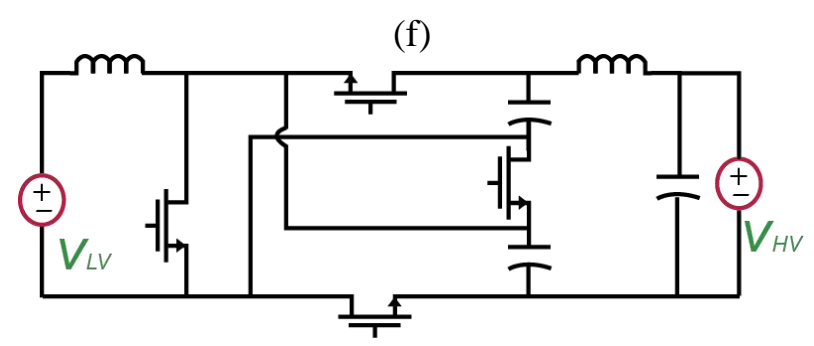

(g)

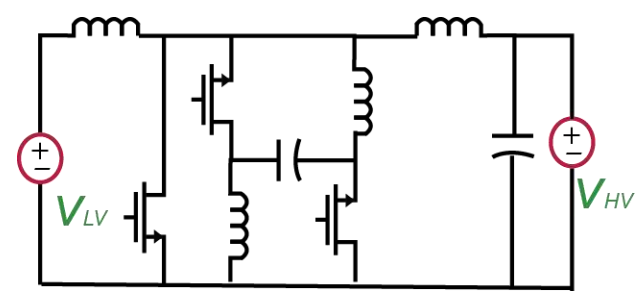

(h)

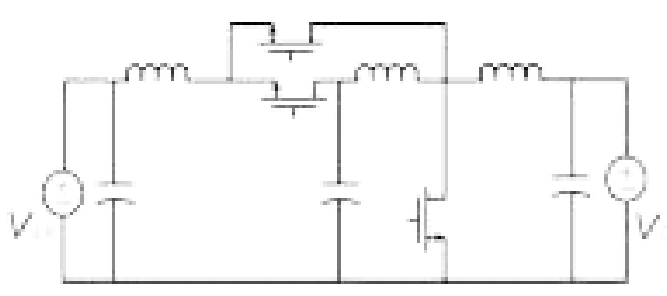

(i)

Figure 2.33: The bidirectional versions of the switched-capacitor converters discussed in subsection 2.2.3.

\subsubsection{Switched- Inductor Bidirectional DC-DC Converters}

The switched-inductor bidirectional dc-dc converters have the same operational concepts as those unidirectional ones discussed in subsection 2.2.4. The bidirectional versions of these converters can be directly derived by replacing the diodes with power switches, as shown in Figure 2.34, in order to allow power flow in both directions.

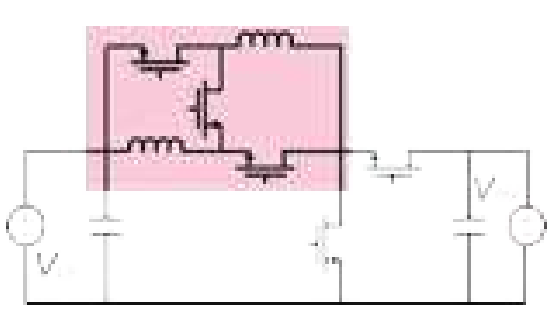

(a)

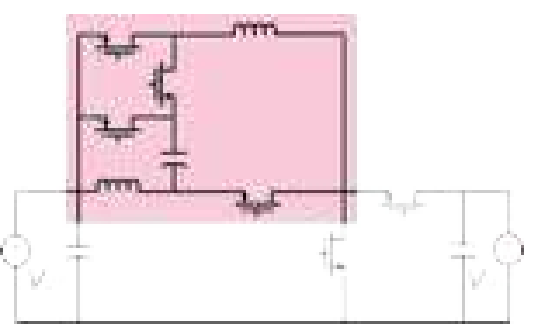

(b) 


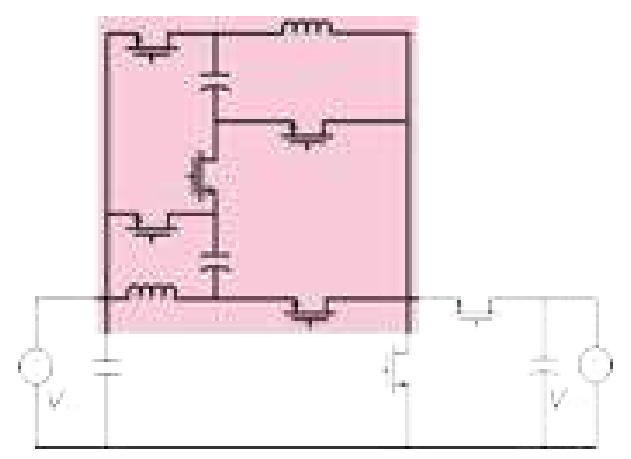

(c)

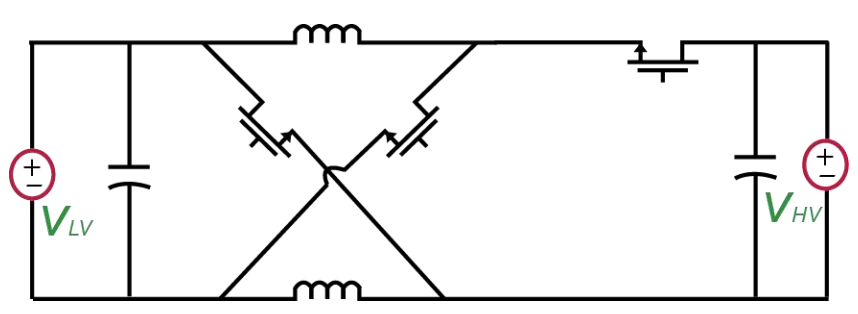

(d)

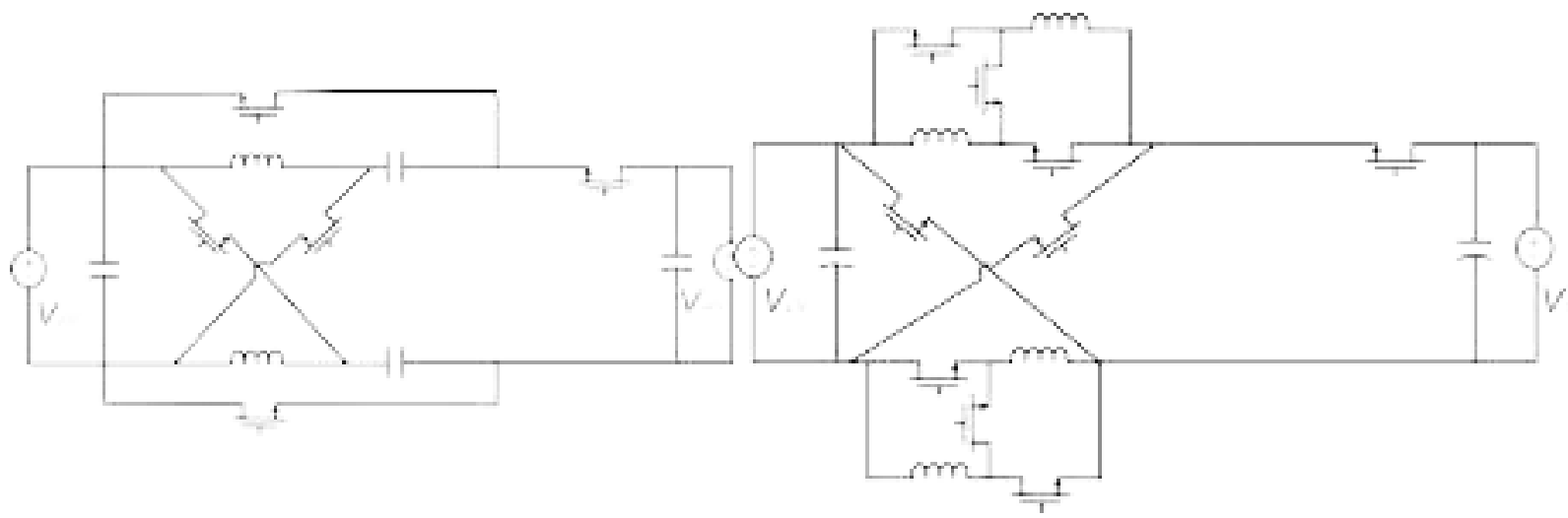

(e)

(f)

Figure 2.34: The bidirectional versions of the switched-inductor converters discussed in subsection 2.2.4.

\subsubsection{Quadratic Bidirectional DC-DC Converters}

The quadratic bidirectional dc-dc converters have the same operational concepts as those unidirectional ones discussed in subsection 2.2.5. The bidirectional versions of these converters can be directly derived by replacing the diodes with power switches, as shown in Figure 2.35, in order to allow power flow in both directions.

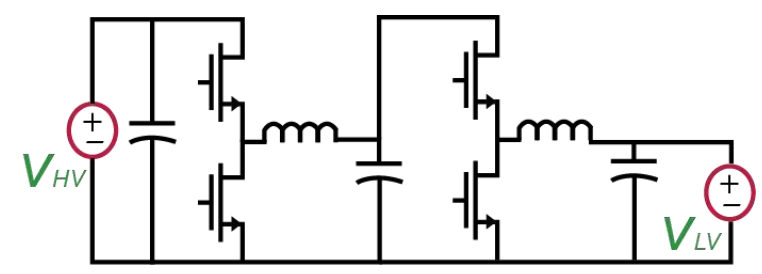

(a)

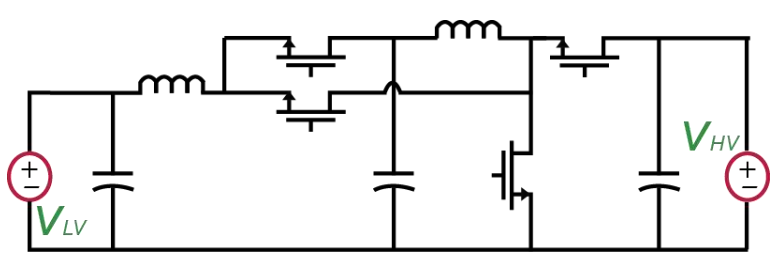

(b) 


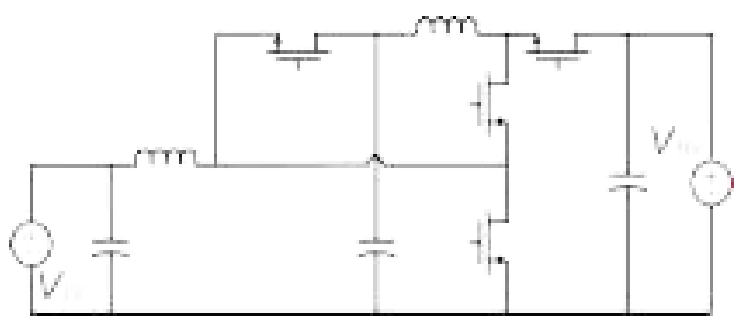

(c)

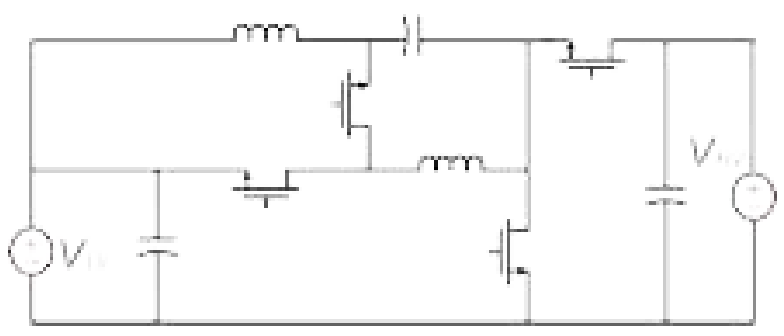

(e)

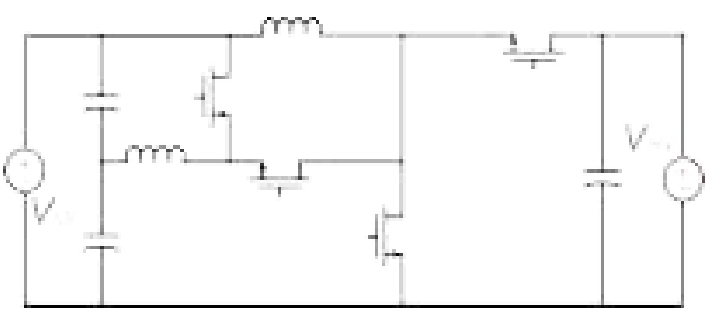

(d)

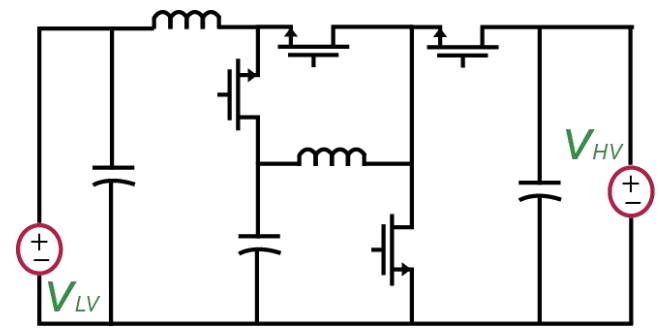

(f)

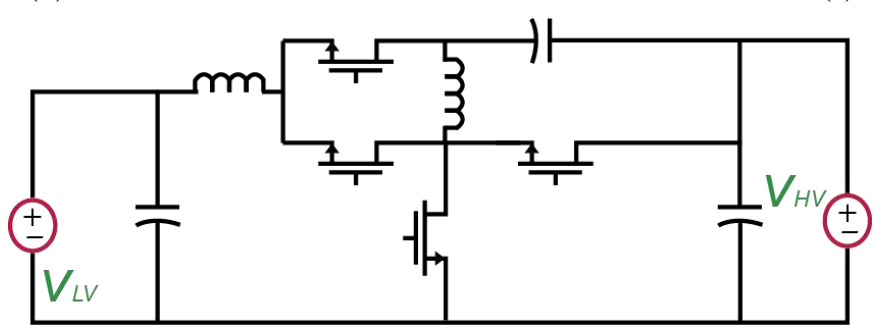

$(\mathrm{g})$

Figure 2.35: The bidirectional versions of the quadratic converters discussed in subsection 2.2.5.

\subsection{Non-Isolated DC-AC Structures}

The six-step buck VSI, shown in Figure 2.36, is the most commonly utilized three-phase inverter; it is composed of three legs in push-pull configuration. A common-mode voltage has to be added to the output of each leg. In this three-phase buck VSI, there are six switches operating at high frequency.

A boost stage can be added before the three-phase buck VSI to increase the voltage level of the dc supply $\left(V_{i n}\right)$. This boost converter can be unidirectional, as in Figure 2.36 (b), or bidirectional, as in Figure 2.36 (c). For systems shown in Figure 2.36 (b) and Figure 2.36 (c) there are at least seven switches operating at high frequency. 


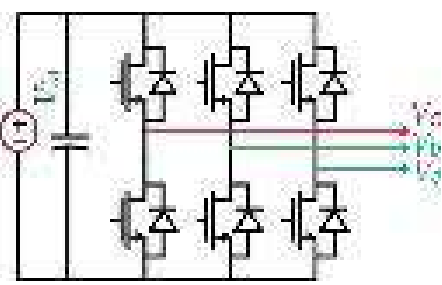

(a)

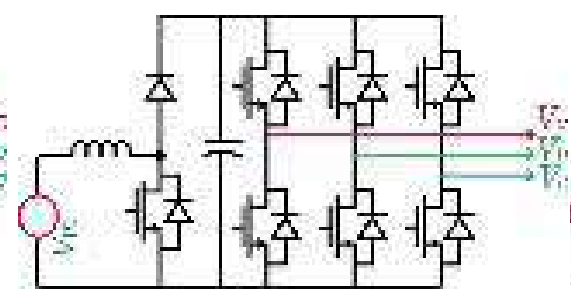

(b)

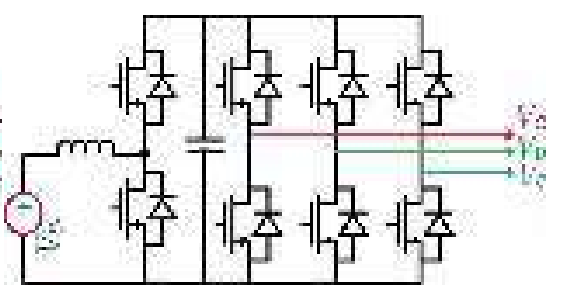

(c)

Figure 2.36: Three-phase voltage source inverter, (a) for Buck operation only, (b) With a unidirectional boost converter. (c) With a bidirectional boost converter.

The Z-source inverter (ZSI) is a single-stage buck-boost inverter, where the dc supply voltage level can be pushed up without the need to a separate boost converter. The first versions of the ZSI are shown in Figure 2.37 (a) and Figure 2.37 (b), as Figure 2.37 (a) shows the unidirectional version and Figure 2.37 (b) shows the bidirectional version.

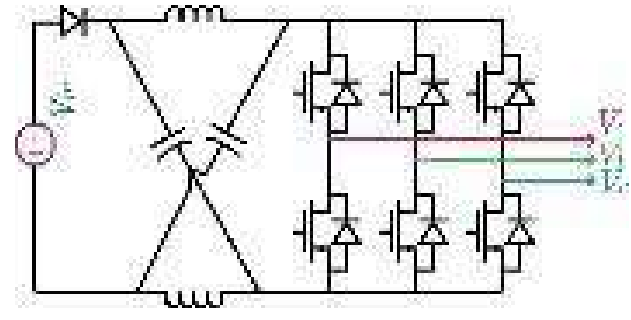

(a)

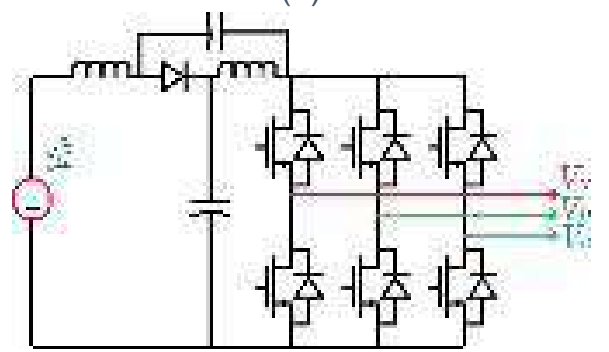

(c)

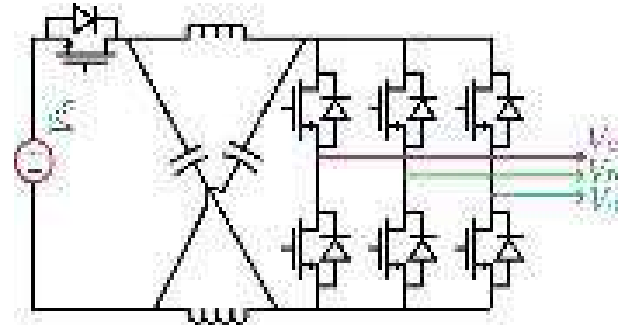

(b)

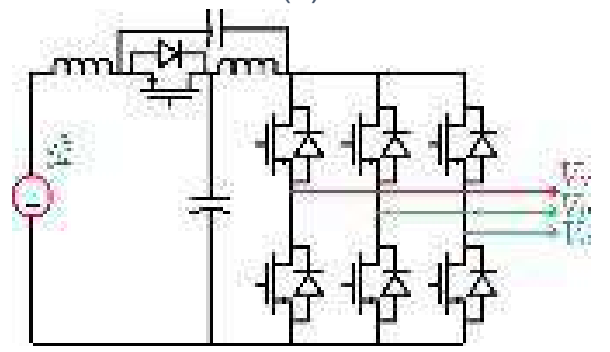

(d)

Figure 2.37: (a) Unidirectional ZSI, (b) Bidirectional ZSI, (c) Unidirectional qZSI, (d) Bidirectional qZSI.

The quasi ZSI (qZSI) is the improved version of the ZSI as it has a smooth input current, making it suitable for renewable energy and energy storage systems. The unidirectional version of the qZSI is presented in Figure 2.37 (c) and the bidirectional version is shown in 
Figure 2.37 (d). Both of ZSI and qZSI have six switches operating at high frequency. A lot of literature have covered different structures of the ZSI and qZSI [138]-[162].

The split-source inverter (SSI) is an alternative to the ZSI and qZSI [163]-[166], where the dc supply voltage can be stepped up without the need to a separate boost converter. The SSI has six switches operating at high frequency (note: the other three switches, in the bidirectional version, operate at low frequency). The unidirectional version of the SSI is depicted in Figure 2.38 (a), and the bidirectional version of the SSI is depicted in Figure 2.38 (b).

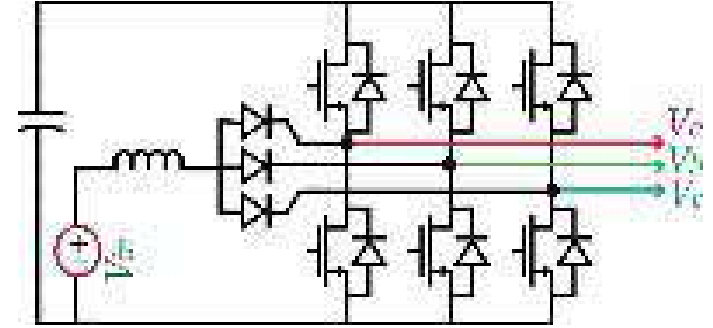

(a)

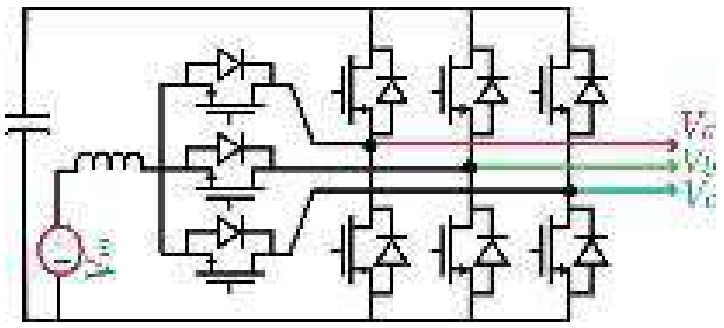

(b)

Figure 2.38: (a) Unidirectional SSI, (b) Bidirectional SSI.

The basic construction of the (differential-mode inverter) DMI is three bidirectional buck or buck-boost dc-dc converters connected in such a way that all of them have a common ground, as shown in Figure 2.39 (a) [167]-[175]. Each converter generates an "ac voltage component" with a dc offset, such that the sum is either in the positive or negative voltage plane. Many dc-dc converters can be used to synthesize the DMI, like: Sepic, Ćuk, buckboost, ....., etc. The least number of switches operating at high frequency for a three-phase DMI is six switches.

Two examples of the three-phase DMI are shown in Figure 2.39 (b) and Figure 2.39 (c). In Figure 2.39 (b), a DMI is synthesized with three bidirectional non-isolated Ćuk converters, 
while Figure 2.39 (c) shows a DMI that is synthesized with three bidirectional isolated Ćuk converters.

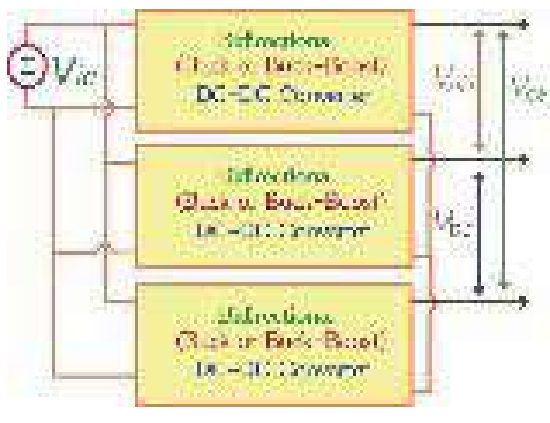

(a)

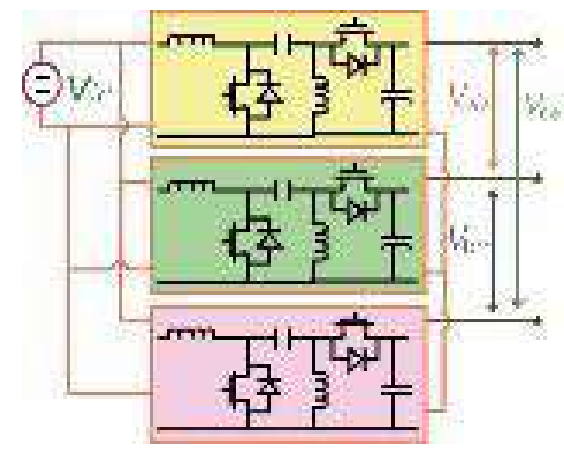

(b)

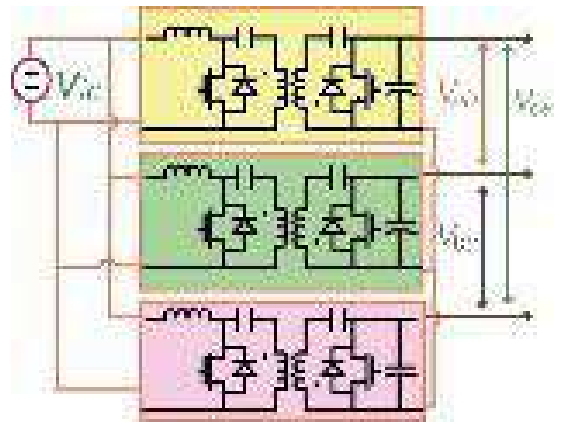

(c)

Figure 2.39: (a) Generic DMI connection diagram, (b) Non-isolated Ćuk DMI, (c) Isolated Ćuk DMI.

\subsection{Isolated DC-AC Structures}

The isolated dc-ac inverter systems have many applications such as in renewable energy systems where they step-up the voltage level of the renewable energy source (by means of the turns ratio of the magnetic coupling component), and they minimize the leakage currents. Added to that, the galvanic isolation between the dc-source and the ac load provides inherent protection to the renewable energy sources against faults in the power grid.

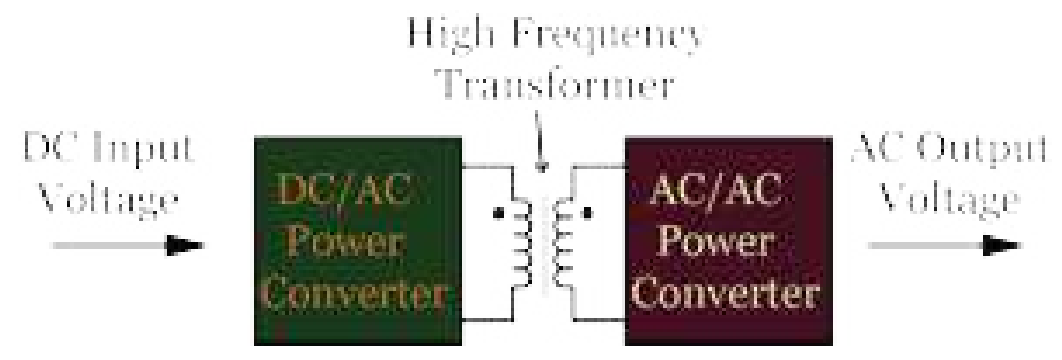

Figure 2.40: The generic structure of an isolated dc-ac inverter. 
The differential-mode inverter that is shown in Figure 2.39 (c) is an example of isolated dc-ac structures. Nevertheless, the most common architecture of the isolated dc-ac structures is given in Figure 2.40

As depicted in Figure 2.40, this type of isolated dc-ac inverters is composed on a dc-ac stage to convert the input dc voltage to high frequency ac voltage to drive the high frequency transformer. An ac-ac power stage follows the high frequency transformer in order to convert the high frequency ac voltage from the transformer to an ac voltage with the low nominal frequency required by the ac load. Typically this kind of isolated inverters is categorized based on the structure of their ac-ac stage to either high frequency dc-link converters or high frequency ac-link converters.

\subsubsection{High-Frequency DC-Link Converter}

The typical topology of this converter is shown in Figure 2.41, as it is composed of a singlephase dc-ac inverter to convert the input dc voltage to high frequency ac voltage to drive the high frequency transformer, a single-phase rectifier to convert the high-frequency ac voltage from the transformer's secondary to dc voltage, and finally an inverter to convert this dc voltage to ac voltage with the voltage magnitude and frequency required by the ac load. This converter has a simple circuit structure and simple control. Nevertheless, the dc-link capacitor following the ac-dc rectifier reduces the power density of the converter and affects its reliability. 


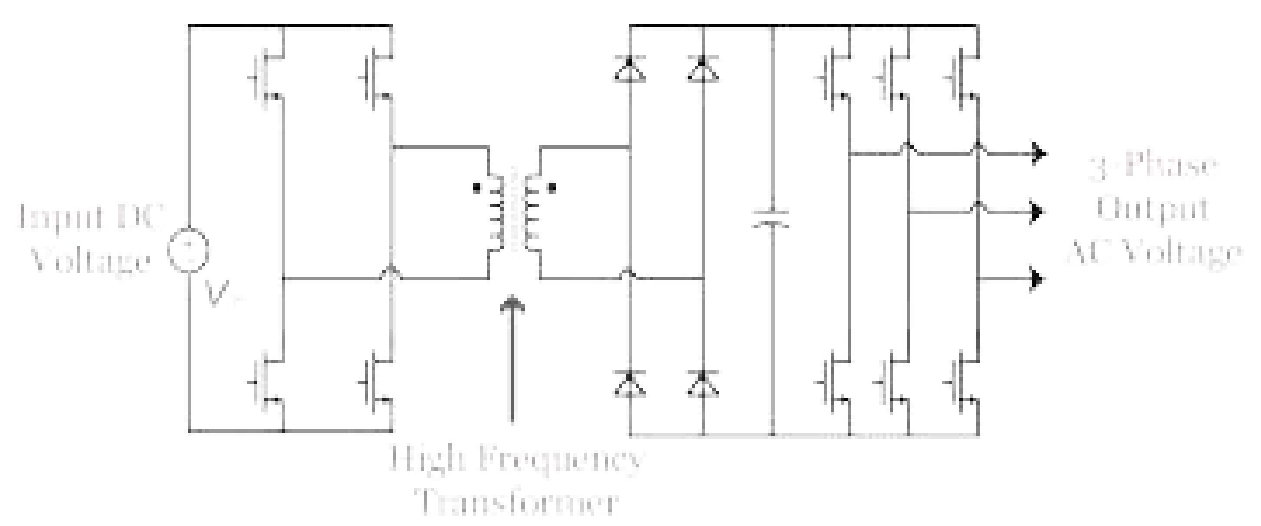

Figure 2.41: The topology of the high-frequency dc-link dc-ac inverter.

\subsubsection{High-Frequency AC-Link Converter}

The typical topology of this converter is shown in Figure 2.42, as it is composed of a single-phase dc-ac inverter to convert the input dc voltage to high frequency ac voltage to drive the high frequency transformer, a matrix converter to directly convert the highfrequency ac voltage from the transformer's secondary to ac voltage with the voltage magnitude and frequency required by the ac load. This converter eliminates the need for dclink capacitors, thus its power density and reliability are better compared to the highfrequency dc-link converter. Nevertheless, the circuit structure and the required gate drivers are relatively more complex.

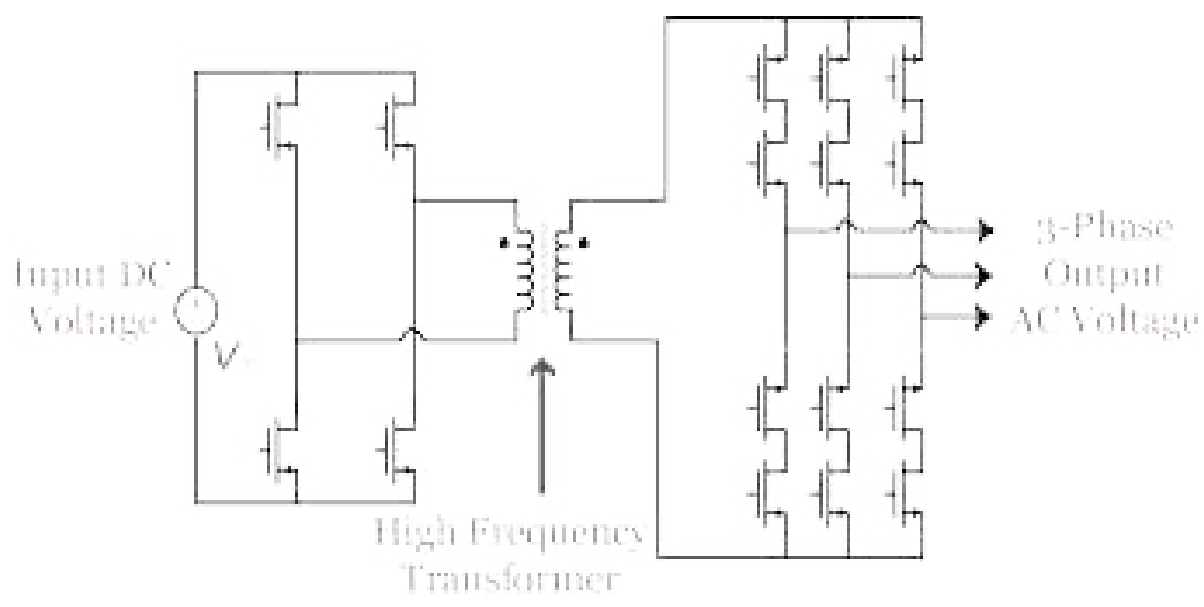

Figure 2.42: The topology of the high-frequency dc-link dc-ac inverter. 


\subsection{Conclusion}

This chapter surveyed of the state of the art power electronic building blocks, as it reviewed the unidirectional and bidirectional dc-dc structures with integrated switchedcapacitor, switched-inductor, quadratic, and multilevel networks. In addition, it reviewed the popular non-isolated and isolated dc-ac inverters. 


\section{Chapter 3 Analysis and Design of a Three-Level Boost Converter with Wide Gain Range for Fuel Cell Automotive Applications}

\subsection{Introduction}

In this chapter, a new three-level boost converter with continuous input current, common ground, reduced voltage stress on the power switches, and wide voltage gain range is proposed. The proposed converter is composed of a three-level flying capacitor switching cell and an integrated $L C^{2} D$ output network. The $L C^{2} D$ output network enhances the voltage gain of the converter and reduces the voltage stress on the power switches. The proposed converter is a good candidate to interface fuel-cells to the dc-link bus of the three-phase inverter of the electric vehicle (EV). Full steady-state analysis of the proposed converter in the continuous conduction mode $(\mathrm{CCM})$, converter components design is given in this chapter. A $1.2 \mathrm{~kW}$ scaled-down laboratory setup was built using Gallium Nitride $(\mathrm{GaN})$ transistors and Silicon Carbide ( $\mathrm{SiC})$ diodes to verify the feasibility of the proposed converter.

\subsection{Structure and Operating Principles of the Proposed Converter}

\subsubsection{General Structure of the Proposed Converter}

The proposed converter is presented in Figure. 2, where it is composed of two active switches $\left(Q_{1}, Q_{2}\right)$, three diodes $\left(D_{1}, D_{2}, D_{3}\right)$, two inductors $\left(L_{1}, L_{2}\right)$, and four capacitors $\left(C_{1}\right.$, $\left.C_{2}, C_{3}, C_{4}\right)$. The fuel cell is depicted as a dc voltage source $\left(V_{i n}\right)$. The network of $\left(Q_{1}, Q_{2}, D_{1}\right.$, $D_{2}, C_{2}, C_{3}$ ) forms a three-level flying-capacitor switching cell. The $L C^{2} D$ output network enhances the voltage gain and reduces the voltage stress on the power switches. 


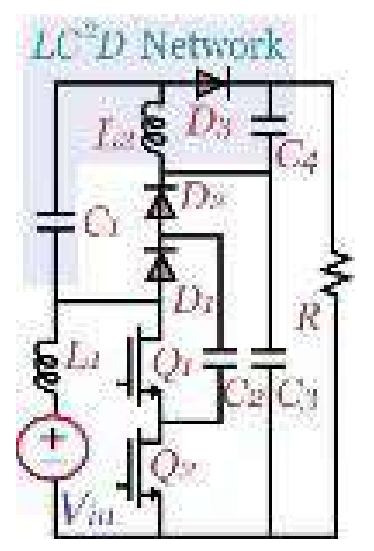

Figure 3.1: The schematic of the proposed converter

\subsubsection{Operation Modes}

The proposed converter has two active switches, hence, it has four possible switching states for $Q_{1}$ and $Q_{2}$. These switching states are: $S_{1} S_{2}=\{00,01,10$, and 11$\}$, as $S_{1}$ and $S_{2}$ are the triggering signals of $Q_{1}$ and $Q_{2}$, respectively.

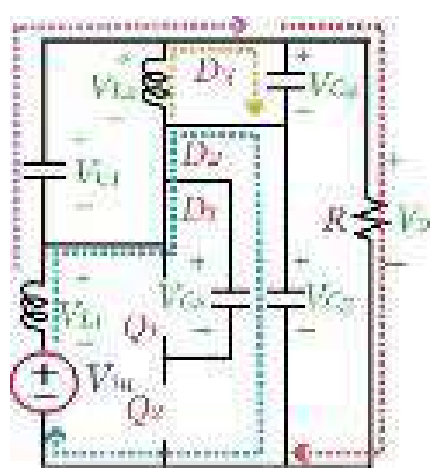

(a)

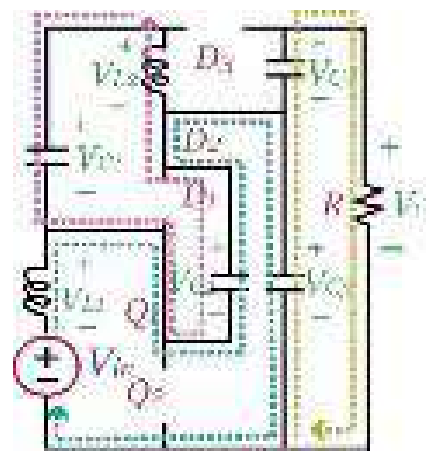

(b)

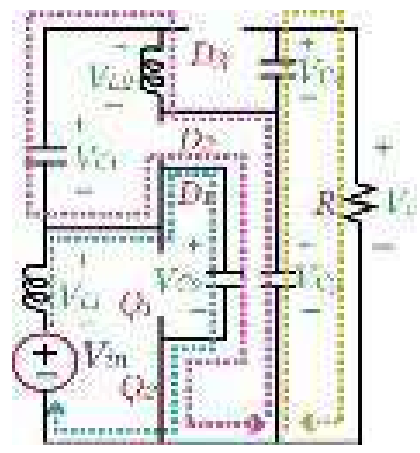

(c)

Figure 3.2: Current flow paths when $\mathrm{D}<0.5$. (a) $\mathrm{S} 1 \mathrm{~S} 2=00$. (b) $\mathrm{S} 1 \mathrm{~S} 2=10$. (c) $\mathrm{S} 1 \mathrm{~S} 2=01$.

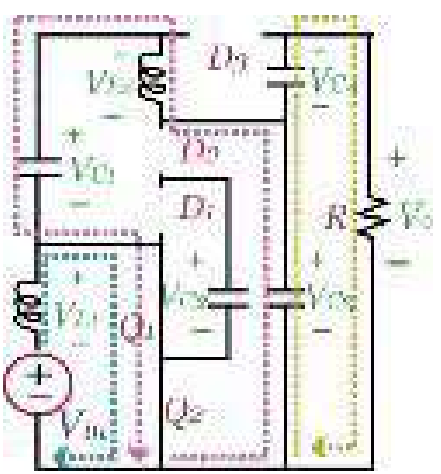

(a)

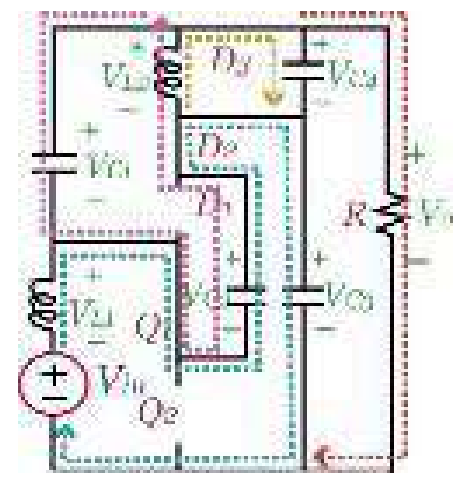

(b)

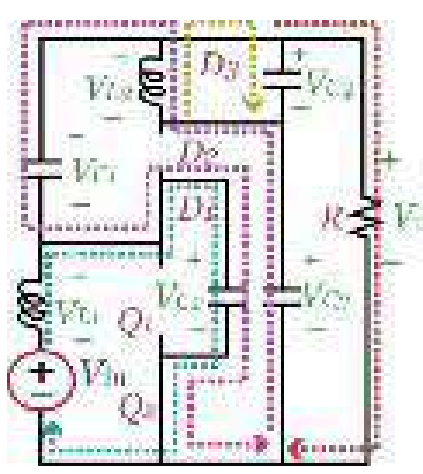

(c)

Figure 3.3: Current flow paths when D $>0.5$. (a) $\mathrm{S} 1 \mathrm{~S} 2=11$. (b) $\mathrm{S} 1 \mathrm{~S} 2=10$. (c) $\mathrm{S} 1 \mathrm{~S} 2=01$. 
The triggering signals $S_{1}$ and $S_{2}$ are generated via comparing two phase-shifted $180^{\circ}$ carrier signals with a modulation signal $(D)$. This means that there are three possible switching sequences, based on the value of $D$. When $D>0.5$, the switching sequence of $S_{1} S_{2}$ is $\{10,11$, $01,11$, and 10$\}$. When $D<0.5$, the switching sequence of $S_{1} S_{2}$ is $\{10,00,01,00$, and 10$\}$. When $D=0.5$, the switching sequence of $S_{1} S_{2}$ is $\{10,01$, and 10$\}$. The key waveforms of the proposed TLB converter are presented in Figure 3.4, and the current flow paths when $D<0.5$ and $D>0.5$ are shown in Figure 3.2 and Figure 3.3, respectively.

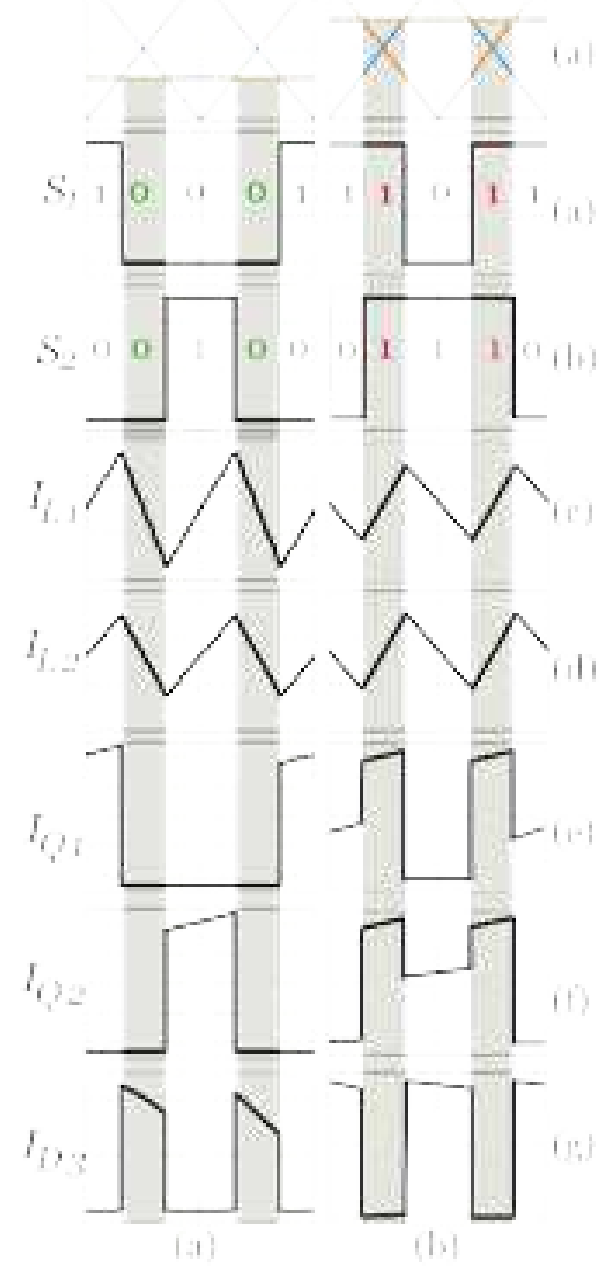

Figure 3.4: Key waveforms of the proposed converter (a) $\mathrm{D}<0.5$. (b) $\mathrm{D}>0.5$. 


\subsubsection{Analysis of Operating States}

In this subsection, the proposed converter is analyzed during each of the four switching states, to be used after that in calculating the voltage gain and the voltage stress associated with each switching sequence.

When $S_{1} S_{2}=01$, shown in Figure 3(c) and 4(c), by applying the Kirchhof's Voltage Law (KVL) we get equations (1) and (2).

$$
\begin{aligned}
& V_{L 1}=V_{i n}-V_{c 2} \\
& V_{L 2}=V_{C 1}+V_{C 2}-V_{C 3}
\end{aligned}
$$

When $S_{1} S_{2}=10$, shown in Figure 3(b) and 4(b), by applying the KVL we get equations (3) and (4).

$$
\begin{aligned}
& V_{L 1}=V_{i n}+V_{C 2}-V_{C 3} \\
& V_{L 2}=V_{C 1}-V_{C 2}
\end{aligned}
$$

When $S_{1} S_{2}=11$, shown in Figure 4(a), by applying the KVL we get equations (5) and (6).

$$
\begin{aligned}
& V_{L 1}=V_{i n} \\
& V_{L 2}=V_{C 1}-V_{C 3}
\end{aligned}
$$

When $S_{1} S_{2}=00$, shown in Figure 3(a), by applying the KVL we get equations (7) and (8).

$$
\begin{aligned}
& V_{L 1}=V_{\text {in }}-V_{C 3} \\
& V_{L 2}=V_{C 1}
\end{aligned}
$$

\subsubsection{Wide Voltage Gain}

In this subsection the voltage gain of the proposed converter is derived for $D>0.5$ and $D<$ 0.5. To simplify the analysis, all inductors and capacitors are assumed to be ideal and very large to apply the small ripple approximation. When $D>0.5$, as shown in Fig. 6(b), the switching sequence of $S_{1} S_{2}$ is $\{10,11,01,11$, and 10$\}$. In this switching sequence the time of 
state $\{01\}, T_{01}$, the time of state $\{10\}, T_{10}$, and the time of state $\{11\}, T_{11}$, are defined as shown in (9):

$$
\left\{\begin{array}{c}
T_{01}=(1-D) T \\
T_{10}=(1-D) T \\
T_{11}=(2 D-1) T
\end{array}\right.
$$

As $T$ is the periodic time of the carrier signals.

By applying the volt-second balance rule on $L_{1}$ and $L_{2}$, we get equations (10) and (11):

$$
\begin{aligned}
& V_{C 3}=\frac{V_{\text {in }}}{1-D} \\
& V_{C l}=\frac{D}{1-D} V_{\text {in }}
\end{aligned}
$$

The output voltage $V_{o}$ can be defined as the biggest value of the sum of " $V_{C 3}$ " and " $V_{L 2}$ ". Thus, when $D>0.5, V_{o}$ can be calculated as following:

$$
V_{o}=V_{C 3}+V_{C 1}-V_{C 2}
$$

Since $C_{2}$ and $C_{3}$ are the two capacitors of a three-level flying capacitor network, thus, $V_{C 2}$ is half $V_{C 3}$, hence:

$$
V_{o}=\frac{V_{C 3}}{2}+V_{C 1}
$$

By substituting by (10) and (11) in (13), we get:

$$
V_{o}=\frac{0.5+D}{1-D} V_{i n}
$$

Thus the voltage gain, $M$, is defined by (15):

$$
M=\frac{V_{O}}{V_{\text {in }}}=\frac{0.5+D}{1-D}
$$

When $D<0.5$, as shown in Fig. 6(a), the switching sequence of $S_{1} S_{2}$ is $\{10,00,01,00$, and $10\}$. In this switching sequence $T_{01}, T_{10}$, and the time of state $\{00\}, T_{00}$, are defined as following: 


$$
\left\{\begin{array}{l}
T_{01}=D T \\
T_{10}=D T \\
T_{00}=(1-2 D) T
\end{array}\right.
$$

By applying the volt-second balance rule on $L_{1}$ and $L_{2}$, we get equations (17) and (18):

$$
\begin{aligned}
& V_{C 3}=\frac{V_{\text {in }}}{1-D} \\
& V_{C l}=\frac{D}{1-D} V_{\text {in }}
\end{aligned}
$$

In this switching sequence $V_{o}$ can be defined as the biggest value of the sum of " $V_{C 3}$ " and " $-V_{L 2}$ ". Thus, when $D<0.5, V_{o}$ can be calculated as following:

$$
V_{o}=V_{C 3}+V_{C l}
$$

(19) By substituting by (17) and (18) in (19), we get:

$$
V_{o}=\frac{1+D}{1-D} V_{i n}
$$

Thus the voltage gain, $M$, is defined by (21):

$$
M=\frac{V_{o}}{V_{\text {in }}}=\frac{1+D}{1-D}
$$

The equations derived for $D>0.5$ case can be applied for $D=0.5$.

When $S_{1} S_{2}$ is $\{10$, or 01$\}$, the states of $L_{1}$ and $L_{2}$ depend on the value of $D$. From equations (1)-(4), the voltage across $L_{1}$ and $L_{2}$ can be defined as following:

$$
\begin{aligned}
& V_{L 1}=\frac{0.5-D}{1-D} V_{i n} \\
& V_{L 2}=\frac{D-0.5}{1-D} V_{i n}
\end{aligned}
$$

By means of equations (22), and (23), and the voltage polarities shown in Figures 3 and 4, both $L_{1}$ and $L_{2}$ are charging when $D$ is less than 0.5 , while they are discharging when $D$ is greater than 0.5 . 


\subsubsection{Voltage Stress Analysis}

The voltages across $C_{4}$ equals $\left(V_{o}-V_{C 3}\right)$. The voltages across $C_{1}, C_{2}$, and $C_{3}$ are described by equations (24), and (25)

$$
\begin{gathered}
V_{C 2}=\frac{V_{C 3}}{2}= \begin{cases}\frac{V_{o}}{2(1+D)} & D<0.5 \\
\frac{V_{o}}{1+2 D} & D \geq 0.5\end{cases} \\
V_{C l}= \begin{cases}\frac{D V_{o}}{(1+D)} & D<0.5 \\
\frac{D V_{o}}{(0.5+D)} & D \geq 0.5\end{cases}
\end{gathered}
$$

The voltage across $Q_{1}, Q_{2}, D_{1}, D_{2}$, and $D_{3}$ can be expressed by (26).

$$
V_{Q 1}=V_{Q 2}=V_{D 1}=V_{D 2}=V_{D 3}=\frac{V_{C 3}}{2}= \begin{cases}\frac{V_{o}}{2(1+D)} & D<0.5 \\ \frac{V_{o}}{1+2 D} & D \geq 0.5\end{cases}
$$

\subsubsection{Current Stress Analysis}

In this subsection the current stresses on both the semiconductor devices and inductors are derived. The analysis is divided into two parts, depending on the value of $D$. In the following equations, the output load current is $I_{o}$, the average currents of inductors $L_{1}$ and $L_{2}$ are $I_{L l}$ and $I_{L 2}$, respectively, the average charging currents of capacitors $C_{1}, C_{2}, C_{3}$, and $C_{4}$ are $I_{C I_{-} c h}$, $I_{C 2 \_c h}, I_{C 3} c h$, and $I_{C 4 \_c h}$, respectively, and the average discharging currents of capacitors $C_{l}$, $C_{2}, C_{3}$, and $C_{4}$ are $I_{C I \_d i s c h}, I_{C 2 \_d i s c h}, I_{C 3 \_d i s c h}$, and $I_{C 4 \_d i s c h}$, respectively.

\section{$($ For $D>0.5)$}

The current stresses can be obtained as following:

$S_{1} S_{2}=11:$

In this switching state $C_{3}$ discharges, $C_{1}$ charges, $C_{2}$ neither charges nor discharges, and $C_{4}$ discharges. Diode $D_{3}$ is reverse biased. By applying Kirchhof's Current Law (KCL), the relationships between the inductor and capacitor currents can be expressed as following: 


$$
\begin{gathered}
I_{C 3 \_d i s c h}=-I_{L 2} \\
I_{C 1 \_c h}=-I_{L 2} \\
I_{C 4 \_ \text {disch }}=-I_{L 2}=-I_{O}
\end{gathered}
$$

$S_{1} S_{2}=10:$

In this switching state $C_{3}$ charges, $C_{1}$ discharges, $C_{2}$ discharges, and $C_{4}$ charges. Diode $D_{3}$ is forward biased. We get the following equations:

$$
\begin{gathered}
I_{C 3 \_c h}=-I_{C 2 \_d i s c h}-I_{L 2} \\
I_{C 4 \_c h}=I_{C 1 \_d i s c h} \\
I_{C 1 \_d i s c h}=-I_{C 2 \_d i s c h}+I_{L 1}
\end{gathered}
$$

$S_{1} S_{2}=01:$

In this switching state $C_{3}$ discharges, $C_{1}$ discharges, $C_{2}$ charges, and $C_{4}$ charges. Diode $D_{3}$ is forward biased. We get the following equations:

$$
\begin{gathered}
I_{C 3 \_d i s c h}=-I_{L 2} \\
I_{C 4 \_c h}=I_{C 1 \_d i s c h} \\
I_{C 1 \_d i s c h}=-I_{C 2 \_c h}+I_{L 1}
\end{gathered}
$$

By using the capacitor charge-second balance rule on capacitors $C_{1}, C_{2}, C_{3}$, and $C_{4}$, the following relationships can be obtained:

$$
\begin{gathered}
I_{C 1 \_d i s c h}=\frac{2 D-1}{2(1-D)} I_{L 2} \\
I_{C 2 \_c h}=-I_{C 2 \_d i s c h}=I_{L 1}-I_{C 1} \_d i s c h \\
I_{C 3 \_c h}=-I_{C 2 \_d i s c h}-I_{L 2} \\
I_{C 4 \_c h}=I_{L 2}+I_{C 1 \_d i s c h}-I_{O} \\
I_{L 2}=I_{O}
\end{gathered}
$$


Assuming a lossless operation, the relationship between $I_{o}$ and $I_{L 1}$ can be obtained as following:

$$
\begin{aligned}
& V_{i n} I_{L 1}=V_{o} I_{o} \\
& I_{L 1}=\frac{(0.5+D) I o}{(1-D)}
\end{aligned}
$$

When $D>0.5$, diode $D_{3}$ conducts only during $S_{1} S_{2}=\{10$, and 10$\}$, and the instantaneous current flowing through $D_{3}$ during $T_{01}$ and $T_{10}$ is $I_{D 3}$. During $S_{1} S_{2}=\{11\}$, the instantaneous current flowing through $Q_{1}$, and $Q_{2}$ is $I_{Q_{-}} 11$. During $S_{1} S_{2}=\{10\}$, the instantaneous currents flowing through $Q_{1}, Q_{2}, D_{1}$, and $D_{2}$ are $I_{Q 1} 10, I_{Q 2_{-} 10}, I_{D 1_{-} 10}$, and $I_{D 2_{-} 10}$ respectively. During $S_{1}$ $S_{2}=\{01\}$, the instantaneous currents flowing through $Q_{1}, Q_{2}, D_{1}$, and $D_{2}$ are $I_{Q 1}{ }_{-}, I_{Q 2 \_01}$, $I_{D 1 \_01}$, and $I_{D 2 \_01}$ respectively.

$$
\begin{gathered}
I_{D 3}=\frac{1}{2(1-D)} I_{L 2} \\
I_{Q \_11}=I_{L 1}+I_{L 2} \\
I_{Q 1 \_10}=I_{Q 2 \_01}=I_{D 2 \_10}=I_{D 1 \_01}=I_{C 2 \_c h} \\
I_{Q 1 \_01}=I_{Q 2 \_10}=I_{D 1} 10=I_{D 2 \_01}=0
\end{gathered}
$$

The root-mean-square (rms) values of currents flowing through the components of the converter are essential for loss analysis. The rms values of $I_{Q 1}, I_{Q 2}, I_{D 1}, I_{D 2}, I_{D 3}, I_{C 1}, I_{C 2}, I_{C 3}$, and $I_{C 4}$ are $I_{Q 1 \_r m s}, I_{Q 2 \_r m s}, I_{D 1 \_r m s}, I_{D 2 \_r m s}, I_{D 3 \_r m s}, I_{C 1 \_r m s}, I_{C 2 \_r m s}, I_{C 3 \_r m s}$, and $I_{C 4 \_r m s}$, respectively. Using equations (9), (27)-(46) we can obtain the following equations:

$$
\begin{gathered}
I_{Q 1 \_r m s}=I_{Q 2 \_r m s}=\sqrt{(2 D-1)\left(I_{L 1}+I_{L 2}\right)^{2}+(1-D)\left(I_{L 1}-I_{C 1 \_d i s c h}\right)^{2}} \\
I_{D 1 \_r m s}=I_{D 2 \_r m s}=\sqrt{(1-D)\left(I_{L 1}-I_{C 1 \_ \text {disch }}\right)^{2}} \\
I_{D 3_{-} r m s}=I_{L 2}=I_{o}
\end{gathered}
$$




$$
\begin{gathered}
I_{C I_{-} r m s}=\sqrt{(2 D-1)\left(I_{L 2}\right)^{2}+2(1-D)\left(\frac{2 D-1}{2(1-D)} I_{L 2}\right)^{2}} \\
I_{C 2_{-} r m s}=\sqrt{2(1-D)\left(I_{L 1}-I_{C 1_{-} \text {disch }}\right)^{2}} \\
I_{C 3_{-} r m s}=\sqrt{(D)\left(I_{L 2}\right)^{2}+(1-D)\left(I_{C 2 \_d i s c h}-I_{L 2}\right)^{2}} \\
I_{C C_{-} r m s}=\sqrt{(2 D-1)\left(I_{o}\right)^{2}+2(1-D)\left(I_{C 1 \_d i s c h}\right)^{2}}
\end{gathered}
$$

\section{(For $D<0.5)$}

The current stresses can be obtained as following:

$S_{1} S_{2}=00$ :

In this switching state $C_{3}$ charges, $C_{1}$ discharges, $C_{2}$ neither charges nor discharges, and $C_{4}$ charges. Diode $D_{3}$ is forward biased. By applying the $\mathrm{KCL}$ rule, the relationships between the inductor and capacitor currents can be expressed as following:

$$
\begin{gathered}
I_{C 3 \_c h}=I_{L 1}-I_{C 1 \_d i s c h}-I_{L 2} \\
I_{C 4 \_c h}=I_{L 2}+I_{C 1 \_d i s c h}-I_{O}
\end{gathered}
$$

$S_{1} S_{2}=10$ :

In this switching state $C_{3}$ charges, $C_{1}$ charges, $C_{2}$ discharges, and $C_{4}$ discharges. Diode $D_{3}$ is reverse biased. We get the following equations:

$$
\begin{gathered}
I_{C 3_{-} c h}=-I_{C 2 \_d i s c h}-I_{L 2}=I_{L 1} \\
I_{C 2 \_d i s c h}=-I_{L 1}-I_{L 2} \\
I_{C 1 \_c h}=-I_{L 2}
\end{gathered}
$$

$S_{1} S_{2}=01:$

In this switching state $C_{3}$ discharges, $C_{1}$ charges, $C_{2}$ charges, and $C_{4}$ discharges. Diode $D_{3}$ is reverse biased. We get the following equations: 


$$
\begin{gathered}
I_{C 3 \_d i s c h}=-I_{L 2} \\
I_{C 2 \_c h}=I_{L 1}+I_{L 2} \\
I_{C 1 \_c h}=-I_{L 2}
\end{gathered}
$$

By using the capacitor charge-second balance rule on capacitors $C_{1}, C_{2}, C_{3}$, and $C_{4}$, the following relationships can be obtained:

$$
\begin{gathered}
I_{C 1 \_d i s c h}=\frac{2 D}{1-2 D} I_{L 2} \\
I_{C 2 \_c h}=-I_{C 2 \_d i s c h}=I_{L 1}+I_{L 2}
\end{gathered}
$$

Assuming a lossless operation and using equation (41), the relationship between $I_{o}$ and $I_{L 1}$ can be obtained as following:

$$
I_{L 1}=\frac{(1+D) I o}{(1-D)}
$$

When $D<0.5$, diode $D_{3}$ conducts only during $S_{1} S_{2}=\{00\}$, and the instantaneous current flowing through $D_{3}$ during $T_{00}$ is $I_{D 3} \_00$. During $S_{1} S_{2}=\{00\}$, the instantaneous current flowing through $D_{3}$ ia $I_{D 3}$ 00. The relationship between transistor, diode, and inductor currents can be obtained as following:

$$
\begin{gathered}
I_{D 3 \_} 00=\frac{1}{1-2 D} I_{L 2} \\
I_{Q 1 \_10}=I_{Q 2 \_01}=I_{D 2 \_10}=I_{D 1 \_01}=I_{L 1}+I_{L 2} \\
I_{Q 1 \_01}=I_{Q 2 \_10}=I_{D 1 \_10}=I_{D 2 \_01}=0
\end{gathered}
$$

Using equations (16), (52)-(66) the rms values of transistor, diode, and capacitor currents can be expressed as following:

$$
\begin{gathered}
I_{Q 1 \_r m s}=I_{Q 2 \_r m s}=\sqrt{D\left(I_{L 1}+I_{L 2}\right)^{2}} \\
I_{D 1_{-} r m s}=I_{D 2 \_r m s}=\sqrt{D\left(I_{L 1}+I_{L 2}\right)^{2}+(1-2 D)\left(\left(I_{L 1}-I_{C 1_{\text {disch }}}\right)^{2}\right.}
\end{gathered}
$$




$$
\begin{gathered}
I_{D 3_{-} r m s}=I_{L 2}=I_{o} \\
I_{C I_{-} r m s}=\sqrt{(2 D)\left(I_{L 2}\right)^{2}+2(1-D)\left(\frac{2 D}{1-2 D} I_{L 2}\right)^{2}} \\
I_{C 2 \_r m s}=\sqrt{2 D\left(I_{L 1}+I_{L 2}\right)^{2}} \\
I_{C 3_{-} r m s}=\sqrt{(1-2 D)\left(I_{L 2}\right)^{2}+D\left(I_{L 1}-I_{C 1 \_d i s c h}-I_{L 2}\right)^{2}+D\left(I_{L 1}\right)^{2}} \\
I_{C C_{-} r m s}=\sqrt{(1-2 D)\left(I_{C 1 \_d i s c h}\right)^{2}+2 D\left(I_{L 2}\right)^{2}}
\end{gathered}
$$

\subsubsection{Comparative Study With Other Three-Level Boost Converters}

Based on the derived equations (15), (21), and (26), that define the voltage gain and stress of the proposed converter, comparative analysis can be made between the proposed converter and other multilevel converters, as shown in TABLE 3.1. In this comparison, the proposed converter is compared with the conventional TLB converter, a three-level quasi-z-source (TLQZS) converter in [176], and an input-parallel-output-series (IPOS) converter in [177].

The conventional TLB converter has an ideal voltage gain of $1 /(1-D)$. The voltage stress across the semiconductor devices of the conventional TLB converter is $V_{o} / 2$. In [176], this converter has a voltage gain $2 /(3-4 D)$, and voltage stress across the semiconductor devices $V_{o} / 2$. The duty cycle of this converter is limited between $50 \%$ to $75 \%$, which makes the converter very sensitive to any change in duty. In [177], the converter discussed in this paper has a voltage gain $2 /(1-D)$, and voltage stress across the power switches $V_{o} / 2$. Table 3.1

presents a peer-to-peer comparison between the proposed converter, the TL-QZS converter in [176], and the IPOS converter in [177]. 
Table 3.1: Comparisons Between Proposed and Other Step-Up Solutions Comparisons Between Proposed and Other Step-Up Solutions

\begin{tabular}{|c|c|c|c|c|}
\hline & $\begin{array}{c}\text { Conventional } \\
\text { TLB } \\
\text { Converter }\end{array}$ & $\begin{array}{c}\text { TL-QZS } \\
\text { Converter in } \\
\text { [12] }\end{array}$ & $\begin{array}{l}\text { IPOS Converter } \\
\text { in [22] }\end{array}$ & Proposed Converter \\
\hline $\begin{array}{l}\text { Voltage } \\
\text { Gain }\end{array}$ & $\frac{1}{1-D}$ & $\begin{array}{c}\frac{2}{3-4 D} \\
(0.5 \leq D< \\
0.75)\end{array}$ & $\begin{array}{c}\frac{2}{1-D} \\
(0 \leq D<1)\end{array}$ & $\begin{array}{c}\frac{1+D}{1-D},(0<D<0.5) \\
\frac{0.5+D}{1-D},(D \geq 0.5)\end{array}$ \\
\hline $\begin{array}{l}\text { Voltage } \\
\text { Stress }\end{array}$ & $\frac{V_{o}}{2}$ & $\frac{V_{o}}{2}$ & $\frac{V_{o}}{2}$ & $\begin{array}{c}\frac{V_{O}}{2(1+D)},(0<D<0.5) \\
\frac{V_{o}}{1+2 D},(D \geq 0.5)\end{array}$ \\
\hline $\begin{array}{l}\text { Number of } \\
\text { Transistors }\end{array}$ & 2 & 2 & 2 & 2 \\
\hline $\begin{array}{l}\text { Number of } \\
\text { Diodes }\end{array}$ & 2 & 3 & 3 & 3 \\
\hline $\begin{array}{l}\text { Number of } \\
\text { Inductors }\end{array}$ & 1 & 2 & 2 & 2 \\
\hline $\begin{array}{l}\text { Number of } \\
\text { Capacitors }\end{array}$ & 2 & 4 & 3 & 4 \\
\hline
\end{tabular}

Figure 3.5 (a) and Figure 3.5 (b) show a comparison of the voltage gain $M$ versus duty cycle $D$, and the normalized voltage stress $\left(V_{s} / V_{o}\right)$ versus $D$ among the four converters, respectively. This comparison shows that the proposed converter has a higher voltage gain compared to the conventional TLB converter. The TL-QZS converter has a higher voltage gain compared to the proposed converter, but the main drawback for the TL-QZS converter is the limited 
operational range $(0.5 \leq D<0.75)$. The IPOS converter in [177] has the highest voltage gain, however, the proposed converter has the least voltage stress on the semiconductor devices, which means that it can be built using semiconductor devices with lower rated voltage, leading to higher efficiency, less cooling system requirement, hence, higher power density.

From equation (26), the stress voltage in the proposed converter depends on both $V_{O}$ and $D$, and the stress voltage swings between $50 \%$ of $V_{O}$ and $33.33 \%$ of $V_{O}$.

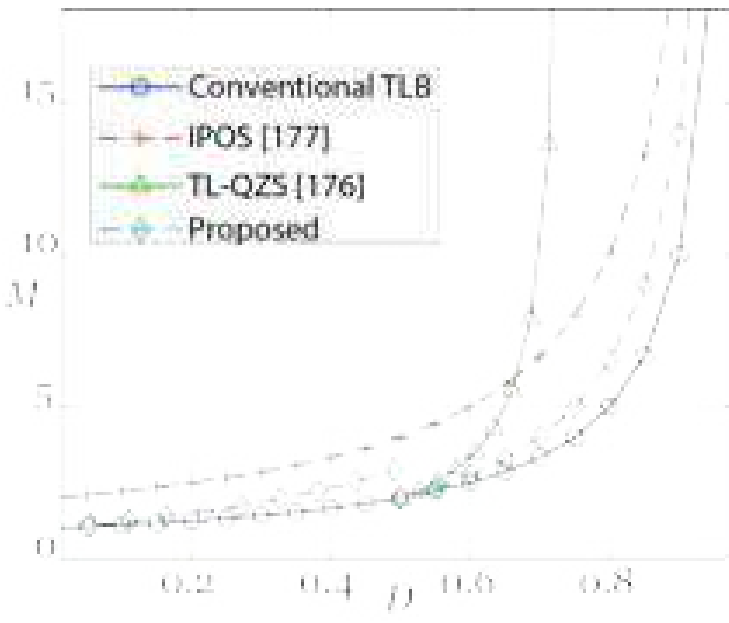

(a)

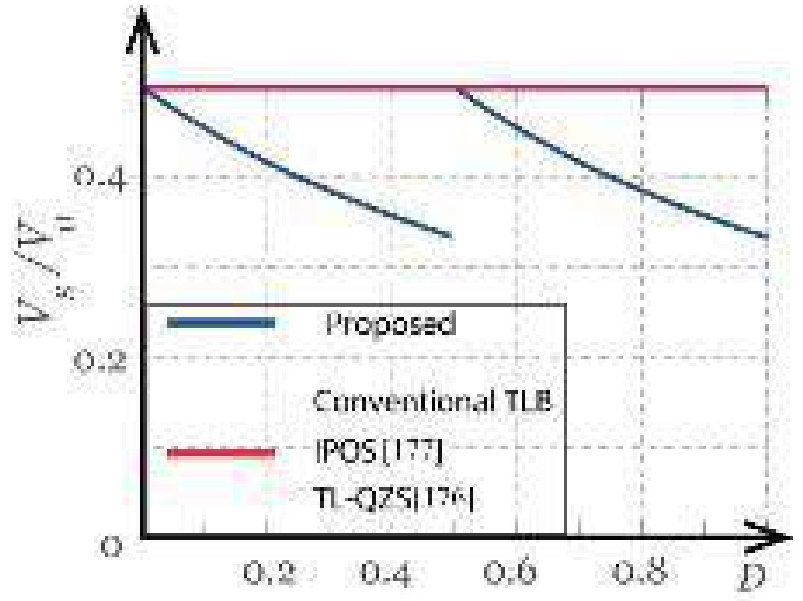

(b)

Figure 3.5: Comparison between the proposed converter and other step-up converters. (a) Gain vs. duty cycle. (b) Voltage stress vs. duty cycle.

\subsection{Component Parameters Design}

\subsubsection{Selection of The Semiconductor Devices}

From equations (15), (21), and (26) the voltage stress across the semiconductor devices depends on both the output voltage and the value of $D$, as depicted in Fig. 7(b). The peak current flowing through $Q_{1}$, and $Q_{2}$ when the proposed converter is operating at $D<0.5$ and $D>0.5$ is the sum of the input and output currents. The peak current flowing through $D_{1}$, and $D_{2}$ when the proposed converter is operating at $D<0.5$ and $D>0.5$ is described by (75). Equations (43) and (65) show the peak instantaneous current that flows through $D_{3}$. 


$$
I_{d I_{\text {ppeak }}}=I_{d 2 \_ \text {peak }}= \begin{cases}I_{L 1}+I_{L 2} & D<0.5 \\ I_{L 1}-I_{L 2} \frac{2 D-1}{2(1-D)} & D \geq 0.5\end{cases}
$$

With the growing advancements in the area of wide bandgap (WBG) semiconductor devices, utilizing these devices in the proposed converter enhances the efficiency of the converter, leading to reduction in the cooling system requirement, which in the end yields high power density and high specific power. For diodes $D_{1}, D_{2}$, and $D_{3}$, Silicon Carbide (SiC) schottky diodes can be utilized since they have zero reverse recovery charges $\left(Q_{r r}=0\right)$, which alleviates the problem of the reverse recovery current that causes EMI problems. For $Q_{1}$, and $Q_{2}$, there are three major technologies available in the market for transistors, namely: $\mathrm{SiC}$ metal oxide field effect transistor (SiC MOSFET), Gallium Nitride ( $\mathrm{GaN}$ ) enhancement high electron mobility transistor (E-HEMT), and GaN cascode HEMT. The lateral GaN HEMT is based on the piezoelectric effect between a layer of $\mathrm{GaN}$ and a layer of Aluminum Gallium Nitride (AlGaN), which results in a 2-D electron gas (2-DEG) electron gas layer between the drain (D) and source (S) of the GaN HEMT, which reduces the on resistance of the device. The GaN E-HEMT has the lowest on resistance $\left(R_{o n}\right)$ and the lowest gate charge $\left(Q_{G D}\right)$ compared to SiC MOSFETs, and GaN cascode HEMTs. The driving of GaN E-HEMTS is very challenging since they are very sensitive to the parasitics of the printed circuit board (PCB). The GaN cascode HEMT is composed of a high voltage depletion $\mathrm{GaN}$ die and a low voltage enhancement Silicon (Si) MOSFET, and it does not have the driving circuits' problems as in the GaN E-HEMT as the GaN cascode HEMT is driven like a typical $\mathrm{Si}$ MOSFET. The GaN cascode HEMT has a slightly higher $R_{o n}$ and $Q_{G D}$ compared to the GaN E-HEMT, thus, if the power electronics designer can afford the time to optimize the PCB to minimize the power-loop and the gate-to-source-loop parasitic inductances, the utilization of the GaN E-HEMT is recommended. In Table 3.2, a peer-to-peer comparison between three 
WBG transistors available in the market. This shows that if the converter is built using GaN E-HEMTs, it will have lower conduction and switching losses.

Table 3.2: COMPARISON BETWEEN WBG TRANSISTORS AVAILABLE IN THE MARKET

\begin{tabular}{|l|c|c|c|}
\cline { 2 - 4 } \multicolumn{1}{l|}{} & SCT2120AF & TPH3212PS & GS66508T \\
\hline $\begin{array}{l}\text { Manufacturer } \\
\text { Material }\end{array}$ & $\mathrm{SiC}$ & $\mathrm{GaN}$ & $\mathrm{GaN}$ \\
\hline Transistor Technology & MOSFET & $\begin{array}{c}\text { Cascode } \\
\text { HEMT }\end{array}$ & $\begin{array}{c}\text { Enhancement } \\
\text { HEMT }\end{array}$ \\
\hline ID Continuous & $29 \mathrm{~A}$ & $27 \mathrm{~A}$ & $30 \mathrm{~A}$ \\
\hline Device Package & $\mathrm{TO} 220 \mathrm{AB}$ & $\mathrm{TO}-220$ & $\mathrm{GaNPX}-4$ \\
\hline Switch Dimensions & - & $15 \mathrm{X} 10 \mathrm{~mm}{ }^{2}$ & $7 \mathrm{X} 4.5 \mathrm{~mm}{ }^{2}$ \\
\hline Ron & $120 \mathrm{~m} \Omega$ & $72 \mathrm{~m} \Omega$ & $55 \mathrm{~m} \Omega$ \\
\hline QGD & $17 \mathrm{nC}$ & $14 \mathrm{nC}$ & $1.8 \mathrm{nC}$ \\
\hline Qrr & $53 \mathrm{nC}$ & $90 \mathrm{nC}$ & 0 \\
\hline $\begin{array}{l}\text { Junction to Case } \\
\text { Thermal Resistance }\end{array}$ & $0.86{ }^{\circ} \mathrm{C} / \mathrm{W}$ & $1.2{ }^{\circ} \mathrm{C} / \mathrm{W}$ & $0.5{ }^{\circ} \mathrm{C} / \mathrm{W}$ \\
\hline $\begin{array}{l}\text { Figure of Merit }(\mathbf{Q} \text { GD X } \\
\text { Ron) }\end{array}$ & 2040 & 1008 & 99 \\
\hline
\end{tabular}

\subsubsection{Design of The Inductors}

If the maximum allowed current ripples allowed for $L_{1}$, and $L_{2}$ are $\Delta I_{L 1}$ and $\Delta I_{L 2}$, respectively, both inductors can be designed as following: The inductances can be calculated in the charging state:

$$
\begin{aligned}
& L_{1}=\frac{\Delta \mathrm{T}}{\Delta I_{L 1}} V_{L 1} \\
& L_{2}=\frac{\Delta \mathrm{T}}{\Delta I_{L 2}} V_{L 2}
\end{aligned}
$$

Where $\Delta T$ is the charging time, which is $T_{11}$ (when $D>0.5$ ), and is $T_{10}$ or $T_{01}$ (when $D<0.5$ ). The values of $L_{1}$, and $L_{2}$ can be determined using (78). 


$$
L_{1} \text { or } L_{2}= \begin{cases}\frac{D(0.5-D)}{\Delta I_{L} f_{S}(1-D)} V_{\text {in }} & D<0.5 \\ \frac{(2 D-1)(D-0.5)}{\Delta I_{L} f_{S}(1-D)} V_{\text {in }} & D>0.5\end{cases}
$$

Where $f_{s}$ is the switching frequency, and $\Delta I_{L}$ can be $\Delta I_{L 1}$ or $\Delta I_{L 2}$.

\subsubsection{Design of Capacitors}

Assuming that the maximum allowed voltage ripples allowed for $C_{1}, C_{2}, C_{3}$, and $C_{4}$ are $\Delta$ $C_{1}, \Delta C_{2}, \Delta C_{3}$ and $\Delta C_{4}$, respectively, the capacitances of these four capacitors can be calculated as following where $\Delta T$ can be the charging time or the discharging time. The following relationships define the correlation between the capacitors' ripple voltages and their capacitances.

$$
\begin{aligned}
& C_{1}=\frac{\Delta T}{\Delta V_{C 1}} I_{C 1} \\
& C_{2}=\frac{\Delta T}{\Delta V_{C 2}} I_{C 2} \\
& C_{3}=\frac{\Delta T}{\Delta V_{C 3}} I_{C 3} \\
& l_{4}=\frac{\Delta T}{\Delta V_{C 4}} I_{C 4} \\
& \frac{D I_{O}}{\Delta V_{C 1} f_{S}} \quad D<0.5 \\
& C_{1}= \\
& \left(\frac{(2 D-1) I_{o}}{\Delta V_{C 1} f_{S}} \quad D>0.5\right. \\
& \frac{D\left(I_{L 1}+I_{o}\right)}{\Delta V_{C 2} f_{S}} \quad D<0.5 \\
& C_{2}= \\
& \left(\left(I_{L 1}-\frac{2 D-1}{2(1-D)} I_{o}\right)\left(\frac{1-D}{\Delta V_{C 2} f_{S}}\right) \quad D>0.5\right.
\end{aligned}
$$




$$
\begin{array}{ll}
C_{3}= & D<0.5 \\
C_{4}= & D>0.5 \\
\frac{D V_{C 3} f_{S}}{\frac{(1-D) I_{O}}{\Delta V_{C 3} f_{S}}} & \\
\frac{D I_{O}}{\Delta V_{C o} f_{S}} & D<0.5 \\
\frac{(2 D-1) I_{O}}{\Delta V_{C 4} f_{S}} & D>0.5
\end{array}
$$

\subsection{Loss Analysis}

The losses in the proposed converter can be divided into five major contributors, namely: conduction and switching losses of the transistors $Q_{1}$, and $Q_{2}$, losses of the diodes $D_{1}, D_{2}$, and $D_{3}$, losses of the inductors $\left(L_{1}\right.$, and $\left.L_{2}\right)$, and losses of the capacitors $\left(C_{1}, C_{2}, C_{3}\right.$, and $\left.C_{4}\right)$.

\subsubsection{Conduction Loss of Transistors}

Since the rms currents flowing through $Q_{1}$, and $Q_{2}$ are the same, as shown in equations (47), and (68), and assuming that both transistors have the same on resistance, $R_{o n}$, hence, the total conduction loss of both $Q_{1}$, and $Q_{2}$ can be calculated by (84).

$$
P_{t r \_c o n d}=2 I_{Q 1 \_r m s}^{2} R_{o n}
$$

\subsubsection{Switching Loss of Transistors}

In a typical transistor, there are four major contributors to the switching loss, namely: 1) The overlap of the transistor current and voltage at the instant of turning on and off, 2) Gate charge losses, and this power loss component is caused by the charge stored in the gate capacitance. 3) The loss caused by the parasitic capacitance of the transistor, this loss component is caused by the energy stored in Coss when the transistor is off, 4) The loss caused by the reverse recovery charge of the body diode of the transistor (since the experimental work was implemented with GaN E-HEMTs, which do not have a body diode and have zero reverse 
recover charge, this loss component can be neglected). Equation (85) describes the total switching loss of the two transistors of the proposed converter, where $f_{s}$ is the switching frequency, $t_{r}$, and $t_{f}$ are the rise and fall times of the transistor, $Q_{T}$ is the gate charge, and $V_{G}$ is the gate driver voltage. The drain-to-source voltage of the E-HEMTs equals half $V_{C 3}$, thus, depicted as $V_{C 2}$.

$$
P_{t r_{-} s w}=2 f_{s}\left(0.5 V_{C 2} I_{Q 1}\left(t_{r}+t_{f}\right)+0.5 V_{C 2}^{2} C_{O S S}+Q_{T} V_{G}\right)
$$

\subsubsection{Diode's Losses}

Since the experimental setup is implemented using $\mathrm{SiC}$ schottky diodes, the reverse recovery switching loss of the diodes is neglected, however, the loss caused by the capacitive charge $\left(Q_{C}\right)$ of the Schottky diodes is considered. The conduction loss of these diodes depends on the forward voltage and the rms currents flowing through the diodes. Equation (86) calculates the total losses of the three diodes of the proposed converter:

$$
P_{d}=V_{f d}\left(2 I_{D 1 \_a v g}+I_{D 3 \_a v g}\right)+Q_{C} V_{C 2} f_{s}(86) \text { Where } V_{f d} \text {, and } Q_{C} \text { are the forward }
$$

voltage, and the total capacitive charge of the $\mathrm{SiC}$ diode, respectively.

\subsubsection{Inductor's Losses}

The inductors have two main loss components, namely: the conduction loss, and the core loss. The conduction loss is caused by the dc current component flowing in the inductors' windings, while the core loss is caused by the inductors' ripple currents. The core loss equation should be provided by the core manufacturer. The inductors' total conduction loss, $P_{L_{-} c o n d}$, can be calculated using (87), the inductors' core loss, $P_{L_{-} \text {core }}$, can be calculated using (88), and the total losses in the inductors, $P_{L_{-} t o t}$, using (89). 


$$
P_{L \_c o n d}=I_{L 1}^{2} R_{L 1}+I_{L 2}^{2} R_{L 2}
$$

Where $R_{L 1}$ and $R_{L 2}$ are the series parasitic resistances of $L_{1}$ and $L_{2}$, respectively.

$$
P_{L \_ \text {core }}=\frac{f}{\frac{a}{B^{3}}+\frac{b}{B^{2.3}}+\frac{c}{B^{1.65}}}+\left(\mathrm{df}^{2} \mathrm{~B}^{2}\right)
$$

Equation (88) is provided by "Micrometals" (the manufacturer of the inductor cores used in the experimental prototype), where the equation's parameters can be derived from the datasheet of each specific core size and dimensions:

$$
P_{L_{-} t o t}=P_{L_{-} \text {core }}+P_{L_{-} \text {cond }}
$$

\subsubsection{Capacitor's Losses}

The losses of the capacitors in the proposed converter are calculated as the conduction loss of these capacitors caused by their equivalent series resistance, ESR. The power loss of the four capacitors of the proposed converter, $P_{C}$ is expressed by (90), where $E S R_{C 1}, E S R_{C 2}$, $E S R_{C 3}$, and $E S R_{C 4}$ are the equivalent series resistances of the four capacitors.

$$
P_{C}=I_{C 1 \_r m s}^{2} E S R_{C 1}+I_{C 2 \_r m s}^{2} E S R_{C 2}+I_{C 3 \_r m s}^{2} E S R_{C 3}+I_{C 4 \_r m s}^{2} E S R_{C 4}
$$

\subsection{Experimental Results and Analysis}

A scaled-down experimental prototype was built, as shown in Figure 3.6, in order to validate the proposed converter topology and its theoretical analysis. In this experimental work, the fuel cell is depicted by a dc-voltage source. The converter is controlled by a TMS320f28377s microcontroller, and the currents are sensed by a hall-effect current transducer ACS730KLCTR-40AB-T. The power circuit is constructed using GS66508T EHEMTs (rated voltage is $650 \mathrm{~V}$, and rated current is $30 \mathrm{~A}$ ), and C3D10065E SiC Schottky diodes (rated voltage is $650 \mathrm{~V}$, and rated current is $32 \mathrm{~A}$ ). The switching frequency, $f_{s}$, is 100 $\mathrm{kHz}$, and the values of the two inductors $L_{1}$, and $L_{2}$ are $350 \mu \mathrm{H}$ and $250 \mu \mathrm{H}$, respectively. The 
capacitors $C_{1}, C_{2}, C_{3}$, and $C_{4}$ have the same value (capacitance $=80 \mu \mathrm{F}$, and rated dc-voltage $=700 \mathrm{~V})$. The load is represented by a $120 \Omega$ resistance, $R_{L}$.

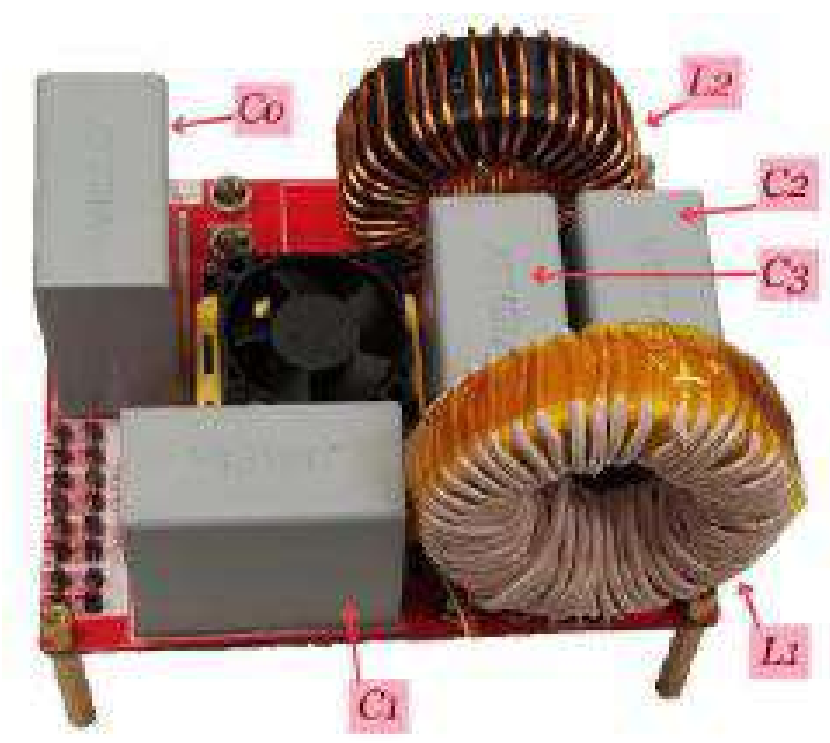

Figure 3.6: Experimental setup.

Table 3.3: MAIN EXPERIMENTAL PARAMETERS OF THE PROPOSED CONVERTER

\begin{tabular}{|l|c|}
\hline Components and parameters & Values \\
\hline Output power $\left(\boldsymbol{P}_{\text {out }}\right)$ & $1.15 \mathrm{~kW}, 1.3 \mathrm{~kW}$ \\
\hline Input dc-voltage $\left(\boldsymbol{V}_{\text {in }}\right)$ & $200 \mathrm{~V}, 100 \mathrm{~V}$ \\
\hline Switching frequency $\left(\boldsymbol{f}_{\boldsymbol{s}}\right)$ & $100 \mathrm{kHz}$ \\
\hline Inductor $\left(\boldsymbol{L}_{\boldsymbol{1}}\right)$ & $350 \mu \mathrm{H}$ \\
\hline Inductor $\left(\boldsymbol{L}_{\boldsymbol{2}}\right)$ & $250 \mu \mathrm{H}$ \\
\hline Capacitors $\left(\boldsymbol{C}_{\boldsymbol{1}}, \boldsymbol{C}_{\mathbf{2}}, \boldsymbol{C}_{\mathbf{3}}, \boldsymbol{C}_{\mathbf{4}}\right)$ & $80 \mu \mathrm{F}, 700 \mathrm{~V}$ \\
\hline E-HEMTs $\left(\boldsymbol{Q}_{\boldsymbol{1}}, \boldsymbol{Q}_{2}\right)$ & $\mathrm{GS} 66508 \mathrm{~T}($ from GaN \\
& Systems) \\
\hline Diodes $\left(\boldsymbol{D}_{\boldsymbol{1}}, \boldsymbol{D}_{\boldsymbol{2}}, \boldsymbol{D}_{\mathbf{3}}\right)$ & $\mathrm{C} 3 \mathrm{D} 10065 \mathrm{E}($ from Cree) \\
\hline Load $\left(\boldsymbol{R}_{\boldsymbol{L}}\right)$ & $120 \Omega$ \\
\hline
\end{tabular}


The main experimental parameters of the proposed converter prototype are shown in table 3.3 .

In this experimental work, two case studies are investigated:

1) Case study I: $V_{\text {in }}=200 \mathrm{~V}, D=0.3, R_{L}=120 \Omega$.

2) Case study II: $V_{\text {in }}=100 \mathrm{~V}, D=0.7, R_{L}=120 \Omega$.

The experimental results of case study I are intended to verify the theoretical analysis of the converter when $D<0.5$, and are presented in Figure 3.7, while the experimental results of case study II are intended to verify the theoretical analysis of the converter when $D>0.5$, and are presented in Figure 3.8.

$\left(\right.$ Case Study I $\left.\left(D=0.3, V_{\text {in }}=200 V, R_{L}=120 \Omega\right)\right)$

When $D$ is less than 0.5 , equations (18), (20), and (24) describe the four capacitors' voltages, and hence, they can be calculated as following: $V_{C 1}=85.7 \mathrm{~V}, V_{C 2}=142.9 \mathrm{~V}, V_{C 3}=$ 285.7 V, and $V_{o}=371.4 \mathrm{~V}$. Figure 3.7(a) validates these findings. The two inductor currents, $I_{L 1}$, and $I_{L 2}$ are shown in Figure 3.7(b), the frequency of the ripple currents is $200 \mathrm{kHz}$, which is double the switching frequency. The currents flowing through the two inductors $I_{L 1}$, and $I_{L 2}$ are close to $5.5 \mathrm{~A}$, and $3 \mathrm{~A}$, respectively, which comply with the theoretical equations (64), and (70). The voltage stresses across the E-HEMTs $\left(Q_{1}\right.$ and $\left.Q_{2}\right)$, and the diodes $\left(D_{1}, D_{2}\right.$, and $D_{3}$ ), are shown in Figure 3.7(c), and Figure 3.7(d), respectively, where the voltage stresses swing between $0 \mathrm{~V}$, and $140 \mathrm{~V}\left(=V_{C 2}\right)$, which comply with equation (26). Figure 3.7(e), and Figure 3.7(f) show the currents flowing through the E-HEMTs, and the diodes, where the currents of $\left(Q_{1}, Q_{2}, D_{1}\right.$, and $\left.D_{2}\right)$ swing between $0 \mathrm{~A}$, and 9 A, which comply with equations (66), and (67). Also, Figure 3.7(e) shows $I_{D 3}$, where $D_{3}$ conducts only when both $Q_{1}$ and $Q_{2}$ are off, and the magnitude of $I_{D 3}$ during conduction is close to $7.5 \mathrm{~A}$ which complies with 
equation (65). It is worth noting that the semiconductor devices should be selected with higher rated voltage and current to assure operating in the safe operation area (SOA) of these devices and account for the voltage spikes (caused by the parasitic inductance of the PCB), and current spikes (caused by the parasitic capacitance of the SiC Shottky diodes).

\section{$\left(\right.$ Case Study II $\left.\left(D=0.7, V_{\text {in }}=100 \mathrm{~V}, R_{\mathrm{L}}=120 \Omega\right)\right)$}

From equations (11), (15), and (24), the voltage across the four capacitors can be calculated as following: $V_{C 1}=233.33 \mathrm{~V}, V_{C 2}=166 \mathrm{~V}, V_{C 3}=333 \mathrm{~V}$, and $V_{o}=400 \mathrm{~V}$. These findings are verified by Figure 3.8(a). Figure 3.8(b) shows the currents flowing through the two inductors. $I_{L 1}$, and $I_{L 2}$ which have ripple currents with frequency equals double the switching frequency of the converter (the periodic time of the ripple currents $=5 \mu \mathrm{S}$, and the periodic time of the switching $=10 \mu \mathrm{S})$. From Figure $3.8(\mathrm{~b}), I_{L 2}$ is close to $3.3 \mathrm{~A}$, and $I_{L 1}$ is close to 13 A, which verify equations (40), and (42). Figure 3.8(c), and Figure 3.8(d) show the voltage stress across the E-HEMTs and the diodes $\left(D_{1}, D_{2}\right.$, and $\left.D_{3}\right)$, respectively, where the voltage stress swings between $0 \mathrm{~V}$, and $166 \mathrm{~V}$, namely: between $0 \mathrm{~V}$, and half the voltage across $C_{3}$, which verifies equation (26). The currents of the E-HEMTs $\left(Q_{1}\right.$, and $\left.Q_{2}\right)$ are shown in Figure 3.8(e), each current swings between three levels, 0 A (the E-HEMT is off, and the other one is on), $11 \mathrm{~A}$ (the E-HEMT is on, and the other one is off), and $16 \mathrm{~A}$ (both of the E-HEMTs are on), which verify equations (37), (44) and (45).

Figure 3.8(e) and Figure 3.8(f) show the currents flowing through the diodes $\left(D_{1}, D_{2}\right.$, and $D_{3}$ ). From equations (45), and (46), diode $D_{1}$ conducts only when $S_{1} S_{2}=\{01\}$, while diode $D_{2}$ conducts only when $S_{1} S_{2}=\{10\}$, and the magnitude of the current flowing during conduction $=I_{L 1}-\left((2 D-1) I_{L 2} /(2 D-2)\right)=11$ A, which is verified by Figure 3.8(f). 


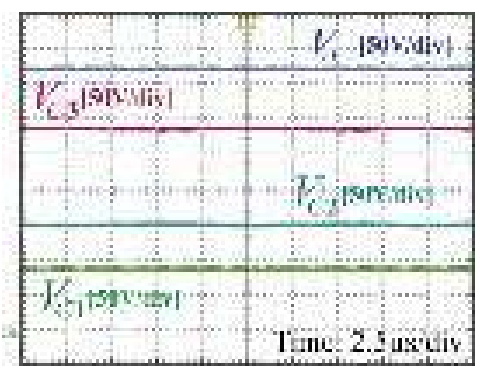

(a)

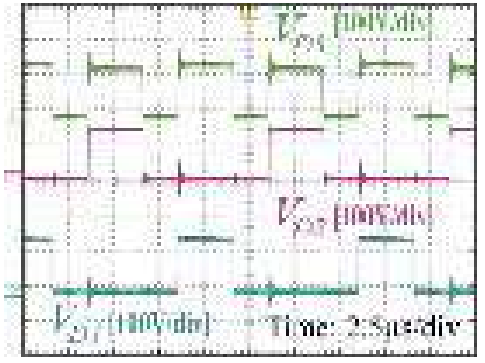

(d)

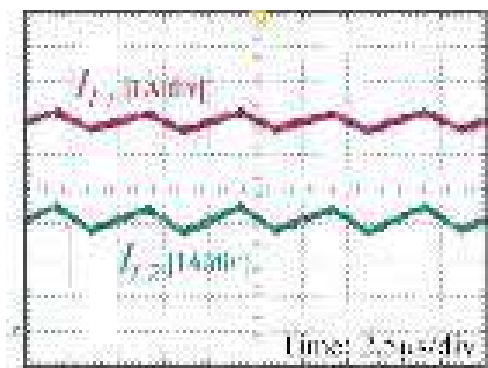

(b)

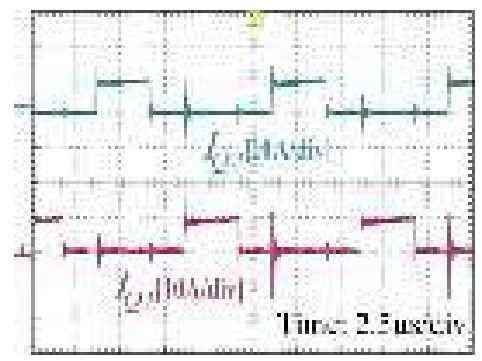

(e)

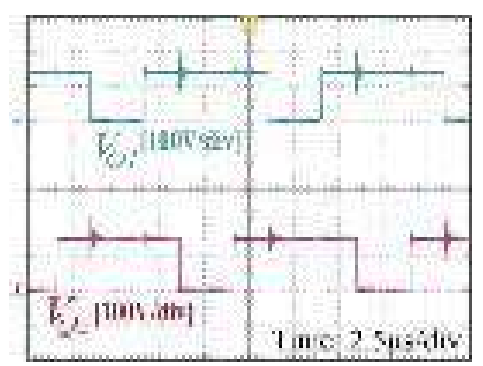

(c)

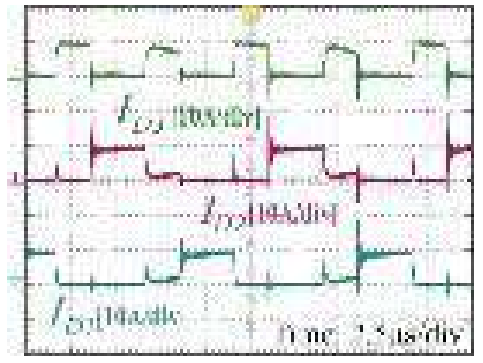

(f)

Figure 3.7: Experimental results when Vin $=200 \mathrm{~V}, \mathrm{D}=0.3, \mathrm{RL}=120 \Omega$, Pout $=1.15 \mathrm{~kW}$.

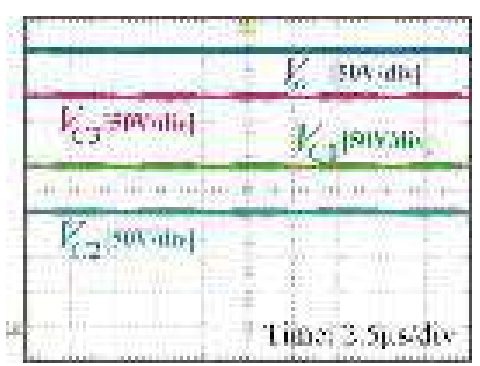

(a)

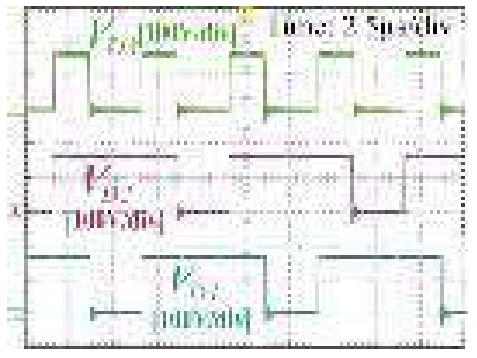

(d)

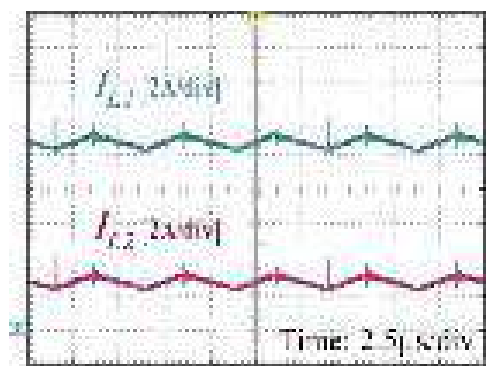

(b)

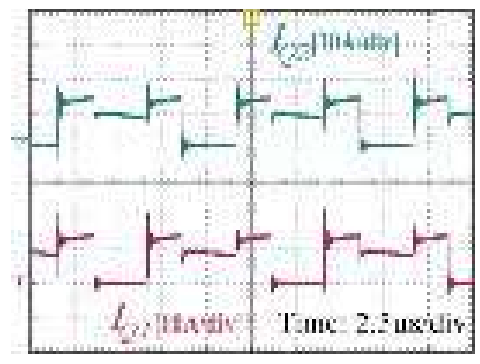

(e)

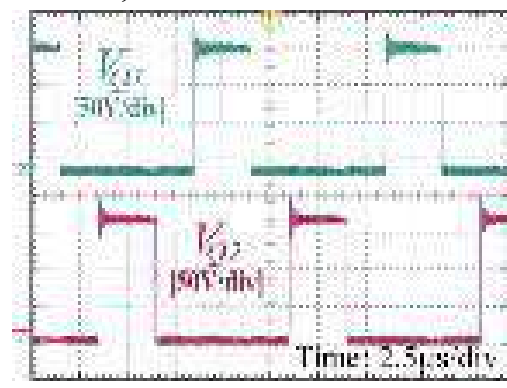

(c)

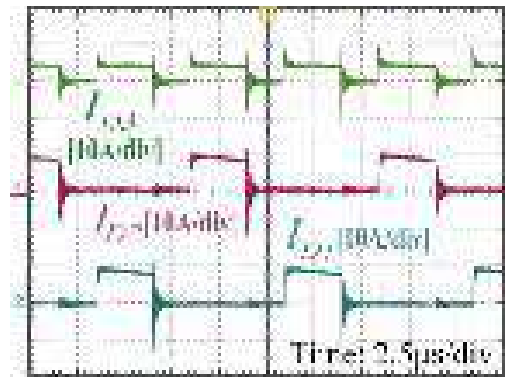

(f)

Figure 3.8: Experimental results when Vin $=100 \mathrm{~V}, \mathrm{D}=0.7, \mathrm{RL}=120 \Omega$, Pout $=1.3 \mathrm{~kW}$.

Figure 3.8(e) shows that $D_{3}$ conducts only when either of the E-HEMTs is off, and the current flowing during conduction is close to $6 \mathrm{~A}$ which verifies equation (43). Using equations (84)-(90) the losses of the proposed converter can be calculated for any value of $V_{\text {in }}$, $D$, and $R_{L}$. The converter losses for case studies I and III are investigated and analyzed. Figure 
3.9 shows the loss distributions for the proposed converter for both case of study I and case of study II.

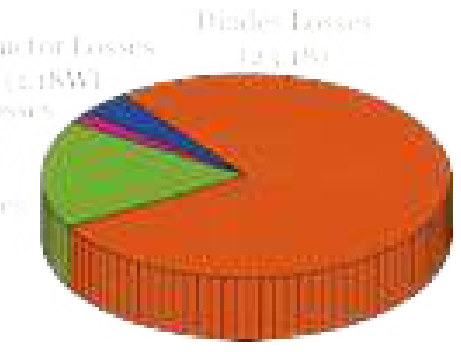

(a)

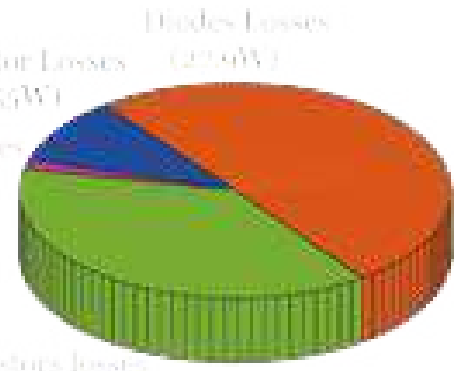

(b)

Figure 3.9: Calculated loss distributions for the experiment (a) When Vin $=200 \mathrm{~V}, \mathrm{D}=$ 0.3 , and $\mathrm{RL}=120 \Omega$. (b) When $\mathrm{Vin}=100 \mathrm{~V}, \mathrm{D}=0.7$, and $\mathrm{RL}=120 \Omega$.

Figure 3.9(a) shows the loss distributions when $D=0.3, V_{\text {in }}=200 \mathrm{~V}$, and $R_{L}=120 \Omega, P_{\text {out }}$ $=1.15 \mathrm{~kW}$. The total losses of the converter in this case of study equals $27.16 \mathrm{~W}$, and the efficiency of the converter equals $97.6 \%$. The main contributor of losses in this case is the

diodes (85.3\% of total losses), because of their relatively high forward voltage $\left(V_{f d}\right)=1.8 \mathrm{~V}$. The total losses of the E-HEMTs are $19 \%$ of the total losses, and this is because of their low

on resistance and zero reverse recovery charges. The losses of the inductors and capacitors

account for $4.3 \%$ and $2.8 \%$ of the total losses of the proposed converter, respectively.

Figure 3.9(b) shows the loss distributions when $D=0.7, V_{\text {in }}=100 \mathrm{~V}$, and $R_{L}=120 \Omega, P_{\text {out }}$ $=1.333 \mathrm{~kW}$. The total losses of the converter in this case of study equals $55.21 \mathrm{~W}$, and the 
efficiency of the converter equals $95.86 \%$. The main contributor of losses in this case is also the diodes (50.5\% of total losses).

The total losses of the E-HEMTs are $38 \%$ of the total losses. The losses of the inductors and capacitors account for $10 \%$ and $1.37 \%$ of the total losses of the proposed converter, respectively.

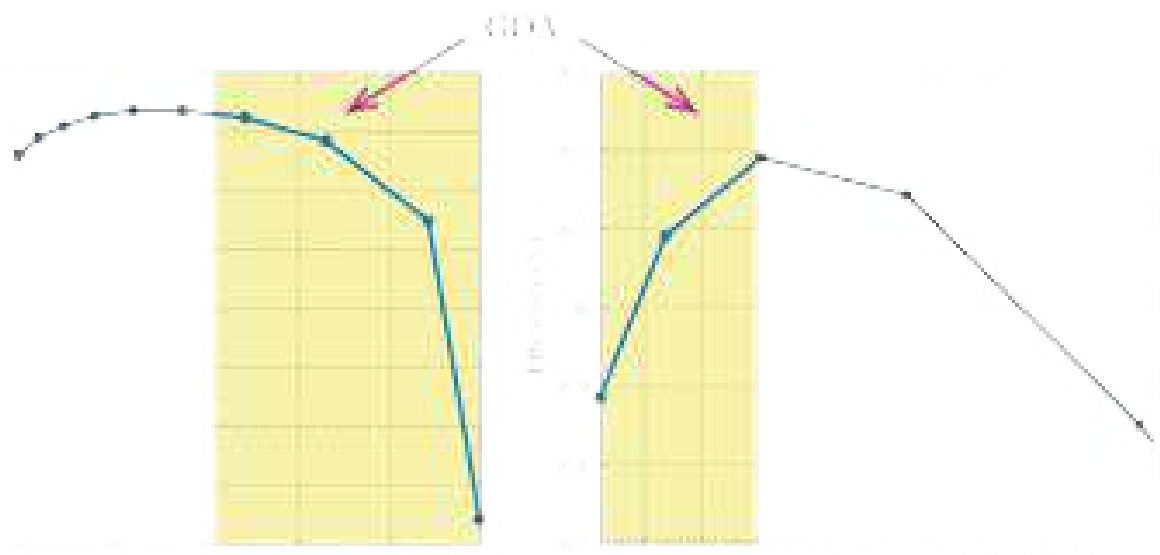

Figure 3.10: Efficiency curves of the proposed converter (Vin $=100 \mathrm{~V}, \mathrm{RL}=120 \Omega)(\mathrm{a})$ When $\mathrm{D}<0.5$. (b) When $\mathrm{D} \geq 0.5$.

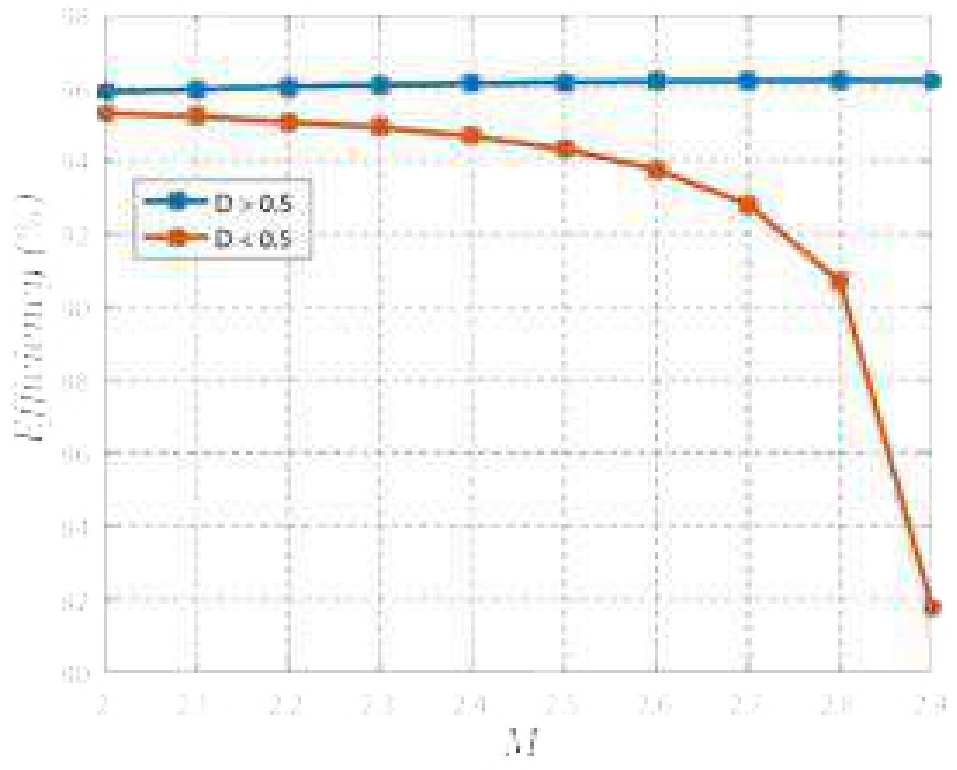

Figure 3.11: Calculated efficiency curves in the GOA $(\mathrm{Vin}=100 \mathrm{~V}, \mathrm{RL}=120 \Omega)$. 
The efficiency curves of the proposed converter that depict the efficiency at different power levels are shown in Figure 3.9, and they were obtained from the experimental setup $\left(V_{\text {in }}=100 \mathrm{~V}, f_{s}=100 \mathrm{kHz}, R_{L}=120 \Omega\right.$ ). The efficiency is depicted by two curves, one for operation when $D<0.5$, and the other one for operation when $D \geq 0.5$.

In the GOA, the same voltage gain $(M)$ can be achieved by two different values of $D$, one of them is less than 0.5 , and the other one is greater than 0.5. Figure 3.10 shows the calculated efficiency of the proposed converter in the GOA, when $V_{i n}=100 \mathrm{~V}$, and $R_{L}=$ $120 \Omega$, one curve presents the efficiency versus $M$ when $D$ is less than 0.5 , while the other curve shows the efficiency versus $M$ when $D$ is greater than 0.5. From Figure 3.11 , it is obvious that if the desired $M$ is in the GOA $(2<M<3)$, the efficiency of the proposed converter is higher when $D$ is selected to be higher than 0.5 .

\subsection{Conclusion}

A new three-level boost (TLB) converter was introduced and presented. It can be used as an interface between the fuel cells and the dc-link bus of the three-phase inverter in the EV powertrain. It has several advantages of continuous input current, extended voltage gain, lower voltage stress on the semiconductor devices, common ground between the input and output ports, and wide voltage gain range. The steady state analysis of the proposed converter under the continuous conduction mode (CCM) was investigated. The voltage gain, the voltage stress on the semiconductor devices, and the number of the semiconductor devices and passive components of the proposed converter were compared with other three-level step-up solutions, and the importance of the proposed converter was verified experimentally. The proposed converter was built using GaN E-HEMTs and SiC Shottky diodes, and the experimental results validated the theoretical analysis. 


\section{Chapter 4 A Single-Switch Transformerless DC-DC Converter with Universal Input Voltage for Fuel Cell Vehicles: Analysis and Design}

\subsection{Introduction}

A new single-switch high step-up dc-dc converter is proposed in this chapter for fuel cell vehicles. The proposed topology utilizes a $L^{2} C^{3} D^{2}$ network to obtain high voltage gain and reduce the voltage stress on the power switch. Additionally, the proposed converter has a universal input voltage in order to suit the soft output characteristics of the fuel cell. Comprehensive analyses of the steady-state operation in continuous conduction mode $(\mathrm{CCM})$ and discontinuous conduction mode (DCM), and design considerations of the proposed converter are given. Finally, a $400 \mathrm{~V} / 1.6 \mathrm{~kW}$ scaled-down prototype is developed to validate the effectiveness and feasibility of the proposed converter.

\subsection{Structure and Operating Principles of the Proposed Converter}

\subsubsection{Configuration of the Proposed Converter}

The topology of the proposed converter is shown in Figure 4.1 It is composed of one power switch $(Q)$, three diodes $\left(D_{1}, D_{2}\right.$, and $\left.D_{3}\right)$, three inductors $\left(L_{1}, L_{2}\right.$, and $\left.L_{3}\right)$, five capacitors $\left(C_{1}, C_{2}, C_{3}, C_{4}\right.$, and $\left.C_{o}\right)$, and $R$ represents a resistive load.

A conventional boost switching network is formed by $\left(L_{l}, Q, D_{l}\right.$, and $\left.C_{3}\right)$, and an $L^{2} C^{3} D^{2}$ network formed by $\left(L_{2}, L_{3}, C_{1}, C_{2}, C_{4}, D_{2}\right.$, and $\left.D_{3}\right)$ is integrated between the conventional boost switching network and the output capacitor $C_{o}$. The $L^{2} C^{3} D^{2}$ network enhances the voltage gain of the proposed converter and reduces the voltage stress on the power switch. 


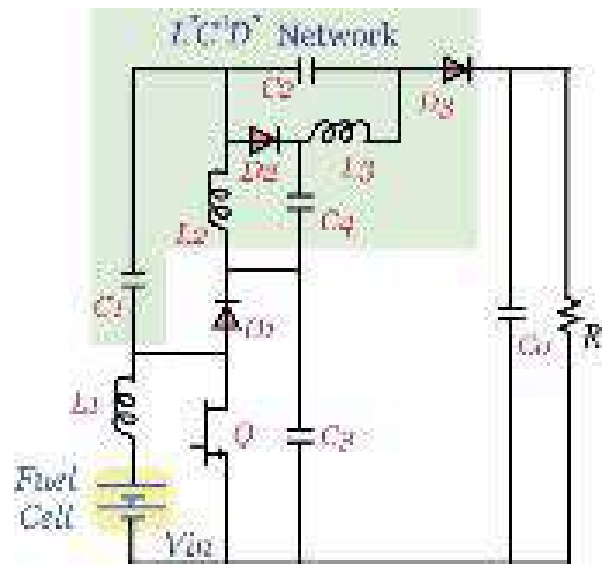

Figure 4.1: The schematic of the proposed converter.

\subsubsection{Switching States Analysis}

According to the conduction states of the semiconductor devices, the operation of the proposed converter can be divided into three switching states, as shown in Table 4.1. In this analysis, the following abbreviations are used: $V_{i n}, V_{o}, V_{C 1}, V_{C 2}, V_{C 3}, V_{C 4}, V_{L 1}, V_{L 2}, V_{L 3}$, $I_{L 1}, I_{L 2}, I_{L 3}$ and $I_{o}$, to refer to the input voltage, the output voltage, the instantaneous voltages across $L_{1}, L_{2}$, and $L_{3}$, the dc currents flowing through $L_{1}, L_{2}$, and $L_{3}$, and the output current, respectively.

Table 4.1: SWITCHING STATES OF THE SEMICONDUCTOR DEVICES

\begin{tabular}{lcccc}
\hline \hline Switching state & $Q$ & $D_{1}$ & $D_{2}$ & $D_{3}$ \\
\hline$I(\mathrm{CCM} \&$ DCM $)$ & ON & OFF & OFF & OFF \\
$I I(\mathrm{CCM} \&$ DCM $)$ & OFF & ON & ON & ON \\
$I I I(\mathrm{DCM})$ & OFF & OFF & OFF & OFF \\
\hline \hline
\end{tabular}

Additionally, $i_{C 1 \_c h}, i_{C 1 \_d i s}, i_{C 2 \_c h}, i_{C 2 \_d i s}, i_{C 3 \_c h}, i_{C 3 \_d i s}, i_{C 4 \_c h}, i_{C 4 \_d i s}, i_{C o \_c h}$, and $i_{C o \_d i s}$, refer to the charging and discharging currents of the five capacitors. For convenience of analysis, the following assumptions are made: 
- The power switch and diodes are ideal.

- The equivalent series resistances of the inductors and capacitors equal zero.

- The capacitors and inductors are large enough, so, the small ripple principle can be applied.

\section{1) Switching State I:}

This switching state is for CCM and DCM operations and it takes place when the gate voltage $V_{g s}$ of the power switch is high, and $Q$ is turned on. In this switching state, the three diodes are reverse-biased, the three inductors are charging, $C_{3}$ and $C_{4}$ are discharging, $C_{1}$ and $C_{2}$ are charging, and $C_{o}$ is discharging. Figure 4.3(a) shows the current flow paths for this switching state. By applying Kirchhof's Voltage Law (KVL), and Kirchhof's Current Law (KCL) on the equivalent circuit depicted in Figure 4.3(a), we can extract the following relationships:

$$
\begin{aligned}
& \left\{\begin{array}{l}
V_{L 1}=V_{i n} \\
V_{L 2}=V_{C 3}-V_{C 1} \\
V_{L 3}=V_{C 3}+V_{C 4}-V_{C 2}-V_{C 1}
\end{array}\right. \\
& i_{C 1_{\_} c h}=I_{L 2}+I_{L 3} \\
& i_{C 2_{c h}}=I_{L 3} \\
& i_{C 3_{-} \text {dis }}=I_{L 2}+I_{L 3} \\
& i_{C 4 \_d i s}=I_{L 3} \\
& i_{C o \_d i s}=I_{O}
\end{aligned}
$$

\section{2) Switching State II:}

This switching state is for CCM and DCM operations and it takes place when $V_{g s}$ is low, and $Q$ is turned off. . In this switching state, the three diodes are forward-biased, the three inductors are discharging, $C_{3}$ and $C_{4}$ are charging, $C_{1}$ and $C_{2}$ are discharging, and $C_{o}$ is charging. 
Figure 4.3(b) shows the current flow paths for this switching state. By applying KVL and KCL laws on the equivalent circuit depicted in Figure 4.3(b), we can extract the following relationships:

$$
\begin{aligned}
& \left\{\begin{array}{l}
V_{L 1}=V_{i n}-V_{C 3} \\
V_{L 2}=-V_{C 1}=-V_{C 4} \\
V_{L 3}=-V_{C 2}
\end{array}\right. \\
& \left\{\begin{array}{c}
i_{C 1_{-} d i s}=i_{C 2 \_d i s}+I_{L 3}+i_{C 4_{-} c h}-I_{L 2} \\
i_{C 3_{-} c h}=I_{L 1}-i_{C 1 \_d i s}-I_{L 2}+i_{C 4_{-} c h} \\
i_{C o_{-} c h}=i_{C 2 \_d i s}+I_{L 3}-I_{O}
\end{array}\right.
\end{aligned}
$$

\section{3) Switching State III:}

This switching state is for DCM operation and it takes place when $V_{g s}$ is low, $Q$ is turned off, and all the diodes are reverse-biased.

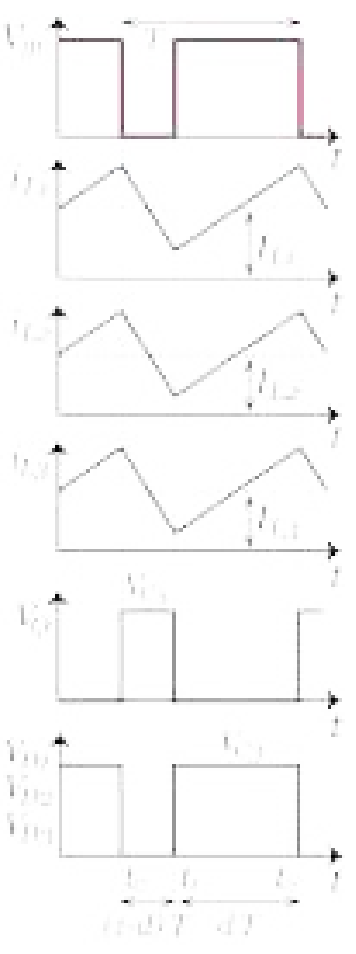

(a)

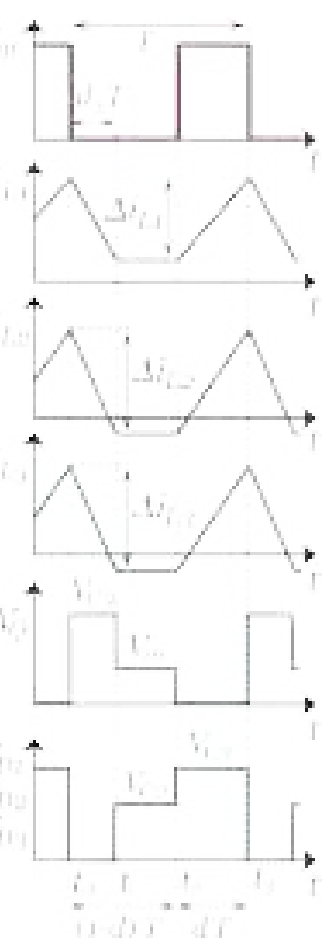

(b)

Figure 4.2: Key waveforms of the proposed converter. (a) CCM operation. (b) DCM operation. 
Since all the semiconductor devices do not conduct in this switching state, a positive constant current $I_{L I_{\_} m i n}$ flows through $L_{1}$, and negative constant currents $I_{L 2 \_m i n}, I_{L 3 \_m i n}$ flow through $L_{2}$ and $L_{3}$, as shown in Figure 4.3(c). The summation of the inductor currents is zero, and the voltages across the inductors in this switching state are null, as depicted in (5) and (6).

$$
\begin{aligned}
& I_{L 1 \_ \text {min }}+I_{L 2 \_ \text {min }}+I_{L 3 \_ \text {min }}=0 \\
& \left\{\begin{array}{l}
V_{L 1}=0 \\
V_{L 2}=0 \\
V_{L 3}=0
\end{array}\right.
\end{aligned}
$$

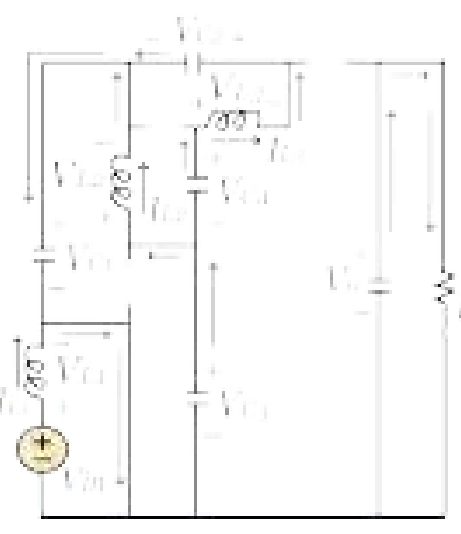

(a)

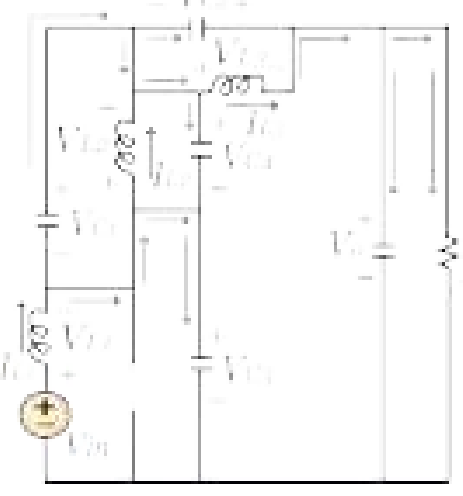

(b)

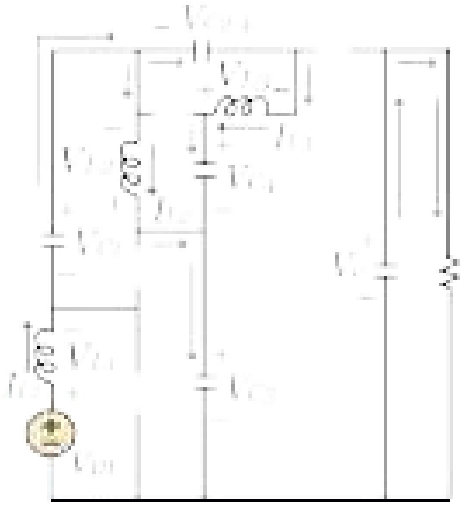

(c)

Figure 4.3: Equivalent circuits of the proposed converter. (a) Switching state I. (b) Switching state II. (c) Switching state III.

\subsection{Steady-State Analysis of the Proposed Converter}

\subsubsection{CCM Operation}

The key waveforms for this operation is presented in Figure 4.2(a). In this subsection, the voltage gain, the voltage stresses, the current stresses, and the efficiency analysis of the proposed converter operating in CCM are extracted. The operation in CCM is composed of switching state $I($ period $=d T)$ and switching state II $($ period $=(1-d) T)$, where $d$ and $T$ are the duty cycle and the periodic switching time, respectively. 


\section{1) Voltage Gain:}

By applying the voltage second principle on the inductors $L_{1}, L_{2}$, and $L_{3}$ and using equations (1) and (3), we can obtain (7)-(9):

$$
\begin{aligned}
& V_{C 1}=V_{C 2}=V_{C 4}=\frac{d}{1-d} V_{i n} \\
& V_{C 3}=\frac{1}{1-d} V_{\text {in }} \\
& V_{o}=\frac{1+2 d}{1-d} V_{\text {in }}
\end{aligned}
$$

Thus, the voltage gain $M_{C C M}$ can be calculated by (10):

$$
M_{C C M}=\frac{V_{o}}{V_{\text {in }}}=\frac{1+2 d}{1-d}
$$

\section{2) Analysis of Voltage Stress}

The stress across the five capacitors is delivered by (7)-(9). As shown in Figure 4.2(a), the voltage across the semiconductor devices swings between $0 \mathrm{~V}$ and $V_{C 3}$, hence the voltage stress across the power switch $V_{Q}$ and the voltage stress across the diodes $V_{D}$ can be obtained by (11):

$$
V_{Q}=V_{D}=V_{C 3}=\frac{1}{1-d} V_{\text {in }}
$$

Additionally, using (10), and (11) the voltage stress across the power switch and diodes can be represented as a function of $M_{C C M}$, as in (12):

$$
V_{Q}=V_{D}=\frac{2+M_{C C M}}{3 M_{C C M}} V_{o}
$$

\section{3) Analysis of Current Stress}

Assuming the input power equals the output power of the converter (i.e. $V_{i n} \times I_{L 1}=V_{o} \times I_{o}$ ), hence, the currents $I_{L 2}, I_{L 3}$, and $I_{L 1}$ can be calculated as in (13) and (14): 


$$
\begin{aligned}
& I_{L 2}=I_{L 3}=I_{o} \\
& I_{L 1}=\frac{1+2 d}{1-d} I_{o}=M_{C C M} I_{o}
\end{aligned}
$$

By applying the charge-second balance principle on the five capacitors to calculate the charging and discharging currents of them, we can get (15)-(19):

$$
\begin{aligned}
& \left\{\begin{array}{l}
i_{C 1_{-} \text {ch }}=2 I_{o} \\
i_{C 1_{-} d i s}=2 I_{o} \frac{d}{(1-d)}=2 I_{o}\left(\frac{M_{C C M}-1}{3}\right)
\end{array}\right. \\
& \left\{\begin{array}{l}
i_{C 2 \_c h}=I_{o} \\
i_{C 2 \_d i s}=I_{o} \frac{d}{(1-d)}=I_{o}\left(\frac{M_{C C M}-1}{3}\right)
\end{array}\right. \\
& \left\{\begin{array}{l}
i_{C 3_{-} c h}=2 I_{o} \frac{d}{(1-d)}=2 I_{o}\left(\frac{M_{C C M}-1}{3}\right) \\
i_{C 3_{-} \text {dis }}=2 I_{o}
\end{array}\right. \\
& \left\{\begin{array}{l}
i_{C 4 \_c h}=I_{o} \frac{d}{(1-d)}=I_{o}\left(\frac{M_{C C M}-1}{3}\right) \\
i_{C 4 \_ \text {dis }}=I_{o}
\end{array}\right. \\
& \left\{\begin{array}{l}
i_{C o_{-} c h}=I_{o} \frac{d}{(1-d)}=I_{o}\left(\frac{M_{C C M}-1}{3}\right) \\
i_{\text {Co_dis }}=I_{o}
\end{array}\right.
\end{aligned}
$$

By means of (13)-(19), Figure 4.3(a), and Figure 4.3(b), the currents flowing through $Q, D_{l}$, $D_{2}$, and $D_{3}$ can be described as following:

$$
\begin{aligned}
& i_{Q}=I_{L 1}+I_{L 2}+I_{L 3}=\frac{3}{1-d} I_{o} \\
& i_{D 1}=I_{L 1}-i_{C 1 \_d i s}=\frac{1}{1-d} I_{o} \\
& i_{D 2}=I_{L 2}+i_{C 1_{-} d i s}-I_{C 2 \_d i s}=\frac{1}{1-d} I_{o}
\end{aligned}
$$




$$
i_{D 3}=i_{C 2 \_d i s}+I_{o}=\frac{1}{1-d} I_{o}
$$

Using (10), equations (20)-(23) can be depicted as functions of $M_{C C M}$, as following:

$$
\begin{aligned}
& i_{Q}=\left(M_{C C M}+2\right) I_{O} \\
& i_{D 1}=i_{D 2}=i_{D 3}=\left(\frac{M_{C C M}+2}{3}\right) I_{O}
\end{aligned}
$$

The root-mean-square (rms) values of the currents flowing through the power switch, diodes, and capacitors are important in the efficiency analysis, and they can be extracted as following:

$$
\begin{aligned}
& i_{Q_{\_} r m s}=\sqrt{\left(M_{C C M}+2\right)\left(M_{C C M}-1\right)} I_{o} \\
& i_{D 1_{\_} r m s}=i_{D 2 \_r m s}=i_{D 3_{\_} r m s}=\sqrt{\frac{M_{C C M}+2}{3}} I_{O} \\
& i_{C 1_{\_} r m s}=i_{C 3_{-} r m s}=2 \sqrt{\frac{M_{C C M}-1}{3}} I_{o} \\
& i_{C 2_{-} r m s}=i_{C 4_{-} r m s}=i_{C o_{-} r m s}=\sqrt{\frac{M_{C C M}-1}{3}} I_{O}
\end{aligned}
$$

\section{4) Effect of Parasitic Elements on the Voltage Gain}

In order to evaluate the effect of the parasitic elements of the passive and active components of the proposed converter on its voltage gain, some of these parasitic parameters were modeled in the proposed converter circuit, shown in Figure 4.4. In the non-ideal model of the converter, the following parameters are included: the resistances of the windings of inductors $\left(r_{L 1}=r_{L 2}\right.$ $\left.=r_{L}\right)$, the equivalent-series-resistances of capacitors $\left(r_{C 1}=r_{C 2}=r_{C 3}=r_{C 4}=r_{C o}=r_{C}\right)$, the on- 
resistance of the power switch $\left(r_{S}\right)$, the forward voltages of the diodes $\left(V_{F 1}=V_{F 2}=V_{F 3}=V_{F}\right)$, and their respective on-resistances $\left(r_{D 1}=r_{D 2}=r_{D 3}=r_{D 4}=r_{D}\right)$.

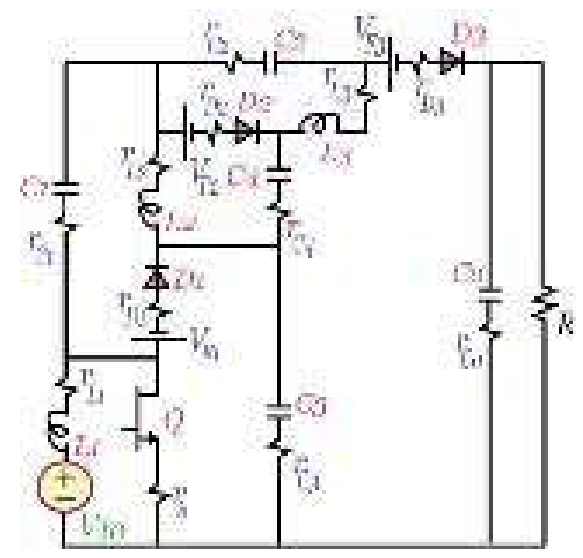

Figure 4.4: Equivalent circuit of the proposed converter with the parasitic elements.

After accounting for these parasitic parameters, the voltage gain of the proposed converter in its non-ideal model $\left(M_{C C M}\right)$ is depicted by equation (30). Figure 4.5 shows the graphical comparison between the voltage gain curves using the ideal and non-ideal models of the proposed converter, where the parasitic and operating parameters are considered as following: $V_{\text {in }}=50 \mathrm{~V}, R=100 \Omega, r_{L}=30 \mathrm{~m} \Omega, r_{C}=15 \mathrm{~m} \Omega, r_{S}=20 \mathrm{~m} \Omega, V_{F}=1 \mathrm{~V}$, and $r_{D}=$ $70 \mathrm{~m} \Omega$. It shows that the voltage gain of the non-ideal model of the converter is close to that of the ideal model when $d$ is between 0 and 0.8 (where $M_{C C M} \approx 13$ ) which indicates the high step-up capability of the proposed converter.

$$
M_{C C M}=\frac{R(1-d)\left(V_{i n}-3 V_{F}+3 d V_{F}+2 d V_{i n}\right)}{V_{i n}\left[R+3 r_{D}+3 r_{L}+d\left(6 r_{C}-2 R-3 r_{D}+3 r_{S}+d\left(R-6 r_{C}+6 r_{L}-12 r_{S}\right)\right)\right]}
$$




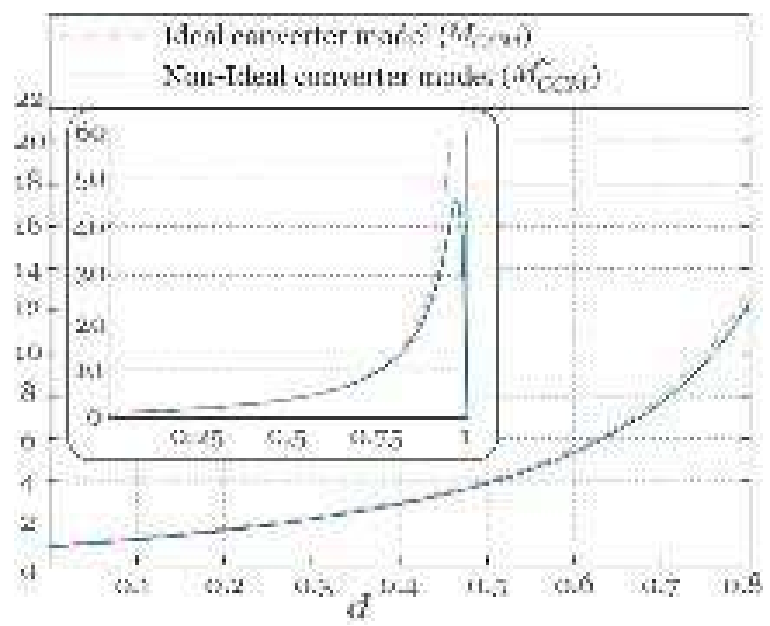

Figure 4.5: Voltage gain curves of the proposed converter.

\subsubsection{DCM Operation}

The key waveforms for this operation is shown in Figure 4.2(b). In this subsection, the voltage gain in DCM, boundary operating condition between CCM and DCM, and current stresses in DCM are given.

The operation in DCM is composed of Switching State I (period =dT), Switching State II $\left(\right.$ period $\left.=d_{x} T\right)$, and Switching State III $\left(\right.$ period $\left.=1-\left(d+d_{x}\right) T\right)$.

\section{5) Voltage Gain}

From (7)-(9), the capacitors' voltages can be rewritten as:

$$
\begin{aligned}
& V_{o}=V_{C 3}+2 V_{C 2} \\
& V_{C 3}=V_{i n}+V_{C 2}=\frac{V_{o}+2 V_{i n}}{3} \\
& V_{C 1}=V_{C 2}=V_{C 4}=\frac{V_{o}-V_{i n}}{3}
\end{aligned}
$$

By means of (1), (3), (6), (31)-(33), and applying the voltage second principle on $L_{1}$, we get the following: 


$$
\frac{1}{T}\left(\int_{0}^{d T} V_{i n} d t-\int_{0}^{d_{x} T} \frac{V_{o}-V_{i n}}{3} d t\right)=0
$$

To solve (34) in order to extract the voltage gain in DCM, $d_{x}$ should be determined.

As shown in Figure 4.6, and using equations (20)-(23), $i_{Q}$ equals the summation of the three inductors' currents, and the current flowing in any of the three diodes equals one third $i_{Q}$. Thus, the peak diode current $i_{D(\text { Peak })}$ can be calculated as following:

$$
i_{D(\text { Peak })}=\frac{1}{3}\left(\Delta i_{L 1}+\Delta i_{L 2}+\Delta i_{L 3}\right)
$$

The three inductors' currents in DCM can be calculated as:

$$
\begin{aligned}
\Delta i_{L 1} & =\frac{d V_{i n}}{f_{s} L_{1}} \\
\Delta i_{L 2} & =\frac{d V_{i n}}{f_{S} L_{2}} \\
\Delta i_{L 3} & =\frac{d V_{i n}}{f_{s} L_{3}}
\end{aligned}
$$

By substituting (36) into (35), we get (37):

$$
i_{D(\text { Peak })}=\frac{d V_{\text {in }}}{3 f_{s} L_{e q}}
$$

Where,

$$
L_{e q}=\left(\frac{1}{L_{1}}+\frac{1}{L_{2}}+\frac{1}{L_{3}}\right)^{-1}
$$

The average current flowing through any of the three diodes equals $I_{o}$, hence, we get the following:

$$
\frac{1}{2} d_{x} i_{D(\text { Peak })}=\frac{V_{o}}{R}
$$

By substituting (37) into (39), we can get $d_{x}$ as following: 


$$
d_{x}=\frac{6 V_{o}}{d V_{\text {in }}} \mathrm{T}
$$

Where $T$ is the normalized inductor time constant, defined as:

$$
\mathrm{T}=\frac{L_{e q} f_{s}}{R}
$$

By substituting (40) into (34), we get the following:

$$
V_{\text {in }}+\left(V_{\text {in }}-V_{o}\right) \frac{V_{o}}{d V_{\text {in }}} \mathrm{T}=0
$$

By solving this quadratic equation (42), the voltage gain in DCM $M_{D C M}$ can be extracted as in (43):

$$
M_{D C M}=\frac{1}{2}\left(1+\sqrt{1+\frac{2 d^{2}}{\mathrm{~T}}}\right)
$$

\section{6) Boundary Operating Conduction}

In boundary conduction mode (BCM) operation, $M_{C C M}$ equals $M_{D C M}$, and accordingly, from (10) and (43), the boundary normalized inductor time constant $T_{b}$ can be obtained, as in (44).

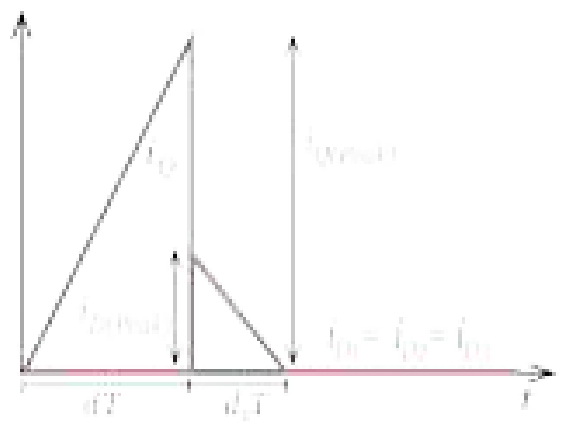

Figure 4.6: Power switch and diodes currents in DCM.

$$
\mathrm{T}_{b}=\frac{d(1-d)}{12 d+6}
$$

The relationship between $T_{b}$ and $d$ is presented in Figure 4.7. If $T>T_{b}$, then the proposed converter is working in CCM. 


\section{7) Voltage Stress Analysis}

As shown in Figure 4.2(b), the voltage stress across $Q$ during Switching State $I V_{Q}(I)$ is null, while during Switching State II $V_{Q}(I I)$ and Switching State III $V_{Q}(I I I)$ are expressed in (45):

$$
\left\{\begin{array}{l}
V_{Q}(I I)=V_{C 3}=\frac{M_{D C M}+2}{3} V_{i n} \\
V_{Q}(I I I)=V_{i n}
\end{array}\right.
$$

The voltage stress across any of the three diodes during Switching State II $V_{D}(I I)$ is null, while during Switching State I $V_{D}(I)$ and Switching State III $V_{D}(I I I)$ are shown in (46):

$$
\left\{\begin{array}{l}
V_{D}(I)=V_{C 3}=\frac{M_{D C M}+2}{3} V_{i n} \\
V_{D}(I I I)=V_{C 2}=\frac{M_{D C M}-1}{3} V_{i n}
\end{array}\right.
$$

\section{8) Current Stress Analysis}

Figure 4.6 depict the currents flowing through the semiconductor devices of the proposed converter in DCM. The peak currents flowing through $Q$, and the diodes, $i_{Q(P e a k)}$, and $i_{D(P e a k)}$, respectively, are expressed as shown in (47):

$$
\begin{aligned}
i_{Q(\text { Peak })} & =\Delta i_{L 1}+\Delta i_{L 2}+\Delta i_{L 3}=\frac{d V_{i n}}{f_{S} L_{e q}} \\
i_{D(\text { Peak })} & =\frac{1}{3}\left(\Delta i_{L 1}+\Delta i_{L 2}+\Delta i_{L 3}\right)=\frac{d V_{i n}}{3 f_{S} L_{e q}}
\end{aligned}
$$

The rms currents of the power switch and diodes are expressed in (48):

$$
\begin{aligned}
i_{Q(r m s)} & =\frac{d V_{i n}}{f_{s} L_{e q}} \sqrt{\frac{d}{3}} \\
l^{i_{D(r m s)}} & =\frac{d V_{i n}}{3 f_{s} L_{e q}} \sqrt{\frac{d_{x}}{3}}
\end{aligned}
$$


Figure 4.7: Boundary condition of the proposed converter.

\subsection{Comparative Study with Other Step-Up Converters}

In this section, the proposed converter is compared with other non-isolated step-up converters. The static voltage gain, the normalized voltage stress across the semiconductor devices, components counts, and the voltage gain range of these converters are summarized in Table 4.2. Figure4.8 shows $M_{C C M}$ versus $d$ for the compared converters, while Figure 4.9 and Figure 4.10 show the maximum normalized voltage stress across the power switches and diodes, respectively, among the compared converters.

In order to properly compare the added weight and size of the capacitors and inductors used in each topology of the compared converters, the energy stored in inductors $\left(E_{L}\right)$ and the energy stored in capacitors $\left(E_{C}\right)$ are calculated for each converter in Table 4.2 at the same output power, switching frequency, output voltage, voltage gain, and specific percentage of ripple current in inductors and ripple voltage in capacitors. 

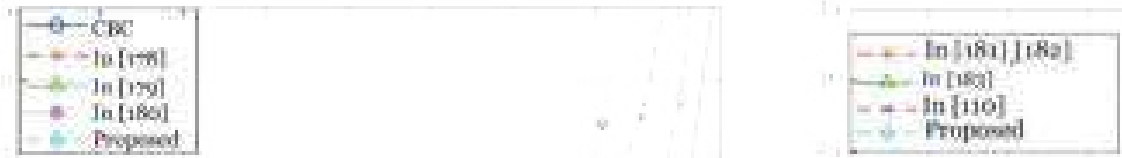

(a)

(b)

Figure 4.8: Comparison of voltage gain M_CCM versus duty cycle d. (a) Between the proposed converter, conventional boost converter, converters in [179], [180], and [178]. (b) Between the proposed converter, converters in [181], [182], [33], and [110].

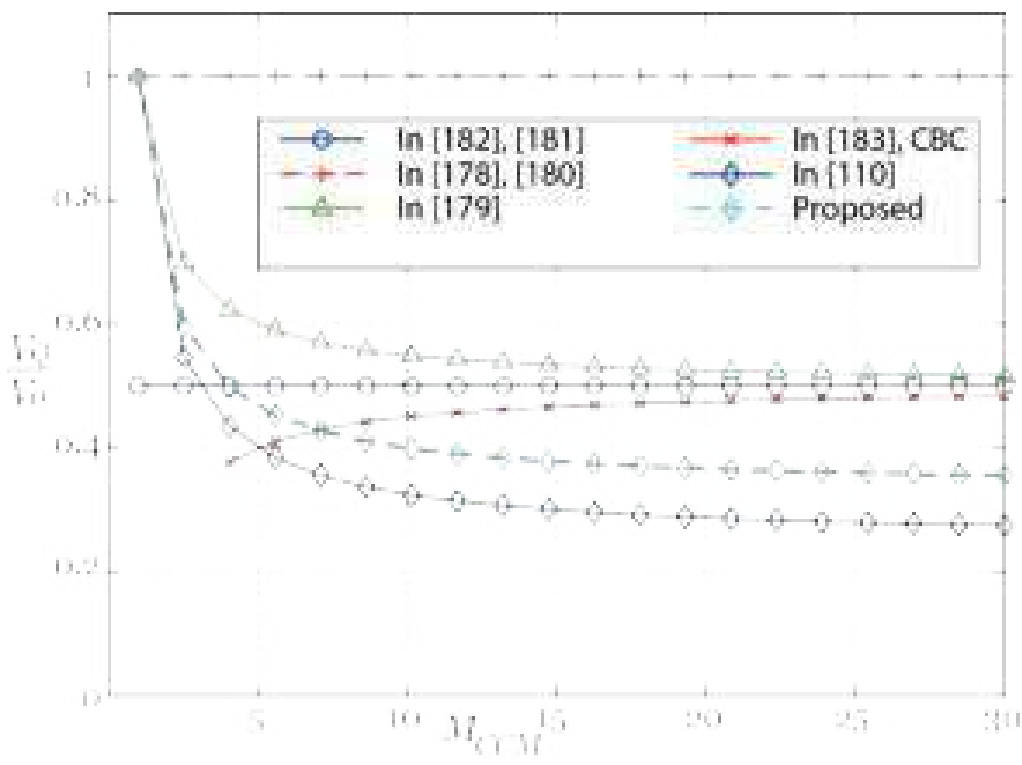

Figure 4.9: Normalized maximum voltage stress across the power switches in the compared converters 

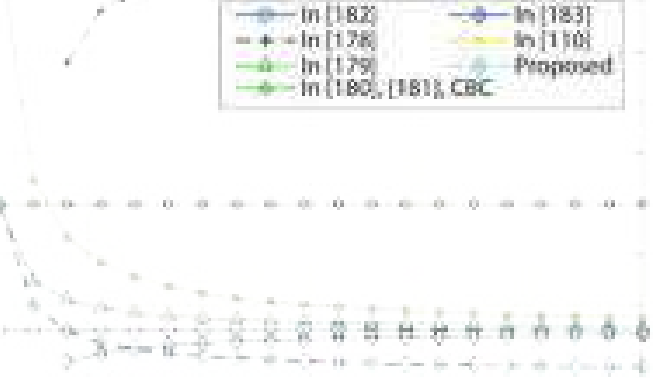

Figure 4.10: Normalized maximum voltage stress across the diodes in the compared converters

\begin{tabular}{|c|c|}
\hline - propoled, CEC & in[185: \\
\hline$\ldots-\ln \mid 1751$ & $-4 \ln [282]$ \\
\hline$-\ln \{179\}$ & $-4-\ln [183]$ \\
\hline$\rightarrow$ In:180| & $\ln [10]$ \\
\hline
\end{tabular}

Figure 4.11: Stored energy in the inductors of the compared converters at different voltage gain values.

\begin{tabular}{|c|c|}
\hline$-7+$ progosed & Inttei \\
\hline$-F-C B C$ & $-\ln \mid \frac{182 \mid}{1}$ \\
\hline$=+4$ In[178: & $-4=\ln [183]$ \\
\hline$\rightarrow-\ln [179$ & $\ldots+$ in[110] \\
\hline Inttecy & \\
\hline
\end{tabular}

Figure 4.12: Stored energy in the capacitors of the compared converters at different voltage gains. 


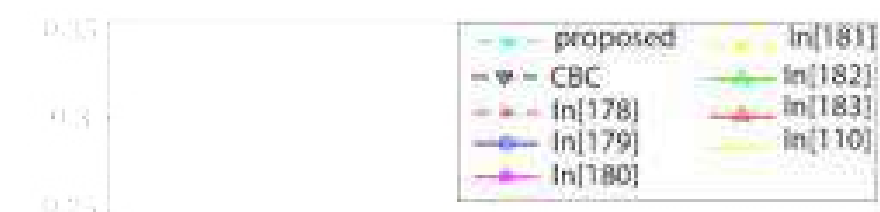

Figure 4.13: Semiconductor utilization factor of the compared converters at different voltage gain values.

The stored energy in the inductors of a converter can be calculated by (49), where $d_{M}$ is the value of duty cycle at the specific voltage gain, $\Delta_{L} \%$ is the percentage of ripple current, $V_{L i}$ is the voltage across inductor $L_{i}$ when the main switch is on, and $I_{L i}$ is the dc current flowing in inductor $L_{i}$.

$$
E_{L}=\sum \frac{L_{i} I_{L i}^{2}}{2}=\sum \frac{I_{L i}}{2}\left(\frac{d_{M} V_{L i}}{\Delta_{L} \% f_{s}}\right)
$$

The stored energy in the capacitors of a converter can be calculated by (50), where $\Delta_{C} \%$ is the percentage of ripple voltage, $i_{C i}$ is the current of capacitor $C_{i}$ when the main switch is on, and $V_{C i}$ is the dc voltage of capacitor $C_{i}$.

$$
E_{C}=\sum \frac{C_{i} V_{C i}^{2}}{2}=\sum \frac{V_{C i}}{2}\left(\frac{d_{M} i_{C i}}{\Delta_{C} \% f_{s}}\right)
$$

In order to compare the estimated cost of the semiconductor devices used in the converters in Table 4.2, the utilization factor of these semiconductor devices $\left(U_{S}\right)$ is used, and it is defined as given in (51): 


$$
U_{S}=\frac{P_{o}}{\sum V_{K i} I_{K i(r m s)}}
$$

Table 4.2: COMPARISON BETWEEN THE PROPOSED AND OTHER STEP-UP DC-DC CONVERTERS

\begin{tabular}{|c|c|c|c|c|c|c|c|c|}
\hline Topology & $\begin{array}{c}\text { Voltage gain } \\
\qquad(M)\end{array}$ & $V_{Q} / V_{o}$ & $V_{D} / V_{o}$ & $\begin{array}{c}\text { Semiconductor } \\
\text { devices }\end{array}$ & $\begin{array}{l}\text { Inductors \& } \\
\text { Capacitors }\end{array}$ & $\begin{array}{l}\text { Input } \\
\text { current }\end{array}$ & $\begin{array}{l}\text { Common } \\
\text { ground }\end{array}$ & $\begin{array}{c}\text { Voltage gain } \\
\text { range } \\
d: 0 \rightarrow 0.9\end{array}$ \\
\hline $\mathrm{CBC}$ & $\frac{1}{1-d}$ & 1 & 1 & $\begin{array}{l}1 \text { Switches } \\
1 \text { Diodes }\end{array}$ & $\begin{array}{l}1 \text { Inductor } \\
1 \text { Capacitors }\end{array}$ & Continuous & No & $1 \rightarrow 10$ \\
\hline In [178] & $\frac{1}{d(1-d)}$ & $\frac{1}{2}+\sqrt{\frac{1}{4}-\frac{1}{M_{C C M}}}, 1$ & $\begin{array}{l}\frac{1}{2}+\sqrt{\frac{1}{4}-\frac{1}{M_{C C M}}} \\
\frac{3}{2}+\sqrt{\frac{1}{4}-\frac{1}{M_{C C M}}}\end{array}$ & $\begin{array}{l}2 \text { Switches } \\
3 \text { Diodes }\end{array}$ & $\begin{array}{l}2 \text { Inductors } \\
2 \text { Capacitors }\end{array}$ & Continuous & No & $--\rightarrow 11$ \\
\hline In [179] & $\frac{1+d}{1-d}$ & $\frac{1+M_{C C M}}{2 M_{C C M}}$ & $\frac{1+M_{C C M}}{2 M_{C C M}}$ & $\begin{array}{l}1 \text { Switch } \\
3 \text { Diodes }\end{array}$ & $\begin{array}{l}2 \text { Inductors } \\
3 \text { Capacitors }\end{array}$ & Pulsating & Yes & $1 \rightarrow 19$ \\
\hline In [180] & $\frac{1}{(1-d)^{2}}$ & 1 & $\begin{array}{l}1, \sqrt{1-\frac{M_{C C M}-1}{M_{C C M}}}, \\
1-\sqrt{1-\frac{M_{C C M}-1}{M_{C C M}}}\end{array}$ & $\begin{array}{l}1 \text { Switch } \\
3 \text { Diodes }\end{array}$ & $\begin{array}{l}2 \text { Inductors } \\
2 \text { Capacitors }\end{array}$ & Pulsating & Yes & $1 \rightarrow 100$ \\
\hline In [181] & $\frac{2}{1-d}$ & $\frac{1}{2}$ & $\frac{1}{2}, 1$ & $\begin{array}{l}2 \text { Switches } \\
2 \text { Diodes }\end{array}$ & $\begin{array}{l}2 \text { Inductors } \\
2 \text { Capacitors }\end{array}$ & Pulsating & No & $2 \rightarrow 20$ \\
\hline In [182] & $\frac{2}{1-d}$ & $\frac{1}{2}$ & $\frac{1}{2}$ & $\begin{array}{l}1 \text { Switch } \\
3 \text { Diodes }\end{array}$ & $\begin{array}{l}1 \text { Inductor } \\
3 \text { Capacitors }\end{array}$ & Continuous & Yes & $2 \rightarrow 20$ \\
\hline In [183] & $\frac{3-d}{1-d}$ & $\frac{M_{C C M}-1}{2 M_{C C M}}$ & $\frac{M_{C C M}-1}{2 M_{C C M}}$ & $\begin{array}{l}1 \text { Switch } \\
4 \text { Diodes }\end{array}$ & $\begin{array}{l}1 \text { Inductor } \\
4 \text { Capacitors }\end{array}$ & Pulsating & No & $3 \rightarrow 21$ \\
\hline In [110] & $\frac{1+3 d}{1-d}$ & $\frac{3+M_{C C M}}{4 M_{C C M}}$ & $\frac{3+M_{C C M}}{2 M_{C C M}}$ & $\begin{array}{l}2 \text { Switches } \\
2 \text { Diodes }\end{array}$ & $\begin{array}{l}3 \text { Inductors } \\
3 \text { Capacitors }\end{array}$ & Pulsating & No & $1 \rightarrow 37$ \\
\hline Proposed & $\frac{1+2 d}{1-d}$ & $\frac{2+M_{C C M}}{3 M_{C C M}}$ & $\frac{2+M_{C C M}}{3 M_{C C M}}$ & $\begin{array}{l}1 \text { Switch } \\
3 \text { Diodes }\end{array}$ & $\begin{array}{l}3 \text { Inductors } \\
5 \text { Capacitors }\end{array}$ & Continuous & Yes & $1 \rightarrow 28$ \\
\hline
\end{tabular}

Where $V_{K i}$ is the voltage stress on a semiconductor device $K_{i}$, and $I_{K i}(\mathrm{rms})$ is the rms value of the current stress on semiconductor device $K_{i}$. Figure 4.11, Figure 4.12, and Figure 4.13 show the energy stored in inductors and capacitors and the semiconductor utilization factor 
for the compared converters in Table 4.2, respectively, when $V_{o}=400 \mathrm{~V}, P_{o}=1.6 \mathrm{~kW}, f_{s}=$ $100 \mathrm{kHz}, \Delta_{L} \%=25 \%, \Delta_{C} \%=10 \%$ (for the output capacitors) and $20 \%$ (for the middle capacitors), and $M_{C C M}=4 \rightarrow 8$.

Comparing the proposed converter with the conventional boost converter (CBC), on one hand, the CBC has lower number of diodes and passive components, on the other hand, the proposed converter has higher voltage gain, lower voltage stress on the semiconductor devices, and wider voltage gain range. The converter in [178], is composed of less number of inductors and capacitors, however, it utilizes an extra power switch compared to the proposed converter, does not have a common ground and has a high voltage stress on the output diode. Additionally, the converter in [178] has a narrower voltage gain range and its voltage gain is less compared to the proposed converter for $d>0.5$. In [179], the voltage lift-based converter has the same number of semiconductor devices, and utilizes less capacitors and less inductors compared to the proposed converter. Nevertheless, the converter in [179] has high input current ripple, narrower voltage gain range, less voltage gain, and higher voltage stress on its power switch and diodes compared to the proposed converter. The quadratic converter presented in [180], on one hand has higher voltage gain and less number of inductors and capacitors compared to the proposed converter, and on the other hand it has high input current ripple and higher voltage stress on the power switch. In [181], converter II, on one side has double the voltage gain of the conventional boost converter and utilizes less number of diodes, inductors, and capacitors compared to the proposed converter, but on the other side, it utilizes an extra power switch compared to the proposed converter, has a pulsating input current, does not have a common ground, and the voltage stress on its output diode is high. The voltage gain of the proposed converter is higher for $d>0.5$, and the voltage stress on the 
semiconductor devices of the proposed converter is less for $d>0.5$, compared to the converter II in [181]. The boost converter that utilizes diode-capacitor voltage multipliers in [182] has less inductors compared to the proposed converter, however, to increase its voltage gain, the number of diodes of the voltage multipliers duplicates, leading to increased conduction losses and decreased efficiency. Additionally, as the number of voltage multipliers increases, the minimum boosting gain increases, rendering it not sufficient for applications with wide voltage fluctuations such as fuel cells. Comparing the hybrid boost converter in [183] with the proposed converter, the number of inductors and capacitors in the converter in [183] is less, while it utilizes an extra diode. The input current ripple of the converter in [183] is high which can affect the life time of the fuel cell. Additionally, the proposed converter has higher voltage gain for $d>0.65$, and less voltage stress on the semiconductor devices for $M_{C C M}>7$ compared to the converter in [183]. The converter presented in [110] has less capacitors, less diodes, and an extra power switch compared to the proposed converter. Also, it has a wider voltage gain range, and less voltage stress on the semiconductor devices. The main drawbacks of this converter are the higher number of power switches, the pulsating input current and the lack of common ground between its input and output ports, as the potential difference between the two grounds is high frequency PWM voltage which can increase the EMI and requires more maintenance.

Based on Figure 4.11, the energy stored in the inductors of the proposed converter is the same as the CBC, while it is lower than that of the converters in [178]-[180], and is higher than that of the converters in [181], [110], [183], and [182]. This means that the estimated weight and size of inductors for the proposed converter is close to that of the CBC while it is lower than that of the converters in [178]-[180], and is higher than that of the converters in 
[181]-[183], and [110]. Similarly, based on Figure 4.12, the energy stored in the capacitors of the proposed converter is lower than that of the converters in [179], [181], [183] and [178] (when $M_{C C M}<6.5$ ), while it is higher than that of the CBC and the converters in [180], [182], and [110]. This means that the estimated weight and size of capacitors for the proposed converter is lower than that of the converters in [179], [181], [183], and [178] (when $M_{C C M}<6.5$ ), and is higher than that of the converters in [180], [182], and [110]. Figure 4.13 shows that the proposed converter has the highest utilization factor compared to all the converters in Table 4.2, which means that the estimated cost of the semiconductor devices of the proposed converter is lower than that of the other compared converters.

From the above comparisons, it is evident that the proposed converter integrates many advantages such as: high conversion ratio, wide voltage gain range, low voltage stress on the semiconductor devices, common ground between its input and output ports, low input current ripple, and utilizes a single power switch. This makes it an excellent candidate for fuel cell vehicles application.

\subsection{Design Considerations and Components Selection}

\subsubsection{Semiconductor Devices Selection}

By knowing the maximum value of $M_{C C M}(\max )$ needed by the converter, and the maximum output load current, the peak currents flowing through the power switch and diodes can be calculated using (24) and (25), respectively. From (12), the maximum voltage stress on the power switch and diodes can be calculated when $M_{C C M}(\max )$ is known. These maximum voltage and current stresses should be within the safe operating area (SOA) of the selected power switch and diodes. 


\subsubsection{Inductors Design}

By knowing the maximum output load current and by means of (13) and (14), the currents flowing through the three inductors can be calculated. Assuming the maximum ripple currents $\Delta i_{L 1}, \Delta i_{L 2}$, and $\Delta i_{L 3}$ are known. The minimum required inductances can be determined using (52).

$$
\begin{aligned}
L_{1} & \geq \frac{d V_{i n}}{f_{s} \Delta i_{L 1}} \\
L_{2} & \geq \frac{d V_{i n}}{f_{S} \Delta i_{L 2}} \\
L_{3} & \geq \frac{d V_{i n}}{f_{S} \Delta i_{L 3}}
\end{aligned}
$$

\subsubsection{Capacitors Design}

By means of (7)-(9), the voltages across the five capacitors can be calculated. Assuming the maximum ripple voltages $\Delta V_{C 1}, \Delta V_{C 2}, \Delta V_{C 3}, \Delta V_{C 4}$ and $\Delta V_{C o}$ are known. The minimum required capacitances can be determined using (53).

$$
\begin{array}{rlrl}
C_{1} & \geq \frac{2 I_{o} d}{f_{s} \Delta V_{C 1}} & C_{4} & \geq \frac{I_{o} d}{f_{s} \Delta V_{C 4}} \\
C_{2} & \geq \frac{I_{o} d}{f_{s} \Delta V_{C 2}} \\
C_{3} & \geq \frac{2 I_{o} d}{f_{s} \Delta V_{C 3}}
\end{array} \quad C^{C_{o}} \geq \frac{I_{o} d}{f_{s} \Delta V_{C o}}
$$

\subsection{Experimental Results and Analysis}

In order to validate the theoretical analysis of the proposed converter, a scaled-down $1.6 \mathrm{~kW}$ laboratory prototype was built, presented in Figure 4.14. The input voltage to the converter is depicted by an adjustable dc power supply, and the converter is controlled by a microcontroller TMS320f28377s. 


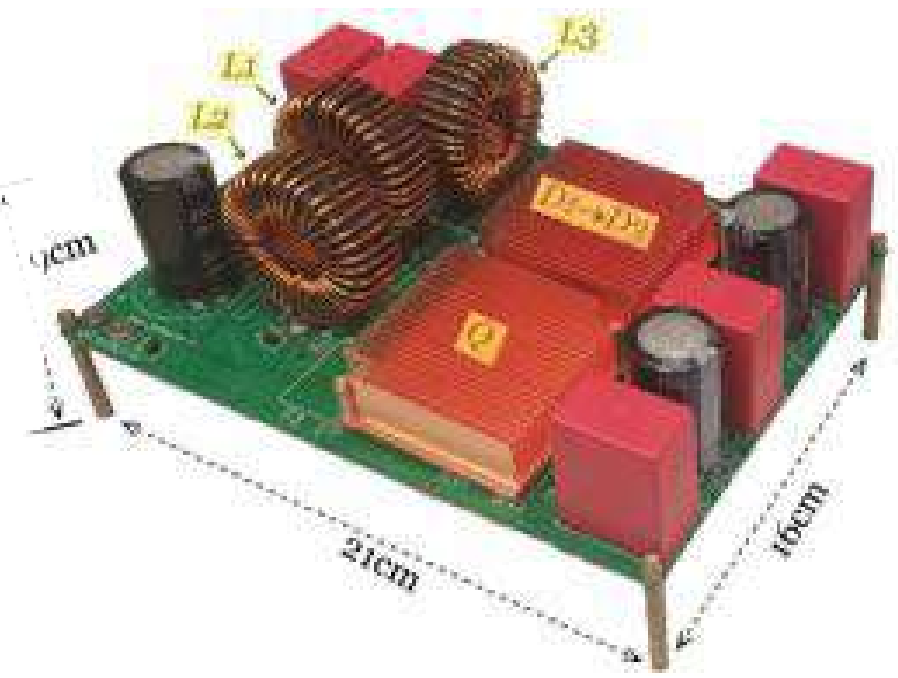

Figure 4.14: Experimental prototype.

Table 4.3: EXPERIMENT PARAMETERS

\begin{tabular}{lc}
\hline \hline Parameters and & Values \\
Components & \\
\hline Rated power $P_{o}$ & $1.6 \mathrm{~kW}$ \\
Output voltage $V_{o}$ & $400 \mathrm{~V}$ \\
Power MOSFET $Q$ & IXFP72N30X3M \\
Power Diodes $D_{1}, D_{2}, D_{3}$ & $\mathrm{MBRF} 40250 \mathrm{TG}$ \\
Inductors $L_{1}, L_{2}, L_{3}$ & $250 \mu \mathrm{H}$ \\
Capacitors $C_{1}, C_{2}$ & $40 \mu \mathrm{F}$ \\
Capacitors $C_{3}, C_{4}$ & $220 \mu \mathrm{F}$ \\
Capacitor $C_{o}$ & $240 \mu \mathrm{F}$ \\
Switching frequency $f_{s}$ & $100 \mathrm{KHz}$ \\
Load $R$ & $100 \Omega$ \\
Microcontroller & $\mathrm{TMS} 320 \mathrm{f} 28377 \mathrm{~s}$ \\
\hline \hline
\end{tabular}

The power circuit is built using (IXFP72N30X3M) power MOSFET and (MBRF40250TG) Schottky diodes. The values of inductors and capacitors used in the developed prototype are as following: $L_{1}=L_{2}=L_{3}=250 \mu \mathrm{H}, C_{1}=C_{2}=40 \mu \mathrm{F}, C_{3}=C_{4}=220$ 
$\mu \mathrm{F}$, and $C_{o}=240 \mu \mathrm{F}$. In addition, the load $R=100 \Omega$, and switching frequency $f_{s}=100$ KHz. The case study investigated in this section is $V_{i n}=50 \mathrm{~V}$, and the duty cycle $d=0.7$.

According to equations (7)-(9), the voltages across the five capacitors can be calculated as following: $V_{C 1}=V_{C 2}=V_{C 4} \approx 116.7 \mathrm{~V}, V_{C 3} \approx 166.7 \mathrm{~V}$, and $V_{o} \approx 400 \mathrm{~V}$, which closely agree with the experimental results in Figure 4.15(c) and Figure 4.15(d).

The output current can be theoretically calculated as: $I_{o}=V_{o} /_{R}=4 \mathrm{~A}$, which agrees with the experimental result shown in Figure 4.15(d). Accordingly, the currents of the three inductors can be calculated using (13) and (14), as following: $I_{L 2}=I_{L 3}=I_{o}=4 \mathrm{~A}$, and $I_{L 1}=$ 32A, which closely agree with the experimental results shown in Figure 4.15(a) and Figure 4.15(b). Additionally, the ripple currents of the three inductors can be calculated using (52), as following: $\Delta i_{L 1}=\Delta i_{L 2}=\Delta i_{L 3}=1.4 \mathrm{~A}$, which comply with the experimental results presented in Figure 4.15(a) and Figure 4.15(b).

The voltage stresses across the power switch and the three diodes can be calculated using equation (11), as following: $V_{Q}=V_{D 1}=V_{D 2}=V_{D 3} \approx 166.7 \mathrm{~V}$, which closely comply with the experimental results given in Figure 4.15(a) and Figure 4.15(e). The current stresses on the power switch and the three diodes can be derived via equations (20) and (21), as following: $i_{Q}=40 \mathrm{~A}$, and $i_{D 1}=i_{D 2}=i_{D 3} \approx 13.3 \mathrm{~A}$, which closely agree with the experimental results shown in Figure 4.15(f) and Figure 4.15(g).

In order to test the wide-input feature of the proposed converter, Figure $4.15(\mathrm{~h})$ shows the input voltage of proposed converter changed from $40 \mathrm{~V}$ to $120 \mathrm{~V}$, while the output voltage is fixed at $400 \mathrm{~V}$. In this test, the converter is controlled by a closed-loop proportional-integral (PI) voltage controller. Figure 4.15(i) shows the effect of the change in the input voltage from $40 \mathrm{~V}$ to $120 \mathrm{~V}$ on the input current (current flowing in $L_{1}$ ) and it shows that $I_{L 1}=$ 
$40 \mathrm{~A}$ when $V_{\text {in }}=40 \mathrm{~V}$, while $I_{L 1} \approx 13.3 \mathrm{~A}$ when $V_{\text {in }}=120 \mathrm{~V}$, as $I_{L 1}$ is directly proportional to the voltage gain of the converter (when the output current is constant).
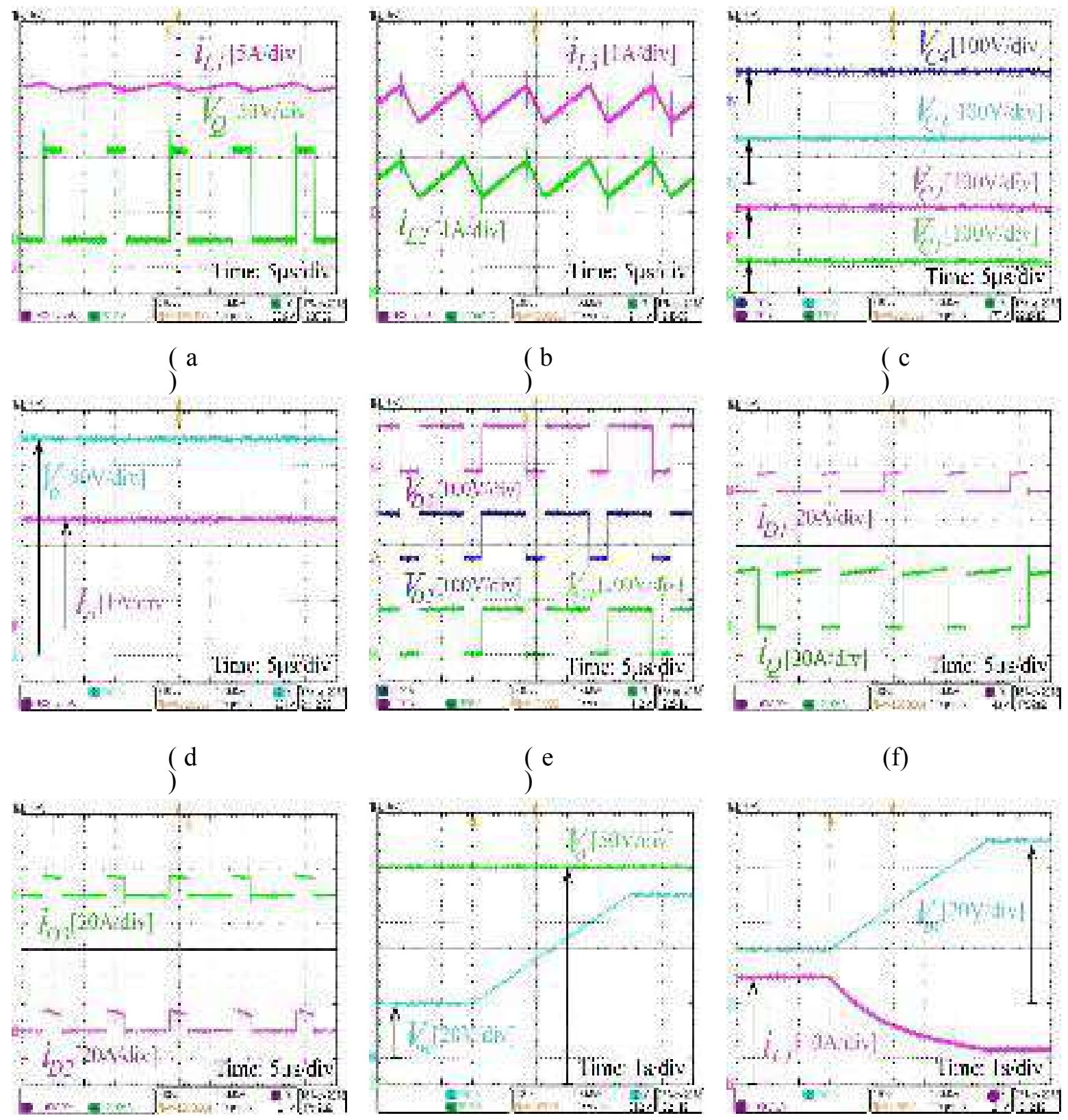

\section{(f)}

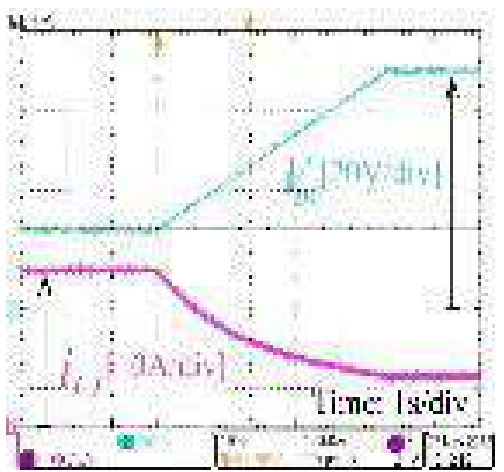

)$^{(g}$

)$^{(h}$

)

Figure 4.15: Experimental results. (a) Current of L1, and voltage stress across Q, (b) Currents of L2 and L3, (c) Voltages across C1, C2, C3, and C4, (d) Output voltage and output current, (e) Voltage stresses across D1, D2, and D3, (f) Current stresses of Q and D1 


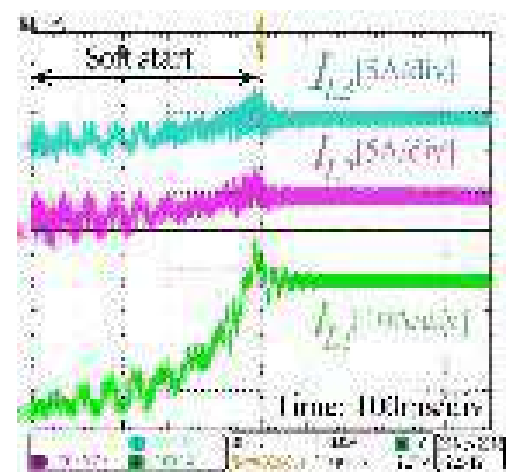

(a)

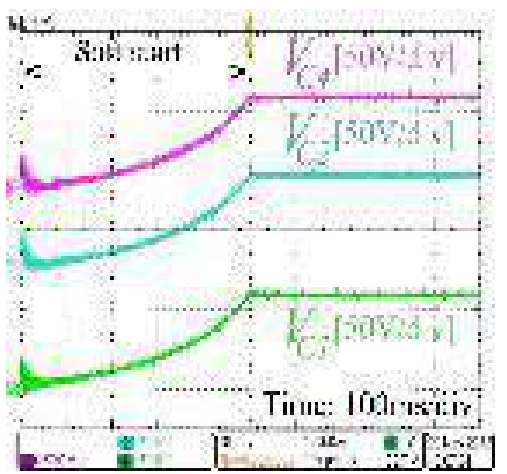

$(b$

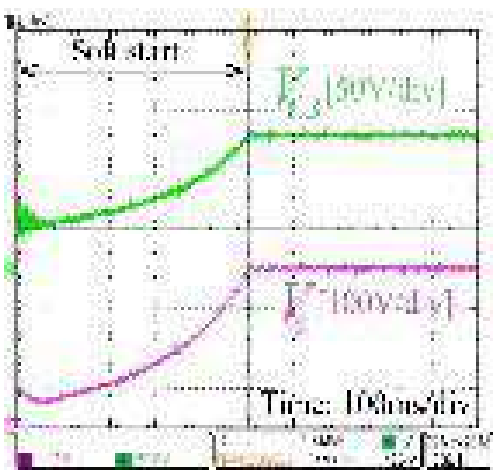

(c)

Figure 4.16: (a) Inductor currents during start-up, (b) Voltages across C1, C2, and C4 during start-up, (c) Voltages across C3 and Co during stat-up.

The results given in Figure 4.15(h) and Figure 4.15(i) show evidently that the proposed converter has an acceptable dynamic performance under wide changes in its input voltage.

In order to build the initial voltages across the capacitors of the proposed converter without having high inrush currents that may damage the semiconductor devices, a softstarting algorithm is adopted. This soft-starting algorithm gradually increases the value of duty cycle from zero to the desired value during the starting instant. Figure 4.16 shows the currents of the three inductors and the voltages of the five capacitors during the soft start and during steady state. Based on these results, the converter appears to not have high inrush inductor currents during the start instant, and the capacitor voltages increase gradually without having high voltage overshoots during the start instant. The calculated loss distributions for the investigated case study of the experiment is presented in Figure 4.17. The total losses of this case study $P_{\text {Loss }}=73.88 \mathrm{~W}$, and it is distributed as following: The conduction losses of $D_{1}, D_{2}$, and $D_{3}$ are $14.4 \mathrm{~W}$ and they account for $19 \%$ of the total losses of the converter, the conduction loss of $Q$ is $21.28 \mathrm{~W}$ and it accounts for $29 \%$ of the total converter losses, the switching loss of $Q$ is $13.11 \mathrm{~W}$ and it accounts for $18 \%$ of the total converter losses, the conduction losses of $L_{1}, L_{2}$, and $L_{3}$ are $16.88 \mathrm{~W}$ and they account for $23 \%$ of the total converter 
losses, and finally, the conduction losses of $C_{1}, C_{2}, C_{3}, C_{4}$, and $C_{o}$ are $8.21 \mathrm{~W}$ and they account for $11 \%$ of the total converter losses.

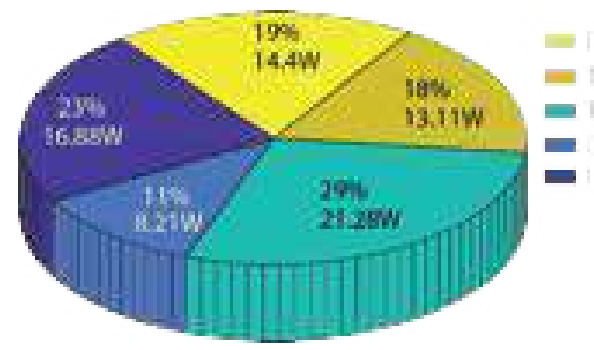

Figure 4.17: Calculated power loss distributions for the experiment $(\mathrm{Vin}=50 \mathrm{~V}, \mathrm{Vo}=400 \mathrm{~V}$, and $\mathrm{R}=100 \Omega)$.

Figure 4.18: Efficiency curves of the proposed converter $(\mathrm{Vo}=400 \mathrm{~V}, \mathrm{Vin}=40 \rightarrow 120 \mathrm{~V}$, output power $=800 \mathrm{~W}, 1200 \mathrm{~W}$, and $1600 \mathrm{~W})$.

The conduction and switching losses of $Q$ are low due to the utilization of low voltage power MOSFET with low $R_{D S}$ and low $C_{O S S}$. The efficiency curves of the laboratory prototype at different values of $V_{i n}\left(V_{i n}=40 \rightarrow 120\right)$, and different output powers $\left(P_{o}=800 \mathrm{~W}, 1200 \mathrm{~W}\right.$, and $1600 \mathrm{~W}$ ), while keeping $V_{o}$ fixed at $400 \mathrm{~V}$, are shown in Figure 4.18. The measured efficiency curves are obtained using a power analyzer (Tektronix PA3000). The maximum recorded efficiency is $97.8 \%$, when $P_{o}=800 \mathrm{~W}$ and $V_{\text {in }}=120 \mathrm{~V}$, while the minimum recorded efficiency is $92.5 \%$, when $P_{o}=1600 \mathrm{~W}$ and $V_{\text {in }}=40 \mathrm{~V}$. 


\subsection{Conclusion}

In this chapter, a new single-switch dc-dc converter with an integrated $L^{2} C^{3} D^{2}$ network is presented. The proposed converter has many merits such as: high voltage gain without magnetic coupling, low voltage stress on the semiconductor devices, common ground, and universal input voltage. These features make it an excellent candidate for fuel cell vehicles. Steady-state analyses in CCM and DCM operations of the proposed converter were discussed. The proposed converter is compared with other step-up converters in literature regarding the voltage gain, the voltage stress on the semiconductor devices, the number of components, and other specifications, and the privilege of the proposed topology is justified. Finally, a $1.6 \mathrm{~kW} 400 \mathrm{~V}$ prototype for the proposed topology was built, and the theoretical analysis was verified by the experimental results. 


\section{Chapter 5 A New Single-Switch Structure of a DC-DC Converter with Wide Conversion Ratio for Fuel Cell Vehicles: Analysis and Development}

\subsection{Introduction}

In this chapter a new single-switch transformerless boost dc-dc converter is proposed for fuel cell vehicles. The developed topology utilizes a switched-capacitor multiplier and an integrated $L C^{2} D$ output network in order to enhance the voltage gain of the converter and reduce the voltage stress on the power switch. In addition, the proposed converter has a wide voltage gain range to suit the wide voltage swings of the fuel cell. The operating principles and the steady-state analyses of the proposed converter when it operates in continuous conduction mode (CCM) and discontinuous conduction mode (DCM) are illustrated in this paper. Additionally, the dynamic modeling and the compensator design for the developed converter are discussed. A scaled-down $800 \mathrm{~V}, 1.3 \mathrm{~kW}$ experimental prototype was built using a Gallium Nitride (GaN) transistor and Silicon Carbide ( $\mathrm{SiC}$ ) diodes to validate the theoretical analyses of the proposed converter.

\subsection{Structure and Steady-State Analysis of the Proposed Converter}

\subsubsection{The Proposed Topology}

The schematic of the proposed converter is shown in Figure 5.1, where it is composed of one switch $(Q)$, four diodes $\left(D_{1}, D_{2}, D_{3}\right.$, and $\left.D_{4}\right)$, two inductors $\left(L_{1}\right.$, and $\left.L_{2}\right)$, five capacitors $\left(C_{1}, C_{2}\right.$, $C_{3}, C_{4}$, and $C_{5}$ ), and the load is represented by a resistance $(R)$. The proposed topology is based on a two-level boost switching network, an integrated switched capacitor multiplier, and an integrated $L C^{2} D$ output network. The integrated switched capacitor multiplier and the $L C^{2} D$ output network enhance the voltage gain of the converter and reduce the voltage stress on the switch, hence, a 
switch with lower rated voltage (= lower on resistance, lower total charge, and higher efficiency) can be used.

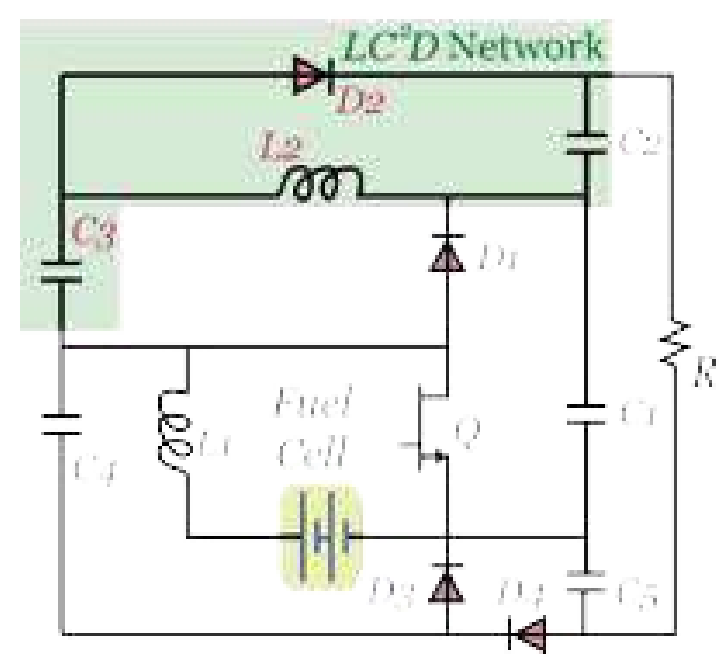

Figure 5.1: The proposed step-up converter.

\subsubsection{Operating States Analysis}

Based on the conduction state of the switch and the four diodes, the operation of the proposed converter can be classified into three operating states, presented in Table 5.1. The analyses of the converter during the three switching states refer to the currents of the five capacitors $\left(C_{1} \rightarrow C_{5}\right)$ during charging as: $i_{C l_{\_} c h}, i_{C 2_{-} c h}, i_{C 3_{-} c h}, i_{C A_{-} c h}$, and $i_{C S_{-} c h}$, and during discharging as: $i_{C l_{-} d i s}, i_{C 2 \_d i s}$, $i_{C C_{-} d i s}, i_{C 4} \_i s$, and $i_{C 5} \_d i s$. Also, in these analyses the currents of inductors $\left(L_{1}\right.$ and $\left.L_{2}\right)$ are referred to as $I_{L 1}$ and $I_{L 2}$, the voltages of the five capacitors are referred to as $V_{C 1}, V_{C 2}, V_{C 3}, V_{C 4}$, and $V_{C 5}$, and the input and output voltages and the output current are referred to as $V_{i n}, V_{o}$, and $I_{o}$, respectively.

In order to simplify the analysis, the following assumptions were made: 1) The ripple currents of inductors $\left(L_{1}\right.$ and $\left.L_{2}\right)$ equal zero. 2$)$ The ripple voltages of the five capacitors $\left(C_{1} \rightarrow C_{5}\right)$ equal zero. 3) The inductors and capacitors are ideal with no equivalent series resistances. 4) The switch and diodes are ideal. 
Table 5.1: OPERATING STATES OF THE SEMICONDUCTOR DEVICES

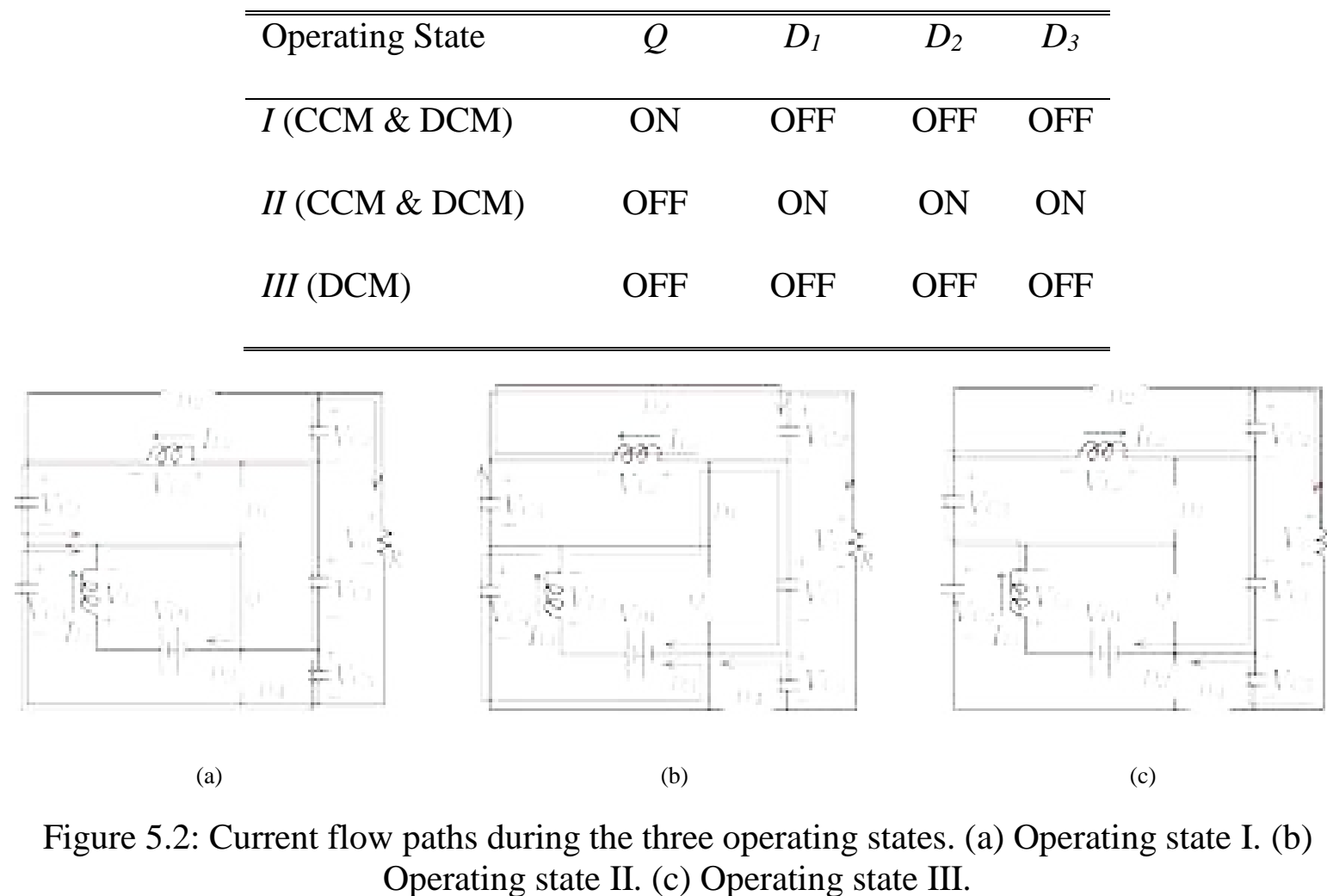

\section{9) Operating State I:}

In this mode, the switch is on, $D_{1} \rightarrow D_{3}$ are reverse biased, and $D_{4}$ is forward biased. This

operating state is for the converter when it operates in CCM and DCM, and the period of this state is $d T$, where $d$ is the duty cycle and $T$ is the periodic switching time. Figure 5.3 shows the important waveforms of the proposed converter when it operates in CCM and DCM, and the converter is in operating state $I$ when $t_{0}<t<t_{1}$.

During this state, both inductors charge, capacitors $\left(C_{3}\right.$ and $\left.C_{5}\right)$ charge, and capacitors $\left(C_{1}, C_{2}\right.$, and $C_{4}$ ) discharge. The current flow paths during this operating state are shown in Figure 5.2(a). By means of Kirchhof's Current Law (KCL), and Kirchhof's Voltage Law (KVL) on the equivalent circuit shown in Figure 5.2(a), we can deduce (1) and (2): 


$$
\begin{gathered}
\left\{\begin{array}{l}
V_{L 1}=V_{i n} \\
V_{L 2}=V_{C 1}-V_{C 3}
\end{array}\right. \\
I_{C 1 \_d i s}=2 I_{L 2} \\
I_{C 2 \_d i s}=\frac{V_{o}}{R} \\
I_{C 3_{-} c h}=I_{L 2} \\
\left(I_{C 5_{-} c h}=I_{C 4 \_d i s}-\frac{V_{o}}{R}\right.
\end{gathered}
$$

\section{0) Operating State II:}

In this mode, the switch is off, $D_{1} \rightarrow D_{3}$ are forward biased, and $D_{4}$ is reverse biased. This operating state is for the converter when it operates in CCM and DCM, and the period of this state is $(1-d) T$ (in CCM) or $d_{e} T$ (in DCM). These time internals are shown in Figure 5.3, and the converter is in operating state $I I$ when $t_{1}<t<t_{2}$.

During this state, both inductors discharge, capacitors $\left(C_{3}\right.$ and $\left.C_{5}\right)$ discharge, and capacitors $\left(C_{1}, C_{2}\right.$, and $\left.C_{4}\right)$ charge. The current flow paths during this operating state are shown in Figure 5.2(b). By means KCL and KVL laws on the equivalent circuit shown in Figure 5.2(b), we can deduce (3) and (4):

$$
\begin{aligned}
& \left\{\begin{array}{l}
V_{L 1}=V_{i n}-V_{C 4}=V_{i n}-V_{C 1} \\
V_{L 2}=-V_{C 3}=-V_{C 2}
\end{array}\right. \\
& \left\{\begin{array}{l}
I_{L 1}=I_{C 4 \_c h}+I_{C C_{-} c h}+I_{L 2}+I_{C 1 \_c h}-I_{C 2 \_c h} \\
I_{C 5 \_d i s}=\frac{V_{o}}{R}
\end{array}\right.
\end{aligned}
$$

\section{1) Operating State III:}

In this mode the switch is off, and $D_{1} \rightarrow D_{4}$ are reverse biased. This operating state is for the converter when it operates only in DCM, and the period of this state is $\left(1-d-d_{e}\right) T$. The converter is in operating state $I I I$ when $t_{2}<t<t_{3}$. In this operating state, the voltages across $L_{1}$ and 
$L_{2}$ equal zero, a positive constant current $I_{L I_{-} I I I}$ flows through $L_{1}$, and a negative constant current $I_{L 2 \_I I I}$ flows through $L_{2}$. The relationship between $I_{L 1} I I I$ and $I_{L 2 \_I I I}$ is presented in (6) where their summation equals null.

$$
\begin{aligned}
& \left\{\begin{array}{l}
V_{L 1}=0 \\
V_{L 2}=0
\end{array}\right. \\
& I_{L 1 \_I I I}+I_{L 2 \_I I I}=0
\end{aligned}
$$

\subsection{Steady-State Analysis for CCM Operation}

In CCM operation, the converter has two states of operation, namely: operating state $I$ and operating state $I I$, and the important waveforms of this operation is presented in Figure 5.3(a). The voltage gain, the voltage and current stresses on the semiconductor devices, and the efficiency analysis of the proposed converter are deduced in this subsection.

\subsubsection{Voltage Gain}

By using the voltage second balance on $L_{1}$ and $L_{2}$ we can extract the output voltage, and the voltages of the five capacitors, as following:

$$
\begin{aligned}
& \frac{1}{T}\left(\int_{0}^{d T} V_{i n} d t+\int_{d T}^{T}\left(V_{i n}-V_{C 1}\right) d t\right)=0 \\
& \frac{1}{T}\left(\int_{0}^{d T} V_{i n} d t+\int_{d T}^{T}\left(V_{i n}-V_{C 4}\right) d t\right)=0 \\
& \frac{1}{T}\left(\int_{0}^{d T}\left(V_{C 1}-V_{C 3}\right) d t-\int_{d T}^{T} V_{C 2} d t\right)=0
\end{aligned}
$$




$$
\frac{1}{T}\left(\int_{0}^{d T}\left(V_{C 1}-V_{C 3}\right) d t-\int_{d T}^{T} V_{C 3} d t\right)=0
$$

By solving equations (7)-(10), we can deduce the following relationships:

$$
\begin{aligned}
& V_{C 1}=V_{C 4}=V_{C 5}=\frac{V_{i n}}{(1-d)} \\
& V_{C 2}=V_{C 3}=\frac{d V_{i n}}{(1-d)} \\
& V_{o}=\frac{2+d}{1-d} V_{i n}
\end{aligned}
$$

Hence, the voltage gain $M$ can be calculated as following:

$$
M=\frac{2+d}{1-d}
$$

\subsubsection{Voltage Stresses on Semiconductor Devices}

The voltage stresses on the switch $\left(V_{Q}\right)$ and all the diodes $\left(V_{D 1}, V_{D 2}, V_{D 3}\right.$, and $\left.V_{D 4}\right)$ equal $V_{C l}$ and are depicted by (13):

$$
V_{Q}=V_{D 1}=V_{D 2}=V_{D 3}=V_{D 4}=V_{C 1}=\frac{V_{i n}}{(1-d)}
$$

By using (12) and (13), these voltage stresses can be presented in a normalized form as a function of $V_{O}$ and $M$ as shown in (14):

$$
V_{Q}=V_{D 1}=V_{D 2}=V_{D 3}=V_{D 4}=V_{C 1}=\frac{1+M}{3 M} V_{o}
$$

\subsubsection{Current Stresses on Semiconductor Devices}

Assuming a lossless operation where the input power equals the output power (i.e. $V_{i n} \times I_{L I}=V_{o}$ $\left.\times I_{o}\right)$, hence, $I_{L 1}$ and $I_{L 2}$ can be calculated as in (15) and (16):

$$
\begin{aligned}
& I_{L 2}=I_{o}=\frac{V_{o}}{R} \\
& I_{L 1}=M I_{L 2}=\frac{(2+d) V_{o}}{(1-d) R}=\left(\frac{2+d}{1-d}\right)^{2} \frac{V_{i n}}{R}
\end{aligned}
$$




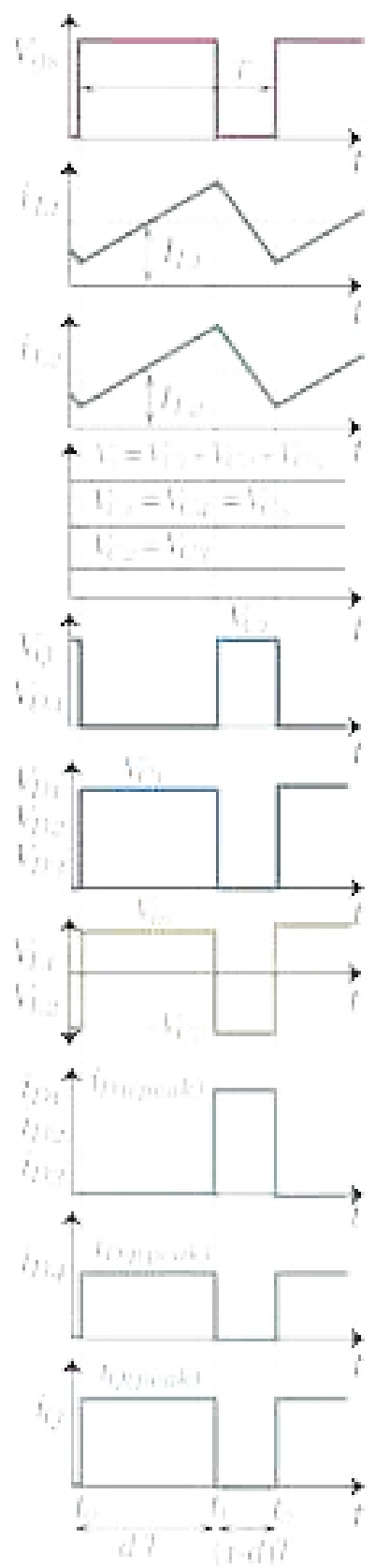

(a)

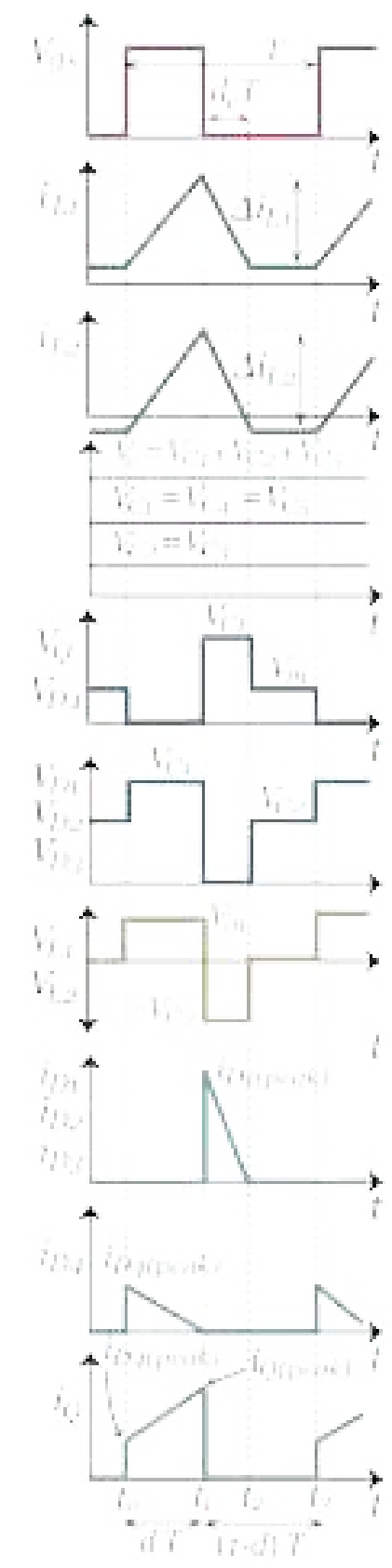

(b)

Figure 5.3: Key waveforms of the proposed converter. (a) CCM operation. (b) DCM operation.

By using the charge-second balance rule on $C_{1} \rightarrow C_{5}$ to extract their charging and discharging currents, as shown in (17)-(22): 


$$
\begin{aligned}
& i_{C 1 \_d i s} \times d T=i_{C 1 \_c h} \times(1-d) T \\
& i_{C Z_{-} d i s} \times d T=i_{C 2_{-} c h} \times(1-d) T \\
& i_{C 3_{-} c h} \times d T=i_{C 3_{-} d i s} \times(1-d) T \\
& i_{C 4_{-} d i s} \times d T=i_{C 4_{-} c h} \times(1-d) T \\
& i_{C 5_{-} c h} \times d T=i_{C 5_{-} d i s} \times(1-d) T \\
& \left\{\begin{array}{l}
i_{C 1 \_c h}=2 I_{o} \frac{d}{(1-d)} \\
i_{C 1 \_d i s}=2 I_{o}
\end{array}\right. \\
& \left\{\begin{array}{l}
i_{C 2_{-} c h}=I_{o} \frac{d}{(1-d)} \\
i_{C 2_{-} d i s}=I_{o}
\end{array}\right. \\
& \left\{\begin{array}{l}
i_{C 3_{-} \text {ch }}=I_{O} \\
i_{\text {C3_dis }}=I_{O} \frac{d}{(1-d)}
\end{array}\right. \\
& i_{C 4 \_c h}=\frac{I_{O}}{(1-d)} \\
& \left\lfloor i_{C 4 \_d i s}=\frac{I_{o}}{d}\right. \\
& \left\{\begin{array}{l}
i_{C 5_{-} c h}=I_{o} \frac{(1-d)}{d} \\
i_{C 5_{-} d i s}=I_{o}
\end{array}\right.
\end{aligned}
$$

By using equations (15)-(22) and the current flow paths shown in Figure 5.2, the current stress on the switch $i_{Q}$ and the current stresses on the four diodes $\left(i_{D 1} \rightarrow i_{D 4}\right)$ can be extracted as shown in (23)-(27):

$$
\begin{aligned}
& i_{Q}=I_{L 1}+I_{L 2}+i_{C 4 \_d i s}=\frac{1+2 d}{d(1-d)} I_{O} \\
& i_{D 1}=I_{L 1}-i_{C 4_{-} \_c}-i_{C C_{-} d i s}=\frac{I_{O}}{(1-d)} \\
& i_{D 2}=I_{L 2}+i_{C 3_{-} d i s}=\frac{I_{O}}{(1-d)} \\
& i_{D 3}=i_{C 4_{-} c h}=\frac{I_{o}}{(1-d)} \\
& i_{D 4}=i_{C 4 \_d i s}=\frac{I_{O}}{d}
\end{aligned}
$$

By means of (23)-(27), and the current flow paths shown in Figure 5.2, the root-mean-square (rms) values of the currents of the switch and diodes can be calculated as following: 


$$
\begin{aligned}
& i_{Q \_r m s}=\frac{1+2 d}{\sqrt{d}(1-d)} I_{o} \\
& i_{D 1 \_r m s}=i_{D 2 \_r m s}=i_{D 3 \_r m s}=\frac{I_{o}}{\sqrt{1-d}} \\
& i_{D 4 \_r m s}=\frac{I_{o}}{\sqrt{d}}
\end{aligned}
$$

Similarly, the rms values of the five capacitors' currents can be extracted using (18)-(22), as following:

$$
\begin{aligned}
& i_{C 1 \_r m s}=2 I_{o} \sqrt{\frac{d}{1-d}} \\
& i_{C 2 \_r m s}=i_{C 3 \_r m s}=I_{o} \sqrt{\frac{d}{1-d}} \\
& i_{C 4 \_r m s}=I_{o} \sqrt{\frac{1}{d(1-d)}} \\
& i_{C 5 \_r m s}=I_{o} \sqrt{\frac{1-d}{d}}
\end{aligned}
$$

\subsubsection{Efficiency Analysis}

In order to properly select the components and design an adequate cooling system, the power dissipated from the various components should be calculated. Equation (35) calculates the total power loss $P_{\text {Loss }}$ of the proposed converter, where $P_{L_{-} c o n d}, P_{L_{-} c o r e}, P_{C}, P_{D}, P_{Q_{-} s w}$, and $P_{Q_{c} c o n d}$ are the inductors' conduction losses, the inductors' core losses, the capacitors' conduction losses, the diodes' conduction losses, the switching losses of the switch, and the conduction loss of the switch, respectively.

$$
P_{\text {Loss }}=P_{L_{-} \text {cond }}+P_{L_{-} \text {core }}+P_{C}+P_{D}+P_{Q_{-} s w}+P_{Q_{-} \text {cond }}
$$

The core losses and conduction losses of $L_{1}$ and $L_{2}$ can be calculated using (36) and (37), respectively, where $R_{L 1}, R_{L 2}, f_{s}, l_{c 1}, l_{c 2}, A_{c 1}, A_{c 2}, \Delta B_{1}$, and $\Delta B_{2}$ are the equivalent series resistances 
of $L_{1}$ and $L_{2}$, the switching frequency, the magnetic flux path lengths of the two inductors' cores, the cross sectional areas of the two inductors' cores, and ac magnetic flux density of $L_{1}$ and $L_{2}$.

$$
\begin{aligned}
& P_{L_{\text {c core }}}=l_{c 1} A_{c 1}\left(a \Delta B_{1}^{b} f_{s}^{C}\right)+l_{c 2} A_{c 2}\left(a \Delta B_{2}^{b} f_{s}^{C}\right) \\
& P_{L_{-} \text {cond }}=I_{L 1}^{2} R_{L 1}+I_{L 2}^{2} R_{L 2}
\end{aligned}
$$

Equation (36) is the Steinmetz equation and it is an empirical formula to calculate the core loss of an inductor where $\mathrm{a}, \mathrm{b}$, and $\mathrm{c}$ are fitting parameters and can be found in the datasheet of the core.

The conduction losses of the five capacitors can be calculated using (38), where ESR $1 \rightarrow E S R 5$ are the equivalent series resistances of the five capacitors $C_{1} \rightarrow C_{5}$.

$$
\begin{gathered}
P_{C}=I_{C 1_{\_} r m s}^{2} E S R 1+I_{C 2 \_r m s}^{2} E S R 2+I_{C{ }_{-} r m s}^{2} E S R 3+I_{C 4_{-} r m s}^{2} E S R 4 \\
+I_{C 5 \_r m s}^{2} E S R 5
\end{gathered}
$$

The conduction and switching losses of the four diodes can be calculated by (39), where $V_{f 1} \rightarrow$ $V_{f 4}$ and $Q_{C 1} \rightarrow Q_{C 4}$ are the forward voltages and capacitive charges of the Schottky diodes $D_{1} \rightarrow$ $D_{4}$, respectively.

$$
\begin{array}{r}
P_{D}=\left[(1-d)\left(i_{D 1} V_{f 1}+i_{D 2} V_{f 2}+i_{D 3} V_{f 3}\right)+d i_{D 4} V_{f 4}\right] \\
+f_{S}\left(\frac{V_{i n}}{1-d}\right)\left[Q_{C 1}+Q_{C 2}+Q_{C 3}+Q_{C 4}\right]
\end{array}
$$

The conduction and the switching losses of $Q$ can be calculated using (40) and (41), respectively, where $R_{o n}, C_{o s s}, t_{r}$, and $t_{f}$, are the on resistance, the parasitic output capacitance, the rise and fall times of the switch.

$$
\begin{aligned}
& P_{Q_{-} \text {cond }}=I_{Q \_r m s}^{2} R_{\text {on }} \\
& P_{Q_{-} s w}=0.5 f_{s}\left(V_{Q} i_{Q}\left(t_{r}+t_{f}\right)+C_{O S S} V_{Q}^{2}\right)
\end{aligned}
$$

The efficiency $\eta$ can be calculated as following

$$
\eta=\frac{V_{o} I_{L 2}}{V_{o} I_{L 2}+P_{\text {Loss }}}
$$




\subsection{Steady-State Analysis of DCM}

When the proposed converter operates in DCM, it has three operating states, namely: operating state $I$, operating state $I I$, and operating state $I I I$. Figure 5.3(b) shows the important waveforms of the proposed converter during DCM operation, where the period of the operating state $I$ is $d T$, the period of the operating state $I I$ is $d_{e} T$, and the period of operating state $I I I$ is $\left(1-\left(d+d_{e}\right)\right) T$. The first two operating states are the same as in CCM, while the additional third operating state is only for DCM operation. The voltage gain of the proposed converter, the boundary operating condition between DCM and CCM, the voltage and current stresses on the semiconductor devices are deduced in this subsection.

\subsubsection{Voltage Gain}

During DCM, the ripple currents of the two inductors $\left(\Delta i_{L 1}\right.$ and $\left.\Delta i_{L 2}\right)$ can be calculated as following:

$$
\begin{aligned}
\Delta i_{L 1} & =\frac{d V_{i n}}{f_{s} L_{1}} \\
l^{\Delta i_{L 2}} & =\frac{d V_{i n}}{f_{s} L_{2}}
\end{aligned}
$$

Based on (15), (16), (24)-(26), and (43), the peak current of $D_{1}, D_{2}$, or $D_{3}$ can be calculated as following:

$$
\begin{gathered}
i_{D 1 \text { (peak })}=i_{D 2(\text { peak })}=i_{D 3(\text { peak })}=\frac{\Delta i_{L 1}+\Delta i_{L 2}}{3}=\frac{d V_{\text {in }}}{3 f_{S} L_{e q}} \\
L_{e q}=\left[\frac{1}{L_{1}}+\frac{1}{L_{2}}\right]^{-1}
\end{gathered}
$$

The fraction of the periodic switching time associated with operating state $I I\left(d_{e}\right)$ can be deduced by equating the average current of $D_{1}, D_{2}$, or $D_{3}$ to the output current, as following:

$$
\left\langle i_{D 1}\right\rangle=\frac{1}{T}\left(\frac{d_{e} T}{2} \frac{d V_{i n}}{3 f_{s} L_{e q}}\right)=\frac{V_{o}}{R}
$$

Hence, $d_{e}$ can be extracted as shown in (46): 


$$
d_{e}=\frac{6 f_{s} L_{e q} V_{o}}{d V_{\text {in }} R}=\frac{6 V_{o}}{d V_{\text {in }}} K
$$

Where $K$ is a dimensionless parameter and is defined by (47).

$$
K=\frac{f_{s} L_{e q}}{R}
$$

By means of equation (11), the five capacitors' voltages can be formulated as following:

$$
\left\{\begin{array}{l}
V_{C 1}=V_{C 4}=V_{C 5}=\frac{V_{i n}+V_{o}}{3} \\
V_{C 2}=V_{C 3}=\frac{V_{o}-2 V_{i n}}{3}
\end{array}\right.
$$

Based on Figure 5.3, the average inductor voltage can be calculated and equated to zero to calculate the voltage gain of the proposed converter during DCM $\left(M_{D C M}\right)$ operation, as following:

$$
\begin{aligned}
& \frac{1}{T}\left(\int_{0}^{d T} V_{i n} d t-\int_{0}^{d_{e} T} V_{C 2} d t\right)=0 \\
& V_{i n} d+\left(\frac{2 V_{i n}-V_{o}}{3}\right) d_{e}=0
\end{aligned}
$$

By solving (50), the voltage gain during DCM $\left(M_{D C M}\right)$ can be calculated as shown in (51):

$$
M_{D C M}=1+\sqrt{1+\left(\frac{d^{2}}{2 K}\right)}
$$

\subsubsection{Boundary Operating Condition}

During the boundary conduction mode (BCM) the voltage gain of the proposed converter during the CCM and DCM operations is the same, thus, the critical value of $K\left(K_{\text {critical }}\right)$ can be deduced by equating (12) and (51) as following:

$$
K_{\text {critical }}=\frac{d(1-d)^{2}}{6(d+2)}
$$

Figure 5.4 shows a plot of $K_{\text {critical }}$ versus $d$. When $K<K_{\text {critical }}$ the converter operates in DCM, otherwise, in CCM. 


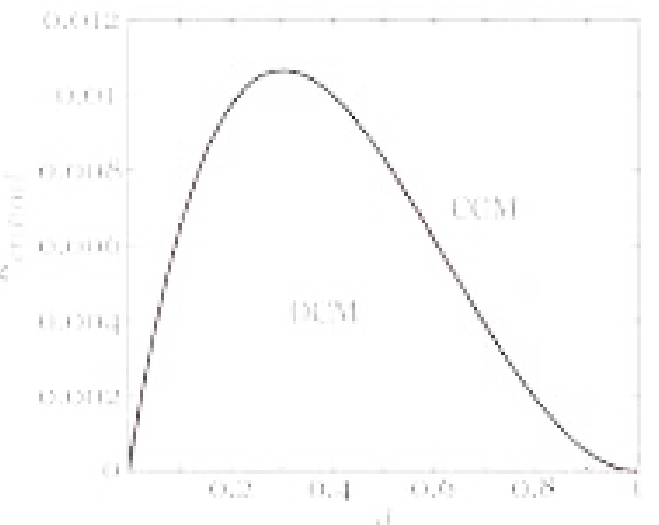

Figure 5.4: Boundary condition between DCM and CCM operations for the proposed converter.

\subsubsection{Voltage Stresses on the Semiconductor Devices}

During operating state $I$, the voltage stresses across $Q$ and $D_{4}$ equal zero, while the voltage stresses across $D_{1} \rightarrow D_{3}$ equal $V_{C l}$. During operating state $I I$, the voltage stresses across $Q$ and $D_{4}$ equal $V_{C l}$, while the voltage stresses across $D_{1} \rightarrow D_{3}$ equal zero. During operating state $I I I$, the voltage stresses across $Q$ and $D_{4}$ equal $V_{i n}$, while the voltage stresses across $D_{1} \rightarrow D_{3}$ equal $V_{C 2}$. Accordingly and by means of (48), the voltage stresses on the switch and diodes during the three operating states can be formulated as in (53):

$$
\begin{aligned}
& V_{Q}(I)=V_{D 4}(I)=V_{D 1}(I I)=V_{D 2}(I I)=V_{D 3}(I I)=0 \\
& V_{Q}(I I)=V_{D 4}(I I)=V_{D 1}(I)=V_{D 2}(I)=V_{D 3}(I)=V_{C 1}=V_{i n}\left(\frac{M_{D C M}+1}{3}\right) \\
& V_{Q}(I I I)=V_{D 4}(I I I)=V_{i n} \\
& \left(V_{D 1}(I I I)=V_{D 2}(I I I)=V_{D 3}(I I I)=V_{C 2}=V_{\text {in }}\left(\frac{M_{D C M}-2}{3}\right)\right.
\end{aligned}
$$

\subsubsection{Current Stresses on the Semiconductor Devices}

As shown in Figure 5.3(b), the currents of the four diodes have a triangular shape, the peak values for $i_{D 1}, i_{D 2}, i_{D 3}$, and $i_{D 4}$ are calculated by (44) and (54).

$$
i_{D 4(\text { peak })}=\frac{2 I_{o}}{d}=\frac{2 V_{o}}{d R}=\frac{2 M_{D C M} V_{\text {in }}}{d R}
$$


The current of $Q$ has a trapezoidal shape, the two heights of it are $i_{D 4(p e a k)}$ and $i_{Q(p e a k)}$ as shown in Figure 5.3(b), and the value of $i_{Q(p e a k)}$ can be calculated by (55).

$$
i_{Q(\text { peak })}=\Delta i_{L 1}+\Delta i_{L 2}=\frac{d V_{i n}}{f_{s} L_{e q}}
$$

The rms values of the diode currents and the switch currents can be obtained by (56).

$$
\begin{aligned}
& i_{D 1(r m s)}=i_{D 2(r m s)}=i_{D 3(r m s)}=\frac{d V_{i n}}{3 f_{S} L_{e q}} \sqrt{\frac{d_{e}}{3}} \\
& i_{D 4(r m s)}=\frac{2 M_{D C M} V_{i n}}{R \sqrt{3 d}} \\
& i_{Q(r m s)}=\sqrt{\frac{d}{3}\left(i_{Q(\text { peak })}^{2}+i_{D 4(\text { peak })}^{2}+i_{Q(\text { peak })} i_{D 4(\text { peak })}\right)}
\end{aligned}
$$

\subsection{Comparative Study with other Step-Up Solutions}

This subsection compares the proposed converter with twelve other step-up converters that do not utilize any magnetic coupling components. The converters are compared based on the voltage gain, the number of active and passive components, the normalized voltage stresses on the power switches and diodes, the amount of input current ripple, the potential difference between the grounds of the input and output terminals $\left(V_{\text {Grounds }}\right)$, and the voltage gain range. Table 5.2 summarizes the components and the features for each of the compared converters. The plots of the voltage gain versus the duty cycle for the compared converters are shown in Figure 5.5. The maximum normalized voltage stresses on the power switches and diodes versus the voltage gain are shown in Figure 5.6 and Figure 5.7, respectively.

Comparing the conventional three-level boost (TLB) converter with the proposed converter, on one hand, the proposed converter has one inductor, three capacitors, and two diodes more, and one power switch less compared to the conventional TLB converter. On the other hand, the proposed converter has higher voltage gain, lower voltage stresses on the semiconductor devices, and wider voltage gain range compared to the conventional TLB converter. 
conventional TLB converter is HF PWM voltage, which causes more EMI noise and increases the periodic maintenance costs, on the contrary with the proposed converter which has $V_{\text {Grounds }}$ equals a constant voltage. The voltage quadrupler boost converter in [184] has higher voltage gain and lower voltage stress on its switches compared to the proposed converter.

Table 5.2: COMPARISON BETWEEN THE PROPOSED AND OTHER STEP-UP DC-DC CONVERTERS

\begin{tabular}{|c|c|c|c|c|c|c|c|c|}
\hline Reference & $\begin{array}{l}\text { Voltage } \\
\text { gain }(M)\end{array}$ & $\begin{array}{l}\text { Active } \\
\text { components } \\
\text { counts }\end{array}$ & $\begin{array}{c}\text { Passive } \\
\text { components } \\
\text { counts }\end{array}$ & $\begin{array}{c}\text { Voltage stress on } \\
\text { transistors } \\
\left(V_{Q} / V_{o}\right)\end{array}$ & $\begin{array}{c}\text { Voltage stress on } \\
\text { diodes } \\
\left(V_{D} / V_{o}\right)\end{array}$ & $\begin{array}{l}\text { Continuous } \\
\text { input } \\
\text { current }\end{array}$ & $V_{\text {Grounds }}$ & $\begin{array}{c}\text { Voltage } \\
\text { gain range } \\
\qquad \begin{array}{c}(d=0 \\
\rightarrow 0.9)\end{array}\end{array}$ \\
\hline TLB & $\frac{1}{1-d}$ & $\begin{array}{l}2 \text { Switches } \\
2 \text { Diodes }\end{array}$ & $\begin{array}{l}1 \text { Inductor } \\
2 \text { Capacitors }\end{array}$ & $\frac{1}{2}$ & $\frac{1}{2}$ & Yes & $\begin{array}{c}\text { HF } \\
\text { PWM } \\
\text { voltage }\end{array}$ & $1 \rightarrow 10$ \\
\hline In [184] & $\frac{4}{1-d}$ & $\begin{array}{l}2 \text { Switches } \\
4 \text { Diodes }\end{array}$ & $\begin{array}{l}2 \text { Inductors } \\
4 \text { Capacitors }\end{array}$ & $\frac{1}{4}$ & $\frac{1}{2}, \frac{1}{4}$ & Yes & $\begin{array}{c}\text { HF } \\
\text { PWM } \\
\text { voltage }\end{array}$ & $\begin{array}{c}8 \rightarrow 40 \\
(\text { minimum } \\
d=0.5 \text { ) }\end{array}$ \\
\hline In [185] & $\frac{3+d}{2(1-d)}$ & $\begin{array}{l}1 \text { Switches } \\
4 \text { Diodes }\end{array}$ & $\begin{array}{l}2 \text { Inductors } \\
4 \text { Capacitors }\end{array}$ & $\frac{1}{2}+\frac{1}{4 M}$ & $\frac{1}{2}+\frac{1}{4 M}$ & Yes & $0 \mathrm{~V}$ & $1.5 \rightarrow 19.5$ \\
\hline In [180] & $\frac{1}{(1-d)^{2}}$ & $\begin{array}{l}1 \text { Switch } \\
3 \text { Diodes }\end{array}$ & $\begin{array}{l}2 \text { Inductors } \\
2 \text { Capacitors }\end{array}$ & 1 & $\begin{array}{l}1, \sqrt{1-\frac{M-1}{M}} \\
1-\sqrt{1-\frac{M-1}{M}}\end{array}$ & No & $0 \mathrm{~V}$ & $1 \rightarrow 100$ \\
\hline In [178] & $\frac{1}{d(1-d)}$ & $\begin{array}{l}2 \text { Switches } \\
3 \text { Diodes }\end{array}$ & $\begin{array}{l}2 \text { Inductors } \\
2 \text { Capacitors }\end{array}$ & $\frac{1}{2}+\sqrt{\frac{1}{4}-\frac{1}{M}}, 1$ & $\begin{array}{l}\frac{1}{2}+\sqrt{\frac{1}{4}-\frac{1}{M}} \\
\frac{3}{2}+\sqrt{\frac{1}{4}-\frac{1}{M}}\end{array}$ & Yes & $\begin{array}{c}\text { HF } \\
\text { PWM } \\
\text { voltage }\end{array}$ & $--\rightarrow 11$ \\
\hline In [181] & $\frac{2}{1-d}$ & $\begin{array}{l}2 \text { Switches } \\
2 \text { Diodes }\end{array}$ & $\begin{array}{l}2 \text { Inductors } \\
2 \text { Capacitors }\end{array}$ & $\frac{1}{2}$ & $\frac{1}{2}, 1$ & Yes & $\begin{array}{c}\mathrm{HF} \\
\mathrm{PWM}\end{array}$ & $2 \rightarrow 20$ \\
\hline In [186] & $\frac{2+d}{(1-d)^{2}}$ & $\begin{array}{l}2 \text { Switches } \\
5 \text { Diodes }\end{array}$ & $\begin{array}{l}3 \text { Inductors } \\
6 \text { Capacitors }\end{array}$ & $\begin{array}{c}\frac{\sqrt{1+12 M}-1}{1+6 M-\sqrt{1+12 M}} \\
\frac{2 M}{1+6 M-\sqrt{1+12 M}}\end{array}$ & $\begin{array}{c}\frac{\sqrt{1+12 M}-1}{1+6 M-\sqrt{1+12 M}} \\
\frac{2 M}{1+6 M-\sqrt{1+12 M}}\end{array}$ & No & $\begin{array}{c}\mathrm{HF} \\
\text { PWM }\end{array}$ & $2 \rightarrow 290$ \\
\hline In [183] & $\frac{3-d}{1-d}$ & $\begin{array}{l}1 \text { Switch } \\
4 \text { Diodes }\end{array}$ & $\begin{array}{c}1 \text { Inductor } \\
4 \text { Capacitors }\end{array}$ & $\frac{M-1}{2 M}$ & $\frac{M-1}{2 M}$ & No & $\begin{array}{l}\text { Constant } \\
\text { voltage }\end{array}$ & $3 \rightarrow 21$ \\
\hline In [187] & $\frac{2}{1-d}$ & $\begin{array}{l}1 \text { Switch } \\
3 \text { Diodes }\end{array}$ & $\begin{array}{l}2 \text { Inductors } \\
4 \text { Capacitors }\end{array}$ & $\frac{1}{2}$ & $\frac{1}{2}$ & Yes & $\begin{array}{l}\text { Constant } \\
\text { voltage }\end{array}$ & $2 \rightarrow 20$ \\
\hline In [179] & $\frac{1+d}{1-d}$ & $\begin{array}{l}1 \text { Switch } \\
3 \text { Diodes }\end{array}$ & $\begin{array}{c}2 \text { Inductors } \\
3 \text { Capacitors }\end{array}$ & $\frac{1+M}{2 M}$ & $\frac{1+M}{2 M}$ & No & $0 \mathrm{~V}$ & $1 \rightarrow 19$ \\
\hline In [110] & $\frac{1+3 d}{1-d}$ & $\begin{array}{l}2 \text { Switches } \\
2 \text { Diodes }\end{array}$ & $\begin{array}{l}3 \text { Inductors } \\
3 \text { Capacitors }\end{array}$ & $\frac{3+M}{4 M}$ & $\frac{3+M}{2 M}$ & Yes & $\begin{array}{c}\text { HF } \\
\text { PWM } \\
\text { voltage }\end{array}$ & $1 \rightarrow 37$ \\
\hline In [182] & $\frac{2}{1-d}$ & $\begin{array}{l}1 \text { Switch } \\
3 \text { Diodes }\end{array}$ & $\begin{array}{c}1 \text { Inductor } \\
3 \text { Capacitors }\end{array}$ & $\frac{1}{2}$ & $\frac{1}{2}$ & Yes & $0 \mathrm{~V}$ & $2 \rightarrow 20$ \\
\hline Proposed & $\frac{2+d}{1-d}$ & $\begin{array}{l}1 \text { Switch } \\
4 \text { Diodes }\end{array}$ & $\begin{array}{l}2 \text { Inductors } \\
5 \text { Capacitors }\end{array}$ & $\frac{1+M}{3 M}$ & $\frac{1+M}{3 M}$ & Yes & $\begin{array}{l}\text { Constant } \\
\text { voltage }\end{array}$ & $2 \rightarrow 29$ \\
\hline
\end{tabular}

It also has one capacitor less and one power switch more compared to the proposed converter.

This converter has two main drawbacks, first, its $V_{\text {Grounds }}$ is HF PWM voltage, on the contrary with 
the proposed converter where its $V_{\text {Grounds }}$ is a constant voltage, second, the maximum normalized voltage stress on its diodes is higher compared to that of the proposed converter. The recently proposed single-switch converter in [185] has one less capacitor and the same number of switches, diodes and inductors compared to the proposed converter. The voltage gain of the proposed

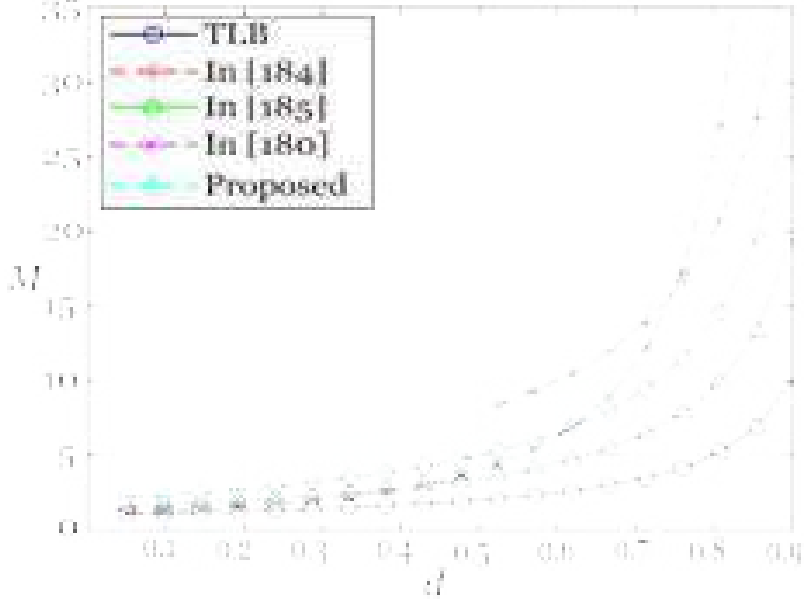

(a)

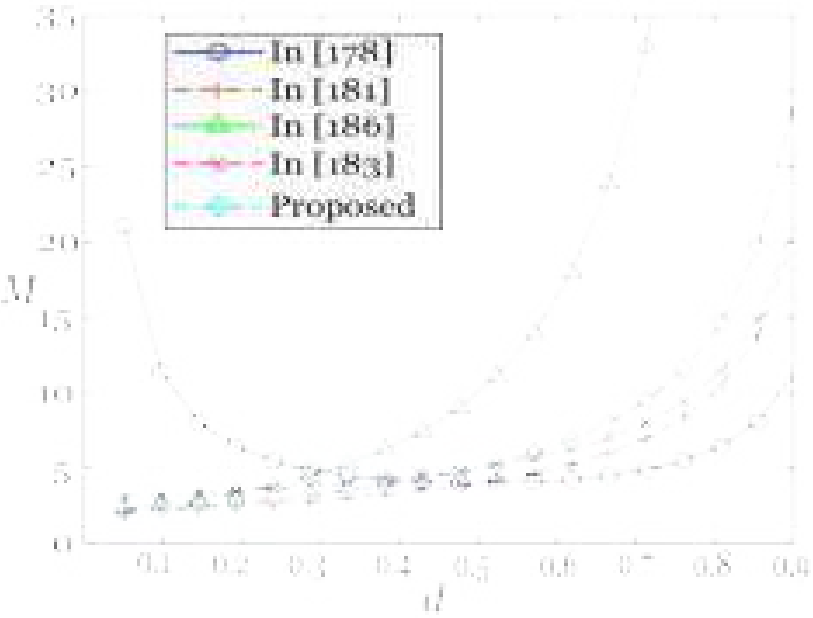

(b)

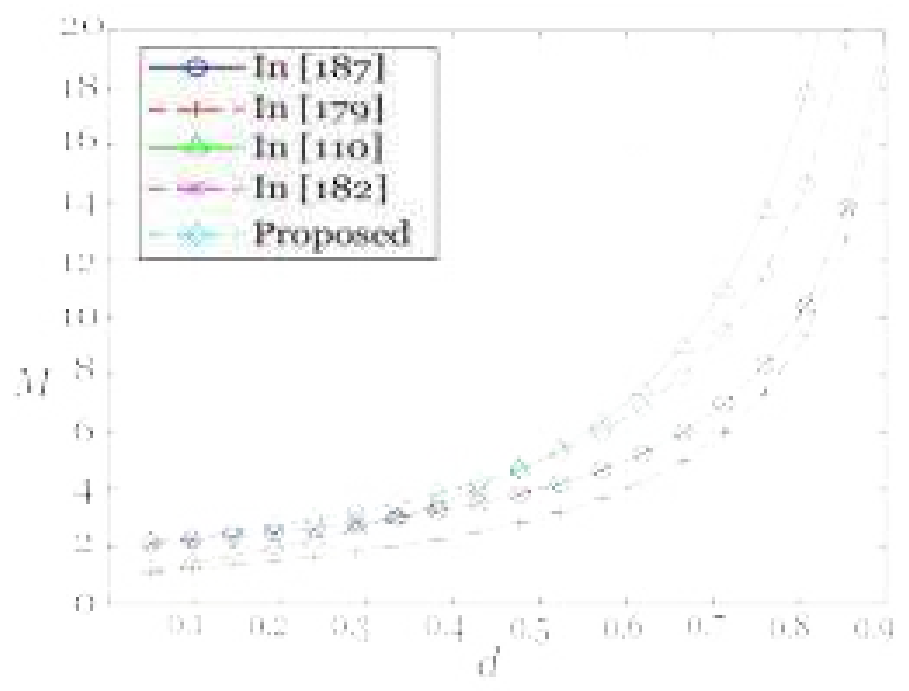

(c)

Figure 5.5: Comparison of voltage gain $M$ versus duty cycle d. (a) Between the proposed converter, the TLB converter, converters in [184], [185], and [180]. (b) Between the proposed converter, converters in [178], [181], [186], and [183]. (c) Between the proposed converter and the converters in [187], [179], [110], and [182] 
converter is higher and the voltage stresses on the switch and diodes of the proposed converter are lower compared to the converter in [185]. Comparing the proposed converter with the quadratic boost converter in [180], on one hand, the converter in [180] has one diode and three capacitors less than the proposed converter, on the other hand, this converter has lower voltage gain (for $d<0.6$ ) and higher voltage stresses on its switch and diodes compared to the proposed converter. Additionally, the input current ripple of the converter in [180] is high, which can reduce the lifetime of the fuel cell. The extendable step-up dc-dc converter in [178] has one diode and three capacitors less than the proposed converter, while the proposed converter has one power switch less. The proposed converter has higher voltage gain (for $d>0.4$ ) and lower voltage stresses on the power switches and diodes compared to the converter in [178]. Comparing the proposed converter with converter II in [181], on one hand, it has two diodes and three capacitors less than the proposed converter, while the proposed converter has one power switch less. The voltage gain of the proposed converter is higher and the voltage stress on its semiconductor devices is less than that in converter II in [181]. In addition, the $V_{\text {Grounds }}$ of the converter in [181] is HF PWM voltage which may add a lot of EMI noise. The converter in [186] has one power switch, one diode, one inductor, and one capacitor more than the proposed converter. The proposed converter has lower voltage gain compared to the converter in [186], nevertheless, the maximum normalized voltage stresses on the semiconductor devices of the 


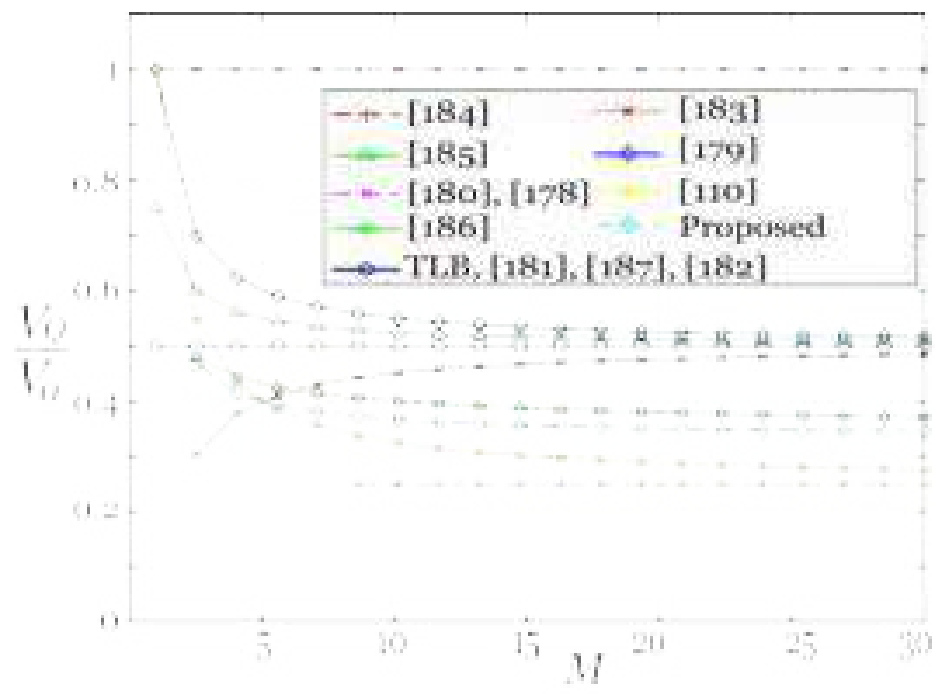

Figure 5.6: Maximum normalized voltage stress on the power switches in the compared converters.

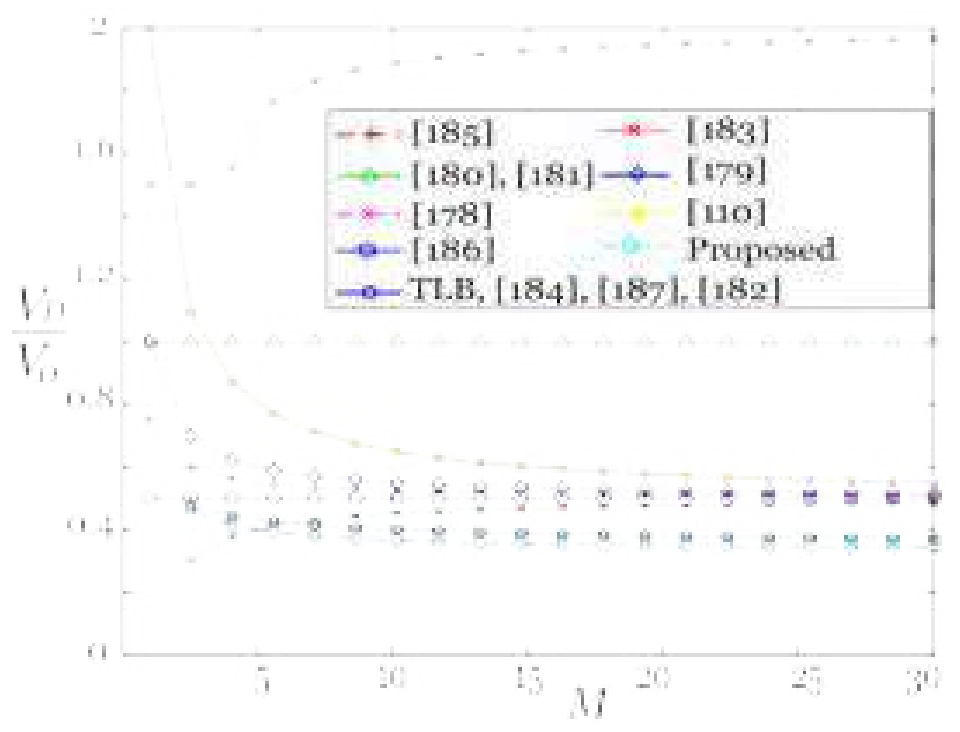

Figure 5.7: Maximum normalized voltage stress on the diodes in the compared converters. proposed converter are less. The converter in [186] also suffers from high input current ripple and its $V_{\text {Grounds }}$ is HF PWM voltage, which render this converter not suitable for fuel cell EV application. The hybrid converter presented in [183] has one less inductor, one less capacitor and the same number of semiconductor devices compared to the proposed converter. The converter in [183] has lower voltage gain (when $d>0.5$ ), and higher voltage stresses on the semiconductor devices (when $M>5$ ) compared to the proposed converter. Added to that, the converter in [183] 
has a high input current ripple. Comparing the proposed converter with the single-switch hybrid boost converter in [187], on one hand, this converter has one diode and one capacitor less compared to the proposed converter. On the other hand, the proposed converter has higher voltage gain, less voltage stresses on the semiconductor devices, and wider voltage gain compared to the converter in [187]. The voltage-lift based boost converter in [179] has one less diode and two less capacitors compared to the proposed converter. The proposed converter has a wider voltage gain, less voltage stresses on the power switch and diodes, and higher voltage gain compared to the converter in [179]. In addition, the input current ripple of the converter in [179] is high. The converter in [110] integrates active switchedinductor and passive switched-capacitor networks to enhance the voltage gain and reduce the voltage stress on the semiconductor devices. The converter in [110] has lower voltage gain (when $d<0.5$ ), higher voltage stress on its power switches (when $M<5$ ), and higher voltage stress on its diodes compared to the proposed converter. Regarding the number of components, the converter in [110] has two less diodes, two less capacitors, one more power switch and one more inductor compared to the proposed converter. The converter in [110] also suffers from additional EMI noise because its $V_{\text {Grounds }}$ is HF PWM voltage. The multilevel boost converter in [182], on one hand, has one less diode, one less inductor, and two less capacitors compared to the proposed converter. This converter has low input current ripple and a common ground between its input and out terminals. Nevertheless, the proposed converter has higher voltage gain, lower voltage stress on its semiconductor devices, and a wider voltage gain range compared to the converter in [182].

Based on the comparisons above, it is clear that the proposed converter combines many merits such as: low number of power switches, high step-up voltage conversion ratio, wide voltage gain range, low input current ripple, and low voltage stresses on its semiconductor devices. All these 
features make the proposed converter a good choice as a power electronic interface between the fuel cell and the high voltage dc-link bus of the EV.

\subsection{Design of Components}

\subsubsection{Selection of Semiconductor Devices}

Equation (14) calculates the voltage stress on the power switch and diodes, hence, by knowing the maximum values of $V_{o}$ and $M$, the maximum voltage stress on the semiconductor devices can be calculated. Similarly, equations (23)-(27) calculate the current stresses on the power switch and diodes in CCM operation, while (44), (54) and (55) calculate the current stresses on the semiconductor devices in DCM operation. Accordingly, by knowing the maximum voltage stress and current stress on each semiconductor device, the ratings of the power switch and diodes can be determined such that the maximum voltage and current stresses should be within the safe operating area (SOA) of the selected diodes and power switch.

\subsubsection{Design of Inductors}

By means of (15) and (16), the inductor currents can be calculated, hence, the saturation currents of $L_{1}$ and $L_{2}$ should be higher than the maximum currents flowing through $L_{1}$ and $L_{2}$, respectively. When the maximum ripple currents $\Delta i_{L 1}$, and $\Delta i_{L 2}$ are known, the minimum values of inductances can be obtained by (57).

$$
\begin{gathered}
L_{1} \geq \frac{d V_{\text {in }}}{f_{s} \Delta i_{L 1}} \\
L_{2} \geq \frac{d V_{i n}}{f_{S} \Delta i_{L 2}}
\end{gathered}
$$




\subsubsection{Design of Capacitors}

Equation (11) calculates the voltages across the five capacitors, accordingly the selected capacitors should be able to withstand these voltage levels.

When the maximum ripple voltages $\Delta V_{C 1}, \Delta V_{C 2}, \Delta V_{C 3}, \Delta V_{C 4}$ and $\Delta V_{C 5}$ are known, the minimum values of capacitances can be obtained by (58).

$$
\begin{aligned}
C_{1} & \geq \frac{2 I_{o} d}{f_{s} \Delta V_{C 1}} \\
C_{2} & \geq \frac{I_{o} d}{f_{s} \Delta V_{C 2}} \\
C_{3} & \geq \frac{I_{o} d}{f_{s} \Delta V_{C 3}} \\
C_{4} & \geq \frac{I_{o}}{f_{s} \Delta V_{C 4}} \\
\left(C_{5}\right. & \geq \frac{I_{o}(1-d)}{f_{s} \Delta V_{C 5}}
\end{aligned}
$$

\subsection{Dynamic Modeling and Voltage Loop Controller Design}

\subsubsection{Small-Signal Modeling}

In this analysis, the equivalent series resistances of the inductors and capacitors are omitted, the power switch and diodes are assumed to be ideal. Fig. 3(b) shows that there is mutual coupling between the capacitors $\left(C_{1} \rightarrow C_{5}\right.$ ) of the proposed converter, accordingly, to remove this coupling, small resistances $\left(r_{C 2}=0.1 \Omega\right.$ and $\left.r_{C 4}=0.1 \Omega\right)$ are considered in series with $C_{2}$ and $C_{4}$, respectively. In this subsection, the state-space average and small-signal models of the proposed converter are derived for the converter when it operates in CCM, thus, the converter has only two operating states $(I$ and $I I)$. By applying the averaging method on the inductors' voltages and 
capacitors' currents during operating states $I$ and $I I$, calculated by (1)-(4), the state-space average model of the proposed converter can be obtained as shown in (59).

In order to derive the small-signal model of the proposed converter, all the state variables, output variable, input variable, and control variable should be replaced by their dc quiescent values and ac perturbation signals, as in (60).

$$
\begin{array}{ll}
v_{i n}(t)=V_{\text {in }}+\hat{v}_{i n} & \left|\hat{v}_{i n}\right| \ll\left|V_{\text {in }}\right| \\
v_{C 1}(t)=V_{C 1}+\hat{v}_{C 1} & \left|\hat{v}_{C 1}\right| \ll\left|V_{C 1}\right| \\
v_{C 2}(t)=V_{C 2}+\hat{v}_{C 2} & \left|\hat{v}_{C 2}\right| \ll\left|V_{C 2}\right| \\
v_{C 3}(t)=V_{C 3}+\hat{v}_{C 3} & \left|\hat{v}_{C 3}\right| \ll\left|V_{C 3}\right| \\
v_{C 4}(t)=V_{C 4}+\hat{v}_{C 4} & \left|\hat{v}_{C 4}\right| \ll\left|V_{C 4}\right| \\
v_{C 5}(t)=V_{C 5}+\hat{v}_{C 5} & \left|\hat{v}_{C 5}\right| \ll\left|V_{C 5}\right| \\
i_{L 1}(t)=I_{L 1}+\hat{\imath}_{L 1} & \left|\hat{\imath}_{L 1}\right| \ll\left|I_{L 1}\right| \\
i_{L 2}(t)=I_{L 2}+\hat{\imath}_{L 2} & \left|\hat{\imath}_{L 2}\right| \ll\left|I_{L 2}\right| \\
v_{o}(t)=V_{o}+\hat{V}_{o} & \left|\hat{v}_{o}\right| \ll\left|V_{o}\right| \\
l_{d}(t)=d+\hat{d} & |\hat{d}| \ll|d|
\end{array}
$$

Where $V_{i n}, V_{C 1}, V_{C 2}, V_{C 3}, V_{C 4}, V_{C 5}, V_{o}, I_{L 1}, I_{L 2}$, d are the dc quiescent values of the input variable, state variables, output variable, and the control variable, and $\hat{v}_{i n}, \hat{v}_{C 1}, \hat{v}_{C 2}, \hat{v}_{C 3}, \hat{v}_{C 4}, \hat{v}_{C 5}, \hat{\imath}_{L 1}$, $\hat{\imath}_{L 2}, \hat{v}_{o}$, and $\hat{d}$ are the corresponding small ac perturbation signals. The small-signal model of the proposed converter is given in (61). 


$$
\begin{aligned}
& \begin{array}{llllllll}
d i_{L 1}(t) & 0 & 0 & \frac{d(t)-1}{d t} & 0 & 0 & 0 & 0
\end{array} \\
& \begin{array}{cccccccc}
d t & 0 & 0 & \frac{d(t)}{L_{2}} & 0 & \frac{-1}{L_{2}} & 0 & 0 \\
\frac{d i_{L 2}(t)}{d t} & 0 & 1 & -1
\end{array} \\
& \frac{d v_{C 1}(t)}{d t} \quad \frac{1-d(t)}{C_{1}} \frac{-d(t)}{C_{1}} \frac{-1}{R C_{1}}+\frac{d(t)-1}{C_{1} r_{C 4}} \quad \frac{-1}{R C_{1}} \quad 0 \quad \frac{1-d(t)}{C_{1} r_{C 4}} \quad \frac{-1}{R C_{1}}
\end{aligned}
$$

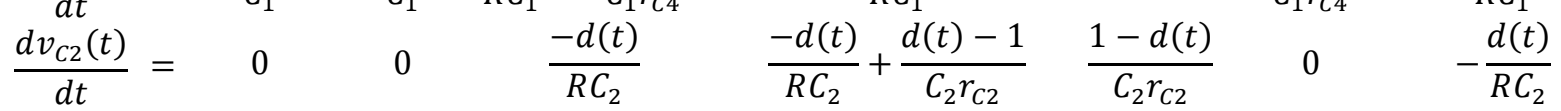

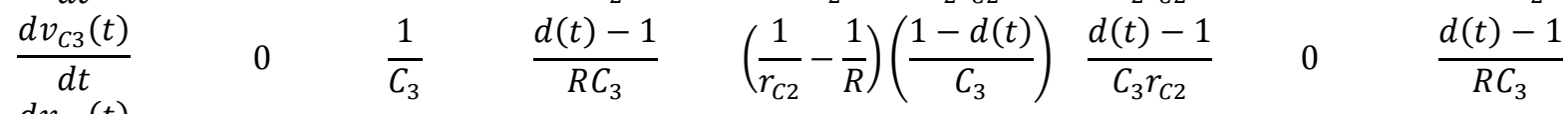

$$
\begin{aligned}
& \begin{array}{lllllll}
\frac{d v_{C 4}(t)}{d t} & 0 & 0 & \frac{1-d(t)}{C_{4} r_{C 4}} & 0 & 0 & \frac{-1}{C_{4} r_{C 4}}
\end{array} \\
& \left\lfloor\frac{d v_{C 5}(t)}{d t}\right\rfloor\left\lfloor\begin{array}{lllllll}
C_{4} r_{C 4} & -1 & -1 & C_{4} r_{C 4} & \frac{d(t)}{R C_{5}} & -d(t) & 1 \\
C_{5} r_{C 4} & 0 & \frac{-1}{R C_{5}} & \left.\frac{C_{C 4} C_{5}}{R C_{5}}\right\rfloor
\end{array}\right. \\
& i_{L 1}(t) \\
& i_{L 2}(t) \\
& \begin{array}{l}
v_{C 1}(t) \\
v_{C 2}(t) \\
v_{C 3}(t)
\end{array}+\left[\begin{array}{lllllll}
\frac{1}{L_{1}} & 0 & 0 & 0 & 0 & 0 & 0
\end{array}\right]^{T} v_{i n}(t) \\
& \left\lfloor\begin{array}{c}
v_{C 4}(t) \\
v_{C 5}(t)
\end{array}\right\rfloor
\end{aligned}
$$

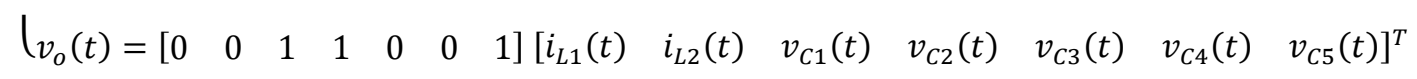

$$
\begin{aligned}
& v_{i n}(t)=V_{i n}+\hat{v}_{i n} \quad\left|\hat{v}_{i n}\right| \ll\left|V_{i n}\right| \\
& v_{C 1}(t)=V_{C 1}+\hat{v}_{C 1} \quad\left|\hat{v}_{C 1}\right| \ll\left|V_{C 1}\right| \\
& v_{C 2}(t)=V_{C 2}+\hat{v}_{C 2} \quad\left|\hat{v}_{C 2}\right| \ll\left|V_{C 2}\right| \\
& v_{C 3}(t)=V_{C 3}+\hat{v}_{C 3} \quad\left|\hat{v}_{C 3}\right| \ll\left|V_{C 3}\right| \\
& v_{C 4}(t)=V_{C 4}+\hat{v}_{C 4} \quad\left|\hat{v}_{C 4}\right| \ll\left|V_{C 4}\right| \\
& v_{C 5}(t)=V_{C 5}+\hat{v}_{C 5} \quad \text { with } \quad\left|\hat{v}_{C 5}\right| \ll\left|V_{C 5}\right| \\
& i_{L 1}(t)=I_{L 1}+\hat{\imath}_{L 1} \quad\left|\hat{\imath}_{L 1}\right| \ll\left|I_{L 1}\right| \\
& i_{L 2}(t)=I_{L 2}+\hat{\imath}_{L 2} \quad\left|\hat{\imath}_{L 2}\right| \ll\left|I_{L 2}\right| \\
& v_{o}(t)=V_{o}+\hat{V}_{o} \quad\left|\hat{v}_{o}\right| \ll\left|V_{o}\right| \\
& l_{d}(t)=d+\hat{d} \quad|| \hat{d}|\ll| d \mid
\end{aligned}
$$




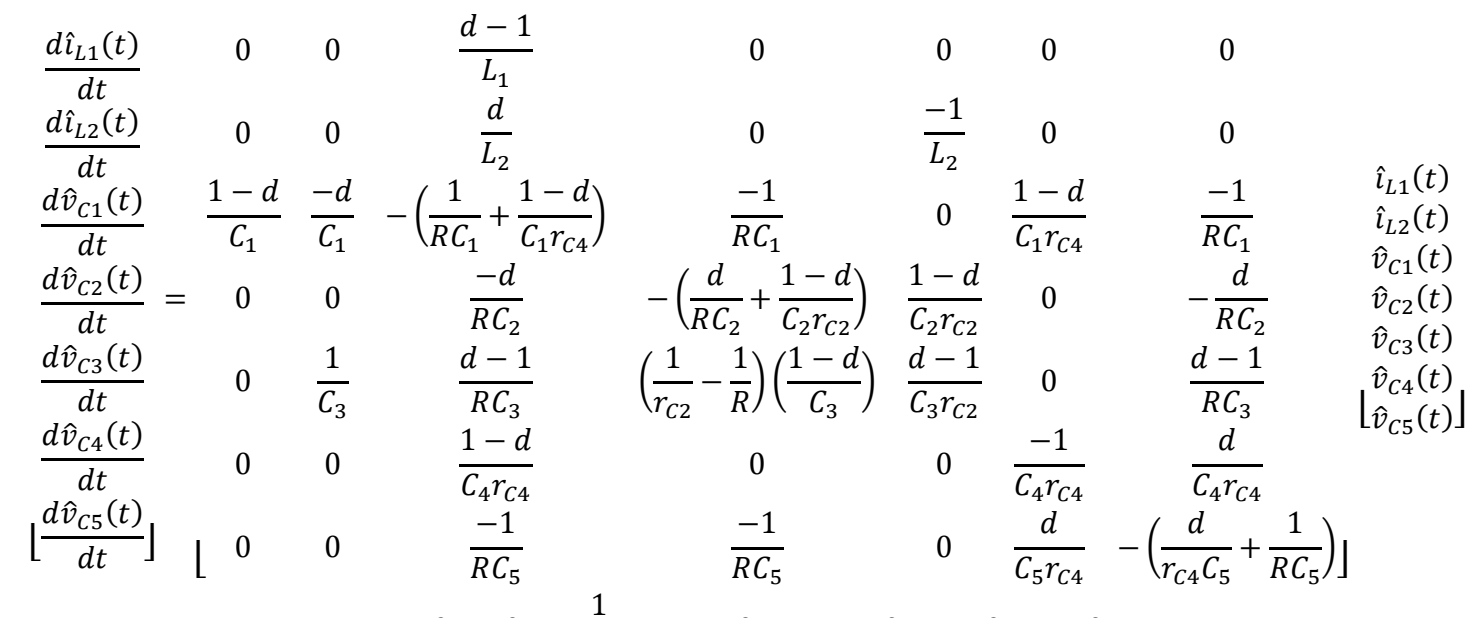

$$
\begin{aligned}
& \begin{array}{lllllll}
0 & 0 & \frac{1}{L_{1}} & 0 & 0 & 0 & 0
\end{array}
\end{aligned}
$$

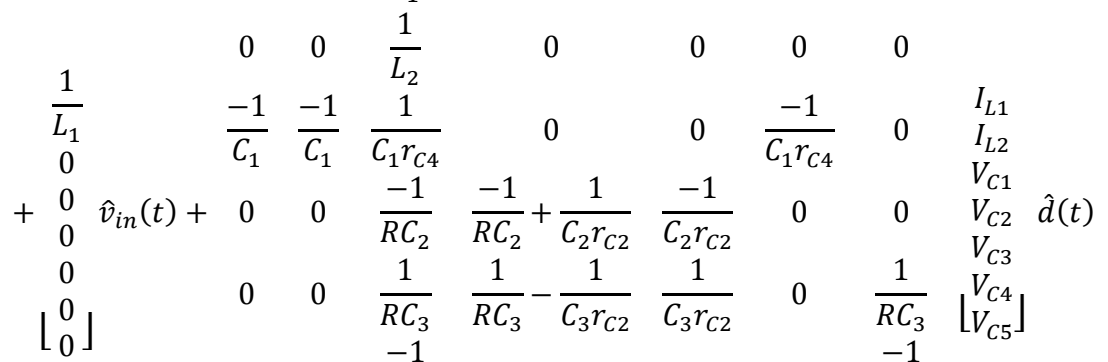

$$
\begin{aligned}
& \begin{array}{lllllll}
0 & 0 & \frac{-1}{C_{4} r_{C 4}} & 0 & 0 & 0 & \frac{-1}{C_{4} r_{C 4}}
\end{array} \\
& {\left[\begin{array}{lllllll}
0 & 0 & 0 & 0 & 0 & \frac{1}{C_{4} r_{C 4}} & \frac{-1}{C_{4} r_{C 4}}
\end{array}\right\rfloor}
\end{aligned}
$$

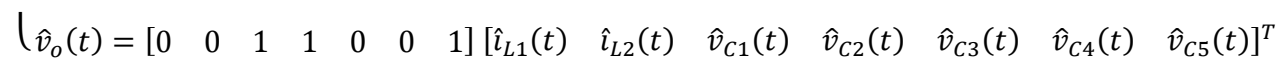

$$
\begin{gathered}
G_{v_{o} d}(S) \\
\left(\hat{v}_{i n}=0\right)
\end{gathered}=\frac{\hat{v}_{o}}{\hat{d}}=\frac{S^{6}+a_{5} S^{5}+a_{4} S^{4}+a_{3} S^{3}+a_{2} S^{2}+a_{1} S+a_{0}}{b_{7} S^{7}+b_{6} S^{6}+b_{5} S^{5}+b_{4} S^{4}+b_{3} S^{3}+b_{2} S^{2}+b_{1} S+b_{0}}
$$

Where $a_{6}=-5.299 \mathrm{e} 22, a_{5}=-1.276 \mathrm{e} 32, a_{4}=-6.333 \mathrm{e} 37, a_{3}=-7.675 \mathrm{e} 42, a_{2}=-1.157 \mathrm{e} 45, a_{1}=-9.863 \mathrm{e} 49, a_{0}=-2.191 \mathrm{e} 50$, $b_{7}=8.503 \mathrm{e} 17, b_{6}=1.094 \mathrm{e} 24, b_{5}=3.775 \mathrm{e} 29, b_{4}=3.839 \mathrm{e} 34, b_{3}=8.207 \mathrm{e} 36, b_{2}=5.137 \mathrm{e} 41, b_{1}=1.192 \mathrm{e} 43, b_{0}=2.192 \mathrm{e} 47$.

$$
G_{C}=\left(K_{P}+\frac{K_{I}}{S}\right) \times G_{v_{o} d}(S) \quad=\frac{e_{7} S^{7}+e_{6} S^{6}+e_{5} S^{5}+e_{4} S^{4}+e_{3} S^{3}+e_{2} S^{2}+e_{1} S+e_{0}}{f_{8} S^{8}+f_{7} S^{7}+f_{6} S^{6}+f_{5} S^{5}+f_{4} S^{4}+f_{3} S^{3}+f_{2} S^{2}+f_{1} S}
$$

Where $e_{7}=-1.59 \mathrm{e} 19, e_{6}=-3.828 \mathrm{e} 28, e_{5}=-1.9 \mathrm{e} 34, e_{4}=-2.303 \mathrm{e} 39, e_{3}=-3.495 \mathrm{e} 41, e_{2}=-2.959 \mathrm{e} 46, e_{1}=-9.829 \mathrm{e} 46$, $e_{0}=-7.232 \mathrm{e} 46, f_{8}=8.5 \mathrm{e} 17, f_{7}=1.094 \mathrm{e} 24, f_{6}=3.775 \mathrm{e} 29, f_{5}=3.839 \mathrm{e} 34, f_{4}=8.207 \mathrm{e} 36, f_{3}=5.137 \mathrm{e} 41, f_{2}=1.192 \mathrm{e} 43, f_{1}$ $=2.192 \mathrm{e} 47$. 
By means of Laplace transform on (61), and the parameters of the experimental setup in Table III, the control-to-output transfer function $G_{v_{o} d}(\mathrm{~S})$ can be obtained in the frequency domain from the time domain as in (62).

\subsection{Closed-Loop Voltage Controller}

In the developed experiment, a proportional integral (PI) controller is utilized to regulate the output voltage of the proposed converter. The structure of the closed-loop voltage controller is shown in Figure.5.8 and the parameters of the adopted PI controller are $K_{P}=0$. .0003 and $K_{I}=$ 0.00033. The compensated transfer function of the proposed converter is given in (63). The Bode plots of the compensated transfer function of the proposed converter are shown in Figure 5.9. These bode plots show that the proposed converter with the adopted PI voltage controller has positive gain and phase margins, which indicates a stable operation.

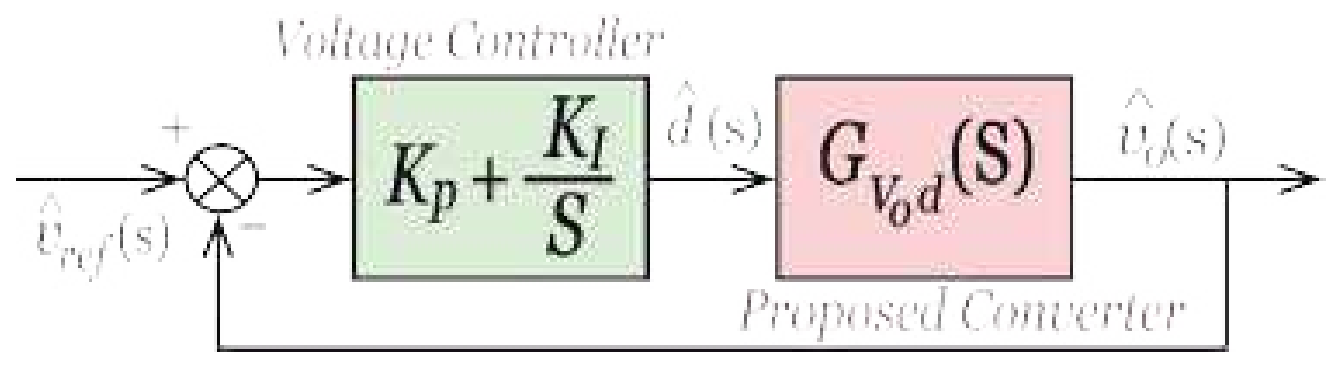

Figure 5.8: Closed-loop PI voltage controller of the proposed converter. 


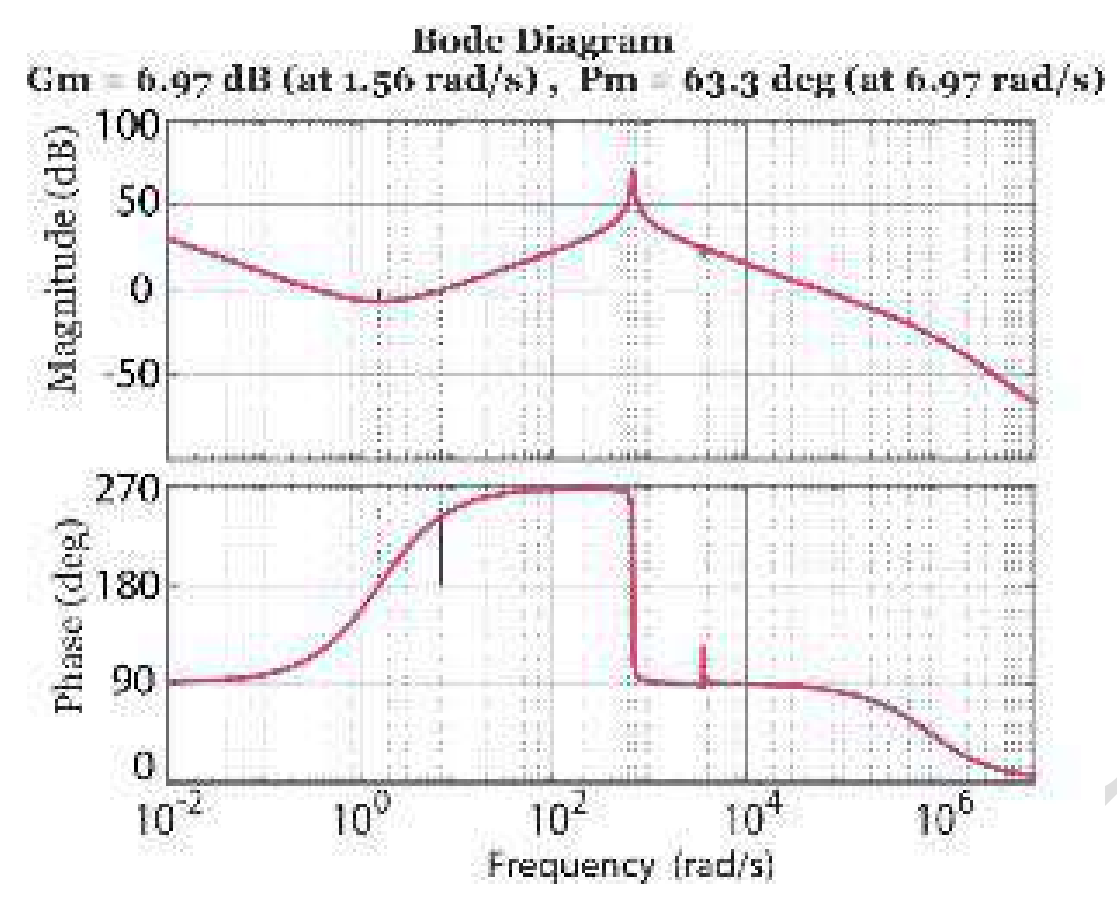

Figure 5.9: Bode plot of the compensated transfer function of the proposed converter.

\subsection{Experimental Results and Analysis}

To verify the theoretical analyses of the proposed converter, a scaled-down experimental prototype was built, as shown in Figure 5.10. The developed prototype has a rated output power of $1.3 \mathrm{~kW}$, and its power circuit is built with (GS66516T) GaN HEMT and (IDH20G65C6) SiC diodes. The currents and voltages are measured via sense resistors, and the converter operation is controlled by a (TMS320f28377s) microcontroller. The values of the used inductors and capacitors used in the developed prototype are enlisted in Table 5.3. The voltage profile of "CH40020F-S" fuel cell from "Zahn Electronics INC." is depicted by a programmable power supply. 


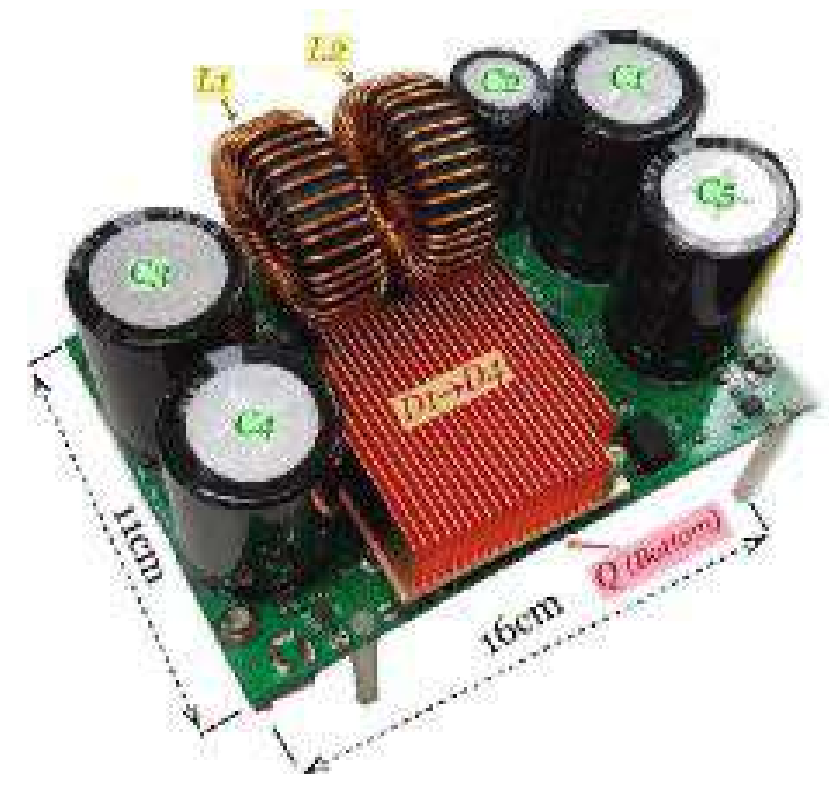

Figure 5.10: Experimental setup.

Table 5.3: EXPERIMENT PARAMETERS

\begin{tabular}{lc}
\hline \hline Parameters and Components & Values \\
\hline Rated power $P_{o}$ & $1.3 \mathrm{~kW}$ \\
Output voltage $V_{o}$ & $800 \mathrm{~V}$ \\
Power switch $Q$ & GS66516T \\
Power Diodes $D_{l}, D_{2}, D_{3}, D_{4}$ & IDH20G65C6 \\
Inductors $L_{1}, L_{2}$ & $250 \mu \mathrm{H}$ \\
Capacitors $C_{1}, C_{2}, C_{3}, C_{4}, C_{5}$ & $220 \mu \mathrm{F}$ \\
Switching frequency $f_{s}$ & $100 \mathrm{KHz}$ \\
Load $R$ (Case study I) & $650 \Omega$ \\
Load $R$ (Case study II) & $2000 \Omega$ \\
Microcontroller & TMS320f $28377 \mathrm{~s}$ \\
\hline \hline
\end{tabular}

Two case studies are investigated in this section, namely: 1) Case study I: aims to verify the theoretical analysis of the proposed converter when it operates in CCM. 2) Case study II: aims to validate the important relationships in the theoretical analysis of the proposed converter when it operates in DCM.

The values of inductors and capacitors are enlisted in Table 5.3. In case study I, the input voltage $V_{\text {in }}$ is $90 \mathrm{~V}$, the load resistor $R$ is $650 \Omega$, and $d=0.7$. In case study II, $V_{\text {in }}$ is $150 \mathrm{~V}$, the load resistor $R$ is $2000 \Omega$, and $d=0.4$. 
Case study I investigates the operation of the proposed converter during CCM. The values of inductors, capacitors, load resistance, input voltage, and duty cycle are as following: $L_{1}=L_{2}=250$ $\mu \mathrm{H}, C_{1} \rightarrow C_{5}=220 \mu \mathrm{F}, R=650 \Omega$, and $d=0.7$. The experimental results for this case study are shown in Figure 5.11. The dimensionless parameter $K$ is defined by (47), thus, it can be calculated for case study I as following:

$$
K=\frac{f_{s} L_{e q}}{R}=\frac{10^{5} \times 125 \times 10^{-6}}{650}=0.019
$$

The critical value of $K$ can be calculated by (52), as shown in (65):

$$
K_{\text {critical }}=\frac{d(1-d)^{2}}{6(d+2)}=\frac{0.7 \times(0.3)^{2}}{6 \times(2.7)}=3.89 \times 10^{-3}
$$

Since $K$ is greater than $K_{\text {critical }}$, the converter operates in CCM during case study I. The voltage on the five capacitors and the output voltage can be calculated using (11) as following:

$$
\begin{gathered}
V_{C 1}=V_{C 4}=V_{C 5}=\frac{V_{\text {in }}}{(1-d)}=\frac{90}{0.3}=300 \mathrm{~V} \\
V_{C 2}=V_{C 3}=\frac{d V_{\text {in }}}{(1-d)}=\frac{0.7 \times 90}{0.3}=210 \mathrm{~V} \\
V_{o}=\frac{2+d}{1-d} V_{\text {in }}=\frac{2.7}{0.3} \times 90=810 \mathrm{~V}
\end{gathered}
$$

Which closely agree with the experimental results in Figure 5.11(b), (c), and (d). Also, the inductor currents and the load current can be calculated by (15) and (16), additionally, the ripple currents can be calculated using (57).

$$
\begin{aligned}
& \left\{\begin{array}{l}
I_{L 2}=I_{O}=\frac{V_{O}}{R}=\frac{(2+d) V_{\text {in }}}{R(1-d)}=\frac{2.7 \times 90}{650 \times 0.3} \approx 1.25 \mathrm{~A} \\
I_{L 1}=M I_{L 2}=\frac{(2+d) V_{O}}{(1-d) R}=\left(\frac{2+d}{1-d}\right)^{2} \frac{V_{\text {in }}}{R}=\left(\frac{2.7}{0.3}\right)^{2} \frac{90}{650}=11.2 \mathrm{~A}
\end{array}\right. \\
& \Delta i_{L 1}=\frac{d V_{\text {in }}}{f_{S} L_{1}}=\frac{0.7 \times 90}{10^{5} \times 250 \times 10^{-6}}=2.5 \mathrm{~A} \\
& \Delta i_{L 2}=\frac{d V_{\text {in }}}{f_{S} L_{2}}=\frac{0.7 \times 90}{10^{5} \times 250 \times 10^{-6}}=2.5 \mathrm{~A}
\end{aligned}
$$


Which closely agree with the experimental results in Figure 5.11(a). The voltage stresses on the power switch and diodes can be obtained by (13), as following:

$$
V_{Q}=V_{D 1}=V_{D 2}=V_{D 3}=V_{D 4}=\frac{V_{\text {in }}}{(1-d)}=\frac{90}{0.3}=300 \mathrm{~V}
$$

These voltage stresses calculated by (69) are close to the experimental results in Figure 5.11(e) and (f). The current stresses on the power switch and diodes can be calculated using (23)-(27).

$$
\begin{aligned}
& i_{Q}=\frac{1+2 d}{d(1-d)} I_{O}=\frac{(1+1.4)}{0.7 \times 0.3} \times 1.26=14.4 \mathrm{~A} \\
& i_{D 1}=i_{D 2}=i_{D 3}=\frac{I_{o}}{(1-d)}=\frac{1.26}{0.3}=4.2 \mathrm{~A} \\
& i_{D 4}=\frac{I_{o}}{d}=\frac{1.26}{0.7}=1.8 \mathrm{~A}
\end{aligned}
$$

The current stresses calculated in (70) are verified by the experimental results in Figure 5.11(h) and $(\mathrm{g})$.

In order to evaluate the dynamic performance of the proposed converter and the adopted PI voltage controller, the input voltage is changed gradually from $320 \mathrm{~V}$ to $80 \mathrm{~V}$ while keeping the reference output voltage fixed at $800 \mathrm{~V}$. Figure 5.11(i) shows the output voltage and the current of $L_{1}$ when the input voltage gradually goes down from $320 \mathrm{~V}$ to $80 \mathrm{~V}$, and it is clear that the proposed converter with the adopted PI controller is capable of holding the output voltage fixed during the wide fluctuation in the input voltage. Based on equation (12), $I_{L 1}$ can be calculated when $V_{i n}=320 \mathrm{~V}$ and when $V_{i n}=80 \mathrm{~V}$, as $I_{L 1} \approx 3 \mathrm{~A}$ and $I_{L 1} \approx 12.3 \mathrm{~A}$, respectively, which closely agree with the measured current of $L_{l}$ shown in Figure 5.11(i).

Figure 5.13 shows the calculated power loss distributions for the experiment in case study I. The capacitors' conduction losses are dominant with $20.14 \mathrm{~W}$ which account for $31 \%$ of the total power loss in this case study. The reason for the high capacitors' losses is the utilization of electrolytic capacitors in the experimental prototype, if film capacitors were used, the capacitors' conduction losses would have been lower. The switching loss of the power switch comes next with 
$15.8 \mathrm{~W}$ which accounts for $25 \%$ of the total power loss. The losses of the diodes equal $13.5 \mathrm{~W}$ which account for $21 \%$ of the total power loss. The conduction losses of the two inductors equal $8.6 \mathrm{~W}$ and account for $13 \%$ of the total power loss, and the conduction loss of the power switch equal $6 \mathrm{~W}$ which accounts for $9 \%$ of the total power loss. The low switching and conduction losses of the power switch is due to the utilization of a GaN HEMT as a power switch, which has lower on resistance, lower total charge, and lower output capacitance compared to its silicon (Si) and $\mathrm{SiC}$ power counterparts.

The plots between the measured efficiency and the input voltage of the proposed converter are shown in Figure 5.14 (a), as they were measured using a power analyzer (Tektronix PA3000). Two measured efficiency curves are given in Figure 5.14 to depict the efficiency of the proposed converter when the output power equals $1 \mathrm{~kW}$ and $1.3 \mathrm{~kW}$, the output voltage is fixed at $800 \mathrm{~V}$, and the input voltage varies from $90 \mathrm{~V}$ up to $300 \mathrm{~V}$. When $P_{o}$ equals $1.3 \mathrm{~kW}$, the minimum efficiency is $94.6 \%$ when the input voltage is $90 \mathrm{~V}$, and the maximum efficiency is $97.3 \%$ when the input voltage is $220 \mathrm{~V}$. When $P_{o}$ is $1 \mathrm{~kW}$, the minimum efficiency is $95.5 \%$ when the input voltage is $90 \mathrm{~V}$, and the maximum efficiency is $97.6 \%$ when the input voltage is 220 V. For the efficiency curves in Figure 5.14(a), the efficiency is low when input voltage is low and this is because of the high conduction losses in the input inductor, capacitors, diodes, and switch (since the converter is operating at relatively high values of duty cycle), and the efficiency keeps improving as the input voltage increases. After a certain input voltage value, the efficiency starts dropping due to the increased switching loss of the power switch. The calculated efficiency curves of the proposed converter when the output power equals $1 \mathrm{~kW}$ and $1.3 \mathrm{~kW}$, the output voltage is fixed at $800 \mathrm{~V}$, and the input voltage varies from $90 \mathrm{~V}$ up to $300 \mathrm{~V}$ are presented in Figure 5.14(a). The small deviations between the measured and calculated efficiency curves is due to the 
assumptions used in loss calculation. The measured efficiency curves when the output voltage is fixed at $800 \mathrm{~V}$ and the output power is changed from $500 \mathrm{~W}$ to $1.3 \mathrm{~kW}$ when the input voltage is $100 \mathrm{~V}$ and $200 \mathrm{~V}$ are shown in Figure 5.14(b). Based on Figure 5.14(b), the maximum efficiency is $97.8 \%$ when the input voltage is $200 \mathrm{~V}$ and the output power is $500 \mathrm{~W}$, while the maximum efficiency is $97 \%$ when the input voltage is $100 \mathrm{~V}$ and the output power is $500 \mathrm{~W}$.

Case study II investigates the operation of the proposed converter in DCM. The load is represented by a $2000 \Omega$ resistance, and the input voltage is set at $150 \mathrm{~V}$. In this case study, the closed-loop voltage controller is deactivated, and the converter operates with duty cycle of 0.4. The dimensionless parameter $K$ is defined by (47), hence, it can be calculated for case study II as following:

$$
K=\frac{f_{s} L_{e q}}{R}=\frac{10^{5} \times 125 \times 10^{-6}}{2000}=6.25 \times 10^{-3}
$$

The critical value of $K$ can be calculated by (52), as shown in (72):

$$
K_{\text {critical }}=\frac{d(1-d)^{2}}{6(d+2)}=\frac{0.4 \times(0.6)^{2}}{6 \times(2.4)}=0.01
$$

Since $K_{\text {critical }}$ is greater than $K$, the converter operates in DCM during case study II.

The current ripples of the two inductors can be obtained by means of (43), as following:

$$
\begin{aligned}
\Delta i_{L 1} & =\frac{d V_{\text {in }}}{f_{S} L_{1}}=\frac{0.4 \times 150}{10^{5} \times 250 \times 10^{-6}}=2.4 \mathrm{~A} \\
\Delta i_{L 2} & =\frac{d V_{\text {in }}}{f_{S} L_{2}}=\frac{0.4 \times 150}{10^{5} \times 250 \times 10^{-6}}=2.4 \mathrm{~A}
\end{aligned}
$$




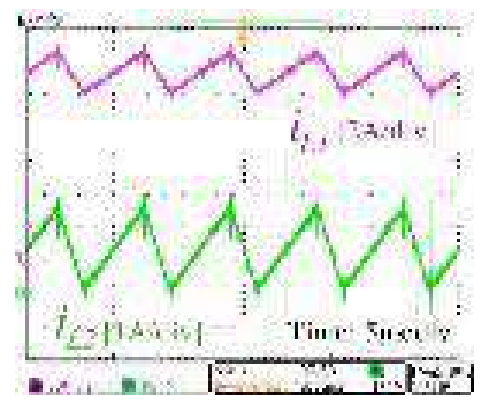

(a)

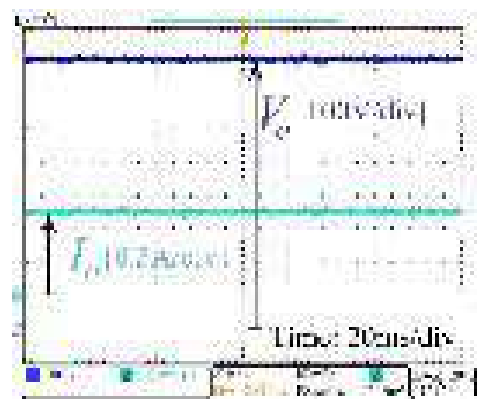

(d)

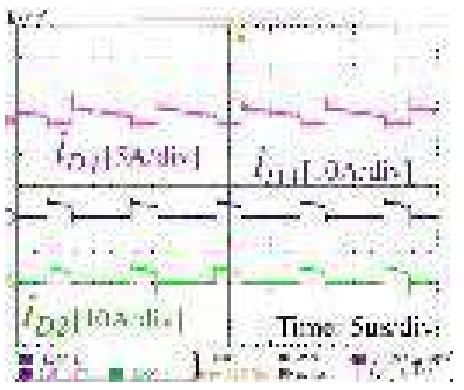

(g)

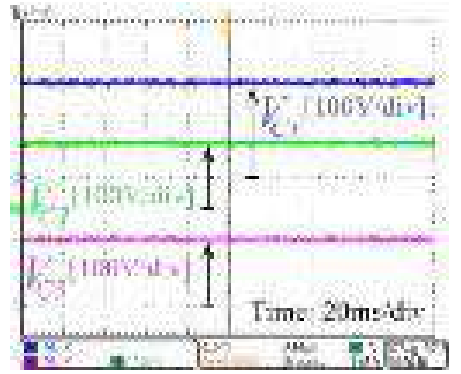

(b)

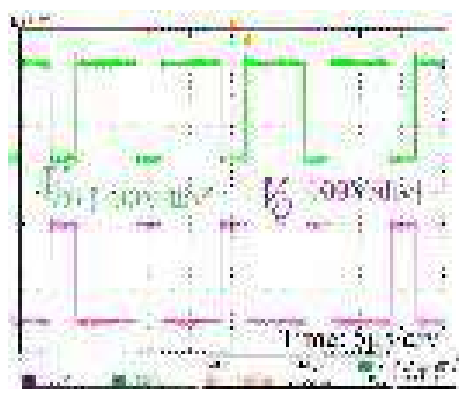

(e)

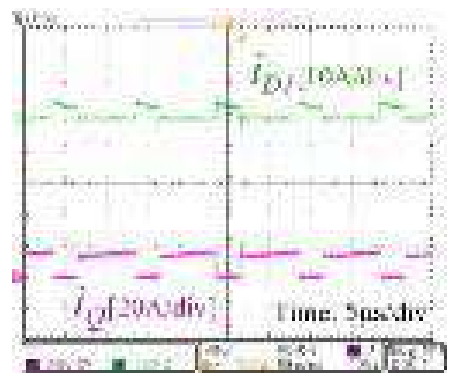

(h)

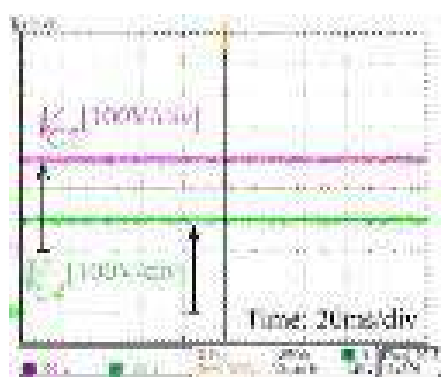

(c)

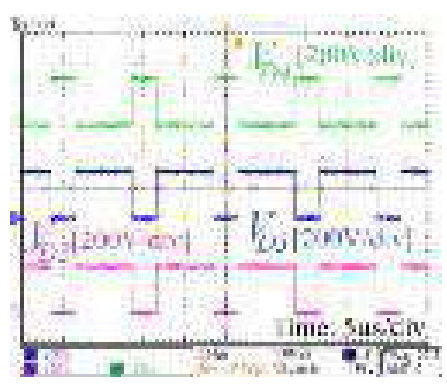

(f)

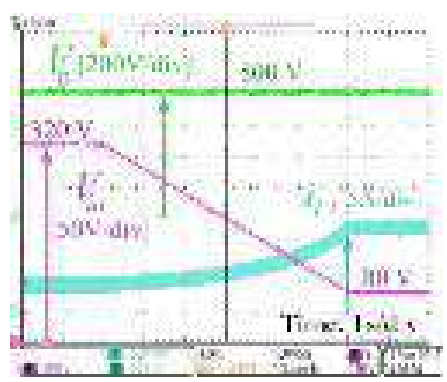

(i)

Figure 5.11: Experimental results of case study I

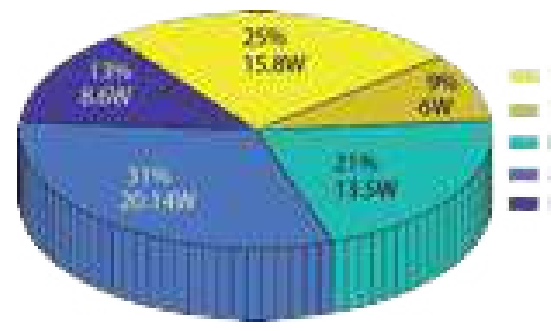

Figure 5.12: Breakdown of losses in Case I 


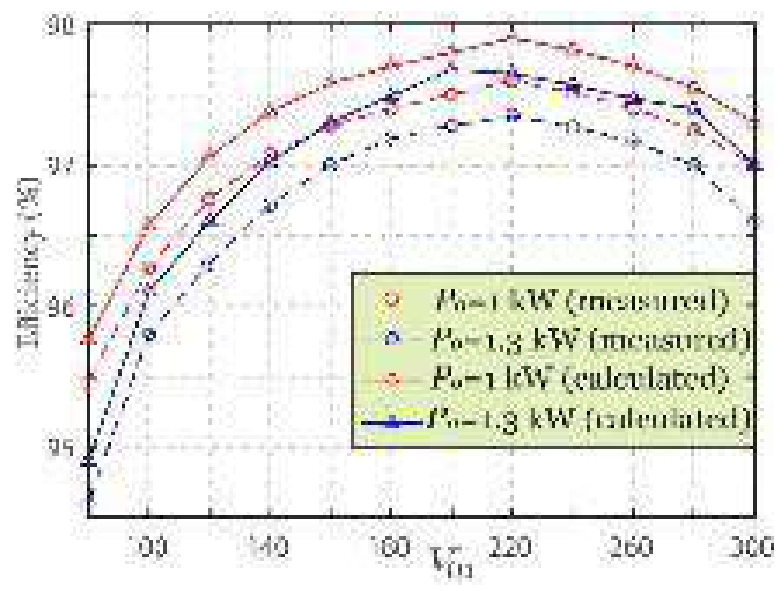

(a)

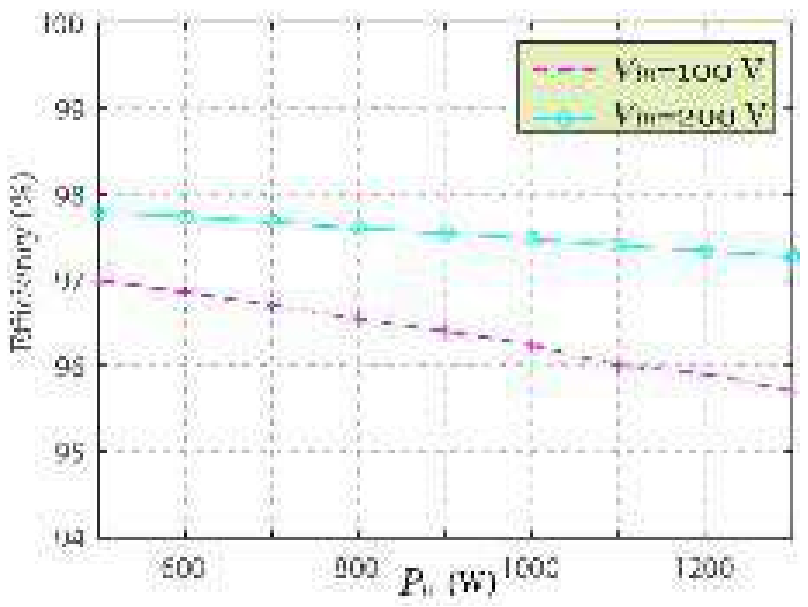

(b)

Figure 5.13: Measured efficiency curves.

Which closely agree with the experimental results in Figure 5.15(a). The voltages on the five capacitors and the output voltage can be calculated using (48) and (51).

$$
\begin{aligned}
V_{o}=M_{D C M} \times V_{\text {in }} & =\left(1+\sqrt{1+\left(\frac{d^{2}}{2 K}\right)}\right) \times V_{\text {in }}=\left(1+\sqrt{1+\left(\frac{0.4^{2}}{2 \times 6.25 \times 10^{-3}}\right)}\right) \times 150 \\
& \approx 707 \mathrm{~V} \\
& \left\{\begin{array}{l}
V_{C 1}=V_{C 4}=V_{C 5}=\frac{V_{i n}+V_{o}}{3}=\frac{150+707}{3}=285.7 \mathrm{~V} \\
V_{C 2}=V_{C 3}=\frac{V_{o}-2 V_{i n}}{3}=\frac{707-2 \times 150}{3}=135.7 \mathrm{~V}
\end{array}\right.
\end{aligned}
$$




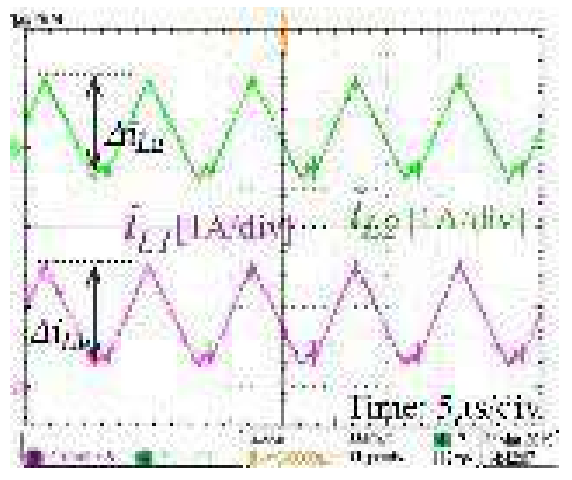

(a)

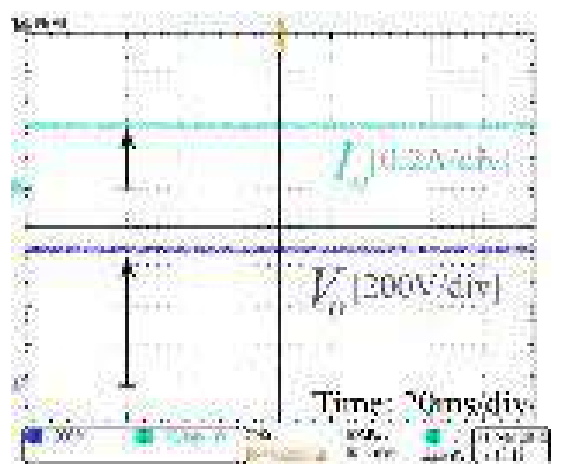

(d)

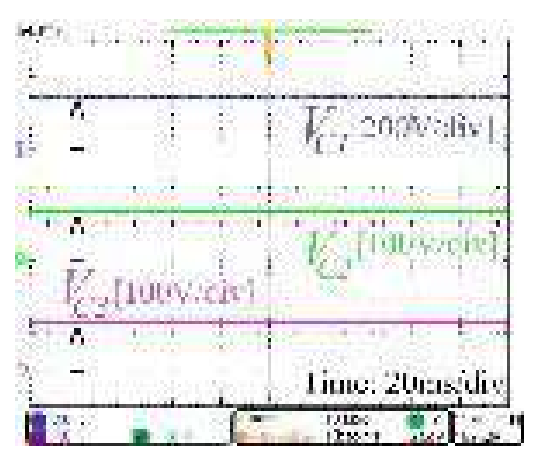

(b)

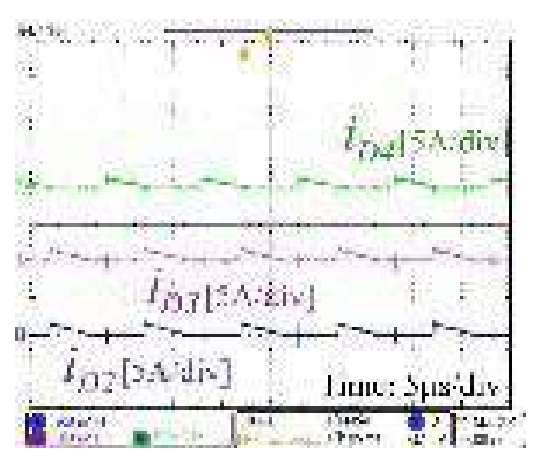

(e)

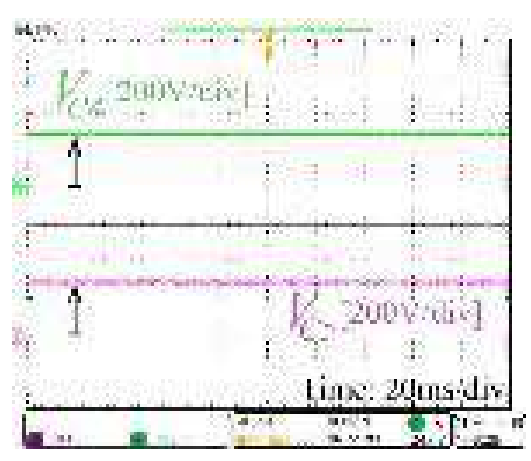

(c)

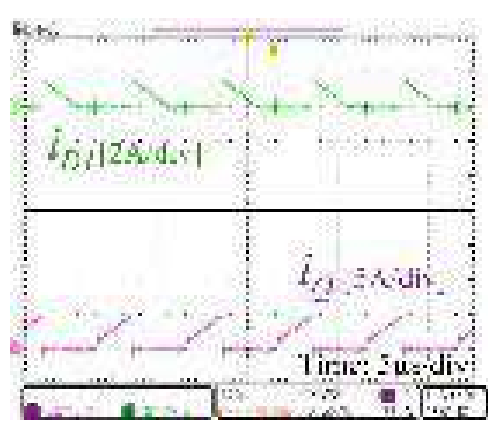

(f)

Figure 5.14: Experimental results for case study II.

The experimental results in Figure 5.15(b) and (c) closely agree with the calculated values in (74) and (75). The peak switch and diodes currents can be obtained by means of (44), (54), and (55), as shown in (76).

The experimental results in Figure 5.15(e) and (f) are close to the values calculated by (76). The spikes in the switch and diode currents are mainly caused by the capacitive charges of the $\mathrm{SiC}$ Schottky diodes. 


$$
\begin{aligned}
i_{D 1 \text { (peak })} & =i_{D 2(\text { peak })}=i_{D 3(\text { peak })}=\frac{d V_{\text {in }}}{3 f_{S} L_{e q}}=\frac{0.4 \times 150}{3 \times 10^{5} \times 125 \times 10^{-6}}=1.6 \mathrm{~A} \\
i_{d 4(\text { peak })} & =\frac{2 V_{o}}{d R}=\frac{2 \times 707}{0.4 \times 2000} \approx 1.8 \mathrm{~A} \\
i_{Q(\text { peak })} & =\frac{d V_{\text {in }}}{f_{S} L_{e q}}=\frac{0.4 \times 150}{10^{5} \times 125 \times 10^{-6}}=4.8 \mathrm{~A}
\end{aligned}
$$

\section{$5.10 \quad$ Conclusion}

A new single-switch step-up dc-dc converter that utilizes a switched-capacitor multiplier and an integrated $L C^{2} D$ output network was proposed for fuel cell vehicles in this chapter. The proposed converter has a wide voltage gain range to suit the wide voltage swings of the fuel cell. The voltage stress on the semiconductor devices of the proposed converter is less than half of the output voltage, which enables the utilization of a power switch with lower rated voltage. In addition, the input current ripple is low and the potential difference between the grounds of its input and output terminals is a constant voltage, which prolongs the lifetime of the fuel cell and reduces the radiated EMI. A $1.3 \mathrm{~kW} 800 \mathrm{~V}$ prototype was built using a $\mathrm{GaN}$ transistor and $\mathrm{SiC}$ diodes, and the experimental measurements verified the theoretical analysis. 


\section{Chapter 6 A New SEPIC-Based Step-Up DC-DC Converter with Wide Conversion Ratio for Fuel Cell Vehicles: Analysis and Design}

\subsection{Introduction}

In this chapter, a new SEPIC-based step-up dc-dc converter which integrates discontinuous-current quasi-Z-source (qZS) and switched-capacitor networks is proposed. The proposed converter has a low input current ripple, wide voltage gain range, low voltage stress on the semiconductor devices, and a constant potential difference between the grounds of its input and output ports. These features make the proposed converter an excellent interface between the fuel cell and the dc-link bus inside the electric vehicle. The analysis of the proposed converter for steady-state operations in continuous conduction mode (CCM) and discontinuous conduction mode (DCM) are given. Finally, a 3-kW/800-V scaled-down prototype was built using a Gallium Nitride $(\mathrm{GaN})$ power switch and Silicon Carbide (SiC) diodes to validate the feasibility of the proposed converter and its theoretical analysis.

\subsection{Structure and Operating Principles of the Proposed Converter}

\subsubsection{Configuration of the Proposed Converter}

The proposed step-up dc-dc converter topology is shown in Figure 6.1, and it is composed of one power switch $(Q)$, five diodes $\left(D_{1} \rightarrow D_{5}\right)$, seven capacitors $\left(C_{l} \rightarrow C_{7}\right)$, and three inductors $\left(L_{1}\right.$ $\left.\rightarrow L_{3}\right)$. The fuel cell is represented by a voltage source $\left(V_{i n}\right)$, and the load is represented by a resistance $(R)$. The proposed converter is based on the conventional SEPIC converter, as $Q$ is the main switch, $L_{l}$ is the input inductor, $D_{1}$ is the output diode, and $C_{6}$ is the energy transfer capacitor of the conventional SEPIC. The second inductor of the conventional SEPIC is replaced by a discontinuous-current qZS network $\left(L_{2}, L_{3}, D_{2}, C_{2}, C_{7}\right)$. In addition, a switched-capacitor network $\left(D_{3} \rightarrow D_{5}, C_{3} \rightarrow C_{5}\right)$ is utilized. The capacitors of the qZS and the switched-capacitor networks 
are stacked in-series with the output capacitor of the conventional SEPIC to enhance the voltage gain of the proposed converter, and reduce the voltage stresses on the semiconductor devices and capacitors.

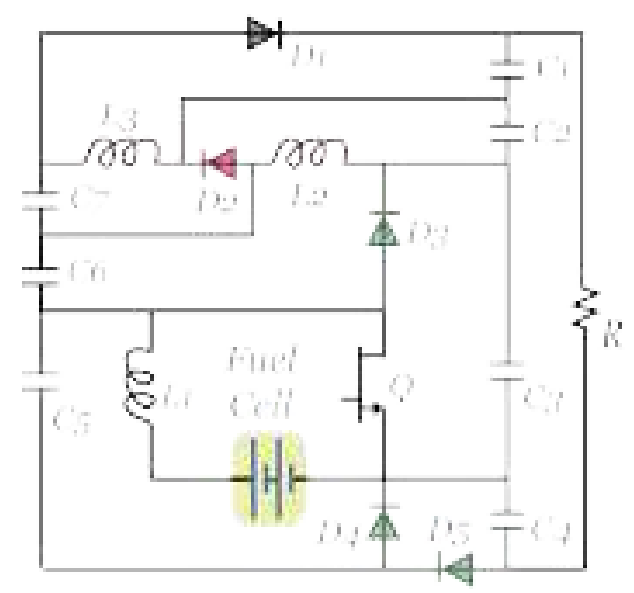

Figure 6.1: The schematic of the proposed converter.

\subsubsection{Switching States Analysis}

The proposed converter has two switching states, namely: State 0, and State 1. In State 1, $Q$ is on, $D_{1} \rightarrow D_{4}$ are off, and $D_{5}$ is on. In this switching state, $C_{1}, C_{2}, C_{3}$, and $C_{5}$ discharge, while $C_{4}$, $C_{6}$, and $C_{7}$ charge. Figure 6.3(a) shows the current flow paths during switching state 1 . By means of Kirchhof's Voltage Law (KVL), and the equivalent circuit shown in Figure 6.3(a), we can deduce the following relationships:

$$
\left\{\begin{array}{l}
V_{L 1}=V_{i n} \\
V_{L 2}=V_{C 3}-V_{C 6} \\
V_{L 3}=V_{C 2}+V_{C 3}-V_{C 6}-V_{C 7} \\
V_{C 4}=V_{C 5}
\end{array}\right.
$$

In State $0, Q$ is off, $D_{1} \rightarrow D_{4}$ are on, and $D_{5}$ is off. In this switching state, $C_{1}, C_{2}, C_{3}$, and $C_{5}$ charge, while $C_{4}, C_{6}$, and $C_{7}$ discharge. Figure 6.3(b) shows the current flow paths during switching 
state 0. By applying the KVL rule on the equivalent circuit shown in Figure 6.3(b), we get the following relationships:

$$
\left\{\begin{array}{l}
V_{L 1}=V_{i n}-V_{C 3}=V_{i n}-V_{C 5} \\
V_{L 2}=-V_{C 2}=-V_{C 6} \\
V_{L 3}=-V_{C 1}=-V_{C 7}
\end{array}\right.
$$

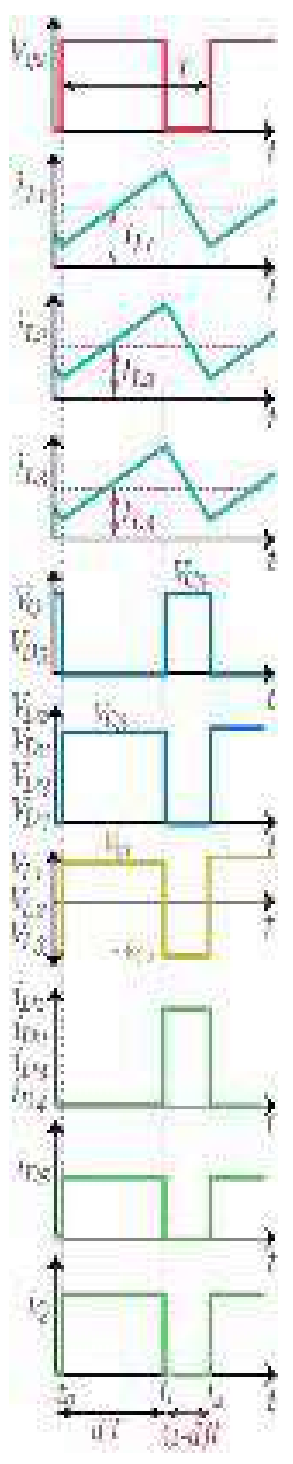

(a)

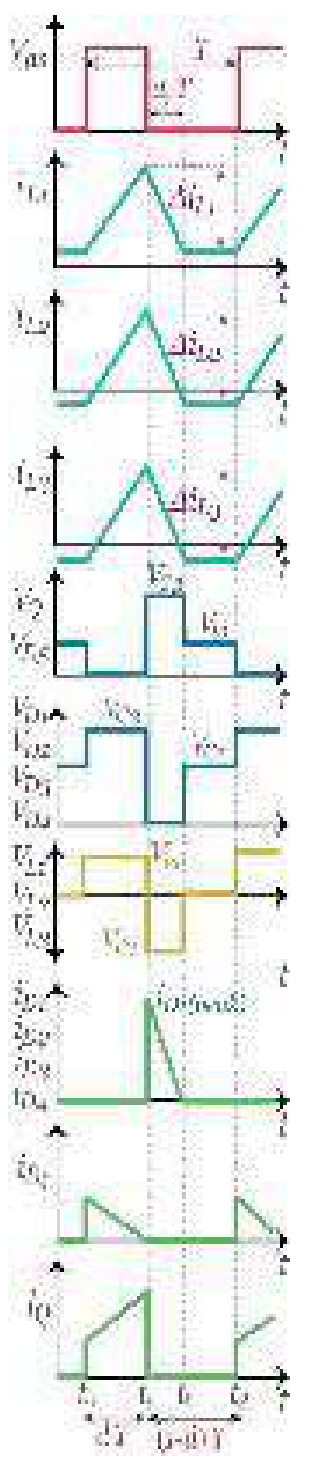

(b)

Figure 6.2: Figure 6.2: Key waveforms of the proposed converter. (a) CCM operation. (b) DCM operation. 


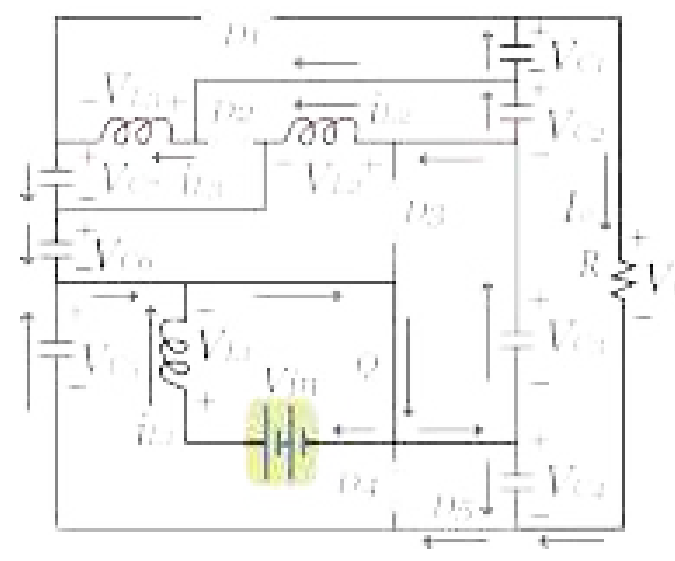

(a)

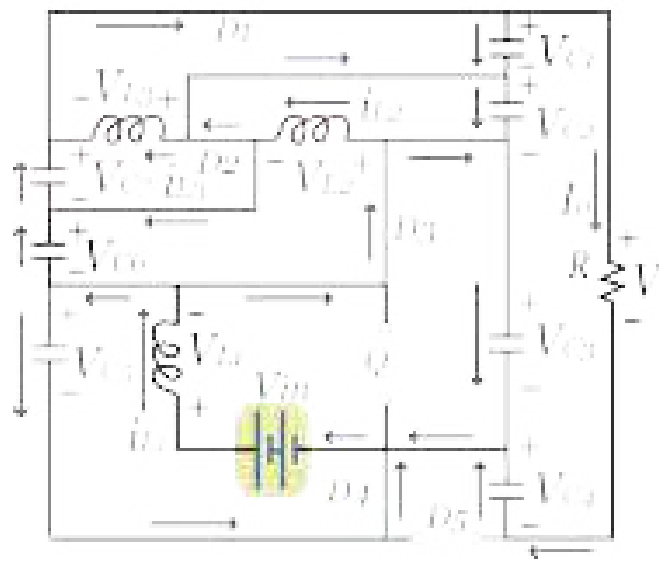

(b)

Figure 6.3: Equivalent circuits of the proposed converter (a) During State 1. (b) During State 0 .

\subsubsection{Analysis of Voltage Gain and Voltage Stress}

By means of equations (1) and (2), and by applying the voltage second balance rule on the three inductors, where the period of State 1 is $d T$ and the period of State 0 is $(1-d) T$, as shown in Figure 6.2(a), where $T$ is the switching periodic time, and $d$ is the duty cycle, we get the following relationships:

$$
\begin{aligned}
& V_{C 1}=V_{C 2}=V_{C 6}=V_{C 7}=\frac{d V_{\text {in }}}{1-d} \\
& V_{C 3}=V_{C 4}=V_{C 5}=\frac{V_{\text {in }}}{1-d} \\
& V_{o}=V_{C 1}+V_{C 2}+V_{C 3}+V_{C 4}=\left(\frac{2+2 d}{1-d}\right) V_{i n} \\
& M=\frac{V_{o}}{V_{\text {in }}}=\frac{2+2 d}{1-d}
\end{aligned}
$$

Where $M$ is the voltage gain of the converter, $V_{i n}$ and $V_{o}$ are the input and output voltages, $V_{C 1}$ $\rightarrow V_{C 7}$ are the voltages across the capacitors $C_{1} \rightarrow C_{7}$. By means of Figure 6.3, the voltage stress across the semiconductor devices can be deduced, as following:

$$
V_{Q}=V_{D 1}=V_{D 2}=V_{D 3}=V_{D 4}=V_{D 5}=\frac{V_{\text {in }}}{1-d}
$$


Using (3) and (4), the voltage stress on the semiconductor devices can be expressed as a function on $V_{o}$ and $M$, as follows:

$$
V_{Q}=V_{D 1}=V_{D 2}=V_{D 3}=V_{D 4}=V_{D 5}=\left(\frac{2+M}{4 M}\right) V_{o}
$$

\subsubsection{Analysis of Current Stress}

Assuming a lossless operation of the converter (i.e. $V_{i n} \times I_{L 1}=V_{o} \times I_{o}$ ), thus, the currents $I_{L 2}, I_{L 3}$, and $I_{L 1}$ can be calculated as in (6) and (7), where $I_{O}$ is the output current:

$$
\begin{aligned}
& I_{L 2}=I_{L 3}=I_{o}=\frac{V_{o}}{R} \\
& I_{L 1}=\left(\frac{2+2 d}{1-d}\right) I_{o}=\left(\frac{2+2 d}{1-d}\right) \frac{V_{o}}{R}
\end{aligned}
$$

By applying the Kirchhof's Current Law (KCL) on the equivalent circuits of the proposed converter, shown in Figure 6.3, the current stresses on the power switch and diodes can be deduced as follows:

$$
\begin{gathered}
i_{Q}=\left(\frac{1+3 d}{d(1-d)}\right) I_{O}=\left(\frac{(M-1)(M+2)}{M-2}\right) I_{o} \\
i_{D 1}=i_{D 2}=i_{D 3}=i_{D 4}=\frac{I_{o}}{1-d}=\left(\frac{M+2}{4}\right) I_{o} \\
i_{D 5}=\frac{I_{o}}{d}=\left(\frac{M+2}{M-2}\right) I_{O}
\end{gathered}
$$

\subsubsection{Influence of the Parasitic Elements on Voltage Gain}

In order to investigate the effect of the parasitic elements of the passive and active components on the voltage gain of the proposed converter, some of these elements were taken into account in the model of the converter. The circuit of the proposed converter with the included parasitic elements is shown in Figure 6.4. In this non-ideal converter model, the following parasitic elements were included: the series resistances of the inductors $\left(r_{L 1}=r_{L 2}=r_{L 3} \approx r_{L}\right)$, the equivalent series resistances of the capacitors $\left(r_{C 1}=r_{C 2}=r_{C 3}=r_{C 4}=r_{C 5}=r_{C 6}=r_{C 7} \approx r_{C}\right)$, the on resistance of 
the power $\operatorname{switch}\left(r_{S}\right)$, the forward resistances of the diodes $\left(r_{D 1}=r_{D 2}=r_{D 3}=r_{D 4}=r_{D 5} \approx r_{D}\right)$, and their respective forward voltages $\left(V_{F 1}=V_{F 2}=V_{F 3}=V_{F 4}=V_{F 5} \approx V_{F}\right)$. The values for the operating and assumed parasitic parameters are as follows: $V_{i n}=100, r_{L}=35 \mathrm{~m} \Omega, r_{C}=$ $200 \mathrm{~m} \Omega, r_{D}=80 \mathrm{~m} \Omega, r_{S}=25 \mathrm{~m} \Omega, V_{F}=1.3 \mathrm{~V}, R=300 \Omega$. When these parasitic elements are taken into account, a new equation can be deduced to describe the static voltage gain of the proposed converter $\left(M^{\prime}\right)$, as shown in (11).

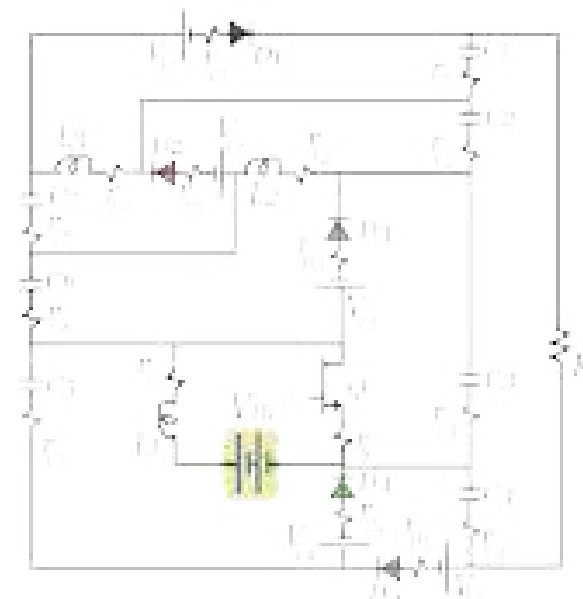

Figure 6.4: The proposed converter with the parasitic elements.

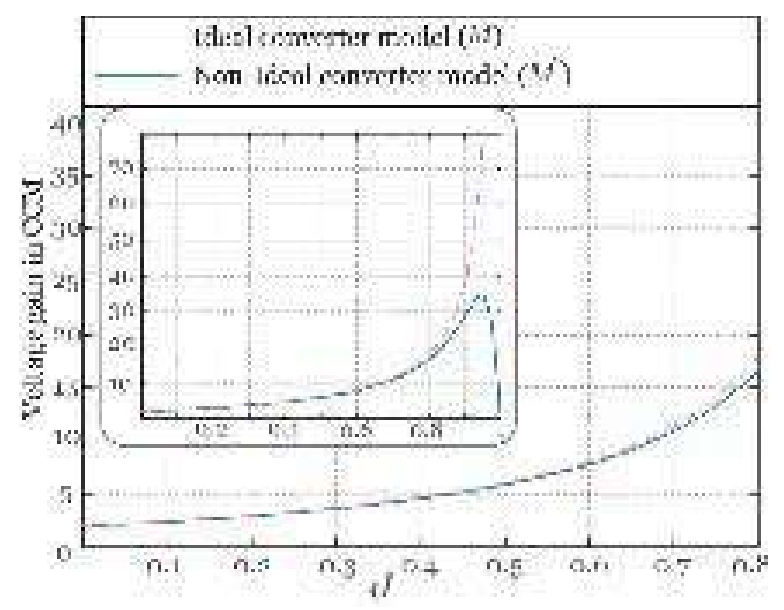

Figure 6.5: Static voltage gain curves for the ideal/non-ideal models of the proposed converter. 
Figure 6.5 shows the voltage gain curves of the proposed converter described by the ideal and non-ideal models of the converter. It is noticed that the ideal and non-ideal models of the proposed converter are close to each other for $d=0 \rightarrow 0.75$, as $M^{`} \approx 13$ at $d=0.75$, which shows the capability of the proposed converter to achieve high step-up voltage gains.

$$
M^{\prime}=\frac{R(1-d)\left(V_{i n}-3 V_{F}+3 d V_{F}+2 d V_{i n}\right)}{V_{\text {in }}\left[R+4 r_{D}(1-d)+4 r_{S}+6 r_{L}+2 d\left(6 r_{C}+2 r_{L}+6 r_{S}-R\right)+d^{2}\left(R+6 r_{L}-2 r_{C}-10 r_{C} d\right)\right]}
$$

\subsubsection{Efficiency Analysis}

Calculating the different power losses in the components of the converter is essential to properly select the cooling system. The total power loss $P_{\text {Loss }}$ of the proposed converter can be calculated by (12), where $P_{Q_{-} s w}, P_{Q_{-} c o n d}, P_{D}, P_{L_{-} c o n d}, P_{L_{-} \text {core }}$, and $P_{C}$ are the switching and conduction losses of the power switch, the conduction loss of the diodes, the conduction and core losses of the inductors, and the conduction loss of the capacitors.

$$
P_{\text {loss }}=P_{Q_{-} s w}+P_{Q_{-} c o n d}+P_{D}+P_{L_{-} \text {cond }}+P_{L_{-} \text {core }}+P_{C}
$$

The losses of the power switch $Q$ can be calculated as follows:

$$
\begin{gathered}
P_{Q_{-} s w}=f_{S}\left(0.5 V_{Q} i_{Q}\left(t_{r}+t_{f}\right)+0.5 V_{S}^{2} C_{O S S}\right) \\
P_{Q_{-} \text {cond }}=\left(\left(\frac{1+3 d}{\sqrt{d}(1-d)}\right) I_{o}\right)^{2} R_{D S}
\end{gathered}
$$

Where $f_{s}, R_{D S}, t_{r}, t_{f}$, and $C_{O S S}$, are the switching frequency, on resistance, rise time, fall time, and the parasitic output capacitance of $Q$, respectively. 
The losses of the inductors can be derived using (15), and (16), where $R_{L 1}, R_{L 2}, R_{L 3}, l_{c 1}, l_{c 2}, l_{c 3}$, $A_{c 1}, A_{c 2}, A_{c 3}, \Delta B_{1}, \Delta B_{2}$, and $\Delta B_{3}$ are the equivalent series resistances of the three inductors, the magnetic flux path lengths of the cores of the three inductors, the cross sectional areas of the cores of the three inductors, and the three inductor's ac magnetic flux density.

$$
\begin{aligned}
& P_{L_{-} \text {cond }}=\sum_{n=1}^{n=3} I_{L n}^{2} R_{L n} \\
& P_{L_{-} \text {core }}=\sum_{n=1}^{n=3} l_{c n} A_{c n}\left(a \Delta B_{n}^{b} f_{n}^{C}\right)
\end{aligned}
$$

Equation (16), is the Steinmetz equation and it is an empirical formula, where $a, b$, and $c$ are fitting parameters and can be gotten from the core manufacturer datasheet.

The conduction losses of the five diodes can be calculated by means of (17), as follows:

$$
P_{D}=5 V_{f d} I_{o}
$$

Where $V_{f d}$ is the forward voltage of each diode. The conduction loss of the capacitors can be extracted as following:

$$
P_{C}=\sum_{n=1}^{n=7} I_{C n \_r m s}^{2} E S R_{C n}
$$

Where $E S R_{C l} \rightarrow E S R_{C 7}$ and $i_{C 1} r m s \rightarrow i_{C 7} r m s$, are the equivalent series resistances and the rms currents of the seven capacitors, respectively. The rms currents of the seven capacitors can be calculated by (19)-(23). 


$$
\begin{aligned}
& i_{C 1 \_r m s}=i_{C 7 \_r m s}=I_{o} \sqrt{\frac{d}{1-d}} \\
& i_{C 2 \_r m s}=i_{C 6 \_r m s}=2 I_{o} \sqrt{\frac{d}{1-d}} \\
& i_{C 3_{r} r m s}=3 I_{o} \sqrt{\frac{d}{1-d}} \\
& i_{C 4 \_r m s}=I_{o} \sqrt{\frac{1-d}{d}} \\
& i_{C 5_{\_} r m s}=I_{o} \sqrt{\frac{1}{d(1-d)}}
\end{aligned}
$$

Finally, the converter's efficiency $\eta$ can be calculated using (24):

$$
\eta=\frac{M V_{\text {in }} I_{o}}{M V_{\text {in }} I_{o}+P_{\text {Loss }}}
$$

\subsubsection{DCM Operation Steady-State Analysis}

In DCM operation, the off state of the transistor is split into two states, the first state has a time period of $d_{z} T$, where $d_{z}$ is a fraction of the periodic switching time $T$, and this state is similar to State 0 in CCM operation where $D_{1} \rightarrow D_{4}$ conduct when $Q$ is off. The second state during the off state of $Q$ takes place when the voltages across the inductors drop to zero and all the diodes are reverse-biased, as shown in Figure 6.6. During this state, positive constant current flows in $L_{1}$ while negative constant currents flow in $L_{2}$ and $L_{3}$. All the important theoretical waveforms of the proposed converter during the DCM operation are shown in Figure 6.2(b). 
Since the average current of each of the five diodes equals the output current, thus, $d_{z}$ can be derived as following:

$$
\frac{1}{2 T} d_{z} T i_{D(\text { peak })}=\frac{V_{o}}{R}
$$

Where $i_{D(p e a k)}$ is the peak current of any diode of $D_{1}, D_{2}, D_{3}$, and $D_{4}$, and it can be calculated by (26).

$$
i_{D(\text { peak })}=\frac{d V_{i n}}{4 f_{s} L_{e q}}
$$

As $L_{e q}$ is defined by (27).

$$
L_{e q}=\left\lceil\frac{1}{L_{1}}+\frac{1}{L_{2}}+\frac{1}{L_{3}}\right\rceil^{-1}
$$

Accordingly, $d_{z}$ can be deduced as given in (28).

$$
d_{z}=\frac{8 V_{o}}{d V_{\text {in }}} \frac{f_{s} L_{e q}}{R}=\frac{8 V_{o}}{d V_{\text {in }}} K
$$

Where $K$ is a dimensionless parameter and it is defined by (29).

$$
K=\frac{f_{s} L_{e q}}{R}
$$

By means of Figure 6.2(b), and applying the voltage second rule on any of the three inductors we get (30)-(31), where $M_{D C M}$ is the voltage gain of the proposed converter in DCM operation.

$$
\begin{aligned}
& \frac{1}{T}\left[\int_{0}^{d T} V_{i n} d t-\int_{0}^{d_{z} T} V_{C 1} d t\right]=0 \\
& V_{i n} d+\left(\frac{2 V_{i n}-V_{o}}{4}\right) d_{z} \\
& M_{D C M}^{2}-2 M_{D C M}-\frac{d^{2}}{2 K}=0
\end{aligned}
$$

By solving the quadratic equation (32), $M_{D C M}$ can be extracted. 


$$
M_{D C M}=\frac{V_{o}}{V_{\text {in }}}=1+\sqrt{1+\frac{d^{2}}{2 K}}
$$

In order to get the boundary condion between the DCM and CCM operations, $M_{C C M}$ equals $M_{D C M}$. Hence, the critical value of $K\left(K_{\text {critical }}\right)$ is defined by (34), and plotted versus $d$ in Figure 6.7, as the converter operates in DCM when $K<K_{\text {critical, }}$ and in $C C M$ otherwise.

$$
K_{\text {critical }}=\frac{d(1-d)^{2}}{8(d+2)}
$$

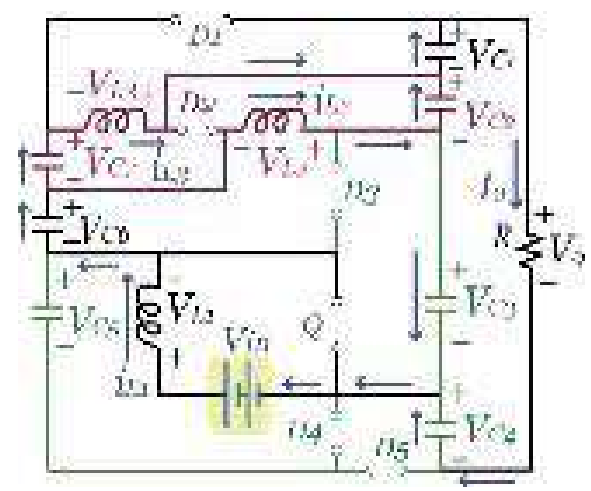

Figure 6.6: Current flow paths during the third switching state (in DCM).

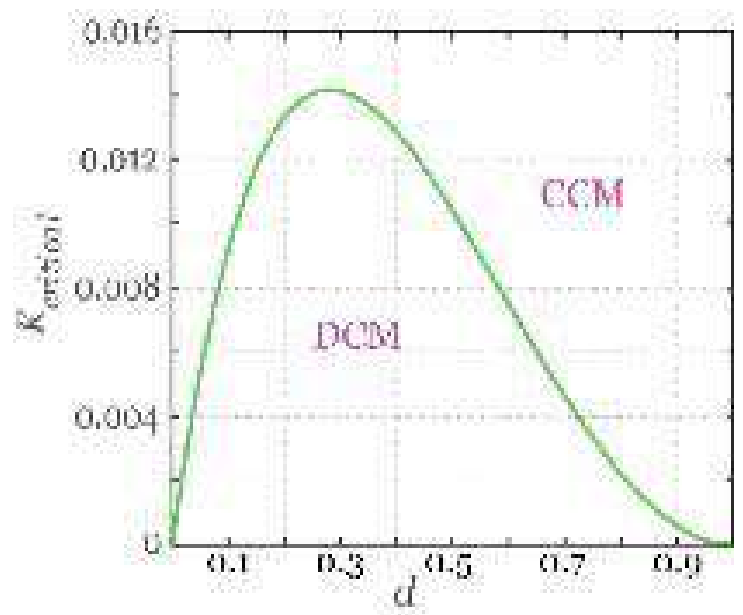

Figure 6.7: Boundary condition between CCM and DCM operations for the proposed topology. 


\subsection{Component Parameters Design}

\subsubsection{Design of the Semiconductor Devices}

The selected power switch should tolerate the maximum voltage and current stresses applied to it. Equations (5) and (8) describe the current and voltage stresses on the switch, hence, by knowing the output voltage and current and the maximum voltage gain, the maximum current and voltage stresses can be determined. These maximum stress values should be within the safe operating area (SOA) of the selected power switch. Similarly, the maximum voltage and current stresses on the diodes can be calculated via (5) and (9), and accordingly the ratings of the selected diodes can be determined.

\subsubsection{Design of Inductors}

Using equations (6) and (7), the three inductors' currents can be deduced. By knowing the maximum ripple currents $\Delta i_{L 1}, \Delta i_{L 2}$, and $\Delta i_{L 3}$, the minimum required inductances can be determined using (35), where $d$ is the duty cycle, and $f_{s}$ is the switching frequency.

$$
\begin{aligned}
L_{1} & \geq \frac{d V_{i n}}{f_{S} \Delta i_{L 1}} \\
L_{2} & \geq \frac{d V_{i n}}{f_{S} \Delta i_{L 2}} \\
L_{3} & \geq \frac{d V_{i n}}{f_{S} \Delta i_{L 3}}
\end{aligned}
$$

\subsubsection{Design of Capacitors}

Using equation (3), the voltages of the seven capacitors can be determined. By knowing the maximum ripple voltages $\Delta V_{C 1}, \Delta V_{C 2}, \Delta V_{C 3}, \Delta V_{C 4}, \Delta V_{C 5}, \Delta V_{C 6}$ and $\Delta V_{C 7}$, the minimum required capacitances can be determined using (36). 


$$
\begin{array}{rlrl}
C_{1} & \geq \frac{I_{o} d}{f_{s} \Delta V_{C 1}} & C_{5} & \geq \frac{I_{o}}{f_{s} \Delta V_{C 5}} \\
C_{2} & \geq \frac{2 I_{o} d}{f_{s} \Delta V_{C 2}} & C_{6} & \geq \frac{2 I_{o} d}{f_{s} \Delta V_{C 6}} \\
C_{3} & \geq \frac{3 I_{o} d}{f_{s} \Delta V_{C 3}} & \left(C_{7}\right. & \geq \frac{I_{o} d}{f_{s} \Delta V_{C 7}} \\
\left(C_{4}\right. & \geq \frac{I_{o}(1-d)}{f_{s} \Delta V_{C 4}} &
\end{array}
$$

\subsection{Comparative Study}

In this section, the proposed converter is compared with seven other step-up dc-dc converter architectures. These other dc-dc topologies are: the 3LB converter, and the converters in [110], [177], [178], [180], [188], and [189]. Table 6.1 summarizes the number of passive and active components, the voltage gain, and the maximum normalized voltage stresses across the switches and diodes of each converter. Also, it shows whether the converter has low input current ripple or not, and the potential difference between the grounds of the input and output ports of each converter. The voltage gain of the compared converters is plotted versus the duty cycle in Figure 6.8, while the maximum normalized voltage stress on

the switches and diodes of the compared converters are graphed in Figure 6.9 and Figure 6.10, respectively.

The 3LB converter, the converters in [110], [178], and [189] have HF PWM potential difference between the input and output grounds, which may increase the radiated EMI noise and the leakage currents of the converters, and accordingly an extra periodic maintenance may be required. The converters in [110], [180], and [189] have a pulsating input current which can affect the lifetime of the fuel cell. 


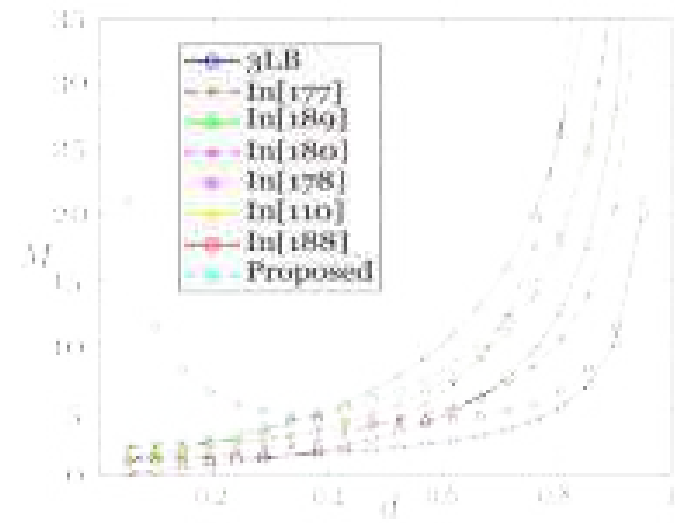

Figure 6.8: Voltage gain curves of the compared converters.

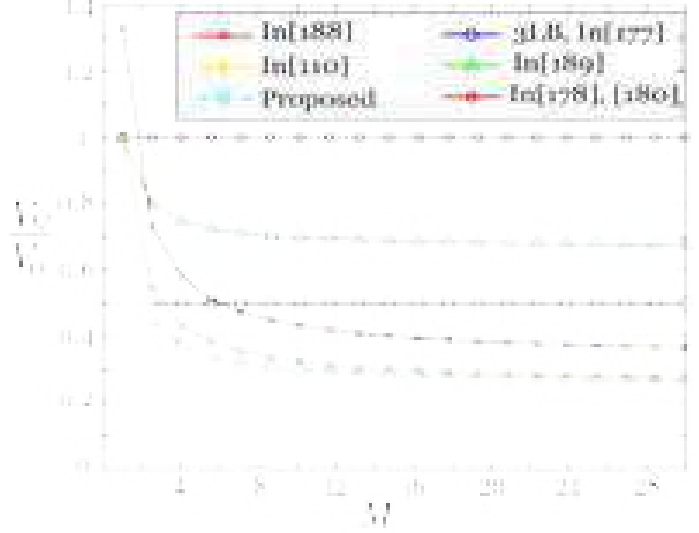

Figure 6.9: Maximum normalized voltage stress on the switches of the compared converters.

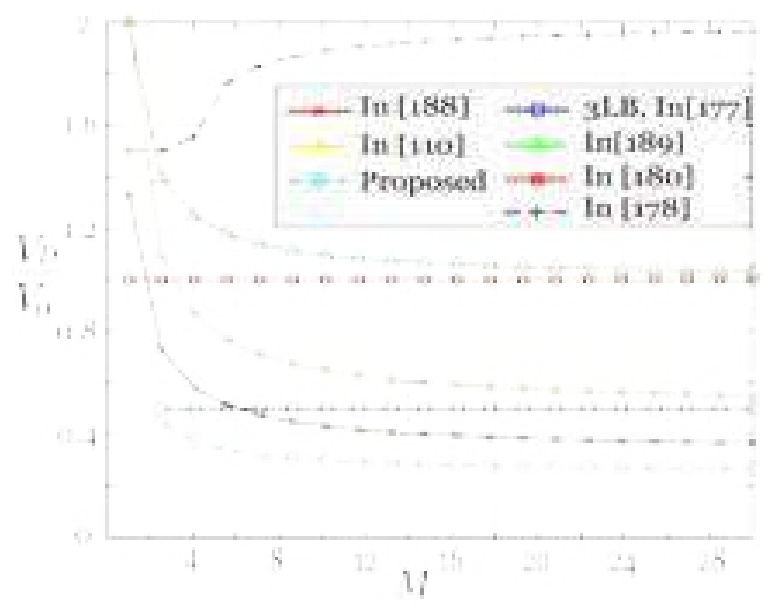

Figure 6.10: Maximum normalized voltage stress on the diodes of the compared converters.

Figure 6.8 shows that the proposed converter has a higher voltage gain compared to the 3LB converter and the converters in [110], [188], [177], [178] (for $d>0.35$ ), [189] (for $d<0.35$ ), and [180] (for $d<0.7$ ). Regarding the voltage stress on the power switches and diodes of the compared 
converters, Figure 6.9 and Figure 6.10 show that the proposed converter has the least maximum voltage stress on its switch and diodes compared to the converters in Table 6.1. In order to properly compare the estimated cost of the power switches and diodes of each converter, the utilization factor of the switches $\left(U_{S}\right)$ and the utilization factor of the diodes are calculated by (37) and (38), respectively.

$$
\begin{gathered}
U_{S}=\frac{P_{o}}{\sum V_{Q i} i_{Q i(r m s)}} \\
U_{D}=\frac{P_{o}}{\sum V_{D j} i_{D j(r m s)}}
\end{gathered}
$$

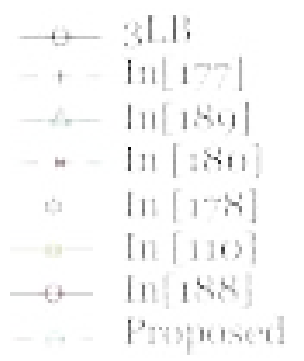

(a)

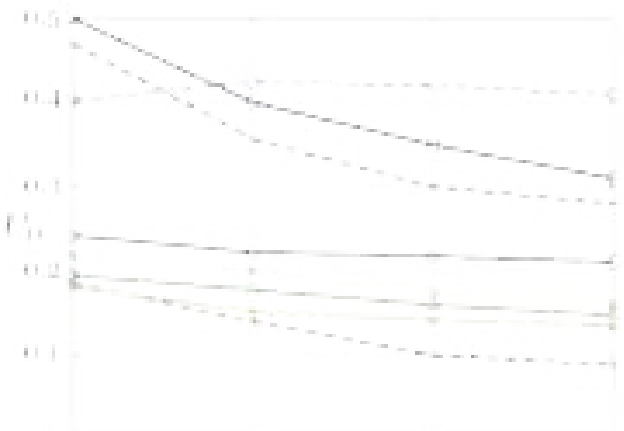

(b)

Figure 6.10: (a) Utilization factor of power switches. (b) Utilization factor of diodes.

Where $P_{o}$ is the output power of the converter, $V_{Q i}, i_{Q i(r m s)}$ are the voltage and the root-meansquare (rms) current stresses on switch $i, V_{D i}, i_{D i(r m s)}$ are the voltage and the rms current stresses on diode $j$. The utilization factors for the power switches and diodes of the converters in Table 6.1 are graphically presented versus the voltage gain in Figure 6.11 when $P_{o}$ is $3 \mathrm{~kW}$ and $V_{o}$ is $800 \mathrm{~V}$. It is clear from Figure 6.11(a) that the proposed converter has the highest switch utilization factor. Figure 6.11(b) shows that the proposed converter has higher diode utilization factor compared to the converters in [110], [188], [178], [180], and [189], while it has higher diode utilization factor compared to the $3 \mathrm{LB}$ converter and the converter in [177] for $M>5$. 
The comparisons above show that the proposed converter integrates a number of features such as: high voltage conversion ratio, wide input voltage range, low voltage stress on the semiconductor devices, low input current ripple, constant voltage difference between its input and output ports' grounds, and high utilization of the semiconductor devices. These features make the proposed topology an excellent interface between the fuel cell and the dc-link bus of the inverter of the EV.

Table 6.1: COMPARISON BETWEEN THE PROPOSED AND OTHER STEP-UP DC-DC SOLUTIONS

\begin{tabular}{|c|c|c|c|c|c|c|c|c|}
\hline Topology & $\begin{array}{l}\text { Voltage gain } \\
\qquad(M)\end{array}$ & $\begin{array}{c}\text { Maximum } \\
\text { voltage stress } \\
\text { across switches }\end{array}$ & $\begin{array}{c}\text { Maximum } \\
\text { voltage stress } \\
\text { across diodes }\end{array}$ & $\begin{array}{c}\text { Number of } \\
\text { semiconductor } \\
\text { devices }\end{array}$ & $\begin{array}{l}\text { Number of } \\
\text { inductors \& } \\
\text { capacitors }\end{array}$ & $\begin{array}{l}\text { Input } \\
\text { current } \\
\text { ripple }\end{array}$ & $\begin{array}{l}\text { Grounds' } \\
\text { potential } \\
\text { difference }\end{array}$ & $\begin{array}{c}\text { Voltage } \\
\text { gain range } \\
d: 0 \rightarrow 0.9\end{array}$ \\
\hline 3LB & $\frac{1}{1-d}$ & $\frac{1}{2}$ & $\frac{1}{2}$ & $\begin{array}{l}2 \text { Switches } \\
2 \text { Diodes }\end{array}$ & $\begin{array}{l}1 \text { Inductor } \\
2 \text { Capacitors }\end{array}$ & Low & $\begin{array}{c}\text { HF PWM } \\
\text { voltage }\end{array}$ & $1 \rightarrow 10$ \\
\hline In [110] & $\frac{1+3 d}{1-d}$ & $\frac{3+M}{4 M}$ & $\frac{3+M}{2 M}$ & $\begin{array}{l}2 \text { Switches } \\
2 \text { Diodes }\end{array}$ & $\begin{array}{l}3 \text { Inductors } \\
3 \text { Capacitors }\end{array}$ & High & $\begin{array}{c}\text { HF PWM } \\
\text { voltage }\end{array}$ & $1 \rightarrow 37$ \\
\hline In [188] & $\frac{3 d}{1-d}$ & $\frac{3+M}{3 M}$ & $\frac{3+M}{3 M}$ & $\begin{array}{l}1 \text { Switch } \\
3 \text { Diodes }\end{array}$ & $\begin{array}{l}4 \text { Inductor } \\
6 \text { Capacitors }\end{array}$ & Low & $0 \mathrm{~V}$ & $0 \rightarrow 27$ \\
\hline In [178] & $\frac{1}{d(1-d)}$ & 1 & $\frac{3}{2}+\sqrt{\frac{1}{4}-\frac{1}{M}}$ & $\begin{array}{l}2 \text { Switches } \\
3 \text { Diodes }\end{array}$ & $\begin{array}{l}2 \text { Inductors } \\
2 \text { Capacitors }\end{array}$ & Low & $\begin{array}{c}\text { HF PWM } \\
\text { voltage }\end{array}$ & $--\rightarrow 11$ \\
\hline In [180] & $\frac{1}{(1-d)^{2}}$ & 1 & 1 & $\begin{array}{l}1 \text { Switch } \\
3 \text { Diodes }\end{array}$ & $\begin{array}{l}2 \text { Inductors } \\
2 \text { Capacitors }\end{array}$ & High & $0 \mathrm{~V}$ & $1 \rightarrow 100$ \\
\hline $\begin{array}{l}\text { In [189] } \\
(n=1)\end{array}$ & $\frac{1+5 d}{1-d}$ & $\frac{1+2 M}{3 M}$ & $\frac{1+M}{M}$ & $\begin{array}{l}3 \text { Switches } \\
12 \text { Diodes }\end{array}$ & $\begin{array}{l}6 \text { Inductor } \\
1 \text { Capacitors }\end{array}$ & High & $\begin{array}{c}\text { HF PWM } \\
\text { voltage }\end{array}$ & $1 \rightarrow 55$ \\
\hline In [177] & $\frac{2}{1-d}$ & $\frac{1}{2}$ & $\frac{1}{2}$ & $\begin{array}{l}2 \text { Switches } \\
3 \text { Diodes }\end{array}$ & $\begin{array}{l}2 \text { Inductors } \\
3 \text { Capacitors }\end{array}$ & Low & $\begin{array}{l}\text { Constant } \\
\text { voltage }\end{array}$ & $2 \rightarrow 20$ \\
\hline Proposed & $\frac{2+2 d}{1-d}$ & $\frac{2+M}{4 M}$ & $\frac{2+M}{4 M}$ & $\begin{array}{l}1 \text { Switch } \\
5 \text { Diodes }\end{array}$ & $\begin{array}{l}3 \text { Inductors } \\
7 \text { Capacitors }\end{array}$ & Low & $\begin{array}{l}\text { Constant } \\
\text { voltage }\end{array}$ & $2 \rightarrow 38$ \\
\hline
\end{tabular}

\subsection{Experimental Results and Analysis}

A scaled-down 3-kW/800-V experimental prototype was built to verify the feasibility of the proposed topology and the correctness of its theoretical analysis, as shown in Figure 6.12. The 
power circuit of the prototype was built using a GaN power switch (GS66516T-E02-MR) and SiC Schottky diodes (IDDD10G65C6XTMA1), and controlled by a TMS320f28335 microcontroller. The currents of the inductors, diodes, and power switch are measured via current sense resistors. The operating frequency is $100 \mathrm{kHz}$, and the selected values of the three inductors and seven capacitors are enlisted in Table 6.2.

Table 6.2: MAIN EXPERIMENTAL PARAMETERS OF THE PROPOSED CONVERTER

\begin{tabular}{|l|c|}
\hline Parameters and Components & Values \\
\hline Rated power $P_{o}$ & $3-\mathrm{kW}$ \\
\hline Output voltage $V_{o}$ & $800-\mathrm{V}$ \\
\hline Power switch $Q$ & GS66516T-E02-MR \\
& (2-in-parallel) \\
\hline Diodes $D_{1} \rightarrow D_{5}$ & IDDD10G65C6XTMA1 \\
\hline Inductor $L_{1}$ & $250 \mu \mathrm{H}$ \\
\hline Inductors $L_{2}, L_{3}$ & $330 \mu \mathrm{H}$ \\
\hline Capacitors $C_{1}, C_{2}, C_{6}, C_{7}$ & $180 \mu \mathrm{F}$ \\
\hline Capacitors $C_{3}, C_{4}, C_{5}$ & $150 \mu \mathrm{F}$ \\
\hline Load resistor & $215 \Omega$ \\
\hline Switching frequency $f_{s}$ & $100 \mathrm{KHz}$ \\
\hline Microcontroller & TMS320f28335 \\
\hline
\end{tabular}




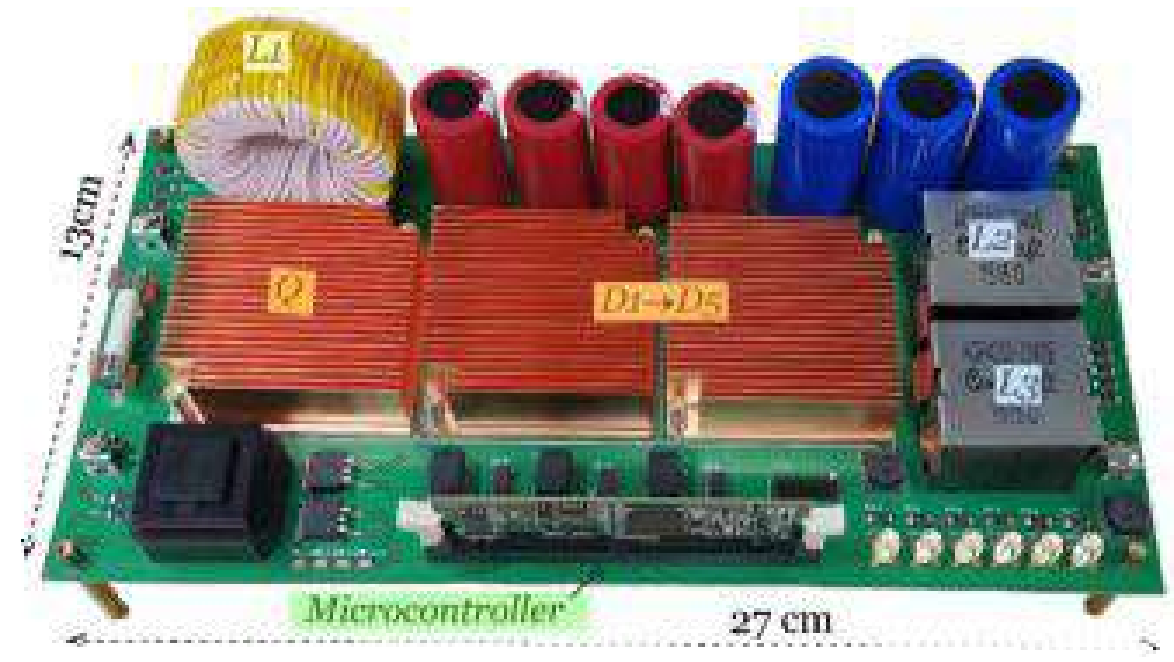

Figure 6.11: Experimental prototype.

The operating parameters are as following: $V_{\text {in }}=100 \mathrm{~V}, R=215 \Omega, d=0.6$. The experimental test results are presented in Figure 6.13.

The voltage gain and the output voltage of the developed converter can be calculated using equation (3), as following: $M=8, V_{o}=800 \mathrm{~V}$, which closely agrees with the experimental results in Figure 6.13(d). Similarly, the voltages across the seven capacitors can be calculated by (3) as: $V_{C 1}=V_{C 2}=V_{C 6}=V_{C 7}=150 \mathrm{~V}$, and $V_{C 3}=V_{C 4}=V_{C 5}=250 \mathrm{~V}$, which closely agree with the results shown in Figure 6.13(b) and Figure 6.13(c).

The inductor currents and their respective ripple currents can be calculated by (6), (7), and (35), as follows: $I_{L 1} \approx 29.77 \mathrm{~A}, I_{L 2}=I_{L 3} \approx 3.72 \mathrm{~A}, \Delta i_{L 1}=2.4 \mathrm{~A}, \Delta i_{L 2} \approx 1.8 \mathrm{~A}, \Delta i_{L 3} \approx 1.8 \mathrm{~A}$, which is close to the experimental results shown in Figure 6.13(a). The voltage stress across the power switch and the five diodes can be calculated by equation (4), as follows: $V_{Q}=V_{D 1}=$ $V_{D 2}=V_{D 3}=V_{D 4}=V_{D 5}=250 \mathrm{~V}$, which comply with the experimental results shown in Figure 6.13(e) and Figure 6.13(f). 


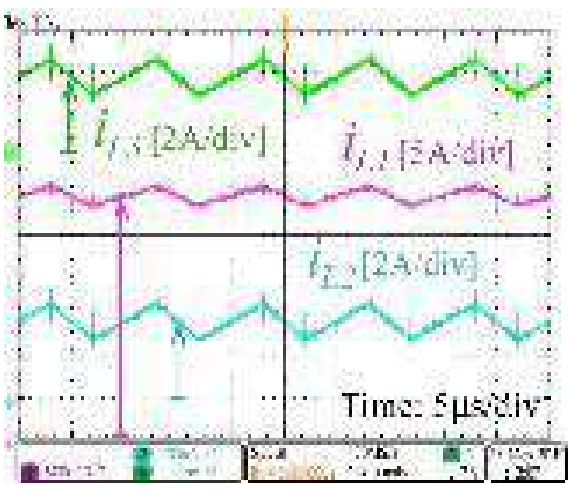

(a)

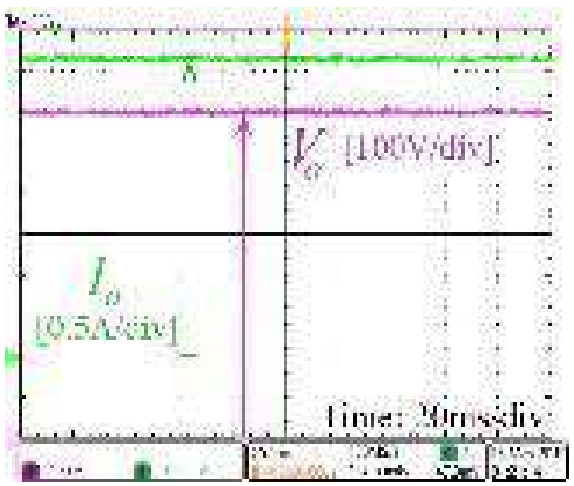

(d)

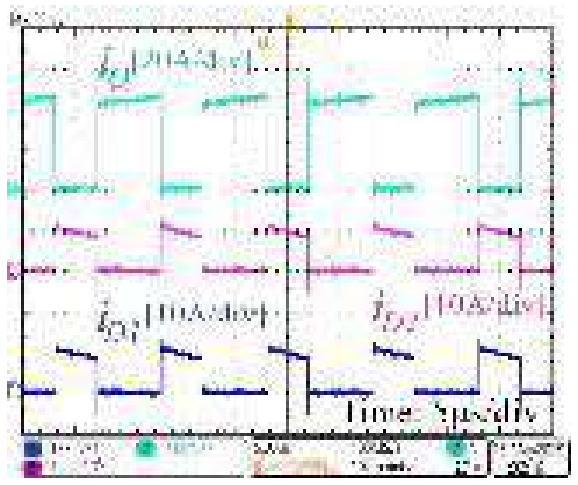

(g)

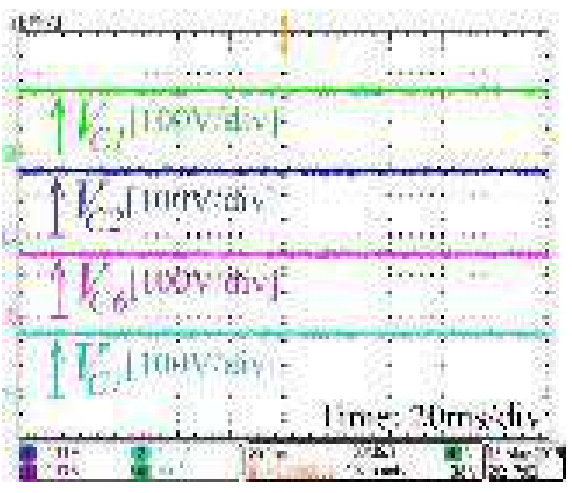

(b)

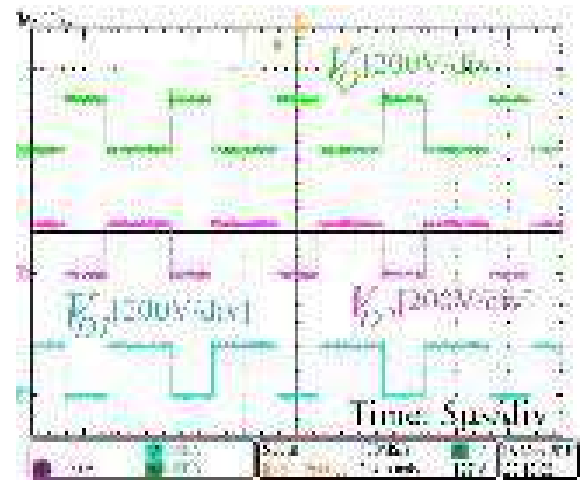

(e)

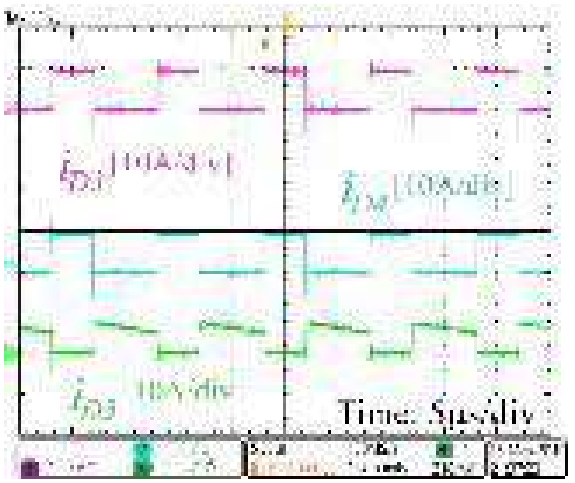

(h)

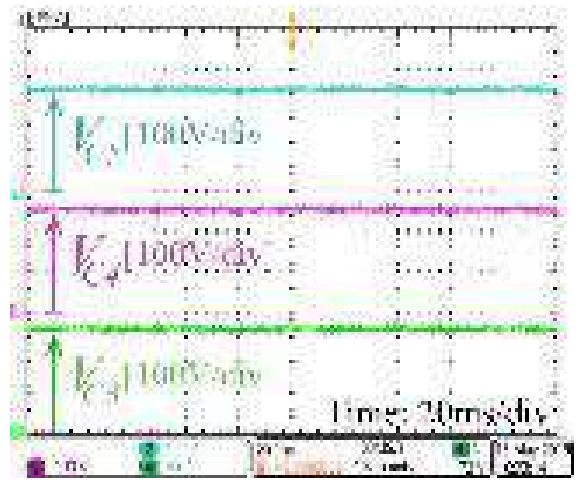

(c)

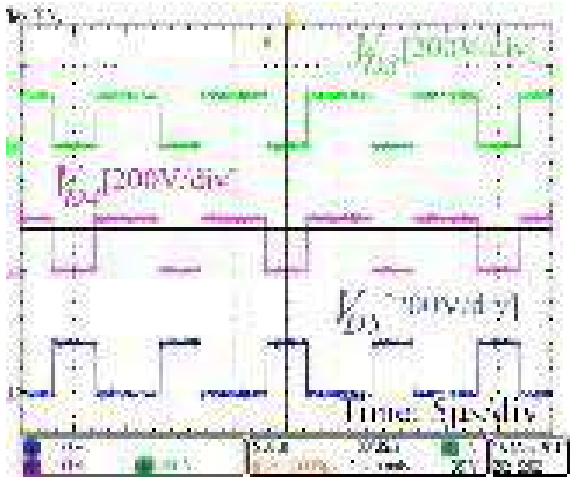

(f)

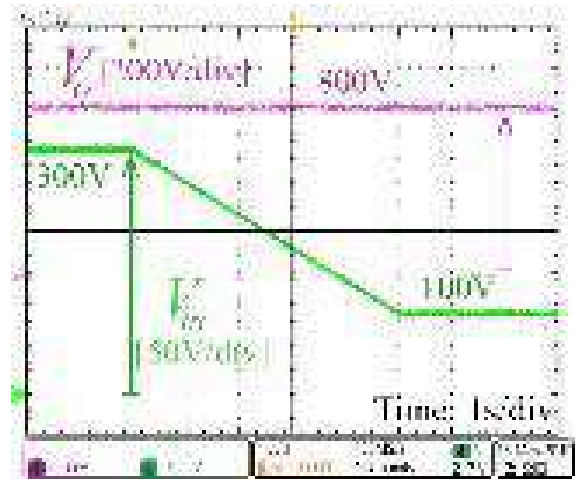

(i)

Figure 6.12: Experimental results. 


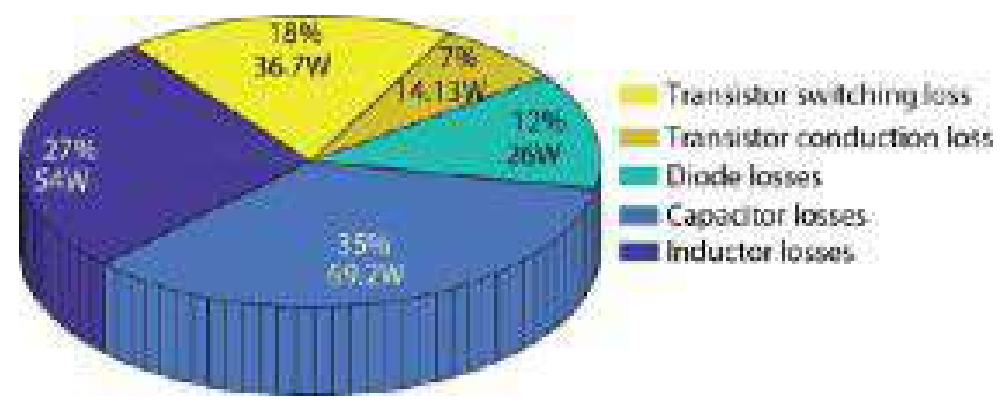

\section{Figure 6.13: Distributions of the calculated power loss for the experiment}

The current stress of the power switch $Q$ can be calculated via equation (8), as: $i_{Q} \approx 43.4 \mathrm{~A}$, which closely agrees with the experimental results presented in Figure 6.13(g). Similarly, the current stresses of the five diodes can be calculated by equations (9) and (10), as: $i_{D 1}=i_{D 2}=$ $i_{D 3}=i_{D 4} \approx 9.3 \mathrm{~A}$, and $i_{D 5} \approx 6.2 \mathrm{~A}$, which comply with the experimental results in Figure $6.13(\mathrm{~g})$ and Figure 6.13(h).

To evaluate the wide input voltage capability of the proposed converter, the input voltage of the converter is changed gradually from $300 \mathrm{~V}$ to $100 \mathrm{~V}$, while a closed-loop Type III voltage controller is utilized to set the output voltage of the converter at $800 \mathrm{~V}$. Figure 6.13(i) shows the result of this test where the output voltage is fixed at $800 \mathrm{~V}$ while the input voltage changed from $300 \mathrm{~V}$ to $100 \mathrm{~V}$. This result shows that proposed converter has an acceptable dynamic performance with wide changes in the input voltage.

The calculated losses of the active and passive components of the proposed converter for the case study investigated in this section $\left(V_{i n}=100 \mathrm{~V}, V_{o}=800 \mathrm{~V}, d=0.6, f_{s}=100 \mathrm{kHz}, R=215 \Omega\right)$, is shown in Figure 6.14. The total calculated losses $P_{\text {loss }}$ equal 197.37W. The conduction losses of the capacitors account for $35 \%$ of the total converter losses (replacing the electrolytic capacitors used in the experimental prototype with film or ceramic capacitors can reduce this loss segment). 
The switching and conduction losses of the power switch account for $18 \%$ and $7 \%$, respectively, of the total losses. The conduction losses of the diodes account for $12 \%$ of the converter losses.

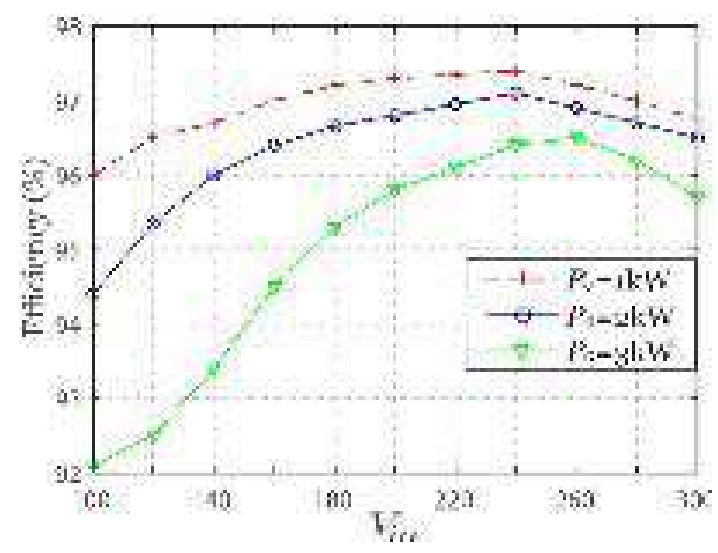

Figure 6.14: Measured efficiency curves of the proposed converter versus $V_{\text {in }}$

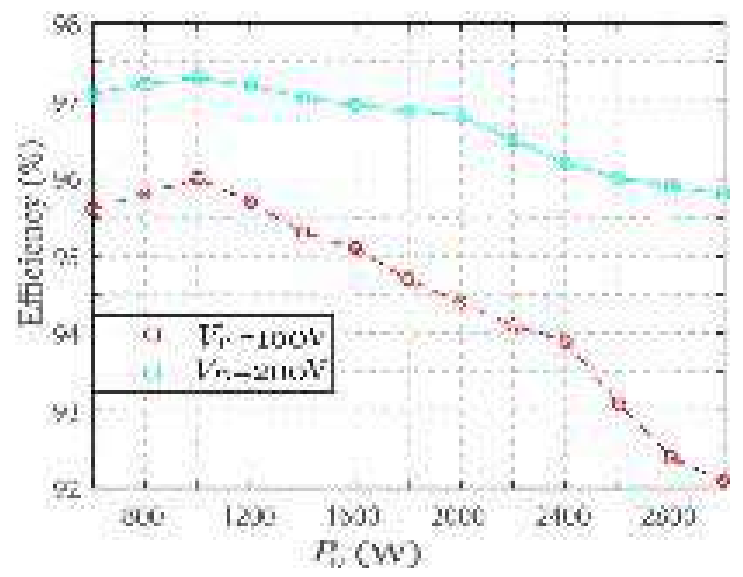

Figure 6.15: Measured efficiency curves of the proposed converter versus $\boldsymbol{P}_{o}$

Finally, the conduction losses of the three inductors account for $27 \%$ of the total losses of the converter. Figure 6.15 shows the measured efficiency curves of the proposed converter versus the input voltage $\left(V_{\text {in }}=100 \rightarrow 300 \mathrm{~V}\right)$, for $P_{o}$ equals $1 \mathrm{~kW}, 2 \mathrm{~kW}$, and $3 \mathrm{~kW}$. For $P_{o}=1 \mathrm{~kW}$ curve, the minimum efficiency is $96 \%$ at $V_{i n}=100 \mathrm{~V}$, and the maximum efficiency is $97.4 \%$ at $V_{\text {in }}=240 \mathrm{~V}$. For $P_{o}=2 \mathrm{~kW}$ curve, the minimum efficiency is $94.4 \%$ at $V_{i n}=100 \mathrm{~V}$, and the maximum efficiency is $97.1 \%$ at $V_{i n}=240 \mathrm{~V}$. For $P_{o}=3 \mathrm{~kW}$ curve, the minimum efficiency is $92.1 \%$ at $V_{\text {in }}=100 \mathrm{~V}$, and 
the maximum efficiency is $96.5 \%$ at $V_{i n}=260 \mathrm{~V}$. Figure 6.16 shows the measured efficiency curve of the developed prototype versus the output power. In this efficiency test, $V_{i n}=100 \mathrm{~V}$ and $200 \mathrm{~V}$, $V_{o}=800 \mathrm{~V}, P_{o}=600 \mathrm{~W} \rightarrow 3 \mathrm{~kW}$. In this test, when $V_{i n}=100 \mathrm{~V}$, the maximum efficiency is $96 \%$ at $P_{o}=1 \mathrm{~kW}$, and the minimum efficiency is $92.1 \%$ at $P_{o}=3 \mathrm{~kW}$, while when $V_{\text {in }}=200 \mathrm{~V}$, the maximum efficiency is $97.3 \%$ at $P_{o}=1 \mathrm{~kW}$, and the minimum efficiency is $95.8 \%$ at $P_{o}=3 \mathrm{~kW}$.

\subsection{Conclusion}

A new SEPIC-based step-up dc-dc converter with embedded discontinuous-current quasi-Zsource and switched capacitor networks was proposed in this paper. The proposed topology has the advantages of continuous input current, high step-up voltage gain, wide-input-voltage range, constant potential difference between the grounds of the input and output ports, and low voltage stress on the semiconductor devices. These features make the proposed converter a suitable power electronic interface between the fuel cell and the dc-link of the inverter in the EV. Finally, a 3$\mathrm{kW} / 800-\mathrm{V}$ prototype for the proposed topology was developed, and the theoretical analysis was validated by the experimental results. 


\section{Chapter 7 Design and Implementation of a New Transformerless Bidirectional DC-DC Converter with Wide Conversion Ratios}

\subsection{Introduction}

A new transformerless bidirectional buck-boost converter is proposed in this chapter. The proposed converter has a simple circuit structure, low component count, low voltage stress on the power transistors, and a wide voltage gain range. This makes it applicable in the energy storage charge/discharge systems, such as the electric vehicles (EV), microgrids and nanogrids with energy storage units, and uninterruptible power supplies. In addition, synchronous rectification between the complementary transistors is employed to improve the converter efficiency. A comprehensive analysis of the steady-state operation, small-signal model, component parameters design, and efficiency analysis of the proposed converter operating in a continuous conduction mode $(\mathrm{CCM})$ is given. Finally, a $1.6 \mathrm{~kW}$ scaled-down prototype was built using Silicon Carbide (SiC) MOSFETs to validate the effectiveness and feasibility of the proposed converter.

\subsection{Structure and Operating Principle of the Proposed Converter}

\subsubsection{Configuration of the Proposed Converter}

The configuration of the proposed BBB dc-dc converter is shown in Figure 7.1. It can be seen that the proposed converter is composed of three switches $\left(Q_{1}, Q_{2}\right.$, and $\left.Q_{3}\right)$, two inductors ( $L_{1}$, and $L_{2}$ ), four capacitors $\left(C_{1}, C_{2}, C_{3}\right.$, and $C_{4}$ ), and two ports (port $A$, and port $B$ ). The converter can manage the power flow either from port $A$ to port $B$, or from port $B$ to port $A$. The signals $G_{1}, G_{2}$, and $G_{3}$ are the triggering signals of switches $Q_{1}, Q_{2}$, and $Q_{3}$, respectively. Synchronous rectification is employed, where $G_{2}$, and $G_{3}$ are identical and they are complementary to $G_{1}$. To simplify the analysis, the following assumptions are made: (a) All the components are ideal, thus, the on-resistance of the switches, and the equivalent series resistances of the inductors and 
capacitors are ignored. (b) All the capacitors and inductors are large enough to apply the small ripple approximation.

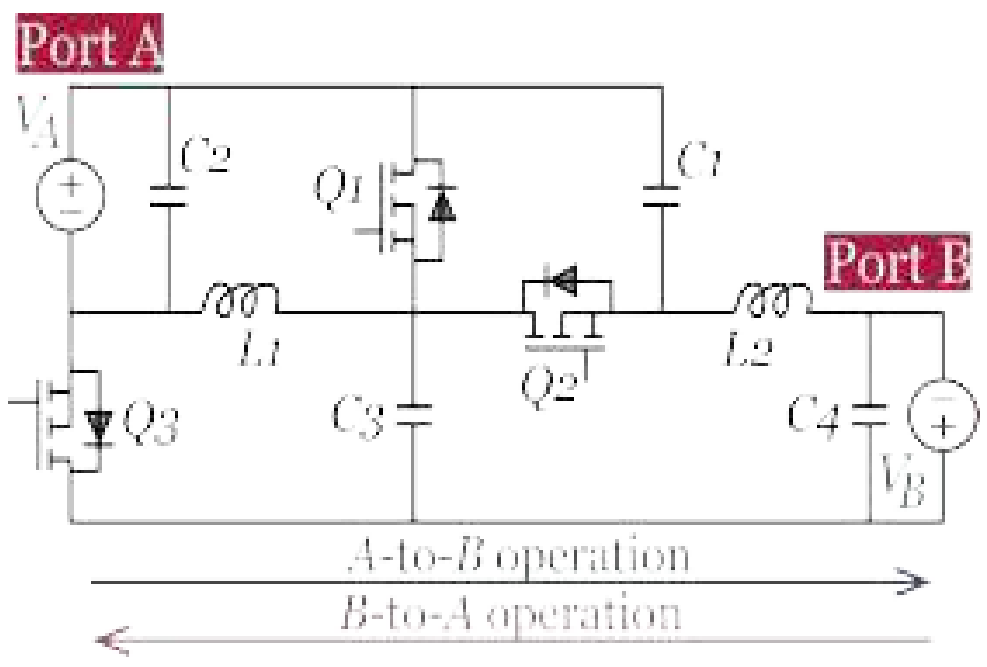

Figure 7.1: The schematic of the proposed converter.

\subsubsection{A-to-B Operation of the Proposed Converter}

In this operation, power flows from port $A$ to port $B$. The equivalent circuit of this operation is shown in Figure 7.2, where a voltage source $V_{A}$ is connected at port $A$, and a resistive load $R_{l}$ is connected at port $B$. The key waveforms for this operation are shown in Figure 7.4(a), as it has two switching states, namely: State 0, and State 1. In this operation, $Q_{1}$ is the main transistor and $Q_{2}$, and $Q_{3}$ are synchronous rectifiers.

There is a dead time between the rising edge of $G_{2}$, and $G_{3}$, and the falling edge of $G_{l}$. Another dead time is present between the falling edge of $G_{2}$, and $G_{3}$, and the rising edge of $G_{l}$. During these dead times, the current flows in the antiparallel diodes of $Q_{2}$, and $Q_{3}$, hence, the voltage across the drain and source of these transistors is close to zero. This provides zerovoltage-switching (ZVS) during turn-on and turn-off for $Q_{2}$, and $Q_{3}$, which enhances the converter efficiency. 


\section{1) State 0}

In this switching state, $Q_{1}$ is turned on, and $Q_{2}$ and $Q_{3}$ are turned off. The period of this state is $d_{1} T$, where $T$ is the periodic switching time, and $d_{1}$ is the duty cycle of $Q_{1}$. Figure $7.2($ a) shows the current flow paths during this switching state, and according to it, the following equations can be derived:

$$
\begin{aligned}
& \left\{\begin{array}{l}
V_{L 1}=V_{A} \\
V_{L 2}=V_{C 1}-V_{B}+V_{C 3}
\end{array}\right. \\
& \left\{\begin{array}{l}
i_{C 1}=i_{c 3}=-I_{L 2} \\
i_{C 4}=I_{L 2}-\frac{V_{B}}{R_{1}}
\end{array}\right.
\end{aligned}
$$

2) State 1

In this switching state, $Q_{1}$ is turned off, and $Q_{2}$ and $Q_{3}$ conduct current in the reverse direction. The period of this state is $d_{2} T=d_{3} T=\left(1-d_{1}\right) T$, where $d_{2}$ and $d_{3}$ are the duty cycle values of $Q_{2}$, and $Q_{3}$, respectively. Figure 7.2(b) shows the current flow paths during this switching state, and according to it, the following equations can be derived:

$$
\begin{gathered}
\left\{\begin{array}{l}
V_{L 1}=-V_{C 3}=V_{A}-V_{C 1} \\
V_{L 2}=-V_{B}+V_{C 3}
\end{array}\right. \\
\left\{\begin{array}{l}
i_{C 1}=i_{C 3}=\frac{I_{L 1}-I_{L 2}}{2} \\
i_{C 4}=i_{L 2}-\frac{V_{B}}{R_{1}}
\end{array}\right.
\end{gathered}
$$

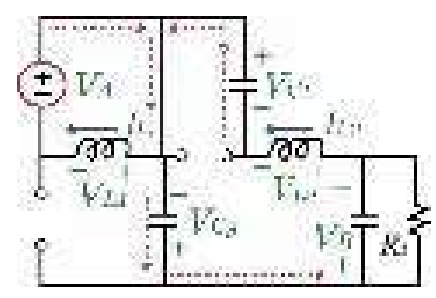

(a)

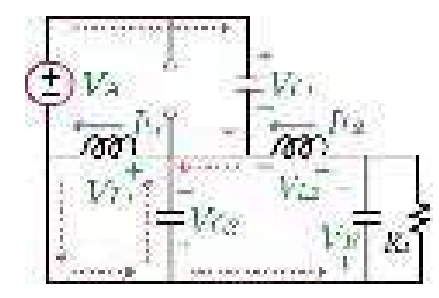

(b)

Figure 7.2: Current-flow paths of the proposed converter in the A-to-B operation. (a) State 0: G1 G2 G3 = 100. (b) State 1: G1 G2 G3 = 011. 


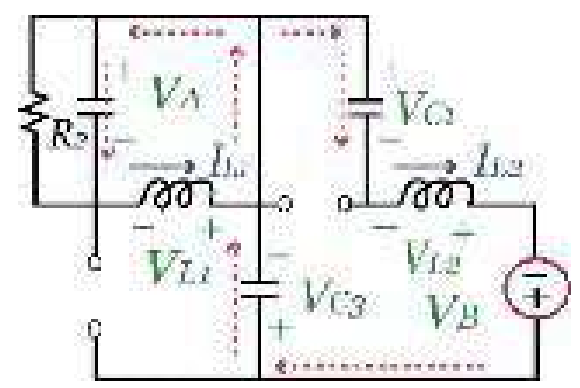

(a)

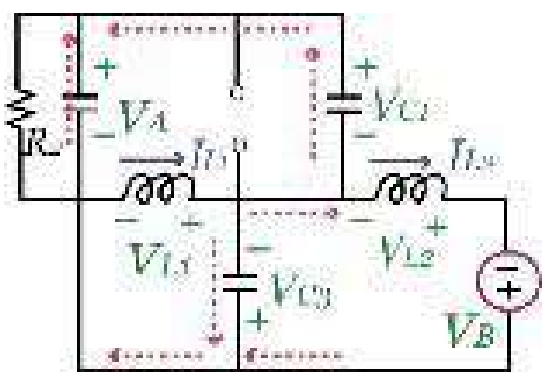

(b)

Figure 7.3: Current-flow paths of the proposed converter in the B-to-A operation. (a) State 0: G1 G2 G3 = 100. (b) State 1: G1 G2 G3 = 011 .

3) Capacitor Voltages and Inductor Currents

From (1), and (3), and using the volt-second balance rule on inductors $L_{1}$, and $L_{2}$, the capacitor voltages, and the voltage gain for $A$-to- $B$ operation $M_{A B}$ can be derived as shown in (5), and (6), respectively:

$$
\begin{aligned}
V_{c 1} & =\frac{V_{A}}{1-d_{1}} \\
V_{c 3} & =\frac{d_{1}}{1-d_{1}} V_{A} \\
V_{B} & =\frac{2 d_{1}}{1-d_{1}} V_{A} \\
M_{A B} & =\frac{V_{B}}{V_{A}}=\frac{2 d_{1}}{1-d_{1}}
\end{aligned}
$$

From (2), and (4), and using the charge-second balance rule on capacitors $C_{1}, C_{3}$ and $C_{4}$, the inductor currents can be derived as shown in (7): 


$$
\begin{aligned}
I_{L 1} & =\frac{1+d_{1}}{1-d_{1}} I_{L 2} \\
I_{L 2} & =\frac{V_{B}}{R_{1}}=\frac{2 d_{1}}{\left(1-d_{1}\right) R_{1}} V_{A}
\end{aligned}
$$

\subsubsection{B-to-A Operation of the Proposed Converter}

In this operation, power flows from port $B$ to port $A$. The equivalent circuit of this operation is shown in Figure 7.3, where a voltage source $V_{B}$ is connected at port $B$, and a resistive load $R_{2}$ is connected at port $A$. In this operation, $Q_{2}$, and $Q_{3}$ are the main power switches and $Q_{1}$ is a synchronous rectifier. Dead time is employed between the main switches and the synchronous rectifier, as shown in Figure 7.4(b), to provide ZVS during turn-on and turn-off for $Q_{1}$. The capacitor voltages, inductor current, and voltage gain $M_{B A}$ for this operation can be derived from (5), (6), and (7), by replacing $d_{1}$ by (1- $\left.d_{2}\right)$, as following:

$$
\begin{aligned}
M_{B A} & =\frac{V_{A}}{V_{B}}=\frac{d_{2}}{2\left(1-d_{2}\right)} \\
V_{c 1} & =\frac{V_{B}}{2\left(1-d_{2}\right)} \\
V_{C 3} & =\frac{V_{B}}{2} \\
V_{A} & =\frac{d_{2}}{2\left(1-d_{2}\right)} V_{B} \\
I_{L 1} & =\frac{2-d_{2}}{d_{2}} I_{L 2} \\
I_{L 2} & =\frac{V_{A}}{R_{2}} M_{B A}=\left(\frac{d_{2}}{2\left(1-d_{2}\right)}\right)^{2} \frac{V_{B}}{R_{2}}
\end{aligned}
$$




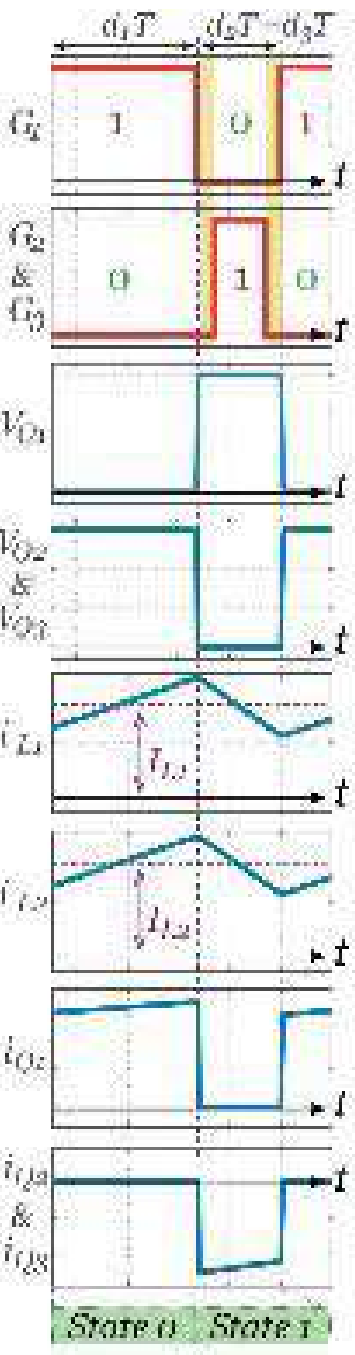

(a)
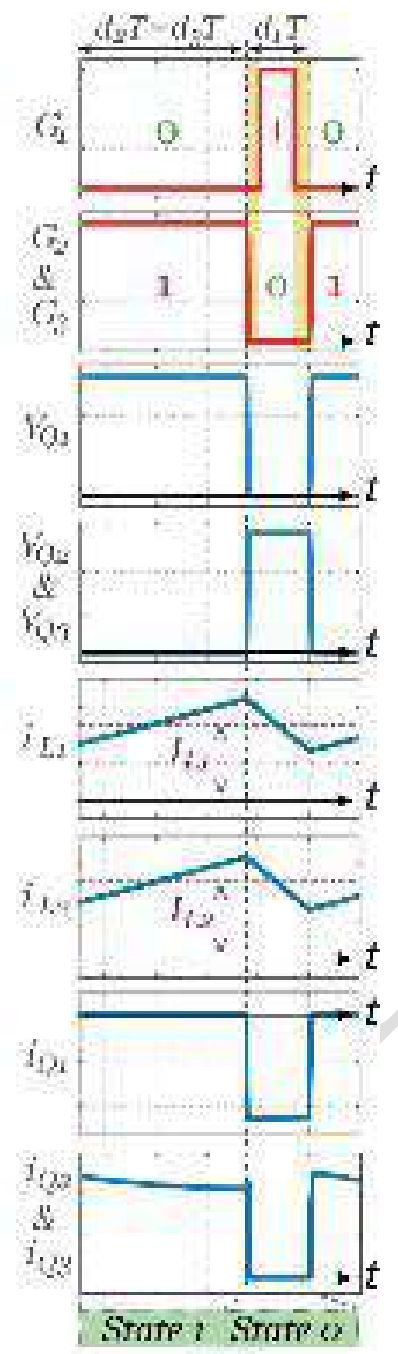

(b)

Figure 7.4: Typical waveforms of the proposed converter. (a) A-to-B operation. (b) B-to-A operation.

\subsubsection{Switches, Capacitors, and Inductors design}

1) Switches Selection:

Equations (11)-(13) describe the voltage and current stresses on $\mathrm{Q}_{1}, \mathrm{Q}_{2}$, and $\mathrm{Q}_{3}$, respectively.

$$
\begin{gathered}
\mathrm{V}_{\mathrm{Q} 1}=\mathrm{V}_{\mathrm{Q} 2}=\mathrm{V}_{\mathrm{Q} 3}=\frac{\mathrm{V}_{\mathrm{B}}}{2 \mathrm{~d}_{1}} \\
\mathrm{I}_{\mathrm{Q} 1}=\mathrm{I}_{\mathrm{L} 1}+\mathrm{I}_{\mathrm{L} 2} \\
\mathrm{I}_{\mathrm{Q} 2}=\mathrm{I}_{\mathrm{Q} 3}=\frac{\mathrm{I}_{\mathrm{L} 1}+\mathrm{I}_{\mathrm{L} 2}}{2}
\end{gathered}
$$


The selected transistors should tolerate these voltage and current stresses.

12) Capacitors Selection:

Equations (5), and (9) describe the voltage stress across $C_{1}, C_{2}, C_{3}$, and $C_{4}$. The relationship between the capacitance of these capacitors and the associated ripple voltages is depicted in (14):

$$
\begin{aligned}
\mathrm{C}_{1} & =\frac{2 \mathrm{~d}_{1}{ }^{2}}{\Delta \mathrm{V}_{\mathrm{C} 1} \mathrm{f}_{\mathrm{s}}\left(1-\mathrm{d}_{1}\right) \mathrm{R}_{1}} \mathrm{~V}_{\mathrm{A}}=\frac{\mathrm{d}_{2}{ }^{2}}{4 \Delta \mathrm{V}_{\mathrm{C} 1} \mathrm{f}_{\mathrm{s}}\left(1-\mathrm{d}_{2}\right) \mathrm{R}_{2}} \mathrm{~V}_{\mathrm{B}} \\
\mathrm{C}_{2} & =\frac{\mathrm{d}_{2}{ }^{3} \mathrm{~V}_{\mathrm{B}}}{4 \mathrm{f}_{\mathrm{s}} \mathrm{R}_{2} \Delta \mathrm{V}_{\mathrm{C} 4}\left(1-\mathrm{d}_{2}\right)^{2}} \\
\mathrm{C}_{3} & =\frac{2 \mathrm{~d}_{1}{ }^{2}}{\Delta \mathrm{V}_{\mathrm{C} 3} \mathrm{f}_{\mathrm{s}}\left(1-\mathrm{d}_{1}\right) \mathrm{R}_{1}} \mathrm{~V}_{\mathrm{A}}=\frac{\mathrm{d}_{2}{ }^{2}}{4 \Delta \mathrm{V}_{\mathrm{C} 3} \mathrm{f}_{\mathrm{s}}\left(1-\mathrm{d}_{2}\right) \mathrm{R}_{2}} \mathrm{~V}_{\mathrm{B}} \\
\mathrm{C}_{4} & =\frac{\Delta \mathrm{i}_{\mathrm{L} 2}}{8 \mathrm{f}_{\mathrm{s}} \Delta \mathrm{V}_{\mathrm{C} 4}}
\end{aligned}
$$

By knowing the switching fresqueand fthe desired capacitor voltaye $1, \Delta \mathrm{l}$ legles $\Delta \mathrm{V}_{\mathrm{C} 3}$, and $\Delta \mathrm{V}_{\mathrm{C} 4}$, the capacitance of $\mathrm{C}_{1}, \mathrm{C}_{2}, \mathrm{C}_{3}$, and $\mathrm{C}_{4}$ can be determined.

\section{3) Inductors Selection:}

Equations (7), and (10) calculate the currents the currents flowing in inductors $\mathrm{L}_{1}$, and $\mathrm{L}_{2}$. The relationship between the inductance of these inductors and the associated ripple currents is depicted in (15). These equations can be used to determine the inductance of $\mathrm{L}_{1}$, and $\mathrm{L}_{2}$, when the desired inductor current ripples $\Delta \mathrm{i}_{\mathrm{L} 1}$, and $\Delta \mathrm{i}_{\mathrm{L} 2}$ are known.

$$
\begin{aligned}
\mathrm{L}_{1} & =\frac{\mathrm{V}_{\mathrm{A}} \mathrm{d}_{1}}{\mathrm{f}_{\mathrm{s}} \Delta \mathrm{i}_{\mathrm{L} 1}}=\frac{\mathrm{V}_{\mathrm{B}} \mathrm{d}_{2}}{2 \mathrm{f}_{\mathrm{s}} \Delta \mathrm{i}_{\mathrm{L} 1}} \\
\mathrm{~L}_{2} & =\frac{\mathrm{V}_{\mathrm{A}} \mathrm{d}_{1}}{\mathrm{f}_{\mathrm{s}} \Delta \mathrm{i}_{\mathrm{L} 2}}=\frac{\mathrm{V}_{\mathrm{B}} \mathrm{d}_{2}}{2 \mathrm{f}_{\mathrm{s}} \Delta \mathrm{i}_{\mathrm{L} 1}}
\end{aligned}
$$

\subsubsection{Comparison with Other Bidirectional Buck-Boost Converters}

In this section, the proposed converter is compared with six other BBB converters. In this comparative study, the proposed converter is compared with the conventional BBB converter, the converter, the bidirectional version of the KY-based converter in [190], the CBB-IIM converter, 
the CBB-CIM converter, and the bidirectional version of the quadratic buck-boost converter in [191]. The circuit diagrams of these converters are shown in Figure 7.5. Table 7.1 shows the static voltage gain for $A$-to- $B$ and $B$-to- $A$ operations, the normalized voltage stress of the power switches, and the number of components of the proposed converter and the other BBB converters in this comparative study.

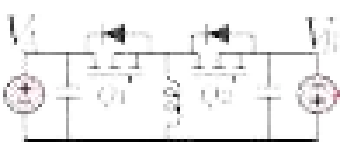

(a)

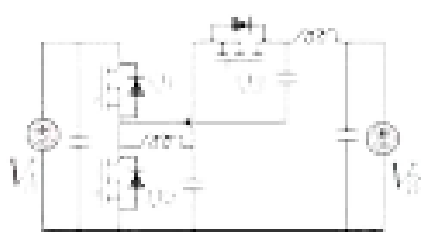

(c)

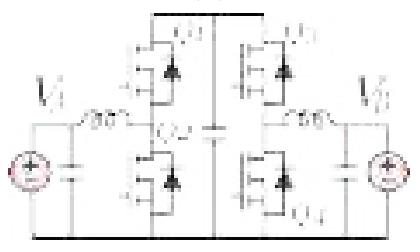

(e)

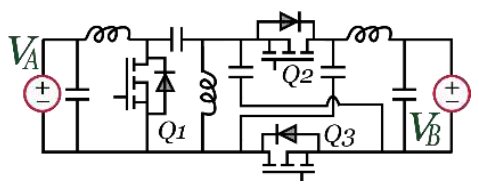

(b)

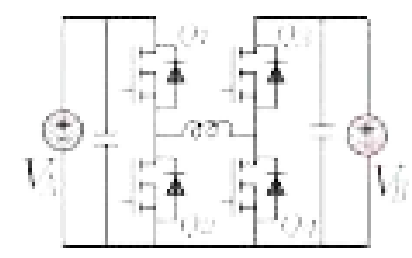

(d)

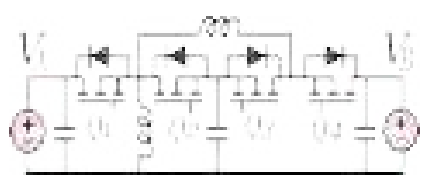

(f)

Figure 7.5: Other BBB converters. (a) Conventional BBB converter. (b) Converter in [192]. (c) Bidirectional version of the KY-based converter in [190]. (d) CBB-IIM. (e) CBB-CIM. (f) Bidirectional version of the quadratic converter in [191].

Figure 7.6(a) and Figure 7.6(b) show the voltage gain of the compared converters versus the duty cycle for $A$-to- $B$ and $B$-to- $A$ operations, respectively. In this comparison, the normalized voltage stress on the power switches is depicted as a function of $V_{B}$ and $M_{A B}$. 

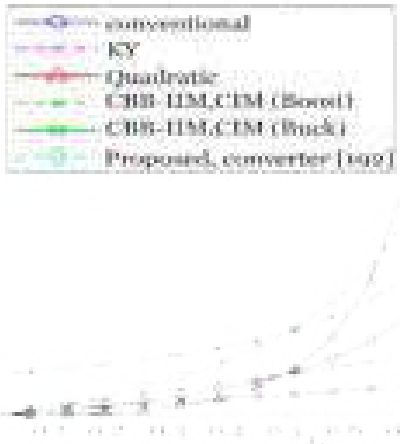

(a)

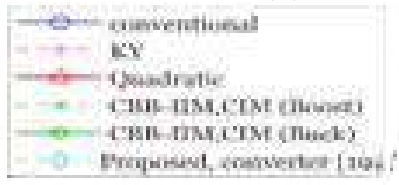

(b)

Figure 7.6: Comparison of voltage gain between the proposed converter and other BBB converters. (a) A-to-B operation. (b) B-to-A operation.

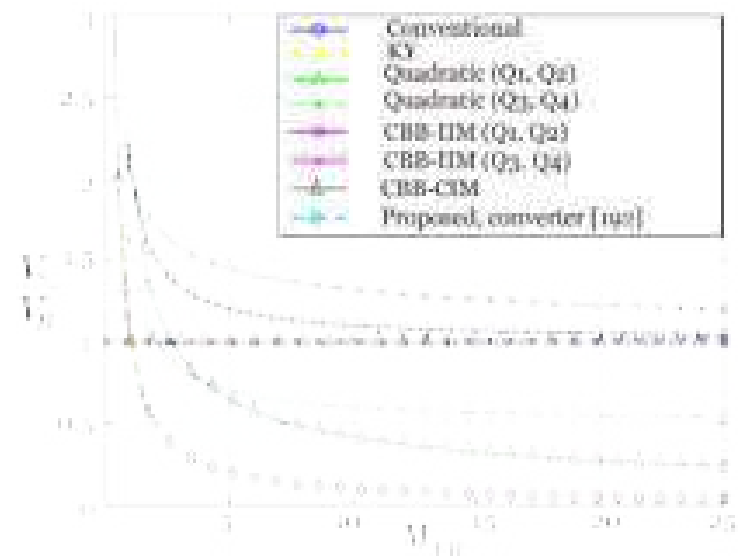

Figure 7.7: Normalized voltage stress on the switches of the compared converters.

The graphical representation of the normalized voltage stress on the power switches of the compared converters is shown in Figure 7.7.

Comparing the proposed converter with the conventional BBB converter, on one hand, the 
conventional BBB converter has lower number of switches and passive components, on the other hand, the voltage gain of the proposed converter is higher in $A$-to- $B$ operation and lower in $B$-to- $A$ operation. This makes the proposed converter better for the applications that require buck and boost operations in both power flow directions, but with boost operation dominant in one power flow direction and buck operation dominant in the other power flow direction (i.e. energy storage systems with large voltage swings). Additionally, the voltage stress in the proposed converter is lower, which enables the utilization of power switches with lower rated voltage. The converter presented in [192] has the same voltage gain in the $A$-to- $B$ and $B$-to- $A$ operations, and the same voltage stress as in the proposed converter. Nevertheless, the proposed converter has one less inductor and one less capacitor.

Table 7.1: COMPARISON BETWEEN THE PROPOSED AND OTHER BBB CONVERTERS

\begin{tabular}{|c|c|c|c|c|c|}
\hline \multirow{2}{*}{ Topology } & \multirow{2}{*}{ Components } & \multirow{2}{*}{\multicolumn{2}{|c|}{ Voltage stress $\left(V_{S}\right)$}} & \multicolumn{2}{|c|}{ Voltage gain } \\
\hline & & & & $A$-to- $B$ operation & $B$-to- $A$ operation \\
\hline $\begin{array}{l}\text { Conventional BBB } \\
\text { converter }\end{array}$ & $\begin{array}{l}2 \text { Switches } \\
1 \text { Inductor } \\
2 \text { Capacitors }\end{array}$ & $Q_{1,2}$ & $\left(\frac{M_{A B}+1}{M_{A B}}\right) V_{B}$ & $M_{A B}=\frac{d_{1}}{1-d_{1}}$ & $M_{B A}=\frac{d_{2}}{1-d_{2}}$ \\
\hline $\begin{array}{l}\text { KY-based } \\
\text { Converter [190] }\end{array}$ & $\begin{array}{l}3 \text { Switches } \\
2 \text { Inductors } \\
4 \text { Capacitors }\end{array}$ & $Q_{1,2,3}$ & $\frac{V_{B}}{M_{A B}}$ & $M_{A B}=2 d_{1}$ & $M_{B A}=\frac{1}{2\left(1-d_{2}\right)}$ \\
\hline \multirow{2}{*}{$\begin{array}{l}\text { Quadratic } \\
\text { Converter [191] }\end{array}$} & 4 Switches & $Q_{l, 2}$ & $\left(\frac{1+\sqrt{M_{A B}}}{M_{A B}}\right) V_{B}$ & \multirow{2}{*}{$M_{A B}=\frac{d_{1}^{2}}{\left(1-d_{1}\right)^{2}}$} & \multirow{2}{*}{$M_{B A}=\frac{d_{2}^{2}}{\left(1-d_{2}\right)^{2}}$} \\
\hline & 3 Capacitors & $Q_{3,4}$ & $\left(\frac{1+\sqrt{M_{A B}}}{\sqrt{M_{A B}}}\right) V_{B}$ & & \\
\hline \multirow{2}{*}{$\begin{array}{l}\text { CBB-IIM } \\
\text { converter }\end{array}$} & $\begin{array}{l}4 \text { Switches } \\
1 \text { Inductor }\end{array}$ & $Q_{1,2}$ & $\frac{V_{B}}{M_{A B}}$ & \multirow{2}{*}{$M_{A B}= \begin{cases}d_{1} & \text { (Buck) } \\
\frac{1}{1-d_{1}} & \text { (Boost) }\end{cases}$} & \multirow{2}{*}{$M_{B A}= \begin{cases}d_{2} & \text { (Buck) } \\
\frac{1}{1-d_{2}} & \text { (Boost })\end{cases}$} \\
\hline & 2 Capacitors & $Q_{3,4}$ & $V_{B}$ & & \\
\hline $\begin{array}{l}\text { CBB-CIM } \\
\text { converter }\end{array}$ & $\begin{array}{l}4 \text { Switches } \\
2 \text { Inductor } \\
3 \text { Capacitors }\end{array}$ & $Q_{l, 2,3,4}$ & $\begin{cases}\frac{V_{B}}{M_{A B}} & M_{A B} \leq 1 \\
V_{B} & M_{A B}>1\end{cases}$ & $M_{A B}= \begin{cases}d_{1} & \text { (Buck) } \\
\frac{1}{1-d_{1}} & \text { (Boost) }\end{cases}$ & $M_{B A}= \begin{cases}d_{2} & \text { Buck) } \\
\frac{1}{1-d_{2}} & \text { (Boost) }\end{cases}$ \\
\hline Converter [192] & $\begin{array}{l}3 \text { Switches } \\
3 \text { Inductors } \\
5 \text { Capacitors }\end{array}$ & $Q_{1,2,3}$ & $\left(\frac{M_{A B}+2}{2 M_{A B}}\right) V_{B}$ & $M_{A B}=\frac{2 d_{1}}{1-d_{1}}$ & $M_{B A}=\frac{d_{2}}{2\left(1-d_{2}\right)}$ \\
\hline Proposed & $\begin{array}{l}3 \text { Switches } \\
2 \text { Inductors } \\
4 \text { Capacitors }\end{array}$ & $Q_{1,2,3}$ & $\left(\frac{M_{A B}+2}{2 M_{A B}}\right) V_{B}$ & $M_{A B}=\frac{2 d_{1}}{1-d_{1}}$ & $M_{B A}=\frac{d_{2}}{2\left(1-d_{2}\right)}$ \\
\hline
\end{tabular}


The KY-based BBB converter has the least voltage stress on its power switches, however, its voltage gain range is limited, and hence, it is not suitable for applications that require wide voltage gain range operation. Comparing the proposed converter with the bidirectional version of the quadratic buck-boost converter in [191], the proposed converter has higher voltage gain in $A$-to- $B$ operation for $d_{l}<0.66$, and lower voltage gain in $B$-to- $A$ operation for $0.33<d_{2}<0.66$. In the quadratic BBB converter, the voltage stress on two of its switches $\left(Q_{3}\right.$ and $Q_{4}$ ) is higher compared to the voltage stress on any switch of the proposed converter.

Additionally, the proposed converter has one less power switch and continuous current at port $B$, on the contrary with the quadratic BBB converter which has discontinuous currents at both of its ports. The CBB-IIM converter, on one hand, has one less inductor and two less capacitors, but on the other hand, it has an extra power switch compared to the proposed converter. The currents at port $A$ and port $B$ of the CBB-IIM converter are discontinuous. Additionally, the voltage stress on two of switches $\left(Q_{3}\right.$ and $\left.Q_{4}\right)$ of the CBB-IIM converter is higher compared to the voltage stress on any switch of the proposed converter. The CBB-CIM converter has one less capacitor and an extra power switch compared to the proposed converter. This converter has continuous currents at port $A$ and port $B$. The voltage stress on the power switches of the CBB-CIM converter is higher compared to the proposed converter. The proposed converter has higher voltage gain in $A$-to- $B$ operation for $d_{1}>0.5$ compared to the CBB-IIM and CBB-CIM converters (in boost mode), and lower voltage gain in $B$-to- $A$ operation for $d_{2}<0.5$ compared to the CBB-IIM and CBB-CIM converters (in buck mode). 


\subsubsection{Efficiency Analysis}

The power losses of the proposed converter are calculated by (16), where $P_{l o s s}, P_{Q_{-} \text {cond, }} P_{Q_{-} s w}$, $P_{L}$, and $P_{C}$ are the total power loss, the conduction loss of the transistors, the switching loss of the transistors, the loss of inductors, and the loss of the capacitors. The switching loss of the transistors is for $Q_{1}$ (in $A$-to- $B$ operation), and for $Q_{2}$ and $Q_{3}$ (in $B$-to- $A$ operation).

$$
P_{\text {loss }}=P_{Q_{-} \text {cond },}+P_{Q_{-} s w}+P_{L}+P_{C}
$$

The terms of (16) are calculated by (17)-(21), where $R_{D S 1}, R_{D S 2}, R_{D S 3}, R_{L 1}, R_{L 2}, E S R_{1}, E S R_{2}$, $E S R_{3}$, and $E S R_{4}$ are the on resistances of $Q_{1}, Q_{2}$, and $Q_{3}$, the series resistances of $L_{1}$, and $L_{2}$, and the equivalent series resistances of $C_{1}, C_{2}, C_{3}$, and $C_{4}$, respectively.

The switching loss of any of the three transistors can be calculated by (19), where $i$ can be 1, 2, or 3, referring to $Q_{1}, Q_{2}$, or $Q_{3}$, respectively. In (19), $t_{r i}, t_{f i}$, and $C_{O S S i}$ are the rise time, fall time, and the parasitic output capacitance of $Q_{i}$, respectively.

$$
\begin{aligned}
& P_{Q \_ \text {cond }}=d_{1} I_{Q 1}{ }^{2} R_{D S 1}+d_{2}\left(I_{Q 2}{ }^{2} R_{D S 2}+I_{Q 3}{ }^{2} R_{D S 3}\right) \\
& P_{Q \_s w}=\left\{\begin{array}{lr}
P_{Q 1}{ }_{s w} & (A \text {-to- } B \text { operation }) \\
P_{Q 2 \_s w}+P_{Q 3 \_s w} & (B \text {-to- } A \text { operation })
\end{array}\right. \\
& P_{Q i_{-} s w}=f_{S}\left(0.5 V_{Q i} I_{Q i}\left(t_{r i}+t_{f i}\right)+0.5 V_{Q i}{ }^{2} C_{O S S i}\right) \\
& P_{L}=I_{L 1}{ }^{2} R_{L 1}+I_{L 2}{ }^{2} R_{L 2} \\
& P_{C}=I_{C 1}{ }^{2} \mathrm{ESR} R_{1}+I_{C 2}{ }^{2} \mathrm{ESR}_{2}+I_{C 3}{ }^{2} \mathrm{ESR}_{3}+I_{C 4}{ }^{2} \mathrm{ESR}_{4}
\end{aligned}
$$


The inductor currents can be calculated by (7), and (10). The current and voltage stresses on the transistors can be calculated by (11)-(13). The root-mean-square (rms) values of the capacitor currents $I_{C 1}, I_{C 2}, I_{C 3}$, and $I_{C 4}$, can be calculated by (22).

$$
\begin{aligned}
I_{C 1} & =I_{C 3}=\sqrt{d_{1} I_{L 2}{ }^{2}+\left(1-d_{1}\right)\left(\frac{I_{L 1}-I_{L 2}}{2}\right)^{2}} \\
I_{C 2} & =\sqrt{d_{1}\left(I_{L 1}-M_{A B} I_{L 2}\right)^{2}+\left(1-d_{1}\right)\left(I_{L 1}-\left(1+M_{A B}\right) I_{L 2}\right)^{2}} \\
I_{C 4} & =\frac{\Delta i_{L 2}}{2 \sqrt{3}}
\end{aligned}
$$

The efficiency $\eta$ can be calculated by (23)

$$
I=\begin{array}{ll}
\frac{V_{A} I_{L 2} M_{A B}-P_{\text {LosS }}}{V_{A} I_{L 2} M_{A B}} & (A \text {-to- } B \text { operation }) \\
\left(\frac{V_{B} I_{L 2}-P_{\text {LosS }}}{V_{B} I_{L 2}}\right. & (B \text {-to- } A \text { operation })
\end{array}
$$

\subsection{Dynamic Modeling and Controller Design}

\subsubsection{Small-Signal Modeling}

The small-signal modeling is used to derive the open-loop transfer functions that can be used in designing the controller, and analyzing the dynamic behavior of the proposed converter. For both $A$-to- $B$ and $B$-to- $A$ operations, the small-signal modeling is done using (1)-(4), by replacing each state variable and input by its dc quiescent value plus a small ac perturbation. 
In $A$-to- $B$ operation, the small-signal model is presented in (24), where $I_{L 1}, I_{L 2}, V_{C l}$, and $d_{1}$ are the dc values of the inductor currents, the voltage across $C_{l}$, and the duty cycle of $Q_{l}$, and $\hat{\imath}_{L 1}$, $\hat{\imath}_{L 2}, \hat{v}_{c 1}, \hat{v}_{C 3}, \hat{d}_{1}$, and $\hat{v}_{B}$ are small perturbations in inductor currents, capacitor voltages, duty cycle, and port $B$ voltage.

$$
\begin{aligned}
& L_{1} \frac{d \hat{\imath}_{L 1}}{d t}=-d_{1} \hat{v}_{C 1}+V_{C 1} \hat{d}_{1} \\
& L_{2} \frac{d \hat{\imath}_{L 2}}{d t}=V_{C 1} \hat{d}_{1}+\left(d_{1}+\frac{C_{1}}{C_{3}}\right) \hat{v}_{C 1}-\hat{v}_{B} \\
& 2 C_{1} \frac{d \hat{v}_{C 1}}{d t}=d_{1} \hat{\imath}_{L 1}-\left(I_{L 1}+I_{L 2}\right) \hat{d}_{1}-\left(1+d_{1}\right) \hat{\imath}_{L 2} \\
& C_{4} \frac{d \hat{v}_{B}}{d t}=\hat{\imath}_{L 2}-\frac{\hat{v}_{B}}{R_{1}} \\
& \left(\hat{v}_{C 3}=\frac{C_{1}}{C_{3}} \hat{v}_{C 1}\right.
\end{aligned}
$$

By using Laplace transform on (24), the control-to-output transfer function can be given, as shown in (25).

$$
G_{V_{B} d_{1}}(\mathrm{~s})=\frac{\hat{v}_{B}(s)}{\hat{d}_{1}(s)}=\frac{a_{0} s^{2}+a_{1} s+a_{2}}{b_{0} s^{4}+b_{1} s^{3}+b_{2} s^{2}+b_{3} s+b_{4}}
$$

Where 


$$
\begin{aligned}
a_{0}= & 2 C_{1} V_{C 1} L_{1} L_{2} \\
a_{1}= & -L_{1} L_{2}\left(I_{L 1}+I_{L 2}\right)\left(d_{1}+\frac{C_{1}}{C_{3}}\right) \\
a_{2}= & \left(L_{1}\left(1+d_{1}\right)+L_{2} d_{1}-\left(1+d_{1}\right) L_{1}\right) V_{C 1}\left(d_{1}+\frac{C_{1}}{C_{3}}\right) \\
& +L_{2} d_{1}^{2} V_{C 1} \\
b_{0}= & 2 C_{1} C_{4} L_{1} L_{2}^{2} \\
b_{1}= & \frac{2 C_{1} L_{1} L_{2}^{2}}{R_{1}} \\
b_{2}= & \left(1+d_{1}\right)\left(d_{1}+\frac{C_{1}}{C_{3}}\right) C_{4} L_{1} L_{2}+d_{1}^{2} L_{2}^{2} C_{4} \\
& +2 C_{1} L_{1} L_{2} \\
b_{3}= & \frac{1}{R_{1}}\left(L_{1} L_{2}\left(1+d_{1}\right)\left(d_{1}+\frac{C_{1}}{C_{3}}\right)+d_{1}^{2} L_{2}^{2}\right) \\
b_{4}= & L_{1}\left(1+d_{1}\right)\left(\left(d_{1}+\frac{C_{1}}{C_{3}}\right)-1\right)+L_{2} d_{1}^{2}
\end{aligned}
$$

In $B$-to- $A$ operation, the small-signal model is presented in (26), where $d_{2}\left(=d_{3}\right)$ is the duty cycle of $Q_{2}$, and $Q_{3}$. Also, $\hat{d}_{2}$ and $\hat{v}_{A}$ are small perturbations in duty cycle, and port $A$ voltage, respectively. By using Laplace transform on (26), the control-to-output transfer function can be given, as shown in (27).

$$
\begin{aligned}
& L_{1} \frac{d \hat{\imath}_{L 1}}{d t}=\hat{v}_{A}-V_{C 1} \hat{d}_{2}-d_{2} \hat{v}_{C 1} \\
& L_{2} \frac{d \hat{\imath}_{L 2}}{d t}=-V_{C 1} \hat{d}_{2}+\left(\frac{C_{1}}{C_{3}}+\left(1-d_{2}\right)\right) \hat{v}_{C 1} \\
& 2 C_{1} \frac{d \hat{v}_{C 1}}{d t}=\left(2-d_{2}\right) \hat{\imath}_{L 2}-\left(I_{L 1}+I_{L 2}\right) \hat{d}_{2}-d_{2} \hat{\imath}_{L 1} \\
& C_{2} \frac{d \hat{v}_{A}}{d t}=\left(1-\frac{d_{2}}{2}\right) \hat{\imath}_{L 1}-\frac{d_{2}}{2} \hat{\imath}_{L 2}-\left(I_{L 1}+I_{L 2}\right) \hat{d}_{2}-\frac{\hat{V}_{A}}{R_{1}} \\
& \left(\hat{v}_{C 3}=\frac{C_{1}}{C_{3}} \hat{v}_{C 1}\right. \\
& G_{V_{A} d_{2}}(\mathrm{~s})=\frac{\hat{v}_{A}(s)}{\hat{d}_{2}(s)}=\frac{e_{0} s^{3}+e_{1} s^{2}+e_{2} s+e_{3}}{f_{0} s^{4}+f_{1} s^{3}+f_{2} s^{2}+f_{3} s+f_{4}}
\end{aligned}
$$


Where

$$
\begin{aligned}
e_{0}= & -2 C_{1} L_{1}{ }^{2} L_{2}{ }^{2} I_{L 2} \\
e_{1}= & 2 C_{1} L_{1} L_{2} V_{C 1}\left(-L_{2}+d_{1} L_{1}\right) \\
e_{2}= & \left(L_{2} d_{2}{ }^{2}+L_{1}\left(2-d_{2}\right)\left(1-d_{2}\right)\right)\left(L_{1} L_{2} I_{L 2}\right)+ \\
& \left(L_{2} d_{2}+L_{1} d_{2}\left(1-d_{2}+\frac{C_{1}}{C_{3}}\right)\right)\left(I_{L 1}+I_{L 2}\right) L_{1} L_{2} \\
e_{3}= & \left(L_{1} d_{2}{ }^{2}+L_{1}\left(2-d_{2}\right)\left(1-d_{2}\right)\right)\left(L_{2}-d_{1} L_{1}\right) V_{C 1} \\
& \left.+\left(L_{2} d_{2}+L_{1} d_{2}\left(1-d_{2}+\frac{C_{1}}{C_{3}}\right)\right)\left(2-d_{2}\right) L_{1} V_{C 1}\right) \\
f_{0}= & -2 d_{2} C_{C 1} C_{2} L_{2}{ }^{2} L_{1}{ }^{2} \\
f_{1}= & \frac{2}{R_{2}} C_{1} L_{1}{ }^{2} L_{2}{ }^{2} \\
f_{2}= & -2 C_{1} L_{1} L_{2}{ }^{2}+\left(\begin{array}{c}
L_{2} d_{2}{ }^{2}+ \\
L_{1}\left(2-d_{2}\right)\left(1-d_{2}\right)
\end{array}\right)\left(L_{1} L_{2} C_{2}\right) \\
f_{3}= & -\left(L_{2} d_{2}{ }^{2}+L_{1}\left(2-d_{2}\right)\left(1-d_{2}\right)\right)\left(\frac{L_{1} L_{2}}{R_{2}}\right) \\
f_{4}= & L_{2}{ }^{2} d_{2}{ }^{2}+L_{1} L_{2}\left(2-d_{2}\right)\left(1-d_{2}\right) \\
- & d_{2} L_{2}\left(L_{2} d_{2}+L_{1} d_{2}\left(1-d_{2}+\frac{C_{1}}{C_{3}}\right)\right) \\
( &
\end{aligned}
$$

\subsubsection{Controller Design}

In the developed experiment, two proportional integral (PI) controllers are adopted to regulate the voltage of port $A$ and port $B$, in the $B$-to- $A$ and $A$-to- $B$ operations, respectively. The parameters of the closed-loop PI voltage controller in the $A$-to- $B$ operation are: $K_{P 1}=0.000025$, and $K_{I 1}=$ 0.00025. The parameters of the closed-loop PI voltage controller in the $B$-to- $A$ operation are: $K_{P 2}$ $=0.001$, and $K_{I 2}=.0001$. The structure of the closed-loop voltage controllers in the $B$-to- $A$ and $A$ to- $B$ operations is shown in Figure 7.8. By means of (25), (27), and the parameters of the experiment in Table 7.2, compensated transfer functions $\left(G_{C_{-} A B}(\mathrm{~s})\right.$ and $\left.G_{C_{-} B A}(\mathrm{~s})\right)$ of the proposed converter in $A$-to- $B$ and $B$-to- $A$ operations are given in (28) and (29), respectively. 


$$
\begin{gathered}
G_{C_{-} A B}(\mathrm{~s})=\left(K_{P 1}+\frac{K_{I 1}}{s}\right) \cdot G_{V_{B} d_{1}}(\mathrm{~s})=\frac{x_{0} s^{3}+x_{1} s^{2}+x_{2} s+x_{3}}{x_{4} s^{5}+x_{5} s^{4}+x_{6} s^{3}+x_{7} s^{2}+x_{8} s} \\
G_{C_{-} B A}(\mathrm{~s})=\left(K_{P 2}+\frac{K_{I 2}}{s}\right) \cdot G_{V_{A} d_{2}}(\mathrm{~s})=\frac{y_{0} s^{4}+y_{1} s^{3}+y_{2} s^{2}+y_{3} s+y_{4}}{y_{5} s^{5}+y_{6} s^{4}+y_{7} s^{3}+y_{8} s^{2}+y_{9} s}
\end{gathered}
$$

Where $x_{0}=3.18 \mathrm{e} 6, x_{1}=-3.16 \mathrm{e} 9, x_{2}=1.12 \mathrm{e} 13, x_{3}=1.1 \mathrm{e} 12, x_{4}=27, x_{5}=1125, x_{6}=2 \mathrm{e} 9, x_{7}=$ $6.89 \mathrm{e} 10, x_{8}=3.83 \mathrm{e} 14, y_{0}=-6.8, y_{1}=-7.97 \mathrm{e} 5, y_{2}=-7.1 \mathrm{e} 9, y_{3}=5.53 \mathrm{e} 13, y_{4}=6.5 \mathrm{e} 14, y_{5}=1, y_{6}=$ $1.4 \mathrm{e} 5, y_{7}=2.8 \mathrm{e} 9, y_{8}=1.4 \mathrm{e} 11, y_{9}=6.23 \mathrm{e} 14$.

Hence, the Bode plots of the compensated transfer functions of the converter with PI voltage controllers in $A$-to- $B$ and $B$-to- $A$ operations are given in Figure 7.9(a) and Figure 7.9(b), respectively. These Bode diagrams show that the compensated transfer functions of the proposed converter in both operations have positive gain and phase margins, which indicate a stable operation of the proposed converter with the adopted PI voltage controllers.

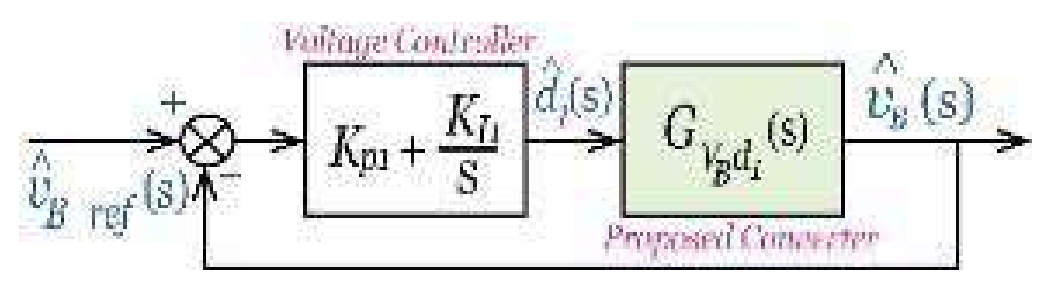

(a)

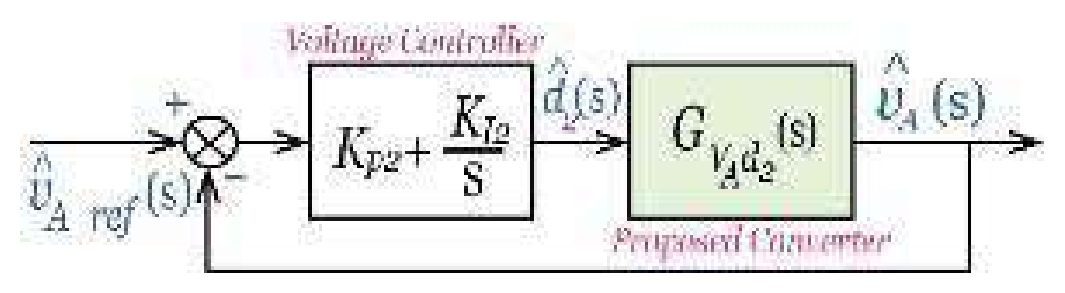

(b)

Figure 7.8: Closed-loop voltage controller. (a) A-to-B operation. (b) B-to-A operation. 


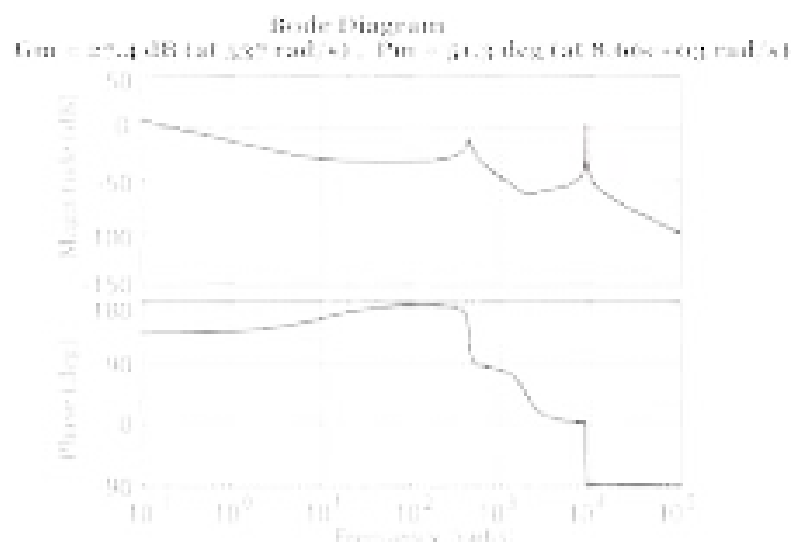

(a)

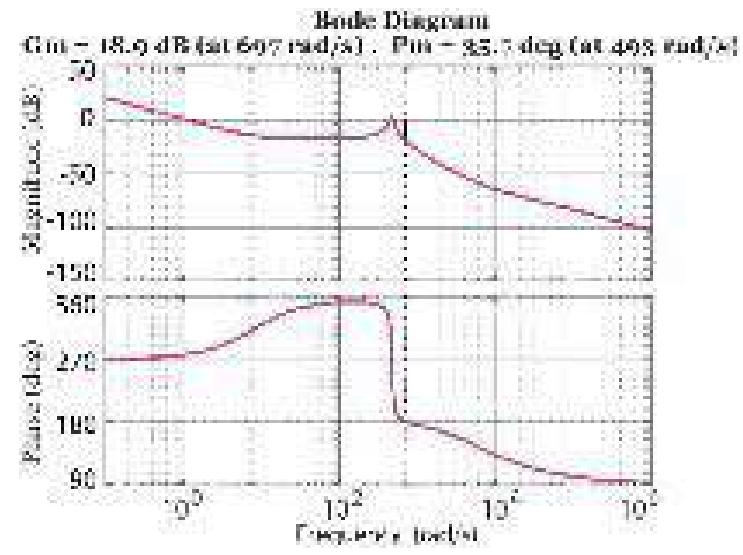

(b)

Figure 7.9: Bode plots of the compensated transfer functions with PI controllers. (a) A-to-B operation. (b) B-to $\neg$-A operation.

\subsection{Experimental Results and Analysis}

In order to validate the effectiveness of the proposed converter, a scaled-down prototype is developed, as shown in Figure 7.10. The parameters of the experimental setup are given in Table 7.2.

The laboratory setup is built using SiC MOSFETs, to have better efficiency at high frequency operation. In this section, two case studies are investigated, namely: case study I, and case study II. Case study I investigates the $A$-to- $B$ operation, while case study II investigates the $B$-to- $A$ operation. 
Table 7.2: Experiment Parameters

\begin{tabular}{|l|c|}
\hline Parameters and Components & Values \\
\hline Rated power $P_{o}$ & $1.6 \mathrm{~kW}$ \\
\hline Power MOSFET $Q_{l}$ & C2M0025120D \\
\hline Power MOSFETs $Q_{2}, Q_{3}$ & SCT3030KL \\
\hline Inductors $L_{1}, L_{2}$ & $300 \mu \mathrm{H}$ \\
\hline Capacitors $C_{2}, C_{4}$ & $2 \mathrm{X} 120 \mu \mathrm{F}$ \\
\hline Capacitors $C_{1}, C_{3}$ & $2 \mathrm{X} 20,3 \mathrm{X} 20 \mu \mathrm{F}$ \\
\hline Switching frequency $f_{s}$ & $100 \mathrm{KHz}$ \\
\hline Microcontroller & TMS32028f377s \\
\hline
\end{tabular}

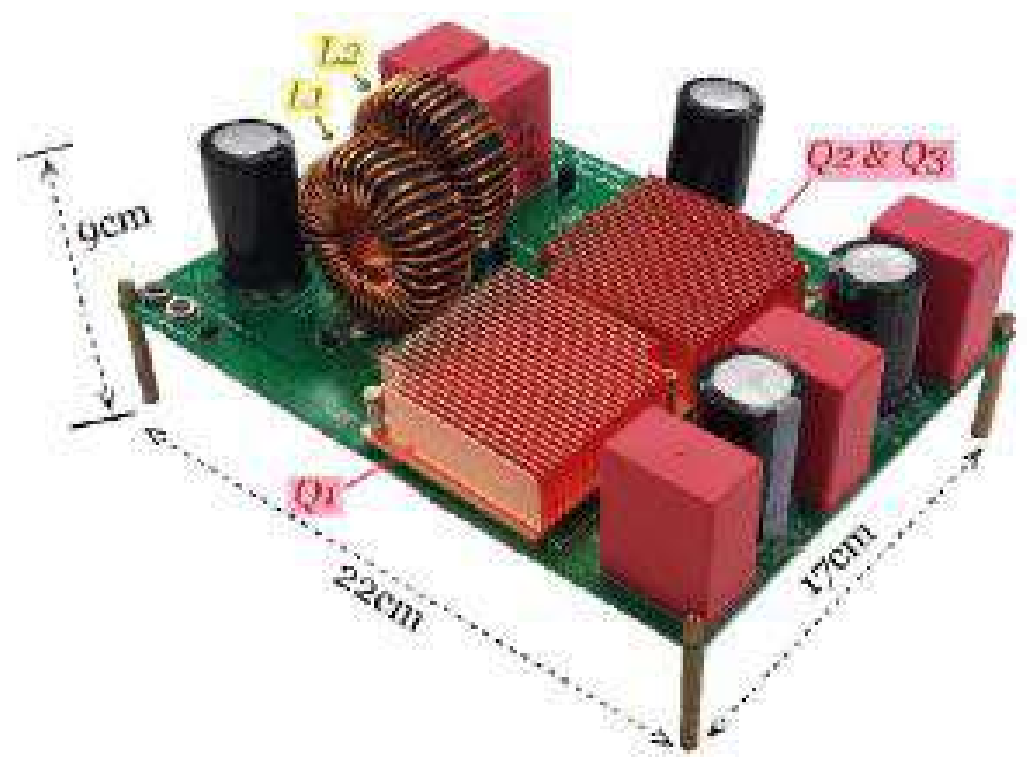

Figure 7.10: Experimental prototype.

\subsubsection{Experimental Results in Case Study I}

This case study investigates the $A$-to- $B$ operation of the proposed converter. In this case, port $A$ is connected to a voltage source $V_{A}=85 \mathrm{~V}$, port $B$ is connected to a resistive load $R_{l}=100 \Omega$, and the duty cycle $d_{1}=0.7$.

The experimental results for case study I are shown in Figure 7.11. According to (7), and (15), the average current values of $L_{1}$, and $L_{2}$ and their ripple currents can be calculated as following: 
$I_{L 1}=22.48 \mathrm{~A}, I_{L 2}=3.97 \mathrm{~A}, \Delta i_{L 1}=\Delta i_{L 2}=1.98 \mathrm{~A}$ (both $L_{1}$ and $L_{2}$ have the same inductance in the experiment), which closely agree with the experimental results in Figure 7.11(a). According to (5) and (6), the average capacitor voltages can be calculated as following: $V_{C l}=283.3 \mathrm{~V}$, $V_{C 3}=198.3 \mathrm{~V}$, and $V_{B}=396 \mathrm{~V}$, which closely agree with the experimental results in Figure 7.11(b). According to (11), the voltage stress on the transistors can be calculated as following: $V_{Q I}=V_{Q 2}=$ $V_{Q 3}=283.3 \mathrm{~V}$, which closely agree with the experimental results in Figure 7.11(c). According to (12), and (13), the current stress on the transistors can be calculated as following: $I_{Q I}=26.4 \mathrm{~A}$, $I_{Q 2}=I_{Q 3}=13.2 \mathrm{~A}$, which closely agree with the experimental results in Figure 7.11(d).

The voltage waveforms of the synchronous rectifiers of the proposed converter in this case ( $A$ to- $B$ operation) are shown in Figure 7.13(a). It is clear, that both $Q_{2}$, and $Q_{3}$ realize ZVS during turn-on and turn-off transitions.

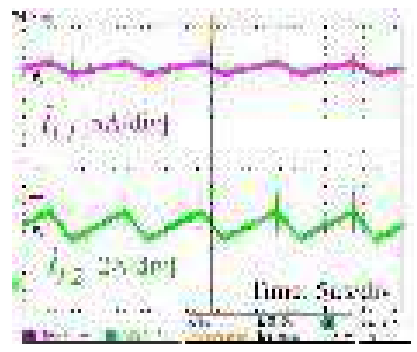

(a)

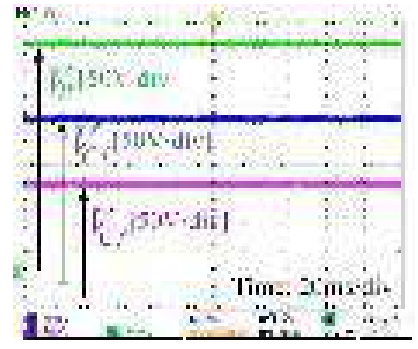

(b)

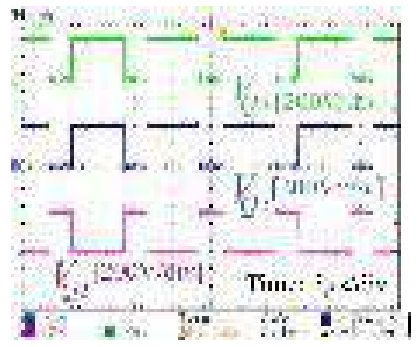

(c)

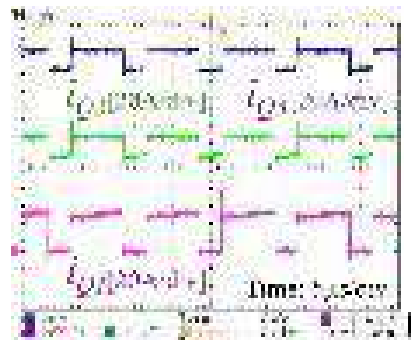

(d)

Figure 7.11: Experimental results for case study I.

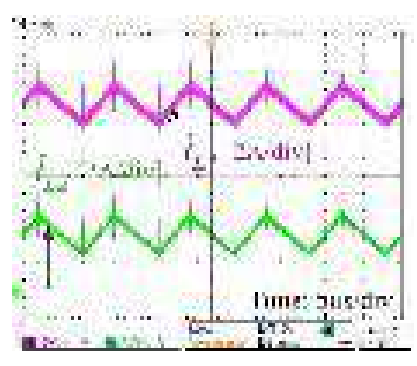

(a)

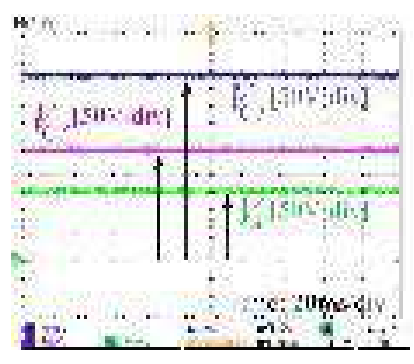

(b)

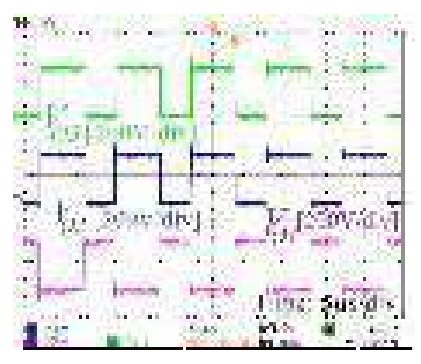

(c)

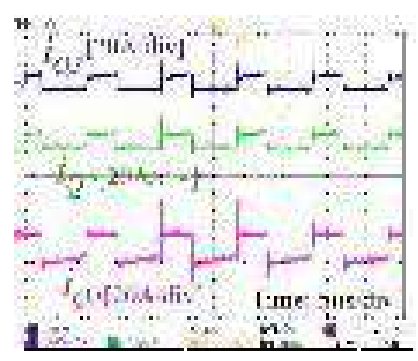

(d)

Figure 7.12: Figure 7.11: Experimental results for case study II. 


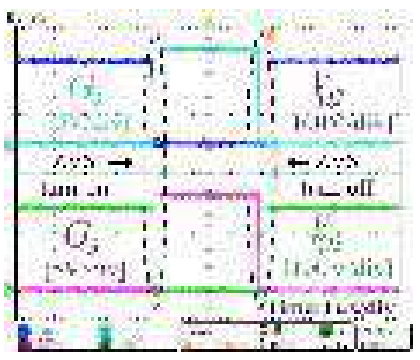

(a)

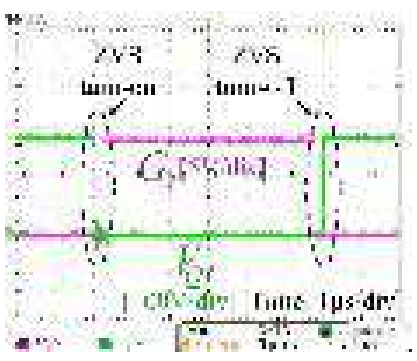

(b)

Figure 7.13: Gate signals and the voltage stress across the synchronous rectification transistors. (a) Case study I. (b) Case study II.

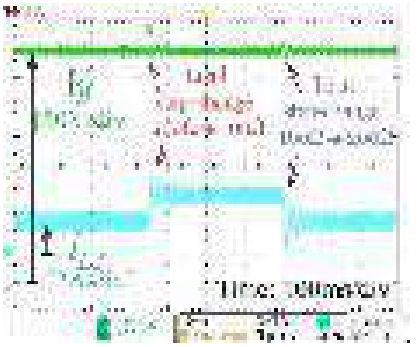

(a)

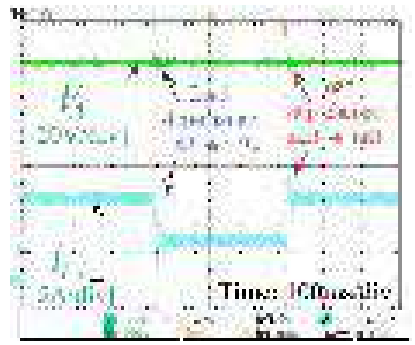

(b)

Figure 7.14: Dynamic behavior of the proposed converter due to step-change in load. (a) In A-to-B operation. (b) In B-to-A operation.

Figure 7.14(a) shows good dynamic behavior of $V_{B}$ which is kept at $400 \mathrm{~V}$ using the closedloop voltage controller while the output power has step-changed from $800 \mathrm{~W}$ to $1.6 \mathrm{~kW}$, then from $1.6 \mathrm{~kW}$ to $800 \mathrm{~W}$.

\subsubsection{Experimental Results in Case Study II}

This case study investigates the $B$-to- $A$ operation of the proposed converter. In this case, port $B$ is connected to a voltage source $V_{B}=400 \mathrm{~V}$, port $A$ is connected to a resistive load $R_{2}=12 \Omega$, and the duty cycle $d_{2}=0.4$.

The experimental results for case study II are shown in Figure 7.12. According to (10), and (15), the average current values of $L_{1}$, and $L_{2}$ and their ripple currents can be calculated as following: $I_{L 1}=14.8 \mathrm{~A}, I_{L 2}=3.7 \mathrm{~A}, \Delta i_{L 1}=\Delta i_{L 2}=2.7 \mathrm{~A}$, which closely agree with the experimental results in Figure 7.12(a). According to (8) and (9), the average capacitor voltages can be calculated as following: $V_{C l}=333.3 \mathrm{~V}, V_{C 3}=200 \mathrm{~V}$, and $V_{A}=133.3 \mathrm{~V}$, which closely agree with the experimental 
results in Figure 7.12(b). According to (11), the voltage stress on the transistors can be calculated as following: $V_{Q 1}=V_{Q 2}=V_{Q 3}=333.3 \mathrm{~V}$, which closely agree with the experimental results in Figure 7.12(c). According to (12), and (13), the current stress on the transistors can be calculated as following: $I_{Q 1}=18.5 \mathrm{~A}, I_{Q 2}=I_{Q 3}=9.3 \mathrm{~A}$, which closely agree with the experimental results in Figure 7.12(d).

The voltage waveforms of the synchronous rectifiers of the proposed converter in this case ( $B$-to- $A$ operation) are shown in Figure 7.13(b). It is clear, that $Q_{1}$ realizes ZVS during turnon and turn-off transitions.

Figure 7.14(b) shows acceptable dynamic behavior of $V_{A}$ which is kept at $133 \mathrm{~V}$ using the closed-loop voltage controller while the output power has step-changed from $1.47 \mathrm{~kW}$ to $737 \mathrm{~W}$, then from $737 \mathrm{~W}$ to $1.47 \mathrm{~kW}$.

\subsubsection{Efficiency Analysis of the Proposed Converter}

The calculated loss distributions for the experiment in case study I and case study II are shown in Figure 7.15. In case study I, the total losses of the converter are $55.63 \mathrm{~W}$, and the loss distribution is shown in Figure 7.15(a). The switching loss in this case is caused by only $Q_{1}$ ( $Q_{2}$ and $Q_{3}$ are soft-switched), and it accounts for $42 \%$ of the total losses. The conduction loss of $Q_{1}, Q_{2}$ and $Q_{3}$ account for $28 \%$ of the total losses. The losses of the capacitors and inductors in case I account for $2 \%$, and $28 \%$ of the total losses, respectively. In case study II, the total losses of the converter are $41.27 \mathrm{~W}$, and the loss distribution is shown in Figure 7.15(b). The switching loss in this case is caused by only $Q_{2}$ and $Q_{3}\left(Q_{1}\right.$ is soft-switched), and it accounts for $55 \%$ of the total losses. The conduction loss of $Q_{1}, Q_{2}$ and $Q_{3}$ account for $23 \%$ of the total losses. The losses of the capacitors and inductors case II account for $5 \%$, and $23 \%$ of the total losses, respectively. The measured efficiency curves for both $A$-to- $B$ and $B$-to- $A$ operations with output power equals $1 \mathrm{~kW}$ and $1.5 \mathrm{~kW}$ 
are presented in Figure 7.16. The measured efficiency curves were obtained using a Power Analyzer (Tektronix PA3000).

In the $A$-to- $B$ operation, the voltage at port $B$ is kept constant at $400 \mathrm{~V}$, the output power (from port $B$ ) equals $1 \mathrm{~kW}$ and $1.5 \mathrm{~kW}$, and the voltage at port $A, V_{A}$ changes from $50 \mathrm{~V}$ to $500 \mathrm{~V}$, the efficiency of the converter is tracked for each value of $V_{A}$. The converter operates in boost mode when $V_{A}$ is less than $400 \mathrm{~V}$, and in buck mode otherwise. In the $B$-to- $A$ operation, the voltage at port $B$ is kept constant at $400 \mathrm{~V}$, the output power (from port $A$ ) equals $1 \mathrm{~kW}$ and $1.5 \mathrm{~kW}$, and the voltage at port $A$ changes from $50 \mathrm{~V}$ to $500 \mathrm{~V}$, the efficiency of In the $A$-to- $B$ operation, the voltage at port $B$ is kept constant at $400 \mathrm{~V}$, the output power (from port $B$ ) equals $1 \mathrm{~kW}$ and $1.5 \mathrm{~kW}$, and the voltage at port $A, V_{A}$ changes from $50 \mathrm{~V}$ to $500 \mathrm{~V}$, the efficiency of the converter is tracked for each value of $V_{A}$. The converter operates in boost mode when $V_{A}$ is less than $400 \mathrm{~V}$, and in buck mode otherwise. In the $B$-to- $A$ operation, the voltage at port $B$ is kept constant at $400 \mathrm{~V}$, the output power (from port $A$ ) equals $1 \mathrm{~kW}$ and $1.5 \mathrm{~kW}$, and the voltage at port $A$ changes from $50 \mathrm{~V}$ to $500 \mathrm{~V}$, the efficiency of $V_{A}=300 \mathrm{~V}$ ) in $A$-to- $B$ operation, and from $91 \%$ (at $V_{A}=50$ ) to $97.3 \%$ (at $V_{A}=300 \mathrm{~V}$ ) in $B$-to- $A$ operation.

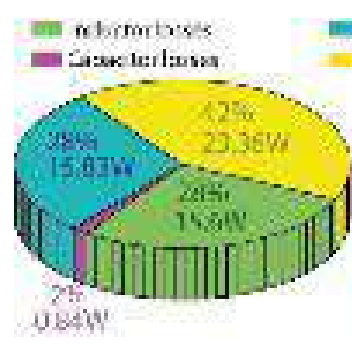

(a)

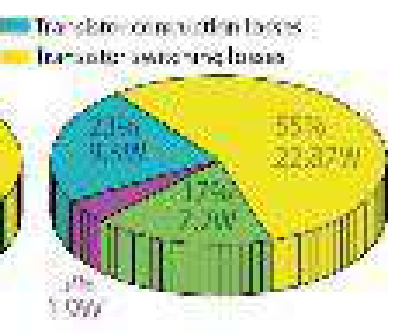

(b)

Figure 7.15: Calculated power loss distributions for the experiment. (a) In case study I. (b) In case study II.

It is noticed that the efficiency increases gradually as $V_{A}$ increases for the same output power, this is due to the reduction in losses caused by the decreased input current. For high values of $V_{A}$, the switching losses become dominant, and the total efficiency drops, as shown in Figure 7.16. 


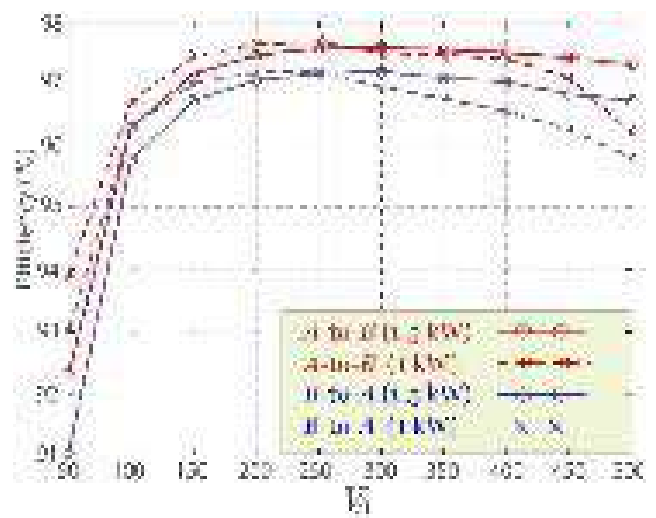

Figure 7.16: Measured efficiency curves of the proposed converter in A-to-B and $B$-to-A operations $(\mathrm{VB}=\mathbf{4 0 0} \mathrm{V}, \mathrm{VA}=\mathbf{5 0} \rightarrow \mathbf{5 0 0 V})$.

\subsubsection{Bidirectional Transition Performance}

In order to evaluate the bidirectional transient performance of the proposed converter, the circuit shown in Figure 7.17 was constructed. Two power supplies (i.e. $P S 1=100 \mathrm{~V}$ and $P S 2=400 \mathrm{~V})$ are connected to port $A$ and port $B$ of the prototype. The power supplies are connected via dc solid-state relays (i.e. SSRI and SSR2) and two series diodes. Two local loads are connected to the two ports (i.e. $R_{A}=15 \Omega$ and $R_{B}=100 \Omega$ ). To test the performance of the converter when it switches from $B$-to- $A$ operation to $A$-to- $B$ operation, the test starts by making $S S R 1$ : OFF and SSR2: ON, in this case the converter is working in B-to- $A$ operation. When the states of the two solid-state relays are inverted SSR1: ON and SSR2: OFF, the converter works in $A$-to- $B$ operation and the $A$-to- $B$ voltage controller sets $V_{B}$ at $400 \mathrm{~V}$. Figure 7.18(a) shows that the converter successfully holds the voltage at port $B$ at $400 \mathrm{~V}$ after the transition with an acceptable dynamic response. In Figure 7.18(a), $V_{B}$ before the transition is the voltage of $P S 2$, while after the transition, $V_{B}$ is the processed voltage by the converter.

To test the performance of the converter when it switches from $A$-to- $B$ operation to $B$-to- $A$ operation, the test starts by making SSR1: ON and SSR2: OFF, in this case the converter is working in $A$-to- $B$ operation. When the states of the two solid-state relays are inverted SSRI: OFF and SSR2: 
$\mathrm{ON}$, the converter works in $B$-to- $A$ operation and the $B$-to- $A$ voltage controller sets $V_{A}$ at $100 \mathrm{~V}$. Figure 7.18(b) shows that the converter successfully holds the voltage at port $A$ at $100 \mathrm{~V}$ after the transition with an acceptable dynamic response. In Figure 7.18(b), $V_{A}$ before the transition is the voltage of $P S 1$, while after the transition, $V_{A}$ is the processed voltage by the converter. In both tests, the polarity of $i_{L 1}$ and $i_{L 2}$ flips after the transitions, referred to the reference inductor currents direction shown in Figure 7.17.

The oscillations in current that are shown in Figure 7.18 when the converter changed its mode of operation is because the converter changed its mode of operation abruptly. In a realistic scenario, the switching between $A$-to- $B$ and $B$-to- $A$ operations should be done softly where the reference voltage ramps up to the desired level.

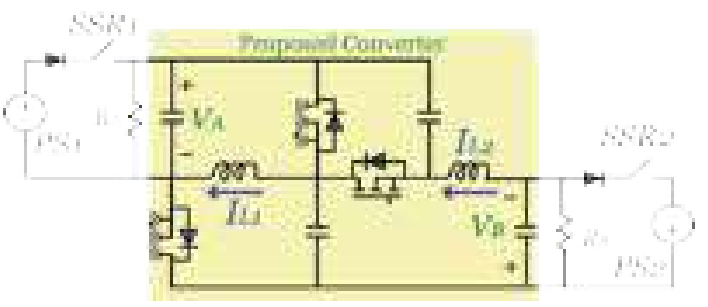

Figure 7.17: Bidirectional power flow transition test circuit.

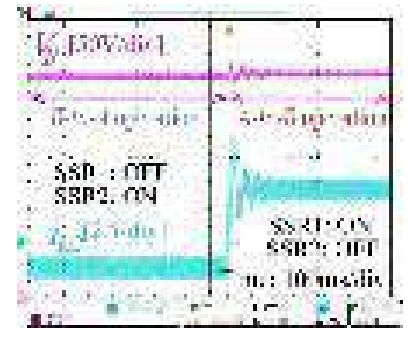

(a)

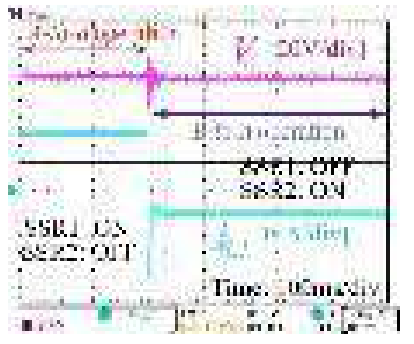

(b)

Figure 7.18: Dynamic behavior of the proposed converter due to step-change in load. (a) In A-to-B operation. (b) In B-to-A operation.

\subsection{Conclusion}

In this chapter, a new bidirectional dc-dc converter that can perform buck and boost operations in both power flow directions has been introduced. The proposed converter has a simple circuit 
structure, low component counts, low voltage stress on the transistors, and wide voltage gain range. Synchronous rectification has been employed to improve the efficiency of the converter since the synchronous rectifiers turn on and turn off with ZVS. The proposed converter has good steady-state and dynamic performance. These features make it a good candidate for applications that require bidirectional power flow with wide conversion ratios, such as energy storage systems with large voltage swings.

\section{Chapter 8 Analysis and Design of A New Bidirectional DC-DC Converter with Broad Voltage Gain Range for Energy Storage Applications}

\subsection{Introduction}

A new bidirectional dc-dc converter for energy storage systems with large voltage fluctuations is presented in this chapter. The proposed topology has a wide range of voltage regulation, a common ground between its ports, continuous current at the low voltage port, high semiconductor utilization factor, and a low voltage stress on the power switches. The principles of operation, the current and voltage stresses on the power switches, and the design of components are discussed in this chapter. Finally, a 2-kW/800-V scaled-down prototype was developed using Silicon Carbide ( $\mathrm{SiC}$ ) MOSFETs to validate the feasibility of the proposed converter and the correctness of its theoretical analysis. 


\subsection{Structure and Operating Principles of the Proposed Converter 8.2.1 Circuit Structure of the Proposed Topology}

The proposed converter is composed of four switches $\left(Q_{1} \rightarrow Q_{4}\right)$, three inductors $\left(L_{1} \rightarrow L_{3}\right)$, and six capacitors $\left(C_{1} \rightarrow C_{6}\right)$. The proposed topology is shown in Figure 8.1, as it has a low voltage side, where the ESS is connected, and a high voltage side, where the dc bus of the load is connected.

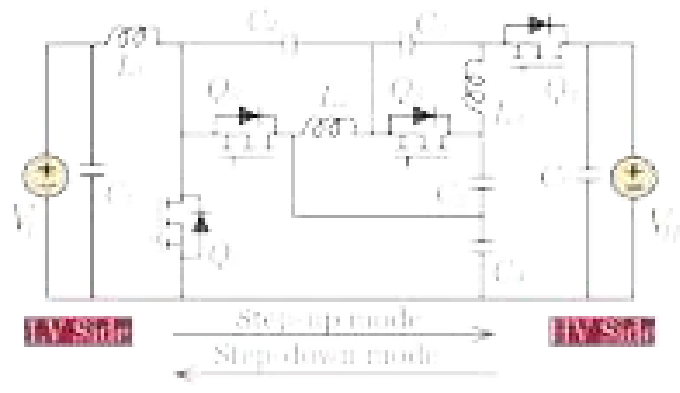

Figure 8.1: The structure of the proposed step-up dc-dc converter.

\subsubsection{Operation in Step-Up Mode}

In this mode, the power flow is from the low voltage (LV) side to the high voltage (HV) side. The current flow paths and the key waveforms for this mode are shown in Figure 8.2 and Figure 8.4(a), respectively. In this mode, $Q_{1}$ acts as the main switch, while $Q_{2} \rightarrow Q_{4}$ act as synchronous rectifiers. The triggering pulses of $Q_{1} \rightarrow Q_{4}$ are $G_{1} \rightarrow G_{4}$. The duty cycle of $Q_{1}$ is $d_{1}$ while the duty cycle of $Q_{2} \rightarrow Q_{4}$ is $d_{2}\left(=1-d_{1}\right)$. A delay is applied between the falling edge of $G_{2} \rightarrow G_{4}$ and the rising edge of $G_{l}$, and another delay is applied between the falling edge of $G_{l}$ and the rising edge of $G_{2} \rightarrow G_{4}$, as shown in Figure 8.4(a). During the delay time, currents flow through the body diodes of the synchronous rectifiers, thus, the drain-to-source voltages of the synchronous rectifiers drop to the forward voltage level of the body diodes, accordingly, ZVS can be realized by $Q_{2} \rightarrow Q_{4}$ during the turn-on and turn-off transitions. 


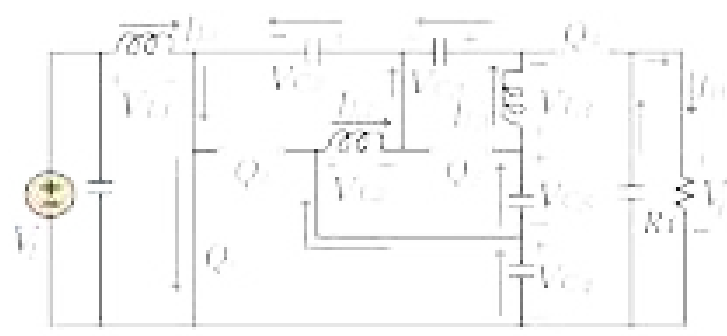

(a)

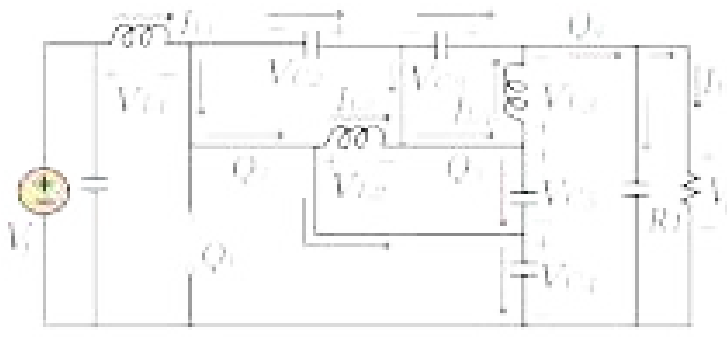

(b)

Figure 8.2: Current flow paths for step-up mode. (a) State 1. (b) State 0.

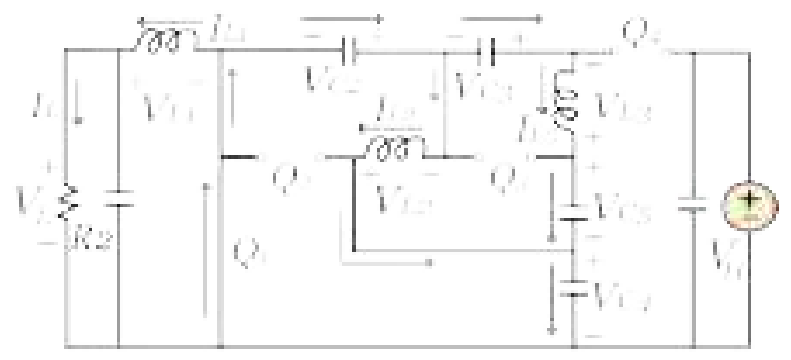

(a)

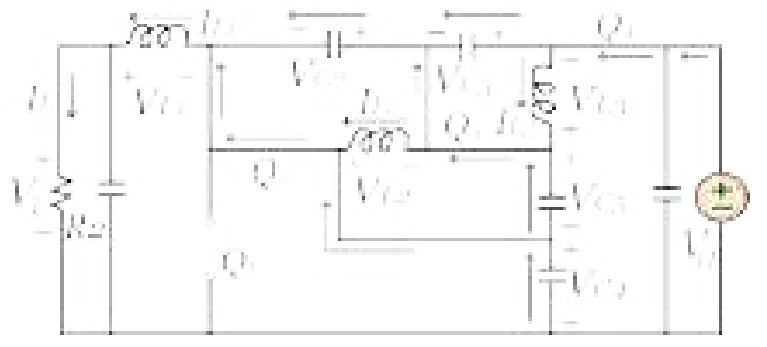

(b)

Figure 8.3: Current flow paths for step-down mode. (a) State 1. (b) State 0.

The proposed converter has two switching states, namely: State1 and State 0. In the following analysis: $i_{C 1_{-} c h} \rightarrow i_{C 6_{-} c h}$, and $i_{C 1_{-} d i s} \rightarrow i_{C 6_{-} d i s}$ are the charging and discharging currents of $C_{1} \rightarrow$ $C_{6}$. The inductor currents and the instantaneous voltages across the inductors are referred to as $I_{L 1} \rightarrow I_{L 3}$ and $V_{L 1} \rightarrow V_{L 3}$, respectively. $V_{H}, V_{L}, I_{H}, I_{L}$, and $V_{C 2} \rightarrow V_{C 5}$ are the voltages of the high 
voltage and low voltage sides, the currents of the high voltage and low voltage sides, and the voltages across $C_{2} \rightarrow C_{5}$.

In State $1, Q_{1}$ is turned on, $Q_{1} \rightarrow Q_{4}$ are turned off, $C_{2}$ and $C_{3}$ charge, and $C_{4} \rightarrow C_{6}$ discharge, as shown in Figure 8.2(a). By applying Kirchhoff's Voltage Law (KVL) and Kirchhoff's Current Law (KCL) on the equivalent circuit in Figure 8.2(a), we can extract the following relationships:

$$
\begin{aligned}
& \left\{\begin{array}{l}
V_{L 1}=V_{L} \\
V_{L 2}=V_{C 4}-V_{C 2} \\
V_{L 3}=V_{C 4}+V_{C 5}-V_{C 3}-V_{C 2}
\end{array}\right. \\
& i_{C 2 \_c h}=I_{L 2}+I_{L 3} \\
& i_{C 3_{-} c h}=I_{L 3} \\
& i_{C 4 \_ \text {dis }}=I_{L 2}+I_{L 3} \\
& i_{C 5 \_ \text {dis }}=I_{L 3} \\
& i_{\text {C6_dis }}=I_{H}
\end{aligned}
$$

In State $0, Q_{1}$ is turned off, $Q_{1} \rightarrow Q_{4}$ are turned on, $C_{2}$ and $C_{3}$ discharge, and $C_{4} \rightarrow C_{6}$ charge, as shown in Figure 8.2(b). By applying the KVL and KCL rules on the equivalent circuit in Figure 8.2(b), we can extract the following relationships:

$$
\begin{aligned}
& \left\{\begin{array}{l}
V_{L 1}=V_{L}-V_{C 4} \\
V_{L 2}=-V_{C 2}=-V_{C 5} \\
V_{L 3}=-V_{C 3}
\end{array}\right. \\
& \left\{\begin{array}{l}
i_{C 2 \_d i s}=i_{C 3_{-} d i s}+I_{L 3}+i_{C 5_{-} c h}-I_{L 2} \\
i_{C 4 \_c h}=I_{L 1}-i_{C 2 \_d i s}-I_{L 2}+i_{C 5 \_c h} \\
i_{C 6 \_c h}=i_{C 3_{-} d i s}+I_{L 3}-I_{H}
\end{array}\right.
\end{aligned}
$$

By applying the volt-second rule on (1) and (3), the capacitor voltages can be calculated, as follows: 


$$
\begin{aligned}
& V_{C 2}=V_{C 3}=V_{C 5}=\frac{d_{1}}{1-d_{1}} V_{L} \\
& V_{C 4}=\frac{1}{1-d_{1}} V_{L} \\
& V_{H}=V_{C 3}+V_{C 4}+V_{C 5}=\frac{1+2 d_{1}}{1-d_{1}} V_{L}
\end{aligned}
$$

Accordingly, the voltage gain in step-up mode $M_{\text {Boost }}$ can be extracted, as follows:

$$
M_{\text {Boost }}=\frac{V_{H}}{V_{L}}=\frac{1+2 d_{1}}{1-d_{1}}
$$

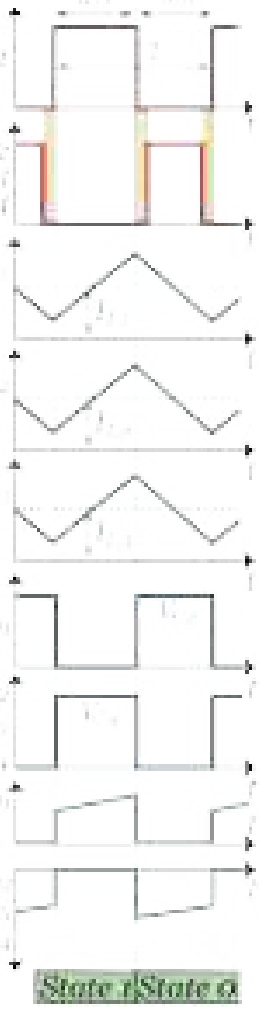

(a)

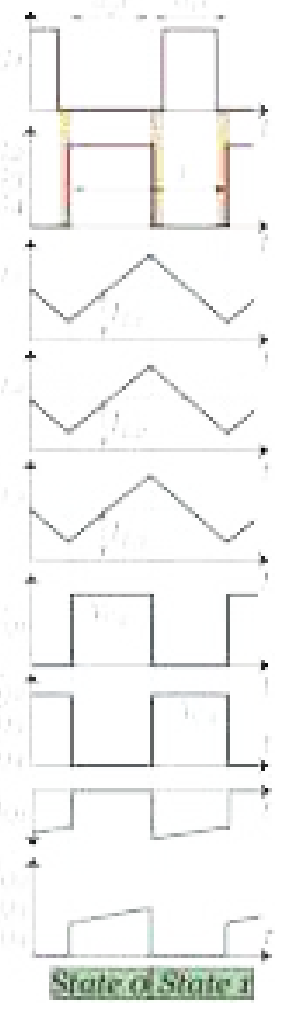

(b)

Figure 8.4: Key waveforms of the proposed converter. (a) Step-up mode. (b) Step-down mode.

\subsubsection{Operation in Step-Down Mode}

In this mode, the power flow is from the HV side to the LV side. The current flow paths and the key waveforms for this mode are shown in Figure 8.3 and Figure 8.4(b), respectively. In this mode, 
$Q_{2} \rightarrow Q_{4}$ act as the main switches, while $Q_{1}$ acts as a synchronous rectifier. The duty cycle of $Q_{2}$ $\rightarrow Q_{4}$ is $d_{2}$ while the duty cycle of $Q_{l}$ is $d_{l}\left(=1-d_{2}\right)$. A delay is applied between the falling edge of $G_{1}$ and the rising edge of $G_{2} \rightarrow G_{4}$, and another delay is applied between the falling edge of $G_{2} \rightarrow$ $G_{4}$ and the rising edge of $G_{l}$, as shown in Figure 8.4(b). The delay between the triggering pulses allows $Q_{1}$ to realize ZVS during the turn-on and turn-off transitions.

Since $Q_{1}$ and $Q_{2} \rightarrow Q_{4}$ work in a complementary fashion, the voltage of the capacitors and the voltage gain in the step-down mode $M_{B u c k}$ can be directly derived from (5), (6), and (7), by replacing $d_{1}$ by (1- $\left.d_{2}\right)$, as follows:

$$
\begin{aligned}
& V_{C 2}=V_{C 3}=V_{C 5}=\frac{1-d_{2}}{3-2 d_{2}} V_{H} \\
& V_{C 4}=\frac{1}{3-2 d_{2}} V_{H} \\
& V_{L}=\frac{d_{2}}{3-2 d_{2}} V_{H} \\
& M_{\text {Buck }}=\frac{V_{L}}{V_{H}}=\frac{d_{2}}{3-2 d_{2}}
\end{aligned}
$$

\subsubsection{Voltage and Current Stresses on the Switches}

By applying KVL rule on the equivalent circuits of the proposed converter, depicted in Figure 8.2 and Figure 8.3, the voltage stress on the switches of the proposed converter $V_{Q}$ can be expressed as shown in (11):

$$
V_{Q}=\frac{V_{L}}{1-d_{1}}=\frac{V_{H}}{3-2 d_{2}}=\left(\frac{M_{\text {Boost }}+2}{3 M_{\text {Boost }}}\right) V_{H}
$$

Assuming a loss-free operation (i.e. $V_{L} I_{L}=V_{H} I_{H}$ ), the currents of the three inductors of the proposed converter can be derived, as follows: 


$$
\begin{aligned}
& I_{L 2}=I_{L 3}=I_{H}=M_{B u c k} I_{L}=\frac{d_{2}}{3-2 d_{2}} I_{L} \\
& I_{L 1}=I_{L}=M_{\text {Boost }} I_{H}=\frac{1}{1-d_{1}} I_{H}
\end{aligned}
$$

By means of the current flow paths shown on the equivalent circuits of the proposed converter in Figure 8.2 and Figure 8.3, the current stresses on the switches can be expressed, as following:

$$
\begin{gathered}
i_{Q 1}=\frac{3 I_{H}}{1-d_{1}}=\frac{3 I_{L}}{3-2 d_{2}}=\left(M_{\text {Boost }}+2\right) I_{H} \\
i_{Q 2}=i_{Q 3}=i_{Q 4}=\frac{I_{H}}{1-d_{1}}=\frac{I_{L}}{3-2 d_{2}}=\frac{M_{\text {Boost }}+2}{3} I_{H}
\end{gathered}
$$

Equations (14) and (15) calculate the magnitude of the current stresses on the switches, the polarity of the current depends on whether the switch is operating as a main switch or as a rectifier.

\subsection{Components Selection and Efficiency Analysis}

\subsubsection{Selection of Switches}

By means of (11), (14), and (15), the voltage and current stresses on the four switches can be calculated. When the voltage gain range of operation, the voltage of the HV side, and the load profile are known, the peak voltage and current stresses of the four switches of the proposed converter can be calculated. Accordingly, these peak electrical stresses should be within the safe operating area (SOA) of the selected switches.

\subsubsection{Design of Inductors}

The magnitude of the currents flowing through the three inductors of the proposed converter can be calculated via (12) and (13), hence, the selected inductors should tolerate these current levels. When the operating voltages at the HV and LV sides, the range of voltage gain, the allowed ripple currents $\left(\Delta i_{L 1} \rightarrow \Delta i_{L 3}\right)$, and the switching frequency $f_{s}$ of the proposed converter are known, the proper inductance values can be calculated by means of (16). 


$$
\begin{gathered}
L_{1} \geq \frac{\left(M_{\text {Boost }}-1\right) V_{L}}{\left(M_{\text {Boost }}+2\right) f_{s} \Delta i_{L 1}}=\frac{\left(1-M_{\text {Buck }}\right) M_{B u c k} V_{H}}{\left(1+2 M_{B u c k}\right) f_{S} \Delta i_{L 1}} \\
L_{2} \geq \frac{\left(M_{\text {Boost }}-1\right) V_{L}}{\left(M_{\text {Boost }}+2\right) f_{S} \Delta i_{L 2}}=\frac{\left(1-M_{\text {Buck }}\right) M_{B u c k} V_{H}}{\left(1+2 M_{B u c k}\right) f_{S} \Delta i_{L 2}} \\
L_{3} \geq \frac{\left(M_{\text {Boost }}-1\right) V_{L}}{\left(M_{\text {Boost }}+2\right) f_{S} \Delta i_{L 3}}=\frac{\left(1-M_{\text {Buck }}\right) M_{B u c k} V_{H}}{\left(1+2 M_{B u c k}\right) f_{S} \Delta i_{L 3}}
\end{gathered}
$$

\subsubsection{Design of Capacitors}

The voltage across the six capacitors can be calculated using (5), (6), (8), and (9), thus, the selected capacitors should tolerate these voltage levels. When the load profile at the HV and LV sides, the range of voltage gain, the allowed ripple voltages $\left(\Delta V_{C 1} \rightarrow \Delta V_{C 6}\right)$, the allowed ripple current in $L_{l}$, and $f_{s}$ of the proposed converter are known, the proper capacitance values can be derived by means of (17).

$$
\begin{aligned}
& C_{1} \geq \frac{\Delta i_{L 1}}{8 f_{s} \Delta V_{C 1}} \\
& C_{2} \geq \frac{2\left(M_{\text {Boost }}-1\right) i_{H}}{\left(M_{\text {Boost }}+2\right) f_{s} \Delta V_{C 2}}=\frac{2\left(1-M_{\text {Buck }}\right) M_{B u c k} i_{L}}{\left(1+2 M_{B u c k}\right) f_{s} \Delta V_{C 2}} \\
& C_{3} \geq \frac{\left(M_{\text {Boost }}-1\right) i_{H}}{\left(M_{\text {Boost }}+2\right) f_{s} \Delta V_{C 3}}=\frac{\left(1-M_{B u c k}\right) M_{B u c k} i_{L}}{\left(1+2 M_{\text {Buck }}\right) f_{s} \Delta V_{C 3}} \\
& C_{4} \geq \frac{2\left(M_{\text {Boost }}-1\right) i_{H}}{\left(M_{\text {Boost }}+2\right) f_{s} \Delta V_{C 4}}=\frac{2\left(1-M_{\text {Buck }}\right) M_{B u c k} i_{L}}{\left(1+2 M_{\text {Buck }}\right) f_{s} \Delta V_{C 4}} \\
& C_{5} \geq \frac{\left(M_{\text {Boost }}-1\right) i_{H}}{\left(M_{\text {Boost }}+2\right) f_{s} \Delta V_{C 5}}=\frac{\left(1-M_{\text {Buck }}\right) M_{\text {Buck }} i_{L}}{\left(1+2 M_{\text {Buck }}\right) f_{s} \Delta V_{C 5}} \\
& C_{6} \geq \frac{\left(M_{\text {Boost }}-1\right) i_{H}}{\left(M_{\text {Boost }}+2\right) f_{s} \Delta V_{C 6}}=\frac{\left(1-M_{\text {Buck }}\right) M_{B u c k} i_{L}}{\left(1+2 M_{\text {Buck }}\right) f_{s} \Delta V_{C 6}}
\end{aligned}
$$

\subsubsection{Efficiency Analysis}

Efficiency calculation is essential to properly select and design the cooling system, in addition, it gives an insight about the operating points where the proposed converter has the highest/lowest 
efficiency. The total power loss $P_{\text {Loss }}$ can be calculated by (18), where $P_{L_{-} \text {cond }}, P_{L_{-} c o r e}, P_{C_{-} c o n d}$, $P_{Q_{-} \text {cond }}$, and $P_{Q_{-} s w}$ are the conduction and core losses of the three inductors, the conduction losses of the six capacitors, the conduction and switching losses of the switches.

$$
P_{\text {loss }}=P_{L_{-} \text {cond }}+P_{L_{-} \text {core }}+P_{C_{-} \text {cond }}+P_{Q_{-} \text {cond }}+P_{Q_{-} s w}
$$

The conduction and core losses of the three inductors can be calculated using (19) and (20), where $R_{L 1}, R_{L 2}, R_{L 3}, l_{c 1}, l_{c 2}, l_{c 3}, A_{c 1}, A_{c 2}, A_{c 3}, \Delta B_{1}, \Delta B_{2}$, and $\Delta B_{3}$ are the equivalent series resistances of the three inductors, the magnetic flux path lengths of the three inductors' cores, the cross sectional areas of the three inductors' cores, and ac magnetic flux density of the three inductors.

$$
\begin{gathered}
P_{L_{-} \text {cond }}=\sum_{i=1}^{i=3} I_{L i}^{2} R_{L i} \\
P_{L_{-} \text {core }}=\sum_{i=1}^{i=3} l_{c i} A_{c i}\left(a \Delta B_{i}^{b} f_{S}^{C}\right)
\end{gathered}
$$

Equation (19), is the empirical Steinmetz equation, and $a, b$, and $c$ are fitting values and can be extracted from the core manufacturer datasheet. The conduction loss of the capacitors can be extracted via (20), where $R_{C 1} \rightarrow R_{C 6}$ are the equivalent series resistances of the six capacitors.

$$
P_{C}=\frac{\Delta i_{L 1}^{2}}{12} R_{C 1}+\frac{d_{1}}{1-d_{1}} I_{H}^{2}\left(4 R_{C 2}+R_{C 3}+4 R_{C 4}+R_{C 5}+R_{C 6}\right)
$$

The conduction losses of the switches can be derived using (21), where $R_{S 1} \rightarrow R_{S 4}$ are the on resistances of the switches. The switching loss of the switches can be calculated by (22) and (23), noting that the switching loss is only considered for the main switches for the considered mode of operation and discarded for the synchronous rectifiers (because they realize ZVS during turn-on and turn-off transitions). Equation (23) is used to calculate the switching loss for any of the four 
switches, where $t_{r i}, t_{f i}$, and $C_{O S S i}$ are the rising and falling times, and the parasitic output capacitance of switch $Q_{i}$.

$$
\begin{aligned}
& P_{Q \_ \text {cond }}=I_{H}^{2}\left(\left(\frac{3 \sqrt{d_{1}}}{1-d_{1}}\right)^{2} R_{S 1}+\left(\frac{R_{S 2}+R_{S 3}+R_{S 4}}{1-d_{1}}\right)\right) \\
& P_{Q \_s w}= \begin{cases}P_{Q 1 \_s w} & \text { (Step-up mode }) \\
P_{Q 2 \_s w}+P_{Q 3 \_s w}+P_{Q 3 \_s w} & \text { (Step-down mode) }\end{cases} \\
& P_{Q i \_s w}=f_{S}\left(0.5 V_{Q i} i_{Q i}\left(t_{r i}+t_{f i}\right)+0.5 V_{Q i}{ }^{2} C_{O S S i}\right)
\end{aligned}
$$

Finally, the efficiency $\eta$ can be calculated using (24):

$$
\eta= \begin{cases}\frac{V_{L} I_{L}}{V_{L} I_{L}+P_{\text {Loss }}} & (\text { Step-up mode }) \\ \frac{V_{H} I_{H}}{V_{H} I_{H}+P_{\text {Loss }}} & (\text { Step-down mode })\end{cases}
$$

\subsection{Comparative Study}

In this section, the proposed topology is compared with five other BDC topologies. These topologies are the B3LC, the switched-capacitor converter (SCC) in [195], the bidirectional version of the quadratic converter in [194], and the converters in [193] and [196]. Table 8.1 gives a summary of the number of passive and active components of the compared topologies. Additionally, it shows the maximum normalized voltage stress on the switches and the voltage gain in the step-up and step-down operations of the compared topologies. The voltage gain relationships with duty cycle of the compared converters are given in Figure 8.5 and Figure 8.6. The maximum normalized voltage stress on the switches of the converters is plotted versus $M_{\text {Boost }}$, as depicted in Figure 8.7. 


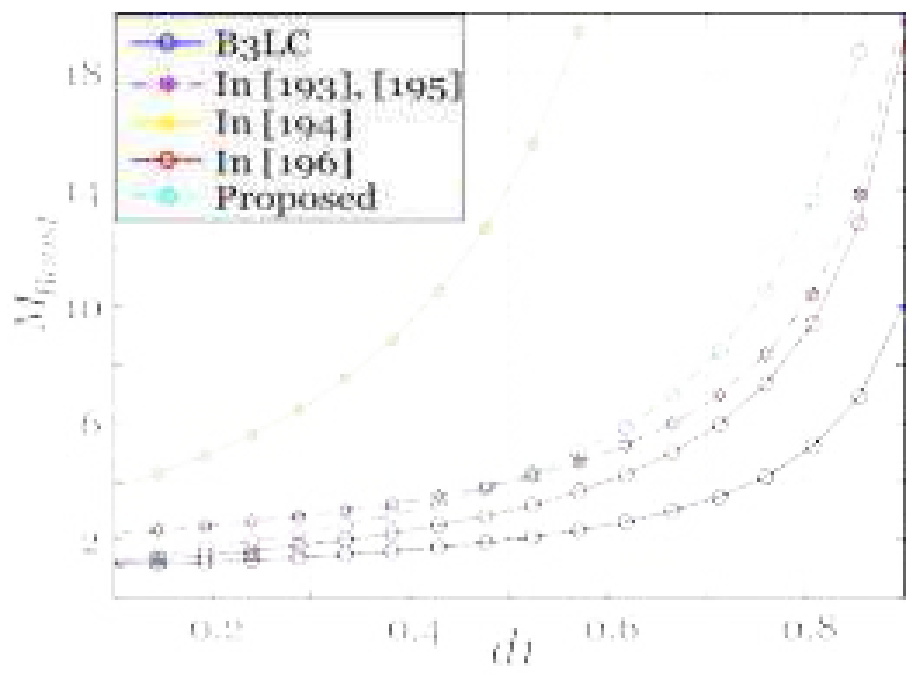

Figure 8.5: Voltage gain of the compared converters in the step-up mode versus the duty cycle.

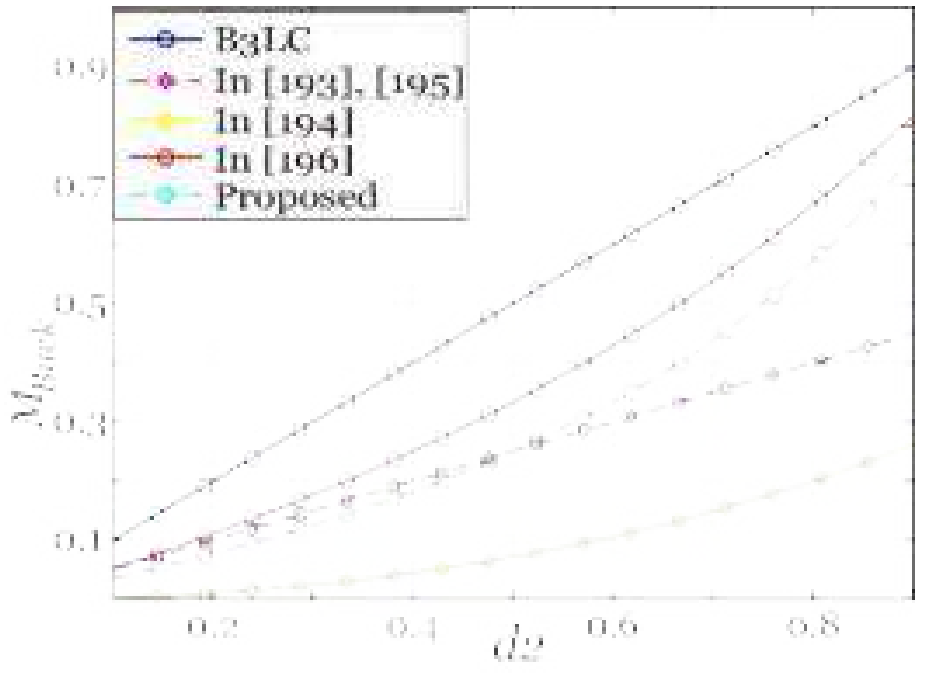

Figure 8.6: Voltage gain of the compared converters in the step-down mode versus the duty cycle.

The B3LC, and the converters in [193] and [196] do not have a common ground between the LV and the HV ports, which may increase the leakage currents and require additional filtering. In the step-up mode, the proposed converter has a higher voltage gain compared to the B3LC, the 
converter in [196], the quadratic converter (for $d_{1}<0.5$ ), the SCC (for $d_{1}>0.5$ ), and the converter in [193] (for $d_{1}>0.5$ ), as shown in Figure 8.5.

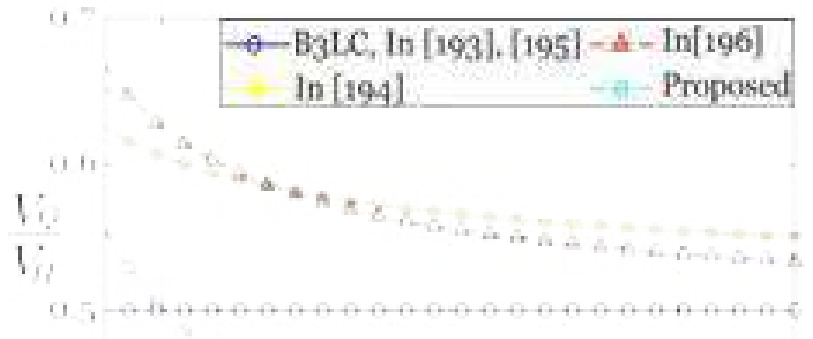

Figure 8.7: Maximum normalized voltage stress on the switches of the compared converters versus the voltage gain.

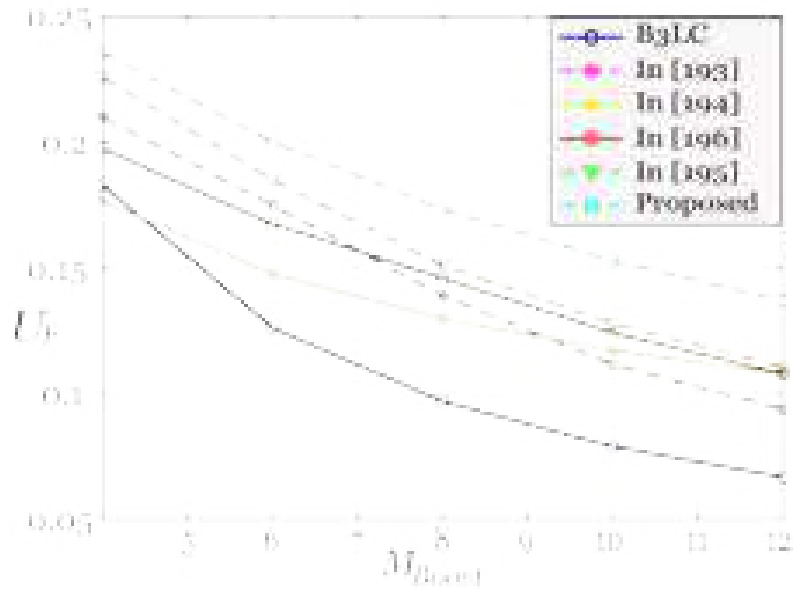

Figure 8.8: Switch utilization factor for the compared converters.

In step-down mode, the proposed converter has a lower voltage gain compared to the B3LC, the converter in [196], the quadratic converter (for $d_{2}>0.5$ ), the SCC (for $d_{2}<0.5$ ), and the converter in [193] (for $d_{2}<0.5$ ), as shown in Figure 8.6. Figure 8.7 shows that the proposed converter has less voltage stress on its power switches in comparison to the quadratic converter, the one in [196], the B3LC (for $M_{B o o s t}>4$ ), the SCC (for $M_{\text {Boost }}>4$ ), and the converter in [193] (for $M_{B o o s t}>4$ ). 
Table 8.1: Comparison Between the Proposed and Other BDC Topologies

\begin{tabular}{|c|c|c|c|c|c|}
\hline \multirow{2}{*}{ Topology } & \multirow{2}{*}{ Components } & \multirow{2}{*}{$\begin{array}{c}\text { Maximum voltage } \\
\text { stress }\left(V_{Q}\right)\end{array}$} & \multirow{2}{*}{$\begin{array}{l}\text { Common } \\
\text { ground }\end{array}$} & \multicolumn{2}{|c|}{ Voltage gain } \\
\hline & & & & Step-up mode & Step-down mode \\
\hline B3LC & $\begin{array}{l}4 \text { Switches } \\
1 \text { Inductor } \\
2 \text { Capacitors }\end{array}$ & $\frac{V_{H}}{2}$ & No & $M_{\text {Boost }}=\frac{1}{1-d_{1}}$ & $M_{\text {Buck }}=d_{2}$ \\
\hline In [193] & $\begin{array}{l}4 \text { Switches } \\
2 \text { Inductors } \\
3 \text { Capacitors }\end{array}$ & $\frac{V_{H}}{2}$ & No & $M_{\text {Boost }}=\frac{2}{1-d_{1}}$ & $M_{B u c k}=\frac{d_{2}}{2}$ \\
\hline $\begin{array}{l}\text { Quadratic in } \\
\text { [194] }\end{array}$ & $\begin{array}{l}4 \text { Switches } \\
2 \text { Inductor } \\
3 \text { Capacitors }\end{array}$ & $\left(1+\sqrt{\frac{1}{M_{\text {Boost }}}}\right) V_{H}$ & Yes & $M_{\text {Boost }}=\left(\frac{1}{1-d_{1}}\right)^{2}$ & $M_{\text {Buck }}=\left(d_{2}\right)^{2}$ \\
\hline SCC in [195] & $\begin{array}{l}5 \text { Switches } \\
2 \text { Inductor } \\
4 \text { Capacitors }\end{array}$ & $\frac{V_{H}}{2}$ & No & $M_{\text {Boost }}=\frac{2}{1-d_{1}}$ & $M_{B u c k}=\frac{d_{2}}{2}$ \\
\hline In [196] & $\begin{array}{l}3 \text { Switches } \\
2 \text { Inductors } \\
4 \text { Capacitors }\end{array}$ & $\left(\frac{M_{\text {Boost }}+1}{2 M_{\text {Boost }}}\right) V_{H}$ & No & $M_{\text {Boost }}=\frac{1+d_{1}}{1-d_{1}}$ & $M_{B u c k}=\frac{d_{2}}{2-d_{2}}$ \\
\hline Proposed & $\begin{array}{l}4 \text { Switches } \\
3 \text { Inductors } \\
6 \text { Capacitors }\end{array}$ & $\left(\frac{M_{\text {Boost }}+2}{3 M_{\text {Boost }}}\right) V_{H}$ & Yes & $M_{\text {Boost }}=\frac{1+2 d_{1}}{1-d_{1}}$ & $M_{B u c k}=\frac{d_{2}}{3-2 d_{2}}$ \\
\hline
\end{tabular}

$$
U_{F}=\frac{P_{o u t}}{\sum V_{Q i} i_{Q i(r m s)}}
$$

In order to assess the comparative cost of the semiconductor devices of the compared converters, the switch utilization factor $\left(U_{F}\right)$ is used, as it is the ratio between the output power of the converter and the total processed power by the switches, as shown in (25). 
Where $P_{\text {out }}$ is the output power of the converter, $V_{Q i}$ and $i_{Q i(r m s)}$ are the voltage stress and the root-mean-square (rms) of the current stress on switch $Q_{i}$. Figure 8.8 shows the utilization factor of the compared converters versus $M_{\text {Boost }}$ when $P_{\text {out }}=2 \mathrm{~kW}$ and $V_{H}=800 \mathrm{~V}$. It is clear that the proposed converter has the highest utilization factor compared to the other five BDC topologies, which indicates that the cost of the semiconductor devices is relatively lower compared to the other converters.

\subsection{Experimental Results and Analysis}

To validate the feasibility of the proposed BDC topology and the correctness of its theoretical analysis, a scaled-down 2-kW/800-V laboratory prototype was developed, presented in Figure 8.9. The power circuit of the prototype was built using SiC MOSFETs, (UJ3C065030K3S) for $Q_{1}$ and (UJ3C065080K3S) for $Q_{2} \rightarrow Q_{4}$, and controlled by a TMS320f28335 microcontroller.

Table 8.2: Main Experimental Parameters of The Proposed Converter

\begin{tabular}{|l|c|}
\hline $\begin{array}{l}\text { Parameters and } \\
\text { Components }\end{array}$ & Values \\
\hline Rated power $P_{\text {out }}$ & 2 -kW \\
\hline HV side voltage $V_{H}$ & $800 \mathrm{~V}$ \\
\hline LV side voltage $V_{L}$ & $80 \mathrm{~V} \rightarrow 200 \mathrm{~V}$ \\
\hline Switch $Q_{1}$ & $\mathrm{UJ} 3 \mathrm{C} 065030 \mathrm{~K} 3 \mathrm{~S}$ \\
\hline Switches $Q_{2} \rightarrow Q_{4}$ & $\mathrm{UJ} 3 \mathrm{C} 065080 \mathrm{~K} 3 \mathrm{~S}$ \\
\hline Inductor $L_{1}$ & $250 \mu \mathrm{H}$ \\
\hline Inductors $L_{2}, L_{3}$ & $330 \mu \mathrm{H}$ \\
\hline Capacitors $C_{1} \rightarrow C_{3}$ & $150 \mu \mathrm{F}$ \\
\hline Capacitors $C_{4}, C_{5}$ & $180 \mu \mathrm{F}$ \\
\hline Capacitor $C_{6}$ & $50 \mu \mathrm{F}$ \\
\hline Switching frequency $f_{s}$ & $100 \mathrm{KHz}$ \\
\hline Microcontroller & $\mathrm{TMS} 320 \mathrm{f} 28335$ \\
\hline
\end{tabular}




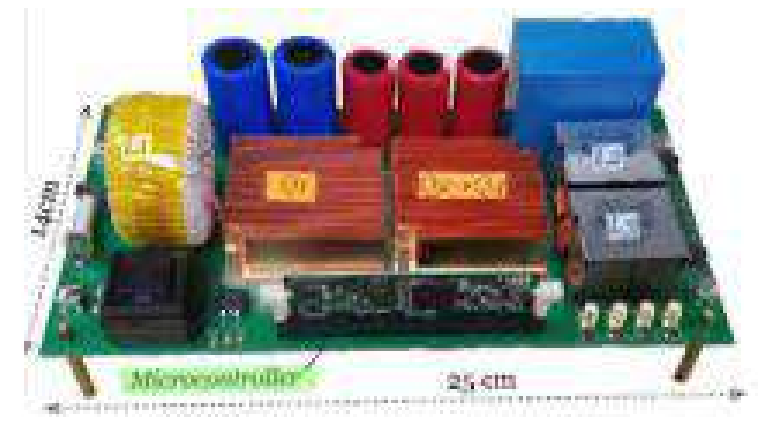

Figure 8.9: Experimental prototype.

Current sense resistors are used to measure the currents of the inductors and the switches. The switching frequency is $100 \mathrm{kHz}$, and the values of the inductors and capacitors are given in Table 8.2. Two case studies are investigated in this section. In case study I, the converter works in stepup mode, while in case study II, the converter works in step-down mode.

\subsubsection{Case Study I}

This case study investigates the performance of the proposed converter when it operates in step-up mode. The operating parameters of this case study are as follows: $V_{L}=100 \mathrm{~V}, d_{1}=0.7$, and $R_{1}=320 \Omega$, where $R_{1}$ is the resistive load connected to the HV side. The experimental results for this case study are shown in Figure 8.10. Based on (5)-(7), the voltage across $C_{2} \rightarrow C_{6}$ and the voltage gain $M_{\text {Boost }}$ can be calculated, as follows: $V_{C 2}=V_{C 3}=V_{C 5} \approx 233.3 \mathrm{~V}, V_{C 4} \approx 333.3 \mathrm{~V}, V_{H}=$ $800 \mathrm{~V}$, and $M_{\text {Boost }}=8$, which closely agree with the experimental results in Figure 8.10(b) and Figure $8.10(\mathrm{c})$. The currents and ripple currents of the three inductors can be calculated using (12), (13), and (16), as follows: $I_{L 1}=20 \mathrm{~A}, I_{L 2}=I_{L 3}=2.5 \mathrm{~A}, \Delta i_{L 1}=2.8 \mathrm{~A}, \Delta i_{L 2} \approx 2.12 \mathrm{~A}, \Delta i_{L 3} \approx$ 2.12A, which closely comply with the experimental results in Figure 8.10(a). The voltage stress on the four switches can be derived via (11), as following: $V_{Q 1}=V_{Q 2}=V_{Q 3}=V_{Q 4} \approx 333.3 \mathrm{~V}$, which closely agree with the results shown in Figure 8.10(d) and Figure 8.10(e). It is also clear from Figure $8.10(\mathrm{~d})$ and Figure $8.10(\mathrm{e})$ that the synchronous rectifiers (i.e. $Q 2 \rightarrow Q 4$ ) realize ZVS during turn-on and turn-off transitions. The current stresses on the switches can be 
(15), as: $i_{Q 1}=25 \mathrm{~A}, i_{Q 2}=i_{Q 3}=i_{Q 4} \approx 8.3 \mathrm{~A}$, which closely comply with the results in Figure $8.10(f)$.

\subsubsection{Case Study II}

This case study investigates the performance of the proposed converter when it operates in step-down mode. The operating parameters of this case study are as follows: $V_{H}=800 \mathrm{~V}, d_{2}=0.5$, and $R_{2}=20 \Omega$, where $R_{2}$ is the resistive load connected to the LV side. The experimental results for this case study are shown in Figure 8.11. The voltage across $C_{1} \rightarrow C_{5}$ can be calculated using (8)-(10), as following: $V_{C 2}=V_{C 3}=V_{C 5}=200 \mathrm{~V}, V_{C 4}=400 \mathrm{~V}, V_{L}=200 \mathrm{~V}$, and $M_{B u c k}=0.25$, which is close to the experimental results in Figure 8.11(b) and Figure 8.11(c). By means of (12), (13), and (16), the currents and the ripple currents of the inductors can be calculated using (12), (13), and (16), as follows: $I_{L 1}=10 \mathrm{~A}, I_{L 2}=I_{L 3}=2.5 \mathrm{~A}, \Delta i_{L 1}=4 \mathrm{~A}, \Delta i_{L 2} \approx 3 \mathrm{~A}, \Delta i_{L 3} \approx 3 \mathrm{~A}$, which closely complies with the experimental results in Figure 8.11(a). The voltage stress on the switches can be calculated using (11), as follows: $V_{Q 1}=V_{Q 2}=V_{Q 3}=V_{Q 4} \approx 400 \mathrm{~V}$, which closely agree with the results shown in Figure 8.11(d) and Figure 8.11(e). In addition, Figure 8.11(d) shows that the synchronous rectifier (i.e. $Q_{1}$ ) realizes ZVS during turn-on and turn-off transitions. Using (14) and (15), the current stresses on the switches can be derived as: $i_{Q 1}=15 \mathrm{~A}, i_{Q 2}=i_{Q 3}=i_{Q 4}=5 \mathrm{~A}$, which closely agree with the results in Figure 8.11(f).

\subsubsection{Performance under Wide-Voltage-Gain Operation}

In order to assess the wide-voltage-gain range capability of the proposed converter in step-up and step-down modes, two tests were performed. In the first test, the converter operates in step-up mode with $V_{L}=80 \mathrm{~V} \rightarrow 200 \mathrm{~V}$, and a closed-loop voltage controller (i.e. proportional integral derivative (PID) controller) is used to set $V_{H}$ at $800 \mathrm{~V}$. Figure 8.12 (a) shows the results of this test, and it is clear that the converter with the adopted controller is capable of holding $V_{H}$ constant at 
$800 \mathrm{~V}$ with $V_{L}$ changing widely, $\left(M_{\text {Boost }}: 10 \rightarrow 4\right)$. In the second test, the converter operates in the step-down mode with $V_{H}=800 \mathrm{~V}$ and a closed-loop PID voltage controller is used to vary $V_{L}$ from $200 \mathrm{~V}$ to $80 \mathrm{~V}$. Figure 8.12 (b) shows the results of this test, and it is clear that the converter with the adopted controller is capable of controlling $V_{L}$ and varying it from $200 \mathrm{~V}$ to $80 \mathrm{~V}$ over six hundred milliseconds while $V_{H}$ is constant at $800 \mathrm{~V},\left(M_{\text {Buck }}: 0.25 \rightarrow 0.1\right)$. Both tests show that the converter has an acceptable dynamic performance under wide range of voltage gain.

\subsubsection{Efficiency Analysis}

The calculated power loss distributions in case study I and case study II are shown in Figure 8.13 . Figure 8.13 (a) shows that the efficiency of the converter in case study I is $95.29 \%$ with total losses of $98.7 \mathrm{~W}$, while Figure $8.13(\mathrm{~b})$ shows that the efficiency of the converter in case study II is $98 \%$ with total losses of $39.3 \mathrm{~W}$. The loss distributions of both case studies show that the conduction losses of the capacitors are dominant, due to the utilization of electrolytic capacitors. These losses can be reduced by using film or ceramic capacitors with low equivalent series resistances.

Figure 8.14. Shows the measured efficiency curves (using Tektronix PA3000 Power Analyzer) when the converter operates in step-up and step-down modes, versus $V_{L}$ when it is changed from $80 \mathrm{~V}$ to $200 \mathrm{~V}$ while keeping $V_{H}$ fixed at $800 \mathrm{~V}$ at output power levels of $1 \mathrm{~kW}$ and $2 \mathrm{~kW}$. In step-up mode, when $P_{\text {out }}$ is $1 \mathrm{~kW}$, the converter has a peak efficiency of $97.8 \%$ at $200 \mathrm{~V}$ and a minimum efficiency of $94.8 \%$ at $80 \mathrm{~V}$, and when $P_{\text {out }}$ is $2 \mathrm{~kW}$, the converter has a peak efficiency of $97.2 \%$ at $200 \mathrm{~V}$ and a minimum efficiency of $92.2 \%$ at $80 \mathrm{~V}$. In step-down mode, when $P_{\text {out }}$ is $1 \mathrm{~kW}$, the converter has a highest efficiency of $98 \%$ at $200 \mathrm{~V}$ and a minimum efficiency of $95.3 \%$ at $80 \mathrm{~V}$, and when $P_{\text {out }}$ is $2 \mathrm{~kW}$, the converter has a maximum efficiency of $97.5 \%$ at $200 \mathrm{~V}$ and a minimum efficiency of $92.7 \%$ at $80 \mathrm{~V}$. 


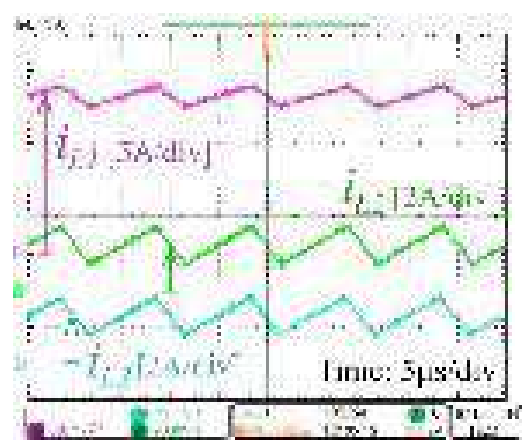

(a)

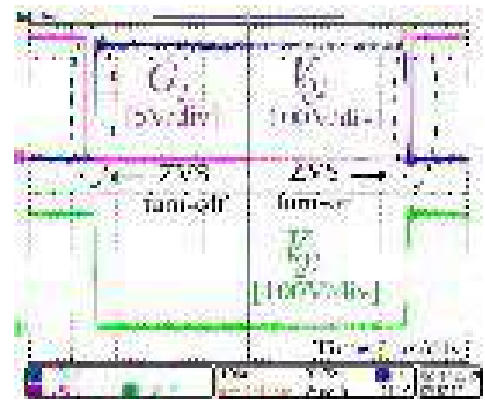

(d)

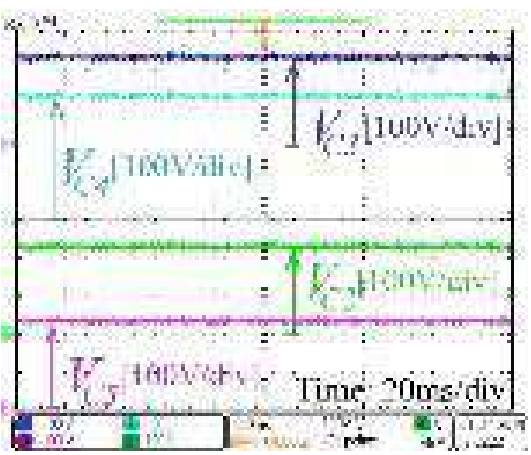

(b)

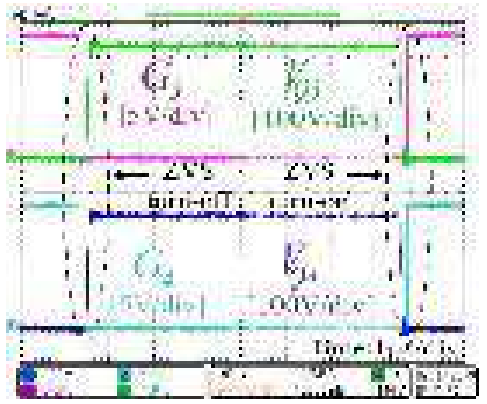

(e)

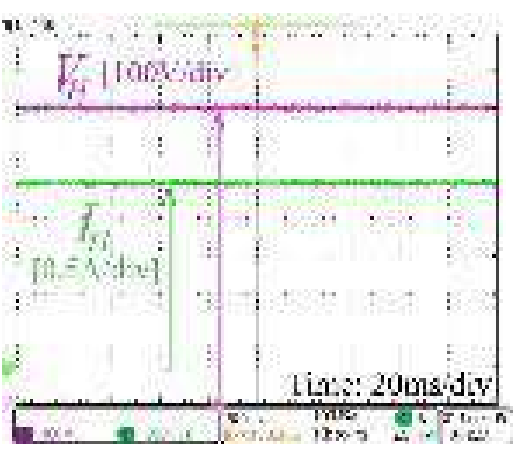

(c)

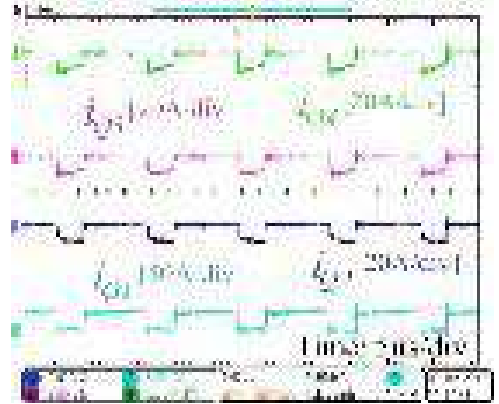

(f)

Figure 8.10: Experimental results of case study I.

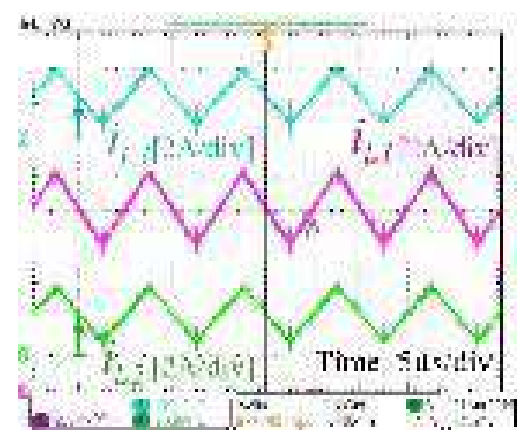

(a)

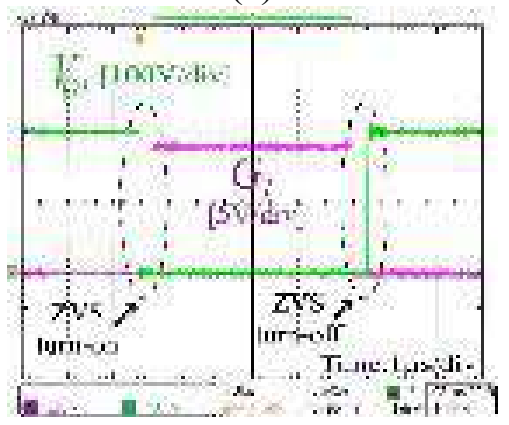

(d)

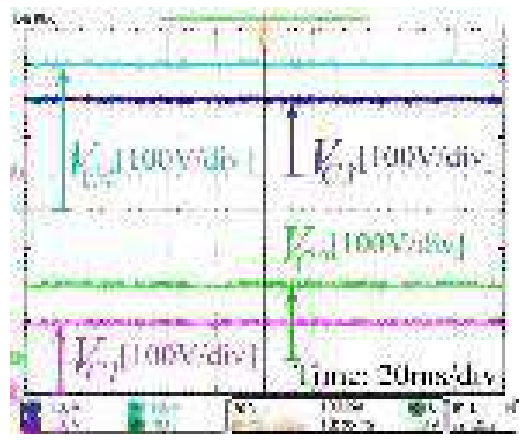

(b)

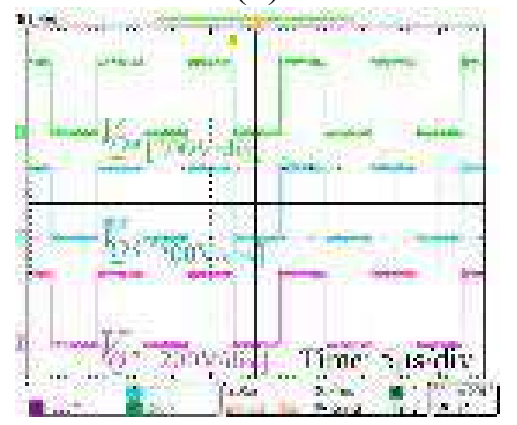

(e)

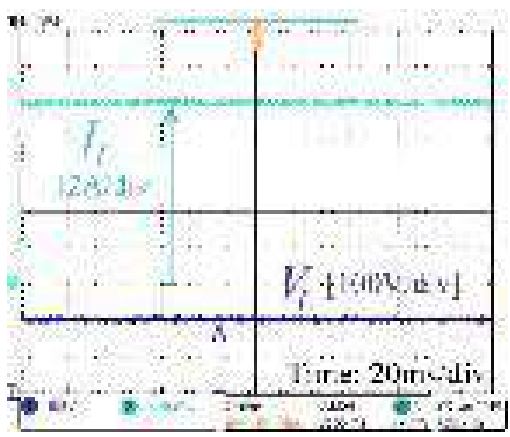

(i)

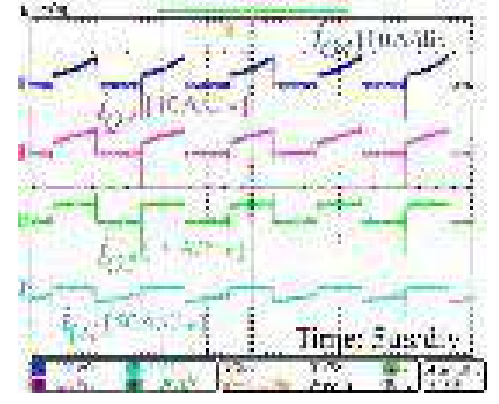

(f)

Figure 8.11: Experimental results of case study II. 


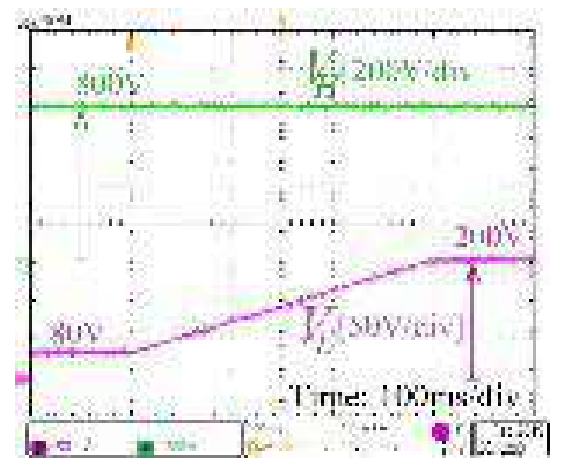

(a)

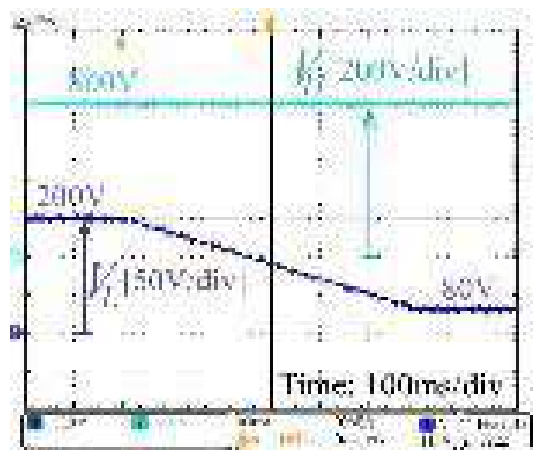

(b)

Figure 8.12: Dynamic performance under wide-range of voltage gain $(\mathrm{VH}=800 \mathrm{~V}, \mathrm{VL}=$ $80 \mathrm{~V} \rightarrow 200 \mathrm{~V}$, and Po $=2 \mathrm{~kW}$ ). (a) Step-up mode. (b) Step-down mode.

It is plain that the proposed converter has acceptable efficiency throughout the broad range of its voltage gains. The reason for this is that the voltage stress on the switches of the proposed topology is inversely proportional with the voltage gain, as described by (11) and shown in Figure 8.7, which alleviates the switching losses of the switches at high voltage conversion ratios, hence, enhances the efficiency of the converter.

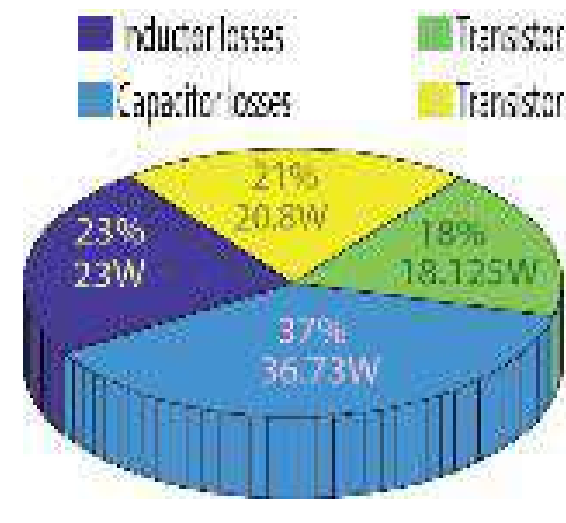

(a)

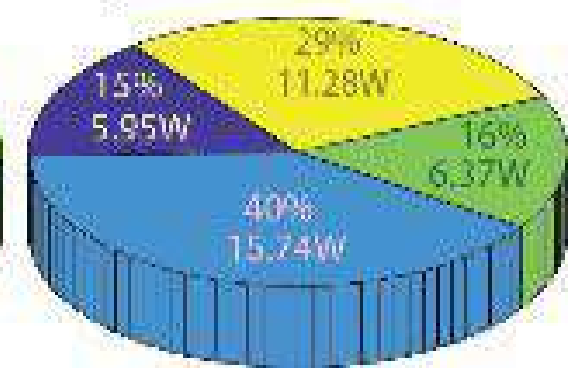

(b)

Figure 8.13: Calculated power loss distributions for the experiment. (a) In case study I. (b) In case study II. 


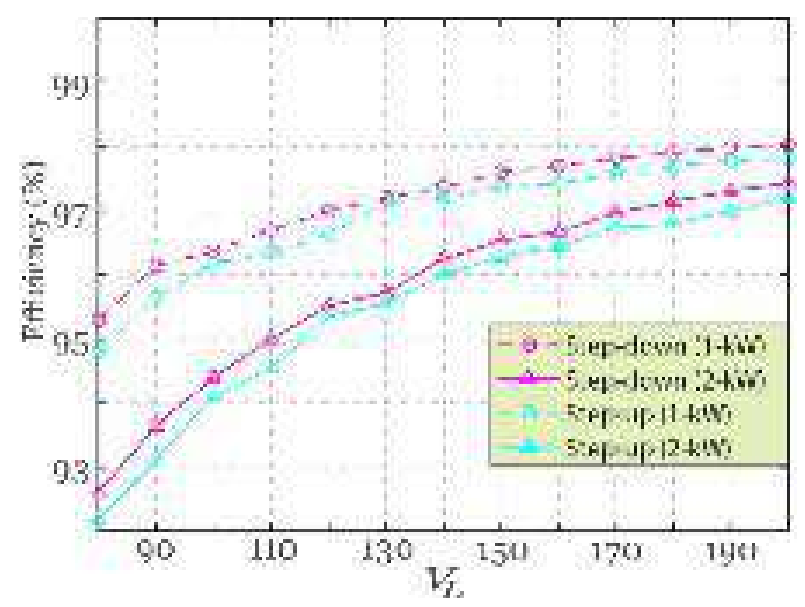

\section{Figure 8.14: Measured efficiency curves of the proposed converter $(\mathrm{VH}=800 \mathrm{~V}, \mathrm{VL}=$ $80 \mathrm{~V} \rightarrow 200 \mathrm{~V}, P_{0}=1 \mathrm{~kW}$, and $\left.2 \mathrm{~kW}\right)$.}

\subsection{Conclusion}

A new topology of a bidirectional dc-dc converter has been proposed. The proposed converter has wide voltage conversion ratios, low voltage stress on the switches, common ground between the LV and HV sides, low current ripple, and high semiconductor utilization factor. at the LV side. Additionally, the adopted synchronous rectification reduces the conduction losses of the synchronous rectifiers. These features make the proposed topology an adequate interface for the energy storage systems with large voltage swings. A scaled-down 2-kW/800-V prototype has been built using SiC MOSFETs to verify the theoretical analysis, and the experimental results show that the converter has an acceptable steady-state and dynamic performance. 


\section{Chapter 9 A New Hybrid Structure of a Bidirectional DC-DC Converter with High Conversion Ratios for Electric Vehicles}

\subsection{Introduction}

In this chapter, a new bidirectional dc-dc conv erter that is based on the quadratic and switched-capacitor structures is proposed for Electric Vehicle applications. The proposed converter has high voltage conversion ratios, low voltage stress on the semiconductor devices, constant potential difference between the grounds of its low voltage and high voltage ports, and continuous current at its low voltage port. Synchronous rectification is utilized to enhance the efficiency of the converter. In addition, an extended version of the proposed converter is discussed in this chapter. Finally, the experimental results obtained from a $2-\mathrm{kW} / 800-\mathrm{V}$ scaled-down prototype validate the feasibility of the proposed topology and the correctness of its theoretical analysis.

\subsection{Circuit Structure and Operating Principles of the Proposed Converter}

\subsubsection{Circuit of the Proposed Topology}

The proposed converter has six switches $\left(Q_{1} \rightarrow Q_{6}\right)$, two inductors $\left(L_{1}\right.$ and $\left.L_{2}\right)$, and five capacitors $\left(C_{1} \rightarrow C_{5}\right)$. The proposed topology is presented in Figure 9.1, as it is composed of a quadratic converter $\left(Q_{1}, Q_{2}, Q_{4}, Q_{5}, L_{1}, L_{2}, C_{1}, C_{3}\right.$, and $\left.C_{4}\right)$ with an integrated switched capacitor network $\left(Q_{3}, Q_{6}, C_{2}\right.$, and $\left.C_{5}\right)$. It has two ports, namely: the low voltage (LV) port, where the ESU is connected, and the high voltage (HV) port, where the dc bus of the load is connected.

\subsubsection{Analysis and Operation in Step-Up Mode}

In this mode, the power flows from the LV side to the HV side. The operation is divided into two switching states, namely: State 0 and State 1 . In state $0, Q_{1} \rightarrow Q_{3}$ are off, $Q_{4} \rightarrow Q_{6}$ are on, $L_{1}$ and $L_{2}$ discharge, $C_{2} \rightarrow C_{4}$ charge, and $C_{5}$ discharges. In state $1, Q_{1} \rightarrow Q_{3}$ are on, $Q_{4} \rightarrow Q_{6}$ are off, 
$L_{1}$ and $L_{2}$ charge, $C_{2} \rightarrow C_{4}$ discharge, and $C_{5}$ charges. In this mode of operation $Q_{1}$ and $Q_{2}$ act as main switches while $Q_{3} \rightarrow Q_{6}$ act as synchronous rectifiers. The current flow paths in the step-up operation during State 0 and State 1 are shown in Figure 9.2.

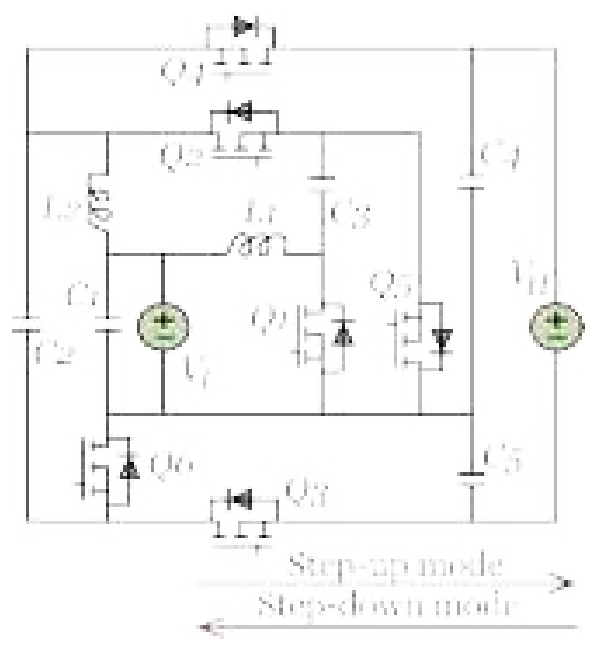

Figure 9.1: The structure of the proposed bidirectional dc-dc converter.

In the mathematical analysis of the converter, the voltages and currents at the $\mathrm{LV}$ and $\mathrm{HV}$ ports are referred to as $V_{L}, V_{H}, I_{L}$, and $I_{H}$, respectively. The voltages across $C_{l} \rightarrow C_{5}$ are referred to as $V_{C l} \rightarrow V_{C 5}$, the dc currents of $L_{1}$ and $L_{2}$ are $I_{L 1}$ and $I_{L 2}$, and the instantaneous voltages across $L_{1}$ and $L_{2}$ are $V_{L 1}$ and $V_{L 2}$, respectively. The charging currents of $C_{1} \rightarrow C_{5}$ are $i_{C I_{-} c h} \rightarrow i_{C C_{-} c h}$, while the discharging currents of $C_{1} \rightarrow C_{5}$ are $i_{C C_{1} d i s} \rightarrow i_{C C_{-} d i s .}$. The duty cycle of $Q_{1} \rightarrow Q_{3}$ is $d_{1}$, while the duty cycle of $Q_{4} \rightarrow Q_{6}$ is $d_{2}\left(=1-d_{1}\right)$. The key waveforms of the proposed converter in the step-up mode are shown in Figure 9.4(a), where $G_{1} \rightarrow G_{6}$ are the gate triggering signals of $Q_{1} \rightarrow Q_{6}$, and $T$ is the periodic switching time.

The converter in State 0 can be analyzed by applying Kirchhoff's Voltage Law (KVL) and Kirchhof's Current Law (KCL) on the equivalent circuit in Figure 9.2(b), we can derive the following relationships: 


$$
\left\{\begin{array}{l}
V_{L 1}=V_{L}-V_{C 3} \\
V_{L 2}=V_{L}-V_{C 4} \\
V_{C 2}=V_{C 4}
\end{array}\right.
$$

$$
\left\{\begin{array}{l}
i_{C 2 \_c h}=I_{L 2}-I_{H}-i_{C 4_{-} c h} \\
i_{C 3_{-} c h}=I_{L 1} \\
i_{C 5 \_d i s}=I_{H}
\end{array}\right.
$$

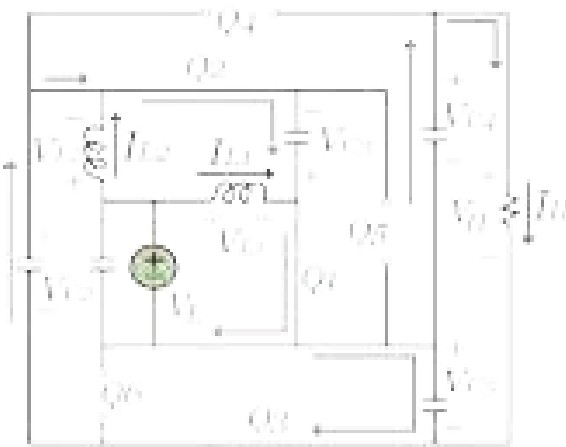

(a)

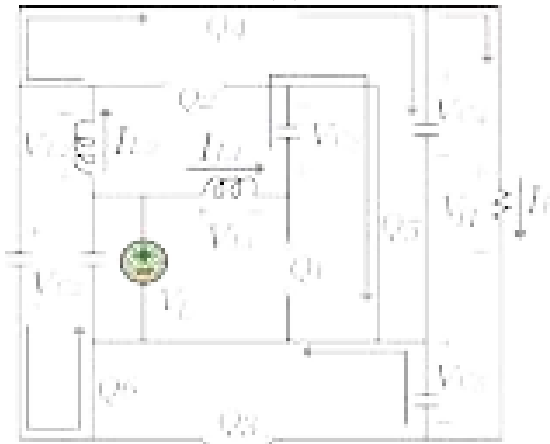

(b)

Figure 9.2: Current flow paths in step-up mode. (a) State 1. (b) State 0.

The converter in State 1 can be analyzed by applying KVL and KCL rules on the equivalent circuit in Figure 9.2(a), we can derive the following relationships:

$$
\begin{gathered}
\left\{\begin{array}{l}
V_{L 1}=V_{L} \\
V_{L 2}=V_{L}+V_{C 3}
\end{array}\right. \\
\left\{\begin{array}{l}
i_{C 2 \_d i s}=I_{H}+i_{C 5 \_c h} \\
i_{C 3 \_d i s}=I_{L 2}+i_{C 5 \_c h} \\
i_{C 4 \_d i s}=I_{H}
\end{array}\right.
\end{gathered}
$$




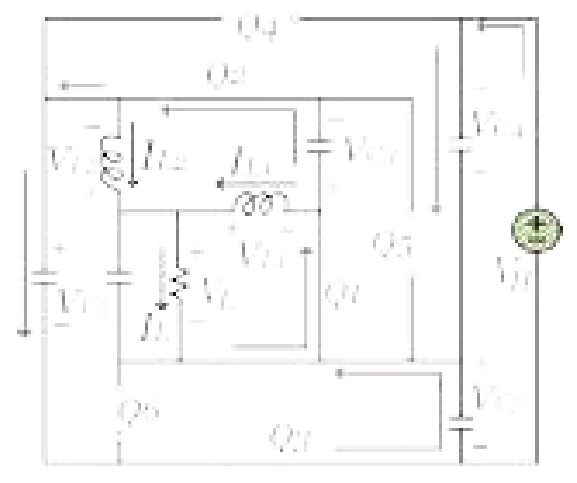

(a)

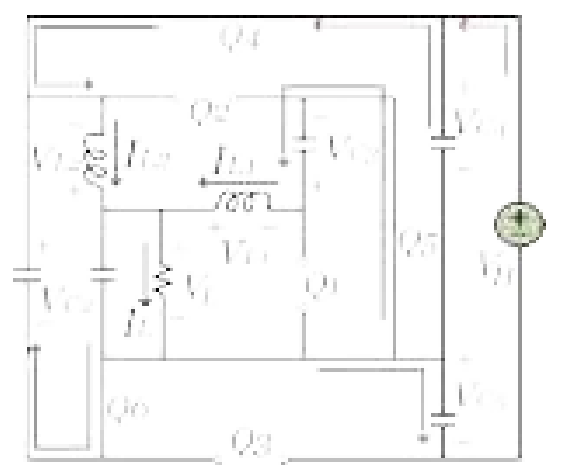

(b)

\section{Figure 9.3: Current flow paths in step-down mode. (a) State 1. (b) State 0.}

In State $1, Q_{1}$ and $Q_{2}$ are turned on by $G_{1}$ and $G_{2}$, respectively. In this switching states, $Q_{3}$ acts as a synchronous rectifier, hence, to provide zero voltage switching (ZVS) for $Q_{3}$ during the turn on and turn off instants a time delay is applied between the rising edge of $G_{3}$ and the rising edge of $G_{1}$ and another time delay is applied between the falling edge of $G_{3}$ and the falling edge of $G_{l}$. During these delay times, current flows through the body diode of $Q_{3}$, thus, the voltage across between its drain and source drops to the forward voltage of the body diode $(\approx 0 \mathrm{~V})$, which allows the ZVS realization. In State $0, Q_{4}, Q_{5}$, and $Q_{6}$ conduct and act as synchronous rectifiers. In order to provide ZVS to them, a time delay should be applied between the rising edge of $G_{4} \rightarrow$ $G_{6}$ and the falling edge of $G_{l}$, and another time delay should be applied between the falling edge of $G_{4} \rightarrow G_{6}$ and the ring edge of $G_{1}$, as shown in Figure 9.4(a). 
By applying the volt-second balance rule on the three inductors, the voltages across the capacitors and the voltage gain in step-mode $\left(M_{\text {Boost }}\right)$ can be extracted, as follows:

$$
\begin{aligned}
& V_{C 2}=V_{C 4}=V_{L}\left(\frac{1}{1-d_{1}}\right)^{2} \\
& V_{C 3}=V_{L} \frac{1}{1-d_{1}} \\
& V_{C 5}=V_{L} \frac{2-d_{1}}{\left(1-d_{1}\right)^{2}} \\
& V_{H}=V_{C 4}+V_{C 5}=V_{L} \frac{3-d_{1}}{\left(1-d_{1}\right)^{2}} \\
& M_{B o o s t}=\frac{V_{H}}{V_{L}}=\frac{3-d_{1}}{\left(1-d_{1}\right)^{2}}
\end{aligned}
$$

\subsubsection{Analysis and Operation in Step-Down Mode}

In this mode, the power flows from the HV side to the LV side. Similarly, the operation has two switching states, namely: State 0 and State 1 . In state $0, Q_{1} \rightarrow Q_{3}$ are off, $Q_{4} \rightarrow Q_{6}$ are on, $L_{1}$ and $L_{2}$ charge, $C_{2} \rightarrow C_{4}$ discharge, and $C_{5}$ charges. In state $1, Q_{1} \rightarrow Q_{3}$ are on, $Q_{4} \rightarrow Q_{6}$ are off, $L_{1}$ and $L_{2}$ discharge, $C_{2} \rightarrow C_{4}$ charge, and $C_{5}$ discharges. In this mode of operation $Q_{3} \rightarrow Q_{6}$ act as main switches while $Q_{1}$ and $Q_{2}$ act as synchronous rectifiers. The current flow paths in the step-down operation during State 0 and State 1 are presented in Figure 9.3. In this mode, $G_{3}$ is complementary to $G_{4} \rightarrow G_{6}$, a time delay is applied between the falling edge of $G_{1}$ and the rising edges of $G_{4} \rightarrow$ $G_{6}$, and another time delay is applied between the rising edge of $G_{l}$ and the falling edges of $G_{4} \rightarrow$ $G_{6}$ to provide ZVS to $Q_{1}$ and $Q_{2}$ during the turn on and turn off instants, as depicted in Figure 9.4(b). 


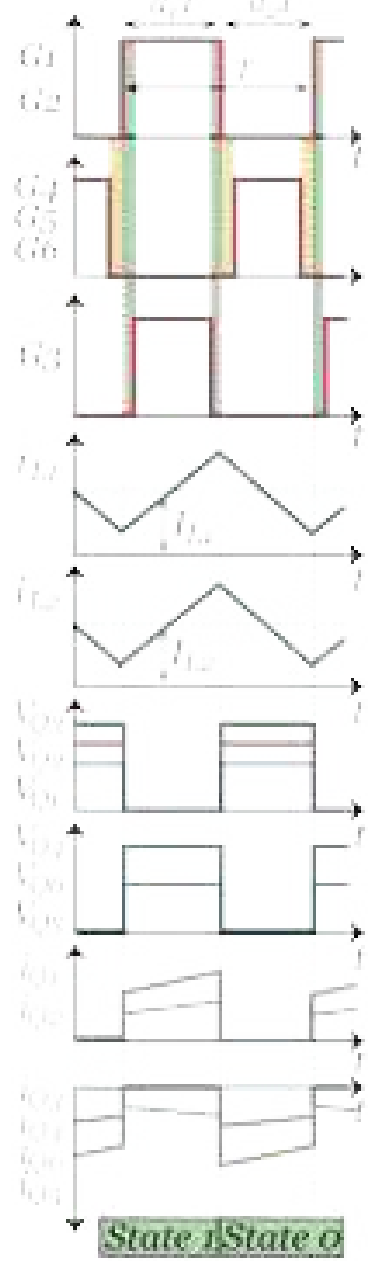

(a)
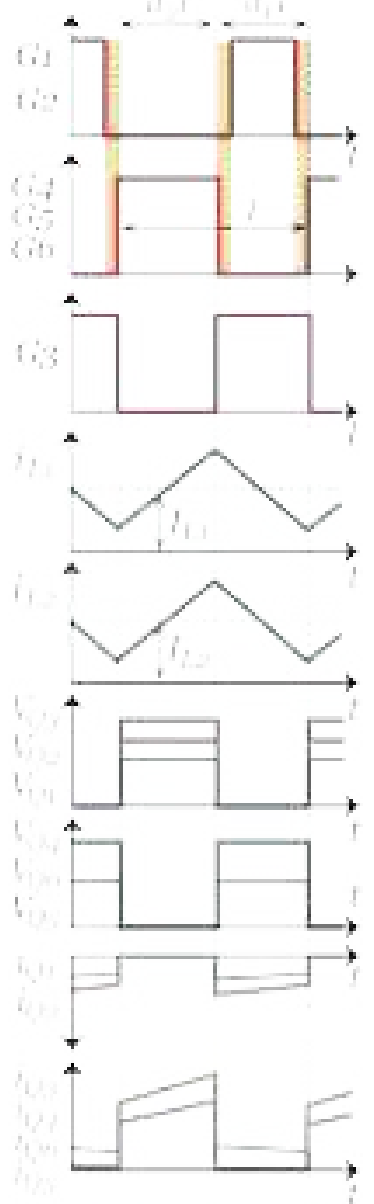

State ol State 1

(b)

Figure 9.4: Important waveforms of the proposed converter. (a) Step-up mode. (b) Stepdown mode.

Since $Q_{1} \rightarrow Q_{3}$ are complementary to $Q_{4} \rightarrow Q_{6}$, hence, the voltages across the capacitors and the voltage gain in step-down operation $\left(M_{B u c k}\right)$ can be directly extracted from (5)-(9) by replacing $d_{1}$ by $\left(1-d_{2}\right)$, as follows:

$$
V_{C 2}=V_{C 4}=V_{H} \frac{1}{2+d_{2}}
$$




$$
\begin{aligned}
& V_{C 3}=V_{H} \frac{d_{2}}{2+d_{2}} \\
& V_{C 5}=V_{H} \frac{1+d_{2}}{2+d_{2}} \\
& V_{L}=V_{H} \frac{d_{2}{ }^{2}}{2+d_{2}} \\
& M_{B u c k}=\frac{V_{L}}{V_{H}}=\frac{d_{2}{ }^{2}}{2+d_{2}}
\end{aligned}
$$

\subsubsection{Voltage and Current Stresses on the Switches}

The voltage stresses across the six switches can be deduced by applying the KVL rule on the equivalent circuits of the proposed converter in Figure 9.2 and Figure 9.3, as follows:

$$
\begin{aligned}
& V_{Q 1}=V_{Q 5}=V_{L} \frac{1}{1-d_{1}}=V_{H} \frac{d_{2}}{2+d_{2}} \\
& V_{Q 2}=V_{L}\left(\frac{1}{1-d_{1}}\right)^{2}=V_{H} \frac{1}{2+d_{2}} \\
& V_{Q 3}=V_{Q 4}=V_{Q 6}=V_{L} \frac{2-d_{1}}{\left(1-d_{1}\right)^{2}}=V_{H} \frac{1+d_{2}}{2+d_{2}}
\end{aligned}
$$

By means of (9), the voltage stresses described by (15)-(17) can be expressed as functions in $M_{\text {Boost }}$, as follows:

$$
V_{Q 1}=V_{Q 5}=V_{H} \frac{\sqrt{1+8 M_{\text {Boost }}}-1}{4 M_{\text {Boost }}}
$$




$$
\begin{aligned}
& V_{Q 2}=V_{H} \frac{4 M_{\text {Boost }}-\sqrt{1+8 M_{\text {Boost }}}+1}{8 M_{\text {Boost }}} \\
& V_{Q 3}=V_{Q 4}=V_{Q 6}=V_{H} \frac{4 M_{\text {Boost }}+\sqrt{1+8 M_{\text {Boost }}}-1}{8 M_{\text {Boost }}}
\end{aligned}
$$

The normalized voltage stresses on the six switches of the proposed converter are plotted in Figure 9.5. The current stresses on the power switches and inductors can be deduced by applying the charge-second balance on (2) and (4), as follows:

$$
\begin{aligned}
& I_{L 1}=I_{H} \frac{1+d_{1}}{\left(1-d_{1}\right)^{2}}=I_{L} \frac{2-d_{2}}{2+d_{2}} \\
& I_{L 2}=I_{H} \frac{2}{1-d_{1}}=I_{L} \frac{2 d_{2}}{2+d_{2}} \\
& i_{Q 1}=I_{H} \frac{1+d_{1}}{d_{1}\left(1-d_{1}\right)^{2}}=I_{L} \frac{2-d_{2}}{\left(2+d_{2}\right)\left(1-d_{2}\right)} \\
& i_{Q 2}=I_{H} \frac{1+d_{1}}{d_{1}\left(1-d_{1}\right)}=I_{L} \frac{d_{2}\left(2-d_{2}\right)}{\left(2+d_{2}\right)\left(1-d_{2}\right)} \\
& i_{Q 3}=I_{H} \frac{1}{d_{1}}=I_{L} \frac{d_{2}^{2}}{\left(2+d_{2}\right)\left(1-d_{2}\right)} \\
& i_{Q 4}=i_{Q 6}=I_{H} \frac{1}{1-d_{1}}=I_{L} \frac{d_{2}}{\left(2+d_{2}\right)}
\end{aligned}
$$




$$
i_{Q 5}=I_{H} \frac{1+d_{1}}{\left(1-d_{1}\right)^{2}}=I_{L} \frac{2-d_{2}}{\left(2+d_{2}\right)}
$$

\subsection{Design of Components and Efficiency Analysis of the Proposed Converter}

\subsubsection{Power Switches Selection}

Equations (15)-(17) and (23)-(27) describe the voltage and current stresses on the six switches, respectively. Accordingly, when the range of voltage gain and load are known, the peak stresses can be calculated. The calculated current and voltage stresses should be within the safe-operatingarea (SOA) of the selected power switches.

\subsubsection{Design of Inductors}

When the ranges of the operating voltage gain and load are known, the allowed maximum current ripples of the inductors (i.e. $\Delta i_{L 1}$ and $\Delta i_{L 2}$ ) and the switching frequency $f_{s}$ are determined, the minimum required inductance can be calculated as follows:

$$
\begin{aligned}
L_{1} & \geq \frac{d_{1} V_{L}}{f_{s} \Delta i_{L 1}} \\
L_{2} & \geq \frac{d_{1} V_{L}}{f_{s} \Delta i_{L 2}}\left(\frac{2-d_{1}}{1-d_{1}}\right)
\end{aligned}
$$

Additionally, the peak current stresses of the two inductors can be deduced by means of (21) and (22), hence, the designed inductors should tolerate these currents.

\subsubsection{Design of Capacitors}

The voltages across the capacitors can be calculated using (5)-(8) and (10)-(13). The relationships between the capacitances of the five capacitors and their corresponding ripple voltage are described by (29). Hence, when the operating voltage gain and loading ranges are knows, the required capacitance and voltage rating of the five capacitors can be deduced. 


$$
\begin{aligned}
C_{1} & \geq \frac{d_{1} V_{L}}{8 f_{S}^{2} \Delta V_{C 1}}\left(\frac{1}{L_{1}}+\frac{1}{L_{2}\left(1-d_{1}\right)}\right) \\
C_{2} & \geq \frac{I_{H}}{f_{S} \Delta V_{C 2}} \\
C_{3} & \geq \frac{\left(1+d_{1}\right) I_{H}}{f_{S}\left(1-d_{1}\right) \Delta V_{C 3}} \\
C_{4} & \geq \frac{d_{1} I_{H}}{f_{S} \Delta V_{C 4}} \\
\left(C_{5}\right. & \geq \frac{\left(1-d_{1}\right) I_{H}}{f_{s} \Delta V_{C 5}}
\end{aligned}
$$

\subsubsection{Efficiency Analysis}

Calculating the efficiency of the power converter is very important to adequately design the cooling system, additionally, it gives an idea about the operating conditions where the proposed topology has the maximum/minimum efficiency. The power loss of the converter $P_{\text {Loss }}$ is described by (30), where $P_{Q(\text { cond })}, P_{Q(\text { sw })}, P_{L(\text { cond })}, P_{L(\text { core })}$, and $P_{C(\text { cond })}$ are the conduction and switching losses of the six switches, the conduction and core losses of the two inductors, and the conduction loss of the five capacitors.

$$
P_{\text {loss }}=P_{Q(\text { cond })}+P_{Q(\text { sw })}+P_{L(\text { cond })}+P_{L(\text { core })}+P_{C(\text { cond })}
$$

These losses can be calculated using (31)-(36), as follows:

$$
\begin{aligned}
& P_{Q(\text { cond })}=\sum_{j=1}^{j=6} i_{Q j(r m s)}^{2} r_{d s j} \\
& P_{Q(s w)}= \begin{cases}P_{Q 1(s w)}+P_{Q 2(s w)} & \text { (Step-up } \\
\sum_{j=3}^{j=6} P_{Q j(s w)} & \text { (Step-do }\end{cases} \\
& P_{Q j(s w)}=f_{S}\left(0.5 V_{Q j} i_{Q j}\left(t_{r j}+t_{f j}\right)+0.5 V_{Q j}{ }^{2} C_{O S S j}\right)
\end{aligned}
$$

Where $r_{d s l} \rightarrow r_{d s 6}, t_{r l} \rightarrow t_{r 6}, t_{f l} \rightarrow t_{f 6}, C_{O S S 1} \rightarrow C_{\text {OSS6 }}$ are the on resistances, the rising times, the falling times, and the parasitic output capacitances of the six switches. The switching loss of the 
proposed converter, described by (32), depends on the mode of operation, as in step-up mode $Q_{3}$ $\rightarrow Q_{6}$ are soft-switched, while in step-down mode $Q_{1}$ and $Q_{2}$ are soft-switched. The root-meansquare (rms) currents of the six switches can be calculated as in (34).

$$
\begin{aligned}
& i_{Q 1(r m s)}=I_{H}\left(\frac{1+d_{1}}{\sqrt{d_{1}}\left(1-d_{1}\right)^{2}}\right) \\
& i_{Q 2(r m s)}=I_{H}\left(\frac{1+d_{1}}{\sqrt{d_{1}}\left(1-d_{1}\right)}\right) \\
& i_{Q 3(r m s)}=I_{H}\left(\frac{1}{\sqrt{d_{1}}}\right) \\
& i_{Q 4(r m s)}=i_{Q 6(r m s)}=I_{H}\left(\frac{1}{\sqrt{1-d_{1}}}\right) \\
& i_{Q 5(r m s)}=I_{H}\left(\frac{1+d_{1}}{\sqrt{\left(1-d_{1}\right)^{3}}}\right)
\end{aligned}
$$

The conduction and core losses of the two inductors are described by (35) and (36), where $r_{L l}$, $r_{L 2}, l_{c 1}, l_{c 2}, A_{c 1}, A_{c 2}, \Delta B_{1}$, and $\Delta B_{2}$ are the series resistances of the two inductors, the lengths of the magnetic flux path of the cores of the two inductors, the cross sectional areas of the cores of the two inductors, and ac magnetic flux density of the two inductors.

$$
\begin{gathered}
P_{L(\text { cond })}=I_{L 1}{ }^{2} r_{L 1}+I_{L 2}{ }^{2} r_{L 2} \\
P_{L(\text { core })}=l_{c 1} A_{c 1}\left(a \Delta B_{1}^{b} f_{s}^{C}\right)+l_{c 2} A_{c 2}\left(a \Delta B_{2}^{b} f_{S}^{C}\right)
\end{gathered}
$$

As $a, b$, and $c$ are fitting parameters that can be derived from the datasheet of the cores. The conduction losses of the five capacitors can be calculated using (37), where $r_{C l} \rightarrow r_{C 5}$ are the equivalent series resistances of the five capacitors. The rms values of the capacitors' currents are described by (38). 


$$
\begin{aligned}
& P_{C(\text { cond })}=\sum_{j=1}^{j=5} i_{C j(r m s)}^{2} r_{C j} \\
& i_{C 1(r m s)}=\frac{d_{1} V_{L}}{2 \sqrt{3} f_{s}\left(\frac{1}{L_{1}}+\frac{1}{L_{2}\left(1-d_{1}\right)}\right)} \\
& i_{C 2(r m s)}=I_{H} \sqrt{\frac{3 d_{1}^{2}-3 d_{1}+1}{d_{1}^{2}\left(1-d_{1}\right)^{2}}} \\
& i_{C 3(r m s)}=I_{H} \sqrt{\frac{\left(1+d_{1}\right)^{2}}{d_{1}\left(1-d_{1}\right)^{3}}} \\
& i_{C 4(r m s)}=I_{H} \sqrt{\frac{3 d_{1}^{2}-3 d_{1}+1}{\left(1-d_{1}\right)^{2}}} \\
& i_{C 5(r m s)}=I_{H} \sqrt{\frac{1-d_{1}}{d_{1}}}
\end{aligned}
$$

Finally, the efficiency $\eta$ is depicted by (39):

$$
\eta= \begin{cases}\frac{V_{L} I_{L}}{P_{\text {Loss }}+V_{L} I_{L}} & \text { (Step-up mode) } \\ \frac{V_{H} I_{H}}{P_{\text {Loss }}+V_{H} I_{H}} & \text { (Step-down mode) }\end{cases}
$$

\subsection{Comparative Study}

The proposed converter is compared with seven other BDC topologies in this section. The BDC architectures in this comparative study are a four-level flying capacitor (FLFC) converter, the quadratic BDC in [194], the switched-capacitor BDC in [195] with two multiplier cells, the new three-level BDC in [193], the hybrid BDC with switched-capacitor cell in [196], the hybrid converter with a quasi-Z-source and a switched-capacitor networks in [95], and the conventional cascaded bidirectional converter (CCBC). Table 9.1 concludes the features of each BDC topology including the number of active and passive components, the voltage gain in step-up and step-down 
modes, and the potential difference between the grounds of the LV and HV ports $\left(V_{\text {Grounds }}\right)$. The voltage gain curves of the compared converters versus the duty cycle in step-up and step-down modes are shown in Figure 9.6. The proposed converter has the highest voltage gain in the stepup mode and the lowest voltage gain in the step-down mode in comparison to the other converters in this study. The converters in [193] and [196] have HF PWM potential difference between the grounds of their ports which limits their applications.

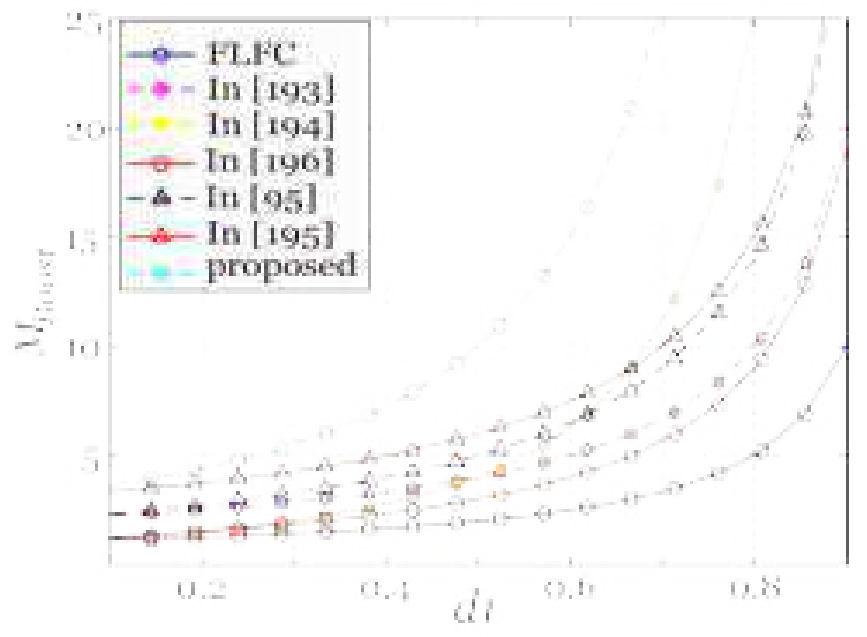

(a)

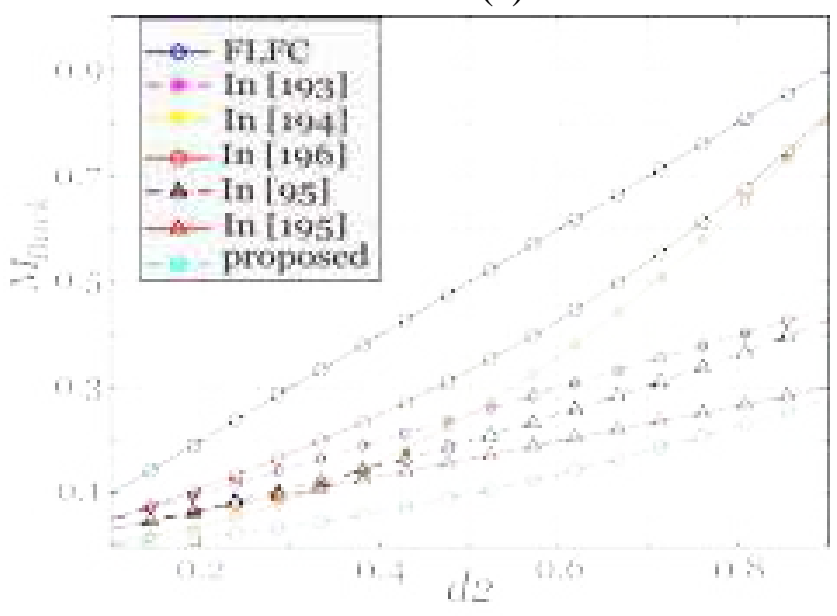

(b)

Figure 9.5: Comparison of voltage gain between the proposed converter and other BDC solutions. (a) In step-up mode. (b) In step-down mode. 
In order to compare the relative total cost of the power switches used in each topology, the semiconductor utilization factor $\left(U_{F}\right)$ is utilizes, and it is defined by (40), where $P_{o}$ is the output power of the converter, $V_{Q j}$ and $i_{Q j(r m s)}$ are the voltage stress and the rms current stress on switch $Q_{j}$

$$
U_{F}=\frac{P_{o}}{\sum V_{Q j} i_{Q j(r m s)}}
$$

Table 9.1: COMPARISON BETWEEN THE PROPOSED AND OTHER BDC SOLUTIONS

\begin{tabular}{|c|c|c|c|c|}
\hline \multirow{2}{*}{ Topology } & \multirow{2}{*}{ Components } & \multirow{2}{*}{$V_{\text {Grounds }}$} & \multicolumn{2}{|c|}{ Voltage gain } \\
\hline & & & Step-up mode & Step-down mode \\
\hline FLFC & $\begin{array}{l}6 \text { Switches } \\
1 \text { Inductor } \\
4 \text { Capacitors }\end{array}$ & $0 \mathrm{~V}$ & $M_{\text {Boost }}=\frac{1}{1-d_{1}}$ & $M_{\text {Buck }}=d_{2}$ \\
\hline Converter in [193] & $\begin{array}{l}4 \text { Switches } \\
2 \text { Inductors } \\
3 \text { Capacitors }\end{array}$ & $\begin{array}{c}\text { HF PWM } \\
\text { voltage }\end{array}$ & $M_{\text {Boost }}=\frac{2}{1-d_{1}}$ & $M_{B u c k}=\frac{d_{2}}{2}$ \\
\hline Quadratic in [194] & $\begin{array}{l}4 \text { Switches } \\
2 \text { Inductor } \\
3 \text { Capacitors }\end{array}$ & $0 \mathrm{~V}$ & $M_{\text {Boost }}=\left(\frac{1}{1-d_{1}}\right)^{2}$ & $M_{B u c k}=d_{2}{ }^{2}$ \\
\hline $\begin{array}{l}\text { Converter in [195] } \\
(\mathrm{n}=2)\end{array}$ & $\begin{array}{l}6 \text { Switches } \\
1 \text { Inductor } \\
6 \text { Capacitors }\end{array}$ & $0 \mathrm{~V}$ & $M_{\text {Boost }}=\frac{3}{1-d_{1}}$ & $M_{B u c k}=\frac{d_{2}}{3}$ \\
\hline Converter in [196] & $\begin{array}{l}3 \text { Switches } \\
2 \text { Inductors } \\
4 \text { Capacitors }\end{array}$ & $\begin{array}{c}\text { HF PWM } \\
\text { voltage }\end{array}$ & $M_{\text {Boost }}=\frac{1+d_{1}}{1-d_{1}}$ & $M_{B u c k}=\frac{d_{2}}{2-d_{2}}$ \\
\hline Converter in [95] & $\begin{array}{l}5 \text { Switches } \\
2 \text { Inductors } \\
6 \text { Capacitors }\end{array}$ & $\begin{array}{l}\text { Constant } \\
\text { voltage }\end{array}$ & $M_{\text {Boost }}=\frac{2+d_{1}}{1-d_{1}}$ & $M_{B u c k}=\frac{d_{2}}{3-d_{2}}$ \\
\hline $\mathrm{CCBC}$ & $\begin{array}{l}4 \text { Switches } \\
2 \text { Inductor } \\
3 \text { Capacitors }\end{array}$ & $0 \mathrm{~V}$ & $M_{\text {Boost }}=\left(\frac{1}{1-d_{1}}\right)^{2}$ & $M_{\text {Buck }}=d_{2}{ }^{2}$ \\
\hline Proposed & $\begin{array}{l}6 \text { Switches } \\
2 \text { Inductors } \\
5 \text { Capacitors }\end{array}$ & $\begin{array}{l}\text { Constant } \\
\text { voltage }\end{array}$ & $M_{\text {Boost }}=\frac{3-d_{1}}{\left(1-d_{1}\right)^{2}}$ & $M_{\text {Buck }}=\frac{d_{2}{ }^{2}}{2+d_{2}}$ \\
\hline
\end{tabular}




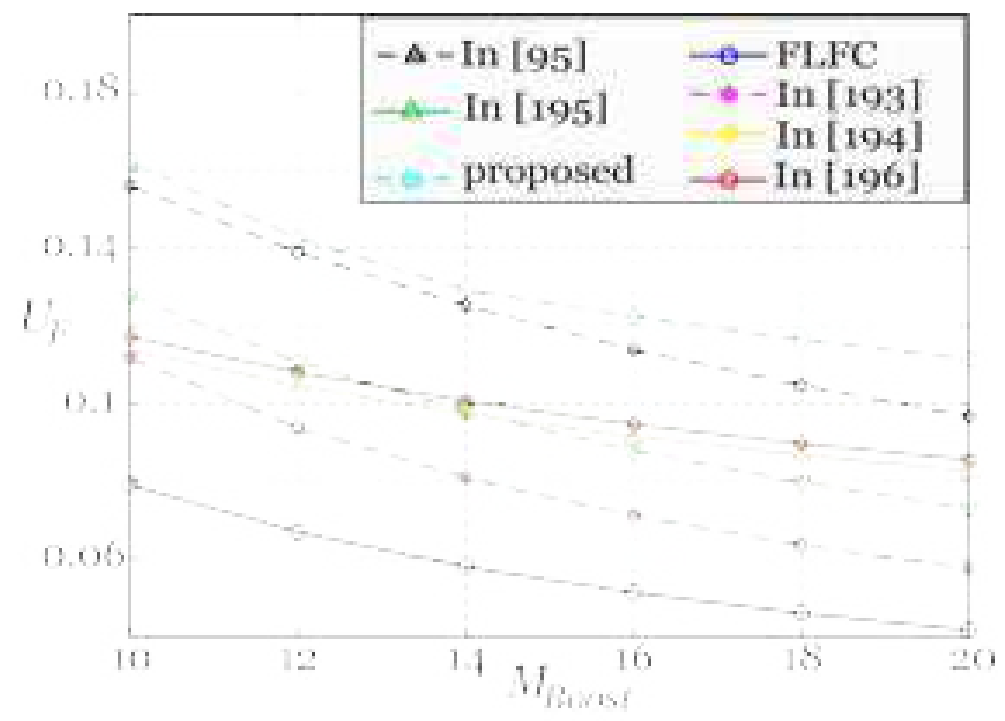

Figure 9.6: Semiconductor utilization factor for the compared BDC solutions.

The ratio between the output power of a dc-dc converter and the total power processed by the power switches of that converter should be as high as possible to reduce the cost of the semiconductor devices. Figure 9.7 shows the semiconductor utilization factor curves of the compared converters versus $M_{\text {Boost }}$ when $P_{o}=2 \mathrm{~kW}$ and $V_{H}=800 \mathrm{~V}$. It is clear that the proposed converter has the highest semiconductor utilization factor compared to the other converters.

The comparative study shows that the proposed BDC topology combines a number of features such as high voltage conversion ratios, high semiconductor utilization factor, and constant potential difference between the grounds of its LV and HV ports, which make it an excellent interface for the ESUs.

\subsection{Extended Structure of the Proposed Converter}

Since the proposed converter encompasses a switched-capacitor network, hence, this network can have more than one switched-capacitor cell in order to extend the voltage gain range and reduce the voltage stress on the individual power switches. 


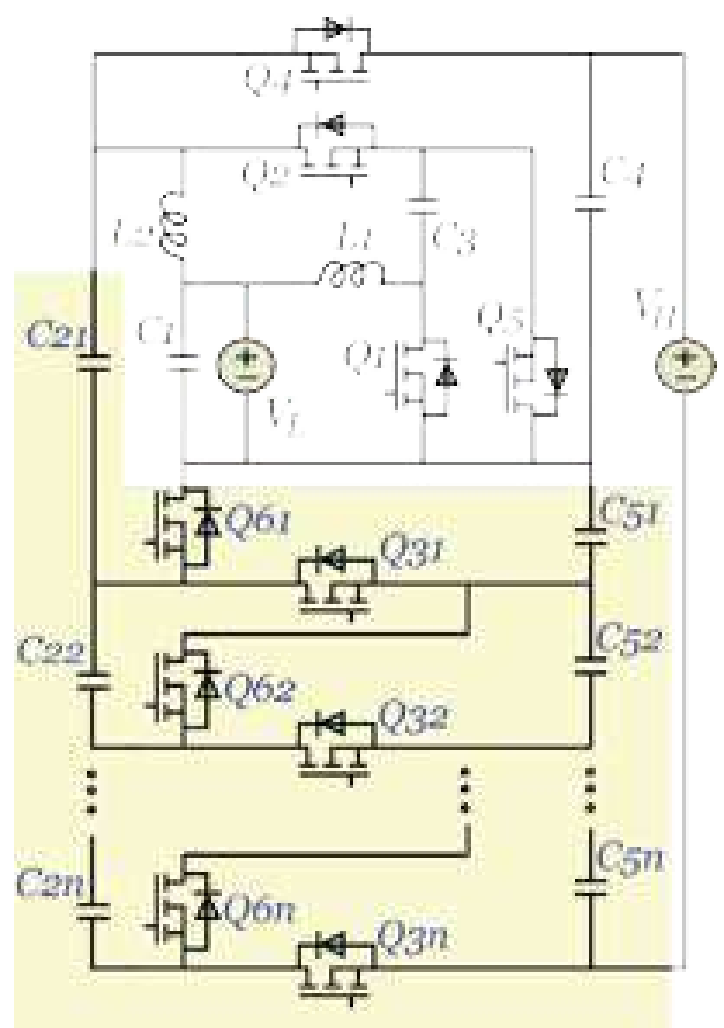

\section{Figure 9.7: The extended structure of the proposed converter with $\mathbf{n}$ switched-capacitor cells.}

Figure 9.8 shows the extended structure of the proposed converter with $n$ switched-capacitor cells. The extended structure with $n$ switched-capacitor cells is composed of $4+2 n$ power switches, $3+2 n$ capacitors, and two inductors. The switches $Q_{31} \rightarrow Q_{3 n}$ and $Q_{61} \rightarrow Q_{6 n}$ have the same switching states as $Q_{3}$ and $Q_{6}$, respectively, discussed in Section II, as $Q_{31} \rightarrow Q_{3 n}$ only conduct in state 1 , while $Q_{61} \rightarrow Q_{6 n}$ only conduct in state 0 . Similarly, $C_{21} \rightarrow C_{2 n}$ and $C_{51} \rightarrow C_{5 n}$ have the same charge/discharge states as $C_{2}$ and $C_{5}$, respectively, illustrated in Section II, where $C_{21} \rightarrow C_{2 n}$ charge in state 0 and discharge in state 1 , while $C_{51} \rightarrow C_{5 n}$ discharge in state 0 and charge in state 1.

The voltage across the capacitors of the extended structure are described by (41), while the voltage at the HV port is defined by (42). 


$$
\begin{gathered}
V_{C 21}=V_{C 4}=\frac{V_{L}}{\left(1-d_{1}\right)^{2}}=\frac{V_{H}}{1+n+n d_{2}} \\
V_{C 22} \rightarrow V_{C 2 n}=\frac{\left(2-d_{1}\right) V_{L}}{\left(1-d_{1}\right)^{2}}=\frac{\left(1+d_{2}\right) V_{H}}{1+n+n d_{2}} \\
V_{C 3}=\frac{V_{L}}{1-d_{1}}=\frac{d_{2} V_{H}}{1+n+n d_{2}} \\
V_{C 51} \rightarrow V_{C 5 n}=\frac{\left(2-d_{1}\right) V_{L}}{\left(1-d_{1}\right)^{2}}=\frac{\left(1+d_{2}\right) V_{H}}{1+n+n d_{2}} \\
V_{H}=V_{C 4}+\sum_{j=1}^{j=n} V_{C 5 j}=V_{L} \frac{1+n\left(2-d_{1}\right)}{\left(1-d_{1}\right)^{2}}
\end{gathered}
$$

Accordingly, the voltage gains in step-up mode $\left(\grave{M}_{\text {Boost }}\right)$ and step-down mode $\left(\grave{M}_{B u c k}\right)$ can be defined as in (43) and (44).

$$
\begin{aligned}
& \grave{M}_{\text {Boost }}=\frac{V_{H}}{V_{L}}=\frac{1+n\left(2-d_{1}\right)}{\left(1-d_{1}\right)^{2}} \\
& \grave{M}_{\text {Buck }}=\frac{V_{L}}{V_{H}}=\frac{d_{2}{ }^{2}}{1+n\left(1+d_{2}\right)}
\end{aligned}
$$

Figure 9.9 shows the voltage gain curves of the extended structure in step-up and step-down modes. The voltage stresses across the power switches of the extended structure are described by (45)-(48).

$$
\begin{aligned}
& V_{Q 1}=V_{Q 5}=\frac{V_{L}}{1-d_{1}}=\frac{d_{2} V_{H}}{1+n+n d_{2}} \\
& V_{Q 2}=\left(\frac{V_{L}}{1-d_{1}}\right)^{2}=\frac{V_{H}}{1+n+n d_{2}}
\end{aligned}
$$




$$
\begin{aligned}
& V_{Q 31} \rightarrow V_{Q 3 n}=V_{Q 4}=\frac{\left(2-d_{1}\right) V_{L}}{\left(1-d_{1}\right)^{2}}=\frac{\left(1+d_{2}\right) V_{H}}{1+n+n d_{2}} \\
& V_{Q 61} \rightarrow V_{Q 6 n}=\frac{\left(2-d_{1}\right) V_{L}}{\left(1-d_{1}\right)^{2}}=\frac{\left(1+d_{2}\right) V_{H}}{1+n+n d_{2}}
\end{aligned}
$$

By means of (43), equations (45-(48) can be defined as functions in the voltage gain, as following:

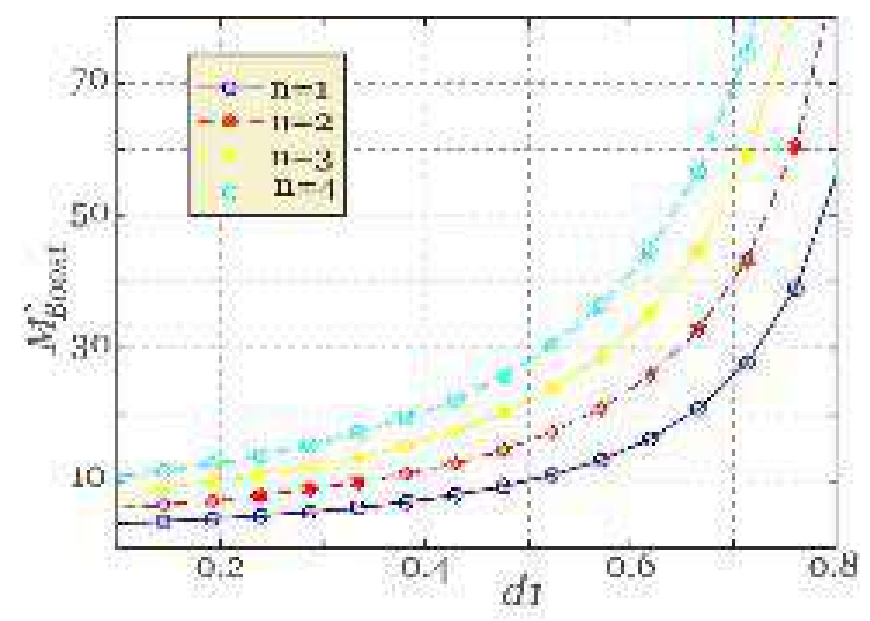

(a)

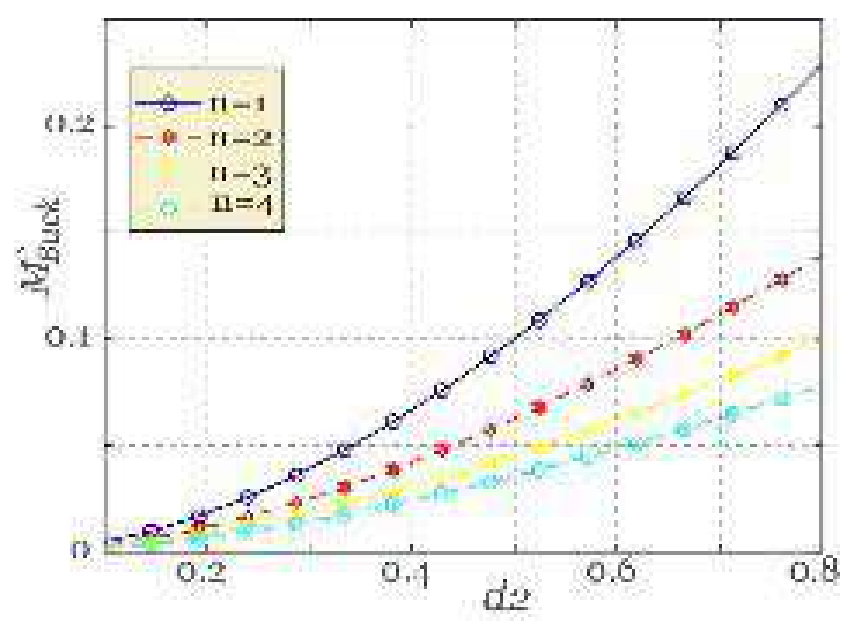

(b)

Figure 9.8: Voltage gain of the proposed extended structure with different number of switchedcapacitor cells. (a) In step-up mode. (b) In step-down mode. 


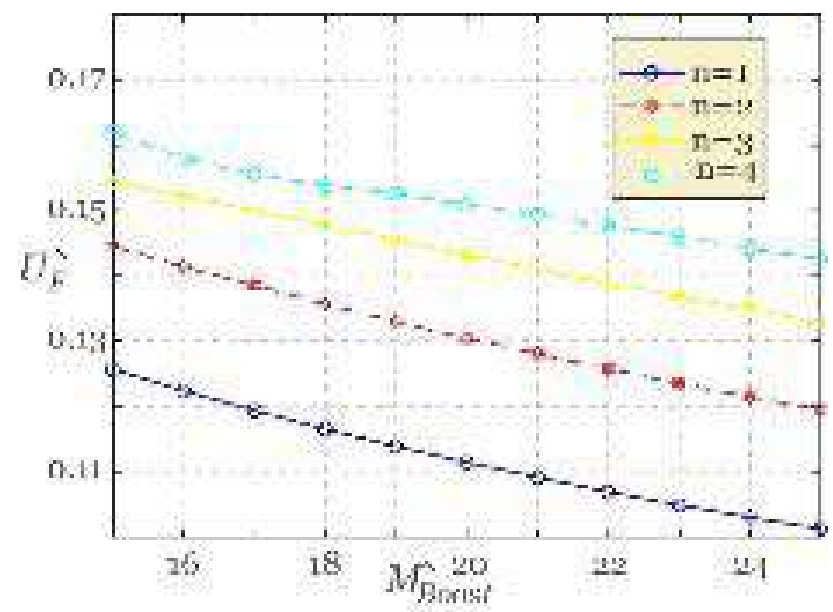

Figure 9.9: Semiconductor utilization factor of the proposed extended structure with different number of switched-capacitor cells.

$$
\begin{gathered}
V_{Q 1}=V_{Q 5}=V_{H}\left(\frac{\sqrt{n^{2}+4 \grave{M}_{\text {Boost }}(1+n)}-n}{2 \grave{M}_{\text {Boost }}(1+n)}\right) \\
V_{Q 2}=V_{H}\left(\frac{2 \grave{M}_{\text {Boost }}(1+n)-n \sqrt{n^{2}+4 \grave{M}_{\text {Boost }}(1+n)}+n^{2}}{2 \grave{M}_{\text {Boost }}(1+n)}\right) \\
V_{Q 31} \rightarrow V_{Q 3 n}=V_{Q 4}=V_{Q 61} \rightarrow V_{Q 6 n} \\
=V_{H}\left(\frac{2 \grave{M}_{\text {Boost }}(1+n)+\sqrt{n^{2}+4 \grave{M}_{\text {Boost }}(1+n)}-n}{2 \grave{M}_{\text {Boost }}(1+n)}\right)
\end{gathered}
$$

The currents of the two inductors can be calculated using (52) and (53), while the current stresses of the power switches are described by (54)-(58).

$$
\begin{gathered}
I_{L 1}=I_{H} \frac{n+d_{1}}{\left(1-d_{1}\right)^{2}}=I_{L} \frac{1+n-d_{2}}{1+n+n d_{2}} \\
I_{L 2}=I_{H} \frac{n+1}{1-d_{1}}=I_{L} \frac{d_{2}(1+n)}{1+n+n d_{2}}
\end{gathered}
$$




$$
\begin{gathered}
i_{Q 1}=I_{H} \frac{n+d_{1}}{d_{1}\left(1-d_{1}\right)^{2}}=I_{L} \frac{1+n-d_{2}}{\left(1-d_{2}\right)\left(1+n+n d_{2}\right)} \\
i_{Q 2}=I_{H} \frac{n+d_{1}}{d_{1}\left(1-d_{1}\right)}=I_{L} \frac{d_{2}\left(1+n-d_{2}\right)}{\left(1-d_{2}\right)\left(1+n+n d_{2}\right)} \\
i_{Q 31} \rightarrow i_{Q 3 n}=I_{H} \frac{1}{d_{1}}=I_{L} \frac{d_{2}{ }^{2}}{\left(1-d_{2}\right)\left(1+n+n d_{2}\right)} \\
i_{Q 4}=i_{Q 61} \rightarrow i_{Q 6 n}=I_{H} \frac{1}{\left(1-d_{1}\right)}=I_{L} \frac{d_{2}}{\left(1+n+n d_{2}\right)} \\
i_{Q 5}=I_{H} \frac{n+d_{1}}{\left(1-d_{1}\right)^{2}}=I_{L} \frac{1+n-d_{2}}{1+n+n d_{2}}
\end{gathered}
$$

The rms currents of the power switches can be calculated via (59), as follows:

$$
\begin{aligned}
& i_{Q 1(r m s)}=I_{H}\left(\frac{n+d_{1}}{\sqrt{d_{1}}\left(1-d_{1}\right)^{2}}\right) \\
& i_{Q 2(r m s)}=I_{H}\left(\frac{n+d_{1}}{\sqrt{d_{1}}\left(1-d_{1}\right)}\right) \\
& i_{Q 31} \rightarrow i_{Q 3 n}=I_{H}\left(\frac{1}{\sqrt{d_{1}}}\right) \\
& i_{Q 4(r m s)}=i_{Q 61(r m s)} \rightarrow i_{Q 6 n(r m s)}=I_{H}\left(\frac{1}{\sqrt{1-d_{1}}}\right) \\
& i_{Q 5(r m s)}=I_{H}\left(\frac{n+d_{1}}{\sqrt{\left(1-d_{1}\right)^{3}}}\right)
\end{aligned}
$$

Figure 9.10 shows the semiconductor utilization factor of the extended structure of the proposed converter with different number of switched-capacitor cells. It shows that as the number of the switched-capacitor cells increases, the semiconductor utilization factor of the converter gets enhanced. 


\subsection{Experimental Results and Analysis}

In order to validate the proposed topology and assess the correctness of its theoretical analysis, an experimental setup was developed, shown in Figure 9.11. The power rating of the prototype is 2 $\mathrm{kW}$, the voltage of the $\mathrm{HV}$ side is $800 \mathrm{~V}$, and the voltage of the $\mathrm{LV}$ port is allowed to swing between $80 \mathrm{~V}$ and $160 \mathrm{~V}$ (with output power of $2 \mathrm{~kW}$ ). The power circuit of the developed setup is composed of Silicon Carbide (SiC) MOSFETs. The controller used is a TMS320f28335 microcontroller from Texas Instruments, and the switching frequency is $100 \mathrm{kHz}$. The values of the used inductors and capacitors, and the part numbers of the power switches are enlisted in Table 9.2. The built prototype has one switched-capacitor network $(n=1)$. Two case studies are discussed in this section, namely: case study I and case study II. In case study I, the operation of the proposed converter is investigated in step-up mode, while in case study II, the operation of the proposed converter is evaluated in step-down mode. The experimental results of case study I and case study II are shown in Figure 9.12 and Figure 9.13, respectively.

Table 9.2: Main Experimental Parameters of The Proposed Converter

\begin{tabular}{lc}
\hline \hline Parameters and Components & Values \\
\hline Rated power $P_{o}$ & $2-\mathrm{kW}$ \\
HV side voltage $V_{H}$ & $800-\mathrm{V}$ \\
LV side voltage $V_{L}$ & $80-\mathrm{V} \rightarrow 160-\mathrm{V}$ \\
Switch $Q_{1}, Q_{2}$ & $\mathrm{UF} 3 \mathrm{C} 065040 \mathrm{~K} 3 \mathrm{~S}$ \\
Switches $Q_{3}, Q_{4}, Q_{6}$ & $\mathrm{E} 3 \mathrm{M} 0120090 \mathrm{D}$ \\
Switch $Q_{5}$ & $\mathrm{UJ} 3 \mathrm{C} 065080 \mathrm{~K} 3 \mathrm{~S}$ \\
Inductors $L_{2}, L_{3}$ & $250 \mu \mathrm{H}$ \\
Capacitors $C_{1}, C_{2}, C_{3}$ & $150 \mu \mathrm{F}$ \\
Capacitors $C_{4}, C_{5}$ & $180 \mu \mathrm{F}$ \\
Switching frequency $f_{s}$ & $100 \mathrm{kHz}$ \\
Microcontroller & $\mathrm{TMS} 320 \mathrm{f} 28335$ \\
\hline \hline
\end{tabular}




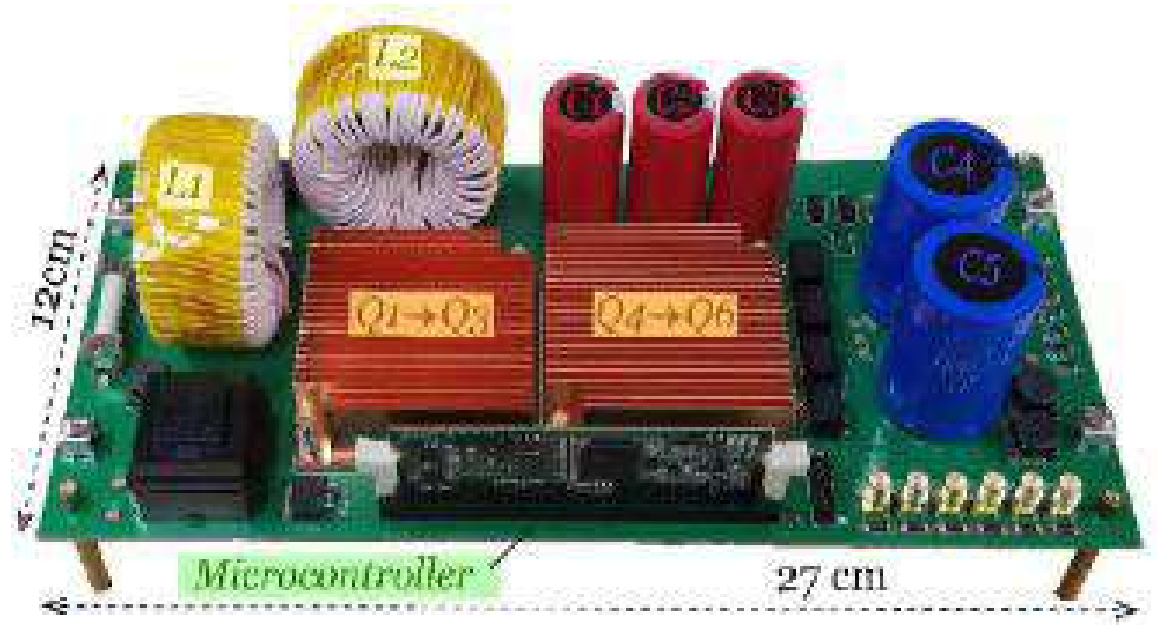

Figure 9.10: Experimental prototype.

\subsubsection{Case Study I}

In this case study, the operation of the proposed converter is evaluated in step-up mode. The parameters of operation are as following: $V_{L}=80 \mathrm{~V}, d_{1}=0.5$, and the load connected to the HV port is represented by a resistor of $320 \Omega$. The voltage across the capacitors of the converter can be calculated using (5)-(7), the voltage at the HV port of the converter and the step-up voltage gain in this case study can be deduced via (8) and (9), respectively, as following: $V_{C 2}=V_{C 4}=320 \mathrm{~V}, V_{C 3}=$ $160 \mathrm{~V}, V_{C 5}=480 \mathrm{~V}, V_{H}=800 \mathrm{~V}$, and $M_{B o o s t}=10$, which closely agree with the experimental results in Figure 9.12(b) and Figure 9.12(c). The currents and the ripple currents of $L_{1}$ and $L_{2}$ can be calculated using (21), (22), and (28), as follows: $I_{L 1}=15 \mathrm{~A}, I_{L 2}=10 \mathrm{~A}, \Delta i_{L 1}=1.6 \mathrm{~A}$, and $\Delta i_{L 2}=4.8 \mathrm{~A}$. These values are in close agreement with the results in Figure 9.12(a). The voltage stress across the six switches can be calculated by means of (15)-(17), as follows: $V_{Q 1}=V_{Q 5}=160 \mathrm{~V}, V_{Q 2}=320 \mathrm{~V}$, $V_{Q 3}=V_{Q 4}=V_{Q 6}=480 \mathrm{~V}$. The experimental results in Figure 9.12(d), Figure 9.12(e), and Figure 9.12(f) confirm the correctness of the calculated values. The current stresses of the six switches can be calculated by (23)-(27), as: $i_{Q 1}=30 \mathrm{~A}, i_{Q 2}=15 \mathrm{~A}, i_{Q 3}=5 \mathrm{~A}, i_{Q 4}=i_{Q 6}=5 \mathrm{~A}$, and $i_{Q 5}=15 \mathrm{~A}$, which closely agree with the results in Figure 9.12(g), Figure 9.12(h), and Figure 9.12(i). 


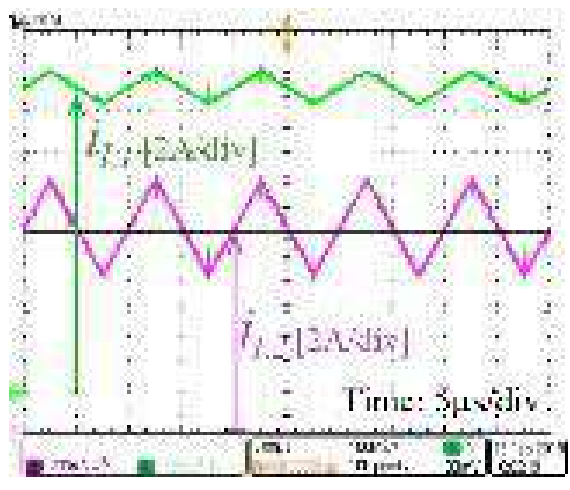

(a)

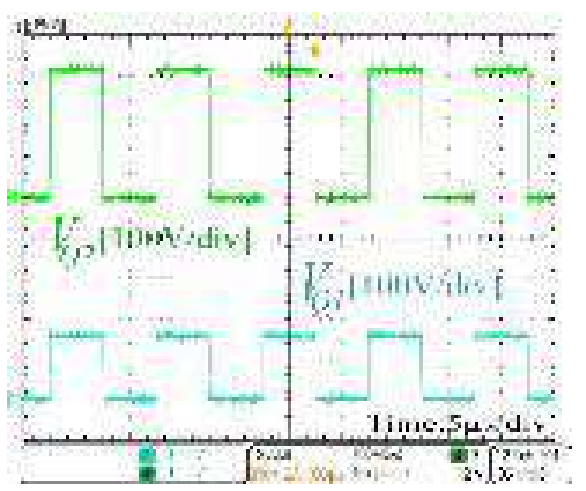

(d)

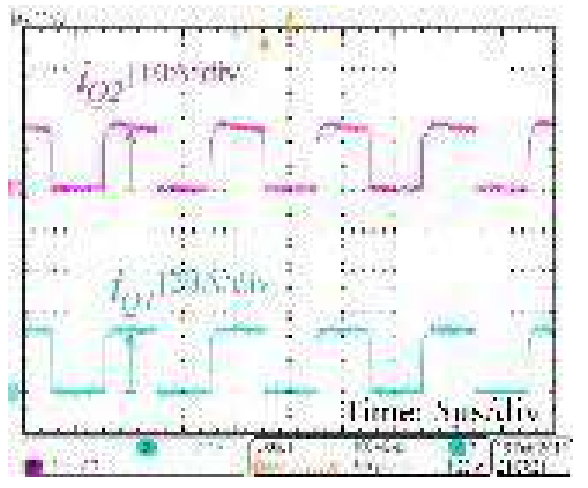

(g)

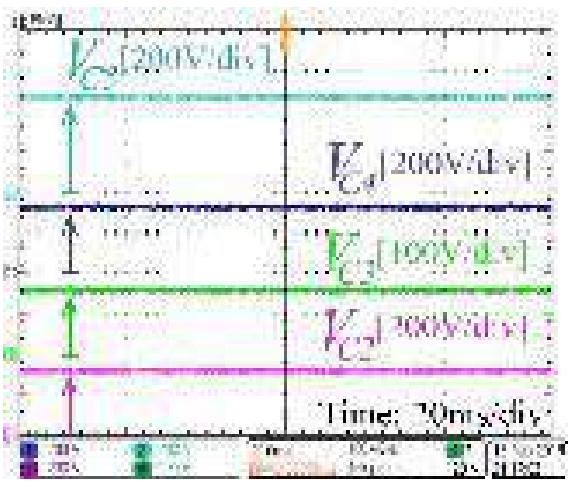

(b)

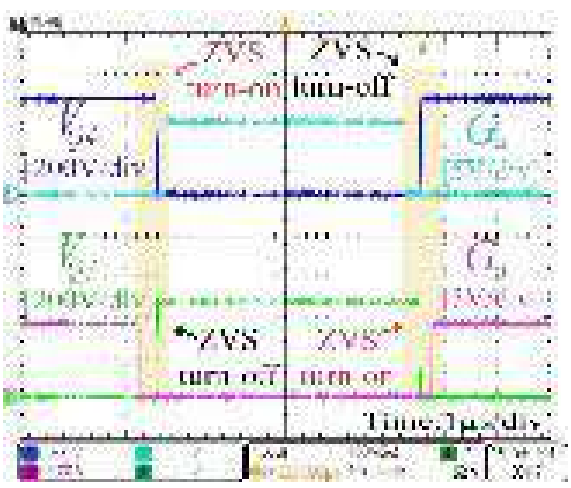

(e)

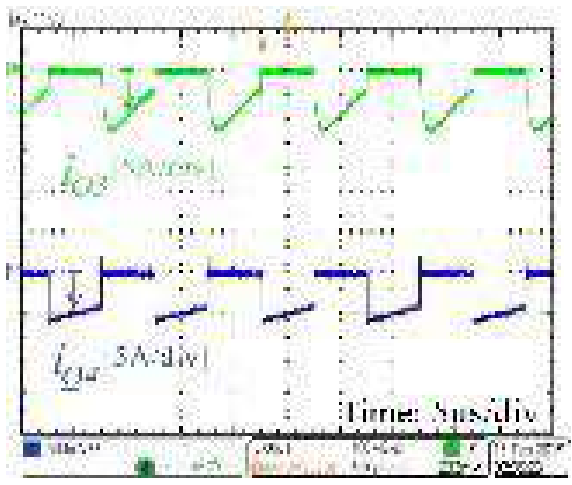

(h)

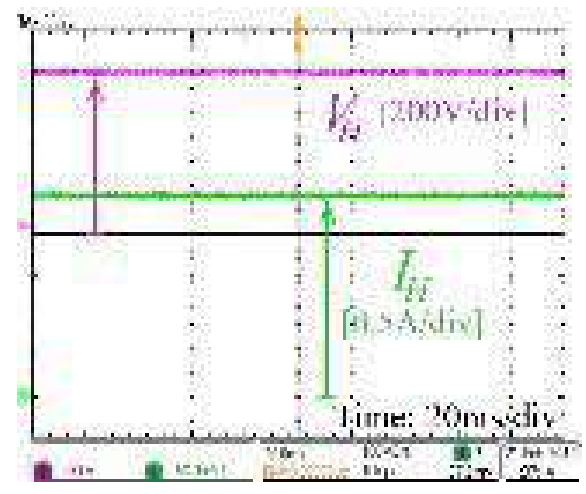

(c)

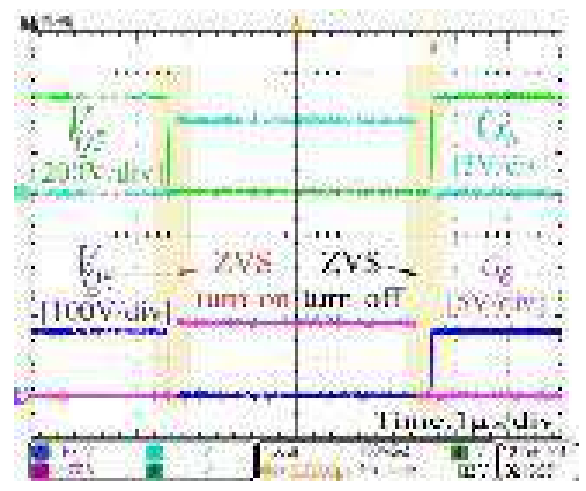

(f)

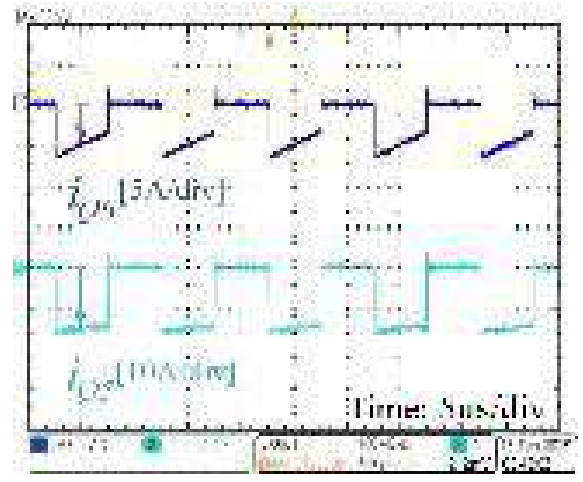

(i)

Figure 9.11: Experimental results of case study $I$.

In this case study, $Q_{3} \rightarrow Q_{6}$ act as synchronous rectifiers, thus, when a delay is applied to their gate pulses, ZVS can be achieved at the turn on and turn off instants, which is confirmed by Figure 9.12(e) and Figure 9.12(f). 


\subsubsection{Case Study II}

In this case study, the operation of the proposed converter is evaluated in step-down mode. The parameters of operation are as following: $V_{H}=800 \mathrm{~V}, d_{2}=0.7$, and the load connected to the LV port is represented by a resistor of $10.5 \Omega$.

The voltage across the capacitors of the converter can be deduced using (10)-(12), the voltage at the LV port of the converter and the step-down voltage gain in this case study can be calculated using (13) and (14), respectively, as following: $V_{C 2}=V_{C 4} \approx 296.3 \mathrm{~V}, V_{C 3} \approx 207.4 \mathrm{~V}, V_{C 5} \approx 503.7 \mathrm{~V}$, $V_{L} \approx 145.19 \mathrm{~V}$, and $M_{B u c k} \approx 0.18$, which closely agree with the experimental results in Figure 9.13(b) and Figure 9.13(c).

The currents and the ripple currents of $L_{1}$ and $L_{2}$ can be calculated using (21), (22), and (28), as follows: $I_{L 1} \approx 6.6 \mathrm{~A}, I_{L 2} \approx 7.14 \mathrm{~A}, \Delta i_{L 1} \approx 1.74 \mathrm{~A}$, and $\Delta i_{L 2} \approx 4.23 \mathrm{~A}$. These values are in close agreement with the results in Figure 9.13(a). The voltage stress across the six switches can be calculated by means of (15)-(17), as follows: $V_{Q 1}=V_{Q 5} \approx 207.4 \mathrm{~V}, V_{Q 2} \approx 296.3 \mathrm{~V}, V_{Q 3}=V_{Q 4}=V_{Q 6}$ $\approx 503.7 \mathrm{~V}$.

The experimental results in Figure 9.13(d), Figure 9.13(e), and Figure 9.13(f) confirm the correctness of the calculated values. The current stresses of the six switches can be calculated by (23)-(27), as: $i_{Q 1} \approx 22.1 \mathrm{~A}, i_{Q 2} \approx 15.48 \mathrm{~A}, i_{Q 3} \approx 8.33 \mathrm{~A}, i_{Q 4}=i_{Q 6} \approx 3.57 \mathrm{~A}$, and $i_{Q 5} \approx 6.63 \mathrm{~A}$, which closely agree with the results in Figure 9.13(g), Figure 9.13(h), and Figure 9.13(i).

In this case study, $Q_{1}$ and $Q_{2}$ act as synchronous rectifiers, hence, when a time delay is applied to their gate pulses, ZVS can be realized at the turn on and turn off transitions, which is confirmed by Figure 9.13(d). 


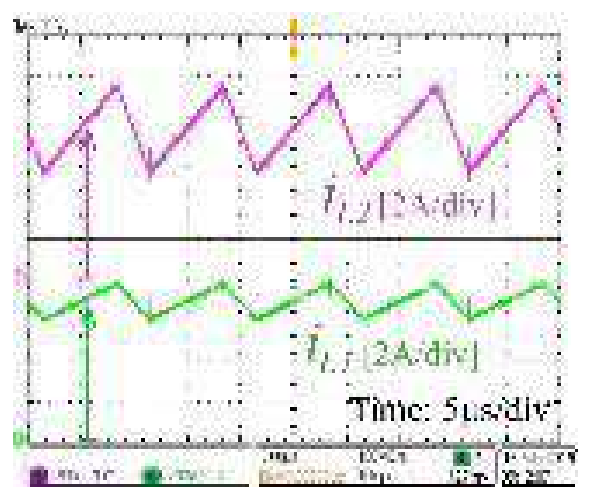

(a)

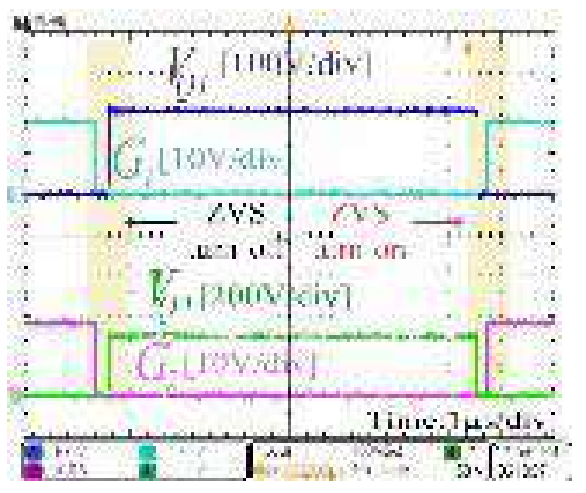

(d)

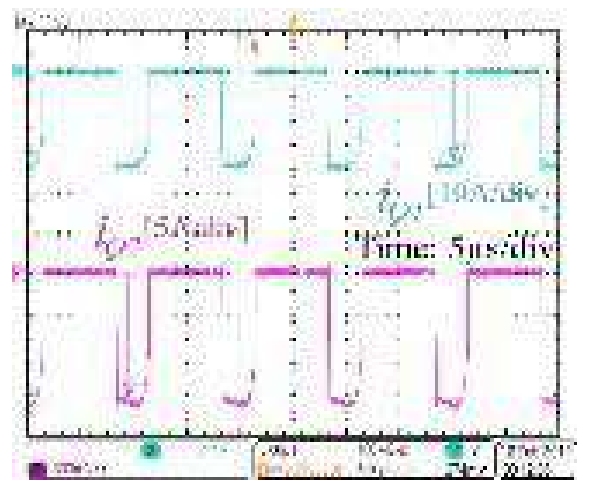

(g)

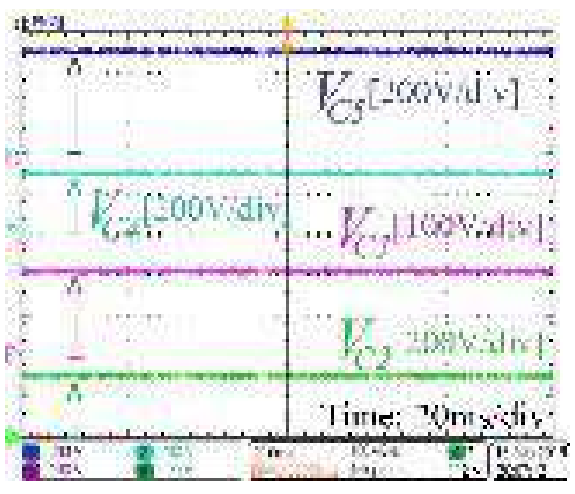

(b)

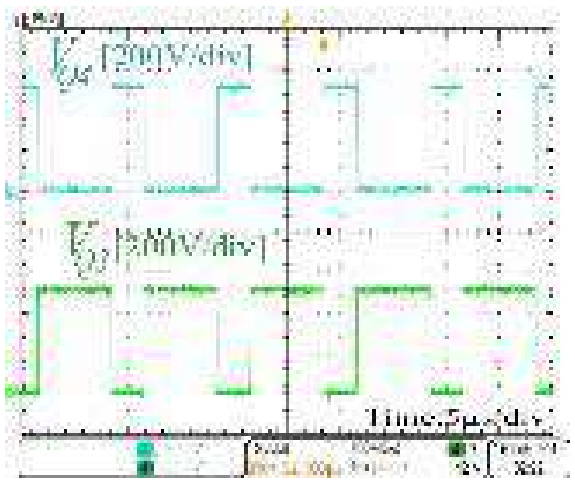

(e)

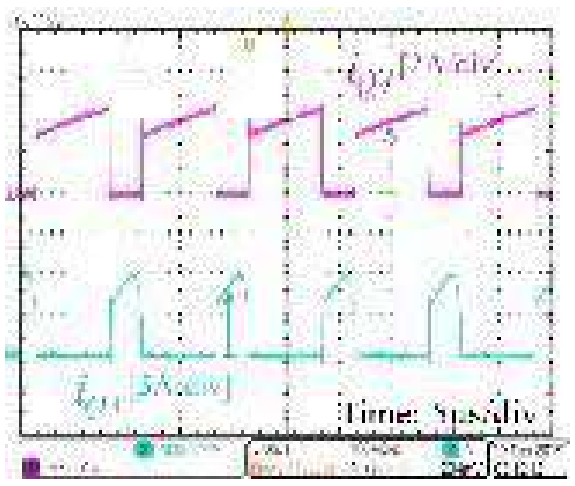

(h)

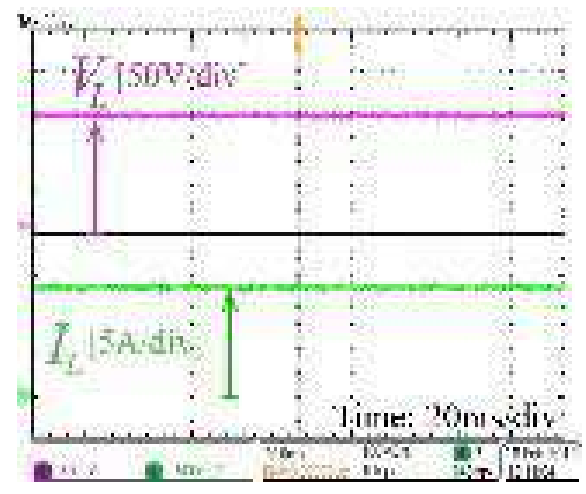

(c)

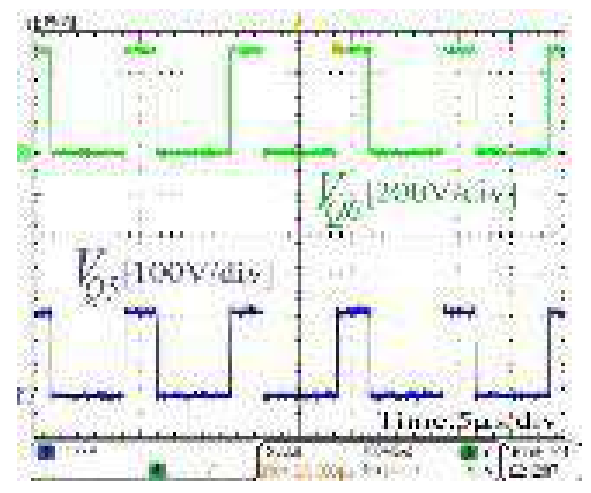

(f)

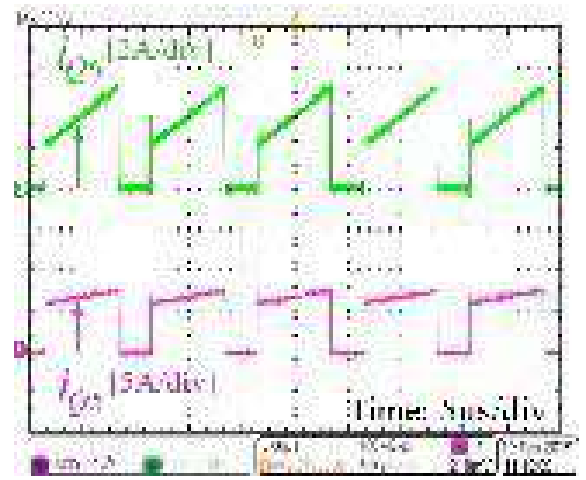

(i)

Figure 9.12: Experimental results of case study II 


\subsubsection{Dynamic Performance with Wide-Voltage-Gain Operation}

To evaluate the capability of the proposed converter to operate successfully with wide voltage gain, two tests have been conducted. The first test is for the step-up operation, while the second test is for the step-down operation. Two closed-loop Type-III voltage controllers are utilized to control the voltage at the LV and HV ports during the step-down and step-up operations, respectively. In the first test, the load is connected to the HV port, and a programmable dc power supply is connected to the $\mathrm{LV}$ port, as $V_{L}$ is changed gradually from $160 \mathrm{~V}$ down to $80 \mathrm{~V}$ and the closed-loop voltage controller holds $V_{H}$ constant at $800 \mathrm{~V}$, as shown in Figure 9.14(a). In the second test, the load is connected to the LV port, and a de power supply is connected to the $\mathrm{HV}$ port, as $V_{H}$ is fixed at $800 \mathrm{~V}$ and the closed-loop voltage controller gradually changes $V_{L}$ from $80 \mathrm{~V}$ up to $160 \mathrm{~V}$, as shown in Figure 9.14(b). The results of these two tests confirm the acceptable performance of the proposed converter to operate stably under wide voltage gain range.

Figure 9.15 shows the dynamic performance of the proposed converter under sudden changes in the load. In the first test, the LV port is connected to an $80 \mathrm{~V}$ power supply and the closed-loop voltage controller holds the voltage of the HV port at $800 \mathrm{~V}$ while the load connected to the HV port has step-changed from $640 \Omega$ to $320 \Omega$, as shown in Figure 9.15(a). In the second test, the HV port is connected to an $800 \mathrm{~V}$ power supply and the closed-loop voltage controller holds the voltage of the LV port at $80 \mathrm{~V}$ while the load connected to the LV port has step-changed from $3.5 \Omega$ to $7 \Omega$, as shown in Figure 9.15(b). The results of both tests prove that the converter with the utilized closed-loop voltage controllers has a good dynamic performance under sudden load changes.

In order to gradually build up the voltage on the capacitors of the converter and avoid high inrush currents during the starting instant, a soft-starting algorithm has been adopted. This 
algorithm is based on gradually increasing the value of the duty cycle from zero to the desired reference value during the starting transition.

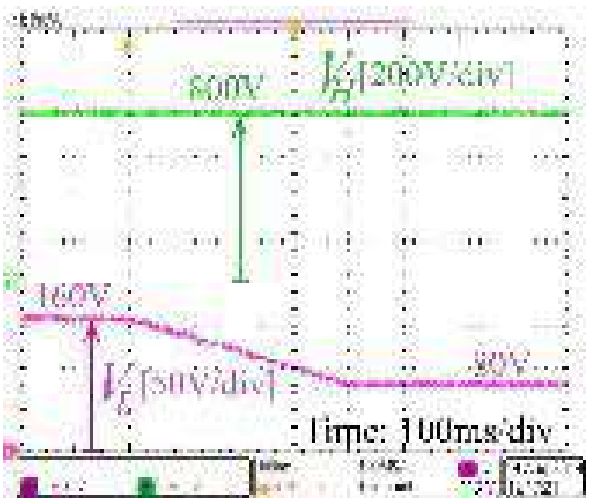

(a)

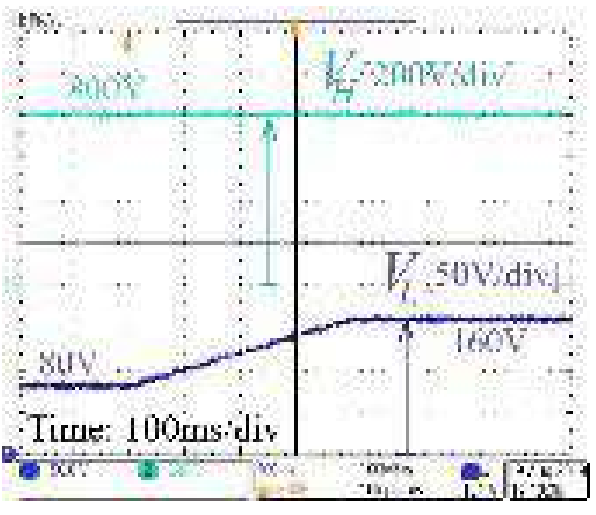

(b)

Figure 9.13: Performance of the proposed converter under wide-range of voltage gain $(\mathrm{VH}=800 \mathrm{~V}, \mathrm{VL}=80 \mathrm{~V} \rightarrow 160 \mathrm{~V}$, and $\mathrm{Po}=2 \mathrm{~kW}$ ). (a) Step-up mode. (b) Step-down mode.

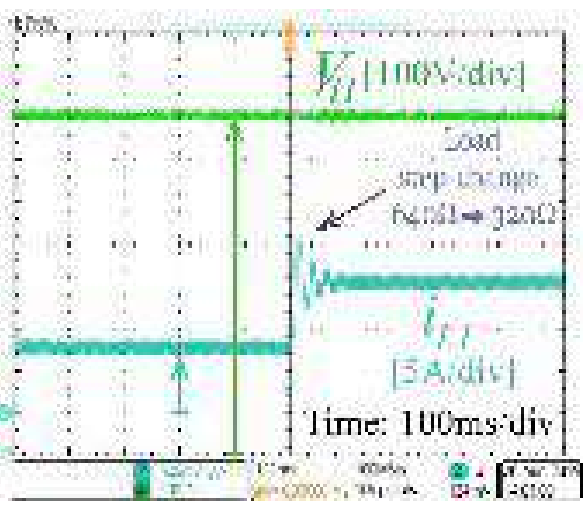

(a)

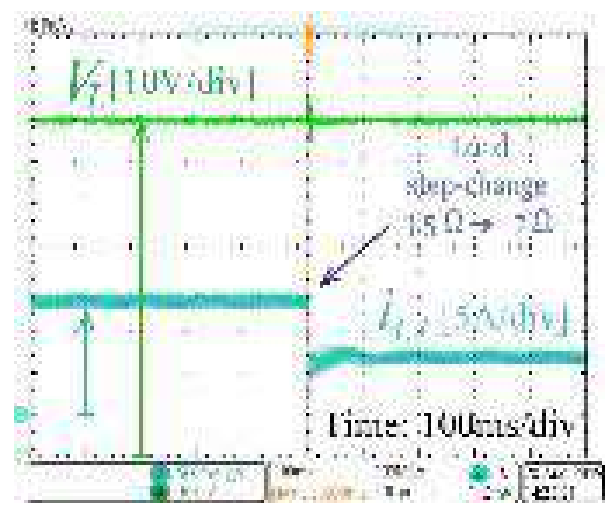

(b)

Figure 9.14: Dynamic performance of the proposed converter under abrupt change in load. (a) Step-up mode. (b) Step-down mode.

\subsection{Efficiency Analysis}

Figure 9.16 shows the calculated loss distributions for case study I and case study II. In case study I, the calculated efficiency of the converter is $95.6 \%$ with total losses of $91.1 \mathrm{~W}$. The conduction and switching losses of the transistors, and the conduction losses of the inductors and capacitors account for $51 \%, 27 \%, 14 \%$, and $8 \%$, respectively, of the total losses of the converter, 
as shown in Figure 9.16(a). In case study II, the calculated efficiency of the converter is $97.7 \%$ with total losses of $46.4 \mathrm{~W}$.

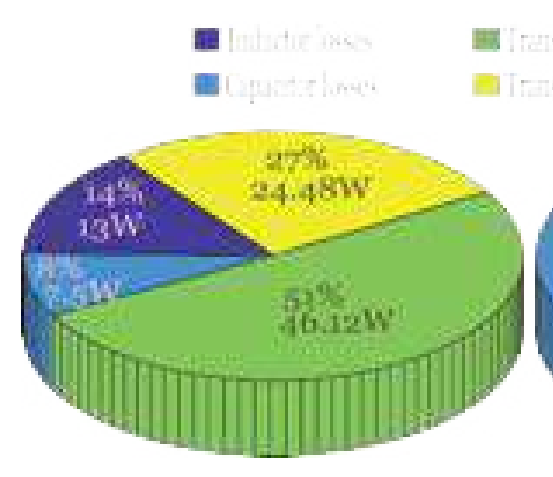

(a)

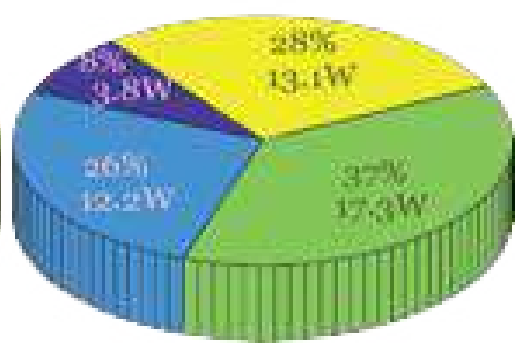

(b)

Figure 9.15: Calculated power loss distributions for the experiment (a) Case study I. (b) Case study II.

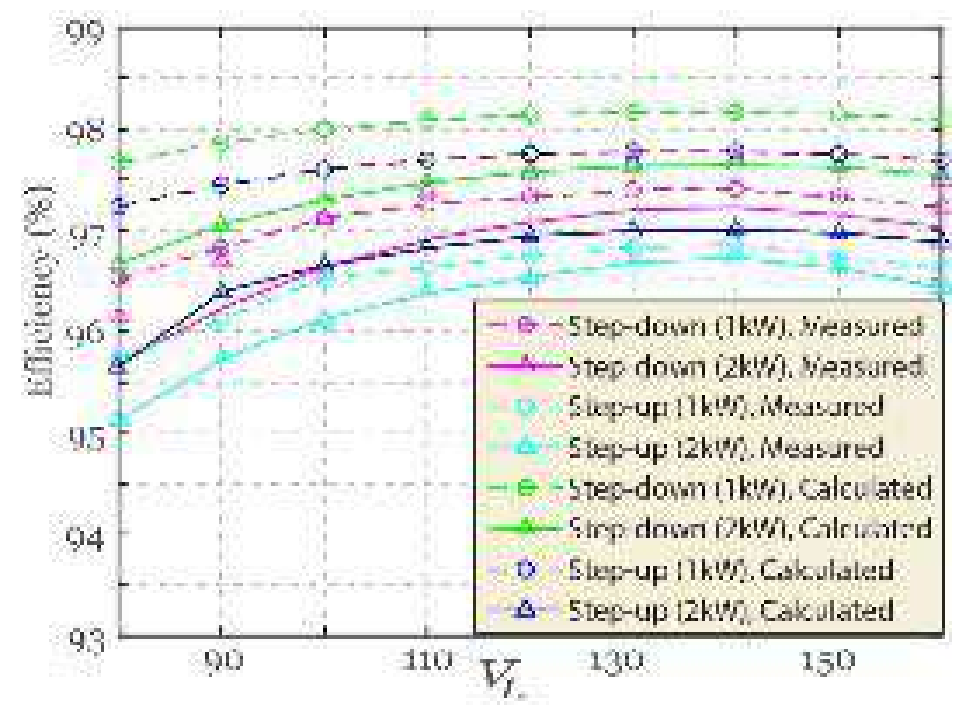

Figure 9.16: Measured efficiency curves of the proposed converter in step-up and stepdown modes $(\mathrm{VH}=800 \mathrm{~V}, \mathrm{Po}=1 \mathrm{~kW}, 2 \mathrm{~kW}$, and $\mathrm{VL}=80 \mathrm{~V} \rightarrow 160 \mathrm{~V})$.

The conduction and switching losses of the transistors, and the conduction losses of the inductors and capacitors account for $37 \%, \%, 28 \%, 8 \%$, and $26 \%$, respectively, of the total losses of the converter, as shown in Figure 9.16(b). 
The measured and calculated efficiency curves in step-up and step-down modes when $V_{H}=$ $800 \mathrm{~V}, V_{L}=80 \mathrm{~V} \rightarrow 160 \mathrm{~V}$, and $P_{o}=1 \mathrm{~kW}$ and $2 \mathrm{~kW}$, are shown in Figure 9.17. In the step-up mode, when $P_{o}=1 \mathrm{~kW}$, the minimum measured efficiency is $95.7 \%$ at $V_{L}=80 \mathrm{~V}$, and the maximum efficiency is $96.8 \%$ at $V_{L}=140 \mathrm{~V}$, while when $P_{o}=2 \mathrm{~kW}$, the minimum efficiency is $95.1 \%$ at $V_{L}$ $=80 \mathrm{~V}$, and the maximum efficiency is $96.6 \%$ at $V_{L}=140 \mathrm{~V}$. In the step-down mode, when $P_{o}=$ $1 \mathrm{~kW}$, the minimum efficiency is $96.5 \%$ at $V_{L}=80 \mathrm{~V}$, and the maximum efficiency is $97.4 \%$ at $V_{L}$ $=140 \mathrm{~V}$, while when $P_{o}=2 \mathrm{~kW}$, the minimum efficiency is $95.7 \%$ at $V_{L}=80 \mathrm{~V}$, and the maximum efficiency is $97.2 \%$ at $V_{L}=140 \mathrm{~V}$. The high efficiency of the converter even with high voltage conversion ratios is due to the low voltage stress on the semiconductor devices, the high voltage gain of the converter, hence, high voltage conversion ratios can be obtained at moderate values of duty cycle, and the utilization of SiC MOSFETs in the prototype.

\subsection{Conclusion}

A new bidirectional dc-dc converter based on a hybrid structure of the quadratic converter with an integrated switched capacitor network has been proposed and analyzed in this chapter. The proposed topology has high voltage conversion ratios, high semiconductor utilization factor, and constant potential difference between the grounds of its ports. These features allow the converter to operate efficiently at high voltage gains without the need to operate at extreme values of duty cycle values, which make the presented topology an excellent interface for electric vehicles' energy storage units and the dc-link of the inverter. In addition, an extended version of the proposed converter has been discussed in order to enhance further the voltage gain of converter and reduce the voltage stress on its individual switches. 


\section{Chapter 10 Cascaded High Frequency AC-Link Systems with Reduced Switch Count for Large-Scale PV-Assisted EV Fast Charging Stations}

\subsection{Introduction}

Electric vehicles are emerged as an alternative to conventional gas engine vehicles. Developing high-power fast charging stations is a promising solution to the problems of long charging time and limited range per charge [197]-[199]. In the literature, there are basically two main architectures for fast charging stations:

1) In the first architecture, there is a common LV ac-bus, where each EV charger in the fast charging station has its own dedicated ac-dc conversion stage to interface it to the ac grid [200], [201].

2) In the second architecture, the fast charging station has a common LV dc bus, where all the EV chargers are comprised of dc-dc converters, and connected to a common LV dc bus, then a central dc-ac conversion stage is utilized to interface the LV dc bus system to the ac grid [202]-[204].

The main advantage of the second architecture is the simple power electronic interface required to interface the EV chargers, renewable energy sources, or energy storage units to the LV dc bus of the charging station.

For a large-scale system, with a multi Megawatt power rating, the fast charging station needs to be directly connected to the MV ac power network. Considering the second fast charging station architecture, the topology of the central dc-ac power conversion stage can be without transformers, or using a transformer. For the topologies without transformers, the cascaded z-source inverter and the cascaded quasi z-source inverter are taking a lot of interest in the recent literature [205]-[207]. They can provide a high boosting gain and by connecting them in series they can reach the voltage 
level of the MV grid without the need for a transformer. On the other hand, both the cascaded zsource inverter and cascaded quasi z-source inverter do not provide galvanic isolation between the input port, where all the EV chargers and the renewable sources are connected, and the output port where the MV ac grid is connected, moreover, they require bulky dc-link capacitors and dc-link inductors which can increase the size and decrease the reliability of the system with large number of cascaded inverters. For the transformer-based topologies, the CHF-link system is gaining a lot of interest [208]-[214] due to the development of high voltage wide-bandgap semiconductor devices that can switch efficiently at high frequencies [215], [216] and the new magnetic core materials like Nanocrystalline that have high maximum flux density and low core losses at high frequencies [217], [218].

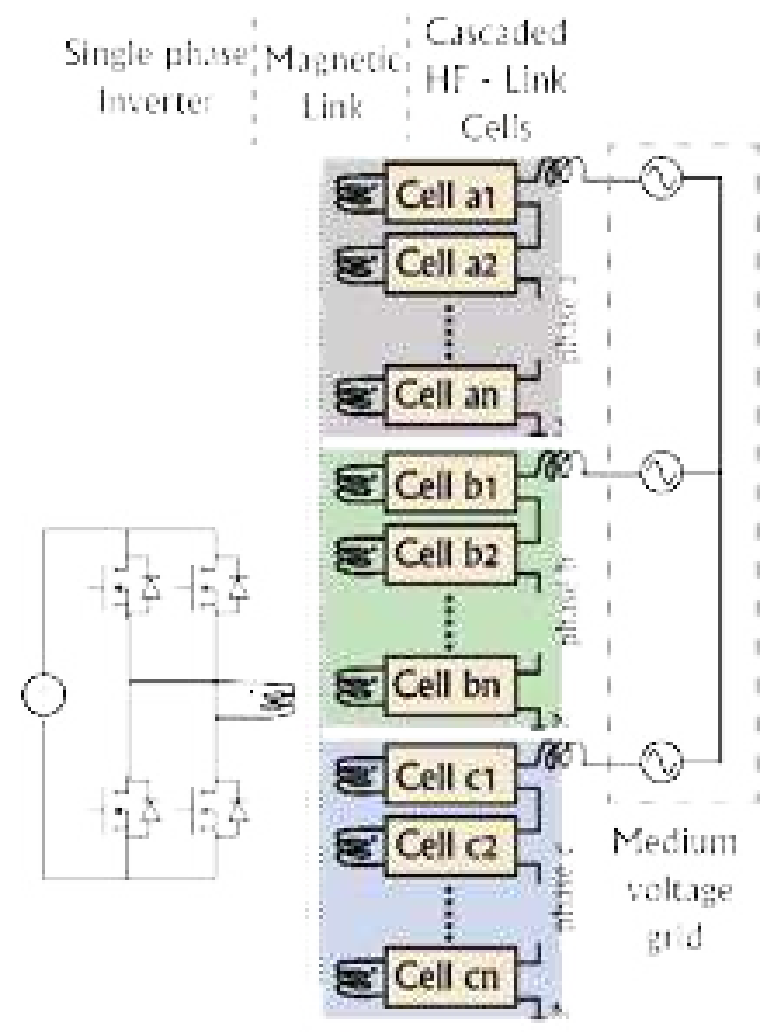

Figure 10.1:Generic Block Diagram of a CHF-link System. 
The CHF-link system is a power electronic interface that interconnects a LV dc bus system with the MV ac grid and provides galvanic isolation via a MF/HF transformer. The generic block diagram of the CHF-link system is shown in Figure 10.1, where it is composed of a single phase inverter (can be multiple of parallel single phase inverters to handle more power), a HF/MF transformer with a multi-winding secondary, and cascaded HF-link cells. The single phase inverter is used to convert the $\mathrm{LV}$ dc input to a HF/MF voltage waveform required for the HF/MF transformer.

The transformer acts as a HF/MF magnetic link. The cell is an AC/AC power converter, and when the cells are connected in series, they convert the HF/MF voltage from the transformer secondary windings to a sinusoidal voltage with the nominal grid frequency. Different cell topologies have been proposed in literature. In [208]-[212], the authors proposed a topology for the cell that is composed of a rectifier bridge to rectify the HF voltage of the transformer, a dc-link capacitor to smooth the rectified voltage, and a single phase inverter to convert the rectified voltage to a lowfrequency voltage component. This cell is a HF dc-link cell. The number of active switches in this cell topology is four switches per cell. The CHF-link system with this cell topology is called CHF dclink system. The main disadvantage of this cell topology is the utilization of dc-link capacitors which are sizable, and with the large number of cells, the size of this system will be large, and the reliability of the system will drop down, added to this, this cell does not provide bidirectional power flow capability.

In [213] and [214], a new topology is proposed for the cell based on a matrix converter to eliminate the dc-link capacitors, and provide bidirectional power flow capability. This cell is a HF aclink cell. The CHF-link system with this cell topology is a CHF ac-link system. The number of active switches in this cell topology is eight switches per cell which is double that needed for the 
HF dc-link cell. The increased number of switches with their associated driving circuits and heat sinks increases the cost, size and weight of the CHF ac-link system.

In this chapter, two new HF ac-link cell topologies are proposed. Both of the proposed cell topologies get rid of the dc-link capacitors, provide bidirectional power flow capability, and require less number of active switches compared to the HF ac-link cell proposed in [213] and [214]. The topologies of the proposed HF ac-link cell 1 and the proposed HF ac-link cell 2 are presented and compared with the previously proposed cell architectures in literature in Table 10.1.

The proposed HF ac-link cell 1 is composed of a center-tapped transformer secondary winding connected to a two-arm half-bridge matrix converter, each arm is composed of anti-series connected IGBTs. This cell is comprised of four active switches and can only work in a bipolar operation, hence, can realize two voltage levels, either a positive voltage or a negative voltage. The proposed HF ac-link cell 2 is comprised of six switches and has the same topology of the proposed HF ac-link cell 1 with an extra third arm that connects between the output terminals of the half-bridge matrix converter. This third arm has two main advantages:

1) Provides a zero state, thus, each cell is able to work in both bipolar and unipolar operation, which results in three voltage levels that can be realized by each cell.

2) Provides a bypass across the cell in case of an open-circuit fault takes place in either the upper or lower arms of the half-bridge matrix converter, which helps to isolate the faulted cells and achieve fault tolerant operation easily.

A novel multilevel $\mathrm{HCC}$ is proposed to directly generate the switching signals from the reference current without the burden of closed-loop controllers used with the conventional voltagecontrolled switching strategies [219]. The proposed multilevel HCC provides a simple and powerful switching strategy that utilizes the slope of the error between the reference current and 
the actual phase current to select the adequate voltage level to be realized in order to reduce the magnitude of this error. Moreover, the proposed multilevel HCC provides natural commutation, which eliminates the need for clamping circuits usually used with matrix converters like in [214]. The PV-assisted fast charging station presented in this chapter utilizes a bidirectional power flow controller that injects the excess in the generated power from the PV system to the grid, and withdraws power from the grid to the LV-dc bus system inside the station when the demand of the EV chargers exceeds the generated PV power. The changing power flow levels between the fast charging station and the MV ac grid can cause severe voltage fluctuations at the point of common coupling (PCC), considering a realistic weak grid. In literature, there are commonly two approaches to damp and eliminate these voltage fluctuations. The first approach utilizes energy storage systems (ESSs) like the batteries, ultra-capacitors and flywheels to smoothen the transitions between different power flow levels [220]-[222]. This approach utilizes the ESSs to manipulate the active power injected to/from the $P C C$ in order to smooth out the abrupt changes in the power flow levels. The second approach manipulates the reactive power injected to the grid to damp any voltage fluctuations at the $P C C$ [226]. The second approach is superior over the first one for large-scale applications, with multi-Megawatt rating, since it eliminates the need for large ESSs. The second approach is adopted in the control scheme of the proposed PV-assisted fast charging station to hold the voltage at the $P C C$, $V_{P C C}$, constant.

With the increasing penetration of distributed generators into the power grids, the grid codes require these sources to remain grid-connected during grid disturbances to ride-through the faults by supplying the grid with active/reactive power to assist the voltage recovery and enhance the grid stability [223]-[228]. This Low-Voltage Ride-Though (LVRT) capability is adopted in the control scheme of the proposed PV-assisted fast charging station to support the grid with the 
necessary reactive power in order to meet the grid code requirements during voltage sags.

\subsection{Proposed Architecture of the PV-Assisted Fast Charging Station \\ 10.2.1 Basic Block Diagram of the Proposed CHF ac-link Systems}

Figures 10.2(a) and 10.2(b) show the architecture of the PV-assisted fast charging station with the proposed HF ac-link cell 1 and the proposed HF ac-link cell 2, respectively. The fast charging station has a LV dc bus where both the EV chargers and the PV system are connected to. A single phase inverter is used to convert the dc voltage of the LV dc bus system to the HF/MF voltage required by the HF/MF transformer. Multiple single phase inverters can be connected in parallel to handle high power levels. The transformer acts as a HF/MF magnetic link that steps-up the voltage level of the LV dc bus system, which has a voltage of VDC, and provides a galvanic isolation between the LV dc bus of the fast charging station and the MV ac grid. The secondary windings of the transformer are connected to the $\mathrm{AC} / \mathrm{AC}$ power conversion stages, in the form of cells connected in series to realize high voltage levels with the voltage stress on the switches held at an acceptable level. Table 10.1 shows the architectures of the cells that have been proposed in literature and compares their features and operational modes with the proposed HF ac-link cells 1 and 2. Both of the proposed cell topologies get rid of the dc-link capacitors, hence, the CHF-link system that utilizes any of them can be considered as a CHF ac-link system. The number of the transformer secondary windings is $2 \mathrm{n}$ for $\mathrm{n}$ cells. Each halfbridge matrix converter is connected to two transformer secondary windings as depicted in figures 10.2(a) and 10.2(b). The transformer turns ratio between the primary winding and one of the secondary windings is $1: m$. 


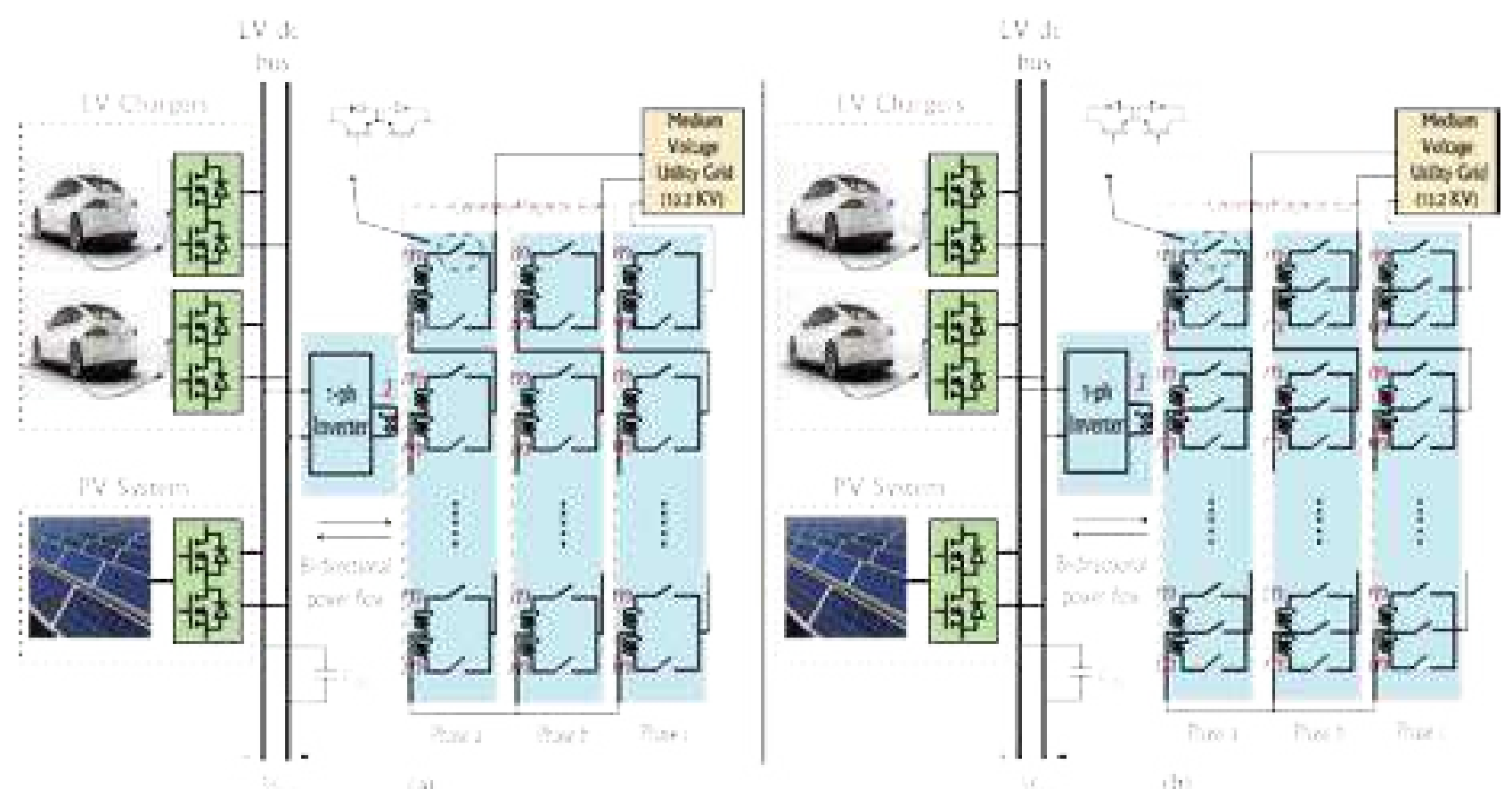

Figure 10.2: (a) The proposed PV-assisted fast charging station with the CHF ac-link cell 1. (b) The proposed PV-assisted fast charging station with the CHF ac-link cell 2.

The reference value for $V_{D C}$ is held constant via the bidirectional power flow controller, as discussed in the next subsections. When the single phase inverter works with a duty cycle of $50 \%$, the voltage at the transformer primary side will be $-V_{D C}$ for $50 \%$ of the periodic time and $V_{D C}$ for the rest of the periodic time. The voltage at one of the transformer secondary windings is $\left(-m . V_{D C}\right)$ for half of the periodic time and $\left(m . V_{D C}\right)$ for the rest of the periodic time.

For the CHF-link system with the proposed HF ac-link cell 1, each cell works only in a bipolar operation, thus each cell can output either $\left(m . V_{D C}\right)$ or $\left(-m . V_{D C}\right)$. On the other hand, the CHF-link system with the proposed HF ac-link cell 2, each cell can work in a unipolar operation, hence, each cell can realize three voltage levels, $\left(m . V_{D C}\right),\left(-m . V_{D C}\right)$, or 0 . By controlling the time of realization of these voltage levels, as discussed in the next subsections, the cell can convert the $\mathrm{HF} / \mathrm{MF}$ voltage to a low-frequency voltage component. 
Table 10.1: CHF-LINK SYSTEM CELLS, THEIR FEATURES AND OPERATIONAL MODES

\begin{tabular}{|c|c|c|c|c|}
\hline Cell Type & HF dc-link Cell in [208]-[212] & HF ac-link Cell in [213], [214] & Proposed HF ac-link Cell 1 & Proposed HF ac-link Cell 2 \\
\hline Schematic & & & & \\
\hline $\begin{array}{ll}\text { Number } & \text { of } \\
\text { levels/cell } & \end{array}$ & 3 & 3 & 2 & 3 \\
\hline $\begin{array}{l}\text { Number of active } \\
\text { switches/cell }\end{array}$ & 4 & 8 & 4 & 6 \\
\hline $\begin{array}{lr}\text { Number } & \text { of } \\
\text { levels/phase (for } n \\
\text { cells/phase) }\end{array}$ & $2 n+1$ & $2 n+1$ & $n+1$ & $2 n+1$ \\
\hline Unipolar Operation & Yes & Yes & No & Yes \\
\hline Bipolar Operation & Yes & Yes & Yes & Yes \\
\hline $\begin{array}{l}\text { DC Link } \\
\text { Capacitor(s) }\end{array}$ & Yes & No & No & No \\
\hline $\begin{array}{l}\text { Bidirectional power } \\
\text { flow capability }\end{array}$ & No & Yes & Yes & Yes \\
\hline
\end{tabular}

\subsubsection{Analysis of the CHF-Link System with the Proposed HF ac-link Cell 1}

As discussed earlier, each cell can convert the transformer secondary winding voltage to either $\left(m . V_{D C}\right)$ or $\left(-m . V_{D C}\right)$. The output voltage of a cell $\mathrm{ij}_{\mathrm{j}}$, where $j$ and $i$ are the cell number and the phase, respectively, can be represented as

$$
\begin{aligned}
V_{i j} & =K_{i j} \cdot\left(Q \cdot m \cdot V_{D C}\right) \\
\text { Or } \quad V_{i j} & =H_{i j} \cdot m \cdot V_{D C}
\end{aligned}
$$

Where $V_{i j}$ is the output voltage of cell $l_{\mathrm{ij}}, K_{i j}$ is the switching state of the cell which is either 1 or $1, Q$ is the switching state of the single phase inverter connected to the transformer primary winding and it can be either 1 or -1 . Here, $H_{i j}$ is equal to $K_{i j} . Q$, which represents the desired output state from cell ${ }_{\mathrm{ij}}$. 
From (1), phase $i$ voltage can be described as:

$$
V_{i}=\sum_{j=1}^{n} V_{i j}
$$

Where $n$ is the total number of cells per phase.

The number of cells of phase $i$ with $H_{i j}$ equal to 1 is $P_{i}$, and $N_{i}$ is the number of cells of phase $i$ with $H_{i j}$ equal to -1 , where

$$
P_{i}+N_{i}=n
$$

Substituting (3) in (4),

$$
V_{i}=\left(P_{i}-N_{i}\right) \cdot m \cdot V_{D C}
$$

From (5), by changing $P_{i}$ and $N_{i}$, the realized phase voltage can be controlled, and thus, for $n$ cells/phase, the number of phase voltage levels are $n+1$.

\subsubsection{Analysis of the CHF-Link System with the Proposed HF ac-link Cell 2}

The proposed HF ac-link cell 2 can realize three voltage levels, $\left(m . V_{D C}\right),\left(-m . V_{D C}\right)$, or 0 . The output voltage of cell $\mathrm{i}_{\mathrm{j} j}, V_{i j}$, can be described by equations (1) and (2), where $K_{i j}$, and $H_{i j j_{2}}$ can be 1 , -1 , or 0 . The total phase voltage for leg $i$ can be described by (3) and (5). As long as each cell can realize three voltage levels, the total number of cells per phase can be depicted by (6)

$$
P_{i}+N_{i}+Z_{i}=n
$$

Where $Z_{i}$ is the number of cells of phase $i$ with $H_{i j}$ equals to 0 . By adequately adjusting $P_{i}, Z_{i}$, and $N_{i}$, the realized phase voltage can be controlled, hence, for $n$ cells/phase, the number of phase voltage levels that can be realized is $2 n+1$. 


\subsection{The Proposed Control Strategy and LVRT Capability of the System}

\subsubsection{A Simplified Multilevel Hysteresis Current Controller}

The proposed simplified multilevel HCC is composed of three stages, namely: level selector, cell selector, and switching logic, as shown in Figure 10.3. The proposed multilevel HCC switching strategy starts by calculating the error, e, between the refereă actual current, $i_{a}$, (phase a is taken as an example). An error sample at instant $k, e(k)$, and a delayed error sample, $e(k-1)$, are fed to the level selector which selects the adequate voltage level that should be realized to minimize $e(k)$. After the level selector determines the reference voltage level, the cell selector determines the desired output state from each cell, $H_{a 1}, H_{a 2}, \ldots, H_{a n}$, to realize the desired voltage level. Each of these states takes a value of $1,-1$, or 0 , in case of the proposed HF ac-link cell 2, while for the proposed HF ac-link cell 1, each state can be 1, or -1 . The desired output states of the cells are then fed to the switching logic block. In addition, the polarity of $i_{a}, r_{a}$, and the switching state of the single phase inverter connected to the HF transformer primary winding, $Q$, are fed to the switching logic block. The switching logic generates the switching signals for the switches of each cell. Similar multilevel HCC to that shown in Figure 10.3 for phase $a$ are used for phases $b$ and $c$. The sampling time of the error, $T_{s}$, determines the maximum switching frequency as shown in (7).

$$
\text { Maximum frequency }=\frac{1}{2 \times T_{S}}
$$

Figure 10.4 illustrates the algorithm of the level selector. It starts by calculating the positive band level, $P B$, the negative band level, $N B$, and the slope of the error, $d e(k)$ as in (8), (9) and (10).

$$
\begin{gathered}
P B=\text { error tolerance } \\
N B=- \text { error tolerance } \\
d e(k)=e(k)-e(k-1)
\end{gathered}
$$


When $e(k)$ is less than $\mathrm{NB}$ and slope of the error is negative, this means the actual current has to be reduced and the present voltage level is not adequate to achieve that, so, the voltage level reference is decremented. When $e(k)$ is greater than PB and the slope of the error is positive, this means the actual current has to be increased by increasing the voltage level reference. Otherwise, the voltage level reference is kept the same without any change.

For the proposed HF ac-link cell2, the switching logic block is fed by the desired output states for each cell, the current polarity and the single-phase inverter switching state to generate the switching signals of the switches of each cell. The $Q$ signal is used to determine whether the voltage at the transformer secondary winding is $\left(m . V_{D C}\right)$ or $\left(-m . V_{D C}\right)$. The desired output state, $H_{i j}$, is used to determine whether the cell needs to output $\left(m . V_{D C}\right),\left(-m . V_{D C}\right)$, or 0 . The current polarity signal of phase $i, r_{i}$, is used to determine whether the cell is working in a current conduction mode or in current natural commutation mode.

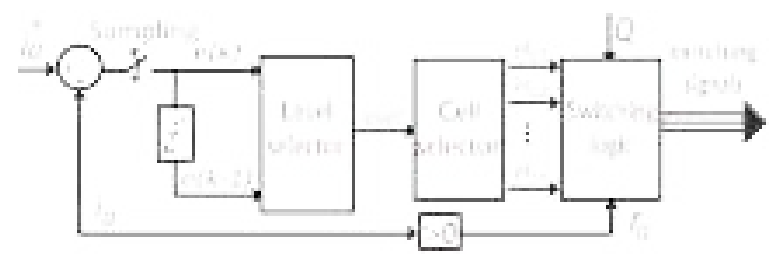

Figure 10.3: The proposed multilevel HCC for phase a.

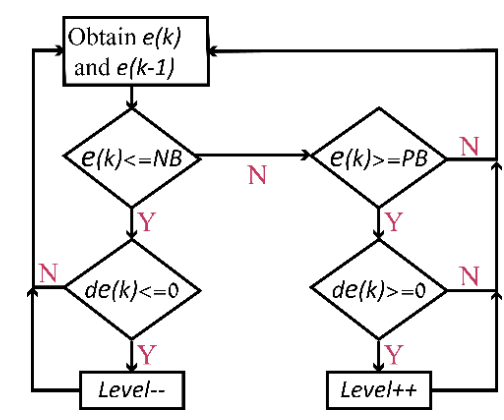

Figure 10.4: The flowchart of the level selector algorithm. 


\section{Figure 10.5: Design example of CHF ac-link}

Figure 10.5 shows a design example of CHF ac-link system (w1th the proposed HF ac-

link cell 2$)$, where each cell can produce either ( $m$

in Figure 10.5 shows the different voltage levels that can be realized by this system, where

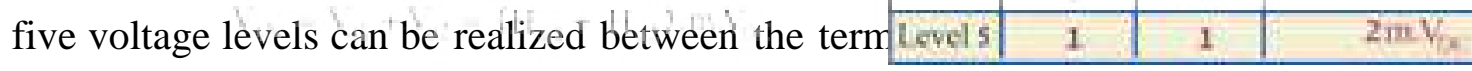

Adjusting the desired output states of the two cells $\left(H_{a 1}\right.$ and $\left.H_{a 2}\right)$ is used to realize a certain voltage level, as shown by equations (2) and (3). As an example, voltage level $2\left(V_{A N}=-\right.$ m. $\left.V_{D C}\right)$ can be realized by $\left(H_{a 1}=-1\right.$ and $\left.H_{a 2}=0\right)$ or by $\left(H_{a 1}=0\right.$ and $\left.H_{a 2}=-1\right)$.

In Figure 10.7, ten modes of operation for the proposed HF ac-link cell 2 are shown. The value of $Q$ is reflected on the polarity of the voltage at the transformer secondary winding, where $\left(m . V_{D C}\right)$ appears when $Q=1$, as depicted in modes $1-4$, and $\left(-m . V_{D C}\right)$ appears when $Q=0$, as in modes 5-8. Modes 9 and 10 are dedicated for the zero state of the cell, where the value of $Q$ is neglected and the phase current polarity, $r_{a}$, is used to determine which switch of the middle arm to turn on.

The investigated cell in Figure 10.7 has three arms, each arm is composed of two antiseries IGBTs to provide four-quadrant-operation, the middle arm is dedicated to provide the zero state of the cell, while the other two arms are used to realize either $\left(m . V_{D C}\right)$ or $(-$ $\left.m . V_{D C}\right)$. The middle arm has switches $\mathrm{S}_{5 \mathrm{a}}$, and $\mathrm{S}_{6 \mathrm{a}}$, the upper arm has switches $\mathrm{S}_{1 \mathrm{a}}$, and $\mathrm{S}_{2 \mathrm{a}}$, and the lower arm has switches $\mathrm{S}_{3 \mathrm{a}}$, and $\mathrm{S}_{4 \mathrm{a}}$ 


\section{Table 10.2: THE SWITCHING MODES FOR CELL J IN PHASE A FOR THE PROPOSED HF AC-LINK CELL 2}

\begin{tabular}{|c|ccc|cccccc|}
\hline \multirow{2}{*}{ Mode } & \multirow{2}{*}{$\boldsymbol{Q}$} & \multirow{2}{*}{$\boldsymbol{H}_{a j}$} & $\boldsymbol{r}_{\boldsymbol{a}}$ & \multicolumn{6}{|c|}{ Switching signals } \\
\cline { 5 - 10 } & & & & $S_{1 a}$ & $S_{2 a}$ & $S_{3 a}$ & $S_{4 a}$ & $S_{5 a}$ & $S_{6 a}$ \\
\hline 1 & 1 & 1 & 1 & 1 & 0 & 0 & 0 & 0 & 0 \\
\hline 2 & 1 & 1 & 0 & 0 & 1 & 0 & 0 & 0 & 0 \\
\hline 3 & 1 & -1 & 1 & 0 & 0 & 1 & 0 & 0 & 0 \\
\hline 4 & 1 & -1 & 0 & 0 & 0 & 0 & 1 & 0 & 0 \\
\hline 5 & 0 & 1 & 1 & 0 & 0 & 1 & 0 & 0 & 0 \\
\hline 6 & 0 & 1 & 0 & 0 & 0 & 0 & 1 & 0 & 0 \\
\hline 7 & 0 & -1 & 1 & 1 & 0 & 0 & 0 & 0 & 0 \\
\hline 8 & 0 & -1 & 0 & 0 & 1 & 0 & 0 & 0 & 0 \\
\hline 9 & $\mathrm{x}$ & 0 & 1 & 0 & 0 & 0 & 0 & 1 & 0 \\
\hline 10 & $\mathrm{x}$ & 0 & 0 & 0 & 0 & 0 & 0 & 0 & 1 \\
\hline
\end{tabular}

The switching logic is depicted in Table 10.2, as it shows the switching modes for cell $j$ in phase $a$ of a CHF ac-link system with the proposed HF ac-link cell 2, where $r_{a}=1$ when $i_{a}>0$ and $r_{a}=0$ otherwise. The shaded rows in Table 10.2 are the modes dedicated to provide natural commutation for the matrix converter, where a path is provided to the phase current to sink to the positive power rail of the transformer secondary winding. This natural current commutation technique eliminates the need for clamp circuits, usually used with matrix converters [214].

For the proposed HF ac-link cell1, the switching logic is the same except it has eight modes of operation, modes 1-8. Modes 9 and 10 are excluded as the middle arm is absent.

\subsubsection{Operation under Normal Conditions}

As shown in Figure 10.6, the proposed fast charging station has a dc bus, where all the EV chargers and the PV system are connected to. The EV chargers withdraw their need of power, from 
the dc bus system. A large PV system is connected to the dc bus system to supply the Megawatt fast charging station with power, in order to decrease the dependency on the main power grid. The power processing unit of the PV system has a Maximum Power Point Tracker (MPPT) which determines the optimal operating points on the PV system characteristic curves in order to extract the maximum power from the PV arrays. Figure 10.6 shows a single line diagram of the proposed $\mathrm{PV}$-assisted fast charging station, where $P_{E V}$ is the withdrawn power from the dc bus system by the EV chargers, and $P_{P V}$ is the injected PV power to the dc bus system. A bidirectional power flow controller is needed to inject the generated power from the PV system that exceeds the demand of the EV chargers to the grid, and withdraw power from the grid to the dc bus system when the EV chargers demand exceeds the generated PV power. By applying a closed-loop controller to set the voltage across the dc-bus capacitor, $C_{d c}, V_{D C}$, at a reference level, $\mathrm{V}_{\mathrm{DC}}^{*}$. This is achieved by a Proportional Integral (PI) controller, which compares $\mathrm{V}_{\mathrm{DC}}^{*}$ with $V_{D C}$. The manipulated variable of this PI controller is the reference direct current component, $\mathrm{i}_{\mathrm{d}}^{*}$. According to (11), when the direct current component of the three phase currents flowing between the fast charging station and the grid, $i_{d}$, is positive, the station injects power to the MV ac grid, and when $i_{d}$ is negative, the station withdraws power from the grid.

$$
P_{P C C}=\frac{3}{2} V_{P C C} X i_{d}
$$

Where $V_{P C C}$ is the voltage at the $P C C$, and $P_{P C C}$ is the active power flowing through the $P C C$, and it equals the difference between $\mathrm{P}_{\mathrm{PV}}, \mathrm{P}_{\mathrm{EV}}$, and losses in the fast charging station converters and feeders. 


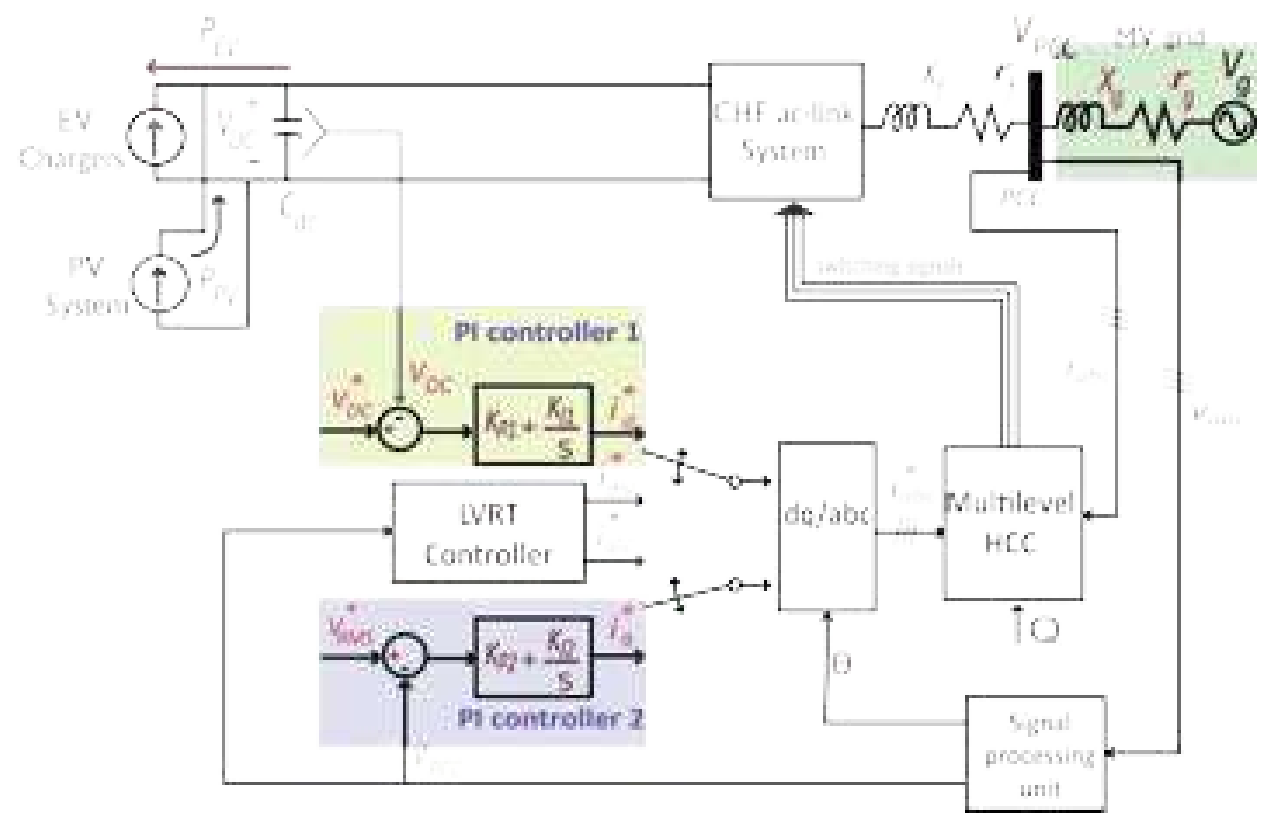

\section{Figure 10.6: Single line diagram of the proposed $P V$-assisted $E V$ charging station and its control scheme in normal operation and during grid faults.}

With the changing levels of $P_{P C C}$ between the fast charging station and the grid, and considering a week grid, with high grid equivalent impedance, noticeable fluctuations will appear in $V_{P C C}$, which can harm any loads connected at the PCC. Figure 10.8(a) shows a phasor diagram of the system presented in Figure 10.6 at two different power levels. Both $I_{1}$ and $I_{2}$ represent the RMS phase current flowing through the $P C C$ at two power flow levels, and the operation in both cases is done at unity power factor, where the phase current is aligned with $V_{P C C}$.

For the first case in Figure 10.8(a), $I_{l}$ is flowing through the $P C C$, the component $\left(I_{l} r_{g}\right)$ represents the voltage drop through the resistive part of the grid equivalent impedance, $r_{g}$, and it is parallel to $I_{l}$ in the phasor diagram. The component $\left(I_{I} x_{g}\right)$ represents the voltage across the reactive component of the grid equivalent impedance, $x_{g}$, and it is perpendicular on the $I_{l}$ vector. The voltage at the $P C C$ in the first case, $V_{P C C l}$, equals the vector sum of the grid voltage, $\mathrm{V}_{\mathrm{g}}, I_{1} r_{g}$, and $I_{1} x_{g}$. For the second case, with the same vector calculations, $V_{P C C 2}$ equals the vector sum of 
the grid voltage, $\mathrm{V}_{\mathrm{g}}, I_{2} r_{g}$, and $I_{2} x_{g}$. From these two cases shown in Figure 10.8(a), as the injected current to the grid increases, $V_{P C C}$ decreases, which means, with different $P_{P C C}$ levels, the system will suffer from noticeable fluctuations in $V_{P C C}$.
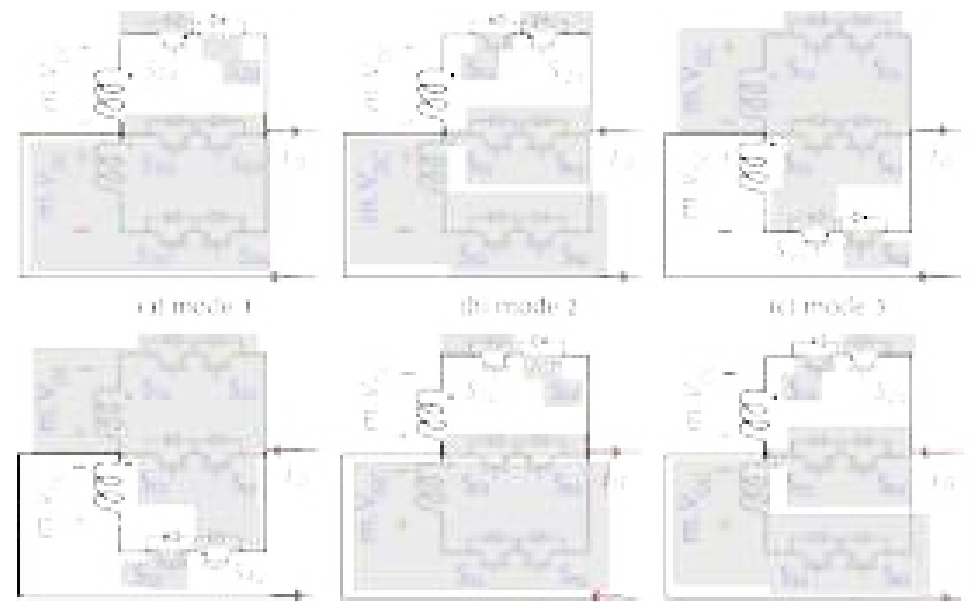
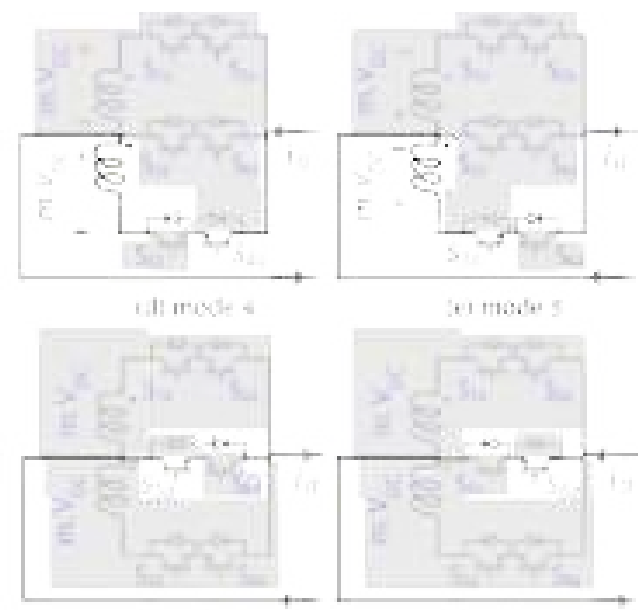

Figure 10.7: Operational modes of the proposed HF ac-link cell 2.

In Figure 10.8(b), the two cases shown in Figure 10.8(a) are reinvestigated, where the first case with $I_{1}$ flowing through the $P C C$ is the same, aligned with $V_{P C C l}$, but in the second case, $I_{2}$ is phase-shifted from $V_{P C C 2}$, this phase shift can be controlled and adjusted to set $V_{P C C}$ at a reference level, $V_{R M S}^{*}$. This can be achieved by a PI controller that is fed by the error between $V_{P C C}$ and the reference RMS voltage at the $P C C, V_{R M S}^{*}$, the manipulated variable of this PI controller is the reference quadrature current component of the three phase currents flowing between the fast charging statieqn and the grid, $i$. Figure 10.6 shows the complete control scheme of the proposed PV-assisted fast charging station, where PI controller 1 is the closed-loop regulator dedicated for managing the bidirectional power flow between the grid and the fast charging station, and PI controller 2 is assigned for regulating $V_{P C C}$. After ${ }_{\mathcal{d}}^{*}$ etting $i_{q}^{*}$ and $i$, inverse Park and inverse Clark transformations are utilized to calculate the reference three phase currents, $i_{a b c}^{*}$. The three phase 
reference currents are then fed to the multilevel HCC to generate the switching signals for the switches inside the cells. The signal processing unit is used to calculate the magnitude of $V_{P C C}$ and the instantaneous angle of $V_{P C C}, \theta$.

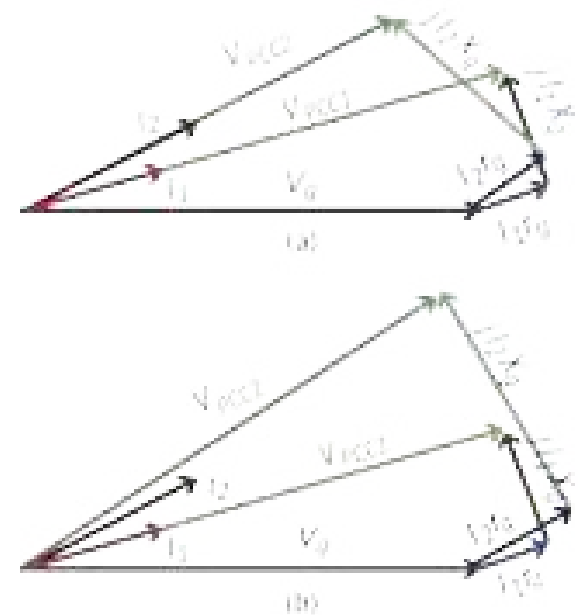

Figure 10.8: (a) Phasor diagram of the system without applying the VPCC regulator, (b) phasor diagram of the system with the VPCC regulator applied.

\subsubsection{The LVRT Capability of the Proposed Fast Charging Station}

The capability of the system to ride-through grid faults and disturbances is very important, and there are many grid codes that put strict requirements for grid-connected converters in order to support the grid with active and reactive power during faults. One of the popular grid codes for LVRT requirement is the E. ON code which is a German grid code and widely adopted in many literature [226]-[228]. Figure 10.9 shows the relationship between the voltage dip and the ratio between the reactive component of the injected current to the grid, and the rated current of the grid-connected converter system, according to the E. ON code. When voltage sag is detected, the LVRT controller is enabled and PI controller 2 is aborted. The LVRT controller calculates, $i_{d l v}^{*}$, and $i_{q l v}^{*}$, which are the reference direct component and the the reference quadrature component of the grid currents, respectively during the voltage sag. From Figure 10.9, the E. ON curve divides 
the operation into three regions, region I is for $V_{P C C}$ less than or equal $50 \%$ of the nominal grid voltage, and in this region the converter injects only reactive current, while in region III, $V_{P C C}$ is close to or equal the nominal grid voltage, and in this region the LVRT controller is disabled and PI controller 1 and PI controller 2 are enabled to calculate the reference grid current components. In region II, there is a linear relationship between $i_{q l v}^{*}$ and the percentage of $V_{P C C}$ to the nominal grid voltage, $V_{P C C} \%$, and this relationship is depicted in (12).

$$
i_{q l v}^{*}=2\left(1-V_{P C C} \%\right)
$$

$i_{d l v}^{*}$ can be calculated using (13)

$$
i_{\text {dlv }}^{*}=\sqrt{i_{\text {rated }}^{2}-i_{q l v}^{* 2}}
$$

Where $i_{\text {rated }}$ is the rated current of the CHF ac-link system. In a voltage sag case, PI controller 1 sets the limit for $i_{d l v}^{*}$ of the LVRT controller at $i_{d}^{*}$, as this is the maximum direct current component the system can supply. During deep voltage sag case, when $i_{d l v}^{*}$ is less than $i_{d}^{*}$, PI controller 1 is aborted, and in this case the MPPT inside the power processing units of the PV system is disabled to avoid overvoltage scenarios on the LV dc bus system.

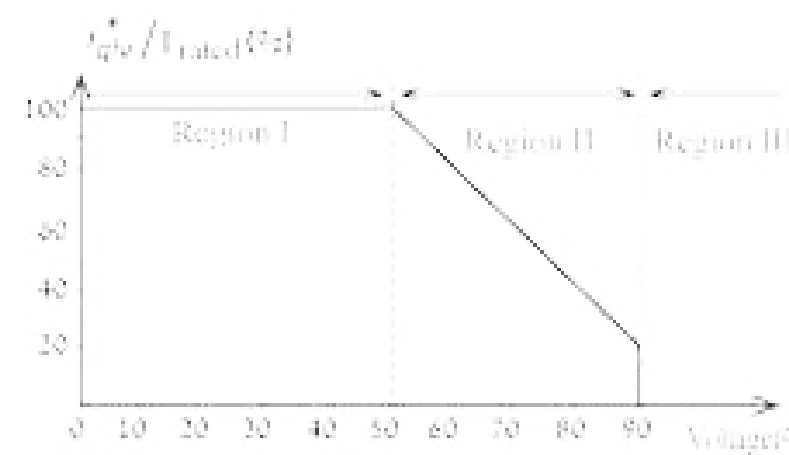

Figure 10.9: Reactive current requirement during grid fault, according to the E.ON code.

\subsection{Simulation Results}

Two simulation models have been built in Matlab/Simulink in order to validate the proposed 
architectures of a PV-assisted fast charging station with a power rating of 6-MW, with model parameters shown in Table 10.3. The single line diagram of the simulated systems is shown in Figure 10.6, where the PV system and the EV chargers are depicted as current sources, pushing power towards the LV dc bus where $C_{d c}$ is connected, in case of the PV system, and withdrawing power from the LV dc bus, in case of the EV chargers. The PV-assisted fast charging station is connected to a $13.2-\mathrm{KV}$ grid.

Table 10.3: SIMULATION MODEL PARAMETERS

\begin{tabular}{|l|c|}
\hline System rating & $6-\mathrm{MW}$ \\
\hline Medium voltage grid & $13.2-\mathrm{KV}, 60 \mathrm{~Hz}$ \\
\hline HF transformer & $2 \mathrm{KHz}$ \\
\hline Error Sampling frequency & $30 \mathrm{KHz}$ \\
\hline Turns ratio $(\mathrm{m})$ & 3.2 \\
\hline Grid inductance $\left(l_{g}\right)$ & $40 \mathrm{mH}$ \\
\hline Feeder inductance $\left(l_{f}\right)$ & $50 \mathrm{mH}$ \\
\hline Feeder resistance $\left(r_{f}\right)$ & $2 \Omega$ \\
\hline Simulation Sampling Time & $1 \mu \mathrm{S}$ \\
\hline \multicolumn{2}{|c|}{ PI CONTROLLER 1 COEFFICIENTS } \\
\hline Proportional coefficient, $\left(K_{P 2}\right)$ & -0.002 \\
\hline Integral coefficient $\left(K_{I 2}\right)$ & -10 \\
\hline
\end{tabular}




\subsubsection{Effect of Number of Cells per Phase on the Power Quality and the Total System Cost}

In this subsection, eight simulation cases are carried out. Figure 10.10 shows the three phase voltages produced by a CHF ac-link system with the proposed HF ac-link cell 1 comprising eight, six, four, and two cells per phase, and the associated total harmonic distortion, THD\%, for each case is shown above its plot. The same four cases are carried out with the proposed HF aclink cell 2 as shown in Figure 10.11. The total number of phase voltage levels that can be realized is $n+1$ in case of the proposed HF ac-link cell 1 , where $n$ is the number of cells per

phase, and $2 n+1$ in case of the proposed HF ac-link cell 2. The total number of switches of the cascaded cells connected to the transformer secondary windings of a three phase CHF aclink system is 3.n.4, in case of the proposed HF ac-link cell 1 is used, and 3.n.6, in case of the proposed HF ac-link cell 2 is used. Figure 10.12(a) shows the THD\% for the four cases for both of the proposed HF ac-link cells. The total number of switches of the cascaded cells connected to the transformer secondary windings for the four cases with the proposed HF ac-link cells are shown in Figure 10.12(b). Figure 10.12 shows that as the number of cells per phase increases, the difference in THD\% for the proposed two architectures is diminished, while the difference in total number of switches increases. This means for a CHF ac-link system with large number of cells, the proposed HF ac-link cell 1 is a better choice from the cost point of view. 

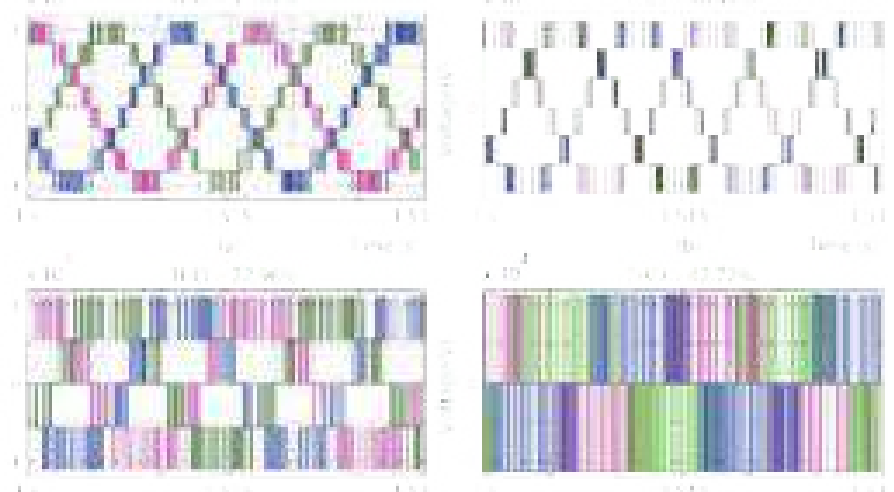

Figure 10.10: Phase voltages of the CHF-link system with the proposed HF ac-link cell 1 with (a) 8 cells, (b) 6 cells, (c) 4 cells, and (d) 2 cells per phase.
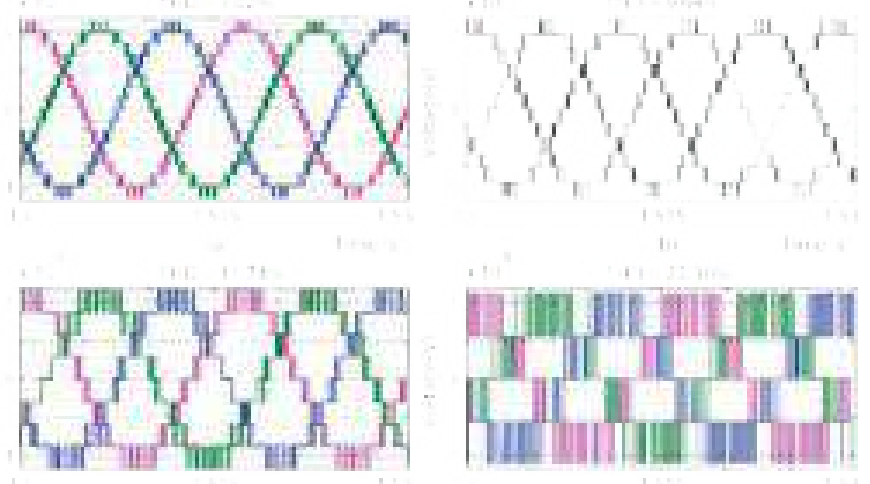

Figure 10.11: Phase voltages of the CHF-link system with the proposed HF ac-link cell 2 with (a) 8 cells, (b) 6 cells, (c) 4 cells, and (d) 2 cells per phase.

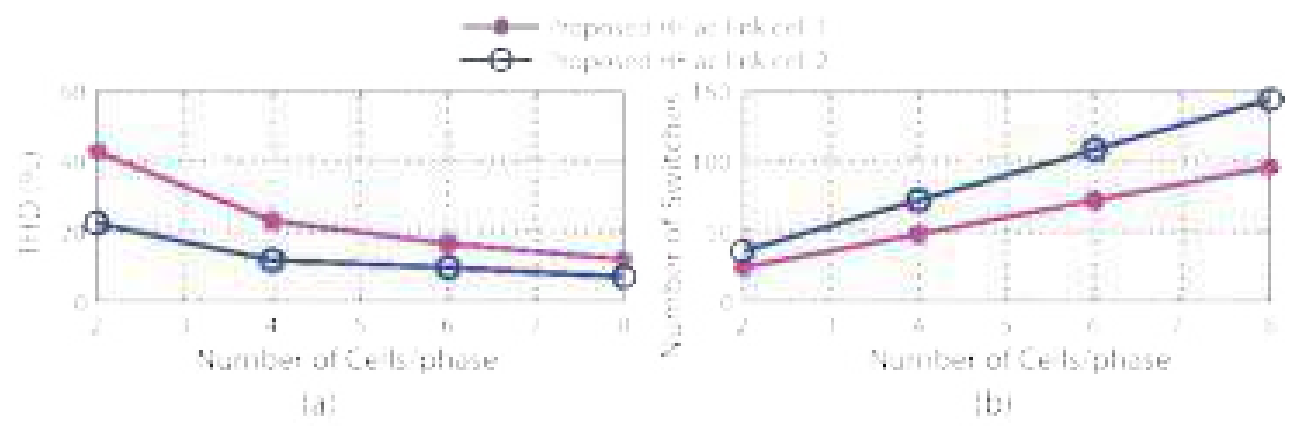

Figure 10.12: (a) THD\% for different number of cells/phase with both of the proposed cells, (b) Total number of switches of the secondary side converters with different number of cells/phase with both of the proposed cells. 


\subsubsection{Evaluation of the bidirectional power flow controller and the PCC voltage regulator performance}

The simulations in this subsection and the next subsection are carried out with a CHF ac-link system with eight cells per phase, and the proposed HF ac-link cell 1 is used.

In Figure 10.13, the dynamic performance of the bidirectional power flow controller is evaluated, as three power flow scenarios are shown. From $t=0.5 \mathrm{~s}$ to $t=1 \mathrm{~s}$, the EV chargers withdraw $0.55 \mathrm{MW}$ from the dc bus system, while the PV system injects 3.3 MW towards the dc bus system. PI controller 1 manipulates the value of $i_{d}$ to hold $V_{D C}$ at the reference level, which is set at $550 \mathrm{~V}$. In this case $i_{d}=165 \mathrm{~A}$, and the active power injected to the grid through the $P C C, P_{P C C}$, is 2.65 MW. From $t=1 \mathrm{~s}$ to $t=2 \mathrm{~s}$, the EV chargers withdraw $3.3 \mathrm{MW}$ from the dc bus system, while the PV system injects $1.65 \mathrm{MW}$ towards the dc bus system, $i_{d}=-104 \mathrm{~A}, P_{P C C}=-1.69 \mathrm{MW}$. The negative sign of $P_{P C C}$ means that the grid is supplying the fast charging station with active power. From $t=2 \mathrm{~s}$ to $t=3 \mathrm{~s}$, the EV chargers withdraw 4.126 MW from the dc bus system, while the PV system injects $0.55 \mathrm{MW}$ towards the dc bus system, $i_{d}=-232 \mathrm{~A}, P_{P C C}=-3.75 \mathrm{MW}$. Which proves the effectiveness of the bidirectional power flow controller in following up with the changing consumption of the EV chargers, and generation of the PV system. The voltage of the dc bus system is held constant with transitional overshoots less than $6 \%$. Figure 10.15 shows the effectiveness of the $V_{P C C}$ regulator, with the same three power flow scenarios investigated in Figure 10.13(c). Figures 10.15(c), 10.15(d), and 10.15(e) show the system response at the three power flow scenarios when PI controller 2 is disabled, while Figures 10.15(f), 10.15(g), and 10.15(h) show the system response at the three power flow scenarios when PI controller 2 is enabled. When PI controller 2 is aborted, the system is working at unity power factor, and Figures 15(a) and 15(e) show noticeable fluctuations in $V_{P C C}$ in response to the changes in $P_{P C C}$, at $t=1 \mathrm{~s}, V_{P C C}$ goes from 7.58-KV to 7.39-KV, and at $t=2 \mathrm{~s}, V_{P C C}$ goes from 7.39-KV to 6.81-KV. When PI controller 2 is 
enabled, the system starts injecting reactive power to the grid, as the closed-loop controller adjusts the value of $i_{q}$ in order to hold the $V_{P C C}$ at a constant level, and in this system the reference value of $V_{P C C}$ equals $13.2 \mathrm{kV} / \sqrt{3}$.

Figure 10.14 is an extension to the simulation case presented in Figures 10.15(f), 10.15(g), and 10.15(h), where both PI controller 1 and 2 are enabled, and it shows the response of the phase current and voltage at the $P C C$ to the change in $P_{P C C}$ at $t=1 \mathrm{~s}$. For $t<1, P_{P C C}=2.65 \mathrm{MW}$, and $Q_{P C C}=0.12 \mathrm{MVAR}$, thus the power factor $=0.37$. For $t>1, P_{P C C}=-1.69 \mathrm{MW}$, and $Q_{P C C}=0.32$ MVAR, thus the power factor $=-0.57$. The change in the phase shift between the phase current and voltage at $P C C$ before and after $t=1 \mathrm{~s}$ is shown in Figure 10.14(b).

\subsubsection{Evaluation of the LVRT Capability of the System}

This subsection is dedicated to test the LVRT capability of the proposed CHF ac-link system. The test scenario is composed of two faults, each fault lasts for 0.8 second, as shown in Figure 10.16. At $t=0.8 \mathrm{~s}$, the first fault takes place, where the grid undergoes a voltage-sag where the grid voltage, $V_{g}$, drops to $70 \%$ of its nominal value. At $t=1.6 \mathrm{~s}$, the second fault takes place, where the grid exhibits a voltage-sag of 50\% of its nominal value. When a voltage-sag is detected, $i_{q l v}^{*}$, and $i_{d l v}^{*}$ are obtained from the E. ON code graph, shown in Figure 10.9 and (13), respectively, where $i_{\text {rated }}$ of the CHF ac-link system is set at 350A for this application.

In the first fault, the voltage sag is $70 \%$ and therefore, from Figure $10.9, i_{q l v}^{*}$ is set to $60 \%$ of $\mathrm{i}_{\text {rated }}$ which is equal to $-210 \mathrm{~A}$. The negative sign indicates reactive power injection to the grid. Consequently, $i_{d l v}^{*}$ is limited to $280 \mathrm{~A}$, according to (13). When the second fault takes place, the voltage-sag is $50 \%$, and according to the $\mathrm{E}$. ON code, $i_{\text {qlv }}^{*}=i_{\text {rated }}=350 \mathrm{~A}$, and $i_{d l v}^{*}=0 \mathrm{~A}$, respectively. As shown in Figure 10.16, when $V_{g}$ drops from $7.62 \mathrm{KV}$ to $5.33 \mathrm{KV}$, $i_{q}^{*}$ is boosted to $-210 \mathrm{~A}$, and as a result, $V_{P C C}$ is alleviated at $7.14 \mathrm{KV}$ which is close to the reference value. At $t=$ 
$\mathrm{s}$, when the second fault takes place and $V_{g}$ dips to $3.81 \mathrm{KV}, i_{q}^{*}$ is increased to celling level of the CHF ac-link system, as a result, $V_{P C C}$ alleviated to $7.48 \mathrm{KV}$. These results prove explicitly the capability of the LVRT controller to effectively support the voltage at the $P C C$ during voltage sags.
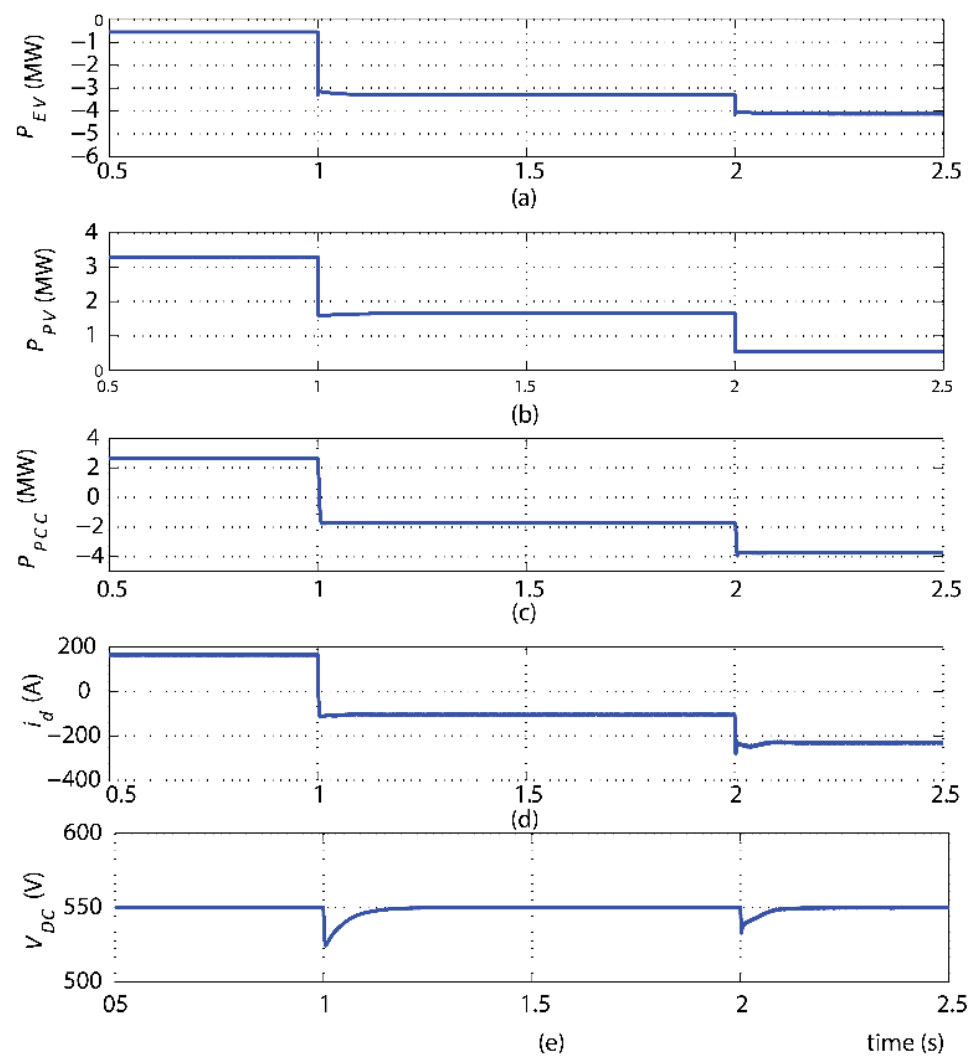

Figure 10.13: Dynamic performance of the bidirectional power flow controller.

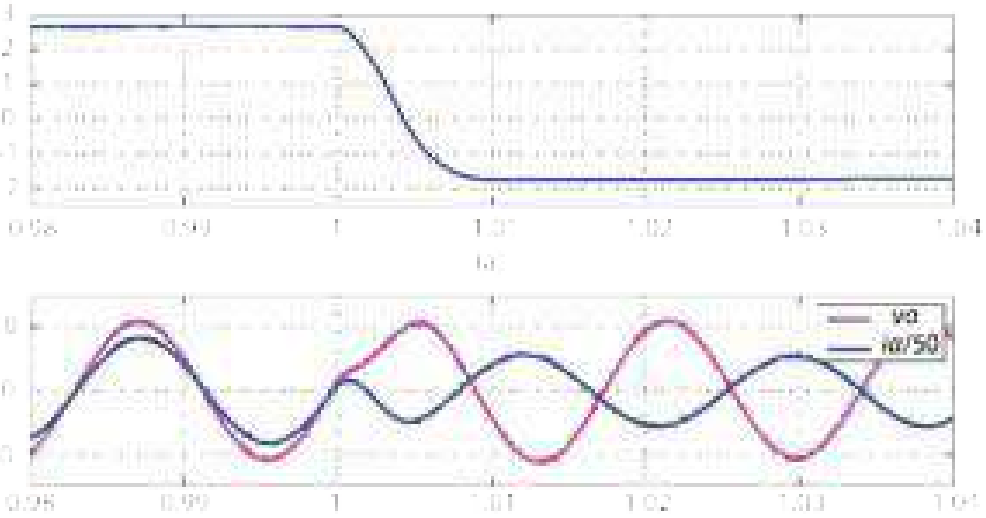

Figure 10.14: System response at two power flow levels (a) Power flow through the PCC, (b) Phase a voltage at PCC, and phase a current. 


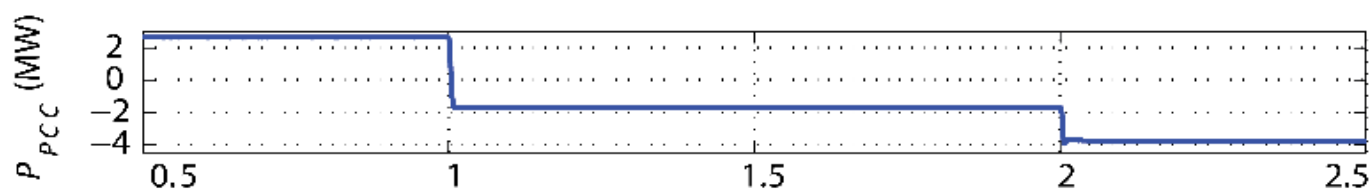

(a)
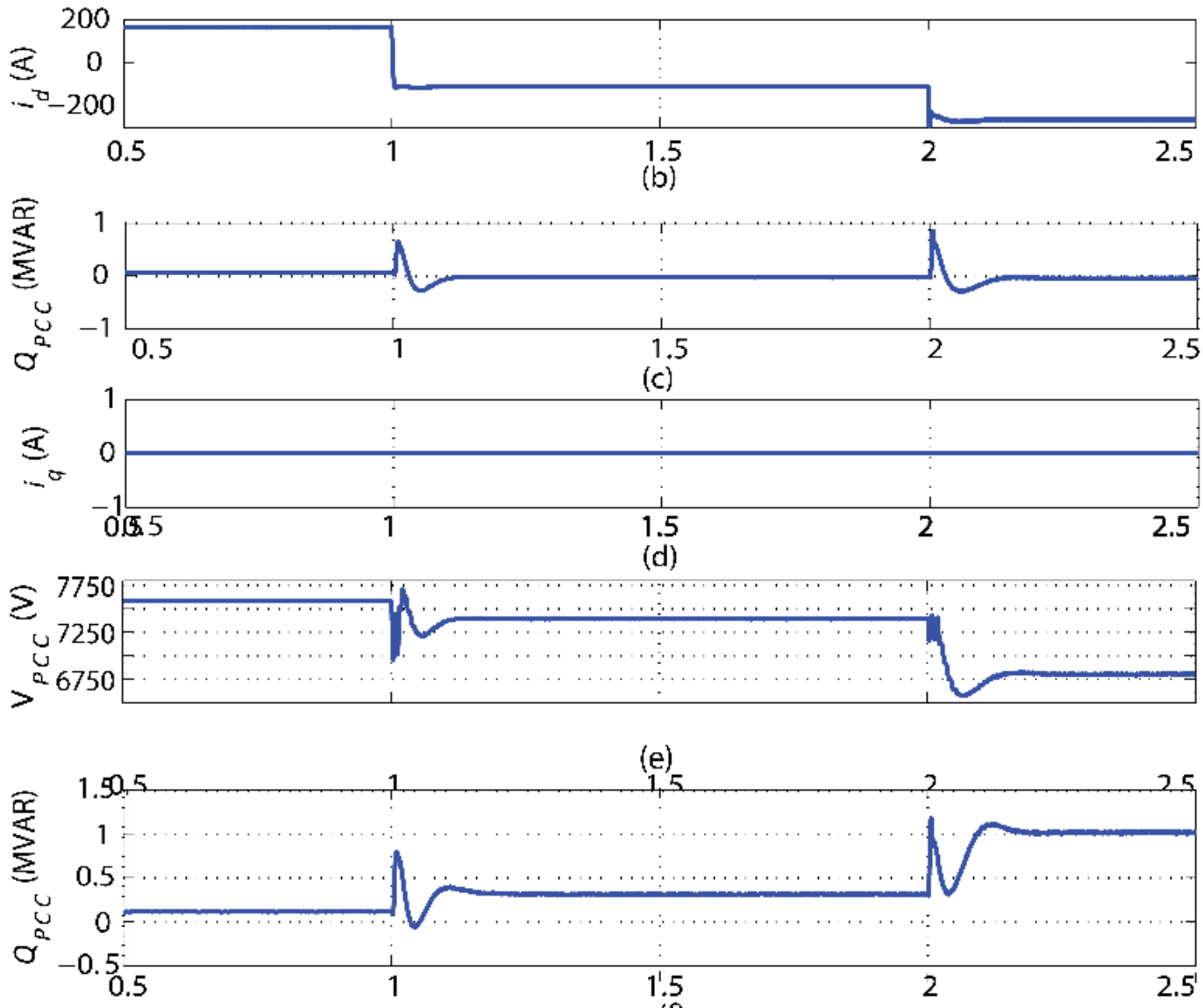

(f)
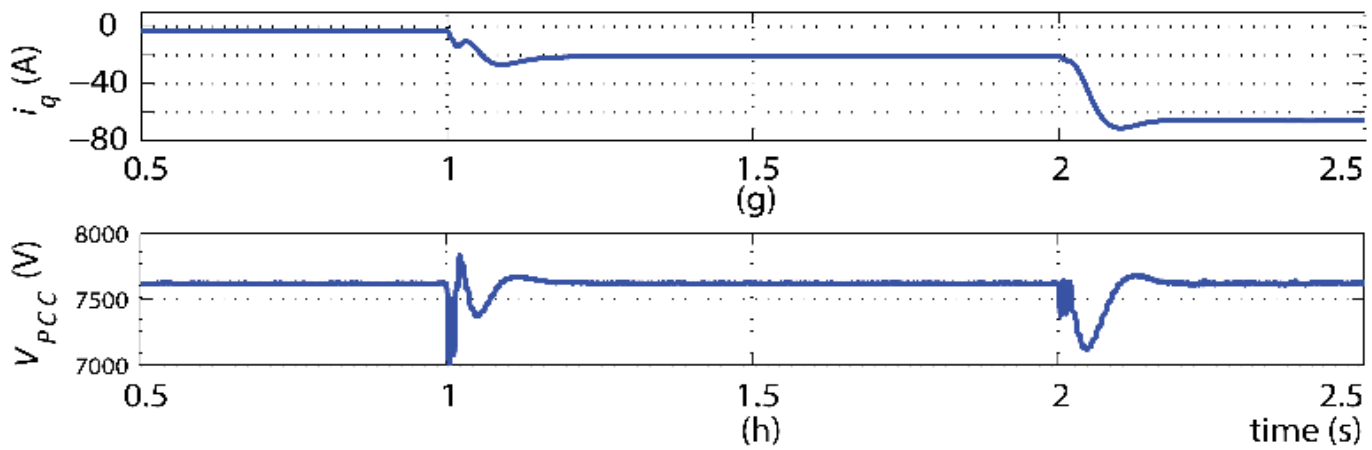

Figure 10.15: Dynamic performance of the PCC voltage regulator. 


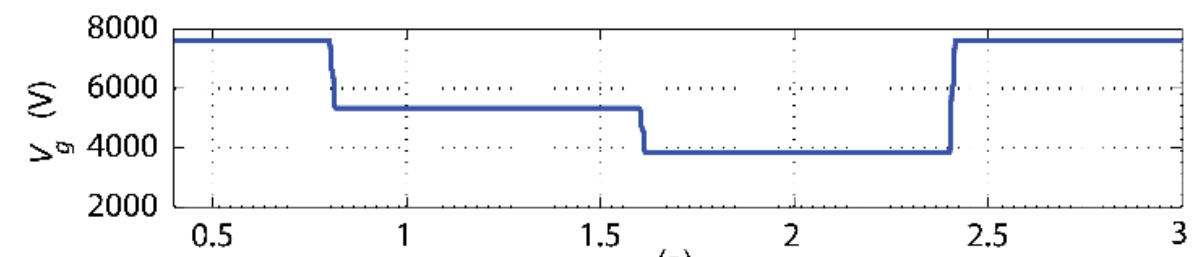

(a)
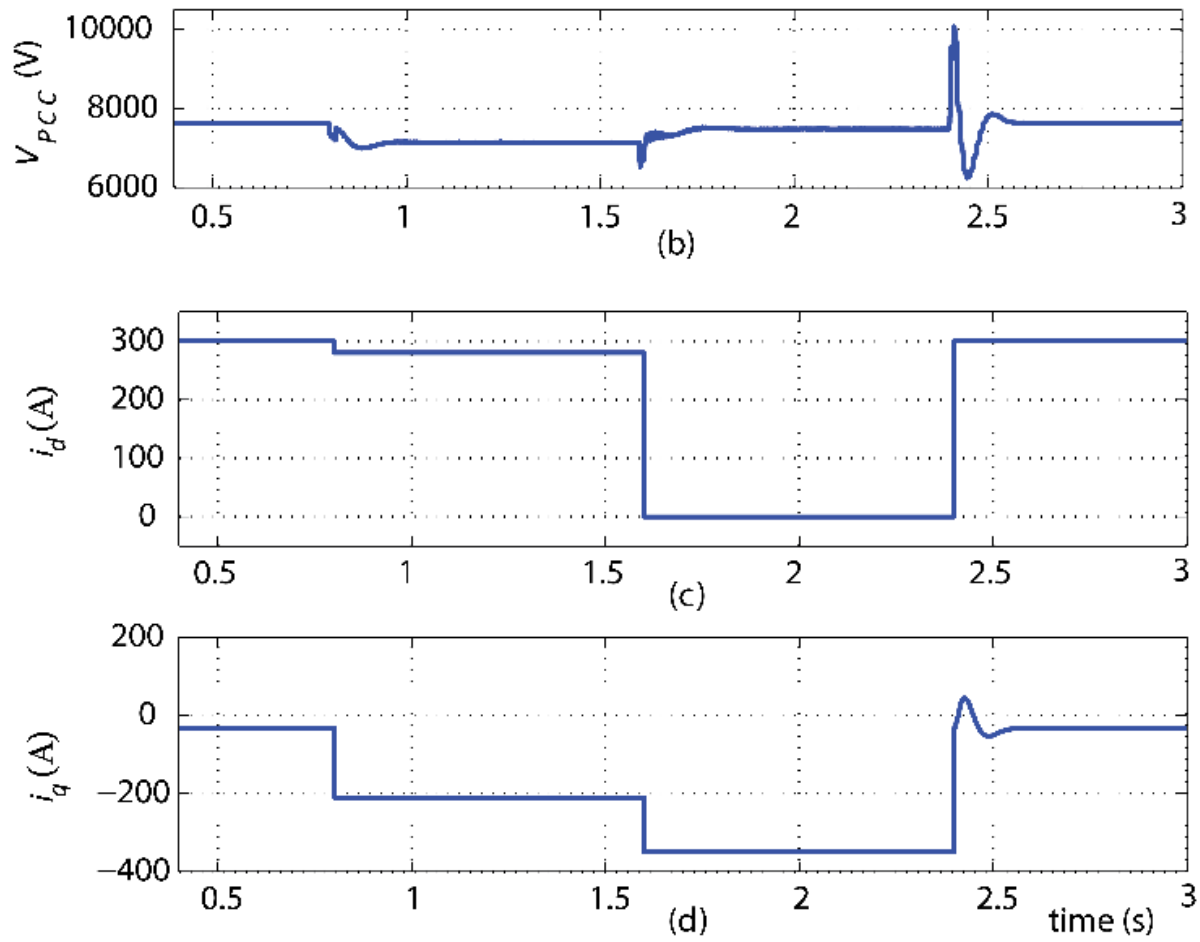

\section{Figure 10.16: Evaluation of the LVRT capability of the proposed CHF ac-link system.}

\subsection{Conclusion}

This chapter presented two new isolated power electronic architectures for a large-scale EV fast charging station assisted by a PV system. The proposed systems require less switches compared to other systems presented in the recent literature. A novel simplified current controller for the system was presented, which eliminates the need for the clamping circuits usually used with matrix converters. A bidirectional power flow controller was used to maximize the extracted power from the PV system without using energy storage systems. Moreover, the developed controller utilizes reactive power to compensate for the fluctuations in the voltage at $P C C$ under changing power flow levels between the grid and the fast charging station. A LVRT controller was adopted to inject 
the adequate active and/or reactive power levels to the grid, to keep the charging station gridconnected during faults to support the grid voltage. An example of a 6-MW system model showed the superior features of the developed system in controlling the power flow between the fast charging station and the medium-voltage ac grid. This was accomplished with high power quality during normal operation in addition to supporting the grid voltage during grid faults and disturbances by utilizing the reactive power. This which eliminates the need for large energy storage systems, commonly used to alleviate voltage sags. 


\section{Chapter 11 An Integrated PEBB using e-GaN FETs and Nanocrystalline Inductors for}

Multiple DC-DC, AC-DC and DC-AC Applications

\subsection{Introduction}

The concept of the power electronic building block (PEBB) has been proposed before [229][235], where a number of generic power electronic modules can be used to synthesize large number of power topologies. This concept is very important for marine and aerospace power systems as it minimizes the number of spare parts required for the power electronic equipment onboard the ship/aero plane. The PEBB has been proposed with different topologies, for instance: a pushpull configuration [229], and an anti-series topology [235]. All the proposed PEBBs were implemented either using Silicon (Si) MOSFETs/IGBTs or Silicon Carbide (SiC) MOSFETs/IGBTs.

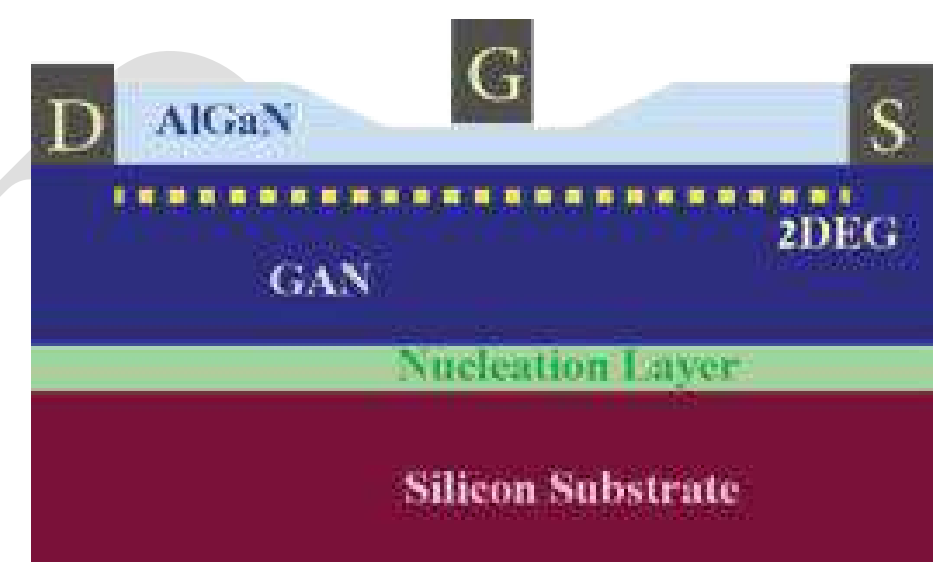

Figure 11.1: Generic structure of the lateral eGaN-FET HEMT.

The advent of enhancement Gallium Nitride (eGaN) High Electron Mobility Transistor (HEMT), with its groundbreaking features compared to its $\mathrm{Si}$ and $\mathrm{SiC}$ counterparts [236], [237], makes it an excellent candidate for the PEBB concept. The features of GaN, SiC, and Si materials are compared in Table 11.1. As shown in Figure 11.1, the generic structure of the lateral GaN 
HEMT is based on the piezoelectric effect between a layer of $\mathrm{GaN}$ and a layer of Aluminum Gallium Nitride $(\mathrm{AlGaN})$, which results in a 2-D electron gas (2-DEG) layer between the drain (D) and source (S) of the GaN HEMT, which reduces the on-resistance of the device [236]. In Table 11.2, a comparison between a number of commercial $\mathrm{SiC}$, and GaN FETs with rated voltage of $600 \mathrm{~V} / 650 \mathrm{~V}$ is presented. From this comparison, the eGaN HEMT from GaN Systems (GS66508T) has less on-resistance, input and output capacitances, reverse recovery charge, and total gate charge, which makes it a FET with lower switching and conduction losses compared to other devices.

In this chapter, an eGaN-FET based PEBB that is constituted by a half-bridge topology is presented. The PEBB has input and output filter capacitors, and a Nanorystalline filter inductor. Nanocrocytalline material is chosen because it has a high saturation flux density level, and high permeability in a broad frequency range [238]. These characteristics provide the possibility that the designed inductor could be small and compact. The rest of this chapter is organized as follows; section II presents the developed non-isolated eGaN PEBB, section III explains the possible topologies that can be synthesized with the developed PEBB. The results are presented in section IV and section V concludes this chapter.

Table 11.1: Material Properties of GaN, SiC, and Si

\begin{tabular}{|l|c|c|c|}
\hline Parameter & $\mathrm{GaN}$ & $\mathrm{SiC}$ & $\mathrm{Si}$ \\
\hline Bandgap (eV) & 3.2 & 3.4 & 1.12 \\
\hline Breakdown Field (MV/cm) & 3.3 & 3.5 & 0.3 \\
\hline Electron Mobility (cm²/V.S) & 2000 & 650 & 1500 \\
\hline
\end{tabular}


Table 11.2: COMPARISON BETWEEN COMMERCIAL WBG DEVICES

\begin{tabular}{|c|c|c|c|}
\hline & $\mathrm{SiC}$ & Ga & \\
\hline & $\begin{array}{c}\text { ROHM } \\
\text { Semiconductor } \\
\text { SiC-MOSFET } \\
\text { SCT2120AF }\end{array}$ & $\begin{array}{c}\text { Transphorm } \\
\text { Cascode- } \\
\text { GaN } \\
\text { TPH3205WS }\end{array}$ & $\begin{array}{c}\text { GaN } \\
\text { Systems } \\
\text { eGaN- } \\
\text { HEMT } \\
\text { GS66508T }\end{array}$ \\
\hline $\mathbf{V}_{\mathrm{DS}}$ & $650 \mathrm{~V}$ & $600 \mathrm{~V}$ & $650 \mathrm{~V}$ \\
\hline Continuous $I_{D}\left(25^{\circ} \mathrm{C}\right)$ & $29 \mathrm{~A}$ & $36 \mathrm{~A}$ & $30 \mathrm{~A}$ \\
\hline$R_{D S(O N)}\left(T_{J}=25^{\circ} \mathrm{C}\right)$ & $120 \mathrm{~m} \Omega$ & $52 \mathrm{~m} \Omega$ & $50 \mathrm{~m} \Omega$ \\
\hline Input Capacitance CISS & $1200 \mathrm{pF}$ & $2150 \mathrm{pF}$ & $260 \mathrm{pF}$ \\
\hline Output Capacitance Coss & $90 \mathrm{pF}$ & $119 \mathrm{pF}$ & $65 \mathrm{pF}$ \\
\hline Reverse Recovery Charge (Qrr) & $53 \mathrm{nC}$ & $136 \mathrm{nC}$ & OnC \\
\hline Total Gate Charge $\left(Q_{G(T O T)}\right)$ & $61 \mathrm{nC}$ & $27 \mathrm{nC}$ & $6.5 \mathrm{nC}$ \\
\hline Gate Charge (QGD) & $21 \mathrm{nC}$ & $6 \mathrm{nC}$ & $1.8 \mathrm{nC}$ \\
\hline
\end{tabular}

\subsection{The Developed Non-Isolated eGaN FET-Based PEBB}

The schematic of the developed non-isolated eGaN PEBB is presented in Figure 11.2, and the layout of the PEBB PCB is shown in Figure 11.3. All the parameters of the eGaN PEBB are enlisted in Table 11.3.

The eGaN PEBB is based on a half-bridge topology with integrated filter inductor, input and output capacitances, which renders it as an integrated compact solution to synthesize most of the 
power electronic topologies (as discussed in section III) without the need to any extra components. Both gate drivers have isolated power supplies, which provide the gate driver of the upper switch independent on the lower switch status, this feature is critical in the cases where the upper switch stays "on" for a long period (ex. bus-clamping PWM). An isolated dc/dc converter provides an isolated supply for each gate driver, followed by a linear voltage regulator to provide $6.5 \mathrm{~V}$ for the driver opto-coupler. The turn-on resistance $\left(r_{o n}\right)$, and the turn-off resistance $\left(r_{o f f}\right)$ control the rising and falling times of the HEMT, which need to be adjusted in order to avoid voltage spikes (due to high $d v / d t$ ) and on the other hand not compromise the switching speed. According to [239], $r_{o n}$ needs to be five to ten times $r_{o f f}$. The ferrite bead (FB) at the gate pin damps the oscillations at the gate, which reduces the possibility of false turn-on.

Table 11.3: eGaN PEBB Parameters

\begin{tabular}{|l|c|}
\hline \multicolumn{1}{|c|}{ Parameter } & Value \\
\hline Switches $\left(\mathrm{S}_{1}, \mathrm{~S}_{2}\right)$ & GS66508T \\
\hline Filter Cap. $\left(\mathrm{C}_{\mathrm{f}}\right)$ & $440 \mu \mathrm{F}$ \\
\hline Isolated DC/DC converter (5V to 9V) & PDS1-S5-S9-M-TR \\
\hline Driver & SI8261BAC-C-IS \\
\hline ron $_{\text {on }}$ & $50 \Omega$ \\
\hline $\mathrm{r}_{\text {off }}$ & $10 \Omega$ \\
\hline Pull-down resistor & $10 \mathrm{k} \Omega$ \\
\hline Ferrite Bead (FB) & 74279268 \\
\hline Zener Diode & MMSZ5235BS-7-F \\
\hline Microcontroller & TMS320f28377s \\
\hline
\end{tabular}


A zener diode with reverse breakdown voltage of $6.8 \mathrm{~V}$ to clip any voltage spikes. The banana jacks $\left(J_{1}, J_{2}, J_{3}, J_{4}, J_{5}, J_{6}\right)$ are used to connect the supplies, loads, and/or an external customized filter inductor,

\subsection{Possible Topologies Using the eGaN PEBB}

In this section, the possible dc/dc, dc/ac (single-phase), and dc/ac (three-phase) are discussed. The possible configurations are shown in Figure 11.4, and two examples of dc/ac systems modulation are explained in Figure 11.5 and Figure 11.6.

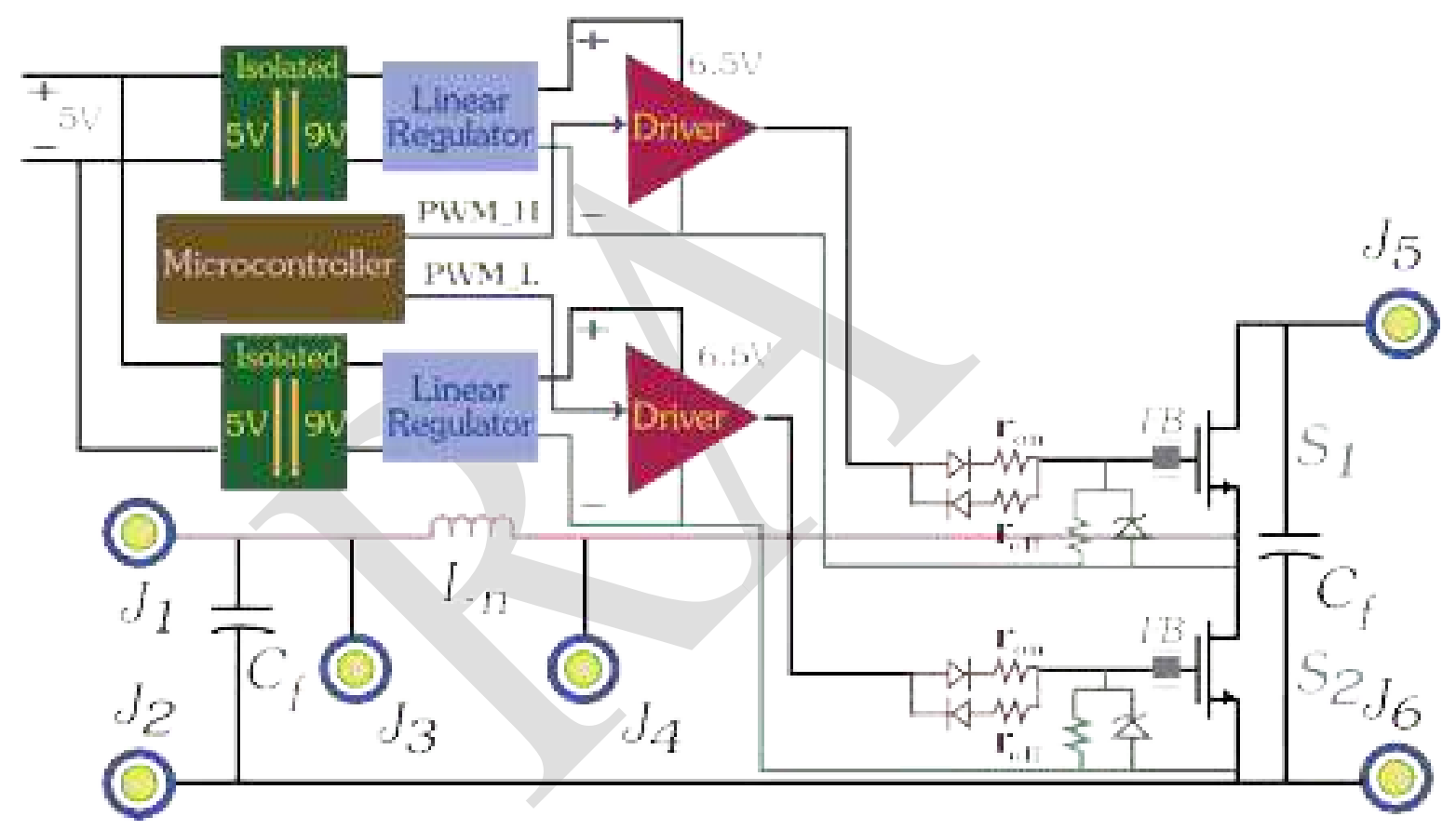

Figure 11.2: eGaN FET PEBB schematic: power stage, driver, voltage regulation, filter stage and control. 


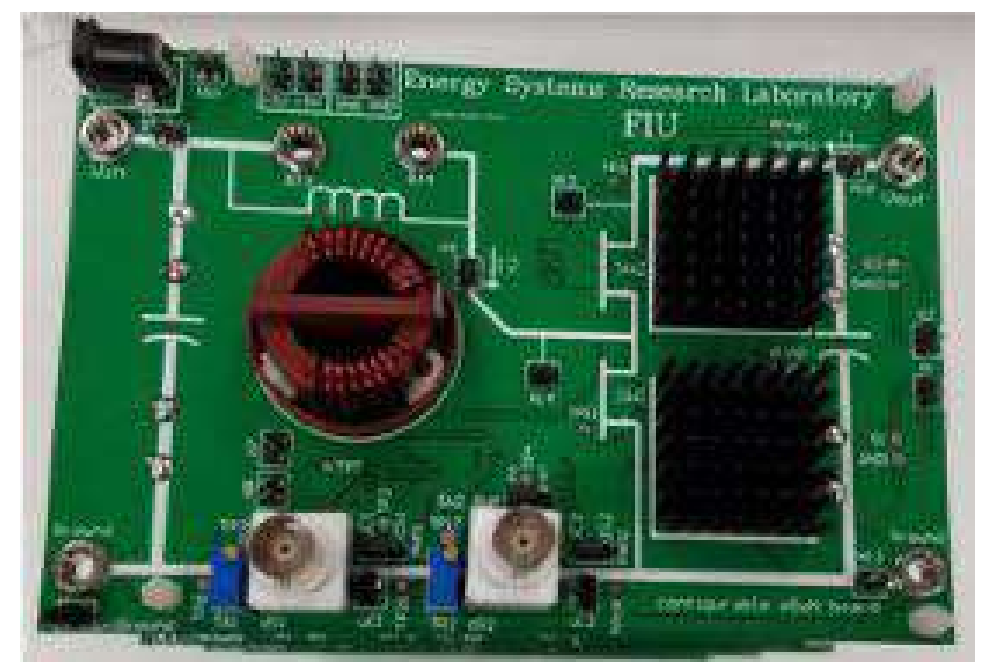

(a)

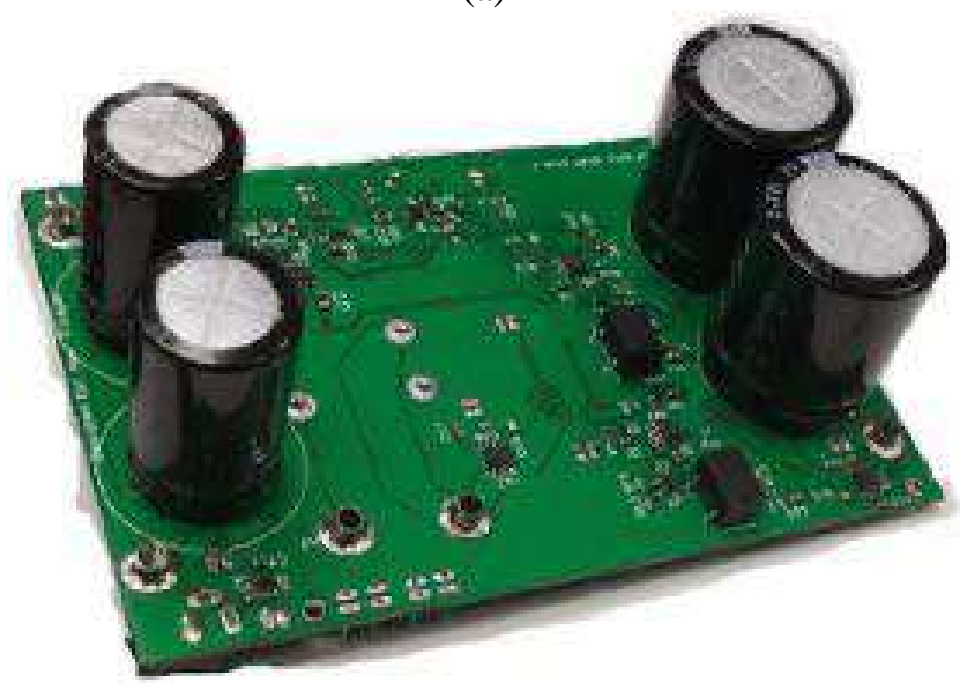

(b)

Figure 11.3: eGaN FET PEBB (a) top side, (b) bottom side.

\subsubsection{DC-DC Topologies}

The developed PEBB can be directly used as a bi-directional buck converter or bi-directional boost converter (depends on the location of source and load) as shown in Figure 11.4(a). The connection of the source and load can be changed as depicted in Figure 11.4(b) to synthesize an inverting bi-directional buck-boost converter. In Figure 11.4(c), a non-inverting buck-boost converter is synthesized using two PEBBs. 


\subsubsection{Single-Phase DC-AC Topologies}

Generating an ac output using dc/dc converters can be achieved using differential mode configuration, which is based on using two bi-directional dc/dc converters to synthesize a singlephase inverter [240].

Adding a dc offset is necessary in such a way that the output of each converter is either positive (non-inverting converters) or negative (inverting converters). An example of a single-phase buckboost inverter is shown in Figure 11.5(a). The output of each converter is depicted by (1), and (2), and the differential output is depicted in (3).

$$
\begin{aligned}
& V_{a}{ }^{*}=V_{D C}+\frac{V_{a b m}^{*} \sin (\omega t)}{2} \\
& V_{b}{ }^{*}=V_{D C}+\frac{V_{a b m}^{*} \sin (\omega t+\pi)}{2} \\
& V_{a b}{ }^{*}=V_{a b m}^{*} \sin (\omega t)
\end{aligned}
$$

Where $\left(V_{a b m}^{*}\right)$ is the magnitude of the reference differential output voltage $\left(V_{a b}^{*}\right)$, and $\left(V_{D C}\right)$ is the dc offset value. If the converters used are non-inverting, thus the output from each converter should be in the positive domain, as in Figure 11.5(b), while if the converters used are inverting, thus the output from each converter should be in the negative domain, as in Figure 11.5(c).

The concept of differential-mode connection can be used with bidirectional buck converters to build a 1-ph buck inverter, as shown in Figure 11.4(d), bidirectional boost converters to build a 1-ph boost inverter, as shown in Figure 11.4(e), inverting bidirectional buck-boost converters to build a 1-ph buck-boost inverter, as shown in Figure 11.4(f), or bidirectional non-inverting buck-boost converters to build a 1-ph buck-boost inverter, as shown in Figure 11.4(g). 


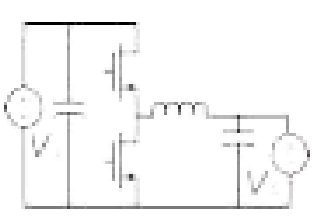

(a)

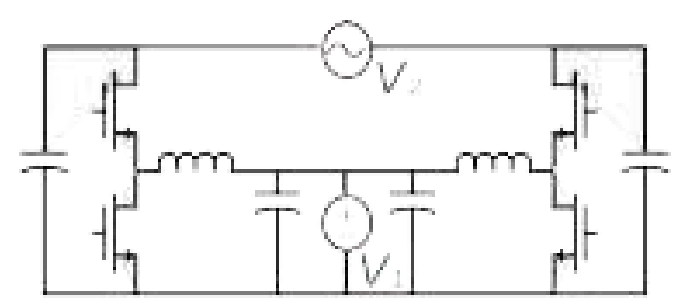

(e)

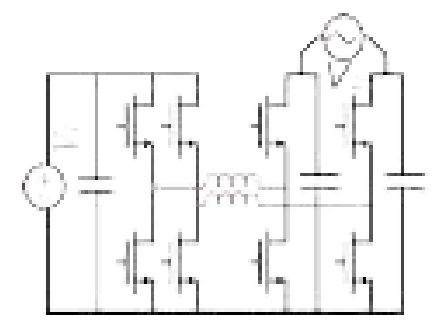

(g)

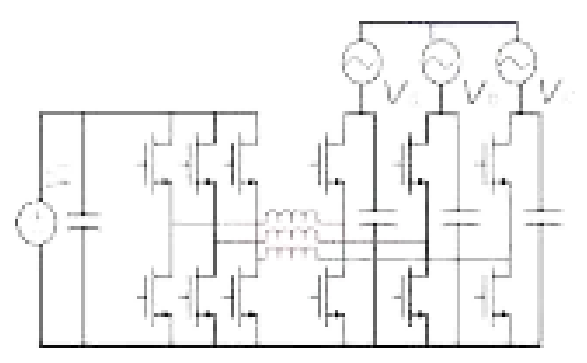

(i)

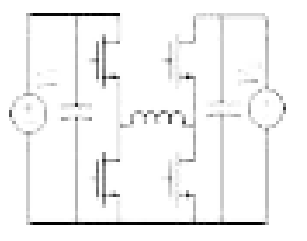

(c)

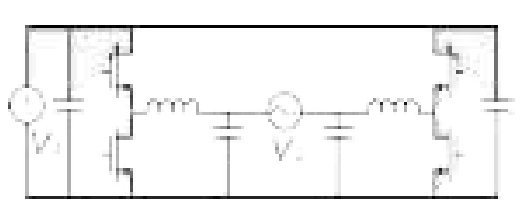

(d)

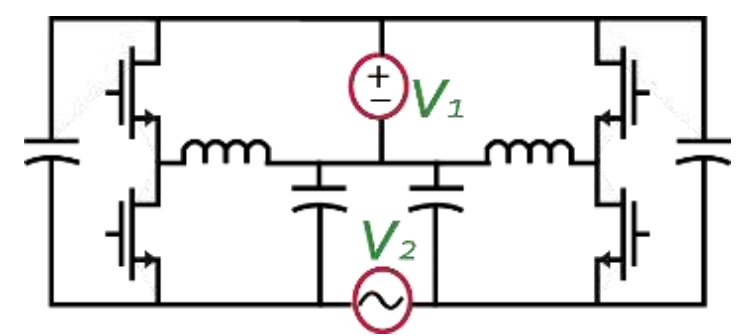

(f)

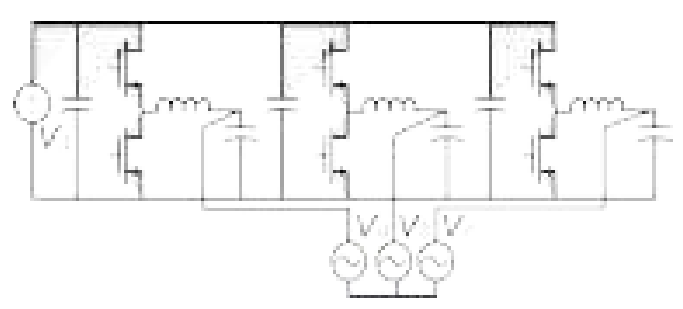

(h)

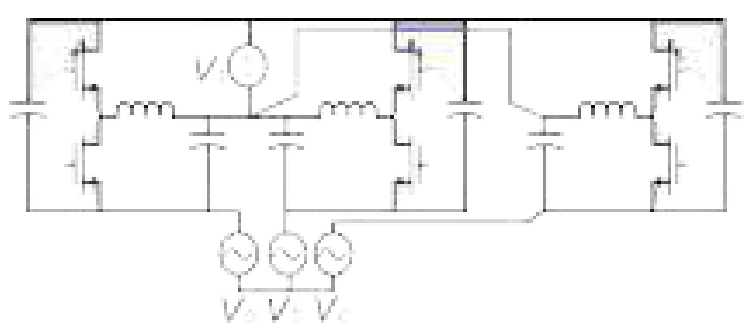

(j)

Figure 11.4: Possible configurations with the eGaN PEBB. 


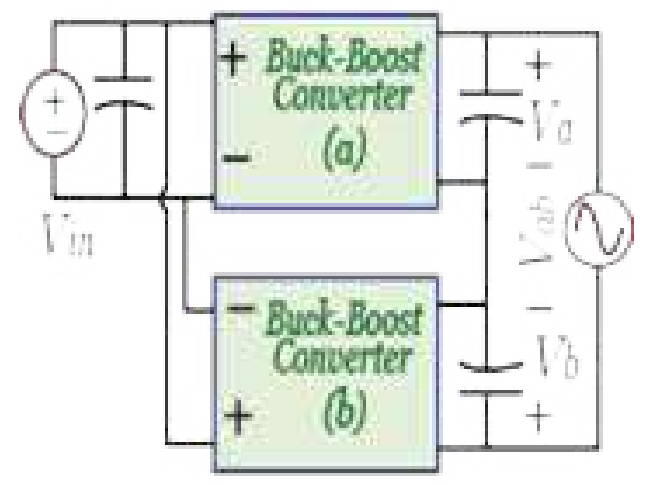

(a)

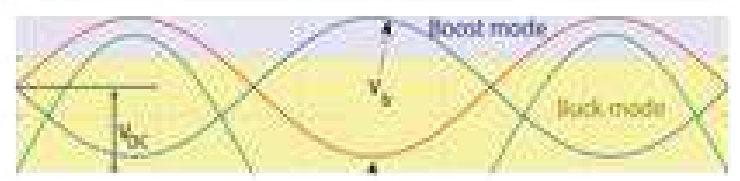

(b)

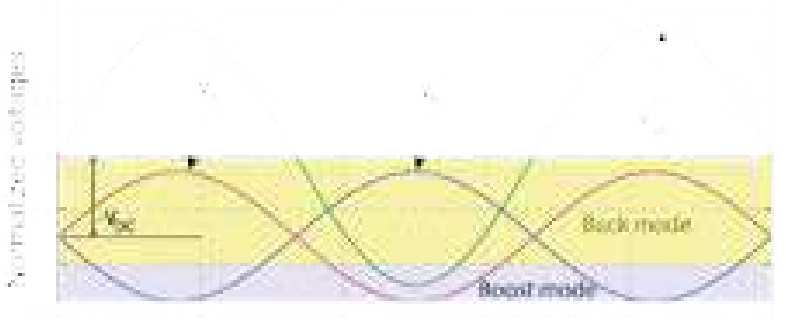

(c)

Figure 11.5: (a) Differential-mode 1-ph buck-boost inverter, (b) modulation (in case of non-inverting converters), (c) modulation (in case of inverting converters).

\subsubsection{Three-Phase DC-AC Topologies}

The idea of differential-mode connection can be extended to synthesize three-phase inverters using dc/dc converters [241], [242]. An example of a three-phase buck-boost inverter is shown in Figure 11.6(a). 


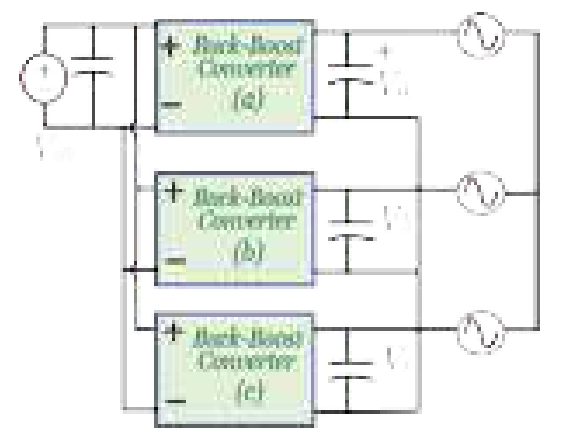

(a)

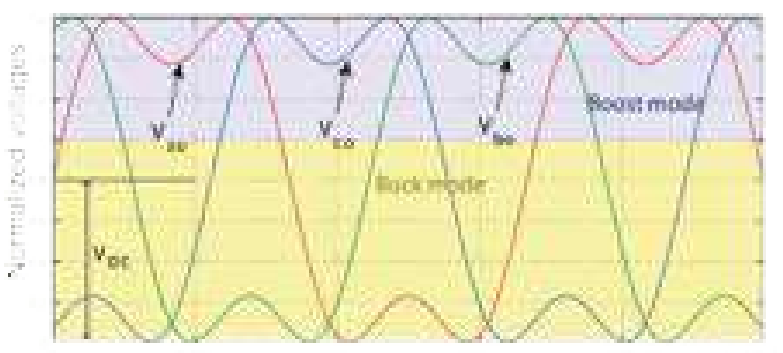

(b)

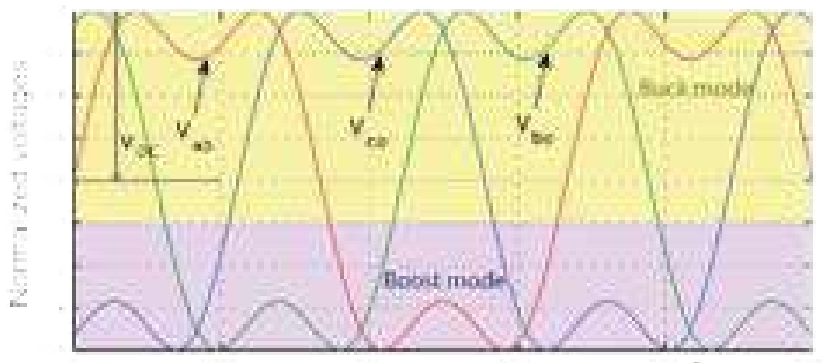

(c)

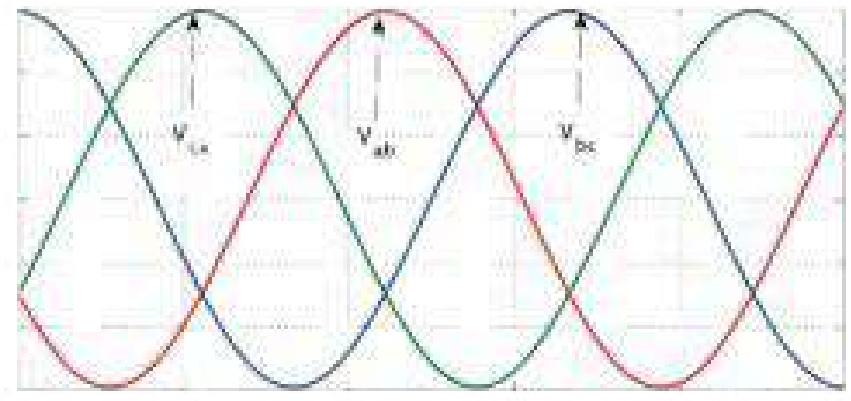

(d)

Figure 11.6: (a) Differential-mode 3-ph buck-boost inverter, (b) modulation (in case of noninverting converters), (c) modulation (in case of inverting converters), (d) 3-ph line-line voltages. 
The output of each converter is depicted in Figure 11.6 (b) (non-inverting converters), and Figure 11.6(c) (inverting converters). A third harmonic component can be added to reduce the voltage stress on the switches. The three-phase line-line voltages are the differential voltages between the three dc/dc converters, as the dc offset and the third harmonic components cancel out and three phase sinusoidal line-line voltages appear at the load terminals, as shown in Figure 11.6(d). This concept can be extended to synthesize a three phase buck inverter, as in Figure 11.4(h), or three phase buck-boost inverters, as in Figure 11.4(i), and Figure 11.4(j).

\subsection{Experimental Results}

A single-phase differential-mode buck-boost inverter (based on non-inverting buck-boost converters, as in Figure $11.4(\mathrm{~g})$ ), is investigated experimentally in this section. The circuit schematic is shown in Figure 11.7(a), as it is composed of four half bridges, two inductors, and input and output filter capacitors.

This system can be synthesized using four PEBBs. The connection diagram of the system is presented in in Figure 11.7(b), while the complete experimental setup is depicted in Figure 11.7(c). The setup is managed by the TMS320F28377S digital signal controller, generating PWM with switching frequency of $100 \mathrm{kHz}$, and the load is a $10 \Omega$ resistor. The eGaN HEMTs used are GS66508T with rated current of 30A, rated drain-to-source voltage of 650V, on-resistance of 50 $\mathrm{m} \Omega$.

In the Table 11.3, the parameters for the experimental setup are shown. The inverter is operating in the buck mode, as the input voltage $\left(V_{i n}\right)$ from the power supply is equal to $189 \mathrm{~V}$, the generated differential output is shown in Figure 11.8(a), with a positive peak voltage of $108 \mathrm{~V}$, 
a negative peak voltage of $-108 \mathrm{~V}$, and a frequency of $18.66 \mathrm{~Hz}$. Figure 11.8(b) shows the output voltage of each converter $\left(V_{a}\right.$ and $\left.V_{b}\right)$.

Table 11.4: Parameters For the Experimental Results

\begin{tabular}{|c|c|}
\hline Parameters & Values \\
\hline$V_{\text {source }}$ & $189 \mathrm{Vpk}$ \\
\hline$f_{\text {generated }}$ & $186 \mathrm{~Hz}$ \\
\hline Load & $10 \Omega$ \\
\hline$f_{s}$ & $100 \mathrm{kHz}$ \\
\hline
\end{tabular}

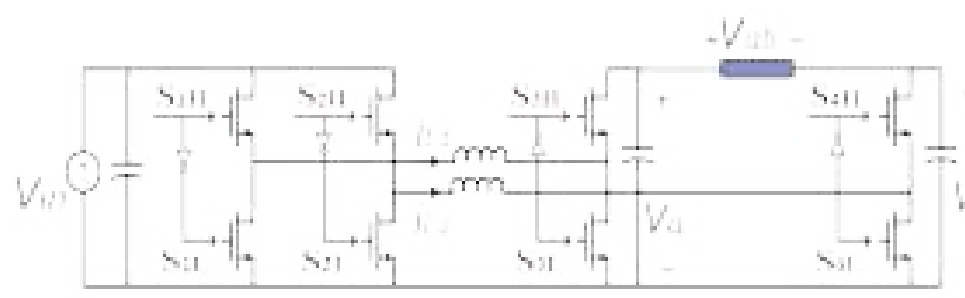

(a)

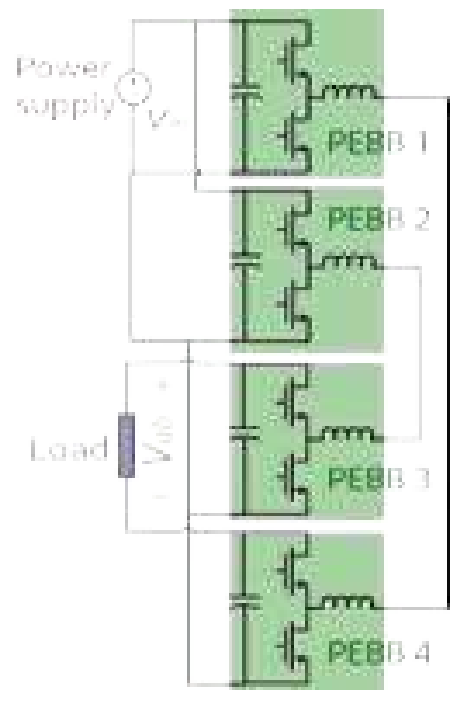

(b)

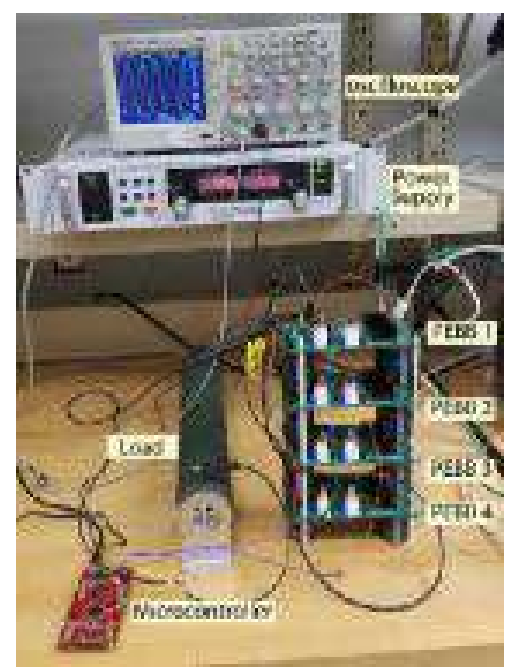

(c)

Figure 11.7: (a) Differential-mode 1-ph buck-boost inverter circuit, (b) Connection diagram, (c) Experimental setup. 


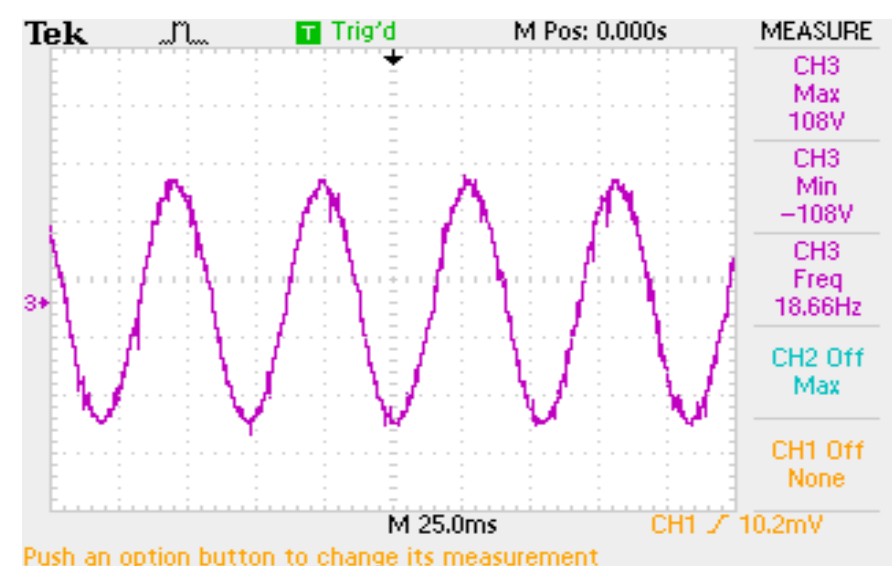

(a)

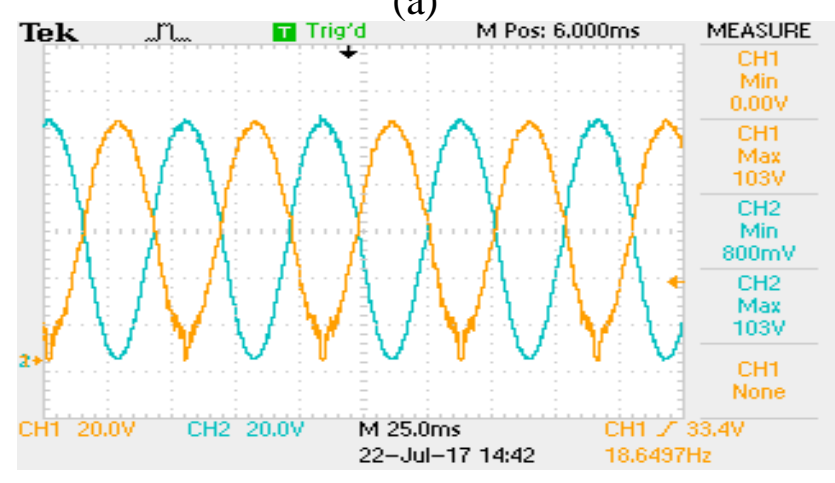

(b)

Figure 11.8: (a) Differential-mode output voltage of the inverter. (b) Output voltage of each converter.

\subsection{Conclusion}

This chapter presents a non-isolated PEBB built with eGaN HEMT devices and Nanocrystalline inductor. The eGaN HEMTs have lower on-resistance and lower device capacitances compared to $\mathrm{Si}$ and $\mathrm{SiC}$ counterparts which make these devices have less conduction and switching losses, this results in less cooling system requirement, hence, a more compact PEBB. The utilization of the GaN HEMTs enables operation at high frequencies $(\geq 100 \mathrm{kHz})$, which yields smaller magnetics and passive components. This enables the integration of a complete system (switches, magnetics, and passive components) on a single board. One of the key challenges in designing power 
converters with GaN HEMTs is the low gate capacitance, which makes the switch vulnerable to oscillations at the gate (because of stray PCB inductance), which can lead to false turn-on since the threshold voltage of the eGaN HEMT is only $1.45 \mathrm{~V}$. This problem can be minimized by optimally designing the PCB and minimizing the stray inductances. The clean experimental results verify the proper operation of the system. 


\section{Chapter 12 Power Electronic Building Blocks Using Series-Stacked GaN eHEMT Modules}

\subsection{Introduction}

The Power Electronic Building Block (PEBB) is a generic power electronic converter circuit that can be configured in different ways to synthesize popular power electronic architectures (DC-DC, DC-AC, AC-DC, and AC-AC converters). This can reduce the number of spare parts needed onboard a ship, plane, ... etc., also the PEBB can reduce the manufacturing cost of the power electronic systems since the mass production of one generic power electronic architecture is more economical than producing application-specific power electronic architectures. Many literature have discussed different possible architectures for the PEBB, however, all of them are either implemented using Silicon (Si), or Silicon Carbide (SiC) Metal Oxide Field Effect Transistors (MOSFETs) or Insulated Gate Bipolar Junction Transistors (IGBTs), which suffer from high conduction and switching losses. A PEBB is built with Gallium Nitride (GaN) High Electron Mobility Transistors (HEMTs) to reduce the conduction and switching losses of the transistors, since the GaN HEMTs have lower on resistance $\left(R_{\text {on }}\right)$ and less device total charge. The major problem with GaN HEMTs is that their break down voltage is relatively lower compared to Si and SiC MOSFETs or IGBTs, which limits the utilization of GaN HEMTs to the low voltage applications. Multilevel half-bridge configurations can enable the utilization of GaN HEMTs in high voltage applications. These multilevel half-bridge configurations can possibly be based on a flying capacitor (FC) leg (as shown in Figure 12.1(a)) or a neutral point clamped (NPC) leg (as 
shown in Figure 12.1(b)). The major problem of multilevel configurations is that they require a complex control scheme and more switches (as in the NPC) or more high voltage capacitors (as in the FC). In this patent application, a two level half-bridge-based PEBB is built with series-stacked GaN HEMTs. A Series-Switch-Driver (SSD) is utilized to balance out the voltage sharing between the series-stacked GaN HEMTs during transitions (turn on and turn off) and during steady state. The presented GaN-based PEBB has the capability to work at high voltages with high efficiency and require a simple control scheme.

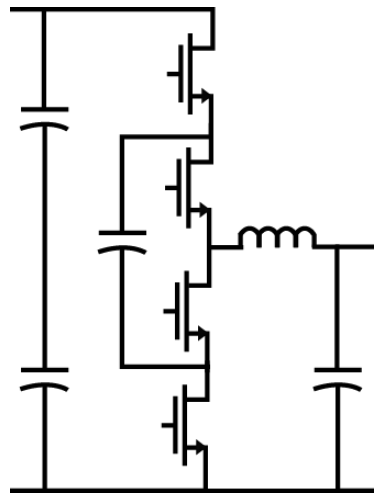

(a)

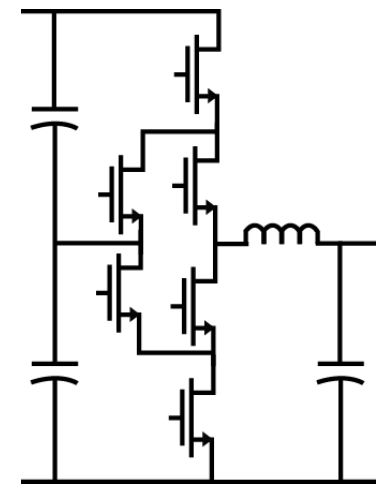

(b)

Figure 12.1: Possible multilevel half-bridge-based PEBBs.

\subsection{Examples of the Existing Half-Bridge PEBBs}

\subsubsection{Two Level Half-Bridge-Based PEBBs Using Si/SiC MOSFETs/IGBTs}

The two level half-bridge-based PEBB is composed of two transistors, these transistors can be either Si or SiC MOSFETs (shown in Figure 12.2(a)) or IGBTs (shown in Figure 12.2(b)).

This PEBB architecture is limited by the rated voltage of the transistors and suffers from high switching and conduction losses. 


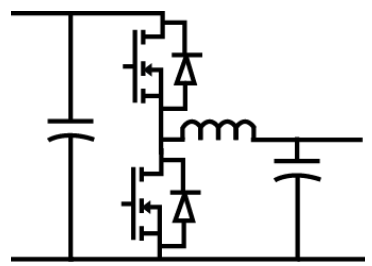

(a)

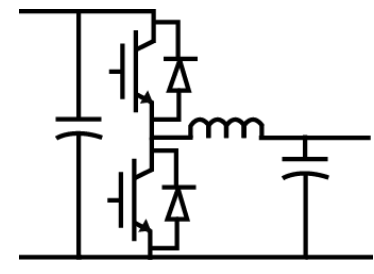

(b) symbol

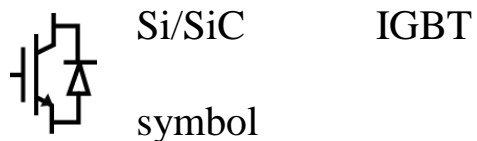

Figure 12.2: Two level half-bridge-based PEBB.

\subsubsection{Two Level Half-Bridge-Based PEBB Using GaN HEMTs.}

A two level half-bridge-based PEBB is built with GaN HEMTs to reduce the switching and conduction losses. The major problem of this PEBB is that the rated voltage is limited by the rated voltage of the GaN HEMTs utilized in the circuit.
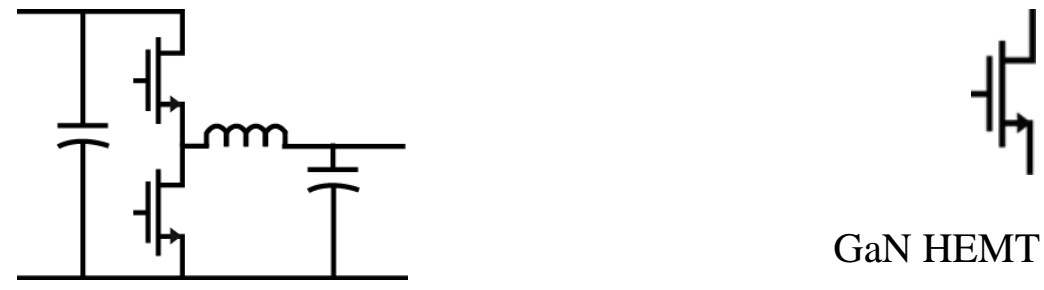

GaN HEMT symbol

Figure 12.3: Two level half-bridge-based PEBB Using GaN HEMTs.

\subsubsection{Multilevel NPC-Based PEBBs Using Si/SiC MOSFETs/IGBTs}

As a solution to extend the operating voltage of the PEBB beyond the rated voltage of the single transistors, a multilevel NPC half-bridge can be a PEBB.

The rated voltage of this $\mathrm{PEBB}=($ number of levels -1$) \times$ rated voltage of each transistor.

A NPC half-bridge-based PEBB built with SiC MOSFETs is presented. This NPC can be built with Si/SiC MOSFETs (as shown in Figure 12.4(a)), Si/SiC IGBTs (as shown in Figure 12.4(b)), or GaN HEMTs (as shown in Figure 12.1(b)). The major disadvantages of this PEBB architecture:

- Requires high number of semiconductor devices. 
- Requires a complex control scheme.

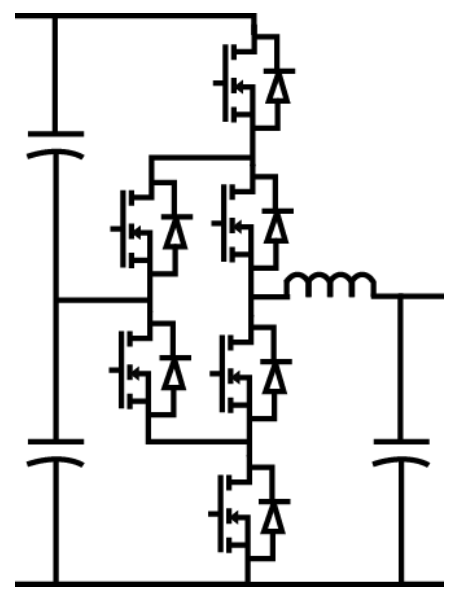

(a)

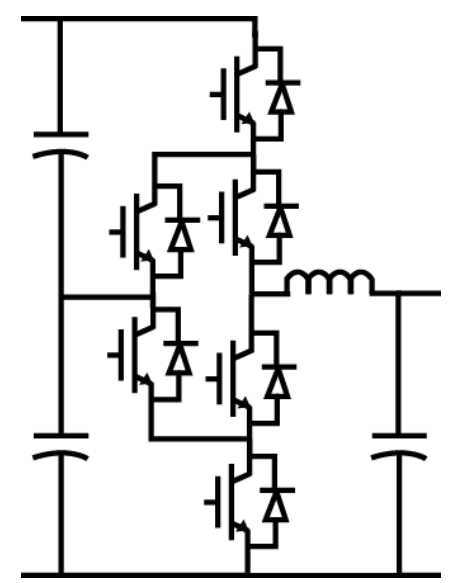

(b)

Figure 12.4: NPC-based PEBB, (a) Using Si/SiC MOSFETs. (b) Using Si/SiC IGBTs.

\subsubsection{Multilevel FC-Based PEBB Using Si/SiC MOSFETs/IGBTs}

Another architecture that can be used to extend the rated voltage of the PEBB beyond the rated voltage of the single transistors is a FC half-bridge-based PEBB, where a FC half-bridge is used as a PEBB.

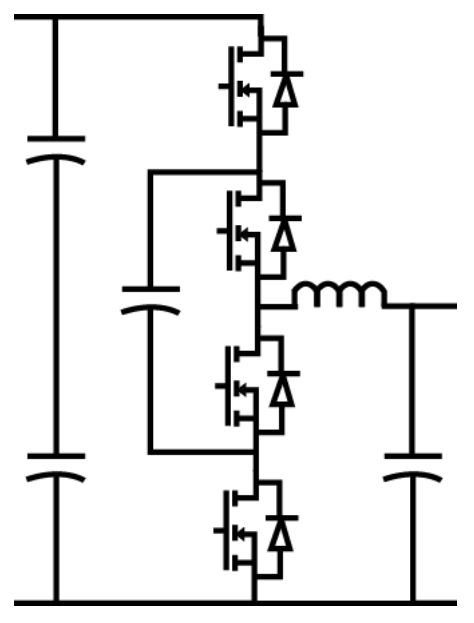

(a)

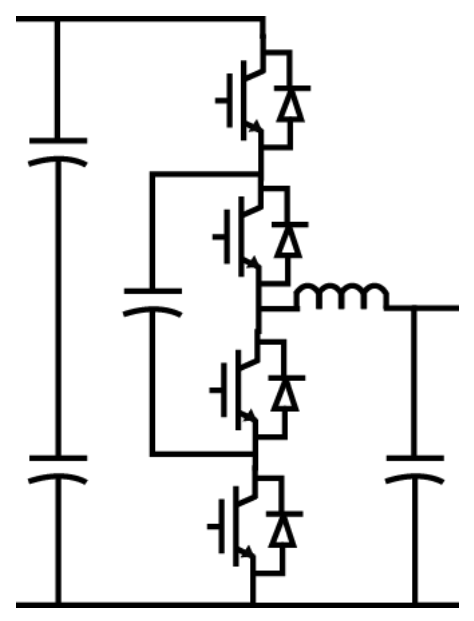

(b)

Figure 12.5: FC-based PEBB, (a) Using Si/SiC MOSFETs. (b) Using Si/SiC IGBTs. 
The rated voltage of this $\mathrm{PEBB}=($ number of levels -1$) \mathrm{X}$ rated voltage of each transistor. This NPC can be built with $\mathrm{Si} / \mathrm{SiC}$ MOSFETs (as shown in Figure 12.5(a)), Si/SiC IGBTs (as shown in Figure 12.5(b)), or GaN HEMTs (as shown in Figure 12.1(a)). The major disadvantages of this PEBB architecture:

- $\quad$ Requires high number of high-voltage capacitors, which increases the weight and size.

- Requires a complex control scheme.

\subsection{The proposed PEBB Using Series-Stacked GaN HEMTs}

The proposed PEBB is presented in figure 12.6. Series-stacked GaN HEMTs with an SSD form a GaN module that is driven via only one gate pin (more details about the structure of the GaN module and its SSD are presented in section 12.4). The proposed PEBB is based on a half-bridge where it is composed of two GaN modules (upper module and lower module), two high voltage capacitors, a power inductor, and power terminals. Possible power electronic architectures that can be synthesized with the proposed PEBB are shown in section 12.5.

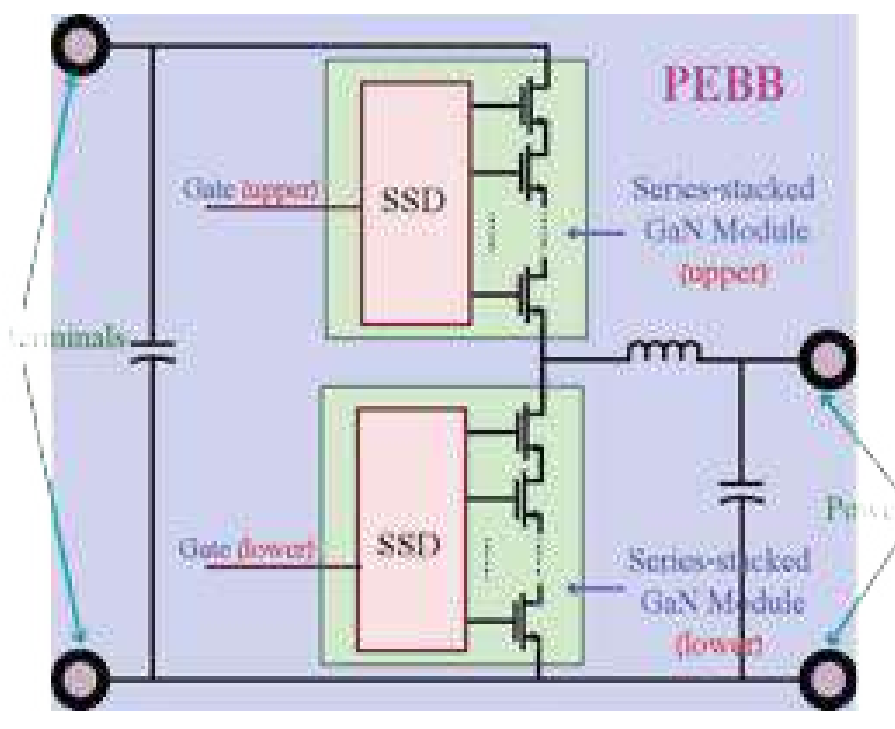

Figure 12.6: The proposed PEBB using series-stacked GaN modules. 


\subsection{The Series-Switch-Driver (SSD)}

The SSD structure is developed to drive series-connected GaN HEMTs (constructing one GaN module). This SSD needs a single gate power supply and one Pulse Width Modulation (PWM) pin is required to drive the GaN module. The operation of the SSD can be explained in two major ways. Firstly, it gives gate charge of the HEMTs during turn-on with a minimum propagation delay between the gate-source potentials of the HEMTs. Secondly, the developed SSD assures balanced voltage sharing between the switches during switching transients and in the off state. Figure 12.7 shows the structure of a two-series-stacked-GaN-switch module and the embedded SSD. Each component of the SSD makes a specific task. The resistors $\mathrm{R}_{\mathrm{s} 1}$ and $\mathrm{R}_{\mathrm{s} 2}$ which are parallel connected with the switches ensures similar voltage sharing between the HEMTs during the off state. The voltage deviation of the HEMTs in this period is associated with the difference between the HEMTs leakage current and also unbalanced voltage at the end of the turn-off period. The capacitor $\mathrm{C}_{\mathrm{d} 1}$ provides the turn-on gate charge of the upper HEMT. This capacitor along with the capacitor $\mathrm{C}_{\mathrm{d} 2}$ are the tools to regulate the variation speed of the HEMTs drain-source voltage $\left(\mathrm{dV}_{\mathrm{ds}} / \mathrm{dt}\right)$ to end up with balanced voltage sharing during switching transitions. The Zener diodes $\mathrm{Z}_{\mathrm{d} 1}$ and $\mathrm{Z}_{\mathrm{d} 2}$ are used to clamp the gatesource voltage at a specified voltage, and the Ferrite Beads $\mathrm{FB}_{1}$ and $\mathrm{FB}_{2}$ and the resistor $r$ damp the ringing in the gate-source voltage. The location and value of the resistor $r$ and the FB specifications depend on the ringing of the gate-source voltage which itself is caused by the parasitic inductance of the gate loop. The FB1 is used in the turn-off loop of the upper HEMT since in this configuration, the gate voltage ringing occurred just in the turn-off transition. If the ringing is also observed in the turn-on transition, the FB2 will be connected in series with resistor $r$. The ferrite beads FB1 and FB2 are specified by their impedance at $100 \mathrm{MHz}$ 
and the appropriate FBs are selected based on the amplitude and the frequency of the gate voltage ringing.

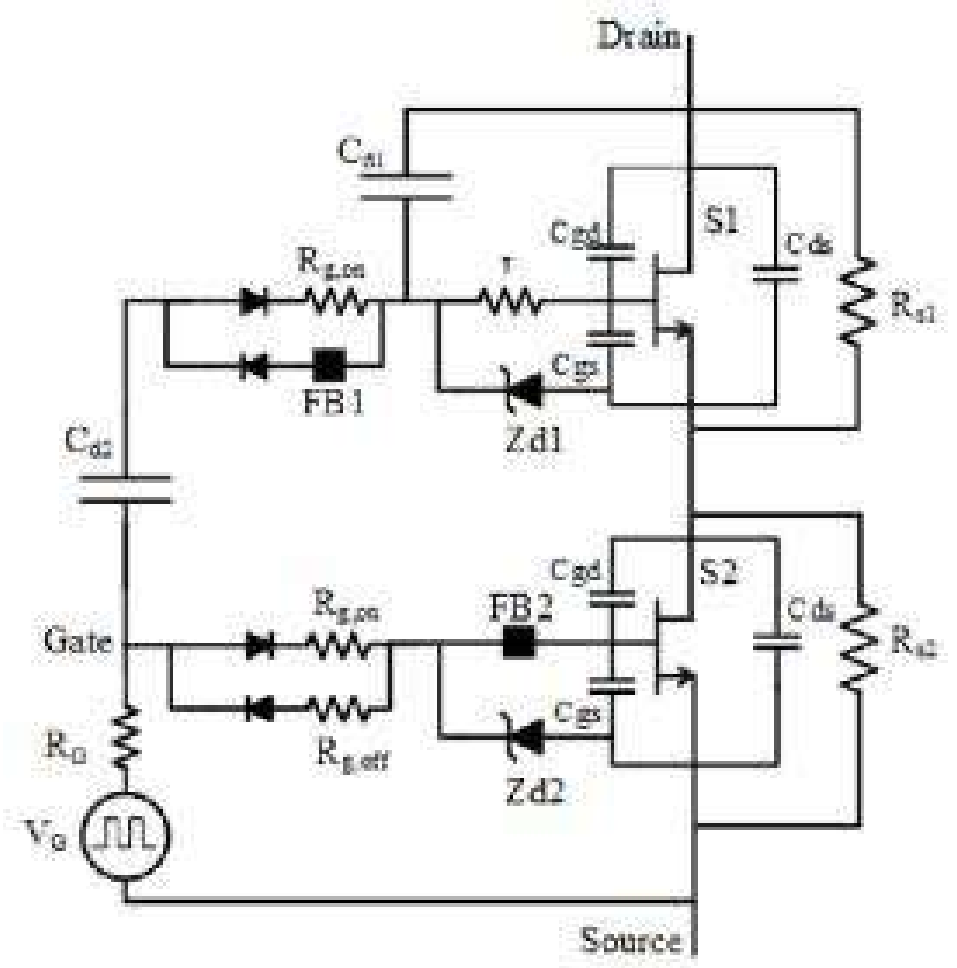

Figure 12.7: A GaN module of two HEMTs and the SSD.

To ensure the proper turning-on process of the upper HEMT, a minimum value of $\mathrm{C}_{\mathrm{d} 2}$ is required which depends on the required gate charge of the HEMT. As $\mathrm{C}_{\mathrm{d} 2}$ increases, the variation slope of the drain-source voltage $\left(\mathrm{V}_{\mathrm{ds}}\right)$ of the lower HEMT during switching transitions decreases which in turn results in longer switching period and higher switching loss. The variation slope of $\mathrm{V}_{\mathrm{ds} 1}$ and $\mathrm{V}_{\mathrm{ds} 2}$ during the turn-on transition can be calculated using the following equations.

$$
\frac{d v_{d s 2}(t)}{d t}=\frac{\left(V_{G}-V_{g s, p}\right)}{\frac{Q_{G D}}{V_{D S}}\left(R_{G}+R_{g, o n 1}\right)+R_{G} C_{d 2}}
$$




$$
\frac{d v_{d s 1}(t)}{d t}=\frac{C_{d 2}}{\left(C_{d 1}+\frac{Q_{G D}}{V_{D S}}\right)} \frac{\left(V_{G}-V_{g s, p}\right)}{\left(\frac{Q_{G D}}{V_{D S}}\right)\left(R_{G}+R_{g, o n 1}\right)+R_{G} C_{d 2}}
$$

Where $V_{g s, p}, Q_{G D}$ and $R_{G}$ represent the Miller plateau voltage, the total gate-drain charge of the HEMT and the internal resistor of the gate driver, respectively.

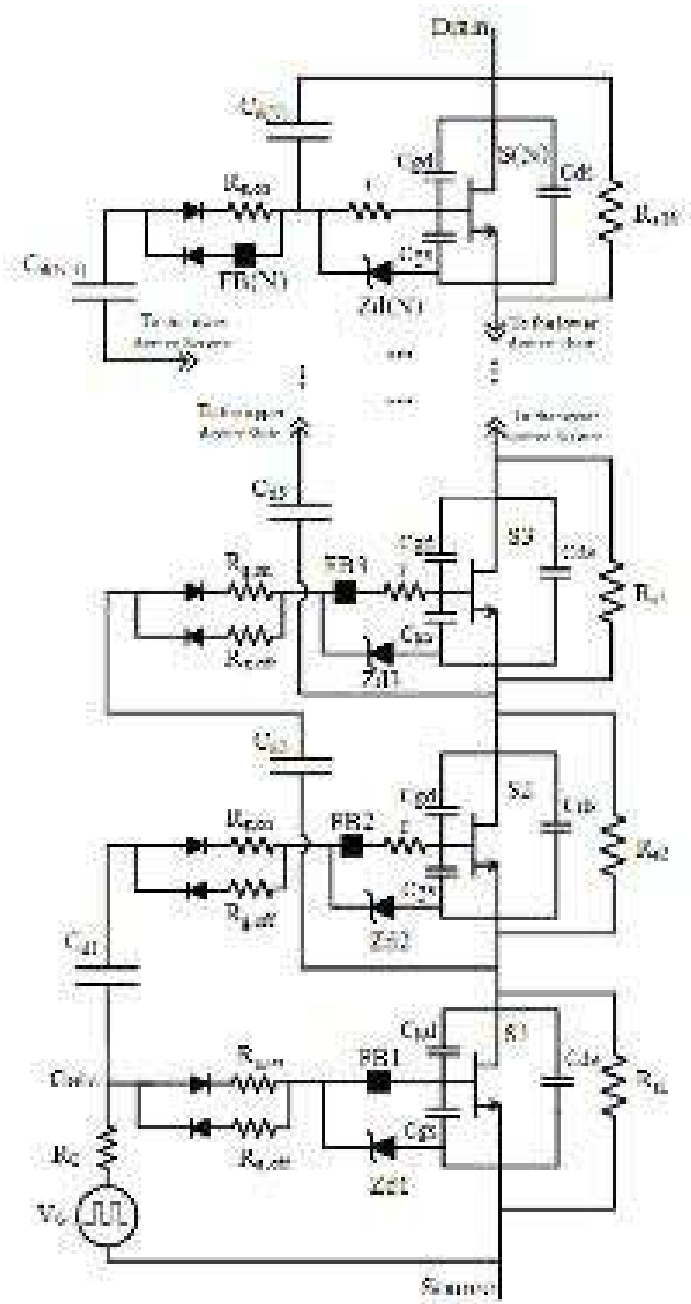

Figure 12.8: A GaN module of more than two HEMTs and the SSD. 
Based on (5) and (6), one can conclude that the higher values of the resistors $R_{G}$, and $R_{g, o n 1}$ result in lower $\frac{d v_{d s}}{d t}$. Moreover, bigger $C_{d 1}$, and $C_{d 2}$ also cause lower $\frac{d v_{d s 1}}{d t}$ and $\frac{d v_{d s 2}}{d t}$, respectively. The described idea for sharing the voltage between two HEMT s can be extended for multiple HEMTs. In this procedure, the main concern is to provide enough gate charge for the upper HEMTs to reach a sufficient gate voltage so that the HEMT is fully turned on. This is required to ensure that the HEMT is operating in the resistive (linear) region with a very low $\mathrm{R}_{\text {on }}$ and consequently low on-state power loss. As the number of HEMTs in the stack exceeds two, this task becomes more challenging. An additional circuit can be used to provide gate charge for the upper HEMTs. In this circuit, a boost capacitor feeds additional charge to the upper HEMTs after the turn-on transition so that a sufficient gate voltage is achieved.

A series-stacked GaN module with more than two GaN HEMTs is presented in Figure 12.8. In this circuit, the gate charge of the third HEMT is provided through $\mathrm{C}_{\mathrm{d} 2}$ which is connected between the gate of the third HEMT and the source of the second HEMT. Similarly, the capacitor $\mathrm{C}_{\mathrm{d}(\mathrm{i}-1)}$ is responsible for the turn-on gate charge of the $\mathrm{i}^{\text {th }}$ HEMT. The stored charge of the capacitor $\mathrm{C}_{\mathrm{d}(\mathrm{i}-1)}$ itself is fed from the load current during the turn-off transition. On the other hand, this capacitor controls the variation rate of the drain-source voltage of the (i-1 $)^{\text {th }}$ HEMT during the switching transitions.

Another challenge in the extension of the series-stacked HEMTs in the GaN module is to ensure voltage balance between the HEMTs specifically the upper HEMTs. There is a slight delay between the gate-source voltages of two adjacent HEMTs, so the delay between the first and the last HEMT would be the summation of all of the adjacent HEMT delays. This delay between the gate voltages of the HEMTs, causes a delay between the times at which the drain-source 
voltages of the HEMTs starts to increase in the turn-off period. The first HEMT waveforms lead those of the last HEMT. In order to compensate for this delay, the $d V_{d s} / d t$ of the first HEMT should be slowed down so that the $\mathrm{V}_{\mathrm{ds}}$ of the both HEMTs reaches their final values at the same time and consequently balanced voltage across the HEMTs at the end of the turn-off period and during the off state of the HEMTs will be guaranteed. To achieve this goal, higher value of $\mathrm{C}_{\mathrm{d} 1}$ (and similarly $\mathrm{C}_{\mathrm{d}(\mathrm{i})}$ ) is needed which in turn prolongs the switching transition. Thus, when using large number of HEMTs in series, to ensure balanced voltage across all of the HEMTs, longer switching transitions will be resulted. Consequently, there is a tradeoff between the number of series-stacked HEMTs and the switching loss and the switching frequency.

\subsection{Possible PEBB Systems}

In this section examples of possible power electronic architectures synthesized with the proposed PEBB are illustrated. For each example the connection diagram is presented along with the circuit (for better illustration).

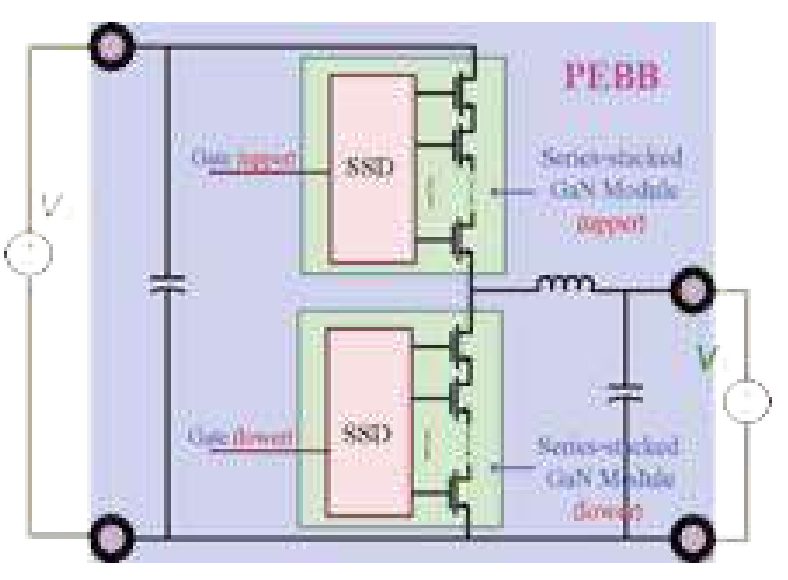

(a)

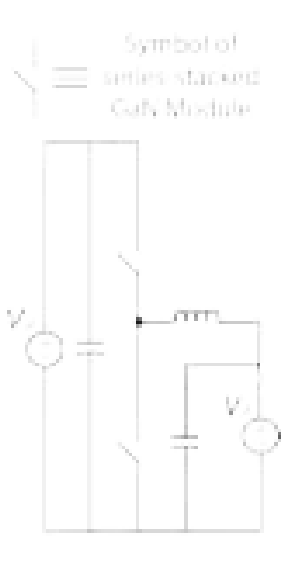

(b)

Figure 12.9: A synchronous buck DC-DC converter (a) Connection diagram. (b) Circuit. 


\subsubsection{Synchronous Buck DC-DC Converter}

A synchronous buck converter can be synthesized with one PEBB, where a source is connected as $\mathrm{V}_{2}$ and a load is connected as $\mathrm{V}_{1}$ (buck mode), or a source is connected as $\mathrm{V}_{1}$ and a load is connected as $\mathrm{V}_{2}$ (boost mode). Figure 12.9(b) shows the circuit diagram of a synchronous buck converter, and Figure8 (a) shows the connection diagram of a synchronous buck converter.

\subsubsection{Bidirectional Inverting Buck-Boost DC-DC Converter}

A bidirectional inverting buck-boost converter can be synthesized with one PEBB, where a source is connected as $\mathrm{V}_{2}$ or $\mathrm{V}_{1}$, and the load is connected as $\mathrm{V}_{1}$ or $\mathrm{V}_{2}$, respectively.

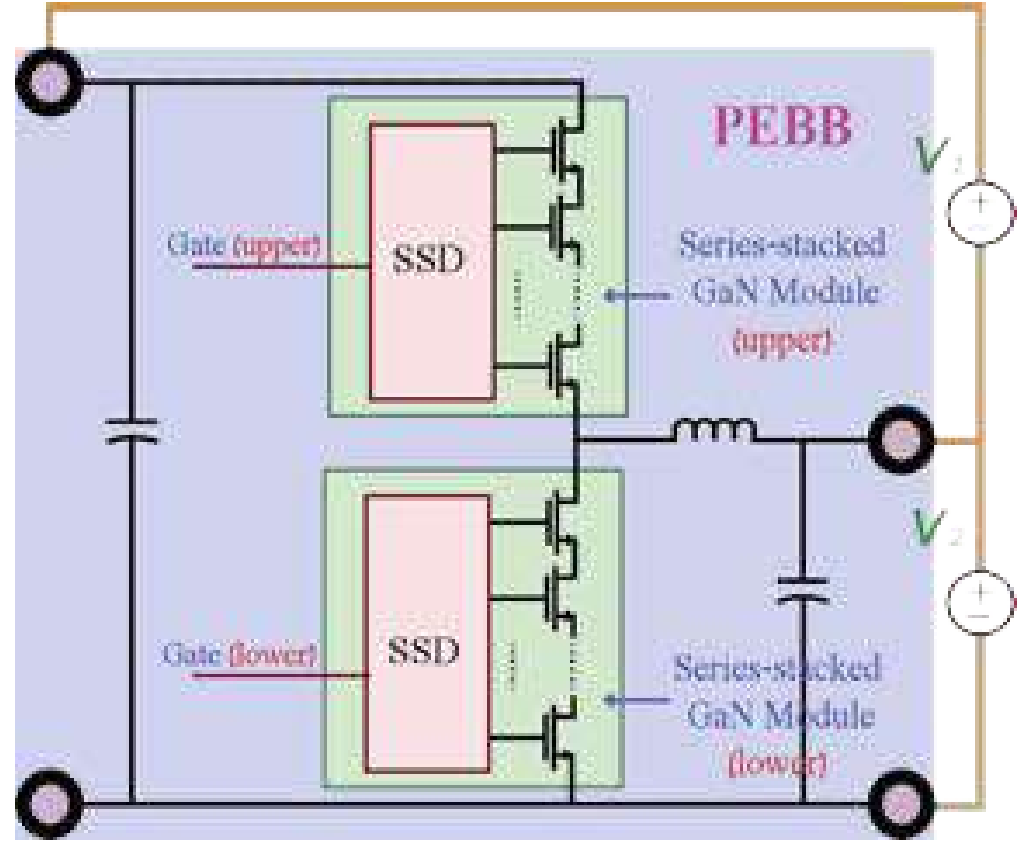

(a)

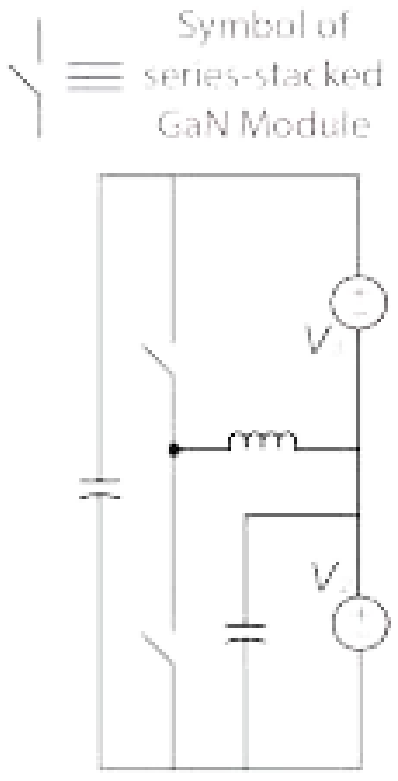

(b)

Figure 12.10: A bidirectional inverting buck-boost DC-DC converter (a) Connection diagram. (b) Circuit.

\subsubsection{Bidirectional Non-Inverting Buck-Boost DC-DC Converter}

A bidirectional non-inverting buck-boost converter can be synthesized with two PEBBs, where a source is connected as $\mathrm{V}_{2}$ or $\mathrm{V}_{1}$, and the load is connected as $\mathrm{V}_{1}$ or $\mathrm{V}_{2}$, respectively. Figure 
12.11(b) shows the circuit diagram of a bidirectional non-inverting buck-boost converter, and Figure 12.11(a) shows the connection diagram of a bidirectional non-inverting buck-boost converter.

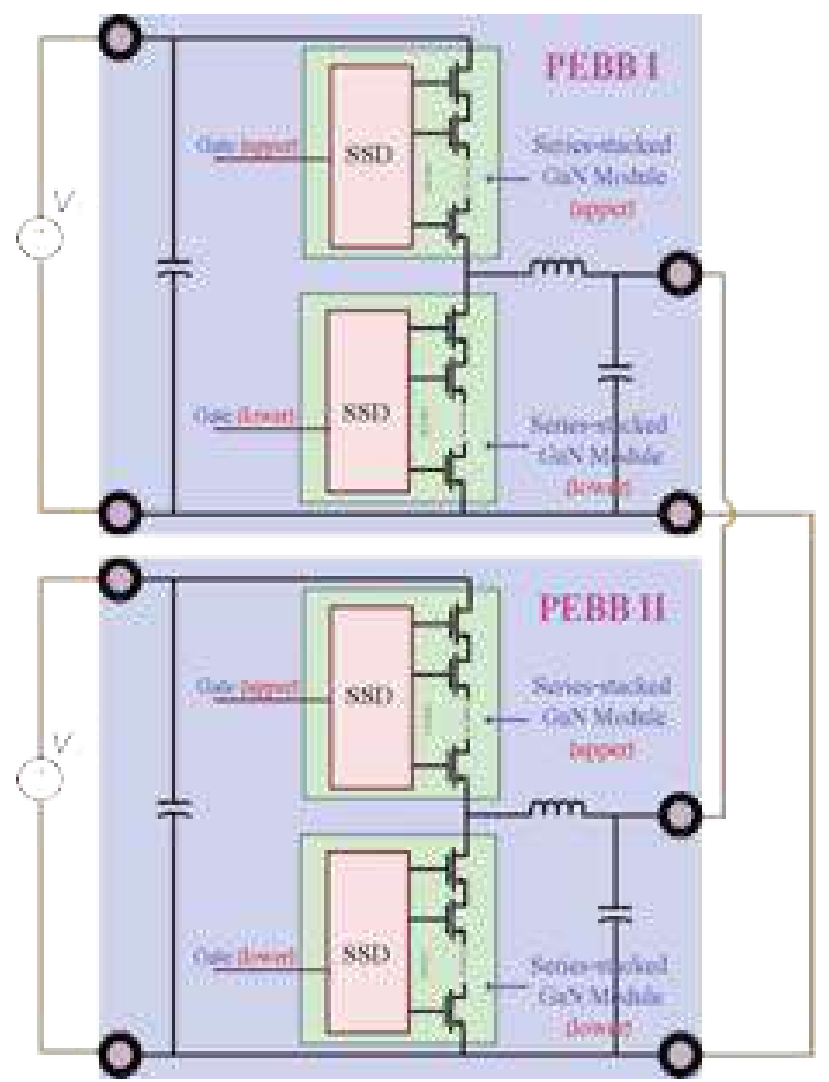

(a)

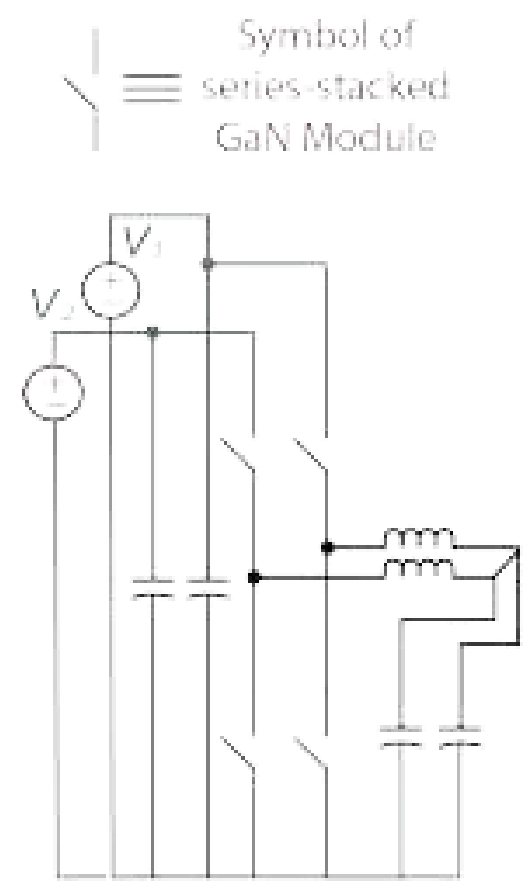

(b)

Figure 12.11: A bidirectional non-inverting buck-boost DC-DC converter (a) Connection diagram. (b) Circuit.

\subsubsection{Single-Phase Buck DC-AC Inverter}

A single-phase buck inverter can be synthesized with two PEBBs, where a dc source is connected as $\mathrm{V}_{1}$, and the ac load is connected as $\mathrm{V}_{2}$. Figure 12.12(b) shows the circuit diagram of a singlephase buck inverter, and Figure 12.12(a) shows the connection diagram of a single-phase buck inverter. 


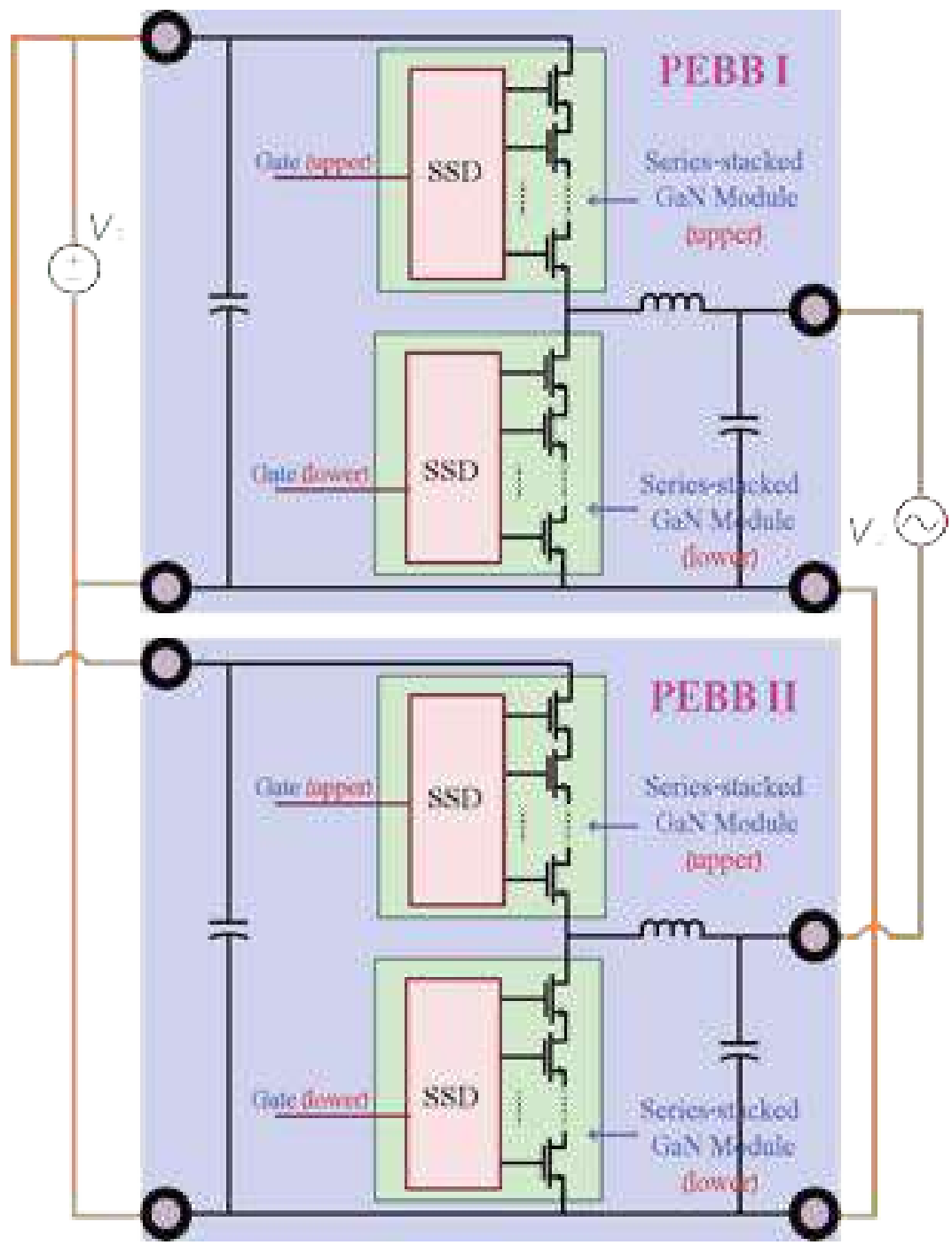

(a)

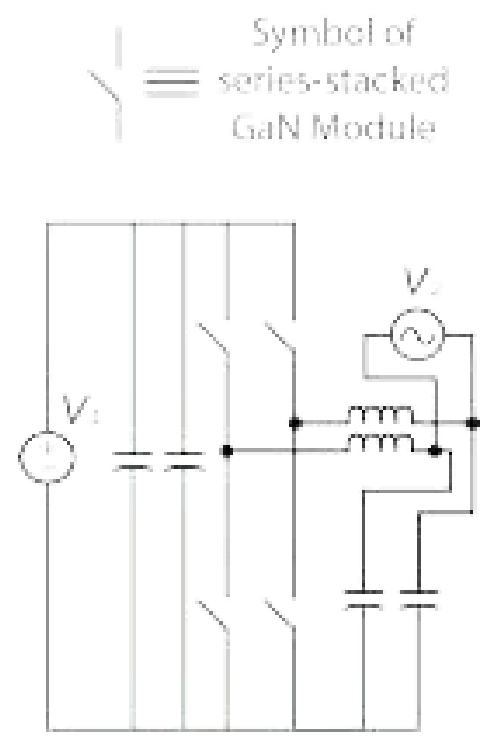

Figure 12.12: A single-phase buck DC-AC inverter (a) Connection diagram. (b) Circuit.

\subsubsection{Single-Phase Boost DC-AC Inverter}

A single-phase boost inverter can be synthesized with two PEBBs, where a dc source is connected as $\mathrm{V}_{1}$, and the ac load is connected as $\mathrm{V}_{2}$. Figure 12.13(b) shows the circuit diagram of a single-phase boost inverter, and Figure 12(a) shows the connection diagram of a single-phase boost inverter. 


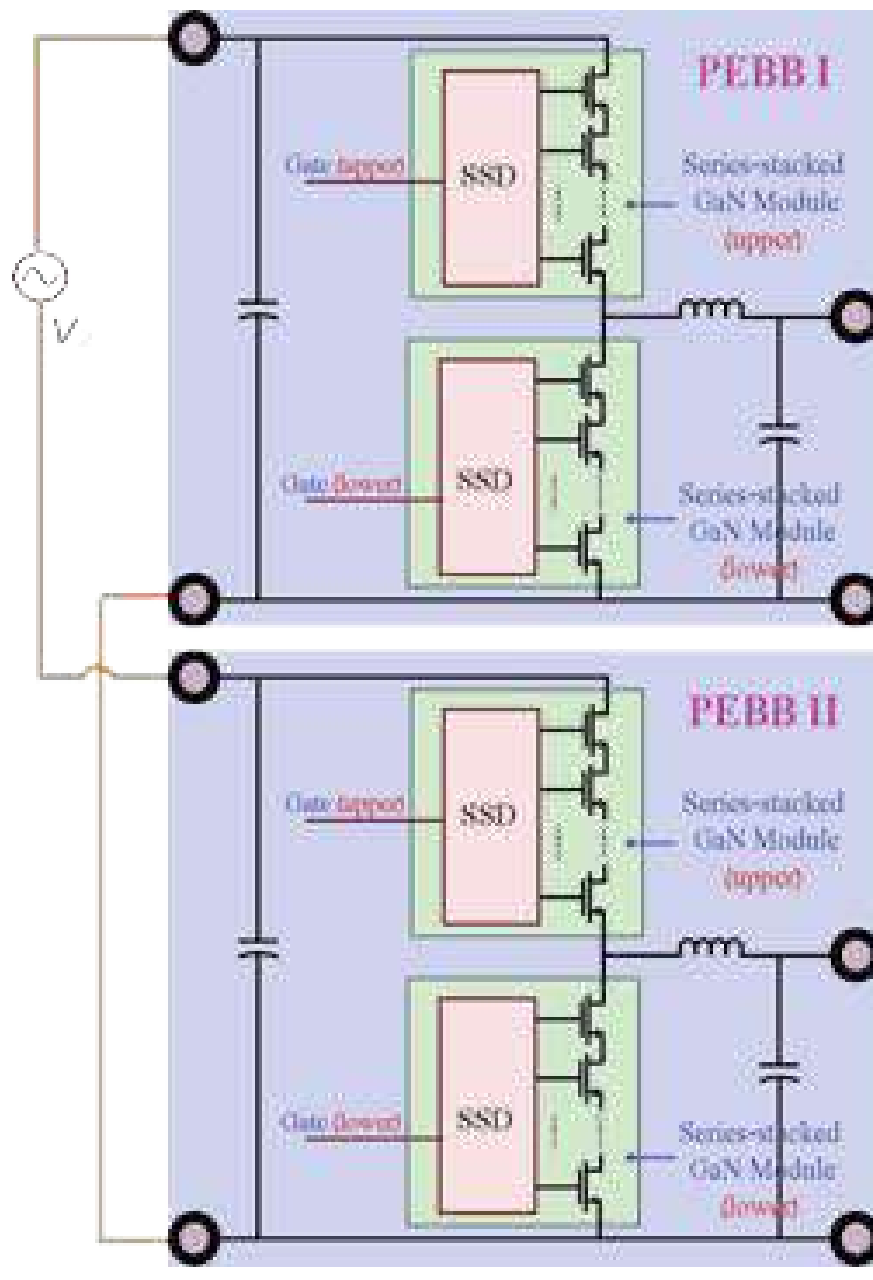

(a)

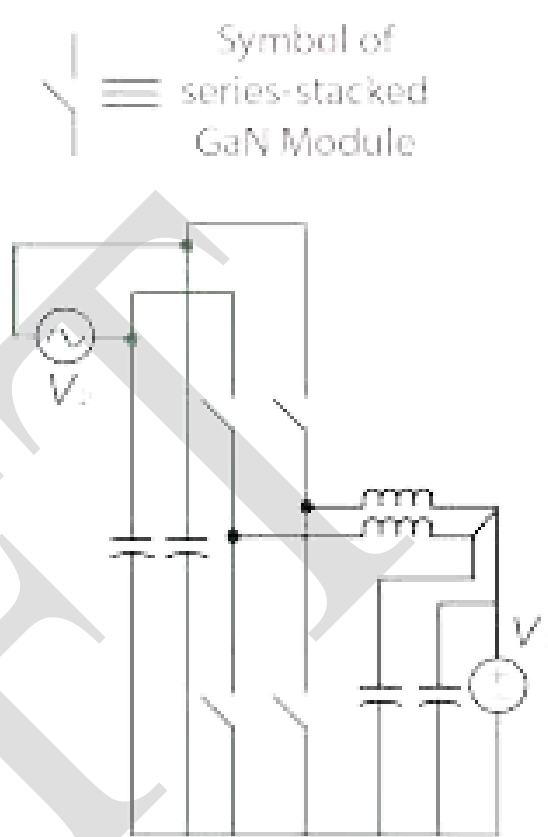

(b)

Figure 12.13: A single-phase boost DC-AC inverter (a) Connection diagram. (b) Circuit.

\subsubsection{Single-Phase Buck-Boost DC-AC}

A single-phase buck-boost inverter can be synthesized with two PEBBs, where a dc source is connected as $\mathrm{V}_{1}$, and the ac load is connected as $\mathrm{V}_{2}$. Figure 12.14(b) shows the circuit diagram of a single-phase buck-boost inverter, and Figure 12.14(a) shows the connection diagram of a singlephase buck-boost inverter. 


\subsubsection{Three-Phase Buck DC-AC Inverter}

A three-phase buck inverter can be synthesized with three PEBBs, where a dc source is connected as $\mathrm{V}_{1}$, and the three ac loads are connected as $\mathrm{V}_{\mathrm{a}}, \mathrm{V}_{\mathrm{b}}$, and $\mathrm{V}_{\mathrm{c}}$. Figure 12.15(b) shows the circuit diagram of a three-phase buck inverter, and Figure 12.15(a) shows the connection diagram of a three-phase buck inverter.

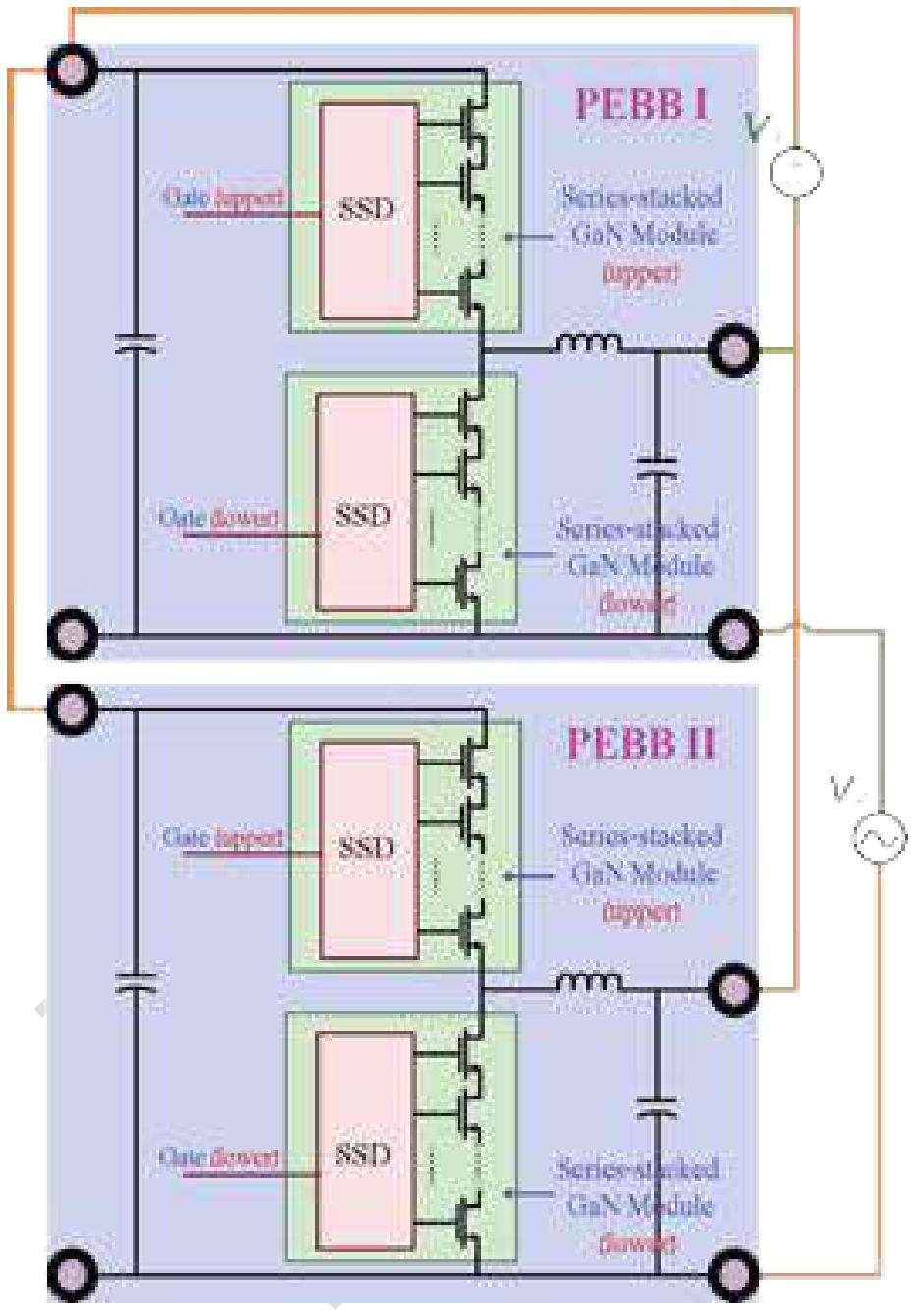

(a)

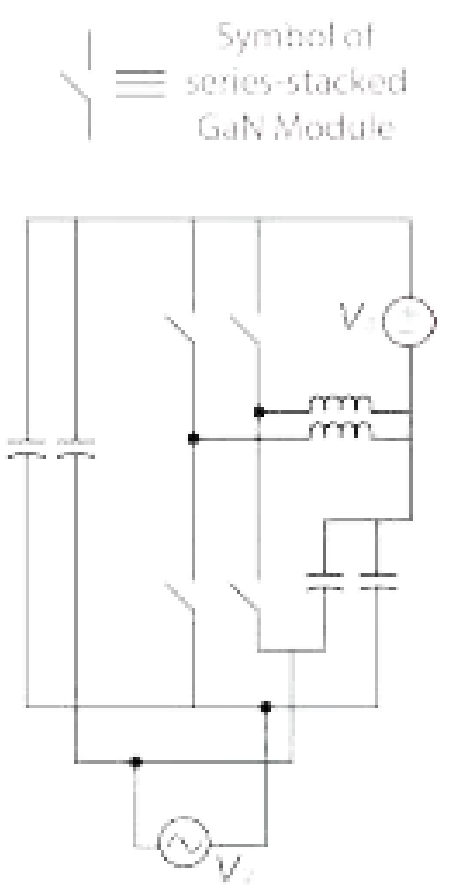

(b)

Figure 12.14: A single-phase buck-boost DC-AC inverter (a) Connection diagram. (b) Circuit. 


\subsubsection{Three-Phase Buck-Boost DC-AC Inverter}

A three-phase buck-boost inverter can be synthesized with three PEBBs, where a dc source is connected as $\mathrm{V}_{1}$, and the three ac loads are connected as $\mathrm{V}_{\mathrm{a}}, \mathrm{V}_{\mathrm{b}}$, and $\mathrm{V}_{\mathrm{c}}$.

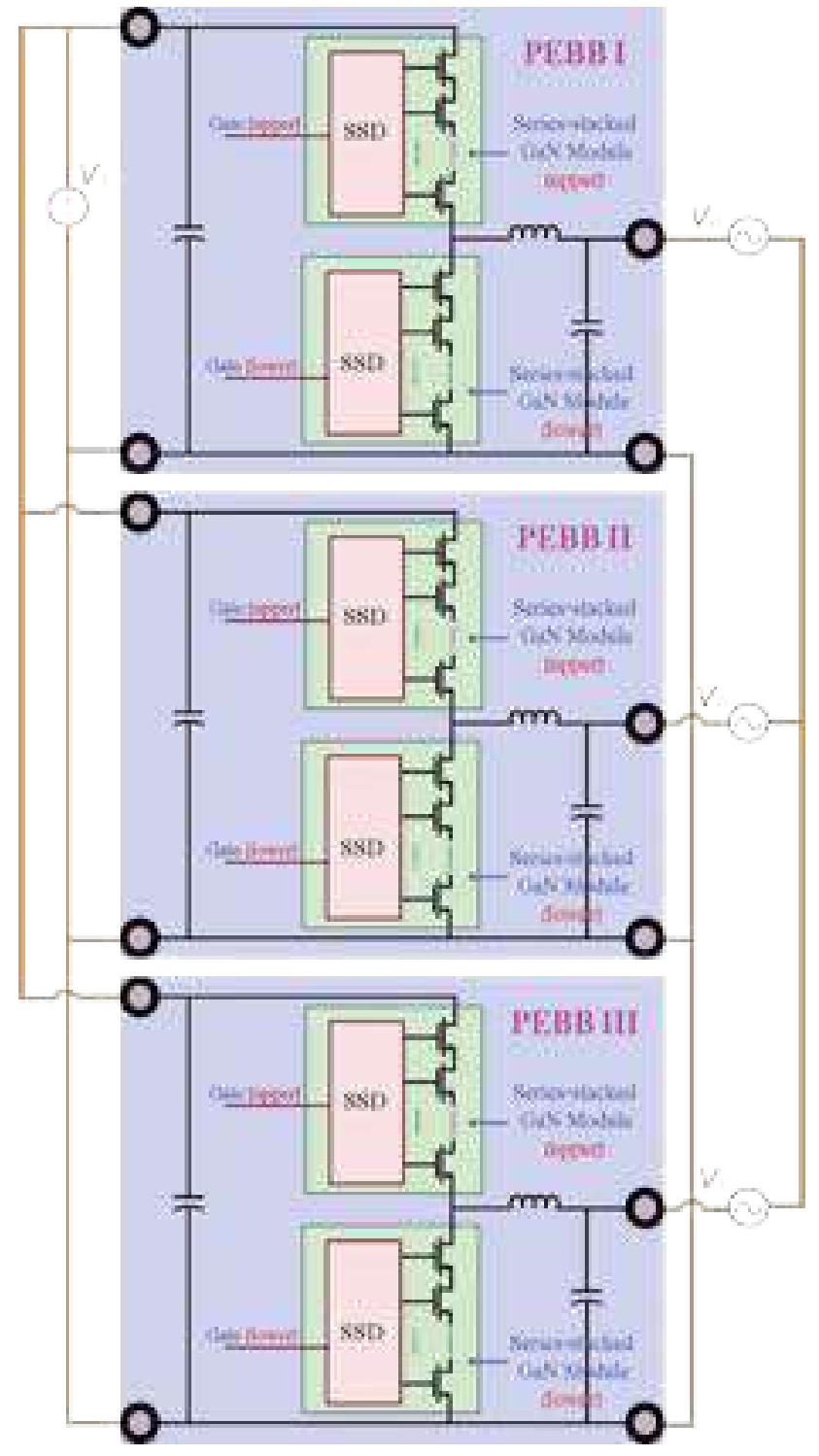

(a)

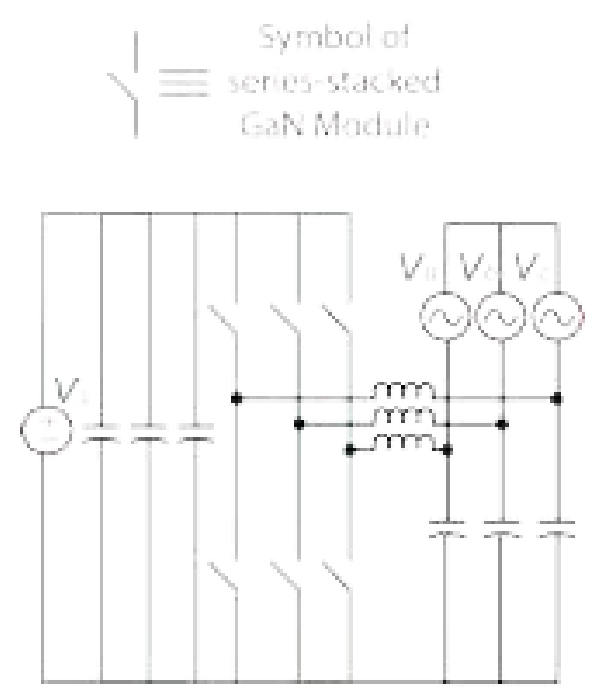

(b)

Figure 12.15: A three-phase buck DC-AC inverter (a) Connection diagram. (b) Circuit. 
Figure 12.16(b) shows the circuit diagram of a three-phase buck-boost inverter, and Figure 12.16(a) shows the connection diagram of a three-phase buck-boost inverter.

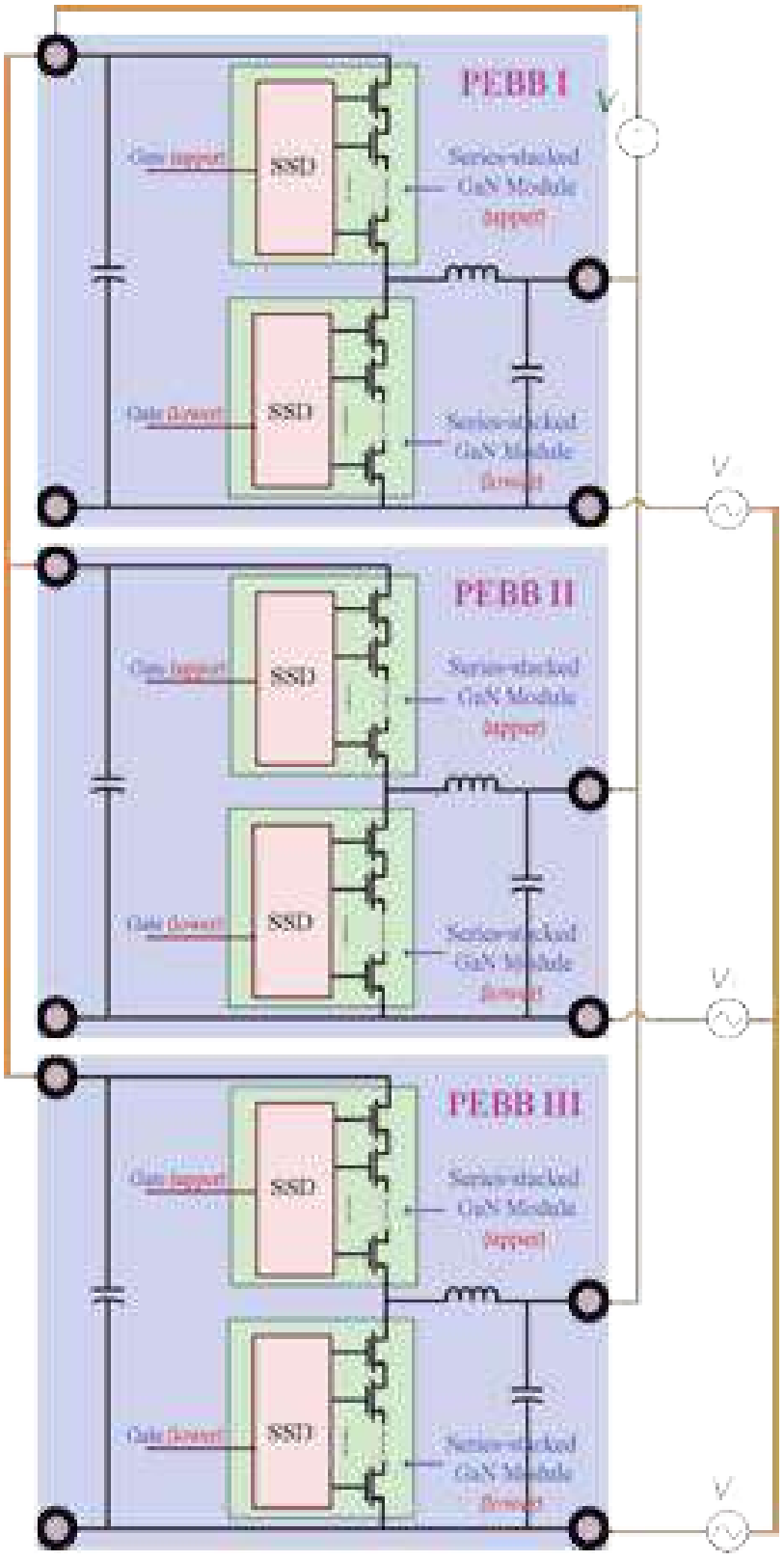

(a)

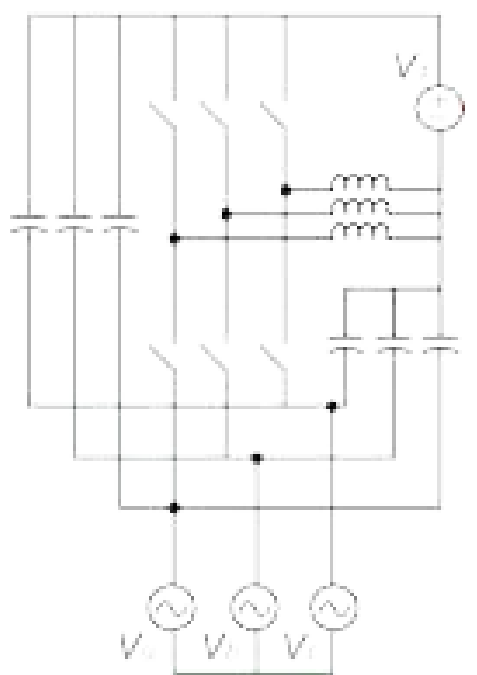

(b)

Figure 12.16: A three-phase buck-boost DC-AC inverter (a) Connection diagram. (b) Circuit. 


\subsection{Conclusion}

In this chapter a new power electronic building block with series-stacked $\mathrm{GaN}$ modules using a series-switch driver. The developed structure has high efficiency, reduced system cooling requirement, high power density, high specific power, simple control since it is driven as a simple two-level push-pull leg, each GaN module requires only one gate driving signal, and the rated voltage of the PEBB can be extended systematically by increasing the number of series GaN HEMTs in the GaN Module. 


\section{Chapter 13 Conclusions and Future Work}

\subsection{Conclusions}

The dissertation provided different cost-effective solutions to allow the wide-bandgap devices (i.e. Gallium Nitride and Silicon Carbide devices) to be utilized in high power applications such as microgrids, electrified means of transportation, and renewable energy systems. These solutions are based on developing new power converter topologies and high voltage series-stacked widebandgap switching modules.

Firstly, the technique of series stacking of the active switches extends the breakdown voltage of the power switch, thus, can be directly utilized for high voltage applications. Typically, seriesstacking of the power switches is either done via an active gate driver or passive snubber circuits. The active gate driver requires an additional control circuit to control the adequate charges injected into the gate of each switch in the series array. This solution is complicated and increases the cost of the switching module. The passive snubber solution utilizes a passive branch that is composed of a capacitor and a resistor in order to balance out the voltage stress across the series-connected switches. This approach has a simple circuit structure, nevertheless, it increases the conduction losses of the switching module. In addition, it slows down the turn-on and turn-off transitions, hence, it increases the switching losses of the module. The solution discussed in this dissertation is based on a quasi-active driving circuit that is based on a number of low voltage capacitors, resistors, and diodes in order to inject adequate charges into the gate of each switch in the series array. The proposed circuit has a relatively less complex circuit structure compared to the active gate driver solution, and lower conduction and switching losses compared to the passive snubber solution. The simulation and experimental results showed that the proposed series connected 
switching module has equally shared voltage stresses across the single switches in the seriesconnected array.

Secondly, the topology of the power converter plays a very important and critical role in enabling the utilization of wide-bandgap devices in high power applications. The topology can reduce the voltage stresses on the semiconductor devices which allows devices with low rated voltage to be used in high voltage systems. Additionally, the converter topology can reduce the common mode noise of the converter by providing either a common ground or a constant potential difference between the ports of the converter, accordingly, the converter will require a more compact EMC filter.

In this dissertation, novel power converter topologies are proposed and analyzed. These converters are categorized into isolated and non-isolated topologies. The isolated topologies utilize a high frequency power transformer to provide galvanic isolation between the power sources and the load, distribute the voltage stress on the semiconductor devices, and provide high voltage conversion ratio. In this dissertation, two new isolated high-frequency ac (HFAC) link dc-ac converters are presented and analyzed. They have reduced number of switch count compared to the state-of-the-art isolated converters in literature. Additionally, the proposed isolated converter can support the voltage and frequency of the power grid during contingences. A new hysteresis current controller is proposed for the developed HFAC link converters. This current controller is simple and enhances the dynamic performance of the system.

The non-isolated converter topologies do not require a magnetic coupling component to achieve high voltage conversion ratios, thus, they are more cost effective compared to the isolated ones. Additionally, the elimination of the magnetic coupling components allows the power converter to operate at relatively higher switching frequencies. In this dissertation, six new transformerless dc- 
dc converter topologies are proposed, discusses and compared with the state-of-the-art topologies in literature. Three of these new topologies are unidirectional power converters, while the other three are bidirectional.

The unidirectional converters have universal input voltage range and can be utilized for applications like photovoltaic and fuel cell systems. In the photovoltaic system application, the wide input range of the unidirectional power converter extends the allowed range of the maximum point power tracing (MPPT) which enhances the efficiency of the system. The universal input voltage of the unidirectional dc-dc converter is an important feature for fuel cells, as they have soft output characteristics where the output voltage drops drastically as the output current increases.

In this dissertation, three new unidirectional step-up dc-dc converters are proposed and discussed. The first one is based on the SEPIC converter with an integrated switched-capacitor cell and a discontinuous current quasi-Z-source network. This converter has a wide voltage gain, reduced voltage stress on the semiconductor devices a common ground between the input and output ports, and a continuous input current. The second converter also based on the SEPIC with an integrated dual-switched capacitor multiplier network. This converter has a higher voltage gain and lower voltage stress on its switches compared to the first converter. It also has a constant potential difference between the grounds of its ports which reduces the radiated EMI noise. The third converter utilizes the two multiplier networks used in the first two converters, as it integrates a dual-switched-capacitor multiplier and a discontinuous current quasi-Z-source network, and it has a high voltage gain and lower voltage stress on its semiconductor devices compared to the first two converters. In addition it has a continuous input current which prolongs the lifetime of the fuel cell and enhances the efficiency of the photovoltaic system. 
Additionally, three novel bidirectional dc-dc converters with wide voltage conversion ratios and reduced voltage stresses on the semiconductor devices are presented and discussed in this dissertation. These converters are excellent candidates for the applications that utilize energy storage systems with wide voltage swings, where the wide voltage conversion ratios of the dc-dc converter either increases the energy exchange from/to the energy storage system for the same capacitance, or reduces the required capacitance of the energy storage system to have the same energy exchange rate. The first converter is based on the bidirectional versions of the inverting buck-boost and Ćuk converters. This converter can perform buck and boost voltage conversion operations in both power flow directions. The second converter is based on the bidirectional version of the SEPIC converter with an integrated switched-capacitor network and an active discontinuous current quasi-Z-source network. It can perform buck operation in one power flow direction and boost operation in the other power flow direction. In addition, it has a common ground between the ports of the converter. This makes it an excellent candidate for microgrid and nanogrids applications. The third converter is based on a quadratic bidirectional converter structure with an integrated switched capacitor multiplier. It can achieve very high voltage conversion ratios which makes it suitable for applications like low voltage energy storage systems. In addition, it can be extended by integrating more than one switched-capacitor multiplier, in order to further extended the voltage conversion ratios of the converter and reduce the voltage stresses of the individual switches.

Finally, a high voltage series-stacked GaN switching module is proposed, thoroughly discussed, and experimentally validated in this dissertation. The switching module utilize a quasi-active gate driver in order to inject adequate charges into the gate of each $\mathrm{GaN}$ switch in the series-stacked array to make sure the voltage stress is equally shared among the switches. This technique has a 
simple circuit structure and does not need an extra controller, on the contrary with the seriesstacked module with active gate drivers. In addition, the quasi-active gate driver does not affect the efficiency of the module, on the contrary with the series-stacked modules with passive snubber circuits. The proposed technique of series-stacking extends the breakdown voltage of the commercial GaN devices which make them suitable candidates to high voltage applications such as electric vehicles and microgrid applications.

\subsection{Recommendations for Future Work}

This dissertation covered several aspects related to the extension of the operating voltage of the wide-bandgap devices via proposing new dc-dc converter topologies and synthesizing a high voltage series-stacked switching module using GaN transistors. Despite the proposed solutions in this dissertation and the influx of research activities on the topic of using wide-bandgap devices in high voltage dc-dc systems in recent years, a number of interesting questions are yet to be addressed properly and comprehensively.

Most of the works either ignored, or only partly addressed, the reliability of the high voltage power electronic systems built with wide-bandgap devices. The thermal performance of these systems especially in harsh working environments is a critical aspect of research and development that needs to be addressed properly.

Another pressing issue is the development of reliable high power ac-dc and dc-ac systems that can be used for traction applications. The utilization of wide-bandgap devices can have huge impact on the efficiency and performance of these systems since they have lower on resistance and lower device charges compared to their Silicon counterparts which result in lower conduction and switching losses. 
The series-stacked GaN switching module proposed in this dissertation is based on the GaN enhancement high electron mobility transistor. This devices have low on resistance and low device charges, nevertheless, they have low threshold voltage which make them susceptible to false turnon cases. The cascade GaN transistor solves this problem by integrating a low voltage Silicon MOSFET in series with a high voltage GaN depletion mode transistor as the Silicon MOSFET controls the turn-on and turn-off operations of the cascode switch, hence, the threshold voltage of the cascode GaN switch is higher compared to the enhancement GaN transistor. A high voltage series-stacked module with cascade GaN transistor should be investigated as it can be a better for high power applications in harsh environments. 


\section{List of References}

[1] K. Thirugnanam, S. K. Kerk, C. Yuen, N. Liu, and M. Zhang, "Energy Management for Renewable Microgrid in Reducing Diesel Generators Usage With Multiple Types of Battery," IEEE Trans. Ind. Electron., vol. 65, no. 8, pp. 6772 - 6786, Aug. 2018.

[2] S. Dasgupta, S. N. Mohan, S. K. Sahoo, and S. K. Panda, "Application of Four-Switch-Based Three-Phase Grid-Connected Inverter to Connect Renewable Energy Source to a Generalized Unbalanced Microgrid System," IEEE Trans. Ind. Electron., vol. 60, no. 3, pp. 1204 - 1215 , Mar. 2013.

[3] S. S. Refaat, H. Abu-Rub, A. P. Sanfilippo, and A. Mohamed, "Impact of grid-tied largescale photovoltaic system on dynamic voltage stability of electric power grids," IET Ren. Pow. Gen., vol. 12, no. 2, pp. 157 - 164, Feb. 2018.

[4] M. Bragard, N. Soltau, S. Thomas, and R. W. Doncker, "The Balance of Renewable Sources and User Demands in Grids: Power Electronics for Modular Battery Energy Storage Systems," IEEE Trans. Pow. Electron., vol. 25, no. 12, pp. 3049 - 3056, Dec. 2010.

[5] J. Pegueroles-Queralt, F. Bianchi, and O. Gomis-Bellmunt, "A Power Smoothing System Based on Supercapacitors for Renewable Distributed Generation," IEEE Trans. Ind. Electron., vol. 62, no. 1, pp. 343 - 350, Jan. 2015.

[6] T. Mai, M. M. Hand, S. F. Baldwin, R. H. Wiser, G. L. Brinkman, P. Denholm, D. J. Arent, G. Porro, D. Sandor, D. J. Hostick, M. Milligan, E. A. DeMeo, and M. Bazilian "Renewable Electricity Futures for the United States,” IEEE Trans. Sust. Ener., vol. 5, no. 2, pp. 372 -378, Apr. 2014.

[7] A. T. Langerudy, A. Mariscotti, and M. A. Abolhassani, "Power Quality Conditioning in Railway Electrification: A Comparative Study," IEEE Trans. Veh. Tech., vol. 66, no. 8, pp. 6653 - 6662, Aug. 2017.

[8] B. Lequesne, "Automotive Electrification: The Nonhybrid Story," IEEE Trans. Transp. Electrif., vol. 1, no. 1, Jun. 2015. 
[9] S. S. Raghavan, and A. Khaligh, "Electrification Potential Factor: Energy-Based Value Proposition Analysis of Plug-In Hybrid Electric Vehicles," IEEE Trans. Veh. Tech., vol. 61, no. 3, pp. 1052 - 1059, Mar. 2012.

[10] E. Du, N. Zhang, B. M. Hodge, Q. Wang, C. Kang, B. Kroposki, and Q. Xia, "The Role of Concentrating Solar Power Toward High Renewable Energy Penetrated Power Systems," IEEE Trans. Pow. Sys., vol. 33, no. 6, pp. 6630 - 6641, May 2018.

[11] J. Zhang, J. Jorgenson, T. Markel, and K. Walkowicz, "Value to the Grid From Managed Charging Based on California's High Renewables Study," IEEE Trans. Pow. Sys., vol. 34, no. 2, pp. 831 - 840, Mar. 2019.

[12] M. H. Nehrir, C. Wang, K. Strunz, H. Aki, R. Ramakumar, J. Bing, Z. Miao, and Z. Salameh, "A Review of Hybrid Renewable/Alternative Energy Systems for Electric Power Generation: Configurations, Control, and Applications," IEEE Trans. Sus. Ener., vol. 2, no. 4, pp. 392 -403 , Oct. 2011.

[13] E. Du, N. Zhang, B. M. Hodge, Q. Wang, Z. Lu, C. Kang, B. Kroposki, and Q. Xia, "Operation of a High Renewable Penetrated Power System With CSP Plants: A Look-Ahead Stochastic Unit Commitment Model," IEEE Trans. Pow. Sys., vol. 34, no. 1, pp. 831 - 840, Jan. 2019.

[14] G. Spagnuolo, G. Petrone, S. V. Araujo, C. Cecati, E. Friis-Madsen, E. Gubia, D. Hissel, M. Jasinski, W. Knapp, M. Liserre, P. Rodriguez, R. Teodorescu, and P. Zacharias, "Renewable Energy Operation and Conversion Schemes: A Summary of Discussions During the Seminar on Renewable Energy Systems," IEEE Ind. Electron. Mag., vol. 4, no. 1, pp. 38 - 51, Mar. 2010.

[15] B. Lequesne, "Automotive Electrification: The Nonhybrid Story," IEEE Trans. Transp. Electrif., vol. 1, no. 1, Jun. 2015.

[16] Y. Wu and H. Gao, "Optimization of fuel cell and supercapacitor for fuel-cell electric vehicles," IEEE Trans. Veh. Tech., vol. 55, no. 6, pp. 1748-1755, Nov. 2006.

[17] U. R. Prasanna, X. Pan, A. K. Rathore, and K. Rajashekara, "Propulsion system architecture and power conditioning topologies for fuel cell vehicles," IEEE Trans. Ind. App., vol. 51, no. 1, pp. 640-650, Feb. 2015. 
[18] A. Debenjak, J. Petrovčič, P. Boškoski, B. Musizza, and Đ. Juričić, "Fuel Cell Condition Monitoring System Based on Interconnected DC-DC Converter and Voltage Monitor," IEEE Trans. Ind. Electron., vol. 62, no. 8, pp. 5293 - 5305, Aug. 2015.

[19] A. Debenjak, J. Petrovčič, P. Boškoski, B. Musizza, and Đ. Juričić, "Fuel Cell Condition Monitoring System Based on Interconnected DC-DC Converter and Voltage Monitor," IEEE Trans. Ind. Electron., vol. 62, no. 8, pp. 5293 - 5305, Aug. 2015.

[20] D. Wu, D. C. Aliprantis, and K. Gkritza, "Electric Energy and Power Consumption by LightDuty Plug-In Electric Vehicles,” IEEE Trans. Pow. Sys., vol. 26, no. 2, pp. 738 - 746, May 2011.

[21] D. Vincent, P. S. Huynh, N. A. Azeez, L. Patnaik, and S. S. Williamson, "Evolution of Hybrid Inductive and Capacitive AC Links for Wireless EV Charging -A Comparative Overview," IEEE Trans. Transp. Elect., Jun. 2019, DOI: 10.1109/TTE.2019.2923883

[22] J. Cao, and A. Emadi, "A New Battery/UltraCapacitor Hybrid Energy Storage System for Electric, Hybrid, and Plug-In Hybrid Electric Vehicles," IEEE Trans. Pow. Electron., vol. 27, no. 1, pp. 122 - 132, Jan. 2012.

[23] Z. Li, Q. Guo, H. Sun, S. Xin, and J. Wang, “A New Real-Time Smart-Charging Method Considering Expected Electric Vehicle Fleet Connections," IEEE Trans. Pow. Sys., vol. 29, no. 6, pp. 3114 - 3115, Nov. 2014.

[24] M. E. Amoli, K. Choma, and J. Stefani, "Rapid-Charge Electric-Vehicle Stations," IEEE Trans. Pow. Deliv., vol. 25, no. 3, pp. 1883 - 1887, Jul. 2010.

[25] H. Yu, F. Cheli, and F. C. Dezza, "Optimal Design and Control of 4-IWD Electric Vehicles Based on a 14-DOF Vehicle Model," IEEE Trans. Veh. Tech., vol. 67, no. 11, pp. 10457 -10469, Nov. 2018.

[26] H. M. Rad, and M. ghamkhari, "Optimal Charging of Electric Vehicles With Uncertain Departure Times: A Closed-Form Solution,” IEEE Trans. Smart Grid, vol. 6, no. 12, pp. 940 - 942, Mar. 2015.

[27] R. Ghorbani, E. Bibeau, and S. Filizadeh, "On Conversion of Hybrid Electric Vehicles to Plug-In,” IEEE Trans. Veh. Tech., vol. 59, no. 4, pp. 2016 - 2020, May 2010. 
[28] H. N. Melo, J. P. F. Trovão, P. G. Pereirinha, H. M. Jorge, and C. H. Antunes, “A Controllable Bidirectional Battery Charger for Electric Vehicles with Vehicle-to-Grid Capability," IEEE Trans. Veh. Tech., vol. 67, no. 1, pp. 114 - 123, Jan. 2018.

[29] L. Li, S. Coskun, F. Zhang, R. Langari, and J. Xi, "Energy Management of Hybrid Electric Vehicle Using Vehicle Lateral Dynamic in Velocity Prediction," IEEE Trans. Veh. Tech., vol. 68, no. 4, pp. 3279 - 3293, Apr. 2019.

[30] A. M. Bozorgi, M. Farasat, and A. Mahmoud, "A Time and Energy Efficient Routing Algorithm for Electric Vehicles Based on Historical Driving Data," IEEE Trans. Int. Veh., vol. 2, no. 4, pp. 308 - 320, Dec. 2017.

[31] X. Chen, Y. Zhang, S. Wang, J. Chen, and C. Gong, "Impedance-Phased Dynamic Control Method for Grid-Connected Inverters in a Weak Grid," IEEE Trans. Pow. Elect., vol. 32, no. 1, pp. 274 - 283, Jan. 2017.

[32] X. Guo, W. Liu, X. Zhang, X. Sun, Z. Lu, and J. M. Guerrero, "Flexible Control Strategy for Grid-Connected Inverter Under Unbalanced Grid Faults Without PLL," IEEE Trans. Pow. Elect., vol. 30, no. 4, pp. 1773 - 1778, Apr. 2015.

[33] X. Zhang, D. Xia, Z. Fu, G. Wang, and D. Xu, “An Improved Feedforward Control Method Considering PLL Dynamics to Improve Weak Grid Stability of Grid-Connected Inverters," IEEE Trans. Ind. App., vol. 54, no. 5, pp. 5143 - 5151, Oct. 2018.

[34] Y. Han, H. Chen, Z. Li, P. Yang, L. Xu, and J. M. Guerrero, "Stability Analysis for the Grid-Connected Single-Phase Asymmetrical Cascaded Multilevel Inverter With SRF-PI Current Control Under Weak Grid Conditions," IEEE Trans. Pow. Elect., vol. 34, no. 3, pp. 2052 -2069, Mar. 2019.

[35] Y. He, H. S. H. Chung, C. T. Lai, X. Zhang, and W. Wu, “Active Cancelation of Equivalent Grid Impedance for Improving Stability and Injected Power Quality of Grid-Connected Inverter Under Variable Grid Condition," IEEE Trans. Pow. Elect., vol. 33, no. 11, pp. 9387

- 9398, Nov. 2018.

[36] Y. He, H. S. H. Chung, C. N. M. Ho, and W. Wu, "Use of Boundary Control With Second-Order Switching Surface to Reduce the System Order for Deadbeat Controller in Grid-Connected Inverter," IEEE Trans. Pow. Elect., vol. 31, no. 1, pp. 2638 - 2653, Mar. 2016. 
[37] L. Jia, X. Ruan, W. Zhao, Z. Lin, and X. Wang, “An Adaptive Active Damper for Improving the Stability of Grid-Connected Inverters Under Weak Grid," IEEE Trans. Pow. Elect., vol. 33, no. 11, pp. 9561 - 9574, Nov. 2018.

[38] K. P. Huang, Y. Wang, and R. J. Wai, "Design of Power Decoupling Strategy for SinglePhase Grid-Connected Inverter Under Nonideal Power Grid," IEEE Trans. Pow. Elect., vol. 34, no. 3, pp. 2938 - 2955, Mar. 2019.

[39] W. Wu, L. Zhou, Y. Chen, A. Luo, Y. Dong, X. Zhou, Q. Xu, L. Yang, and J. M. Guerrero, "Sequence-Impedance-Based Stability Comparison Between VSGs and Traditional Grid-Connected Inverters," IEEE Trans. Pow. Elect., vol. 34, no. 1, pp. 46 - 52 , Jan. 2019.

[40] M. Lu, A. Al-Durra, S. M. Muyeen, S. Leng, P. C. Loh, and F. Blaabjerg, "Benchmarking of Stability and Robustness Against Grid Impedance Variation for LCL-Filtered Grid-Interfacing Inverters," IEEE Trans. Pow. Elect., vol. 33, no. 10, pp. 9033 - 9046, Oct. 2018.

[41] R. P. Alzola, J. R. Pérez, E. Bueno, F. Huerta, D. C. Gaona, M. Liserre, and G. Burt, "Robust Active Damping in LCL-Filter-Based Medium-Voltage Parallel Grid Inverters for Wind Turbines," IEEE Trans. Pow. Elect., vol. 33, no. 12, pp. 10846 - 10857, Dec. 2018.

[42] D. Yang, X. Ruan, and H. Wu, "Impedance Shaping of the Grid-Connected Inverter with LCL Filter to Improve Its Adaptability to the Weak Grid Condition," IEEE Trans. Pow. Elect., vol. 29, no. 11, pp. 5795 - 5805, Nov. 2014.

[43] J. Xu, S. Xie, B. Zhang, and Q. Qian, "Robust Grid Current Control With Impedance-Phase Shaping for LCL-Filtered Inverters in Weak and Distorted Grid," IEEE Trans. Pow.

Elect., vol. 33, no. 12, pp. 10240 - 10250, Dec. 2018.

[44] B. Wen, D. Boroyevich, R. Burgos, P. Mattavelli, and Z. Shen, "Analysis of D-Q SmallSignal Impedance of Grid-Tied Inverters,” IEEE Trans. Pow. Elect., vol. 31, no. 1, pp. 675 -687 , Jan. 2016.

[45] Z. Shuai, Y. Li, W. Wu, C. Tu, A. Luo, and Z. J. Shen, "Divided DQ Small-Signal Model: A New Perspective for the Stability Analysis of Three-Phase Grid-Tied Inverters," IEEE Trans. Pow. Elect., vol. 66, no. 8, pp. 6493 - 6504, Aug. 2019.

[46] R. W. Erickson and D. Maksimovic, Fundamentals of Power Electronics, 2nd ed. Norwell, MA, USA: Kluwer, 2001. 
[47] Christina DiMarino, Igor Cvetkovic, and Zhiyu Shen, " $10 \mathrm{kV}, 120$ a SiC MOSFET modules for a power electronics building block (PEBB)", IEEE Workshop on Wide Bandgap Power Devices and Applications (WiPDA), Oct. 2014.

[48] U. Viscarret, I. Etxeberria-Otadui, and J. M. Azurmendi, "Design of power electronic building blocks (PEBB) for multiMW modular traction converters", IEEE Energy Conversion Congress and Exposition (ECCE), Sep. 2010.

[49] Ingo Staudt, and Michael Sprenger, "Development of a New 1000 V / 1 MVA IGBT 3LNPC-VSC PEBB Type 2 with Independent Modulation, DC-Link Balancing and ShortCircuit Protection", International Conference on Integrated Power Systems (CIPS), Feb. 2014.

[50] Nour Elsayad, Alberto Berzoy, and Osama A. Mohammed, "An integrated PEBB using eGaN FETs and nanocrystalline inductors for multiple DC-DC, AC-DC and DC-AC applications", IEEE Workshop on Wide Bandgap Power Devices and Applications (WiPDA), Nov. 2017.

[51] Ju Won Baek, Dong-Wook Yoo and Heung-Geun Kim, "High-voltage switch using seriesconnected IGBTs with simple auxiliary circuit," in IEEE Transactions on Industry Applications, vol. 37, no. 6, pp. 1832-1839, Nov/Dec 2001.

[52] ] N. Teerakawanich and C. M. Johnson, "Design Optimization of Quasi-Active Gate Control for Series-Connected Power Devices," in IEEE Transactions on Power Electronics, vol. 29, no. 6, pp. 2705-2714, June 2014.

[53] Y. Ren; X. Yang; F. Zhang; K. Wang; W. Chen; L. Wang; Y. Pei, "A Compact Gate Control and Voltage Balancing Circuit for Series-connected SiC MOSFETs and Its Application in DC-Breaker," in IEEE Transactions on Industrial Electronics , vol.PP, no.99, pp.1-1, 2017.

[54] A. Emadi, and S. S. Williamson, "Fuel cell vehicles: Opportunities and challenges," in Proc. IEEE Power Eng. Soc. General Meeting, Denver, CO, Jun. 2004, pp. 1640-1645.

[55] K. Rajashekara, "Present Status and Future Trends in Electric Vehicle Propulsion Technologies," IEEE J. Emerg. Sel. Topics Pow. Electron., vol. 1, no. 1, pp. 3 - 10, Mar. 2013. 
[56] Hurng-Liahng Jou, Jun-Jie Huang, Jinn-Chang Wu, and Kuen-Der Wu, "Novel Isolated Multilevel DC-DC Power Converter," IEEE Trans. Pow. Electron., vol. 31, no. 4, pp. 2690 - 2694, Apr. 2016.

[57] Xiaotian Zhang, and Timothy C. Green, " The Modular Multilevel Converter for High StepUp Ratio DC-DC Conversion," in IEEE Transactions on Industrial Electronics , vol. 62, no. 8, pp. 4925 - 4936, Aug. 2015.

[58] He Liu, Mohamed S. A. Dahidah, James Yu, R. T. Naayagi, and Matthew Armstrong, "Design and Control of Unidirectional DC-DC Modular Multilevel Converter for Offshore DC Collection Point: Theoretical Analysis and Experimental Validation," IEEE Trans. Pow. Electron., vol. 34, no. 6, pp. 5191 - 5208, Jun. 2019.

[59] Xu She, Alex Q. Huang, and Xijun Ni, "Current Sensorless Power Balance Strategy for DC/DC Converters in a Cascaded Multilevel Converter Based Solid State Transformer," IEEE Trans. Pow. Electron., vol. 29, no. 1, pp. 17 - 22, Jan. 2014.

[60] Jan A. Ferreira, "The Multilevel Modular DC Converter," IEEE Trans. Pow. Electron., vol. 28, no. 10, pp. 4460 - 4465, Oct. 2013.

[61] Hirofumi Akagi, and Ryohei Kitada, "Control and Design of a Modular Multilevel Cascade BTB System Using Bidirectional Isolated DC/DC Converters," IEEE Trans. Pow. Electron., vol. 26, no. 9, pp. 2457 - 2464, Sep. 2011.

[62] I. A. Gowaid, G. P. Adam, Ahmed M. Massoud, Shehab Ahmed, and B. W. Williams, "Hybrid and Modular Multilevel Converter Designs for Isolated HVDC-DC Converters," IEEE J. Emerg. Sel. Topics Pow. Electron., vol. 6, no. 1, pp. 188 - 202, Mar. 2018.

[63] Zhongwei Xing, Xinbo Ruan, Hongcheng You, Xiaobo Yang, Dawei Yao, and Chunming Yuan, "Soft-Switching Operation of Isolated Modular DC/DC Converters for Application in HVDC Grids," IEEE Trans. Pow. Electron., vol. 31, no. 4, pp. 2753 - 2766, Apr. 2016.

[64] Yu Chen, Shanshan Zhao, Zuoyu Li, Xiaoguang Wei, and Yong Kang, "Modeling and Control of the Isolated DC-DC Modular Multilevel Converter for Electric Ship Medium Voltage Direct Current Power System," IEEE J. Emerg. Sel. Topics Pow. Electron., vol. 5, no. 1, pp. 124 - 139, Mar. 2017.

[65] Todor Todorčević ; Rick van Kessel ; Pavol Bauer ; Jan Abraham Ferreira, "A Modulation Strategy for Wide Voltage Output in DAB-Based DC-DC Modular Multilevel Converter for 
DEAP Wave Energy Conversion," IEEE J. Emerg. Sel. Topics Pow. Electron., vol. 3, no. 4, pp. 1171 - 1181, Dec. 2015.

[66] Heng Yang ; Maryam Saeedifard ; Amirnaser Yazdani, " An Enhanced Closed-Loop Control Strategy With Capacitor Voltage Elevation for the DC-DC Modular Multilevel Converter," in IEEE Transactions on Industrial Electronics , vol. 66, no. 3, pp. 2366 - 2375, Mar. 2019.

[67] Kia Filsoof; Peter W. Lehn, "A Bidirectional Modular Multilevel DC-DC Converter of Triangular Structure,” IEEE Trans. Pow. Electron., vol. 30, no. 1, pp. 54 - 64, Jan. 2015.

[68] Gregory J. Kish; Mike Ranjram; Peter W. Lehn, "A Modular Multilevel DC/DC Converter With Fault Blocking Capability for HVDC Interconnects," IEEE Trans. Pow. Electron., vol. 30, no. 1, pp. 148 - 162, Jan. 2015.

[69] Stefan P. Engel ; Marco Stieneker ; Nils Soltau ; Sedigheh Rabiee ; Hanno Stagge ; Rik W. De Doncker, "Comparison of the Modular Multilevel DC Converter and the Dual-Active Bridge Converter for Power Conversion in HVDC and MVDC Grids," IEEE Trans. Pow. Electron., vol. 30, no. 1, pp. 124 - 137, Jan. 2015.

[70] S Wuhua Li ; Qun Jiang ; Ye Mei ; Chushan Li ; Yan Deng ; Xiangning He, "Modular Multilevel DC/DC Converters With Phase-Shift Control Scheme for High-Voltage DCBased Systems," IEEE Trans. Pow. Electron., vol. 30, no. 1, pp. 99 - 107, Jan. 2015.

[71] Heng Yang ; Maryam Saeedifard, " A Capacitor Voltage Balancing Strategy With Minimized AC Circulating Current for the DC-DC Modular Multilevel Converter," in IEEE Transactions on Industrial Electronics, vol. 64, no. 2, pp. 956 - 965, Feb. 2017.

[72] S. A. Saleh ; B. Allen ; E. Ozkop ; B. G. Colpitts, " Multistage and Multilevel Power Electronic Converter-Based Power Supply for Plasma DBD Devices," in IEEE Transactions on Industrial Electronics , vol. 65, no. 7, pp. 5466 - 5475, Jul. 2018.

[73] Naresh Kumar Reddi ; Manoj R. Ramteke ; Hiralal M. Suryawanshi ; Koteswararao Kothapalli, " An Isolated Multi-Input ZCS DC-DC Front-End-Converter Based Multilevel Inverter for the Integration of Renewable Energy Sources," in IEEE Transactions on Industry Applications, vol. 54, no. 1, pp. 494 - 504, Jan. 2018.

[74] I. A. Gowaid ; Grain P. Adam ; Shehab Ahmed ; Derrick Holliday ; Barry W. Williams, "Analysis and Design of a Modular Multilevel Converter With Trapezoidal Modulation for 
Medium and High Voltage DC-DC Transformers," IEEE Trans. Pow. Electron., vol. 30, no. 10, pp. 5439 - 5457, Oct. 2015.

[75] Stephan Kenzelmann ; Alfred Rufer ; Drazen Dujic ; Francisco Canales ; Yales Rômulo de Novaes, "Isolated DC/DC Structure Based on Modular Multilevel Converter," IEEE Trans. Pow. Electron., vol. 30, no. 1, pp. 89 - 98, Jan. 2015.

[76] Sixing Du ; Bin Wu ; Kai Tian ; David Xu ; Navid R. Zargari, " A Novel MediumVoltage Modular Multilevel DC-DC Converter," in IEEE Transactions on Industrial Electronics , vol. 63, no. 12, pp. 7939 - 7949, Dec. 2016.

[77] Shenghui Cui ; Nils Soltau ; Rik W. De Doncker, “A High Step-Up Ratio SoftSwitching DC-DC Converter for Interconnection of MVDC and HVDC Grids," IEEE Trans. Pow. Electron., vol. 33, no. 4, pp. 2986 - 3001, Apr. 2018.

[78] Amin Ghazanfari ; Yasser Abdel-Rady I. Mohamed, " A Resilient Framework for Fault-Tolerant Operation of Modular Multilevel Converters," in IEEE Transactions on Industrial Electronics, vol. 63, no. 5, pp. 2669 - 2678, May 2016.

[79] Kangan Wang ; Rongwu Zhu ; Chen Wei ; Feng Liu ; Xiaojie Wu ; Marco Liserre, " Cascaded Multilevel Converter Topology for Large-Scale Photovoltaic System With Balanced Operation," in IEEE Transactions on Industrial Electronics , vol. 66, no. 10, pp. 7694 - 7705, Oct. 2019.

[80] Yu Liu ; Fang Lin Luo, " Trinary Hybrid 81-Level Multilevel Inverter for Motor Drive With Zero Common-Mode Voltage," in IEEE Transactions on Industrial Electronics, vol. 55, no. 3, pp. 1014 - 1021, Mar. 2008.

[81] B. Arntzen ; D. Maksimovic, "Switched-capacitor DC/DC converters with resonant gate drive," IEEE Trans. Pow. Electron., vol. 13, no. 5, pp. 892 - 902, Sep. 1998.

[82] Kisu Kim ; Honnyong Cha ; Siho Park ; Il-Oun Lee, “A Modified Series-Capacitor High Conversion Ratio DC-DC Converter Eliminating Start-Up Voltage Stress Problem," IEEE Trans. Pow. Electron., vol. 33, no. 1, pp. 8 - 12, Jan. 2018.

[83] Yong Shi ; Xu Yang, "Wide Load Range ZVS Three-Level DC-DC Converter: Four Primary Switches, Capacitor Clamped, Two Secondary Switches, and Smaller Output Filter Volume," IEEE Trans. Pow. Electron., vol. 31, no. 5, pp. 3431 - 3443, May 2016. 
[84] Robert Stala ; Zbigniew Waradzyn ; Adam Penczek ; Andrzej Mondzik ; Aleksander Skała, "A Switched-Capacitor DC-DC Converter With Variable Number of Voltage Gains and Fault-Tolerant Operation," in IEEE Transactions on Industrial Electronics , vol. 66, no. 5, pp. 3435 - 3445, May 2019.

[85] Adam Kawa ; Robert Stala ; Andrzej Mondzik ; Stanislaw Pirog ; Adam Penczek, "High-Power Thyristor-Based DC-DC Switched-Capacitor Voltage Multipliers: Basic Concept and Novel Derived Topology With Reduced Number of Switches," IEEE Trans. Pow. Electron., vol. 31, no. 10, pp. 6797 - 6813, Oct. 2016.

[86] Yen-Ting Lin ; Yan-Jiun Lai ; Hung-Wei Chen ; Wen-Hau Yang ; Yu-Sheng Ma ; KeHorng Chen, "A Fully Integrated Asymmetrical Shunt Switched-Capacitor DC-DC Converter With Fast Optimum Ratio Searching Scheme for Load Transient Enhancement," IEEE Trans. Pow. Electron., vol. 34, no. 9, pp. 9146 - 9157, Sep. 2019.

[87] Shih-Ming Chen ; Man-Long Lao ; Yi-Hsun Hsieh ; Tsorng-Juu Liang ; Kai-Hui Chen, " A Novel Switched-Coupled-Inductor DC-DC Step-Up Converter and Its Derivatives," in IEEE Transactions on Industry Applications, vol. 51, no. 1, pp. 309 - 314, Jan. 2015.

[88] Deepak Gunasekaran ; Liang Qin ; Ujjwal Karki ; Yuan Li ; Fang Z. Peng, “A Variable (n/m)X Switched Capacitor DC-DC Converter," IEEE Trans. Pow. Electron., vol. 32, no. 8, pp. 6219 - 6235, Aug. 2017.

[89] Minh-Khai Nguyen ; Truong-Duy Duong ; Young-Cheol Lim, "Switched-CapacitorBased Dual-Switch High-Boost DC-DC Converter," IEEE Trans. Pow. Electron., vol. 33, no. 5, pp. 4181 - 4189, May 2018.

[90] Lanhua Zhang ; Sombuddha Chakraborty, "An Interleaved Series-Capacitor Tapped Buck Converter for High Step-Down DC/DC Application," IEEE Trans. Pow. Electron., vol. 34, no. 7, pp. 6565 - 6574, July 2019.

[91] Tomokazu Mishima ; Yujiro Takeuchi ; Mutsuo Nakaoka, "Analysis, Design, and Performance Evaluations of an Edge-Resonant Switched Capacitor Cell-Assisted Soft-Switching PWM Boost DC-DC Converter and Its Interleaved Topology," IEEE Trans. Pow. Electron., vol. 28, no. 7, pp. 3363 - 3378, July 2013.

[92] Dong-Yun Lee ; Byoung-Kuk Lee ; Sang-Bong Yoo ; Dong-Seok Hyun, " An improved full-bridge zero-voltage-transition PWM DC/DC converter with zero-voltage/zerocurrent 
switching of the auxiliary switches," in IEEE Transactions on Industry Applications, vol. 36, no. 2, pp. 558 - 566, Apr. 2000.

[93] Shelas Sathyan ; H. M. Suryawanshi ; Makarand Sudhakar Ballal ; Amardeep B. Shitole, " Soft-Switching DC-DC Converter for Distributed Energy Sources With High StepUp Voltage Capability," in IEEE Transactions on Industrial Electronics , vol. 62, no. 11, pp. 7039 - 7050, Nov. 2015.

[94] Yan Lu ; Wing-Hung Ki ; C. Patrick Yue, "An NMOS-LDO Regulated SwitchedCapacitor DC-DC Converter With Fast-Response Adaptive-Phase Digital Control," IEEE Trans. Pow. Electron., vol. 31, no. 2, pp. 1294 - 1303, Feb. 2016.

[95] Yun Zhang ; Qiangqiang Liu ; Yongping Gao ; Jing Li ; Mark Sumner, " Hybrid Switched-Capacitor/Switched-Quasi-Z-Source Bidirectional DC-DC Converter With a Wide Voltage Gain Range for Hybrid Energy Sources EVs," in IEEE Transactions on Industrial Electronics, vol. 66, no. 4, pp. 2680 - 2690, Apr. 2019.

[96] Kapil Kesarwani ; Rahul Sangwan ; Jason T. Stauth, "Resonant-Switched Capacitor Converters for Chip-Scale Power Delivery: Design and Implementation," IEEE Trans. Pow. Electron., vol. 30, no. 12, pp. 6966 - 6977, Dec. 2015.

[97] Masatoshi Uno ; Kazuki Sugiyama, "Switched Capacitor Converter Based Multiport Converter Integrating Bidirectional PWM and Series-Resonant Converters for Standalone Photovoltaic Systems," IEEE Trans. Pow. Electron., vol. 34, no. 2, pp. 1394 - 1406, Feb. 2019.

[98] Sutej Reddy Challa ; Debaprasad Kastha ; Amit Patra, "A Cascade Point of Load DCDC Converter With a Novel Phase Shifted Switched Capacitor Converter Output Stage," IEEE Trans. Pow. Electron., vol. 31, no. 1, pp. 353 - 368, Jan. 2016.

[99] Zbigniew Waradzyn ; Robert Stala ; Andrzej Mondzik ; Adam Penczek ; Aleksander Skala; Stanislaw Pirog, " Efficiency Analysis of MOSFET-Based Air-Choke Resonant DC-DC Step-Up Switched-Capacitor Voltage Multipliers," in IEEE Transactions on Industrial Electronics, vol. 64, no. 11, pp. 8728 - 8738, Nov. 2017.

[100] Shouxiang Li ; Yifei Zheng ; Bin Wu ; Keyue Ma Smedley, “A Family of Resonant Two-Switch Boosting Switched-Capacitor Converter With ZVS Operation and a Wide Line Regulation Range," IEEE Trans. Pow. Electron., vol. 33, no. 1, pp. 448 - 459, Jan. 2018. 
[101] Dong Cao ; Fang Zheng Peng, " Zero-Current-Switching Multilevel Modular SwitchedCapacitor DC-DC Converter," in IEEE Transactions on Industry Applications, vol. 46, no. 6, pp. 2536 - 2544, Dec. 2010.

[102] Fang Lin Luo ; Hong Ye, " Positive output multiple-lift push-pull switched-capacitor Luoconverters," in IEEE Transactions on Industrial Electronics, vol. 3, no. 3, pp. 594 - 602, Jun. 2004.

[103] Xuan Zhang ; Chengcheng Yao ; Jin Wang, "A Quasi-Switched-Capacitor Resonant Converter,” IEEE Trans. Pow. Electron., vol. 31, no. 11, pp. 7849 - 7856, Nov. 2016.

[104] Michael D. Seeman ; Seth R. Sanders, "Analysis and Optimization of Switched-Capacitor DC-DC Converters," IEEE Trans. Pow. Electron., vol. 23, no. 2, pp. 841 - 851, Mar. 2008.

[105] Fan Zhang ; Lei Du ; Fang Zheng Peng ; Zhaoming Qian, "A New Design Method for High-Power High-Efficiency Switched-Capacitor DC-DC Converters," IEEE Trans. Pow. Electron., vol. 23, no. 2, pp. 832 - 840, Mar. 2008.

[106] Lukas Müller ; Jonathan W. Kimball, "Effects of Stray Inductance on Hard-Switched Switched Capacitor Converters," IEEE Trans. Pow. Electron., vol. 29, no. 12, pp. 6276 -6280 , Dec. 2014.

[107] Yun Zhang ; Yongping Gao ; Lei Zhou ; Mark Sumner, "A Switched-Capacitor Bidirectional DC-DC Converter With Wide Voltage Gain Range for Electric Vehicles With Hybrid Energy Sources," IEEE Trans. Pow. Electron., vol. 33, no. 11, pp. 9459 - 9469, Nov. 2018.

[108] Yu Tang ; Dongjin Fu ; Ting Wang ; Zhiwei Xu, " Hybrid Switched-Inductor Converters for High Step-Up Conversion," in IEEE Transactions on Industrial Electronics , vol. 62, no. 3, pp. 1480 - 1490, Mar. 2015.

[109] Xiaoquan Zhu ; Bo Zhang ; Zhong Li ; Hong Li ; Li Ran, "Extended Switched-Boost DCDC Converters Adopting Switched-Capacitor/Switched-Inductor Cells for High Step-up Conversion," IEEE J. Emerg. Sel. Topics Pow. Electron., vol. 5, no. 8, pp. 1020 - 1030, Sep. 2017.

[110] Marcos Antonio Salvador ; Telles Brunelli Lazzarin ; Roberto Francisco Coelho, " High Step-Up DC-DC Converter With Active Switched-Inductor and Passive Switched-Capacitor 
Networks," in IEEE Transactions on Industrial Electronics , vol. 65, no. 7, pp. 5644 - 5654, Jul. 2018.

[111] Hongchen Liu ; Fei Li, “A Novel High Step-up Converter With a Quasi-active SwitchedInductor Structure for Renewable Energy Systems," IEEE Trans. Pow. Electron., vol. 31, no. 7, pp. 5030 - 5039, Jul. 2016.

[112] Yu Tang ; Ting Wang ; Dongjin Fu, "Multicell Switched-Inductor/Switched-Capacitor Combined Active-Network Converters," IEEE Trans. Pow. Electron., vol. 30, no. 4, pp. 2063 - 2072, Apr. 2015.

[113] Ricardo Lizana F. ; Sebastian Rivera ; Zhongxi Li ; Jenny Luo ; Angel V. Peterchev, "Modular Multilevel Series/Parallel Converter With Switched-Inductor Energy Transfer Between Modules," IEEE Trans. Pow. Electron., vol. 34, no. 5, pp. 4844 - 4852, May 2019.

[114] Yijie Wang ; Wenli Jing ; Yuping Qiu ; Yuanyuan Wang ; Xiangyuan Deng ; Ke Hua ; Benran Hu, " A Family of Y-Source DC/DC Converter Based on Switched Inductor," in IEEE Transactions on Industry Applications, vol. 55, no. 2, pp. 1587 - 1597, Mar. 2019.

[115] Julio Cezar dos Santos de Morais ; Juliano Luiz dos Santos de Morais ; Roger Gules, " Photovoltaic AC Module Based on a Cuk Converter With a Switched-Inductor Structure," in IEEE Transactions on Industrial Electronics, vol. 65, no. 5, pp. 3881 - 3890, May 2019.

[116] B. R. Ananthapadmanabha ; Rakesh Maurya ; Sabha Raj Arya, "Improved Power Quality Switched Inductor Cuk Converter for Battery Charging Applications," IEEE Trans. Pow. Electron., vol. 33, no. 11, pp. 9412 - 9423, Nov. 2018.

[117] Carlos J. Solis ; Gabriel A. Rincón-Mora, “0.6- $\mu \mathrm{m}$ CMOS-Switched-Inductor DualSupply Hysteretic Current-Mode Buck Converter," IEEE Trans. Pow. Electron., vol. 32, no. 3, pp. 2387 - 2394, Mar. 2017.

[118] Tong Yao ; Chenhao Nan ; Rajapandian Ayyanar, " A New Soft-Switching Topology for Switched Inductor High Gain Boost," in IEEE Transactions on Industry Applications, vol. 54, no. 3, pp. 2449 - 2458, Jun. 2018.

[119] Jia Yao ; Kaisheng Zheng ; A. Abramovitz, "Small-Signal Model of Switched Inductor Boost Converter," IEEE Trans. Pow. Electron., vol. 34, no. 5, pp. 4036 - 4040, May 2019. 
[120] Francesco Alonge ; Roberto Rabbeni ; Marcello Pucci ; Gianpaolo Vitale, " Identification and Robust Control of a Quadratic DC/DC Boost Converter by Hammerstein Model," in IEEE Transactions on Industry Applications, vol. 51, no. 5, pp. 3975 - 3985, Oct. 2015.

[121] Vitor Fernão Pires ; Daniel Foito ; Armando Cordeiro, " A DC-DC Converter With Quadratic Gain and Bidirectional Capability for Batteries/Supercapacitors," in IEEE Transactions on Industry Applications, vol. 54, no. 1, pp. 274 - 285, Feb. 2018.

[122] António Manuel Santos Spencer Andrade ; Márioøeio da Silva Martins, "QuadraticBoost With Stacked Zeta Converter for High Voltage Gain Applications," IEEE J. Emerg. Sel. Topics Pow. Electron., vol. 5, no. 4, pp. 1787 - 1796, Dec. 2017.

[123] Yijie Wang ; Yuping Qiu ; Qing Bian ; Yueshi Guan ; Dianguo Xu, " A Single Switch Quadratic Boost High Step Up DC-DC Converter," in IEEE Transactions on Industrial Electronics , vol. 66, no. 6, pp. 4387 - 4397, Jun. 2019.

[124] L.H.S.C. Barreto ; E.A.A. Coelho ; V.J. Farias ; J.C. de Oliveira ; L.C. de Freitas ; Jr. Joao Batista Vieira, " A quasi-resonant quadratic boost converter using a single resonant network," in IEEE Transactions on Industrial Electronics , vol. 52, no. 2, pp. 552 - 557, Apr. 2005.

[125] L. Calderone ; L. Pinola ; V. Varoli, "Optimal feed-forward compensation for PWM DC/DC converters with 'linear' and 'quadratic' conversion ratio," IEEE Trans. Pow. Electron., vol. 7, no. 2, pp. 349 - 355, Apr. 1992.

[126] Haimeng Wu ; Volker Pickert ; Xu Deng ; Damian Giaouris ; Wuhua Li ; Xiangning He, " Polynomial Curve Slope Compensation for Peak-Current-Mode-Controlled Power Converters," in IEEE Transactions on Industrial Electronics, vol. 66, no. 1, pp. 470 - 481, Jan. 2019.

[127] V.M. Pacheco ; A.J. do Nascimento ; V.J. Farias ; J. Batista Vieira ; L.C. de Freitas, " A quadratic buck converter with lossless commutation," in IEEE Transactions on Industrial Electronics, vol. 47, no. 2, pp. 264 - 272, Apr. 2000.

[128] Jonathan C. Mayo-Maldonado ; Jesus E. Valdez-Resendiz ; Pedro M. Garcia-Vite, " Quadratic Buck-Boost Converter With Zero Output Voltage Ripple at a Selectable Operating Point," in IEEE Transactions on Industry Applications, vol. 55, no. 3, pp. 2813 - 2822, Jun. 2019. 
[129] Sin-Woo Lee ; Hyun-Lark Do, "Quadratic Boost DC-DC Converter With High Voltage Gain and Reduced Voltage Stresses," IEEE Trans. Pow. Electron., vol. 34, no. 3, pp. 2397 -2404, Mar. 2019.

[130] Peyman Saadat ; Karim Abbaszadeh, " A Single-Switch High Step-Up DC-DC Converter Based on Quadratic Boost ," IEEE Trans. Pow. Electron., vol. 63, no. 12, pp. 7733 - 7742, Dec. 2016.

[131] Jing Li ; Jinjun Liu, " A Negative-Output High Quadratic Conversion Ratio DC-DC Converter With Dual Working Modes," IEEE Trans. Pow. Electron., vol. 34, no. 6, pp. 5563 - 5578, Jun. 2019.

[132] Xueshan Liu ; Xuewen Li ; Qun Zhou ; Jianping Xu, " Flicker-Free Single-Switch Quadratic Boost LED Driver Compatible With Electronic Transformers," in IEEE Transactions on Industrial Electronics, vol. 66, no. 5, pp. 3458 - 3467, May 2019.

[133] J. Leyva-Ramos ; R. Mota-Varona ; M. G. Ortiz-Lopez ; L. H. Diaz-Saldierna ; D. Langarica-Cordoba, "Control Strategy of a Quadratic Boost Converter With Voltage Multiplier Cell for High-Voltage Gain," IEEE J. Emerg. Sel. Topics Pow. Electron., vol. 5, no. 4, pp. 1761 - 1770, Dec. 2017.

[134] J Jorge Alberto Morales-Saldana ; JesÚs Leyva-Ramos ; Enrique Eduardo CarbajalGutierrez, "Average Current-Mode Control Scheme for a Quadratic Buck Converter With a Single Switch,” IEEE Trans. Pow. Electron., vol. 23, no. 1, pp. 485 - 490, Jan. 2008.

[135] Shih-Ming Chen ; Tsorng-Juu Liang ; Lung-Sheng Yang ; Jiann-Fuh Chen, "A Cascaded High Step-Up DC-DC Converter With Single Switch for Microsource Applications," IEEE Trans. Pow. Electron., vol. 26, no. 4, pp. 1146 - 1153, Apr. 2011.

[136] Yu-Huei Lee ; Shih-Jung Wang ; Ke-Horng Chen, "Quadratic Differential and Integration Technique in $V^{2}$ Control Buck Converter With Small ESR Capacitor," IEEE Trans. Pow. Electron., vol. 25, no. 4, pp. 829 - 838, Apr. 2010.

[137] Mustafa A. Al-Saffar ; Esam H. Ismail ; Ahmad J. Sabzali, "Integrated Buck-BoostQuadratic Buck PFC Rectifier for Universal Input Applications," IEEE Trans. Pow. Electron., vol. 24, no. 12, pp. 2886 - 2896, Dec. 2009. 
[138] Mohammad Mohammadi ; Javad S. Moghani ; Jafar Milimonfared, " A Novel Dual Switching Frequency Modulation for Z-Source and Quasi-Z-Source Inverters," in IEEE Transactions on Industrial Electronics, vol. 65, no. 5, pp. 5167 - 5176, Jun. 2018.

[139] Vadthya Jagan ; Janardhana Kotturu ; Sharmili Das, " Enhanced-Boost Quasi-Z-Source Inverters With Two-Switched Impedance Networks," in IEEE Transactions on Industrial Electronics , vol. 64, no. 9, pp. 6885 - 6897, Sep. 2017.

[140] Yu Tang ; Shaojun Xie ; Chaohua Zhang ; Zegang Xu, "Improved Z-Source Inverter With Reduced Z-Source Capacitor Voltage Stress and Soft-Start Capability," IEEE Trans. Pow. Electron., vol. 24, no. 2, pp. 409 - 415, Feb. 2009.

[141] Dong Cao ; Shuai Jiang ; Xianhao Yu ; Fang Zheng Peng, "Low-Cost Semi-Z-source Inverter for Single-Phase Photovoltaic Systems," IEEE Trans. Pow. Electron., vol. 26, no. 12, pp. 3514 - 3523, Dec. 2011.

[142] Wei Qian ; Fang Zheng Peng ; Honnyong Cha, "Trans-Z-Source Inverters," IEEE Trans. Pow. Electron., vol. 26, no. 12, pp. 3453 - 3463, Dec. 2011.

[143] Hafiz Furqan Ahmed ; Honnyong Cha ; Su-Han Kim ; Heung-Geun Kim, "SwitchedCoupled-Inductor Quasi-Z-Source Inverter," IEEE Trans. Pow. Electron., vol. 31, no. 2, pp. 1241 - 1254, Feb. 2016.

[144] Poh Chiang Loh ; Chandana Jayampathi Gajanayake ; D. Mahinda Vilathgamuwa ; Frede Blaabjerg, "Evaluation of Resonant Damping Techniquesfor Z-Source Current-Type Inverter," IEEE Trans. Pow. Electron., vol. 23, no. 4, pp. 2035 - 2043, Jul. 2008.

[145] Mohsen Hasan Babayi Nozadian ; Ebrahim Babaei ; Seyed Hossein Hosseini, " SteadyState Analysis and Design Considerations of High Voltage Gain Switched Z-Source Inverter With Continuous Input Current," in IEEE Transactions on Industrial Electronics , vol. 64, no. 7, pp. 5342 - 5350, Jul. 2017.

[146] Yu Tang ; Shaojun Xie ; Jiudong Ding, " Pulsewidth Modulation of Z-Source Inverters With Minimum Inductor Current Ripple," in IEEE Transactions on Industrial Electronics, vol. 61, no. 1, pp. 98 - 106, Jan. 2014.

[147] Minh-Khai Nguyen ; Young-Cheol Lim ; Yi-Gon Kim, " TZ-Source Inverters," in IEEE Transactions on Industrial Electronics , vol. 60, no. 12, pp. 5686 - 5695, Dec. 2013. 
[148] Feng Gao ; Poh Chiang Loh ; Frede Blaabjerg ; D. Mahinda Vilathgamuwa, " Dual ZSource Inverter With Three-Level Reduced Common-Mode Switching," in IEEE Transactions on Industry Applications, vol. 43, no. 6, pp. 1597 - 1608, Dec 2007.

[149] Shuai Dong ; Qianfan Zhang ; Shukang Cheng, "Inductor Current Ripple Comparison Between ZSVM4 and ZSVM2 for Z-Source Inverters," IEEE Trans. Pow. Electron., vol. 31, no. 11, pp. 7592 - 7597, Nov. 2016.

[150] Poh Chiang Loh ; D.M. Vilathgamuwa ; Y.S. Lai ; Geok Tin Chua ; Y. Li, "Pulse-width modulation of Z-source inverters," IEEE Trans. Pow. Electron., vol. 20, no. 6, pp. 1346 -1355, Nov. 2005.

[151] Yushan Liu ; Baoming Ge ; Haitham Abu-Rub ; Fang Zheng Peng, "Overview of Space Vector Modulations for Three-Phase Z-Source/Quasi-Z-Source Inverters," IEEE Trans. Pow. Electron., vol. 29, no. 4, pp. 2098 - 2108, Apr. 2014.

[152] Yu Tang ; Shaojun Xie ; Chaohua Zhang, "Single-Phase Z-Source Inverter," IEEE Trans. Pow. Electron., vol. 26, no. 12, pp. 3869 - 3873, Dec. 2011.

[153] Fang Zheng Peng ; Miaosen Shen ; Zhaoming Qian g, "Maximum boost control of the Zsource inverter," IEEE Trans. Pow. Electron., vol. 20, no. 4, pp. 833 - 838, Jul. 2005.

[154] Quang-Vinh Tran ; Tae-Won Chun ; Jung-Ryol Ahn ; Hong-Hee Lee, " Algorithms for Controlling Both the DC Boost and AC Output Voltage of Z-Source Inverter," in IEEE Transactions on Industrial Electronics, vol. 54, no. 5, pp. 2745 - 2750, Oct. 2007.

[155] Siddhartha A. Singh ; Giampaolo Carli ; Najath A. Azeez ; Sheldon S. Williamson, " Modeling, Design, Control, and Implementation of a Modified Z-Source Integrated $\mathrm{PV} / \mathrm{Grid} / E V$ DC Charger/Inverter," in IEEE Transactions on Industrial Electronics, vol. 65, no. 6, pp. 5213 - 5220, Jun. 2018.

[156] Anh-Vu Ho ; Tae-Won Chun, " Single-Phase Modified Quasi-Z-Source Cascaded Hybrid Five-Level Inverter," in IEEE Transactions on Industrial Electronics, vol. 65, no. 6, pp. 5125 - 5134, Jun. 2018.

[157] Sertac Bayhan ; Haitham Abu-Rub ; Robert S. Balo, " Model Predictive Control of QuasiZ-Source Four-Leg Inverter," in IEEE Transactions on Industrial Electronics , vol. 63, no. 7, pp. 4506 - 4516, Jul. 2016. 
[158] Yan Zhou ; Hongbo Li ; Hui Li, "A Single-Phase PV Quasi-Z-Source Inverter With Reduced Capacitance Using Modified Modulation and Double-Frequency Ripple Suppression Control," IEEE Trans. Pow. Electron., vol. 31, no. 3, pp. 2166 - 2173, Mar. 2016.

[159] Poh Chiang Loh ; Frede Blaabjerg ; Chow Pang Wong, "Comparative Evaluation of Pulse width Modulation Strategies for Z-Source Neutral-Point-Clamped Inverter," IEEE Trans. Pow. Electron., vol. 22, no. 3, pp. 1005 - 1013, May 2007.

[160] Honnyong Cha ; Yuan Li ; Fang Zheng Peng, "Practical Layouts and DC-Rail Voltage Clamping Techniques of Z-Source Inverters," IEEE Trans. Pow. Electron., vol. 21, no. 11, pp. 7471 - 7479, Nov. 2016.

[161] Francis Boafo Effah ; Patrick Wheeler ; Jon Clare ; Alan Watson, "Space-VectorModulated Three-Level Inverters With a Single Z-Source Network," IEEE Trans. Pow. Electron., vol. 28, no. 6, pp. 2806 - 2815, Jul. 2013.

[162] Minh-Khai Nguyen ; Young-Cheol Lim ; Sung-Jun Park, "Improved Trans-Z-Source Inverter With Continuous Input Current and Boost Inversion Capability," IEEE Trans. Pow. Electron., vol. 28, no. 10, pp. 4500 - 4510, Oct. 2013.

[163] Ahmed Abdelhakim ; Paolo Mattavelli ; Giorgio Spiazzi, "Three-Phase Split-Source Inverter (SSI): Analysis and Modulation," IEEE Trans. Pow. Electron., vol. 31, no. 11, pp. 7451 - 7461, Nov. 2016.

[164] Ahmed Abdelhakim ; Paolo Mattavelli ; Valeria Boscaino ; Giuseppe Lullo, " Decoupled Control Scheme of Grid-Connected Split-Source Inverters," in IEEE Transactions on Industrial Electronics, vol. 64, no. 8, pp. 6202 - 6211, Aug. 2017.

[165] Ahmed Abdelhakim ; Paolo Mattavelli ; Pooya Davari ; Frede Blaabjerg, " Performance Evaluation of the Single-Phase Split-Source Inverter Using an Alternative DC-AC Configuration," in IEEE Transactions on Industrial Electronics, vol. 65, no. 1, pp. 363 - 373 , Jan. 2018.

[166] Sze Sing Lee ; Yeh En Heng, " Improved Single-Phase Split-Source Inverter With Hybrid Quasi-Sinusoidal and Constant PWM," in IEEE Transactions on Industrial Electronics, vol. 64, no. 3, pp. 2024 - 2031, Mar. 2017. 
[167] Siamak Mehrnami ; Sudip K. Mazumder ; Harshit Soni, "Modulation Scheme for ThreePhase Differential-Mode Ćuk Inverter," IEEE Trans. Pow. Electron., vol. 31, no. 3, pp. 2654

- 2668, Mar. 2016.

[168] Priyadharshini T. Sivasubramanian ; Sudip K. Mazumder ; Harshit Soni ; Ankit Gupta ; Nikhil Kumar, "A DC/DC Modular Current-Source Differential-Mode Inverter," IEEE J. Emerg. Sel. Topics Pow. Electron., vol. 4, no. 2, pp. 489 - 503, Jun. 2016.

[169] Siamak Mehrnami; Sudip K. Mazumder, "Discontinuous Modulation Scheme for a Differential-Mode Ćuk Inverter," IEEE Trans. Pow. Electron., vol. 30, no. 3, pp. 1242 1254, Mar. 2015.

[170] Abhijit Kulkarni ; Ankit Gupta ; Sudip K. Mazumder, "Resolving Practical Design Issues in a Single-Phase Grid-Connected GaN-FET-Based Differential-Mode Inverter," IEEE Trans. Pow. Electron., vol. 33, no. 5, pp. 3734 - 3751, May 2018.

[171] Harshit Soni ; Sudip K. Mazumder ; Ankit Gupta ; Debanjan Chatterjee ; Abhijit Kulkarni, "Control of Isolated Differential-Mode Single- and Three-Phase Ćuk Inverters at Module Level,” IEEE Trans. Pow. Electron., vol. 33, no. 10, pp. 8872 - 8886, Oct. 2018.

[172] Ahmed Darwish ; Ahmed M. Massoud ; Derrick Holliday ; Shehab Ahmed ; B. W. Williams, "Single-Stage Three-Phase Differential-Mode Buck-Boost Inverters With Continuous Input Current for PV Applications," IEEE Trans. Pow. Electron., vol. 31, no. 12, pp. 8218 - 8236, Dec. 2016.

[173] Daolian Chen ; Guoling Wang, "Differential Buck DC-DC Chopper Mode Inverters With High-Frequency Link," IEEE Trans. Pow. Electron., vol. 26, no. 5, pp. 1444 1451, May 2011.

[174] Abhijit Kulkarni ; Sudip K. Mazumder, " Deadtime Elimination in a GaN-Based GridConnected Differential-Mode Ćuk Inverter," in IEEE Transactions on Industrial Electronics , vol. 66, no. 4, pp. 3296 - 3302, Apr. 2019.

[175] Shuang Xu ; Riming Shao ; Liuchen Chang ; Meiqin Mao, "Single-Phase Differential Buck-Boost Inverter With Pulse Energy Modulation and Power Decoupling Control," IEEE

J. Emerg. Sel. Topics Pow. Electron., vol. 6, no. 4, pp. 2060 - 2072, Dec. 2018. 
[176] Y. Zhang, J. Shi, and L. Zhou " Wide Input-Voltage Range Boost Three-Level DC-DC Converter With Quasi-Z Source for Fuel Cell Vehicles," IEEE Trans. Of Power Electronics, vol. 32, pp. $6728-6738$, Sept. 2017.

[177] Y. Zhang, L. Zhou, M. Sumner, and P. Wang, "Input-Parallel Output-Series DC-DC Boost Converter With a Wide Input Voltage Range, For Fuel Cell Vehicles," in IEEE Trans. on Vehicular Tech., vol. 67, Jan 2018.

[178] F. M. Shahir, E. Babaei, and M. Farsadi, "Extended Topology for Boost DC-DC Converter,” IEEE Trans. Power. Electron., May 2018.

[179] F. M. Shahir, E. Babaei, and M. Farsadi, "Voltage-Lift Technique Based Nonisolated Boost DC-DC Converter: Analysis and Design," IEEE Trans. on Pow. Electron., vol. 33, no. 7, pp. 5917 - 5926, Jul. 2018.

[180] Y. m. Ye, and K. W. E. Cheng, "Quadratic boost converter with low buffer capacitor stress," IET Pow. Electron., vol. 7, no. 5, pp. 1162 - 1170, May 2014.

[181] L. S. Yang, T. Liang, and J. Chen, "Transformerless DC-DC Converters With High StepUp Voltage Gain,” IEEE Trans. Ind. Electron., vol. 56, no. 8, pp. 3144 - 3152, Aug. 2009.

[182] J.C. R. Caro, J.M. Ramirez, F.Z. Peng, and A. Valderrabano, "A DC-DC multilevel boost converter," IET Pow. Electron., vol. 3, no. 1, pp. 129 - 137, Jan. 2010.

[183] B. Wu, S. Li, Y. Liu, and K. M. Smedley, "A New Hybrid Boosting Converter for Renewable Energy Applications," IEEE Trans. on Pow. Electron., vol. 31, no. 2, pp. 1203 -1215, Feb. 2016.

[184] C. T. Pan, C. F. Chuang, C. C. Chu, "A Novel Transformer-less Adaptable Voltage Quadrupler DC Converter with Low Switch Voltage Stress," IEEE Trans. Power. Electron., vol. 29, no. 9, pp. 4787 - 4796, Sep. 2014.

[185] S. Saravanan, and N. R. Babu, "Design and Development of Single Switch High Step-Up DC-DC Converter," IEEE J. Emerg. Sel. Topics Pow. Electron., vol. 6, no. 2, pp. 855 - 863, Jun. 2018.

[186] T. Jalilzadeh, N. Rostami, E. Babaei, and M. Maalandish, "Non-Isolated Topology for High Step-Up DC-DC Converters,” IEEE J. Emerg. Sel. Topics Pow. Electron. , Jun.. 2018. 
[187] V. F. Piresa, D. Foitoa, and J. F. Silvab, "A single switch hybrid DC/DC converter with extended static gain for photovoltaic applications," Elect. Power Syst. Resear., vol. 146, pp. 228-235, May 2017.

[188] M. R. Banaei, and S. G. Sani, "Analysis and Implementation of a New SEPIC-Based Single-Switch Buck-Boost DC-DC Converter with Continuous Input Current," IEEE Trans. Power. Electron., vol. 33, no. 12, pp. 10317 - 10325, Dec. 2018.

[189] E. Babaei, H. M. Maheri, M. Sabahi, and S. H. Hosseini, "Extendable Nonisolated High Gain DC-DC Converter Based on Active-Passive Inductor Cells," IEEE Trans. Ind. Electron., vol. 65, no.12, pp. 9478 - 9487, Dec. 2018.

[190] K. I. Hwu, and T. J. Peng, "A Novel Buck-Boost Converter Combining KY and Buck Converters," IEEE Trans. Pow. Electron., vol. 27, no. 5, pp. 2236 - 2241, May 2012.

[191] S. Miao, F. Wang, and X. Ma, "A New Transformerless Buck-Boost Converter With Positive Output Voltage," IEEE Trans. Ind. Electron., vol. 63, no. 5, pp. 2965 - 2975, May 2016.

[192] A. A. Fardoun, E. H. Ismail, A. J. Sabzali, M. A. Al-Saffar, "Bi-directional converter with low input/output current ripple for renewable energy applications", Proc. IEEE Energy Convers. Congr. Expo., Sep. 2011

[193] H. Kang, and H. Cha, "A New Nonisolated High-Voltage-Gain Boost Converter With Inherent Output Voltage Balancing," IEEE Trans. Ind. Electron., vol. 65, no. 3, pp. 2189 -2198, Mar. 2018.

[194] H. Ardi, A. Ajami, F. Kardan, and S. N. Avilagh, "Analysis and implementation of a nonisolated bidirectional DC-DC converter with high voltage gain," IEEE Trans. Ind. Electron., vol. 63, no. 8, pp. 4878-4888, Aug. 2016.

[195] D. F. Cortez, G.Waltrich, J. Fraigneaud, H. Miranda, and I. Barbi, "DC-DC converter for dual-voltage automotive systems based on bidirectional hybrid switched-capacitor architectures," IEEE Trans. Ind. Electron., vol. 62, no. 5, pp. 3296-3304, May 2015.

[196] O. Cornea, G.-D. Andreescu, N. Muntean, and D. Hulea, "Bidirectional power flow control in a DC microgrid through a switched-capacitor cell hybrid DC-DC converter," IEEE Trans. Ind. Electron., vol. 64, no. 4, pp. 3012-3022, Apr. 2017. 
[197] Tan Ma, and Osama A. Mohammed, "Economic Analysis of Real-Time Large-Scale PEVs Network Power Flow Control Algorithm with the Consideration of V2G Services," IEEE Transactions on Industry Applications, vol. 50, no. 6, pp. 4272-4280, Dec. 2014.

[198] Stefano Mandelli, Claudio Brivio, Emanuela Colombo, and Marco Merlo, "Effect of load profile uncertainty on the optimum sizing of off-grid PV systems for rural electrification," Sustainable Energy Technologies and Assessments, (Elsevier), vol. 18, pp. 34-47, Dec. 2016.

[199] Longcheng Tan, Bin Wu, Venkata Yaramasu, Sebastian Rivera, and Xiaoqiang Guo, "Effective Voltage Balance Control for Bipolar-DC-Bus-Fed EV Charging Station With Three-Level DC-DC Fast Charger," IEEE Transactions on Industrial Electronics, vol. 63, no.7, pp. 4031-4041, Jul. 2016.

[200] Mohammad Ibrahim, Laurent Bernard, Lionel Pichon, Eric Labour'e, Adel Razek, Olivier Cayol, Dimitrios Ladas, and Jo Irving, "Inductive Charger for Electric Vehicle: Advanced Modeling and Interoperability Analysis," IEEE Transactions on Power Electronics, vol. 31, no.12, pp. 8096-8114, Dec. 2016.

[201] Metin Kesler, Mithat C. Kisacikoglu, and Leon M. Tolbert, "Vehicle-to-Grid Reactive Power Operation Using Plug-In Electric Vehicle Bidirectional Offboard Charger," IEEE Transactions on Industrial Electronics, vol. 61, no.12, pp. 6778-6784, Dec. 2014.

[202] Sebastian Rivera, BinWu, Samir Kouro, Venkata Yaramasu, and Jiacheng Wang, "Electric Vehicle Charging Station Using a Neutral Point Clamped Converter With Bipolar DC Bus," IEEE Transactions on Industrial Electronics, vol. 62, no.4, pp. 1999-2009, Apr. 2015.

[203] Sebastian Rivera, and Bin Wu, "Electric Vehicle Charging Station With an Energy Storage Stage for Split-DC Bus Voltage Balancing," IEEE Transactions on Power Electronics, vol. 32, no.3, pp. 2376-2386, Mar. 2017.

[204] Mohamed O. Badawy, and Yilmaz Sozer, "Power Flow Management of a Grid Tied PVBattery System for Electric Vehicles Charging," IEEE Transactions on Power Electronics, Dec. 2016.

[205] Ding Li, Poh Chiang Loh, Miao Zhu, Feng Gao, and Frede Blaabjerg, "Cascaded Multicell Trans-Z-Source Inverters," IEEE Transactions on Power Electronics, vol. 28, no.2, pp. 826-836, Feb. 2013. 
[206] Dongsen Sun, Baoming Ge, Weihua Liang, Haitham Abu-Rub, and Fang Zheng Peng, “An Energy Stored Quasi-Z-Source Cascade Multilevel Inverter-Based Photovoltaic Power Generation System,” IEEE Transactions on Industrial Electronics, vol. 62, no.9, pp. 5458-5467, Sep. 2015.

[207] Yushan Liu, Baoming Ge, Haitham Abu-Rub, and Fang Zheng Peng, "An Effective Control Method for Three-Phase Quasi-Z-Source Cascaded Multilevel Inverter Based GridTie Photovoltaic Power System," IEEE Transactions on Power Electronics, vol. 61, no.12, pp. 6794-6802, Dec. 2014.

[208] Md. Rabiul Islam, Youguang Guo, and Jianguo Zhu, “A High-Frequency Link Multilevel Cascaded Medium-Voltage Converter for Direct Grid Integration of Renewable Energy Systems," IEEE Transactions on Power Electronics, vol. 29, no.8, pp. 4167-4182, Aug. 2013.

[209] Javier Pereda, and Juan Dixon, "High-Frequency Link: A Solution for Using Only One DC Source in Asymmetric Cascaded Multilevel Inverters," IEEE Transactions on Industrial Electronics, vol. 58, no.9, pp. 3884-3892, Sep. 2011.

[210] Yuxiang Shi, Rui Li, Yaosuo Xue, and Hui Li, "High-Frequency-Link-Based Grid-Tied PV System With Small DC-Link Capacitor and Low-Frequency Ripple-Free Maximum Power Point Tracking," IEEE Transactions on Power Electronics, vol. 31, no.1, pp. 328-339, Jan. 2016.

[211] Ricardo P. Aguilera, Pablo Acuna, Member, Yifan Yu, Georgios Konstantinou, Christopher D. Townsend, Bin Wu, and Vassilios G. Agelidis, "Predictive Control of Cascaded H-Bridge Converters Under Unbalanced Power Generation,” IEEE Transactions on Industrial Electronics, vol. 64, no.1, pp. 4-13, Jan. 2017.

[212] Xibo Yuan, "A Set of Multilevel Modular Medium-Voltage High Power Converters for 10-MW Wind Turbines," IEEE Transactions on Sustainable Energy, vol. 5, no. 2, pp. 524-534, Apr. 2014

[213] Somasundaram Essakiappan, Harish S. Krishnamoorthy, Prasad Enjeti, Robert S. Balog, and Shehab Ahmed, "Multilevel Medium-Frequency Link Inverter for Utility Scale Photovoltaic Integration," IEEE Transactions on Power Electronics, vol. 30, no. 6, pp. 3674-3684, Jul. 2015. 
[214] Kartik V Iyer, Rohit Baranwal, Ned Mohan, "A High-Frequency AC-Link Single-Stage Asymmetrical Multilevel Converter for Grid Integration of Renewable Energy Systems," IEEE Transactions on Power Electronics, Sep. 2016.

[215] Kasunaidu Vechalapu, Subhashish Bhattacharya, Edward Van Brunt, Sei-Hyung Ryu, Dave Grider and John W. Palmour, "Comparative Evaluation of $15 \mathrm{kV} \mathrm{SiC} \mathrm{MOSFET} \mathrm{and} 15$ kV SiC IGBT for Medium Voltage Converter under Same dv/dt Conditions," IEEE Transactions on Emerging and Selected Topics in Power Electronics, Oct. 2016.

[216] Zhongda Li, and T. Paul Chow, "Design and Simulation of 5-20-kV GaN EnhancementMode Vertical Superjunction HEMT," IEEE Transactions on Electron Devices, vol. 60, no.10, pp. 3230-3237, Oct. 2013.

[217] Wei Shen, Fei Wang, Dushan Boroyevich, and C. Wesley Tipton, "High-Density Nanocrystalline Core Transformer for High-Power High-Frequency Resonant Converter," IEEE Transactions on Industry Applications, vol. 44, no.1, pp. 213-222, Jan. 2008.

[218] Md. Rabiul Islam, Gang Lei, Youguang Guo, and Jianguo Zhu, “Optimal Design of HighFrequency Magnetic Links for Power Converters Used in Grid-Connected Renewable Energy Systems," IEEE Transactions on Magnetics, vol. 50, no.11, Nov. 2014.

[219] Bailu Xiao, Lijun Hang, Jun Mei, Cameron Riley, Leon M. Tolbert, and Burak Ozpineci, "Modular Cascaded H-Bridge Multilevel PV Inverter With Distributed MPPT for GridConnected Applications," IEEE Transactions on Industry Applications, vol. 51, no.2, pp. 1722-1731, Apr. 2015.

[220] Jordi Pegueroles-Queralt, Fernando D. Bianchi, and Oriol Gomis-Bellmunt, “A Power Smoothing System Based on Supercapacitors for Renewable Distributed Generation,” IEEE Transactions on Industrial Electronics, vol. 62, no.1, pp. 343-350, Jan. 2015.

[221] Mustafa Farhadi, and Osama Mohammed, "Performance Enhancement of Actively Controlled Hybrid DC Microgrid with Pulsed Load," IEEE Transactions on Industry Applications, vol. 51, pp. 3570-3578, Oct. 2015.

[222] Mustafa Farhadi, and Osama Mohammed, "Real-Time Operation and Harmonic Analysis of Isolated and Non-Isolated Hybrid DC Microgrid," IEEE Transactions on Industry Applications, vol. 50, no.4, pp. 2900-2909, Aug. 2014. 
[223] Hossein Ali Mohammadpour, Amin Ghaderi, Hassan Mohammadpour, and Mohd. Hasan Ali, "Low voltage ride-through enhancement of fixed-speed wind farms using series FACTS controllers," Sustainable Energy Technologies and Assessments, (Elsevier), vol. 9, pp. 12-21, Oct. 2014.

[224] Hamid Reza Baghaee, Mojtaba Mirsalim, Gevork B. Gharehpetian, and Heidar Ali Talebi, "A new current limiting strategy and fault model to improve fault ridethrough capability of inverter interfaced DERs in autonomous microgrids," Sustainable Energy Technologies and Assessments, (Elsevier), Feb. 2017.

[225] Mario Ndrekoa, Jose L. Ruedaa, Marjan Popova, Mart A.M.M, and van der Meijden, "Optimal fault ride through compliance of offshore wind power plants with VSC-HVDC connection by meta-heuristic based tuning," Electric Power Systems Research, (Elsevier), vol. 145, pp. 99-111, Dec. 2016.

[226] Mostafa I. Marei, Nour Elsayad, Ahmed A. El-Sattar, "PV interface system with LVRT capability based on a current controlled HFAC link converter," Sustainable Energy Technologies and Assessments, (Elsevier), vol. 9, pp. 55-62, Jan 2015.

[227] Gang Wen, Yu Chen, Zhihao Zhong, and Yong Kang, "Dynamic Voltage and Current Assignment Strategies of Nine-Switch-Converter-Based DFIG Wind Power System for LowVoltage Ride-Through (LVRT) Under Symmetrical Grid Voltage Dip," IEEE Transactions on Industry Applications, vol. 52, no.4, pp. 3422-3434, Aug 2016.

[228] Cheng-Yu Tang, Yao-Ting Chen, and Yaow-Ming Chen, "PV Power System with MultiMode Operation and Low-Voltage Ride-Through Capability," IEEE Transactions on Industrial Electronics, vol. 62, no. 12, pp. 7524-7533, Dec. 2015.

[229] L. Tan, T. Ericsen, Y. Khersonsky, P. Schugart, and P. Steimer, "PEBB - Power Electronics Building Blocks, from Concept to Reality," in PEMD conference, Mar. 2007.

[230] Y. Zhang, H. Ma, F. Xu, "Design issues of building block structure communications for power electronic system," in 37th IEEE Pow. Electron. Spec. Conf., May 2017.

[231] A. Laka, J. A. Barrena, J. Zabalza, M. Á. Rodríguez, "Analysis and Improved Operation of a PEBB-Based Voltage-Source Converter for FACTS Applications," in IEEE Trans. on Pow. Delivery, vol. 28, Apr. 2013. 
[232] A. Monti, and F. Ponci, "PEBB Standardization for High-Level Control: A Proposal," in IEEE Trans. on Ind. Electronics, vol. 59, Oct. 2012.

[233]

[234] L. Solero, D. Boroyevich, Y.P. Li, F.C. Lee, "Design of resonant circuit for zero-currenttransition techniques in 100-kW PEBB applications," in IEEE Trans. on Ind. App., vol. 39, Nov. 2003.

[235] F. Wang, Z. Zhang, T. Ericsen, R. Raju, R. Burgos, D. Boroyevich, "Advances in Power Conversion and Drives for Shipboard Systems," in Proceedings of the IEEE, vol. 103, Dec. 2015.

[236] A. Iyer, R. Kandula, R. Moghe, J. Hernandez, F. Lambert, D. Divan, "Validation of the Plug-and-Play AC/AC Power Electronics Building Block (AC-PEBB) for Medium-Voltage Grid Control Applications," in IEEE Trans. on Ind. App., vol. 50, Oct. 2014.

[237] E. Jones, F. Wang, D. Costinett, " Review of Commercial GaN Power Devices and GaNBased Converter Design Challenges," in IEEE Trans. on Emer. And Selected Top. In Pow. Electron., vol. 4, Sep 2016.

[238] E. Gurpinar, and A. Castellazzi, "Single-Phase T-Type Inverter Performance Benchmark Using Si IGBTs, SiC MOSFETs, and GaN HEMTs," IEEE Trans. on Power Electronics, Vol. 31, No. 10, Oct. 2016.

[239] A. Roc'h, and F. Leferink, "Nanocrystalline Core Material for High-Performance Common Mode Inductors,” IEEE Trans. on Electromagnetic Compatibility, Vol. 54, Aug. 2012.

[240] GS66508T-EVBHB 650V GaN E-HEMT Half Bridge Evaluation Board User's Guide.

[241] S.K. Mazumder and S. Mehrnami, "A low-device-count single-stage direct-powerconversion solar microinverter for microgrid," in IEEE 3rd Int. Symp on Power Electron. For Distributed Generation Systems (PEDG), 25-28 Jun. 2012, pp.725-730.

[242] S. Mehrnami and S.K. Mazumder "Discontinuous modulation scheme for a DifferentialMode Ćuk Inverter” IEEE Trans. Power Electron., vol. 30, Issue: 3, pp. 1242-1254, March 2015.

[243] A. Darwish, A. Massoud, D. Holliday, S. Ahmed, and B. Williams, "Single-stage Threephase Differential-mode Buck-Boost Inverters with Continuous Input Current for PV Applications," IEEE Transactions on pow. Elect., pp. 1-1, 2016. 
[244] Y. Wang, Q. Song, B. Zhao, J. Li, Q. Sun and W. Liu, "Quasi-square-wave Modulation of Modular Multilevel High-frequency DC Converter for Medium-voltage DC Distribution Application," in IEEE Transactions on Power Electronics.

[245] S. Das and P. Swarnkar, "Fuzzy Logic Control of DC-DC converters for Navy shipboard Medium Voltage DC Distribution System," 2016 IEEE 1st International Conference on Power Electronics, Intelligent Control and Energy Systems (ICPEICES), Delhi, 2016, pp. $1-5$.

[246] L. Wang, Q. Zhu, W. Yu and A. Q. Huang, "A Medium-Voltage Medium-Frequency Isolated DC-DC Converter Based on 15-kV SiC MOSFETs," in IEEE Journal of Emerging and Selected Topics in Power Electronics, vol. 5, no. 1, pp. 100-109, March 2017.

[247] J. Yu, R. Burgos, N. R. Mehrabadi and D. Boroyevich, "Design of a SiC-based modular multilevel converter for medium voltage DC distribution system," 2017 IEEE Applied Power Electronics Conference and Exposition (APEC), Tampa, FL, 2017, pp. 467-473.

[248] J. E. Huber and J. W. Kolar, "Optimum Number of Cascaded Cells for High-Power Medium-Voltage AC-DC Converters," in IEEE Journal of Emerging and Selected Topics in Power Electronics, vol. 5, no. 1, pp. 213-232, March 2017.

[249] S. Cui, N. Soltau and R. W. De Doncker, "A High Step-Up Ratio Soft-Switching DC-DC Converter for Interconnection of MVDC and HVDC Grids," in IEEE Transactions on Power Electronics, vol. 33, no. 4, pp. 2986-3001, April 2018.

[250] C. Jung, "Power Up with 800-V Systems: The benefits of upgrading voltage power for battery-electric passenger vehicles," in IEEE Electrification Magazine, vol. 5, no. 1, pp. 53-58, March 2017.

[251] B. Li, Q. Li, F. C. Lee, Z. Liu, and Y. Yang, "A High-Efficiency High-Density WideBandgap Device-Based Bidirectional On-Board Charger", IEEE Jour. of Emerg. and Sel. Top. in Pow. Electron., vol. 6, no. 3, pp. 1627 - 1636, Sept. 2018.

[252] B. Li, Q. Li, F. C. Lee, Z. Liu, and Y. Yang, "High-Efficiency High-Density Critical Mode Rectifier/Inverter for WBG-Device-Based On-Board Charger”, IEEE Trans. Of Ind. Electron., vol. 64, no. 11, pp. 9114 - 9123, Nov. 2017. 
[253] L. F. Costa, G. Buticchi and M. Liserre, "Quad-active-bridge as cross-link for medium voltage modular inverters," 2015 IEEE Energy Conversion Congress and Exposition (ECCE), Montreal, QC, 2015, pp. 645-652.

[254] U. K. Mishra, P. Parikh and Yi-Feng Wu, "AlGaN/GaN HEMTs-an overview of device operation and applications," in Proceedings of the IEEE, vol. 90, no. 6, pp. 1022-1031, Jun 2002.

[255] A. S. Morsy and P. N. Enjeti, "Comparison of Active Power Decoupling Methods for HighPower-Density Single-Phase Inverters Using Wide-Bandgap FETs for Google Little Box Challenge,” IEEE J. Emerg. Sel. Top. Power Electron., vol. 4, no. 3, pp. 790-798, Sep. 2016.

[256] Jason Xu, Di Chen, and Larry Spaziani "A Performance Comparison of GaN E-HEMTs versus SiC MOSFETs in Power Switching Applications," GaN Systems Inc, 2017.

[257] Y. Ren et al., "A Compact Gate Control and Voltage-Balancing Circuit for SeriesConnected SiC MOSFETs and Its Application in a DC Breaker," in IEEE Transactions on Industrial Electronics, vol. 64, no. 10, pp. 8299-8309, Oct. 2017.

[258] K. Vechalapu, S. Hazra, U. Raheja, A. Negi and S. Bhattacharya, "High-speed medium voltage (MV) drive applications enabled by series connection of $1.7 \mathrm{kV} \mathrm{SiC} \mathrm{MOSFET}$ devices," 2017 IEEE Energy Conversion Congress and Exposition (ECCE), Cincinnati, OH, 2017, pp. 808-815.

[259] H. Moradisizkoohi, N. Elsayad, A. Berzoy, C. R. Lashway and O. A. Mohammed, "A multi-level bi-directional buck-boost converter using GaN devices for electric vehicle applications," 2017 IEEE Transportation Electrification Conference and Expo (ITEC), Chicago, IL, 2017, pp. 742-746.

[260] Jih-Sheng Lai and Fang Zheng Peng, "Multilevel converters-a new breed of power converters," in IEEE Transactions on Industry Applications, vol. 32, no. 3, pp. 509-517, May/Jun 1996.

[261] M. Shojaie, N. Elsayad and O. A. Mohammed, "Design of an all-GaN bidirectional DC-DC converter for medium voltage DC ship power systems using series-stacked $\mathrm{GaN}$ modules," 2018 IEEE Applied Power Electronics Conference and Exposition (APEC), San Antonio, TX, 2018, pp. 2155-2161. 
[262] Yaqiang Han et al., "A 4000V input auxiliary power supply with series connected SiC MOSFETs for MMC-based HVDC system," 2016 IEEE 8th International Power Electronics and Motion Control Conference (IPEMC-ECCE Asia), Hefei, 2016, pp. 279-284.

[263] K. Shingu and K. Wada, "Digital control based voltage balancing for series connected SiC MOSFETs under switching operations," 2017 IEEE Energy Conversion Congress and Exposition (ECCE), Cincinnati, OH, 2017, pp. 5495-5500.

[264] K. Vechalapu, A. Negi and S. Bhattacharya, "Performance evaluation of series connected $15 \mathrm{kV}$ SiC IGBT devices for MV power conversion systems," 2016 IEEE Energy Conversion Congress and Exposition (ECCE), Milwaukee, WI, 2016, pp. 1-8.

[265] K. Vechalapu and S. Bhattacharya, "Performance comparison of $10 \mathrm{kV}-15 \mathrm{kV}$ high voltage $\mathrm{SiC}$ modules and high voltage switch using series connected $1.7 \mathrm{kV} \mathrm{LV} \mathrm{SiC} \mathrm{MOSFET}$ devices," 2016 IEEE Energy Conversion Congress and Exposition (ECCE), Milwaukee, WI, 2016, pp. 1-8.

[266] R. Withanage and N. Shammas, "Series Connection of Insulated Gate Bipolar Transistors (IGBTs)," in IEEE Transactions on Power Electronics, vol. 27, no. 4, pp. 2204-2212, April 2012.

[267] F. Bauer, L. Meysenc and A. Piazzesi, "Suitability and optimization of high-voltage IGBTs for series connection with active voltage clamping," in IEEE Transactions on Power Electronics, vol. 20, no. 6, pp. 1244-1253, Nov. 2005.

[268] T. C. Lim, B. W. Williams, S. J. Finney and P. R. Palmer, "Series-Connected IGBTs Using Active Voltage Control Technique," in IEEE Transactions on Power Electronics, vol. 28, no. 8, pp. 4083-4103, Aug. 2013.

[269] I. Baraia, J. A. Barrena, G. Abad, J. M. Canales Segade and U. Iraola, "An Experimentally Verified Active Gate Control Method for the Series Connection of IGBT/Diodes," in IEEE Transactions on Power Electronics, vol. 27, no. 2, pp. 1025-1038, Feb. 2012.

[270] Y. Wang, P. R. Palmer, A. T. Bryant, S. J. Finney, M. S. Abu-Khaizaran and G. Li, "An Analysis of High-Power IGBT Switching Under Cascade Active Voltage Control," in IEEE Transactions on Industry Applications, vol. 45, no. 2, pp. 861-870, March-april 2009.

[271] Ju Won Baek, Dong-Wook Yoo and Heung-Geun Kim, "High-voltage switch using seriesconnected IGBTs with simple auxiliary circuit," in IEEE Transactions on Industry Applications, vol. 37, no. 6, pp. 1832-1839, Nov/Dec 2001. 
[272] C. Abbate, G. Busatto and F. Iannuzzo, "High-Voltage, High-Performance Switch Using Series-Connected IGBTs," in IEEE Transactions on Power Electronics, vol. 25, no. 9, pp. 2450-2459, Sept. 2010.

[273] N. Teerakawanich and C. M. Johnson, "Design Optimization of Quasi-Active Gate Control for Series-Connected Power Devices," in IEEE Transactions on Power Electronics, vol. 29, no. 6, pp. 2705-2714, June 2014.

[274] S. Chowdhury and U. K. Mishra, "Lateral and vertical transistors using the AlGaN/GaN heterostructure," IEEE Trans. Electron Devices, vol. 60, no. 10, pp. 3060-3066, Oct. 2013.

[275] J. Roig et al., "Series-connected GaN transistors for ultra-fast high-voltage switch (>1kV)," 2017 IEEE Applied Power Electronics Conference and Exposition (APEC), pp. 3043-3048, 2017.

[276] X. Huang, Z. Liu, Q. Li, and F. C. Lee, "Evaluation and application of $600 \mathrm{~V}$ GaN HEMT in cascode structure," IEEE Trans. Power Electron.,vol. 29, no. 5, pp. 2453-2461, May 2014.

[277] C. A. Desoer, E. S. Kuh, Basic Circuit Theory, New York: McGraw-Hill, 1969.” 
VITA

\section{NOUR ELSAYAD}

Dec 2019

Aug 2015-present

Doha, Qatar

Feb 2014 - Jul 2015
PhD, Electrical Engineering (Power Electronics)

Florida International University, Dissertation Title: "Isolated single-stage power electronic building blocks using Medium voltage series-stacked wide-bandgap switches". Major Professor: Professor Osama Mohammed

Research Interests

- Multilevel dc-dc converters with wide conversion ratios.

- High frequency power converters design using GaN \& SiC devices.

- Automotive power electronics.

- Inverter/Active rectifier design and control.

Energy Systems Research Laboratory (ESRL), Florida International University Graduate Research Assistant

- Design of new dc-dc converters with wide voltage conversion ratios using $\mathrm{GaN}$ and $\mathrm{SiC}$ devices. (Power rating $>1 \mathrm{~kW}$, voltage $\leq 800 \mathrm{~V}$, frequency $\geq 100 \mathrm{kHz}$ )

Qatar University

Graduate Research Assistant

- Worked on a project funded by the Qatar National Research Fund (QNRF) in order to investigate the impacts of the penetration of renewable energy sources on the power grid that adopts the self-healing technology

Jan 2014 \& Jul 2010 B.Sc. \& M.Sc., Electrical Engineering Ain Shams University

Cairo, Egypt

National Authority for Remote Sensing \& Space Science (Egyptian

Nov 2012 - Jan 2014 Space Program)

Power Electronics Engineer

Responsible for:

- Building MATLAB/SIMULINK modes to simulate the satellite power conditioning unit and its performance.

- Designing the power conditioning unit (PCU) of the satellite (based on the Maximum Power Point Tracking (MPPT) topology and the Shunt Regulator Topology).

- Building check-out equipment using LabVIEW and National Instruments hardware in order to test and verify 
the durability and reliability of the different items of the power subsystem (battery chargers, MPPT controllers, shunt regulators, distributed DC-DC converters, and the communication with the satellite's on-board computer using SSP and MODBUS protocols).

Cairo, Egypt

July 2011-Oct 2012
A.O.I. (Electronics Research Facility)

Embedded Controls Engineer

Responsible for:

- Building microcontroller and FPGA based devices for industrial automation and medical applications

- Building custom motor drives for medical rehabilitation devices

Skills

- 7+ years of hands-on experience in designing, and building various power electronic stages (DC/DC, DC/AC, AC/DC).

- Hands-on experience in high frequency power electronics design using wide bandgap devices ( $\mathrm{SiC} \& \mathrm{GaN}$ (E-Mode and Cascode)).

- Hands-on experience in custom magnetic components design (ex: coupled inductors, HF transformers).

- Hands-on experience in multilayer (6 layers), high frequency, and high density PCB design using Altium Designer.

- Hands-on experience in designer mixed signal electronic circuits (analog + digital) for sensing and gate driving applications.

- Experience with simulation programs: Matlab/Simulink, PSIM, and LTspice.

- Proficiency with lab tools (Oscilloscopes, Network analyzers, Signal Generators etc.).

- Good knowledge of control theory

- 5+ years of hands-on experience in embedded systems developments (using C2000 dsp, ARM cortex M3/4, Microchip PIC and ATMEL AVR microcontrollers) using ANSI C

- Device driver development (using $\mathrm{C}$ language) for LCD, SPI, I2C, DMA, PWM, .. etc.

- Experience with high-speed communication interface 